\title{
Amine Nucleophilic Addition to Nitro-alkene as a New Reaction Mode for the Synthesis of N-heterocycles
}

Lekh Nath Sharma Gautam

West Virginia University

Follow this and additional works at: https://researchrepository.wvu.edu/etd

\section{Recommended Citation}

Gautam, Lekh Nath Sharma, "Amine Nucleophilic Addition to Nitro-alkene as a New Reaction Mode for the Synthesis of N-heterocycles" (2013). Graduate Theses, Dissertations, and Problem Reports. 356.

https://researchrepository.wvu.edu/etd/356

This Dissertation is protected by copyright and/or related rights. It has been brought to you by the The Research Repository @ WVU with permission from the rights-holder(s). You are free to use this Dissertation in any way that is permitted by the copyright and related rights legislation that applies to your use. For other uses you must obtain permission from the rights-holder(s) directly, unless additional rights are indicated by a Creative Commons license in the record and/ or on the work itself. This Dissertation has been accepted for inclusion in WVU Graduate Theses, Dissertations, and Problem Reports collection by an authorized administrator of The Research Repository @ WVU.

For more information, please contact researchrepository@mail.wvu.edu. 


\title{
Amine Nucleophilic Addition to Nitro-alkene as a New Reaction Mode for the Synthesis of $N$-heterocycles
}

\author{
Lekh Nath Sharma Gautam
}

\author{
Dissertation submitted to \\ Eberly College of Arts and Sciences \\ at West Virginia University \\ in partial fulfillment of the requirements \\ for the Degree of \\ Doctor of Philosophy \\ in \\ Chemistry
}

\author{
Xiaodong Shi, Ph.D., Committee Chairperson \\ Kung K. Wang, Ph.D. \\ Björn Söderberg, Ph.D. \\ Jeffrey L. Petersen, Ph.D. \\ Peter Gannett, Ph.D.
}

C. Eugene Bennett Department of Chemistry

Morgantown, West Virginia

2013

Key words: organocatalysis, amino-tethered conjugated esters, $\gamma$-lactam, $N$-heterocycles, piperidine, gold catalysis, Meyer-Schuster rearrangement

Copyright 2013 Lekh Nath Sharma Gautam 


\section{ABSTRACT \\ Amine Nucleophilic Addition to Nitro-alkene as a New Reaction Mode for the Synthesis of $N$-heterocycles}

An efficient stereoselective synthesis of polycyclic lactams has been developed using Michael addition of conjugated amino-esters to nitro-alkenes. Using acyclic and cyclic aminoesters, this method provided a promising approach to the synthesis of bicyclic and tricyclic lactam core $(5,5 ; 6,5 ; 5,5,5 ; 5,6,5 ; 6,5,5 ; 6,6,5$ etc $)$ in moderate to excellent yield (up to 95\%) and excellent diastereoselectivities (up to 99:1 dr). The key steps in this asymmetric synthesis include a heteroatom Michael-Michael addition followed by reductive amidation to $\gamma$-lactams. Lactam cores are biologically active broad spectrum antibiotics.

\section{Enantioselective Synthesis of Piperidines by Exocyclic Chirality Transfer}

Piperidines are very important structural moieties contained in a wide range of biologically active and medicinally significant compounds. An efficient route to chiral piperidines was developed which involved diastereoselective synthesis of substituted piperidines (yields up to $75 \%$ with dr up to 10:1 of single isomer) followed by removal of one chiral fragment also called $N$-deprotection to enantiopure piperidine (yields up to $92 \%$ ) with $100 \%$ chirality retention.

\section{Unique Reactivity of Triazole Gold towards Alkyne Activation to Enones and Chiral Allenes}

1,2,3-Triazole coordinated gold(I) complexes were found as the effective catalysts in promoting propargylic ester/ether rearrangement and sequential allene hydration giving enones with excellent yields (up to $97 \%$ yields, $0.2 \%$ catalyst loading). This catalyst also catalyzed the more challenging Meyer-Schuster rearrangement ( $0.5 \%$ catalyst loading, up to $98 \%$ yields). Unlike other reported Au catalysts, the TA-Au complexes provided effective chirality transfer without racemization over a long period of time, giving enantioriched allenes with excellent stereoselectivity (1\% catalyst loading, up to $99 \%$ ee). 


\title{
DEDICATED TO
}

\author{
My Amazing Parents \\ My Loving Wife \\ My Wonderful Sons \\ My Brothers and Sisters
}




\section{ACKNOWLEDGEMENTS}

My greatest heartily gratitude goes to my supervisor Dr. Xiaodong Michael Shi who offered his endless and energetic advice, encouragement and undertook tremendous responsibility in supervising me for the completion of my research and dissertation. I thank him for the systematic guidance, patience, motivation, enthusiasm, great effort and immense knowledge he put into training me in the scientific field. I could not have imagined having such a better advisor and mentor for my study. It was with his encouragement and help that I could be confident in doing the whole organic chemistry job.

I extend my gratitude to Dr. Peter Gannett, Dr. Bjorn Soderberg, Dr. Kung Wang and Dr. Jeffrey Petersen for their valuable time for academic development and serving on my committee. I would like to express my special thanks to Dr. Novruz Akhmedov, also a collaborator, for his continuous friendly help in NMR analysis. Their valuable advice and suggestions throughout my years in WVU are appreciated and acknowledged.

Also, I would like to thank all the staffs of the C. Eugene Bennett Department of Chemistry for their help in the last five years. In addition, I would like to thank the Eberly College of Arts and Science, WVU foundation and office of Graduate Student Affairs WVU for financial support.

Finally, I take this opportunity to express the profound gratitude to my dear wife Pujya Wagle, my son Prithul Gautam, my beloved parents and siblings for their love, encouragement, understanding and continuous support during all these years. I have to give a special mention for the support and love given by my parents-in-law. Without their inspiration, I could not have finished this thesis. I really appreciate the help and cooperation of my friends and colleagues: Dr. Dawei Wang, Dr Yijin Su, Qiaoyi Wang, Xiaohan Ye, Rong Cai, Sravan Kumar, Yanwei Zhang, Yumeng Xi, Stephen Motika, Boliang Dong, Seyed and other seniors. 


\section{TABLE OF CONTENTS}

ABSTRACT.

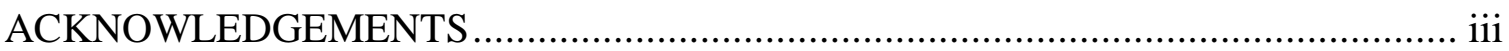

TABLE OF CONTENTS .............................................................................

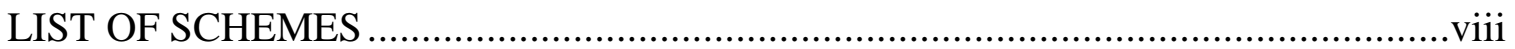

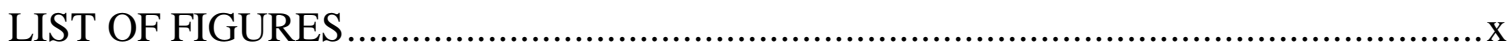

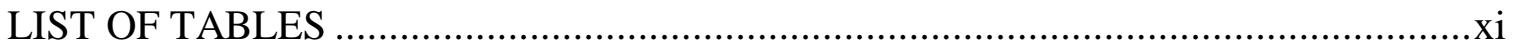

Chapter 1: Amine Nucleophilic Addition to Nitroalkene as a New Reaction Mode for the

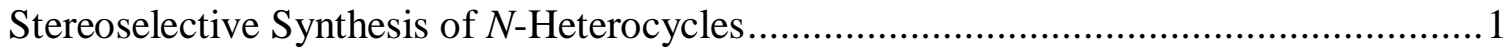

$1.1 \quad$ Introduction.................................................................................... 1

1.1.1 Organocatalysis in Organic Synthesis ............................................. 1

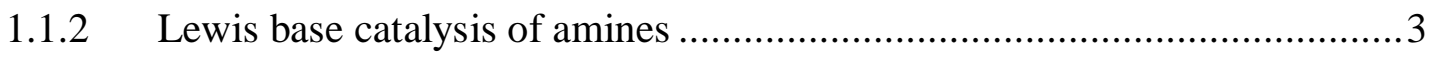

1.2 Amine addition to Nitroalkene..............................................................4

1.2.1 Unique Design of New Reaction Mode and mechanism ..........................4

1.2.2 Enantioselective cross-conjuagate addition of nitroalkenes to enals ...........6

1.2.3 Diastereoselective cascade synthesis of Nitro-substituted cyclohexanes .....7

1.2.4 One pot multicomponent condensation to the synthesis of substituted dihydrofurans and substituted triazoles ................................................. 9

1.3 Stereoselective isoxazoline- $N$-oxide synthesis ..................................... 11

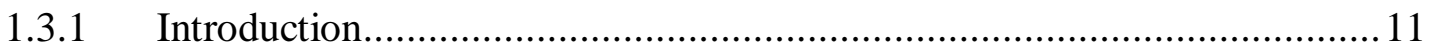

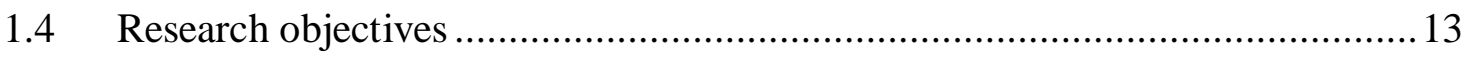

1.4.1 Asymmetric multicomponent synthesis of isoxazoline- $N$-oxide $\ldots \ldots \ldots \ldots \ldots . . . . .13$

1.4.2 Application towards natural products synthesis ...................................13

1.4.3 Henry aldol strategy to isoxazoline- $N$-oxide synthesis ......................... 13

1.4.4 Strategies for the third component (Nu-LG) to isoxazoline-N-oxide .........16 
1.4.5 Asymmetric Synthesis of isoxazoline- $N$-oxide ........................................18

1.5 Total synthesis of (-) Clausenamide derivatives ...........................................21

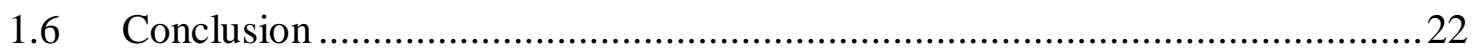

Chapter 2: Stereoselective $N$-heterocycle Syntheses through Cascade Amine Addition to

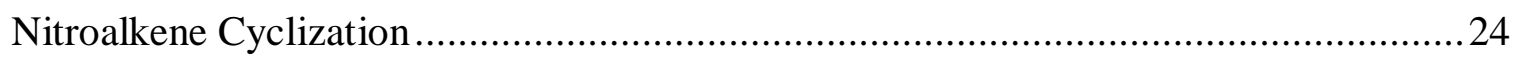

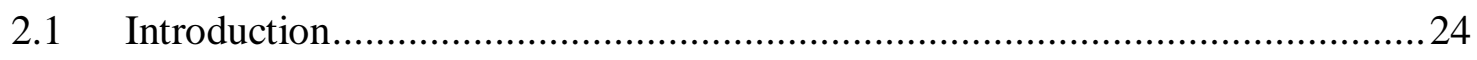

2.1.1 Literature reported synthesis and designs towards $N$-heterocycles ............24

2.1.2 Previous Study in Our group .............................................................2

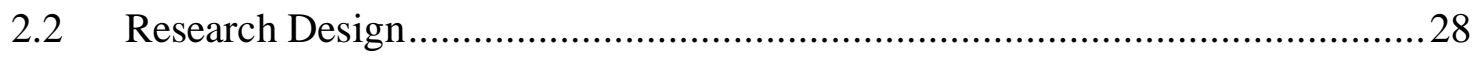

2.2.1 Stereoselective synthesis of $N$-heterocycles by the action of amine to

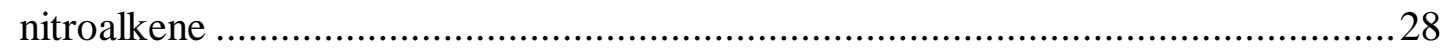

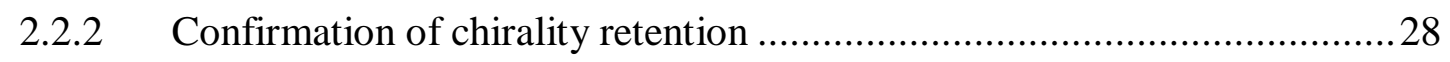

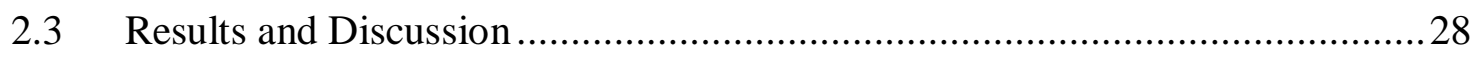

2.3.1 Synthesis of diverse amino pendant conjugated esters ……………….....28

2.3.2 Reaction optimization for Aza-Michael addition ........................................30

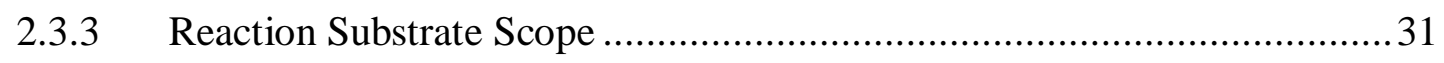

2.4 Application of our methodology in the synthesis of $\gamma$-lactam heterocyclic

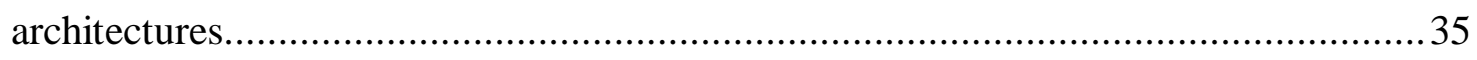

2.4.1 Screening of condition for reductive cyclization ..........................................36

2.4.2 Substrate scope of polycyclic $N$-heterocycles ……….................................. 37

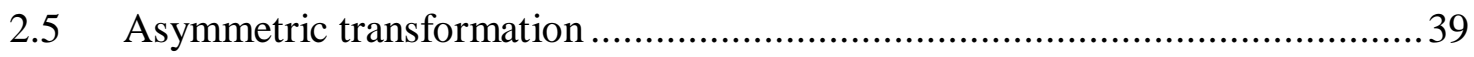

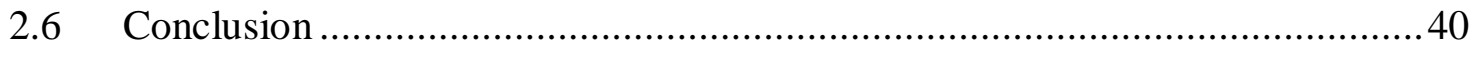

Chapter 3: Synthesis of Enantiopure Piperidines by Exocyclic Chirality Induction .........41

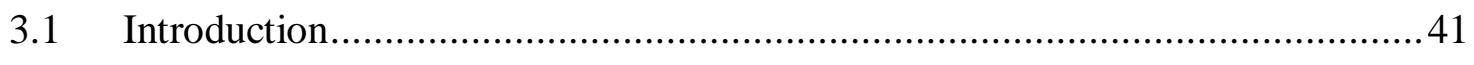

3.1.1 Literature reported asymmetric synthesis of piperidine synthesis ..............41

3.1.2 Rationale for enantiopure piperidine synthesis ..........................................4 


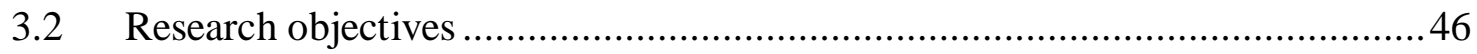

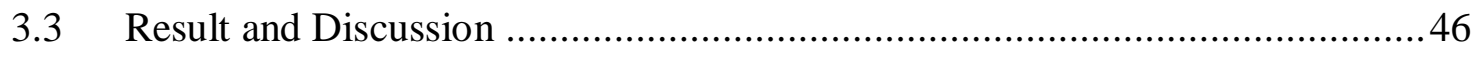

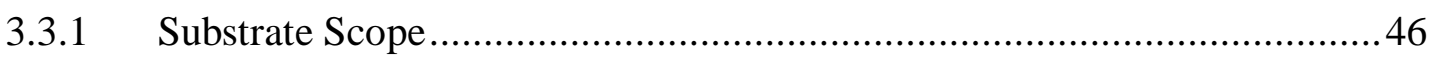

3.3.2 N-Deprotection of exocyclic tethered chiral group ...................................48

3.3.3 Substrate scope of representative enantiopure piperidines ..........................50

3.4 Application of piperidines towards the synthesis of chiral thiourea-based

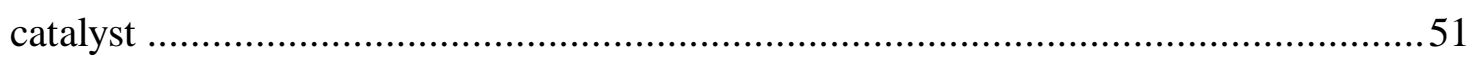

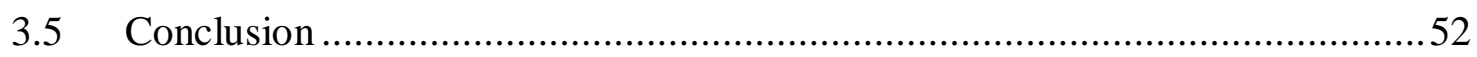

Chapter 4: Unique Reactivity of Triazole gold towards Alkyne Activation to Allene and Enone: Chemoselectivity, Acidity and Ligand Economy ................................................54

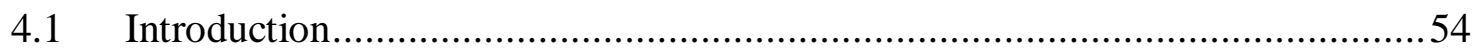

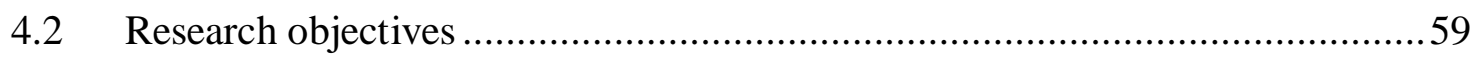

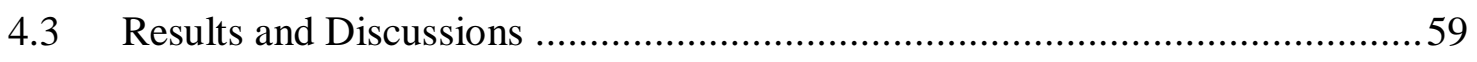

4.3.1 Optimization for Enone synthesis with TA-Au catalyst ..........................59

4.3.2 Substrate Scope of Enone synthesis from the propargylic ester .................62

4.3.3 Meyer-Schuster rearrangement with TA-Au catalyst ...............................63

4.3.4 Asymmetric Synthesis of Substituted allenes ..........................................65

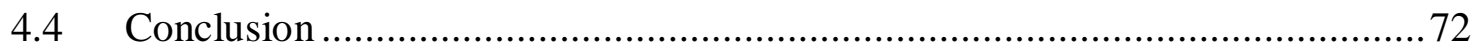

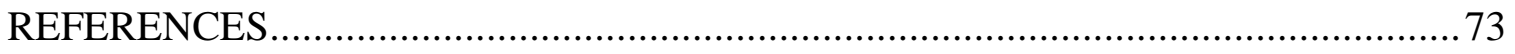

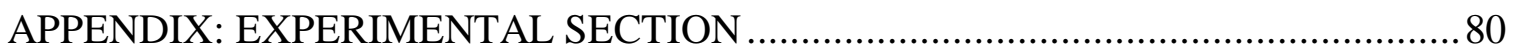

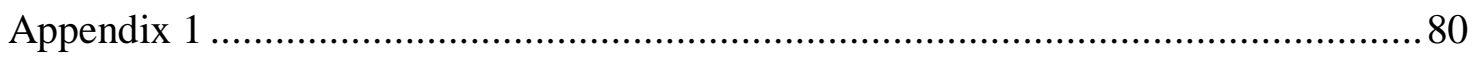

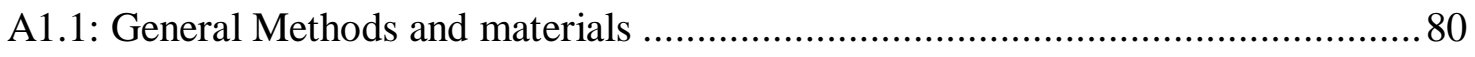

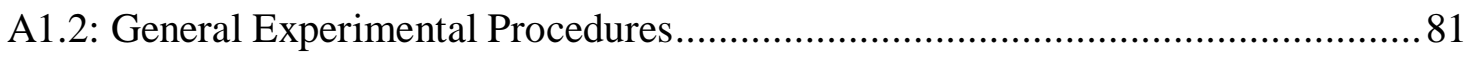

A1.2.1: General Procedure for preparation of homo-isoxazoline- $N$-oxide (1.4.3) ....81

A1.2.2: General Procedure for preparation of isoxazoline- $N$-oxide) ….....................8 81

A1.2.3: Representative procedure of stereoselective synthesis of $N$-heterocycles .......83 
A1.2.3.1: Experimental Procedure for Aza-Michael addition

A1.2.3.2: Representative procedure for the synthesis of $\gamma$-lactam. .84

A1.2.3.3: Typical Procedure for Asymmetric Synthesis of N-Heterocycles. .84

A1.2.4: Experimental procedures for enantioselective synthesis of piperidine .85

A1.2.4.1: Procedure for Synthesis of Substituted Racemic and Chiral $N$-protected piperidine .85

A1.2.4.2: Experiment for $N$-deprotection to piperidine (both chiral and racemic)....86 A1.2.4.3: Representative Procedure for the synthesis of thioureabased piperidine...87 A1.2.4.4: Procedure for Racemic product 3.4d synthesis .88 A1.2.4.5: Asymmetric Michael addition of nitromethane to chalcone for Chiral 3.4d .88

A1.2.5: Representative procedures for Triazole-Gold(I) Catalysis .89

A1.2.5.1: Representative procedure for $\alpha, \beta$-unsatured ketone 4.3.4a from 4.3.1 ......89

A1.2.5.2: Representative procedure for $\alpha, \beta$-unsatured ketone 4.3.4a from 4.3.5 ......89

A1.2.5.3: Representative procedure for the preparation of Allene 4.3.2a from 4.3.1a

A1.2.5.4: Representative procedure for the preparation of Chiral Allene 4.8a from $4.5 \mathrm{a}$ 90

Appendix 2: Compound Characterization $\left({ }^{1} \mathrm{H}-\mathrm{NMR},{ }^{13} \mathrm{C}-\mathrm{NMR}, \mathrm{HRMS}\right)$.................. 91

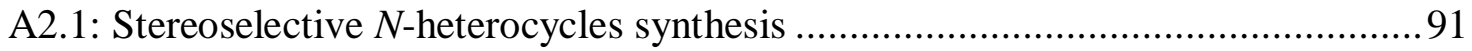

A2.2: Enantioselective piperidine synthesis................................................ 122

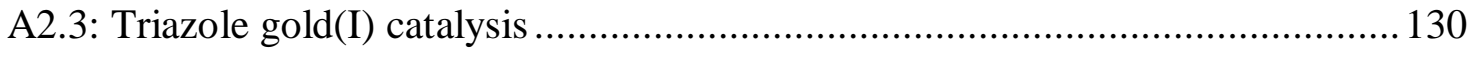

Appendix 3: ${ }^{1} \mathrm{H}$ NMR, ${ }^{13} \mathrm{C}$ NMR, HPLC Spectra and Crystal Structure................... 143

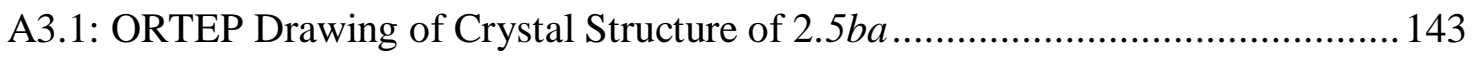

A3.2: NMR Spectra of New Compounds ................................................... 144

A3.3: HPLC Profiles: Racemates and Enantiopure products.............................. 334 


\section{LIST OF SCHEMES}

Scheme 1: Complex natural and medicinal products ........................................... 1

Scheme 2: Example of Pyrolidine type catalysts .................................................... 1

Scheme 3: Iminium and enamine organocatalysis ............................................. 2

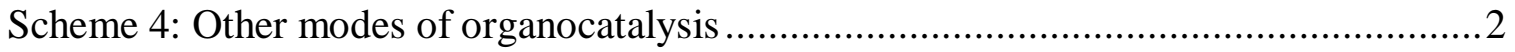

Scheme 5: Modes of activation in proline catalysis ............................................... 3

Scheme 6: Metal catalysis combined with organocatalysis.........................................

Scheme 7: Amine lewis base catalysis by organocatalysis ......................................... 4

Scheme 8: Extension of cross-conjugate addition ................................................

Scheme 9: Mechanism of amine activation of nitroalkenes ...................................... 6

Scheme 10: Selected substrates of cross-conjugate addition of nitroalkenes to enals ........7

Scheme 11: Michael-Aldol condensation of nitroalkenes to enones ............................... 7

Scheme 12: Diastereoselective cross-conjugate addition of nitroalkenes to enones ..........8

Scheme 13: Proposed DHF and Triazole synthesis .............................................

Scheme 14: Substrate scope of the three component dihydrofuran synthesis .................. 10

Scheme 15: One pot three component synthesis of $1,2,3$ triazoles .............................. 11

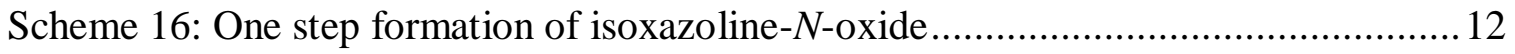

Scheme 17: Proposed reaction mechanism for the synthesis of isoxazoline-N-oxides. ... 13

Scheme 18: Proposed proline catalysed Isoxoazoline-N-oxide syntheisis ..................... 14

Scheme 19: Experimental confirmation of Lewis base catalysis ................................ 14

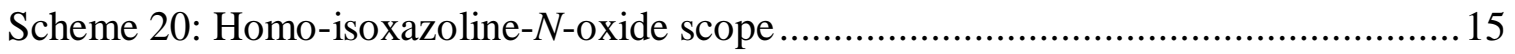

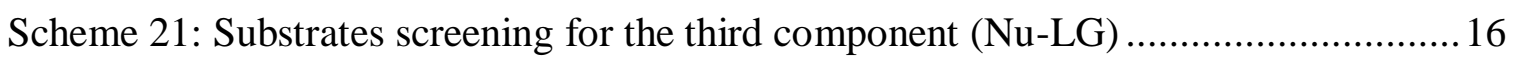

Scheme 22: Synthetic scheme of (-) Clausenamide derivatives ..................................22

Scheme 23: Some skeleton structures and important alkaloids ..................................24

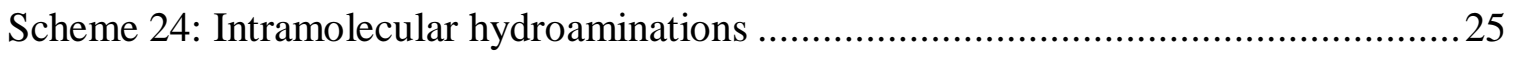

Scheme 25: Cycloaddition reaction involving $\mathrm{C}=\mathrm{N}$ or 1,3 -dipoles ...........................25

Scheme 26: Multiple-component cyclocondensation reactions ..................................26

Scheme 27: Previously reported approach: nitroalkene as receptor ...........................27

Scheme 28: Prevention of polymerization..................................................... 27 


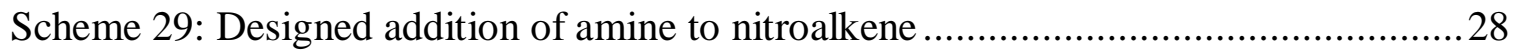

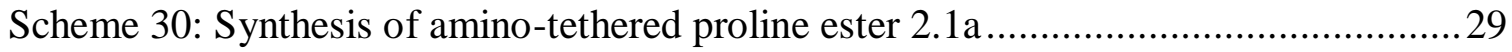

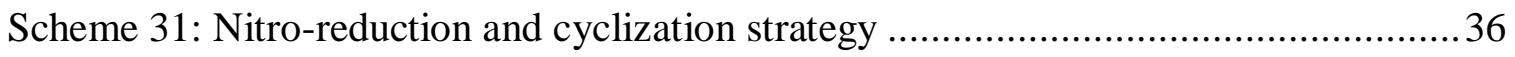

Scheme 32: Retention of stereochemistry in overall transformation .......................... 40

Scheme 33: Biologically active piperidine moieties containing Natural products ...........41

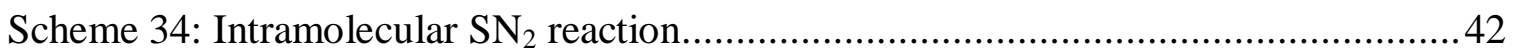

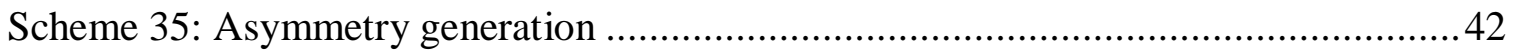

Scheme 36: Rearrangement of prolinols and their derivatives to piperidines ................43

Scheme 37: Ring closing metathesis for piperidine synthesis .................................43

Scheme 38: Intermolecular cross-double-Michael addition by amines via $\beta$-elimination 44

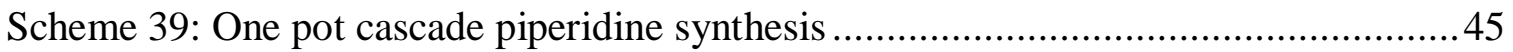

Scheme 40: Asymmetric synthesis of substituted piperidine moiety ............................45

Scheme 41: Reaction hypothesis for enantiopure piperidine synthesis .......................46

Scheme 42: Unreactive nitroalkenes and Michael acceptor in cascade synthesis ...........48

Scheme 43: Short synthesis of thiourea based piperidine organocatalyst .....................51

Scheme 44: Hypothetical proposition of transition state for the control of

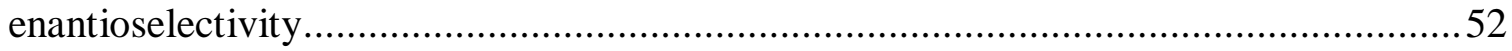

Scheme 45: The counter ligands and modes of reactivity in $\mathrm{Au}(\mathrm{I})$ catalysis ..................54

Scheme 46: $\mathrm{Rh}(\mathrm{I})$ complexes and Pauson-Khand reaction.........................................57

Scheme 47: $\mathrm{Au}(\mathrm{I})$ complexes and Hydroamination of alkynes .................................57

Scheme 48: $\mathrm{Au}(\mathrm{I})$ complexes for Hashmi Phenol Synthesis ...................................58

Scheme 49: Chemoselective alkyne activation to trans $\alpha$-haloenones ..........................58

Scheme 50: $\mathrm{Au}(\mathrm{I})$ catalysis for activation of both alkyne and allene............................60

Scheme 51: Proposed $\mathrm{SN}_{2}{ }^{\prime}$ addition mechanism by Nolan .................................... 60

Scheme 52: Triazole-Gold Catalysis and acidic character .....................................61

Scheme 53: Challenge in homogeneous gold catalysis for selective acitvation ..............65

Scheme 54: Trapping the Allene by Proper Synthetic Partners ...................................66

Scheme 55: Proposed $\mathrm{SN}_{2}{ }^{\prime}$ Addition Mechanism by Nolan......................................67

Scheme 56: Proposed SN2' Addition Mechanism by Nolan ..................................... 68

Scheme 57: Screening of gold catalysts to propargyl ethers and test of racemization .....69

Scheme 58: Synthesis protocol of Chiral and Achiral propargyl vinyl ethers.................70 


\section{LIST OF FIGURES}

Figure 1: Tested Lewis Base Catalyst for Asymmetric Synthesis ............................... 19

Figure 2: Substrate scope of Aza-Michael addition for bicyclic nitro-esters ..................32

Figure 3: Substrate scope of Aza-Michael addition for Monocyclic nitro-esters............33

Figure 4: Substrate scope of with medicinally active function groups ..........................34

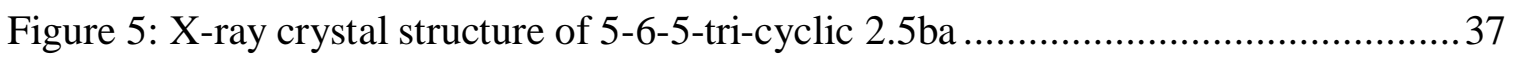

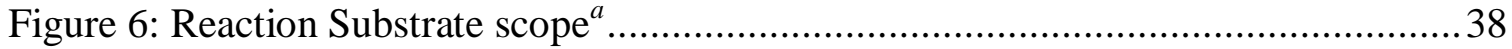

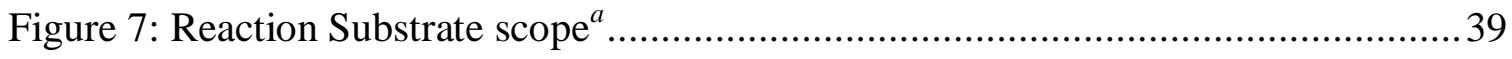

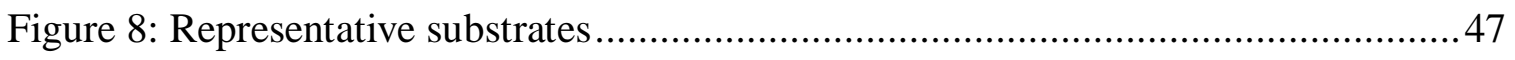

Figure 9: Reaction substrate scope for the formation of enantiopure piperidine ..............50

Figure 10: Triphenyl phosphine and NHC gold (I) catalysts .................................55

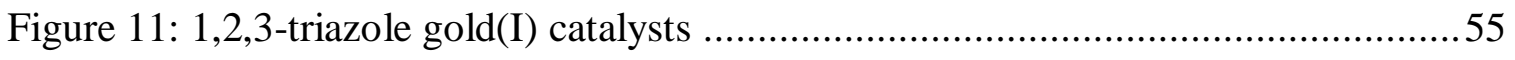

Figure 12: X-ray crystal structures of the two different types of 1,2,3 triazole-Au

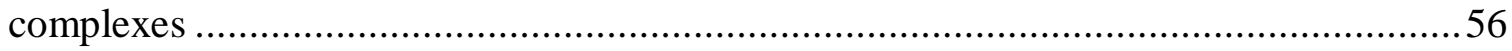

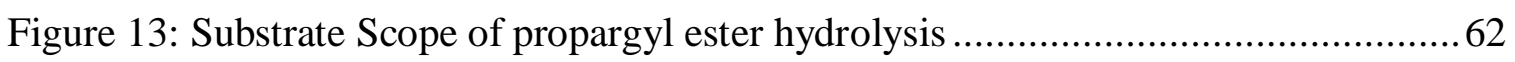

Figure 14: Substrate Scope of TA-Au catalyzed Meyer-Schuster rearrangement of

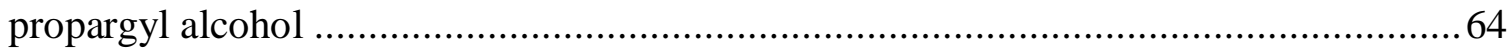

Figure 15: Reaction Substrate Scope of Chiral allenes ............................................ 71 


\section{LIST OF TABLES}

Table 1: Screening of Lewis base catalysis with various third components (Nu-LG)......16

Table 2: Substrate scope of the designed cascade reaction ........................................ 18

Table 3: Condition optimization of different auxiliaries in asymmetric synthesis ..........20

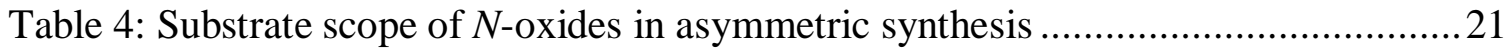

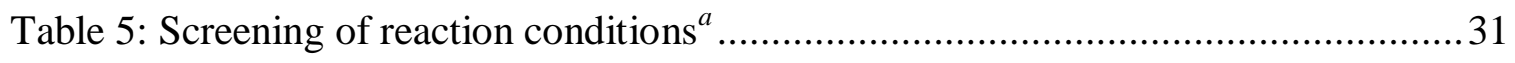

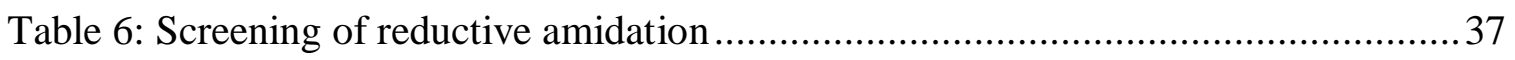

Table 7: $N$-deprotection of angular methyl PMB group...........................................49

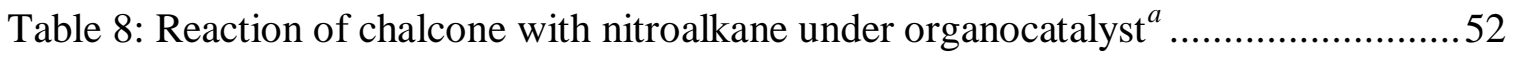

Table 9: Comparision with the best results obtained in the literature ...........................65 


\section{Chapter 1: Amine Nucleophilic Addition to Nitroalkene as a New Reaction Mode for the Stereoselective Synthesis of $N$ - Heterocycles}

\subsection{Introduction}

\subsubsection{Organocatalysis in Organic Synthesis}

In modern synthetic chemistry, unique organic transformations building complex architectures continues to be of great interests as well as their applications in both industry and academia. ${ }^{1}$ One of the fastest growing techniques to date, asymmetric organo-cascade catalysis, has been widely used to build the large collection of complex and challenging natural and artificial products and medicinal agent (Scheme 1). ${ }^{2}$ They are metal free nitrogen containing small organic molecule based catalysts which by high atom-step economic, environmentally benign process perform various organic syntheses development. ${ }^{3}$

\section{Scheme 1: Complex natural and medicinal products}

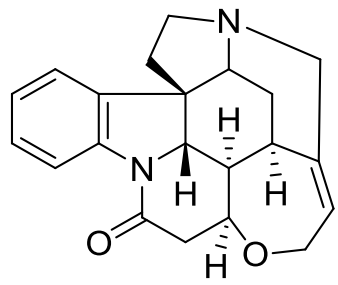

Strychnine

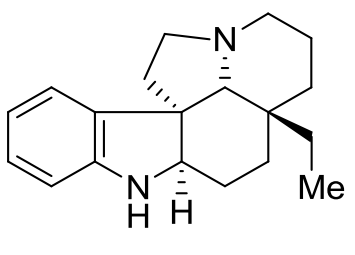

Aspidospermidine

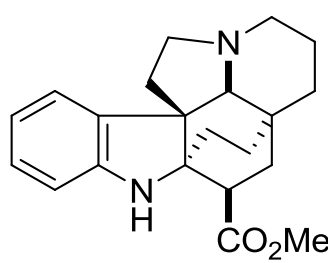

Kopsinine

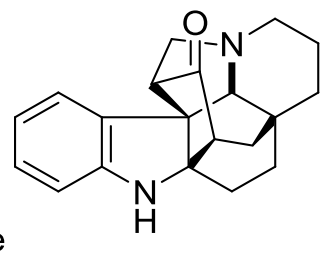

Kopsanone

The MacMillan and Jorgensen's enamine/iminium pyrolidine type catalysts are perfect examples of amines used in cascade reactions (Scheme 2). ${ }^{4}$

Scheme 2: Example of Pyrolidine type catalysts<smiles>O=C(O)C1CCCN1</smiles><smiles>[X][X]N1C(=O)C(Cc2ccccc2)NC1(C)C</smiles><smiles>[R]C(C)(C)C1NC(Cc2ccccc2)C(=O)N1C</smiles><smiles>CN1CC(Cc2ccccc2)NC1C(=O)O</smiles> 
The $\alpha, \beta$ conjugated aldehydes can be densely functionalized with both nucleophiles and electrophiles in one pot with an excellent levels of enantio and diastereoselection via the appropriate selection of amine catalysts (Scheme 3).

\section{Scheme 3: Iminium and enamine organocatalysis}

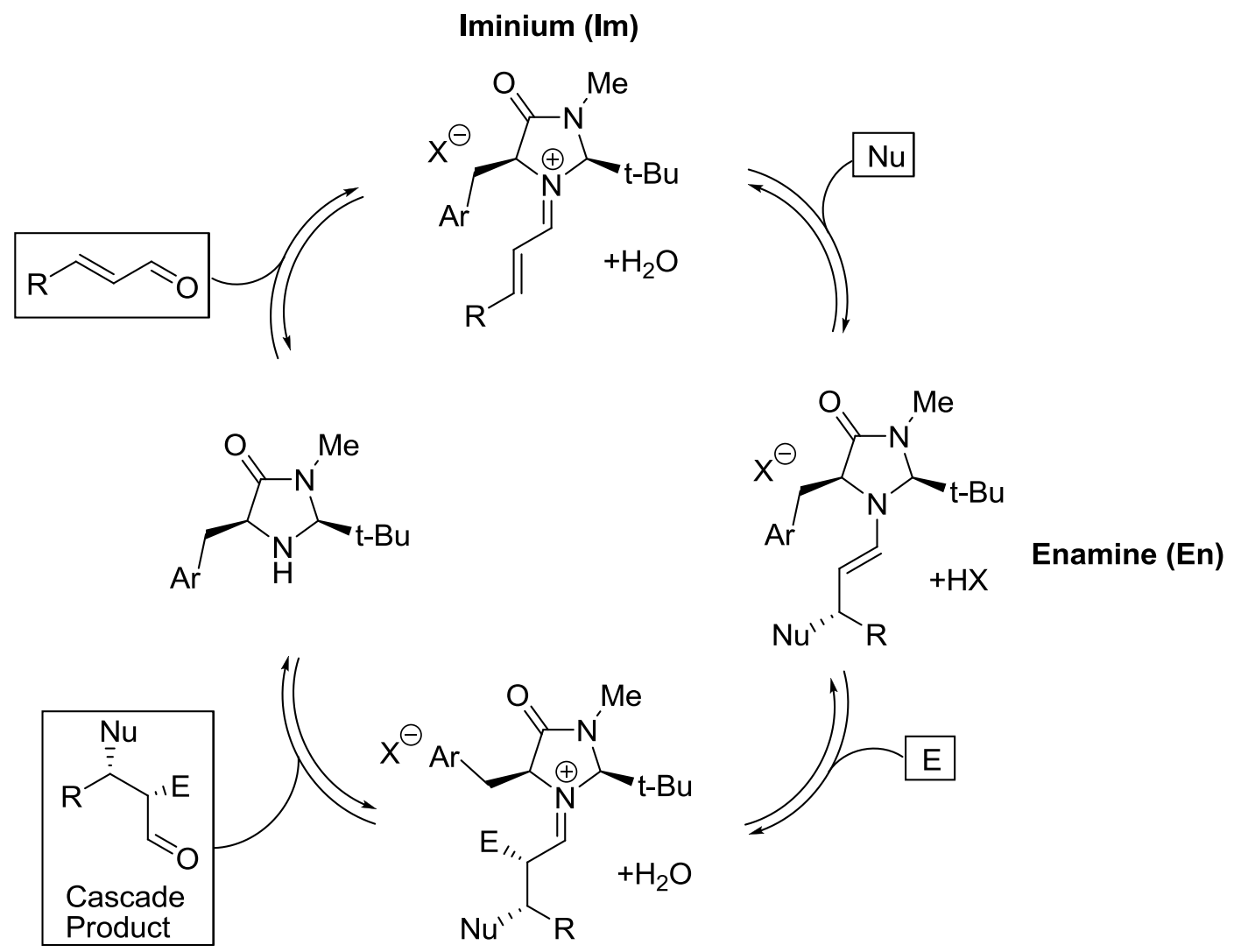

In addition, H-bonding from amine tethered thiourea, SOMO activation and counter ion strategies have been used extensively in organocatalysis (Scheme 4). ${ }^{5}$

Scheme 4: Other modes of organocatalysis

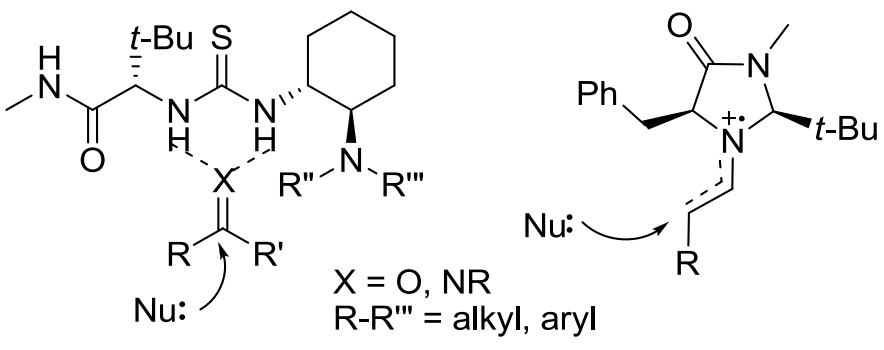

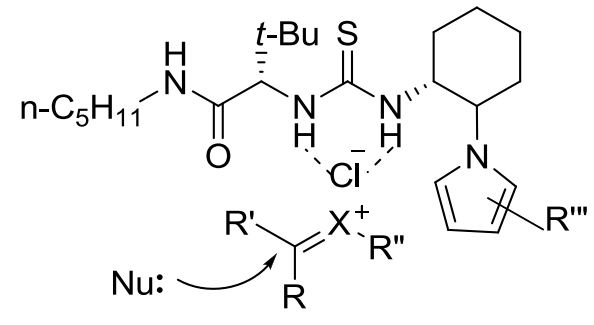


In this respect, proline, a privileged molecule has also been used widely as a universal asymmetric bifunctional catalyst in aldol type reactions because of its unique nucleophilic reactivity compared to other amines (Scheme 5). ${ }^{6}$

\section{Scheme 5: Modes of activation in proline catalysis}<smiles>O=C(O)[C@H]1CCCN1</smiles>

Bifunctional Acid/Base Catalysis

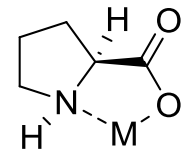

Metal Catalysis

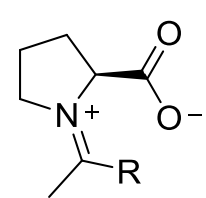

Iminium Catalysis<smiles>[R]C(=C)N1CCCC1C(=O)O</smiles>

Enamine Catalysis
(A)

$\underset{D M F}{(\mathrm{~L}) \text {-Proline }(10 \mathrm{~mol} \%)}$<smiles>[R]C(CC(C)=O)CC(C)=O</smiles>

Recently, enamine catalysis was combined together with other different catalysis successfully and discovered complicated molecules asymmetrically. For example, the addition of enamine to metal activated electrophile is a part of current catalysis research (Scheme 6). ${ }^{7}$

\section{Scheme 6: Metal catalysis combined with organocatalysis}

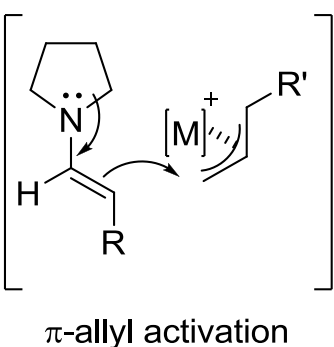

$\pi$-allyl activation

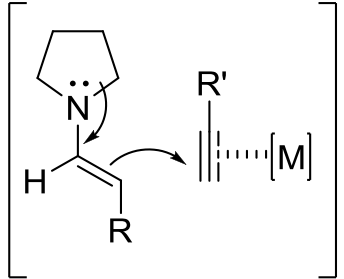

$\pi$-acid activation

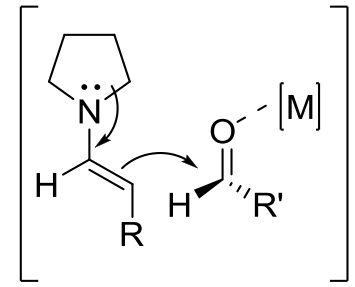

Enamine-aldol

\subsubsection{Lewis base catalysis of amines}

Though amines are well-known for enamine and iminium catalysis, there has been tremendous growth of nitrogen-containing Lewis-base catalysis over the past ten years. Actually, nitrogen containing Lewis bases accelerates the reaction by the action of an electron pair donor (of catalysts) to variety of unsaturated electron pair acceptors. Generally, they are called nucleophilic, $n-\pi^{*}$ interactions. In both cases the attack by the Lewis base 
leads to the formation of zwitterion intermediate with enhanced nucleophilic character at the oxygen atom. If a leaving group is present, this intermediate collapses to a new ionic species with enhanced electrophilic character (Scheme 7A). ${ }^{8 a}$ One example is tertiary amines such as $\mathrm{Et}_{3} \mathrm{~N}$, or 1, 4-diazabicyclo[2.2.2] octane (DABCO), which are typically used for the activation of enones/enals for Baylis-Hillman reaction; another example is the $\mathrm{sp}^{2}$ amine like compounds, such as 4-dimethylaminopyridine (DMAP) or pyridine which activate carbonyl functionalities (Scheme 7B). ${ }^{8 \mathrm{~b}-\mathrm{c}}$

\section{Scheme 7: Amine lewis base catalysis by organocatalysis}

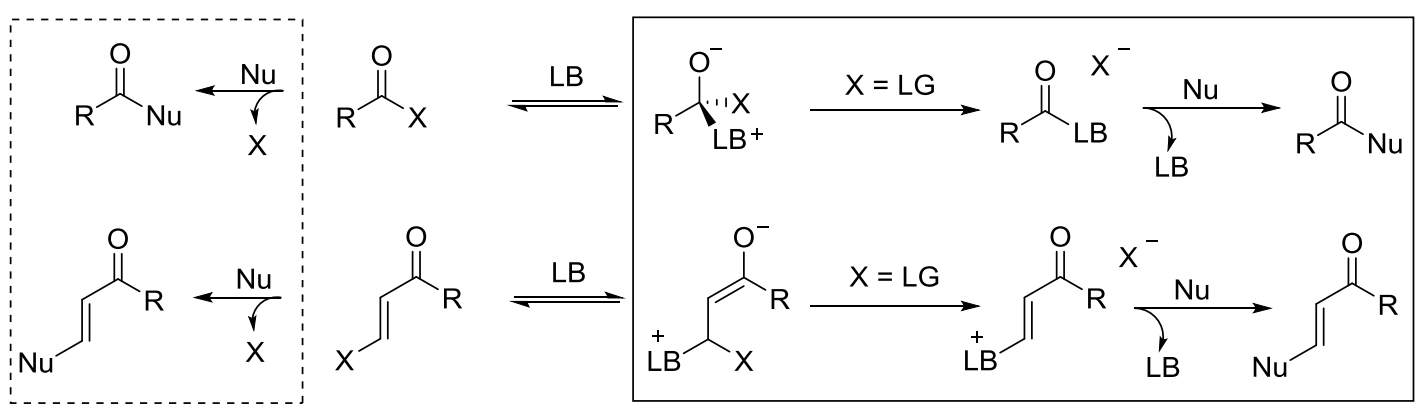

A

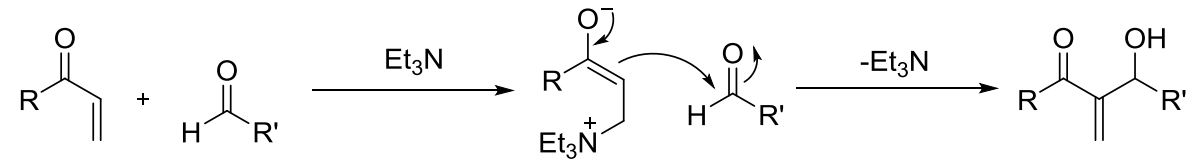

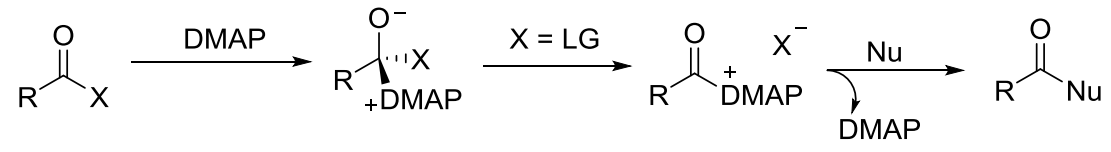

\subsection{Amine addition to Nitroalkene}

\subsubsection{Unique Design of New Reaction Mode and mechanism}

In early 2007, our research group reported the first successful intermolecular double-Michael addition between nitro and carbonyl activated olefins through Lewis base (L-Proline)catalyzed cascade reactions. $^{9 a}$ In this new reaction mode, the rationale of Morita-BaylisHillman reaction (Scheme 8A) were extended to cascade cross-conjugate addition (Scheme 8B). As proposed, the reaction was set up between $\beta$-nitrostyrene and cyclohexanone, unfortunately only 32\% isolated yield (Scheme 8C) of allylic nitro product obtained. In situ 
NMR analysis showed cyclohexanone being a weaker Michael acceptor, favoring nitroalkene homopolymerization. ${ }^{9 b}$ After a careful investigation, it has been found that introducing methyl group to the $\alpha$-position of $\beta$-nitrostyrene provided excellent yield (Scheme 8D). This discovery initiated the previously unexplored field of Lewis base catalysis with amines.

\section{Scheme 8: Extension of cross-conjugate addition}

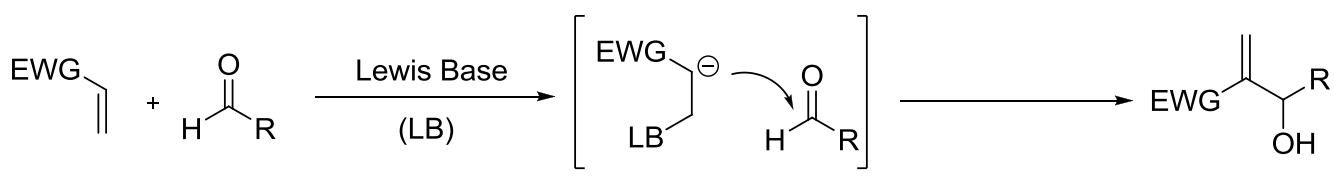

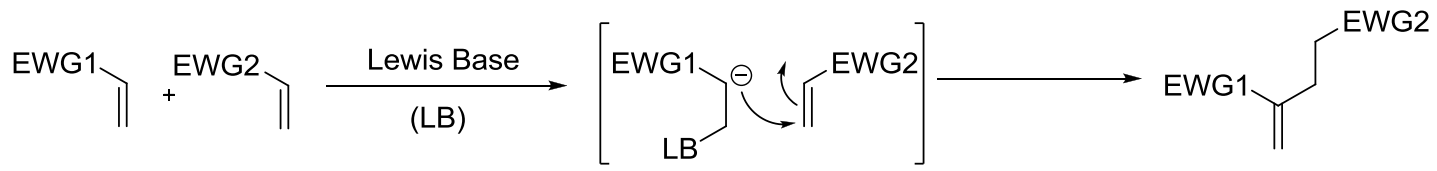

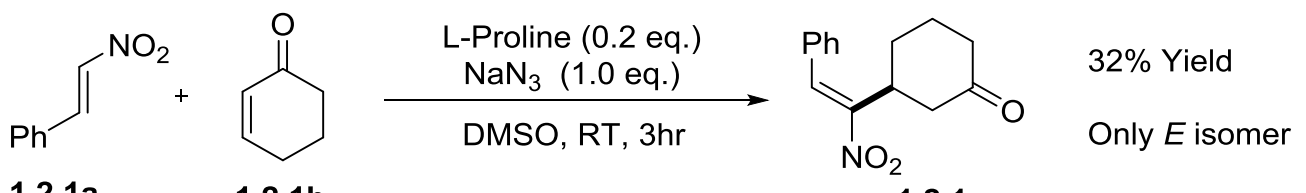

1.2.1a

1.2.1b

1.2.1c

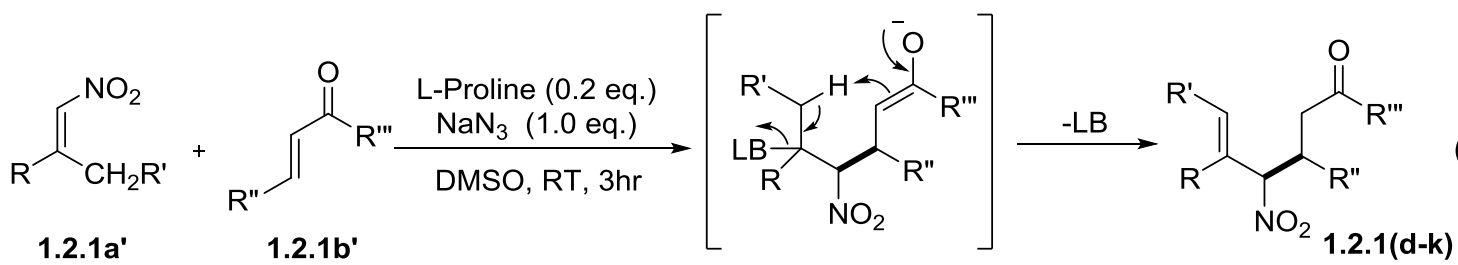

$R, R^{\prime}, R^{\prime \prime}=$ Aliphatic, Aromatic $\mathrm{R}^{\prime \prime \prime}=$ Ketone or ester both $70-90 \%$ Yield Cyclic and acyclic<smiles>C=C(c1ccccc1)C(C1CCCC(=O)C1)[N+](=O)[O-]</smiles>

1.2.1d, $87 \%$, d.r. $1: 1$<smiles>O=C1CCCC(C(C2=CCCCC2)[N+](=O)[O-])C1</smiles>

1.2.1h, $90 \%$, d.r. $1.2: 1$<smiles>C=C(c1ccccc1)C(C(CC(=O)c1ccccc1)c1ccccc1)[N+](=O)[O-]</smiles><smiles>O=C1CCCC(C2([N+](=O)[O-])C=CCCC2)C1</smiles>

1.2.1e, $70 \%$, d.r. $1.6: 1$

1.2.1f, $76 \%$, d.r. $1.3: 1$<smiles>C=C(c1ccccc1)C([N+](=O)[O-])C(C)(C)CC(C)=O</smiles>

1.2.1j, $45 \%$

1.2.1i, $82 \%$, d.r. $1.1: 1$<smiles>CC(=O)C(C)CC1([N+](=O)[O-])C=CCCC1</smiles>

1.2.1g, $92 \%$, d.r. $2: 1$<smiles>CCCCCC(C)(C=CC(C)C)C(C)CC(C)=O</smiles><smiles>C=C(c1ccccc1)C(CCC(=O)OC)[N+](=O)[O-]</smiles>

$1.2 .1 \mathrm{k}, 89 \%$ 
After a brief substrate scope development, a detailed mechanistic investigation was performed. It is found that secondary amine as a Lewis base activates nitroalkene and forms a zwitterion (A) and nitronate (B) which are stabilized by resonance and H-bond in equilibrium. Sequential addition of the proper electrophile followed by $\beta$-elimination releases the secondary amine catalyst to give the allylic nitro products (Scheme 9). During the reaction, the formation of a hydrogen bonded intermediate (B) prevented possible polymerization, which was the key side reaction with other nucleophilic catalysts, such as DMAP, $\mathrm{PPh}_{3}$ and DABCO.

\section{Scheme 9: Mechanism of amine activation of nitroalkenes}

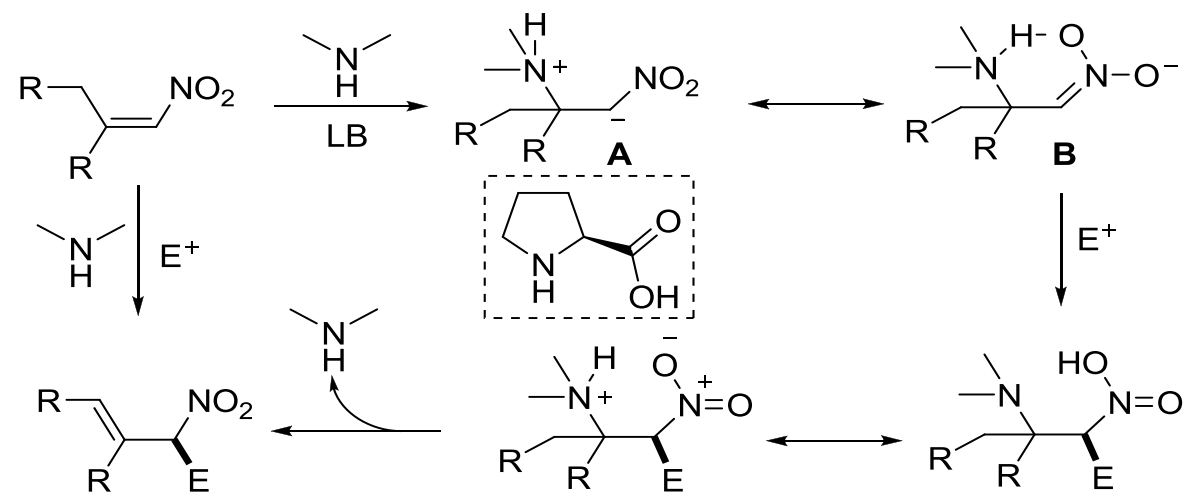

\subsubsection{Enantioselective cross-conjuagate addition of nitroalkenes to enals}

Based on the aforementioned study, asymmetric cross-conjugate reaction was explored in the presence of chiral secondary amines using dual activation approach to form chiral allylic nitro compounds. During transformation, the chiral secondary amine activated enal to form electron deficient iminium intermediate in one hand and nitroalkene to form carbanion nitronate for Michael addition on the other hand. With the aid of trimethoxyphosphine as a nucleophile, conjugated addition products were formed in good to excellent yields and enantioselectivity (Scheme 10). ${ }^{10}$ Aliphatic and aromatic disubstituted nitroalkenes as well as variety of enals performed this transformation. 


\section{Scheme 10: Selected substrates of cross-conjugate addition of nitroalkenes to enals}

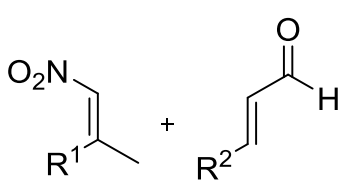

$1.2 .1 a^{\prime}$
1.2.1 b'
1) Cat. (0.2 eq)

$(\mathrm{MeO})_{3} \mathrm{P}(1.0$ eq.

$\mathrm{MeOH},-25^{\circ} \mathrm{C}, 48-60 \mathrm{hr}$

2) $\mathrm{MeOH}, \mathrm{NaBH}_{4}, \mathrm{RT}, 2 \mathrm{hr}$<smiles>[R]C(=C)C([R])C([R])CCO</smiles>

1.2 .2

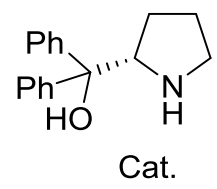

Cat.

Up to $93 \%$ yield, up to $94 \%$ ee

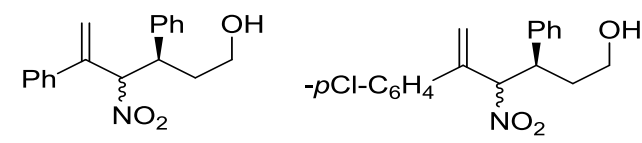

1.2.2a, $91 \%$, d.r. $1: 1.2$ ee $91 \% / 93 \%$ 1.2.2b, $89 \%$, d.r. 1:1.2 ee $88 \% / 90 \%$

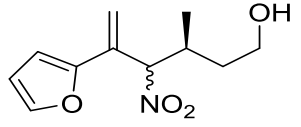

1.2.2c, $64 \%$, d.r. $1: 1.1$ ee $88 \% / 90 \%$<smiles>C=C(N[N+](=O)[O-])[C@H](CCO)[C@H](CCO)ON(C)O</smiles>

1.2.2d, $82 \%$, d.r. $1: 1.3$ ee $90 \% / 88 \%$

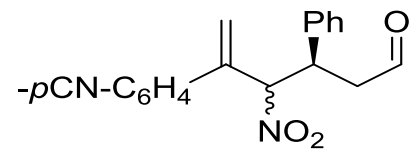

1.2.2e, $86 \%$, d.r. 1:1 ee $80 \% / 82 \%$<smiles>C=C(CCO[N+](=O)[O-])[C@H]([C@H](CC=O)c1ccccc1)[N+](=O)[O-]</smiles>

1.2.2f, $79 \%$, d.r. $1: 1$ ee $77 \% / 81 \%$<smiles>O=[N+]([O-])C(C1=CCCCC1)[C@H](CCO)Pc1ccccc1</smiles>

1.2.2g, $75 \%$, d.r. $1: 2$ ee $70 \% / 75 \%$

\subsubsection{Diastereoselective cascade synthesis of Nitro-substituted cyclohexanes}

With the foundation of proline promoted cross conjugate addition developed, the designed Michael-Michael-Aldol cascade condensation of nitroalkenes and enones were also finished successfully for the synthesis of multi-substituted cyclohexanes. In this strategy, the active nucleophile $\mathbf{E}$, formed from Lewis base activation to nitroalkene followed by conjugate addition to Michael acceptor, added to the second Michael acceptor through Michael addition and formed dicarbonyl compound. Finally, intramolecular aldol reaction leads to the formation of substituted cyclohexanes $\mathbf{G}$ (Scheme 11). ${ }^{11}$

\section{Scheme 11: Michael-Aldol condensation of nitroalkenes to enones}<smiles>[R]CC([R])=C[N+](=O)[O-]</smiles>

A<smiles>[R]CC([R7])([R])C(CCC(=O)P)[N+](=O)[O-]</smiles>

B

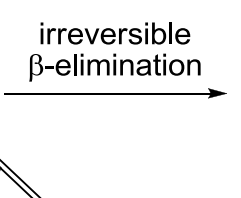<smiles>[R]C=C([R])C(CCC([R])=O)[N+](=O)[O-]</smiles>

C

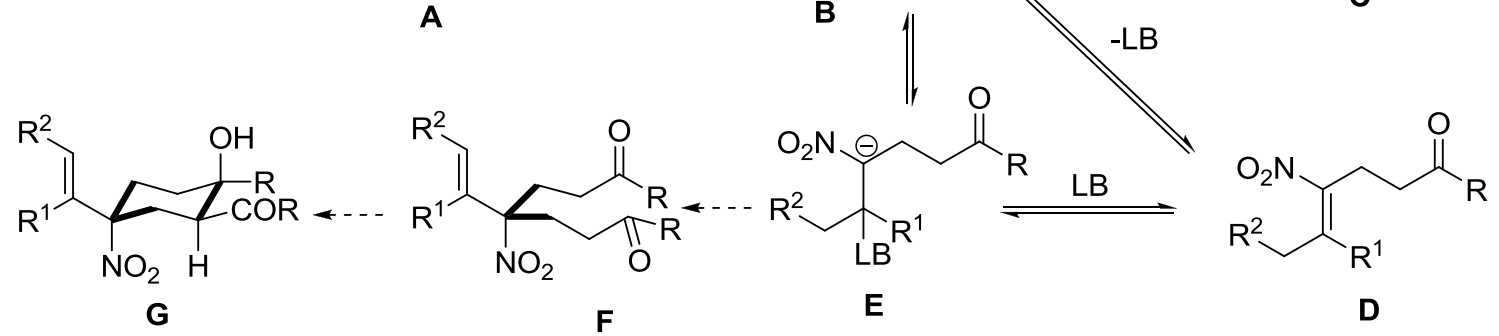


The optimal condition for this cascade synthesis is triethylamine $\left(\mathrm{Et}_{3} \mathrm{~N}\right)$ or sodium azide $\left(\mathrm{NaN}_{3}\right)$ in a stoichiometric amount with organocatyst L-proline in a catalytic amount $(0.2$ mol\%) in the presence of excess unsaturated enone. This Michael-Michael-Aldol condensation gave an excellent yield and diastereoselectivity (Scheme 12). Although enantioselective condensation of dicarbonyl compounds by L-proline were reported in the literature, ${ }^{12}$ poor enantioselectivity were obtained in this cross-conjugate reaction ( $<20 \%$ ee in all cases). Further investigations are required to understand the mechanism and stereochemistry.

\section{Scheme 12: Diastereoselective cross-conjugate addition of nitroalkenes to enones}

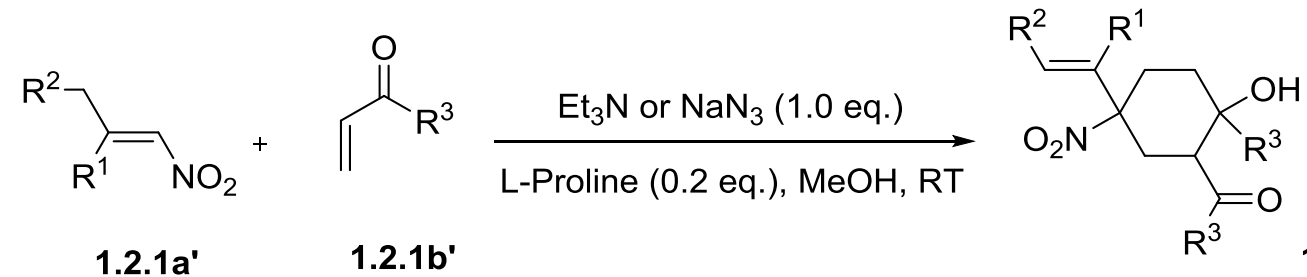

upto $92 \%$ yield and $14: 1$ d.r.

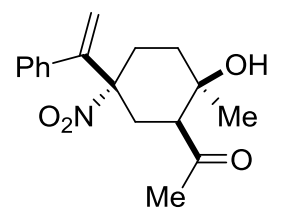

1.2.3a, $90 \%$, d.r. $3.7: 1$

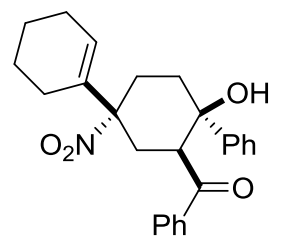

1.2.3e, $82 \%$, d.r. $14: 1$

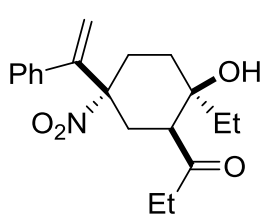

1.2.3b, $81 \%$, d.r. $3.2: 1$

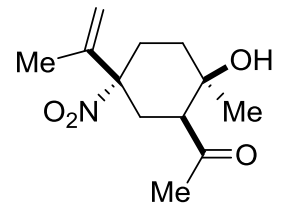

1.2.3f, $80 \%$, d.r. $4.5: 1$

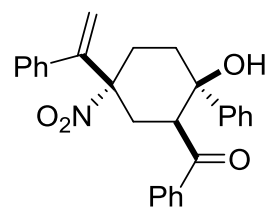

1.2.3c, $82 \%$, d.r. $8.2: 1$

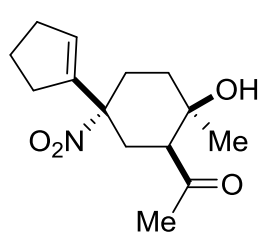

1.2.3g, $76 \%$, d.r. 5:1

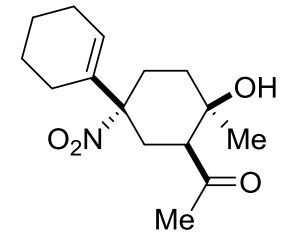

1.2.3d, $88 \%$, d.r. $6.1: 1$

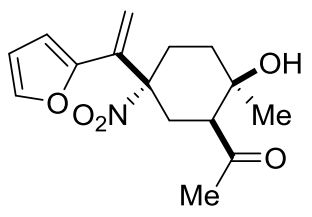

1.2.3h, $76 \%$, d.r. $3: 1$ 


\subsubsection{One pot multicomponent condensation to the synthesis of substituted dihydrofurans and substituted triazoles}

The lesson learned from the Lewis base catalysed nitroalkene mechanism for the formation of the nitrodiene intermediate, various multicomponent cascade processes were invented with the incorporation of dinucleophile species as shown in Scheme 13 A, B and C below. ${ }^{13}$

\section{Scheme 13: Proposed DHF and Triazole synthesis}

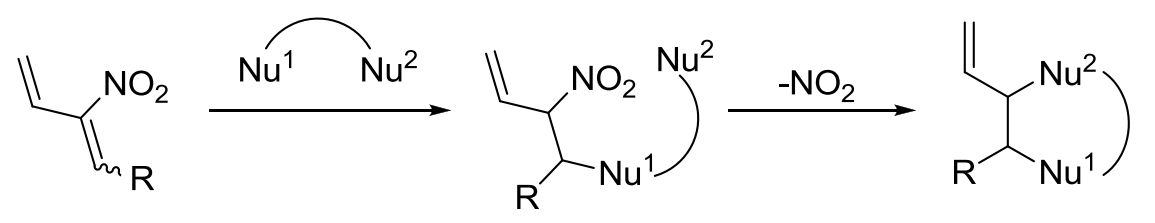

A
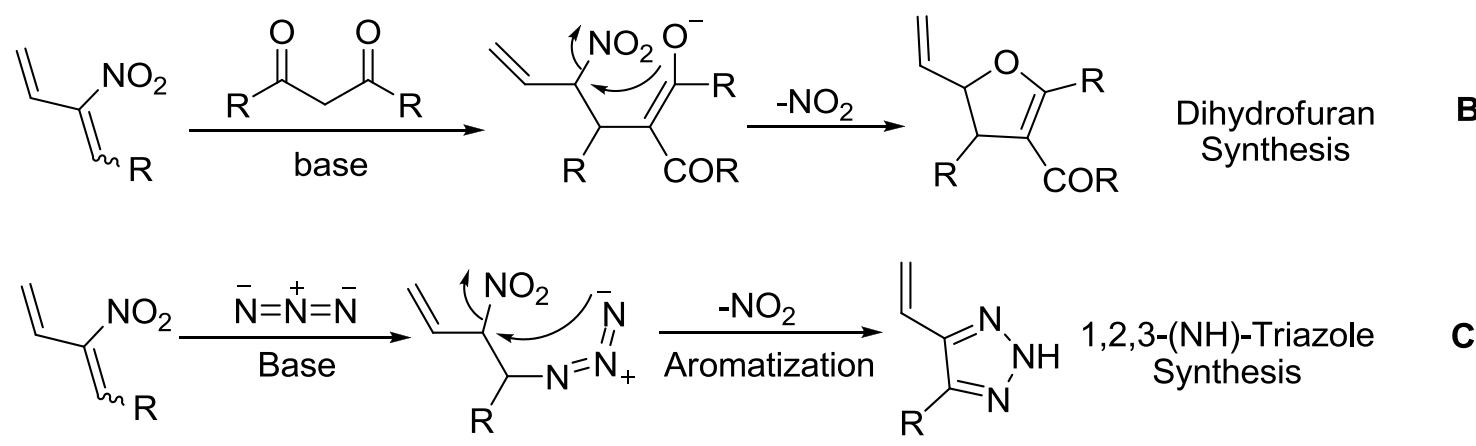

With the application of 1,3 -diketones or $\beta$-ketoesters, successive addition to nitrodiene intermediate lead to the formation of varied dihydrofurans in one pot pattern. C-2 and C-3 functionalized trans-isomers were obtained with great diversity, high efficiency and excellent diastereoselectivity (Scheme 14). 


\section{Scheme 14: Substrate scope of the three component dihydrofuran synthesis}<smiles>[R]C/C([R])=C/[N+](=O)[O-]</smiles>

1.2.1 $\mathrm{a}^{\prime}$<smiles>[R]C(=O)CC([R])=O</smiles><smiles>[R]C=C([R])[C@@H]1OC([R])=C(C([R4])=O)[C@H]1[Al]</smiles>

1.2.4 (a-h) Single trans isomer Upto $95 \%$ yield<smiles>C=C(c1ccccc1)C1OC2=C(C(=O)CCC2)[C@H]1[O]</smiles>

$1.2 .4 a, 91 \%$<smiles>C=C(C1=C(C)OC(C(C)=O)[C@H]1c1ccc([N+](=O)[O-])cc1)c1ccccc1</smiles>

$1.2 .4 e, 94 \%$<smiles>C=C(c1ccccc1)C1OC2=C(C(=O)CCC2)[C@H]1c1cccs1</smiles>

1.2.4b, $81 \%$<smiles>C=C(c1ccco1)C1OC(C)=C(C(C)=O)[C@H]1c1ccc(OC)cc1</smiles>

$1.2 .4 f, 83 \%$<smiles>C=C(c1ccccc1)[C@H]1OC(C)=C(C(=O)OC)[C@H]1c1ccncc1</smiles>

$1.2 .4 c, 93 \%$<smiles>C=C(C)[C@H]1OC(C)=C(C(C)=O)[C@H]1c1ccc([N+](=O)[O-])cc1</smiles>

$1.2 .4 \mathrm{~g}, 85 \%$<smiles>C=C(c1ccccc1)[C@H]1OC(C)=C(C(C)=O)[C@H]1CCC</smiles>

$1.2 .4 \mathrm{~d}, 65 \%$<smiles>O=C1CCCC2=C1C([18O])OC2C1=CCCCC1</smiles>

1.2.4h, $92 \%$

The discovery of click chemistry, from 1,3 dipolar addition of azides ${ }^{14}$ to triple bond which provided various five membered heterocycles, brought our research interest to recognize azides in our new Lewis base catalysis concept. Our strategy was based on azide anion $\left(\mathrm{N}_{3}{ }^{-}\right)$ addition to a nitrodiene to give disubstituted 1,2,3-(NH)-triazole cycloaddition product in one pot with the elimination of nitrite anion $\left(\mathrm{NO}_{2}^{-}\right)$. A large number of aryl aldehydes and $\beta$ alkyl nitroalkenes were suitable for this transformation to provide good yields under this mild cascade process (Scheme 15). This synthesis started the possibility of its use for promising chemical and biological applications. ${ }^{15}$ 


\section{Scheme 15: One pot three component synthesis of 1,2,3 triazoles}

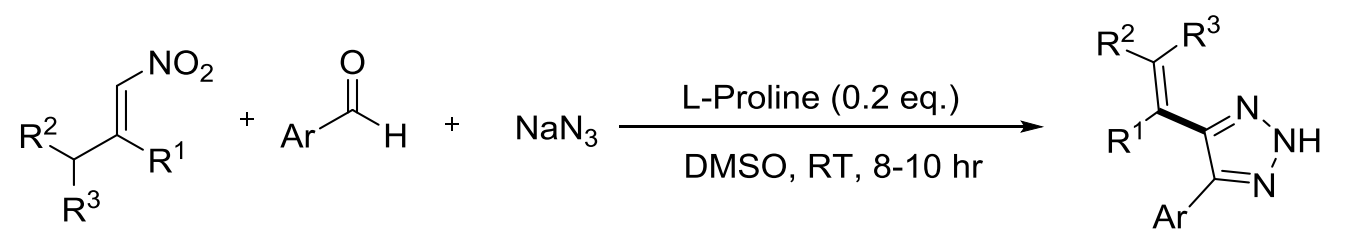

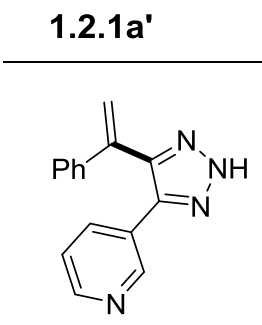

1.2.4i, $76 \%$

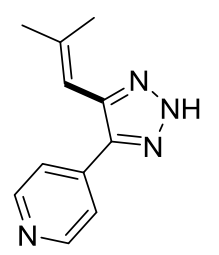

1.2.4m, 56\%
$1.2 .4 b^{\prime}$

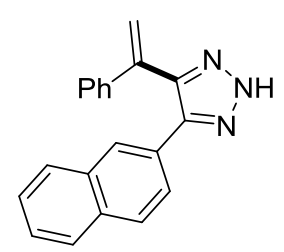

1.2.4j, 81\%

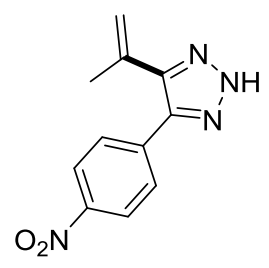

$1.2 .4 n, 58 \%$

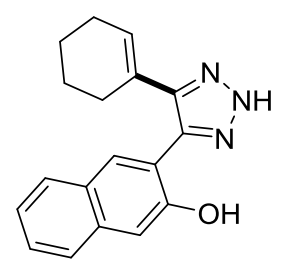

1.2.4k, $65 \%$

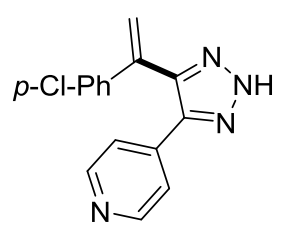

1.2.4o, $81 \%$
1.2.4 (i-p) Upto $89 \%$ yield

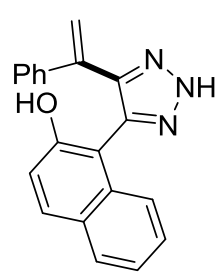

1.2.4I, $56 \%$<smiles>C=C(c1ccccc1)c1n[nH]nc1-c1ccc([N+](=O)[O-])cc1</smiles>

$1.2 .4 p, 58 \%$

\subsection{Stereoselective isoxazoline- $N$-oxide synthesis}

\subsubsection{Introduction}

As mentioned earlier, reactions catalyzed by small chiral organic molecules so called proline analogues were rapidly uncovered due to their accessibility and synthetic efficiency. Iminium/enamine formation and Lewis base catalysis are the two fast growing areas in asymmetric organocatalysis. But, the application of secondary and primary amines as a Lewis base catalyst is much less developed. Experimental and computational studies suggested that L-proline served as an effective Lewis base catalyst for activation of the nitroalkene. In 2008, Shi's group disclosed the reaction of nitroalkenes with electron enriched olefins to form isoxazoline- $N$-oxides based on plausible 1,3-dipolar site of $\mathrm{H}$ bonded nitronate ion for cycloaddition via mechanistic interpretation, as shown below (Scheme 16). ${ }^{16}$ 


\section{Scheme 16: One step formation of isoxazoline- $N$-oxide}

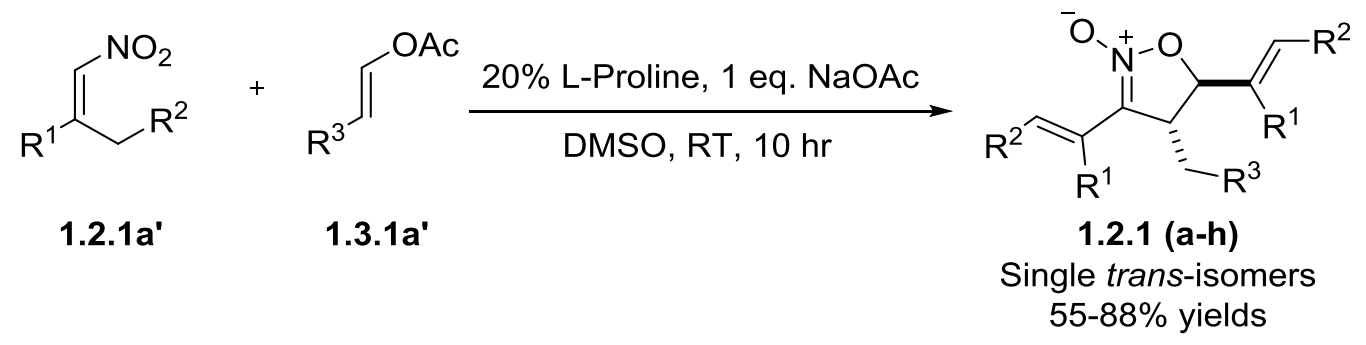

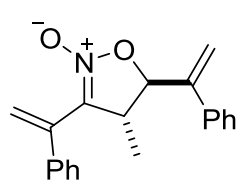

1.3.1a, $88 \%$

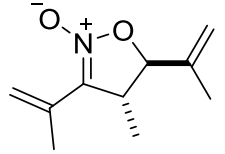

1.3.1e, $55 \%$

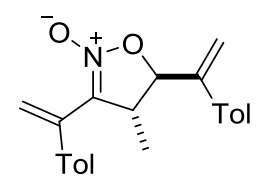

1.3.1b, $83 \%$

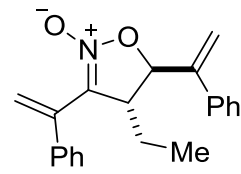

1.3.1f, $76 \%$

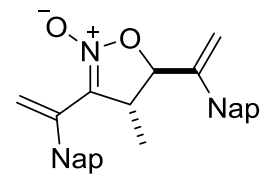

1.3.1c, $75 \%$

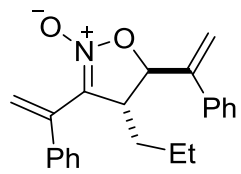

1.3.1g, $71 \%$

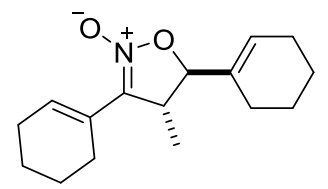

1.3.1d, $72 \%$

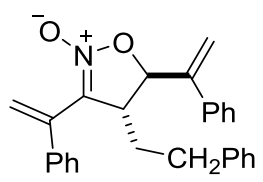

1.3.1h, $65 \%$

The mechanistic investigation of this compelling conversion revealed that the [3+2] cyclization between the L-proline-activated nitroalkene and vinyl ester involved the formation of 1,3-diene (A) as an active intermediate. Subsequent conjugate addition of the second $\alpha$-nitro-carbanion leads to the formation of dinitro-intermediate (B). Additional intramolecular cyclizations give the isoxazoline- $N$-oxides (Scheme 17). This cascade route became more fascinating because it produces diene intermediate $\mathbf{A}$ in-situ which allowed the easy construction of $\mathrm{N}$-oxides in contrast to the other challenging reported methods. Moreover, this reaction mode turned out to be milder and two vinyl groups were introduced at the C-3 and C-5 position. Nonetheless, even with the high potency of these isoxazoline-Noxides synthesis, this cascade reaction has faced three distinct problems.

a) The C-4 substitution has to be aliphatic.(Aliphatic Vinyl acetate)

b) C-3 \& C-5 positions have to be the same. (Same nitroalkene)

c) No enantioselectivity is observed when chiral secondary amines were used.

If we were able to solve those innate problems, there will be the successful discovery of concise synthesis of the isoxazoline- $N$-oxide molecules. 
Scheme 17: Proposed reaction mechanism for the synthesis of isoxazoline-N-oxides.

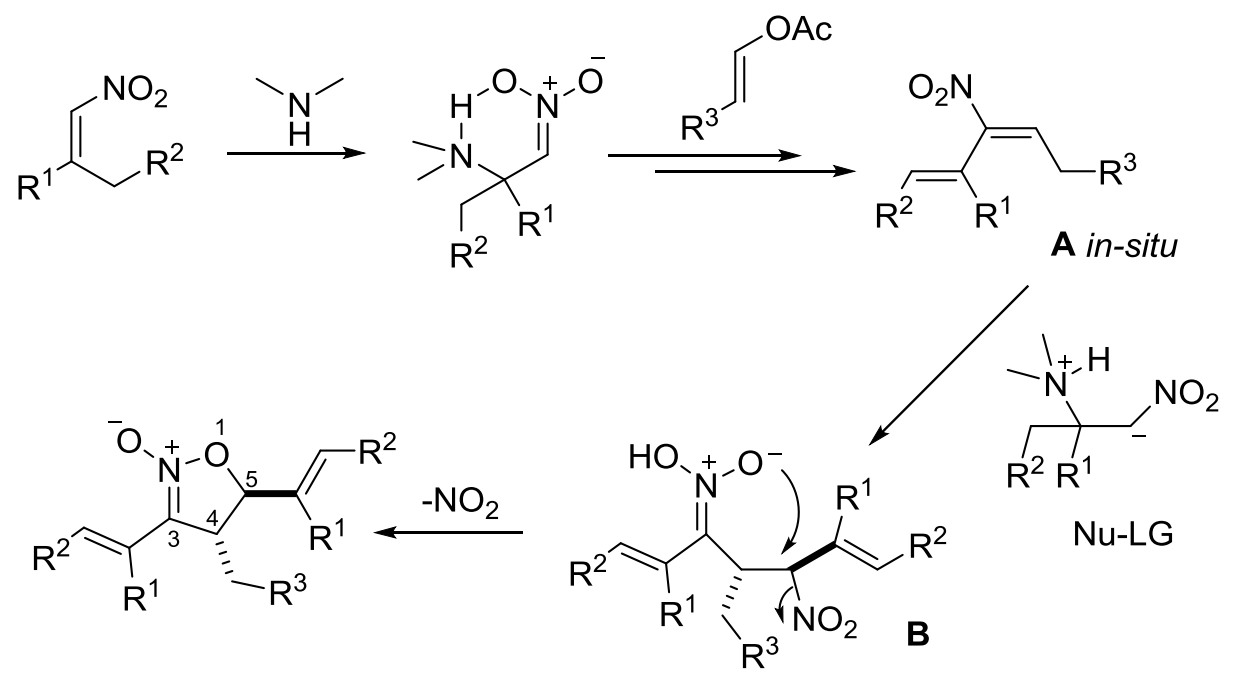

\section{$1.4 \quad$ Research objectives}

\subsubsection{Asymmetric multicomponent synthesis of isoxazoline- $N$-oxide}

To overcome the previous constraint, functional groups at the C-3, C-4, and C-5 positions have to be studied. Special exploration of chiral bases and auxiliaries needs to be done for asymmetric synthesis towards biologically active natural products and their derivatives synthesis.

\subsubsection{Application towards natural products synthesis}

After the recognition of broad synthetic strategy, a comprehensive study of natural products is necessary to find out a similar backbone or easier steps. The multi-functional nature of isoxazoline- $N$-oxide will help to devise synthetic routes to natural products synthesis.

\subsubsection{Henry aldol strategy to isoxazoline- $N$-oxide synthesis}

Similar to the nitro-aldol reaction, nitroalkene under organocatalytic condition produces a resonance stabilized anion which after reaction with carbonyl compounds especially aromatic

\footnotetext{
* Reproduced in parts with permission from Tetrahedron 2011, 67, 4402-4411. Copyright 2011, with permission from Science Direct/Elsevier B. V
} 
aldehyde, produces homo-isoxazoline- $N$-oxide 1.4.3. So, broader substrate scope can be achieved on the C-4 position (Scheme 18).

\section{Scheme 18: Proposed proline catalysed Isoxoazoline-N-oxide syntheisis}

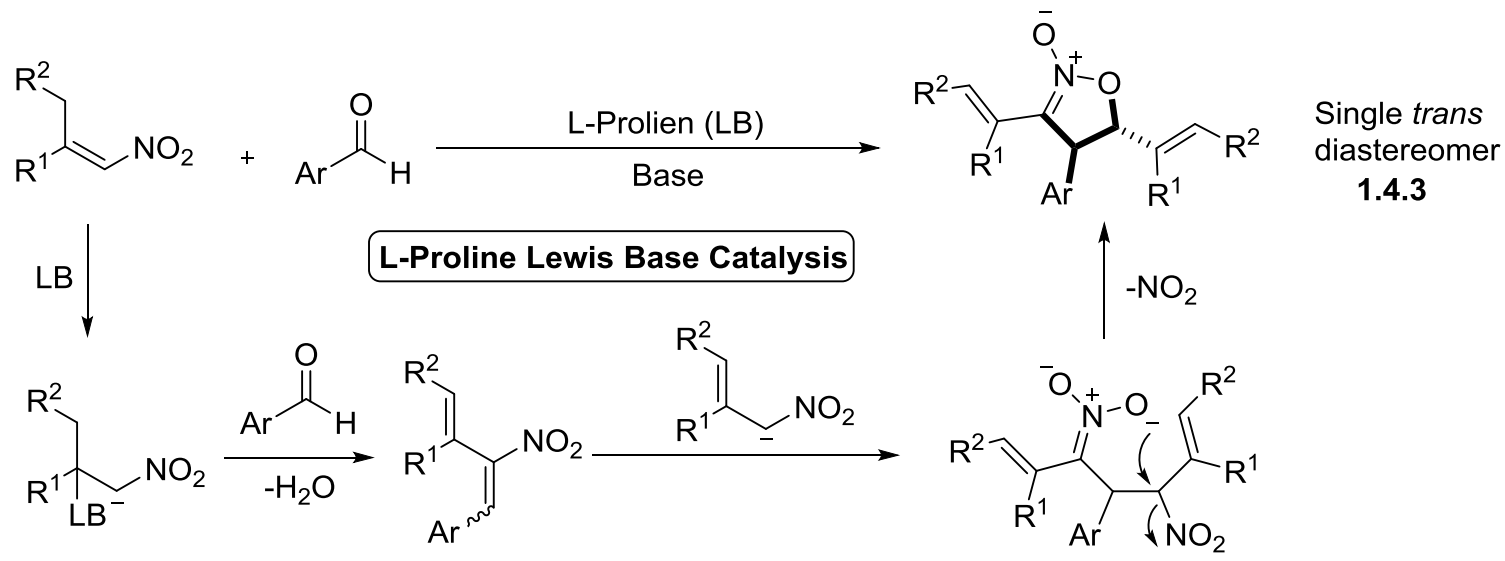

A reaction optimization study found that only proline or a weak base such as $\mathrm{NaOAc}$ had an incomplete reaction. Neutralization and polymerization were found as the major side reactions. However, on combining proline (0.2 eq.) and $\mathrm{NaOAc}(1.0$ eq.) in DMSO the reaction was completed within three hours. Even the pyrrolidine with $\mathrm{K}_{2} \mathrm{CO}_{3}$ ( 0.5 eq.) was found effective for this transformation. To confirm this reaction as a Lewis base catalyzed transformation, the allylic nitro compound was prepared and the reaction was performed. As intended, this reaction was slower with very low yield (Scheme 19).

\section{Scheme 19: Experimental confirmation of Lewis base catalysis}

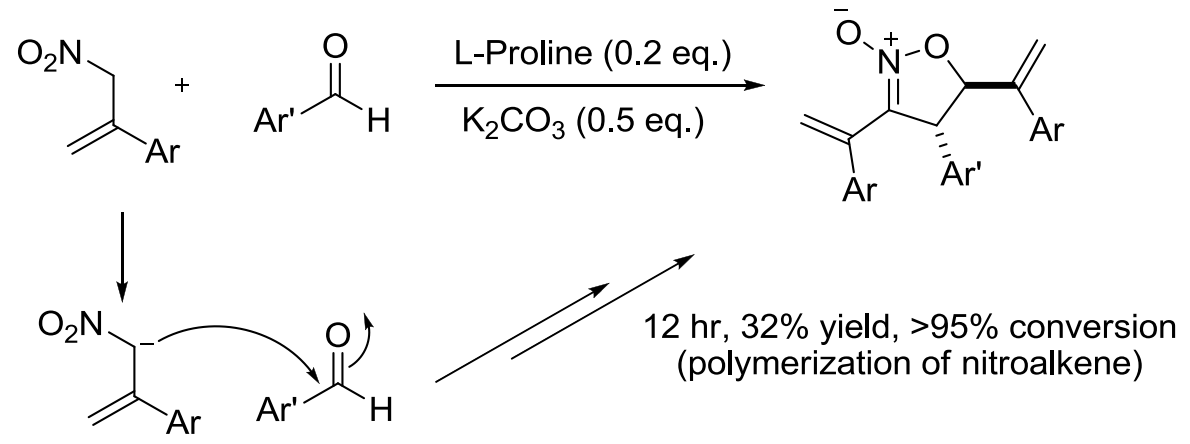

As expected, with the optimal condition in hand, excellent diastereoselectivity was accomplished and only trans products were obtained. Both aliphatic and aromatic nitroalkenes provided reasonable yields. Simple aromatic to heteroaromatic aldehydes 
performed well and gave good to excellent yields. Aliphatic aldehydes showed less reactivity. As a result, side reactions vanquished the desired route due to the formation of enamines. Overall, variety of functional groups can easily be incorporated into the C-4 position with high efficiency (Scheme 20).

\section{Scheme 20: Homo-isoxazoline- $N$-oxide scope}

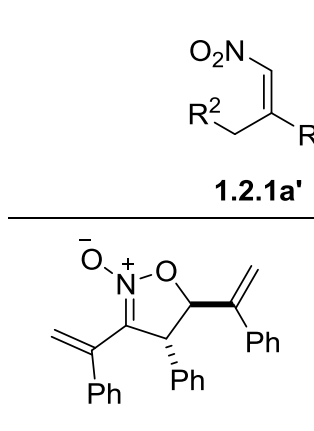

$1.4 .3 a, 92 \%$

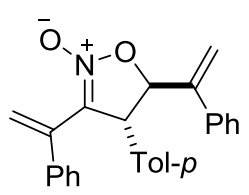

$1.4 .3 e, 93 \%$<smiles>O=[N+]([O-])OCCCCC1C(C2=CCCCC2)=[N+]([O-])OC1C1=CCCCC1</smiles>

$1.4 .3 i, 92 \%$
$\mathrm{Ar}_{\mathrm{H}}^{\mathrm{O}}$

1.2.4b'

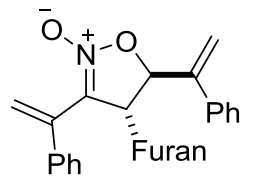

$1.4 .3 \mathrm{~b}, 85 \%$

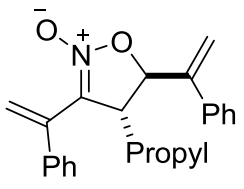

$1.4 .3 f, 61 \%$

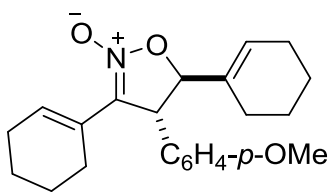

$1.4 .3 \mathrm{j}, 90 \%$
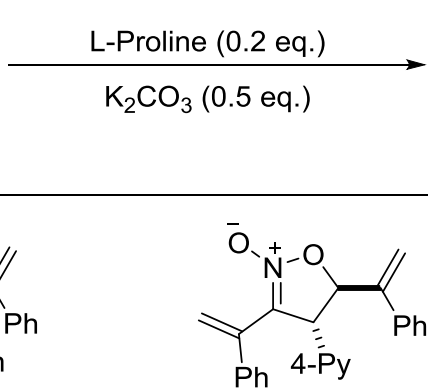

$1.4 .3 \mathrm{c}, 91 \%$

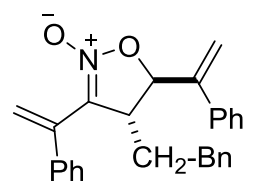

$1.4 .3 \mathrm{~g}, 57 \%$

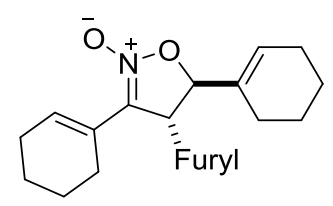

$1.4 .3 \mathrm{k}, 89 \%$

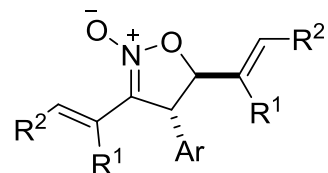

1.4.3 (a-q)

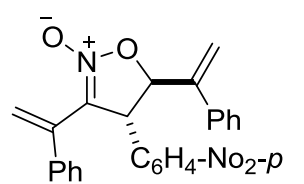

$1.4 .3 d, 95 \%$

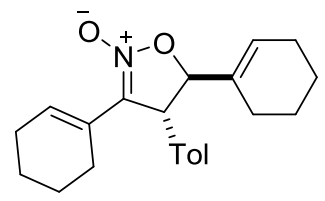

1.4.3h, $94 \%$

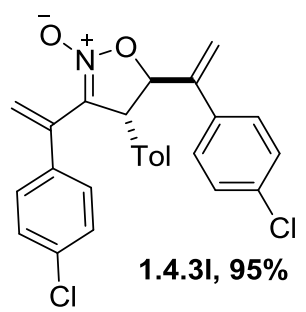<smiles>C=C(C1=[N+]([O-])OC(C(=C)c2ccc(Cl)cc2)[C@@H]1C(=O)c1ccccc1)c1ccc(Cl)cc1</smiles>

$1.4 .3 \mathrm{~m}, 87 \%$

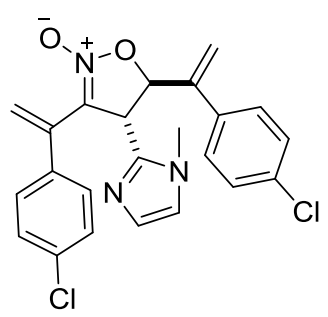

$1.4 .3 n, 87 \%$

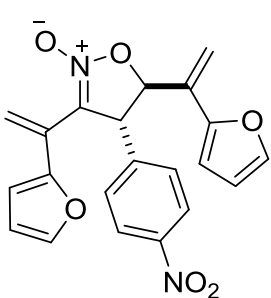

$1.4 .30,46 \%$<smiles>C=C(C)C1=[N+]([O-])OC(C(=C)C)[C@H]1c1ccc(OC)cc1</smiles>

$1.4 .3 p, 74 \%$

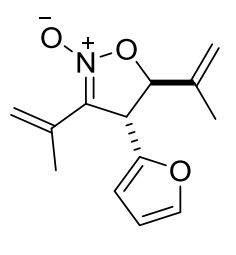

$1.4 .3 q, 71 \%$

Substrate scope study showed this route could be an alternative approach to our previously reported [3+2] cyclization strategy for the synthesis of desired products. So, large diversity in the synthesis of iso-oxazoline- $N$-oxides can be easily done with high efficiency and stereoselelctivity. 
Scheme 21: Substrates screening for the third component (Nu-LG)

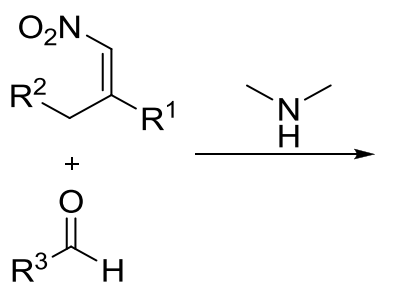<smiles>[R]C=C([R])/C(=C\[R])[N+](=O)[O-]</smiles>

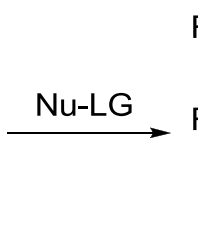<smiles></smiles><smiles>[R]/C=C(/[R])C1=[N+]([O-])ONC1[R]</smiles>

A

\subsubsection{Strategies for the third component (Nu-LG) to isoxazoline-N-oxide}

Based on the Lewis base catalyzed mechanism, thorough screenings of third components as a nucleophile were done (Scheme 21). Previous studies confirmed that diene A is the key reactive species. ${ }^{16}$ So, if the third component with the structural feature like Nu-LG (with nucleophile and leaving group on the same molecule) reacted with diene, there might be the variety of substitution on isoxazoline- $N$-oxide.

Table 1: Screening of Lewis base catalysis with various third components (Nu-LG)

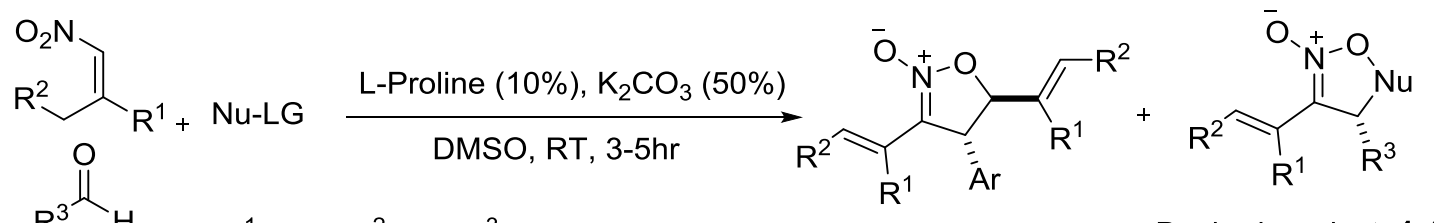

$$
\mathrm{R}^{3^{3}} \mathrm{H} \quad \mathrm{R}^{1}=\mathrm{Ph}, \mathrm{R}^{2}=\mathrm{H}, \mathrm{R}^{3}=\mathrm{Ph} \quad \text { Homo-product } \quad \text { Desired product, 1.4.4.3 }
$$

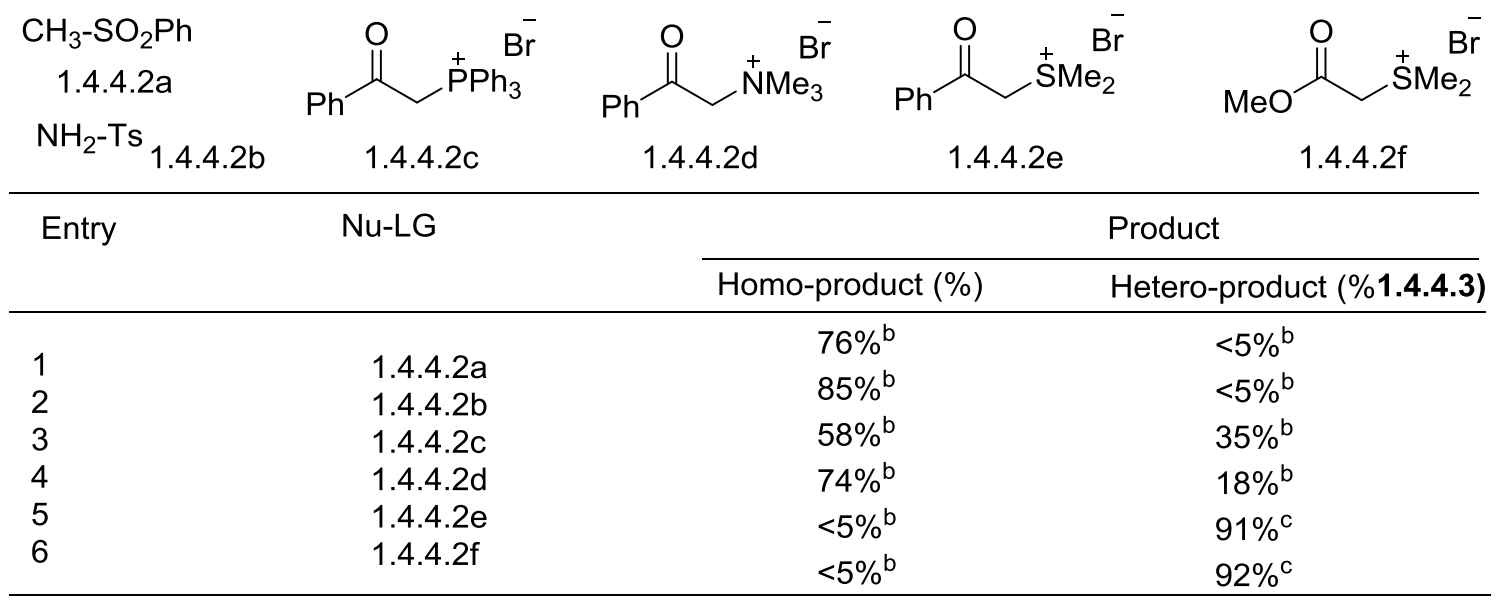

${ }^{b}=$ NMR yields with 1,3,5-trimethoxybenzene as internal standard ${ }^{c}=$ Isolated yield. 


\section{Multicomponent reaction over epoxidation and homo- $N$-oxides}
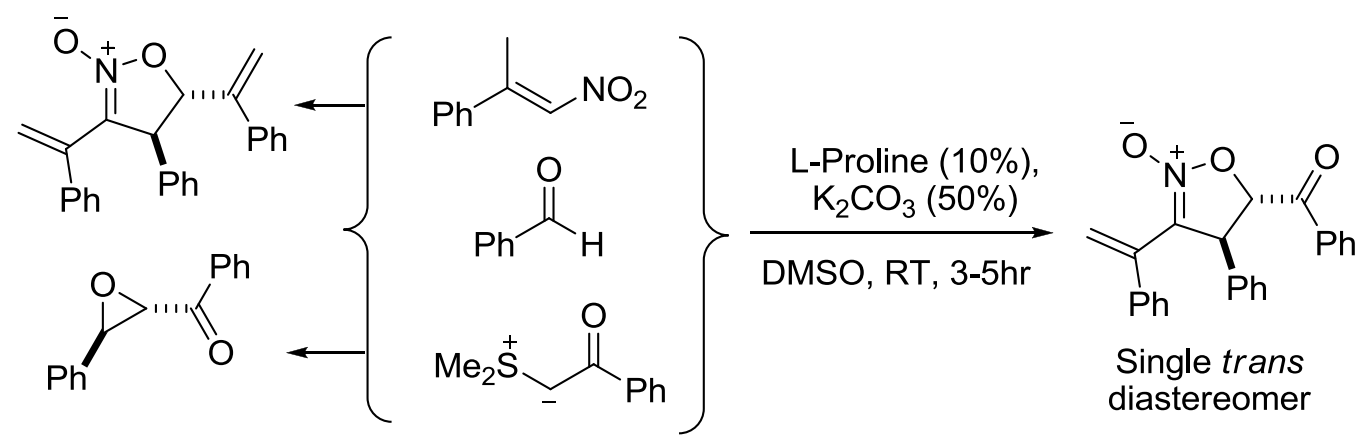

As shown in Table 1, application of 1.4.4.2a and 1.4.4.2b, under the previously developed optimal condition, produced only the homoisoxazoline- $N$-oxide, which was probably due to the low reactivity of the sulfonate nucleophiles (entries 1 and 2). The phosphine ylide 1.4.4.2c and amine ylide 1.4.4.2d did generate the desired product 1.4.4.3. However, the reaction suffered from the significant competition of homo-condensation (entries 3 and 4). Interestingly, application of sulfur ylides 1.4.4.2e and 1.4.4.2f gave the desired compound 1.4.4.3 as the dominant product in excellent yields (entries 5 and 6) with only a trace amount homo-product. Notably, it was well known that the reaction between aldehyde and sulfur ylide 1.4.4.2e could produce the corresponding epoxides in good yields. However, under the reported reaction condition, no significant formation of epoxide was observed. In conclusion, the well documented epoxide formation by the action of ylide to aldehyde is completely conquered by our optimal condition of three component condensation.

At this stage, versatile three-component cascade reactions were developed with different functionalities in the C-3, C-4 and C-5 position of the isoxoazoline- $N$-oxide. The summarized substrate scope varieties are shown in Table 2. Numerous aldehydes with aromatic and heteroaromatic substituents gave good to excellent yields. Similarly, different sulfur ylides were also tolerated. 
Table 2: Substrate scope of the designed cascade reaction

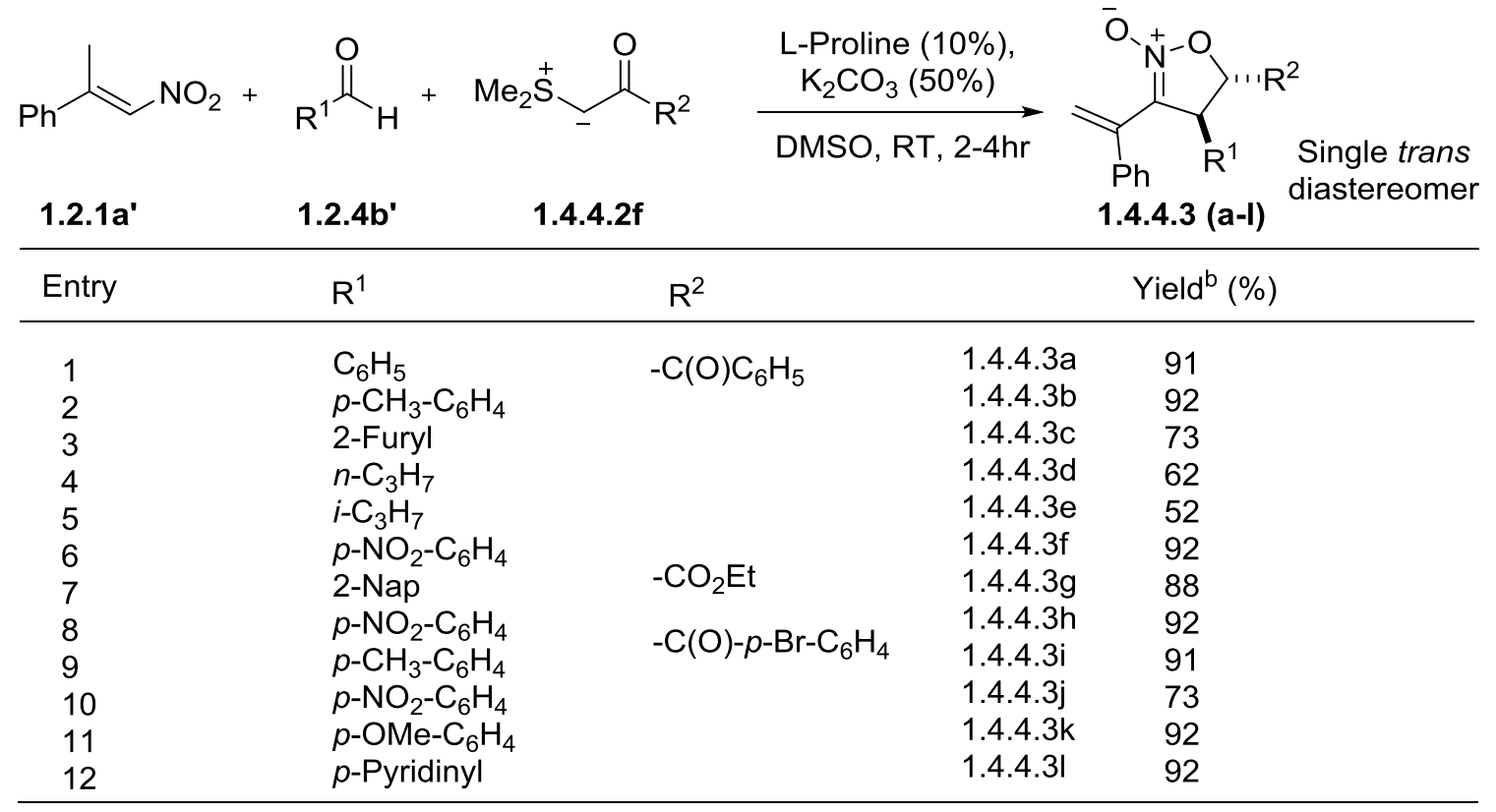

Reaction condition: Nitroalkene (1.1 equiv.), Aldehyde (1.0 equiv., $0.15 \mathrm{M})$ and Ylide (1.1 equiv.) were mixed with DMSO. Reactions monitored by TLC. ${ }^{b}=$ Isolated yield.

\subsubsection{Asymmetric Synthesis of isoxazoline- $N$-oxide ${ }^{\dagger}$}

Although excellent diastereoselectivity for the trans isomer was obtained with this method, enantioselective synthesis of isoxazoline derivatives is considered as challenging. ${ }^{17}$ However on screening with various chiral Lewis-base catalysts, discouraging enantioselectivity was observed (Figure 1, <15\% ee in all cases). In addition, the quinine-derived chiral tertiary amine $^{18}$ did not promote the heterocoupling reaction. This evidenced our previous observation of poor involvement of the catalysts during the formation of the C-4 stereogenic center as well as the poor Z/E selectivity of the nitrodiene intermediate.

\footnotetext{
${ }^{\dagger}$ Reproduced in parts with permission from Chem. Eur. J. 2010, 16, 8605-8609. Copyright 2011, with permission from Willey-VCH Verlag GmbH \& Co. KGaA, Weinheim.
} 
Figure 1: Tested Lewis Base Catalyst for Asymmetric Synthesis

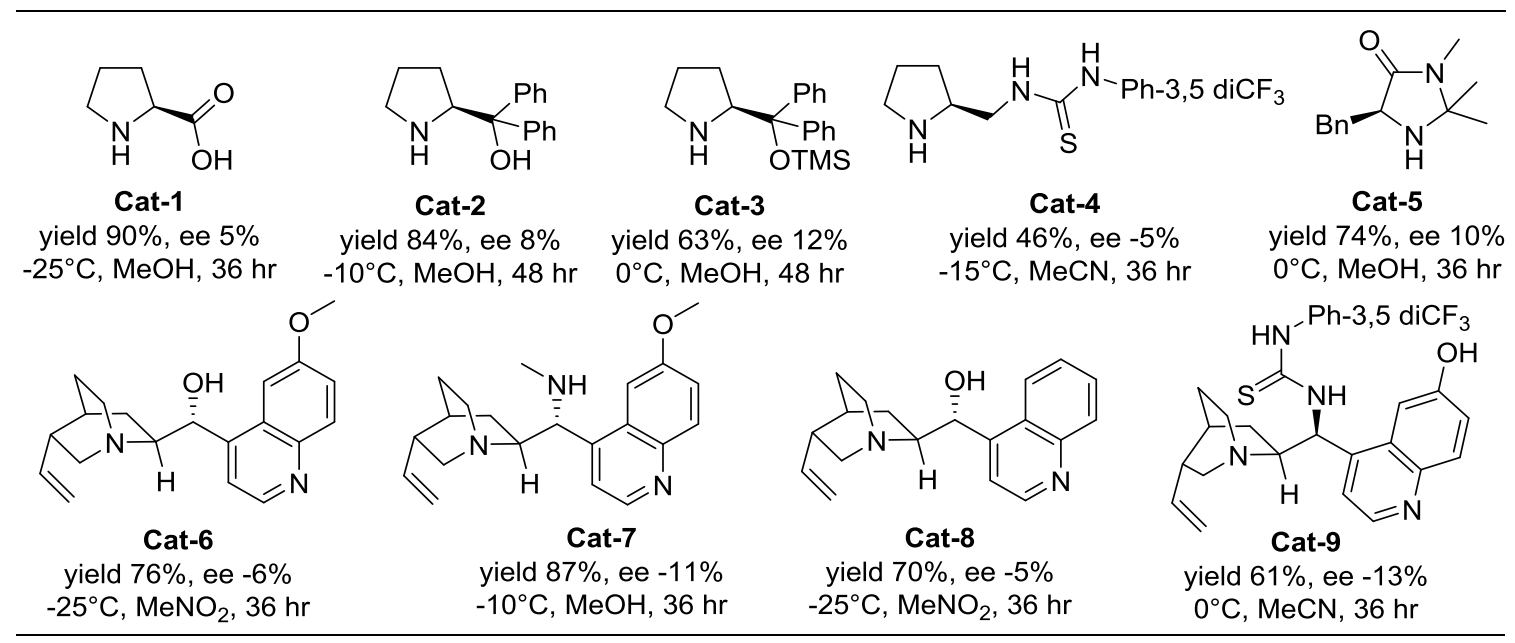

In the next step, to achieve enantioselective synthesis, different chiral ylides were synthesized and tested based on our previous report of ylides as a third nuclephilic reagent for the synthesis of fully substituted isoxazoline- $N$-oxides (Table 3). The quinine derived chiral tertiary amines (cat 6-9) and salts (aux-a) did not promote the desired reaction (entry1). However, readily available champhor-derived thioether ylides gave good yields and excellent enantioselectivity for three component condensation. Though ketone ylide (aux-b) did not promote the reaction, converting into ester and methylated ylide (aux-d) in pyrrolidine as Lewis base and cesium carbonate as pure base completed the reaction. In addition, X-ray crystallographic analysis of the related camphor derived auxiliary (aux-g) showed the evidence of optimal chemical yield and stereoselectivity from an intramolecular H-bonding between the alcohol and sulfonium. 
Table 3: Condition optimization of different auxiliaries in asymmetric synthesis

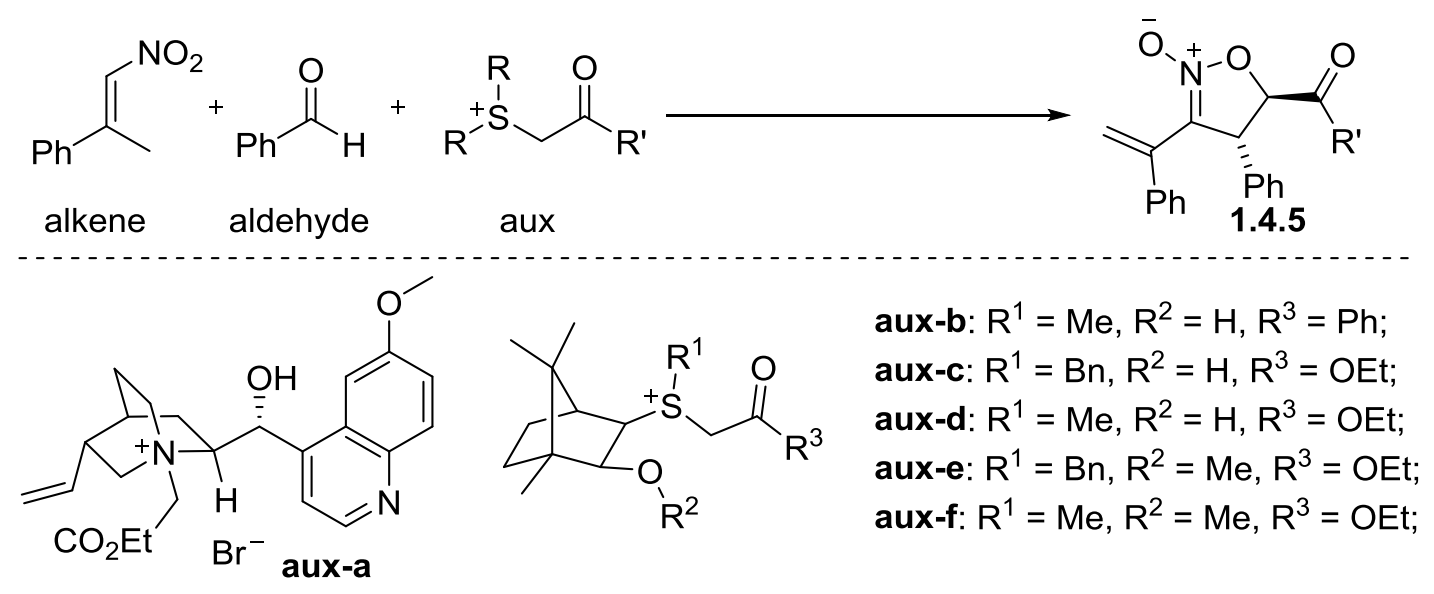

\begin{tabular}{ccccccc}
\hline Entry & Solvent & LB $(0.2$ eq. $)$ & aux & temp $\left({ }^{\circ} \mathrm{C}\right)$ & time $(\mathrm{hr})$ & ${\text { yield } \%{ }^{\mathrm{b}}(\mathrm{ee} \%)^{\mathrm{c}}}^{\mathrm{n}}$ \\
\hline 1 & DMSO & L-proline & aux-a & r.t. & 12 & $<5$ (n.d. $)^{\mathrm{d}}$ \\
2 & $\mathrm{THF}$ & L-proline & aux-c & r.t. & 6 & 13 (n.d.) \\
3 & $\mathrm{MeOH}$ & L-proline & aux-c & r.t. & 6 & $60^{\mathrm{e}}(36)$ \\
4 & $\mathrm{MeOH}$ & L-proline & aux-f & r.t. & 6 & $43^{\mathrm{e}}(59)$ \\
5 & $\mathrm{MeOH}$ & L-proline & aux-d & -25 & 48 & $54^{\mathrm{e}}(76)$ \\
6 & $\mathrm{MeOH}$ & L-proline & aux-d & -40 & 60 & $87^{\mathrm{e}}(82)$ \\
7 & $\mathrm{MeOH}$ & D-proline & aux-d & -25 & 48 & $62^{\mathrm{e}}(82)$ \\
8 & $\mathrm{MeOH}$ & pyrrolidine & aux-d & -25 & 48 & $86^{\mathrm{e}}(91)$ \\
9 & $\mathrm{MeOH}$ & N-Me-Gly & aux-d & -25 & 48 & $51^{\mathrm{e}}(89)$ \\
\hline
\end{tabular}

Base: Entry 1-4 $=\mathrm{K}_{2} \mathrm{CO}_{3}$, for others $\mathrm{Cs}_{2} \mathrm{CO}_{3},{ }^{\mathrm{b}} \mathrm{NMR}$ yields with 1,3,5-tromethoxybenzene;

${ }^{\mathrm{c}}$ determined by chiral HPLC; ${ }^{d}$ major products were homo isoxalonine-N-oxide; ${ }^{e}$ isolated yield

As shown in Table 4, the reaction worked efficiently with various nitroalkenes including aryl, alkyl and cyclic structures. Similarly, aliphatic, aromatic and heteroaromatic aldehydes substrates were also found satisfactory for this transformation. But, aliphatic aldehydes can easily be differentiated on comparing to nitroalkenes. This is because electron deficient nature of aldehyde (1.4.5h) gave excellent yield. However, enantioselectivity was slightly decreased. The high reactivity of the diene intermediate may lead to lower efficiency. Sterically hindered aldehydes $(\mathbf{1 . 4 . 5 f})$ promoted the enantioselectivity. This may be due to better spatial control. Similar asymmetric control was also achieved with aliphatic aldehyde. 
Table 4: Substrate scope of $N$-oxides in asymmetric synthesis<smiles>[R]CC([R])=C[N+](=O)[O-]</smiles>
1.2.1 aux-d

1.4.5 (a-u)

\begin{tabular}{|c|c|c|c|c|c|}
\hline entry & $\mathrm{R}^{1}$ & $\mathrm{R}^{2}$ & & Yield $(\%)^{b}$ & ee $(\%)^{c}$ \\
\hline 1 & & $\mathrm{C}_{6} \mathrm{H}_{5}$ & $1.4 .5 a$ & 86 & 91 \\
\hline 2 & & $p-\mathrm{OMe}-\mathrm{C}_{6} \mathrm{H}_{4}$ & $1.4 .5 \mathrm{~b}$ & 82 & 94 \\
\hline 3 & & $p-\mathrm{Me}-\mathrm{C}_{6} \mathrm{H}_{4}$ & $1.4 .5 \mathrm{c}$ & 89 & 91 \\
\hline 4 & & 2-Py & $1.4 .5 \mathrm{~d}$ & 90 & 80 \\
\hline 5 & & 2-Furanyl & $1.4 .5 \mathrm{e}$ & 71 & 90 \\
\hline 6 & & 1-naphthyl & $1.4 .5 f$ & 86 & 96 \\
\hline 7 & & $n-\operatorname{Pr}$ & $1.4 .5 \mathrm{~g}$ & 63 & 88 \\
\hline 8 & & $p-\mathrm{NO}_{2}-\mathrm{C}_{6} \mathrm{H}_{4}$ & $1.4 .5 \mathrm{~h}$ & 92 & 81 \\
\hline 9 & & $2-\mathrm{NO}_{2}-\mathrm{C}_{6} \mathrm{H}_{4}$ & $1.4 .5 \mathrm{i}$ & 82 & 70 \\
\hline 10 & & 2-OMe- $\mathrm{C}_{6} \mathrm{H}_{4}$ & $1.4 .5 \mathrm{j}$ & 84 & 88 \\
\hline 11 & & 2,4-di-Me- $\mathrm{C}_{6} \mathrm{H}_{3}$ & $1.4 .5 \mathrm{k}$ & 79 & 92 \\
\hline 12 & & 2-Furanyl & $1.4 .5 \mathrm{I}$ & 81 & 76 \\
\hline 13 & & 2-OMe- $\mathrm{C}_{6} \mathrm{H}_{4}$ & $1.4 .5 \mathrm{~m}$ & 88 & 81 \\
\hline 14 & & $p-\mathrm{OMe}-\mathrm{C}_{6} \mathrm{H}_{4}$ & $1.4 .5 n$ & 81 & 92 \\
\hline 15 & & 1-naphthyl & 1.4 .50 & 91 & 93 \\
\hline 16 & & 2-OMe- $\mathrm{C}_{6} \mathrm{H}_{4}$ & $1.4 .5 p$ & 75 & 81 \\
\hline 17 & & 1-naphthyl & $1.4 .5 q$ & 70 & 93 \\
\hline 18 & & $\mathrm{C}_{6} \mathrm{H}_{5}$ & $1.4 .5 r$ & 80 & 85 \\
\hline 19 & & $p-\mathrm{Me}-\mathrm{C}_{6} \mathrm{H}_{4}$ & $1.4 .5 \mathrm{~s}$ & 80 & 90 \\
\hline 20 & & 1-naphthyl & $1.4 .5 \mathrm{t}$ & 85 & 91 \\
\hline 21 & & $p-\mathrm{NO}_{2}-\mathrm{C}_{6} \mathrm{H}_{5}$ & $1.4 .5 \mathrm{u}$ & 93 & 65 \\
\hline
\end{tabular}

General condition: nitroalkene (1.2eq.), aldehyde (1 eq.), and auxiliary (1.1eq.).; $b=$ isolated yield; $\mathrm{c}=$ ee determined by HPLC on chiral stationary phase

\subsection{Total synthesis of (-) Clausenamide derivatives}

Aforementioned enantioselective isoxazoline- $N$-oxides provided a general and highly effective method to prepare varieties of enantiomeric derivatives. In addition, this comprehensive study led us to reach towards some complex, biologically and pharmaceutically important molecules in simple steps. One example we chose was the synthesis of all-cis $\gamma$-lactam, towards the construction of clausenamide derivatives (Scheme 
22). ${ }^{19}$ Relevent literature searches and careful reaction condition optimization provided the desired molecule $\mathbf{1 . 5 c}$ in $57 \%$ yield with $85 \%$ ee (>99\% ee after recrystalization).

\section{Scheme 22: Synthetic scheme of (-) Clausenamide derivatives}
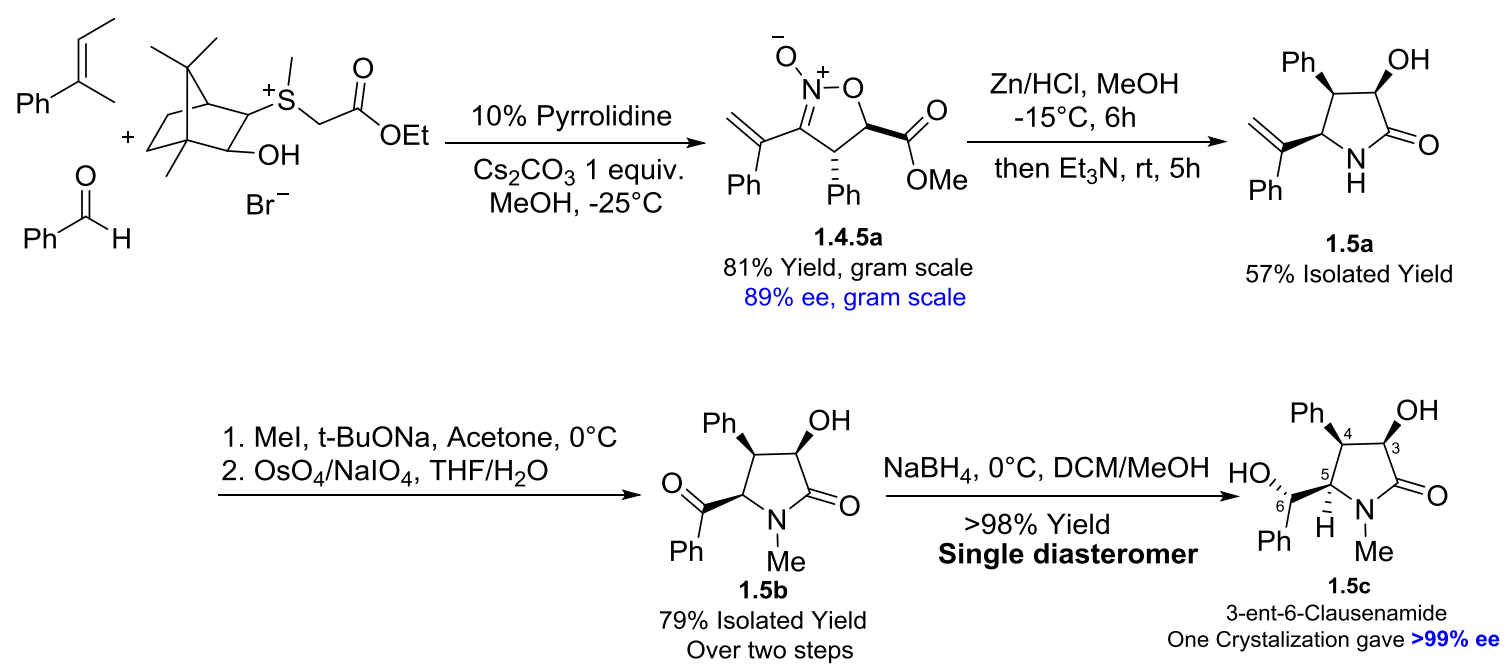

Briefly, the isoxazoline-N-oxide 1.4.5a undergoes diastereoselective zinc reduction followed by base treatment towards pyrolidine molecule 1.5a. After $N$-methylation, the product was treated successively with osmium tetroxide and sodium periodate for compound $\mathbf{1 . 5 b}$ in $\mathbf{7 9 \%}$ yield. Finally, simple borohydride reduction followed by careful recrystalization furnished the clausenamide in $>98 \%$ yield and $>99 \%$ ee. This synthesis is very simple, atom efficient and does not involve expensive reagents and protecting groups.

\subsection{Conclusion}

Various new molecules were developed by the use of proline Lewis base catalyzed, multicomponent condensation of nitroalkene, aldehyde and sulfur ylide. The three limitations associated with the first discovery of iso-oxazoline- $N$-oxide synthesis in 2007 were resolved. In addition, this powerful approach provided chemo and enantioselective synthesis of isoxazoline- $\mathrm{N}$-oxide as well as synthesis of biologically active and enantiopure clausenamide with high atom economy and efficiency. 


\section{Contributions}

Dr. Cheng Zhong was the researcher who had first investigated this reaction. Dr. C. Zhong and Lekh Nath Sharma Gautam were responsible for the detailed reaction conditions, NMR studies, substrate synthesis and for the completion of the supporting information for the successful submission to tetrahedron letters and European journal of organic chemistry. Dr. J. Petersen helped with the X-ray crystallography study to determine relative stereochemistry and structures of isoxazoline compounds. Dr. Akhmedov carried out the extensive NMR studies of the derivatization products. 


\section{Chapter 2: Stereoselective $N$-heterocycle Syntheses through Cascade Amine Addition to Nitroalkene Cyclization}

\subsection{Introduction}

\subsubsection{Literature reported synthesis and designs towards $N$-heterocycles}

$\mathrm{N}$-Heterocyclic structures are unique drug candidates with phenomenal importance in the fields of organic synthesis, catalysis, chemical-biology and pharmaceutical industry. Due to their critical role in medicinal research, continuous efforts have been put into the search and development of new synthetic methodologies for effective construction of heterocyclic natural product like compounds especially those with large substrate scope and good stereoselectivity. Among those privileged structures, pyrrolidine, indolizidine, quinolizidine, and piperidine alkaloids and their derivatives play an important medicinal role due to their interesting framework and biological activities (Scheme 23). ${ }^{20}$ These compounds are ubiquitous in nature and are found in a myriad of organisms. Although the literature describes a plethora of methods to synthesize these heterocyclic systems, a short, direct and diversity-oriented approach is scarce.

\section{Scheme 23: Some skeleton structures and important alkaloids}<smiles>C1CCNC1</smiles>

pyrrolidine<smiles>C1CCNCC1</smiles>

Piperidine<smiles>C1CCN2CCCCC2C1</smiles>

Quinolizidine<smiles>C1CCN2CCCC2C1</smiles>

Indolizidine

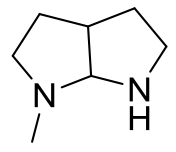

pyrrolopyrrole<smiles>CN1CCCC2CCNC21</smiles>

pyrrolopyridine<smiles>C1CCN2C[C@H]3C[C@H](CN4CCCC[C@H]34)[C@@H]2C1</smiles>

(-) Spertine<smiles>C1CC2C3CCNC3CN2C1</smiles>

pyrrolopyrrolizine<smiles>O[C@H]1CCN2C[C@@H]1[C@@H](O)[C@H](O)[C@@H]2O</smiles>

(+) Castanospermine<smiles>C1CC2CC3CCNC3CN2C1</smiles>

pyrroloindolizine<smiles>O=C1CC=C[C@H]2C3CCCN4CCCC(CN12)C34</smiles>

Lehmannine<smiles>C1CCN2CC3NCCC3CC2C1</smiles>

pyrroloquinolizine

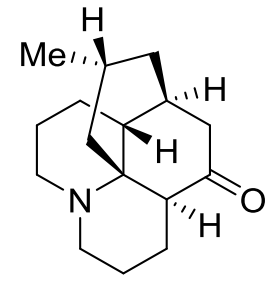

Lycopodine

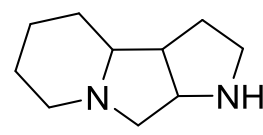

pyrroloindolizine 
The synthesis of these bio-active and medicinally significant molecules has been of longstanding interest. Their construction requires the introduction of a nitrogen-containing moiety through carbon-carbon and carbon-nitrogen bond formation reactions. Many state-ofthe-art approaches for the construction of these heterocycles have been discovered. Among various synthetic routes, metal mediated or catalyzed intramolecular hydroamination for the direct formation of a new $\mathrm{C}-\mathrm{N}$ bond by the addition of an amine to an unsaturated $\mathrm{C}-\mathrm{C}$ bond, is one of the important methods. This reaction offers an atom-efficient pathway from readily accessible alkenes, allenes, alkynes and other conjugated systems (Scheme 24). ${ }^{21}$

\section{Scheme 24: Intramolecular hydroaminations}

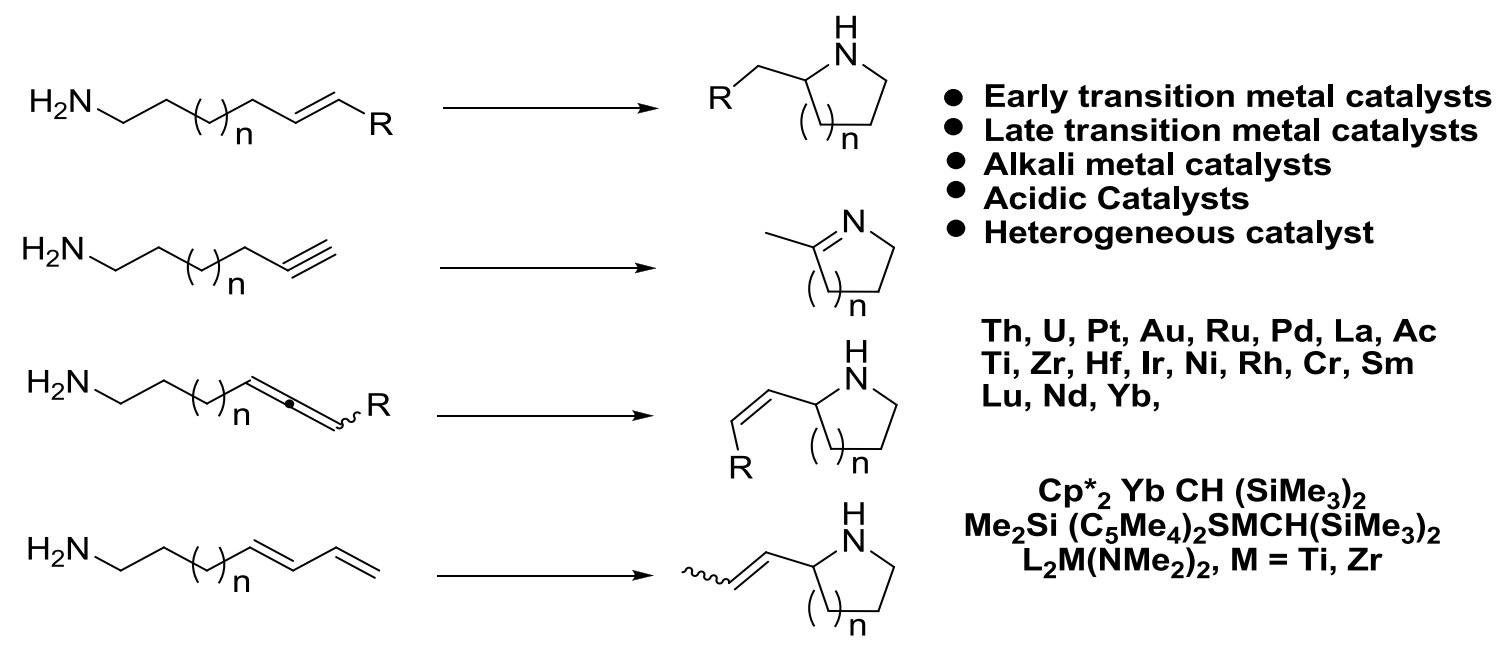

The second method to $N$-heterocycles is cycloaddition involving $\mathrm{C}=\mathrm{N}$ or 1,3 -dipoles also known as the Huisgen reaction. Because of the various possibilities of introducing popular dipoles, they are extremely powerful reactions that can generate multiple chiral centers, various heterocyclic or carbocyclic ring sizes as well as a wide array of pharmacologically active final products (Scheme 25). ${ }^{22}$

Scheme 25: Cycloaddition reaction involving $\mathrm{C}=\mathrm{N}$ or 1,3 -dipoles
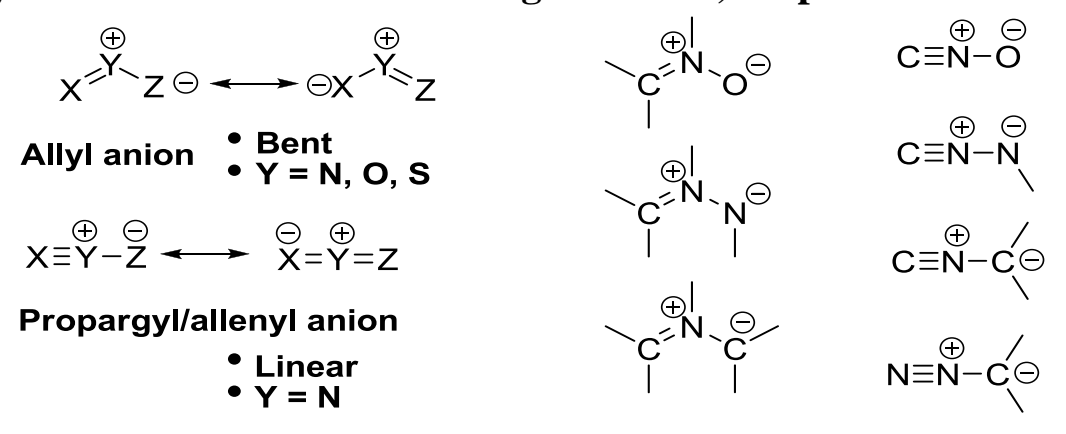
Some recent examples are:<smiles>[R]c1cc2c(cc1[R])N([R])C(=O)C2=O</smiles><smiles>[R]C=CC(=O)OC([R2])=CC[C@H]1[C@@H](C(=O)O[R2])[C@@H]([R1])ON1C</smiles>

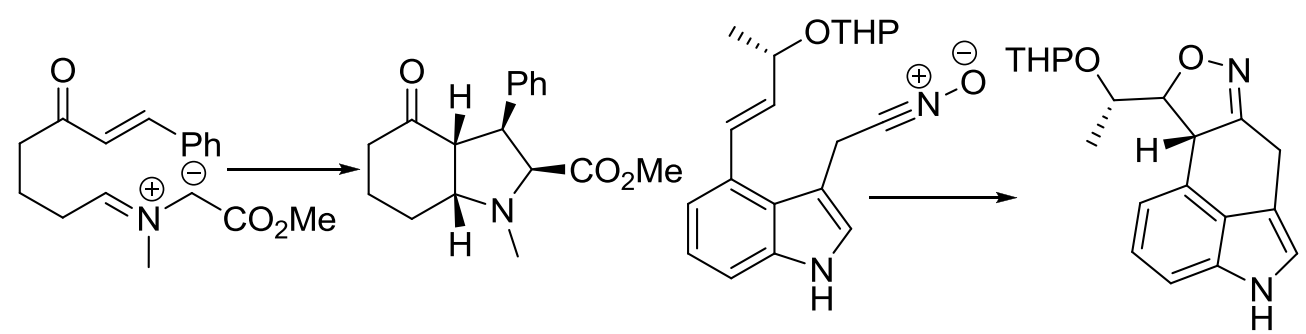

Another approach towards the small molecular weight $N$-heterocycle scaffolds is the multiple components Michael addition cyclocondensation reaction. Common named reaction under this category include Ugi, Ugi-Smiles, Passerini, Groebcke, Heck, RCM, Wittig, Homologation and Aza-Diels-Alder (Scheme 26). ${ }^{23}$

\section{Scheme 26: Multiple-component cyclocondensation reactions}
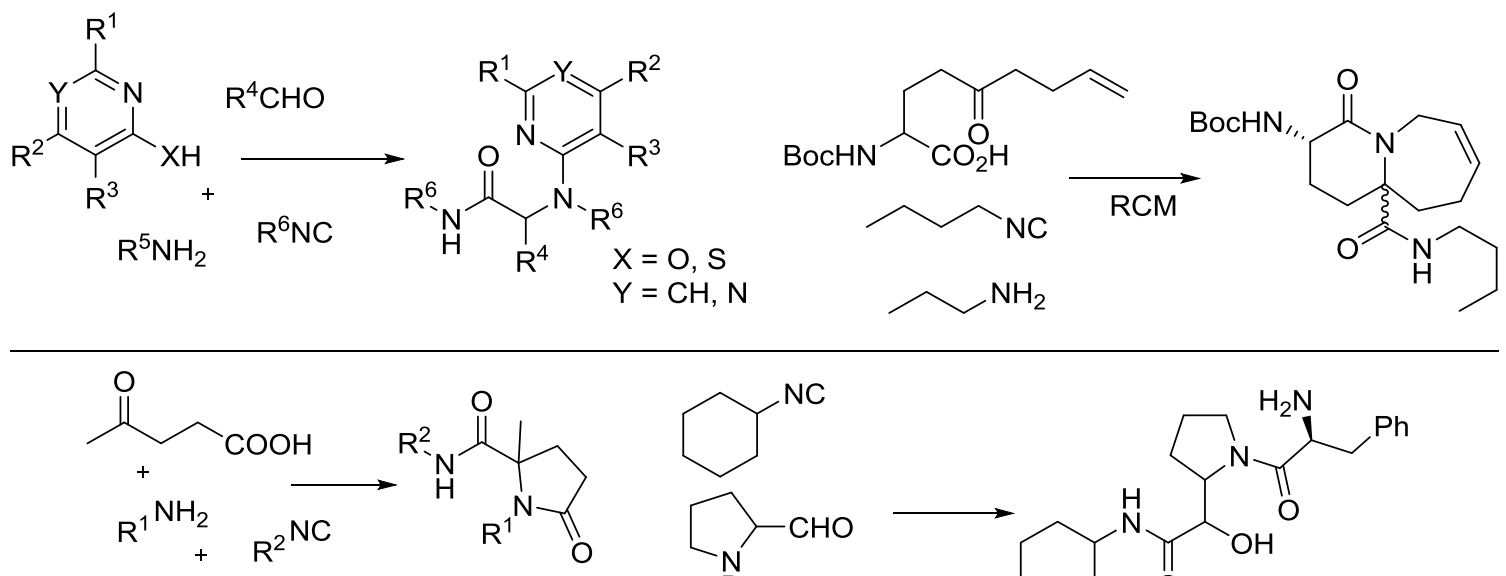<smiles>O=CC1CC2(CCCC2)CC[C@@H]1O</smiles>
$\mathrm{Ph}$<smiles>CCCCCCCCC(=O)O</smiles><smiles>NC(Cc1ccccc1)C(=O)N1CCCC1C(O)C(=O)NC1CCCCC1</smiles> 
As mentioned in the previous chapters, the past decade evidenced the fast growth of organocatalysis. ${ }^{24}$ Numerous new transformations have been reported with good stereoselectivity. Among the reported works, one of the most well studied reactions is the ketone/aldehyde nucleophilic addition to nitroalkenes in the presence of a chiral amine catalyst. ${ }^{25}$ As shown in Scheme 27, the amine catalyst promotes the formation of a nucleophilic enamine to react with the nitroalkene through conjugate addition. Although the nitroalkene is a highly reactive electrophile, it is generally assumed that no reaction occurred between the amine and nitroalkene. $^{26}$

\subsubsection{Previous Study in Our group}

Our recent investigation on the intermolecular cross conjugate addition between nitroalkene and enone/enal confirmed that the nitroalkene is a more reactive Michael receptor than typical enone and enal towards nucleophiles. ${ }^{27}$

\section{Scheme 27: Previously reported approach: nitroalkene as receptor}

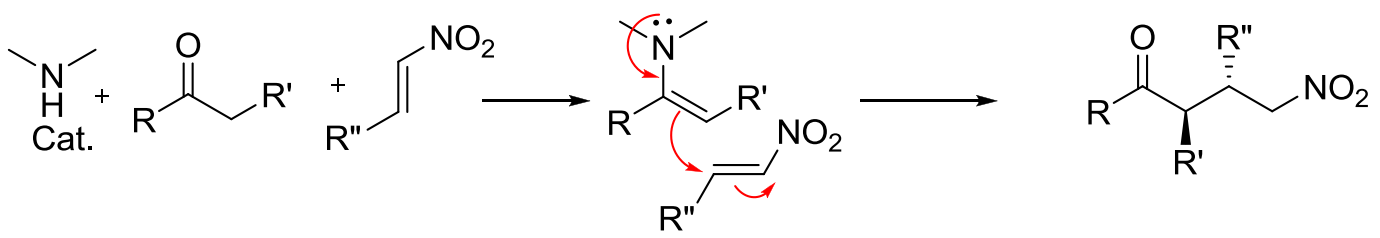

Interestingly, during our mechanistic investigations, we found that the secondary amine addition to the nitroalkene involved a rapid equilibrium. The formation of an intermolecular H-bond successfully prevented polymerization of the nitroalkene, which was typically observed by other nucleophilic catalysts, such as $\mathrm{PR}_{3}$ and $\mathrm{NR}_{3}$ (Scheme 28).

\section{Scheme 28: Prevention of polymerization}

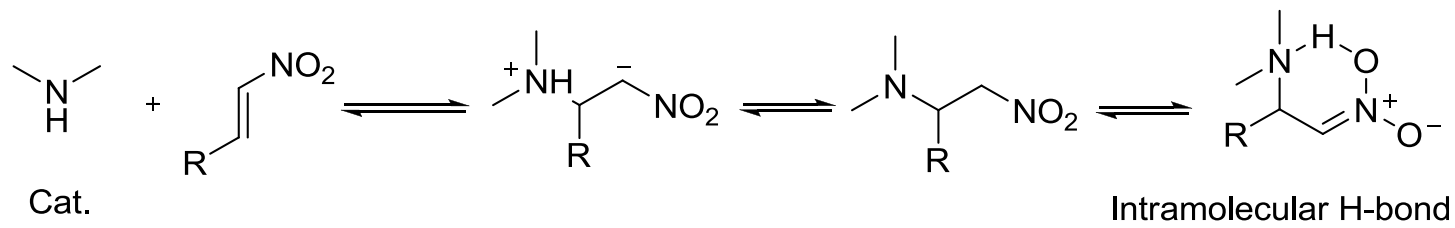

Although these methods have proven quite useful, their substrate scope, mild reaction condition and functional group tolerance is often limited. Therefore, the intellectual 
challenge to invent concise, elegant and conceptually novel synthetic routes through mastering unusual combinations of elementary organic reactions has become a steadily increasing driving force both in academia and industry. Owing to its unique mechanism and efficiency, it is expected that intermolecular double Michael addition between amine tethered conjugated Michael acceptor to nitro-alkenes will lead to the discovery of heterocyclic architectures.

\subsection{Research Design}

\subsubsection{Stereoselective synthesis of $N$-heterocycles by the action of amine to nitroalkene}

With this mechanistic discovery, we postulated that this new reaction mode could be applied in the synthesis of $N$-heterocycles through designated intermolecular condensation (Scheme 29). In addition, we have previously demonstrated that the $\alpha, \beta$-unsaturated esters were valid reaction partners for amine-activated nitroalkenes. It could be possible to vary the substituents and extend to the complex structures like alkaloids and lactams. Another objective could be variation in ring structure and fusion to synthesize conformationally locked rigid bicycle to polycyclic structures. A final application could be variation in pharmaceutically active functionalities like trifluoromethyl and ester groups.

\section{Scheme 29: Designed addition of amine to nitroalkene}
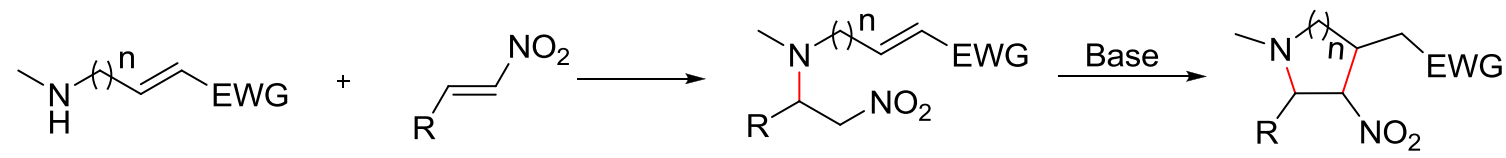

\subsubsection{Confirmation of chirality retention}

Asymmetric synthesis needs to be done to confirm optically activity of the final products which is very important in medicinal and pharmaceutical chemistry.

\subsection{Results and Discussion}

\subsubsection{Synthesis of diverse amino pendant conjugated esters}

The amino connected $\alpha, \beta$-unsaturated ester 2.1 (Scheme $30 \mathrm{~A}$ ) was first selected as the reaction partner with nitroalkene in this study. Various amino esters were readily prepared 
from the commercially available amino acid/alcohol with excellent overall yield on a gram scale (Scheme 30 B \& C), which makes the overall methodology feasible and practical. ${ }^{28}$ The reaction sequence for this process was Boc-protection of aminogroup, hydroboration of carboxylic acid to primary alcohol followed by Swern oxidation to aldehyde. Finally, a Wittig reaction followed by removal of the Boc group afforded the required molecule. To verify our hypothesis, proline derivative 2.1a was tested with nitroalkene. Nitroalkenes (Scheme 30 D) were also synthesized following the literature procedures. ${ }^{29}$

\section{Scheme 30: Synthesis of amino-tethered proline ester 2.1a}

\section{A: Amino-tethered Proline ester}

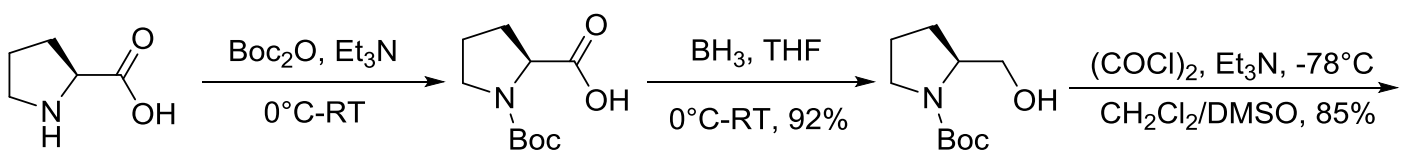

Readily Available

Starting Material

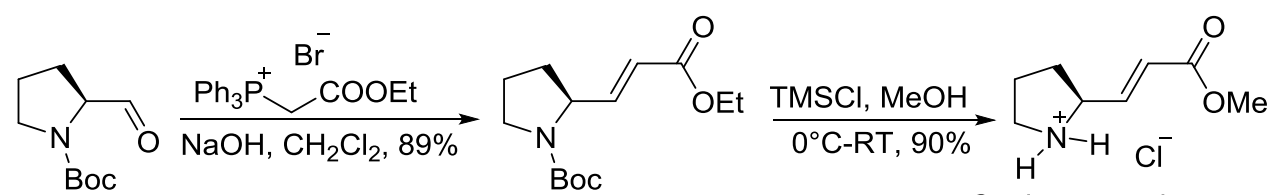

Conjugate amine ester, 2.1a

\section{B: General Synthetic Route to amino-pendent conjugated esters}

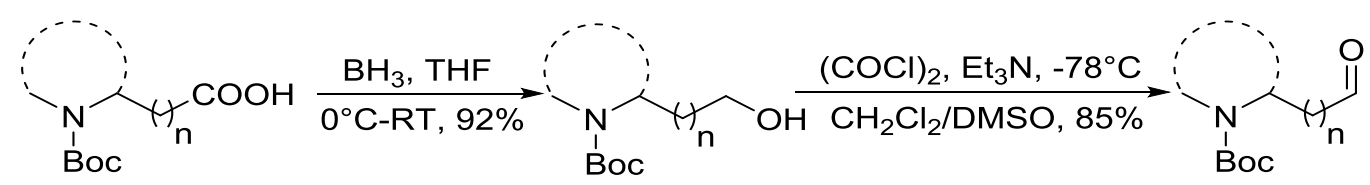

Readily Available Starting Materials

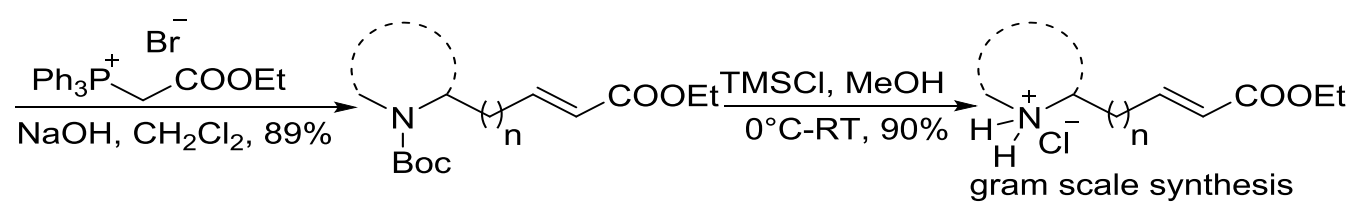

\section{C: Scope of Various amino-tethered conjugated ester synthesized}
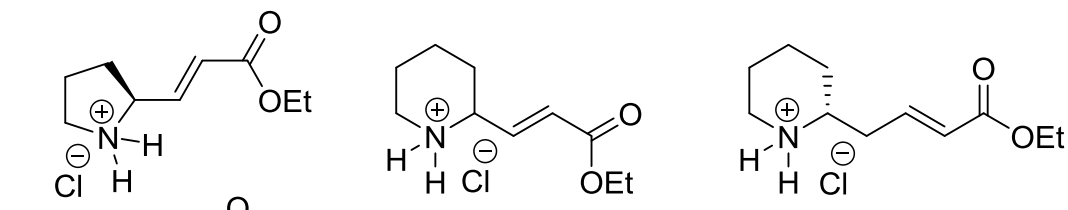<smiles>CCOC(=O)/C=C/CC1CCCN1CCl</smiles><smiles>CCOC(=O)/C=C/C[NH+]([O-])Cl</smiles><smiles>CCOC(=O)/C=C/CCN(O)CC</smiles> 


\section{D: Various Nitroalkenes synthesized}

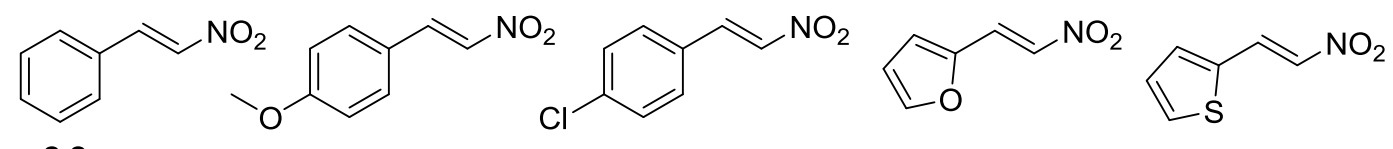

2.2a

\subsubsection{Reaction optimization for Aza-Michael addition}

The aza-Michael addition is one of the widely used reaction for carbon-nitrogen bond formation in recent organic synthesis. Conjugate reaction of various amines with $\alpha, \beta$ unsaturated carbonyl compounds provides $\beta$-amino carbonyl ingredients, which have attracted great attention for their use as key heterocyclic intermediates for anticancer agents, antibiotics and other drugs. ${ }^{30}$

Generally, aza-Michael additions have been catalyzed by strong bases or acids which are detrimental to the desired synthesis because of usual side reactions. Therefore, scientists have paid more attentions to the development of more mild, benign and facile catalytic systems for the aza-conjugate reaction. The reaction condition screening results are summarized in Table 5. We initially carried out several experiments at lower temperature $\left(-10^{\circ} \mathrm{C}\right)$ and did neutralization of the aminoester and treated with nitroalkene. We were not able to promote the reaction. When, we carried out the reaction at ambient temperature, interestingly, insignificant activities were obtained. Then we assumed there must be the necessity of a more equivalent base to promote the reaction. As expected, with the use of four equivalents of Hünig's base (DIPEA) in dichloromethane (DCM), the cyclization product 2.3a was obtained in good yield at room temperature (entry 1). Although the product contained four stereogenic centers, this reaction exhibited excellent stereoselectivity with only two stereoisomers observed (2.3a and 2.3a') in a 3:1 ratio. The relative stereochemistry was verified by comprehensive NMR analysis and later confirmed by X-ray crystallography. Solvent screening revealed the more polar solvent acetonitrile optimizes the reaction condition giving improved yield and dr 9:1 (entry 5). In DMSO, no product was detected though reaction seems $100 \%$ conversion. Switching to methanol also decreased the yield of the desired reaction.

* For NMR and X-ray see Experimental Section 
The use of an inorganic base, such as potassium carbonate, sodium and ammonium acetate, resulted in very slow reaction rates and low overall yields (entries 6-7). This finding is consistent with our previous observation that buffered solutions generally give better results than a simple proton scavenger (the inorganic bases). Notably, the amount of base was critical for the overall performance. Four equivalents of DIPEA were identified as the optimal amount. Decreasing the amount of base caused slower formation of the desired product, which led to the observation of more nitroalkene polymerization side products. On the other hand, further addition of too much base (7 equiv., entry 11) was less effective and caused a decrease of the overall yield due to intramolecular cyclization towards the formation of the lactam and other side reactions. We are still investigating the mechanism behind this.

Table 5: Screening of reaction conditions ${ }^{a}$<smiles>COC(=O)/C=C/[C@H]1CCC[NH2+]1</smiles>

2.1a<smiles>O=[N+]([O-])/C=C/c1ccccc1</smiles>

$2.2 \mathrm{a}$

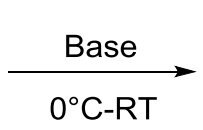

$0^{\circ} \mathrm{C}-\mathrm{RT}$<smiles>COC(=O)C[C@@H]1[C@H]([N+](=O)[O-])[C@@H](c2ccccc2)N2CCC[C@H]12</smiles>

2.3a<smiles>COC(=O)C[C@H]1[C@H]([N+](=O)[O-])[C@@H](c2ccccc2)N2CCC[C@H]12</smiles>

2.3a'

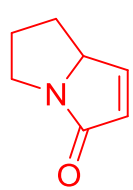

$\mathrm{O}$

\begin{tabular}{|c|c|c|c|c|c|c|}
\hline entry & solvent & base (equiv.) & time $(h)$ & $\operatorname{conv}^{b}(\%)$ & yield $^{b}(\%)$ & $d r^{b} 2.3 a: 2.3 a^{\prime}$ \\
\hline 1 & DCM & DIPEA (4) & 3 & $>99$ & 63 & $3: 1$ \\
\hline 2 & THF & DIPEA (4) & 3 & $>99$ & 65 & 4:1 \\
\hline 3 & DMSO & DIPEA (4) & 3 & 100 & $<1$ & n.a. \\
\hline 4 & $\mathrm{MeOH}$ & DIPEA (4) & 3 & 100 & 61 & $5: 1$ \\
\hline 5 & $\mathrm{CH}_{3} \mathrm{CN}$ & DIPEA (4) & 3 & 100 & 91 & 9:1 \\
\hline 6 & $\mathrm{CH}_{3} \mathrm{CN}$ & $\mathrm{K}_{2} \mathrm{CO}_{3}(4)$ & 3 & $30^{c}$ & 18 & n.d. \\
\hline 7 & $\mathrm{CH}_{3} \mathrm{CN}$ & $\mathrm{NaOAc}(4)$ & 3 & $20^{c}$ & 15 & n.d. \\
\hline 8 & $\mathrm{CH}_{3} \mathrm{CN}$ & $\mathrm{Et}_{3} \mathrm{~N}(4)$ & 3 & 100 & 56 & $2: 1$ \\
\hline 9 & $\mathrm{CH}_{3} \mathrm{CN}$ & DIPEA (2) & 3 & 100 & 51 & $5: 1$ \\
\hline 10 & $\mathrm{CH}_{3} \mathrm{CN}$ & DIPEA (3) & 3 & 100 & 66 & $6: 1$ \\
\hline 11 & $\mathrm{CH}_{3} \mathrm{CN}$ & DIPEA (7) & 3 & 100 & 47 & $1: 1$ \\
\hline
\end{tabular}

${ }^{a}$ General reaction conditions: $2.1 \mathrm{a}(0.25 \mathrm{mmol}, 1.0$ equiv.), $2.2 \mathrm{a}(0.32 \mathrm{mmol}, 1.3$ equiv.), base (equiv.) in different solvents, monitoring the progress of reaction by TLC. ${ }^{b}$ Conversion, yield, and dr were determined by NMR with 1,3,5-trimethoxybenzene as internal standard. ${ }^{c}$ slow conversion. n.a. $=$ not available; n.d. $=$ not determined

\subsubsection{Reaction Substrate Scope}

With the optimized reaction condition, this transformation was subjected to wide varieties of amine connected $\alpha, \beta$-conjugated esters with aromatic and heteroaromatic nitroalkenes (Scheme 30) to evaluate the reaction substrate scope, and the results are described below 
(Figure $2 \&$ Figure 3). The reaction tolerated a large substrate scope including aromatic nitroalkenes with either electron withdrawing (2.3aa, 2.3ac) or electron donating substituted groups (2.3ab). Heteroaromatic substituted nitroalkenes worked well under the optimal condition, giving the desired $N$-heterocycles in good to excellent yields (2.3ad, 2.3ae). Aliphatic nitroalkenes gave very low yields of the desired cyclization products. For example, with substrate $\mathbf{2 . 2 b}$, complex reaction mixtures were observed, likely caused by the rapid polymerization of this highly reactive nitroalkene. The sterically hindered nitroalkene 2.2c/2.2d gave a much slower reaction, and very little of the desired product. This result is likely caused by the amine $\beta$-elimination as previously reported. ${ }^{9-11,31}$

\section{Figure 2: Substrate scope of Aza-Michael addition for bicyclic nitro-esters}

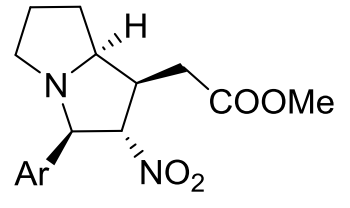

5-5

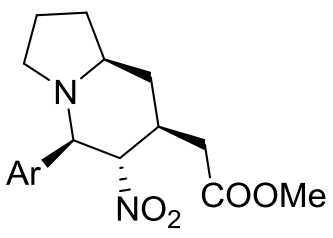

5-6

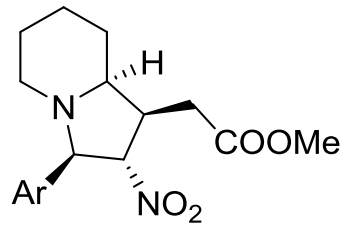

6-5

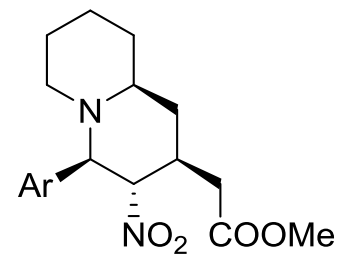

6-6 2.3aa: $\mathrm{Ar}=\mathrm{Ph}, \mathrm{dr}=9: 1,91 \%$

2.3ab: Ar $=$ Ph-p-OMe, dr = 3:1, 79\%

2.3ac: $\mathrm{Ar}=\mathrm{Ph}-\mathrm{p}-\mathrm{Cl}, \mathrm{dr}=7: 1,93 \%$

2.3ad: Ar $=2$-furanyl, $d r=7: 1,87 \%$

2.3ae: $\mathrm{Ar}=2$-thiophenyl, $d r=9: 1,78 \%$

2.3ba: $A r=P h, d r=3: 1,88 \%$

2.3bb: Ar $=$ Ph-p-OMe, dr = 6:1, 79\%

2.3bc: $\mathrm{Ar}=\mathrm{Ph}-\mathrm{p}-\mathrm{Cl}, \mathrm{dr}=6: 1,93 \%$

2.3bd: Ar = 2-furanyl, dr = 7:1, 89\%

2.3be: Ar = 2-thiophenyl, dr = 4:1, 84\%

2.3ca: $\mathrm{Ar}=\mathrm{Ph}, \mathrm{dr}>99: 1,77 \%$

2.3cb: Ar = Ph-p-OMe, dr > 99:1, 69\%

2.3cc: Ar $=$ Ph-p-Cl, dr > 99:1, 73\%

2.3cd: Ar $=2$-furanyl, dr $>99: 1,68 \%$

2.3ce: $\mathrm{Ar}=2$-thiophenyl, dr $>99: 1,64 \%$

2.3da: $A r=P h, d r=3: 2,66 \%$

2.3db: Ar $=\mathrm{Ph}-\mathrm{p}-\mathrm{OMe}, \mathrm{dr}=2: 1,61 \%$

2.3dc: $\mathrm{Ar}=\mathrm{Ph}-\mathrm{p}-\mathrm{Cl}, \mathrm{dr}=3: 2,66 \%$

After we finished the substrate's scope of the [5,5] bicyclic system, we moved to the [5,6] 
system. The $p-\mathrm{Cl}$ substituted nitroalkene gave high yield (3bc) while high diastereoselectivity is obtained in the furan system (2.3bd). To our delight, for the [6,5] nitroester, high yield and diastereoselectivity (>99:1) was obtained in all cases. In the case of [6,6] bicycle, although yields were good, diastereoselectivities were discouraging. In addition, a heteroaromatic nitroalkene did not work under our reaction conditions.

In monocyclic five membered ring cyclization, high yield and excellent diastereoselectivities were obtained while in six membered rings, decent yields were observed with lower diastereoselectivity.

Figure 3: Substrate scope of Aza-Michael addition for Monocyclic nitro-esters

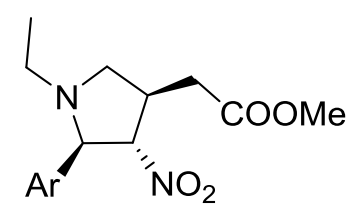

5

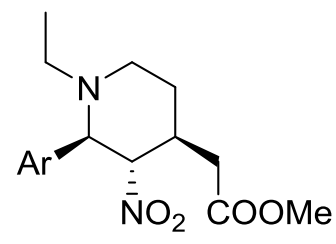

6 2.3ea: $\mathrm{Ar}=\mathrm{Ph}, \mathrm{dr}>99: 1,86 \%$

2.3eb: $\mathrm{Ar}=\mathrm{Ph}-\mathrm{p}-\mathrm{OMe}, \mathrm{dr}>99: 1,76 \%$

2.3ec: Ar $=$ Ph-p-Cl, dr $>99: 1,81 \%$

2.3ed: Ar = 2-furanyl, dr > 99:1, 76\%

2.3ee: $\mathrm{Ar}=2$-thiophenyl, dr $>$ 99:1, 76\%

2.3fa: $\mathrm{Ar}=\mathrm{Ph}, \mathrm{dr}=3: 1,74 \%$

2.3fb: $\mathrm{Ar}=\mathrm{Ph}-\mathrm{p}-\mathrm{OMe}, \mathrm{dr}=3: 1,68 \%$

2.3fc: $\mathrm{Ar}=\mathrm{Ph}-\mathrm{p}-\mathrm{Cl}, \mathrm{dr}=3: 1,73 \%$

2.3fd: $A r=2$-furanyl, $d r=3: 1,72 \%$

2.3fe: $\mathrm{Ar}=2$-thiophenyl, $d r=3: 1,69 \%$

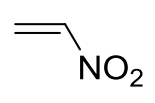

$2.2 b$

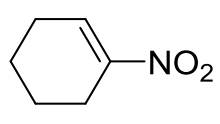

2.2c

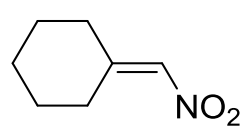

2.2d

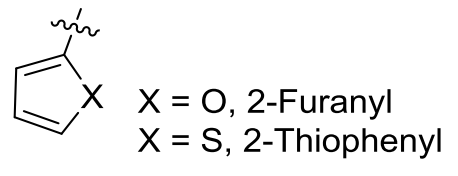

$X=S, 2-T h i o p h e n y l$

To overcome the undesired $\beta$-elimination, $\beta$-nitro- $\alpha, \beta$-unsaturated ester 2.2e $\left(\mathrm{NO}_{2} \mathrm{CH}=\mathrm{CHCOOMe}\right)$ was prepared ${ }^{32 \mathrm{a}}$ to react with the amino-ester 2.1a. The desired cyclization products $(2.4 \mathrm{ab}, 2.4 \mathrm{bb}, 2.4 \mathrm{cb}, 2.4 \mathrm{db}$ and $2.4 \mathrm{eb})$ were obtained in good to excellent yields. As usual the five membered ring gave $>99: 1$ diastereoselectivity. This result provided a potential alternative approach to introducing aliphatic groups through the sequential ester group transformations (such as reduction). Since the $\mathrm{CF}_{3}$ group has significant electronegativity (between $\mathrm{Cl}$ and F), it has strong acidity, lower basicity and 
solvation properties that are found in most of the pharmaceutical drugs. Being $\mathrm{CF}_{3}$ a bioisostere of $\mathrm{Cl}^{-}$and $\mathrm{CH}_{3}$, it adjusts steric and electronic properties as well as protects the reactive methyl group from metabolic oxidation. With these drug like significance in hand, we pursued towards the synthesis of nitroalkene with $\mathrm{CF}_{3}(\mathbf{2 . 2} \mathbf{e}$ and $\mathbf{2 . 2 f}){ }^{32 \mathrm{~b}, \mathrm{c}}$ Notably, the $\mathrm{CF}_{3}$ modified nitroalkene $\mathbf{2 . 2 f}\left(\mathrm{NO}_{2} \mathrm{CH}=\mathrm{CHCF}_{3}\right)$ could also give the corresponding cyclization products in excellent yields (2.4aa, 2.4ba, 2.4ca 2.4da and 2.4ea), with 2.4ea of >99:1 diastereoselectivity which provided an interesting new strategy to incorporate $\mathrm{CF}_{3}$ group into the $N$-heterocycles under very mild conditions (Figure 4). Considering the importance of fluorine containing $N$-heterocycles, these results highlighted the apparent advantages of this new method.

Figure 4: Substrate scope of with medicinally active function groups<smiles>[R]C1[C@H]([N+](=O)[O-])[C@@H](CC(C)=O)[C@H]2CCCN12</smiles>

5-6<smiles>[R]C1[C@H]([N+](=O)[O-])[C@@H](CC(=O)OC)C[C@H]2CCCN12</smiles>

5-6<smiles>[R]C1[C@H](CCOC)[C@@H](COC)[C@@H]1[N+](=O)[O-]</smiles>

6-5

$$
\underbrace{\mathrm{NO}_{2.2 \mathrm{f}}}_{\mathrm{OMe}}
$$

2.4aa: $\mathrm{R}=\mathrm{CF}_{3}, \mathrm{dr}=17: 1,86 \%$

2.4ab: $\mathrm{R}=\mathrm{COOMe}, \mathrm{dr}>99: 1,71 \%$

2.4ba: $\mathrm{R}=\mathrm{CF}_{3}, \mathrm{dr}=8: 1,84 \%$

2.4bb: $R=$ COOMe, $d r=6: 1,79 \%$ 2.4ca: $\mathrm{R}=\mathrm{CF}_{3}, \mathrm{dr}=6: 1,91 \%$

2.4cb: $\mathrm{R}=$ COOMe, $d r>99: 1,78 \%$ 2.4da: $\mathrm{R}=\mathrm{CF}_{3}, \mathrm{dr}=15: 1,86 \%$

2.4db: $R=$ COOMe, $d r=8: 1,84 \%$ 2.4ea: $\mathrm{R}=\mathrm{CF}_{3}, \mathrm{dr}>99: 1,86 \%$

2.4eb: $R=$ COOMe, $d r>99: 1,71 \%$ 
In conclusion, besides the large substrate scope, this method also tolerated various ring sizes, giving the corresponding 5 or 6 exo-trig cyclization products in good yields. Both cyclic secondary amines and acyclic secondary amines were suitable for this transformation (2.3e to 2.3f). With the application of cyclic amines, the 5-5, 5-6, 6-5 or 6-6 bicyclic structures could be readily prepared from the corresponding starting materials with good to excellent yields. The primary amine substrates $\left(\mathrm{NH}_{2} \mathrm{CH}_{2} \mathrm{CH}=\mathrm{CHCOOMe}\right)$ did not work well under the optimal condition, which was consistent with our previous reports. However, this problem can be overcome by the application of protected amines. For example, the PMB (paramethoxy benzyl) modified amine afforded the corresponding cyclization product in good yields. Followed by the deprotection of PMB as reported in literature, the corresponding NHamine can be achieved in good yields. The 7 and 8-exo-trig cyclization products were successfully isolated under the reaction conditions. However, the reaction proceeded very slowly (48 hr, RT) with poor isolated yields $(<25 \%)$. Increasing of the reaction temperature to $80^{\circ} \mathrm{C}$ caused significant decomposition of the nitroalkenes. The use of amines with better leaving groups for the extended ring cyclization is currently under investigation.

\subsection{Application of our methodology in the synthesis of $\gamma$-lactam heterocyclic architectures}

In general, stereochemistry control is one critical factor for the evolution of any $\mathrm{N}$ heterocycle synthesis. As indicated in Table 5, this new method gave excellent stereoselectivity at C-2, C-4 and C-5 positions. The only isomerization observed at the C-3 position, was caused by the racemization of a nitro group on the C-3 position. Since $-\mathrm{NO}_{2}$ is a highly versatile and sensitive functional group, this issue can be overcome by converting the diastereomeric mixture into other derivatives, such as to ketones (NEF reaction) and amides (reductive amidation). Given our interests in developing complex $N$-heterocyclic structures, we took the reductive cyclization route to further convert nitro esters into polycyclic $\gamma$-lactam (Scheme 31). 


\section{Scheme 31: Nitro-reduction and cyclization strategy}

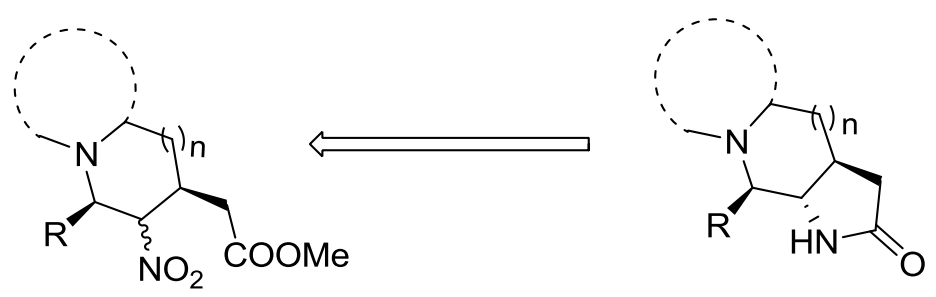

\subsubsection{Screening of condition for reductive cyclization}

At this stage we then began to investigate the reaction condition for route scouting or reduction and plausible cyclization. Initially, we tried a number of reducing reagents such as In, $\mathrm{TiCl}_{4} / \mathrm{Zn}, \mathrm{TiO}_{2}, \mathrm{SmI}_{2}, \mathrm{PtO}_{2}, \mathrm{~N}_{2} \mathrm{H}_{4}, \mathrm{BH}_{3} / \mathrm{NaBH}_{4}$ in different solvents (methanol, ethanol, DMF, acetic acid). They either gave low yields or did not react at all or serious problems due to side reactions and work-up. Screening of some of the other reagents under reflux for desired products is given below (Table 6). Tin/tin chloride gave low yield (entry 1, 9) while the reaction with palladium in ammonium formate remains problematic in yield, although conversion was good. Upon adding sodium borohydride, we observed only the free amine product. Similarly, Raney $\mathrm{Ni} / \mathrm{NiCl}_{2}$ did not promote a reaction to the desired lactam. Interestingly, zinc reduction followed by basic treatment promoted the reaction. Finally, a more convenient procedure of refluxing in the presence of very cheap reagent iron/AcOH was identified as the optimal condition. In this case, the intermediately formed amines were not isolated, but immediately cyclized to lactams in $\mathbf{8 0 \%}$ yields. $^{33}$

The two nitro diastereomers were converted into a single stereoisomer. The relative stereochemistry of the final products was confirmed by 2D-NMR analysis and X-ray crystallography (Figure 5). ${ }^{30}$ 
Table 6: Screening of reductive amidation<smiles>COC(=O)C[C@H]1[C@H]([N+](=O)[O-])C(c2ccccc2)N2CCC[C@H]12</smiles>

2.3aa

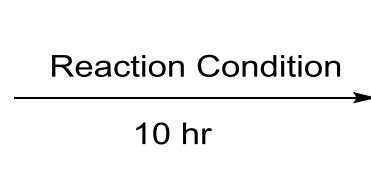

$10 \mathrm{hr}$

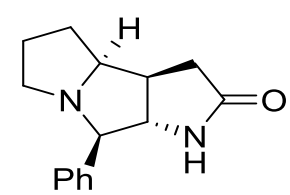

2.5aa

\begin{tabular}{|r|l|l|l|l|}
\hline SN & Screening with Diff. Reducing agents & Temp. $\left({ }^{\circ}\right.$ C) & Conversion (\%) & Yield (\%) \\
\hline 1 & $\mathrm{SnCl}_{2} \cdot 2 \mathrm{H}_{2} \mathrm{O}(2$ equiv.), EtOAc & 74 & 72 & 47 \\
\hline 2 & $10 \% \mathrm{Pd} / \mathrm{C}, \mathrm{HCOONH}{ }_{4}, \mathrm{MeOH}$ & 64 & 93 & 54 \\
\hline 3 & $10 \% \mathrm{Pd} / \mathrm{C}, \mathrm{NaBH}_{4}, \mathrm{THF}$ & 70 & 84 & 53 \\
\hline 4 & $\mathrm{Zn}, \mathrm{AcOH}$ then $\mathrm{K}_{2} \mathrm{CO}_{3}, \mathrm{P}^{\mathrm{H}} 8-9$ & 80 & 81 & 62 \\
\hline 5 & $\mathrm{Fe}, \mathrm{AcOH}: \mathrm{EtOH}, \mathrm{H}_{2} \mathrm{O}$ & 90 & 83 & 60 \\
\hline $\mathbf{6}$ & $\mathbf{F e}, \mathrm{AcOH}$ & $\mathbf{9 0}$ & $>\mathbf{9 9}$ & $\mathbf{8 0}$ \\
\hline 7 & $\mathrm{Raney} \mathrm{Ni}, \mathrm{EtOH}, 40-60 \mathrm{psi}$, then toluene & 110 & 72 & 52 \\
\hline 8 & $\mathrm{NiCl}_{2} \cdot 6 \mathrm{H}_{2} \mathrm{O}(5$ equiv. $), \mathrm{MeOH}$ & 64 & 94 & 59 \\
\hline 9 & $\mathrm{Sn} / \mathrm{HCl}, \mathrm{EtOH}$ & 80 & 87 & 47 \\
\hline
\end{tabular}

General reaction condition: Nitroester 3aa (1.64 mmol, 1 equiv.), and metal powder (16.4 mmol, 10 equiv.) were added to solvent $(4 \mathrm{~mL})$, the reactions were stirred at the specified temperature and monitored by TLC unless otherwise mentioned. Conversion and yields were determined by NMR with 1,3,5-trimethoxybenzene as internal standard based on the consumption of bicyclic nitroester mixture.

\section{Figure 5: X-ray crystal structure of 5-6-5-tri-cyclic 2.5ba}

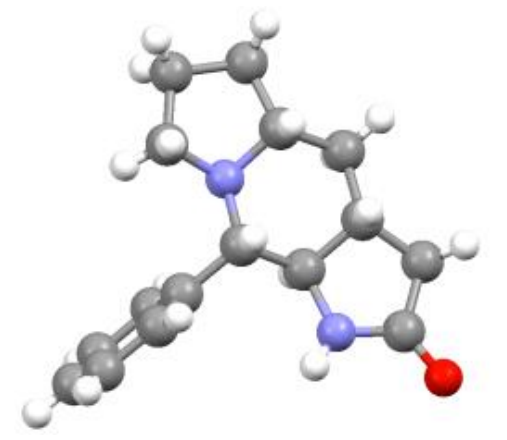

\subsubsection{Substrate scope of polycyclic $N$-heterocycles}

Though, Aza-Michael condensations are known to be a challenging transformation, our optimized condition tolerated various kinds of substrates (Figure 6 \& Figure 7). Those heterocyclic cores are very common to a number of alkaloids. We first examined the [5,5,5] system. Cyclization from [5,5] system gave products faster with decent yields. Lower yields were obtained in the case of a furan substituted nitro-ester. Reductive amidation to [5,6,5] reactions required longer reaction times though as expected a modest output was observed. In 
all cases, it was found that the electron withdrawing group activated cyclization for amidation. In $[6,5,5]$ satisfactory yields were attained.

\section{Figure 6: Reaction Substrate scope ${ }^{a}$}

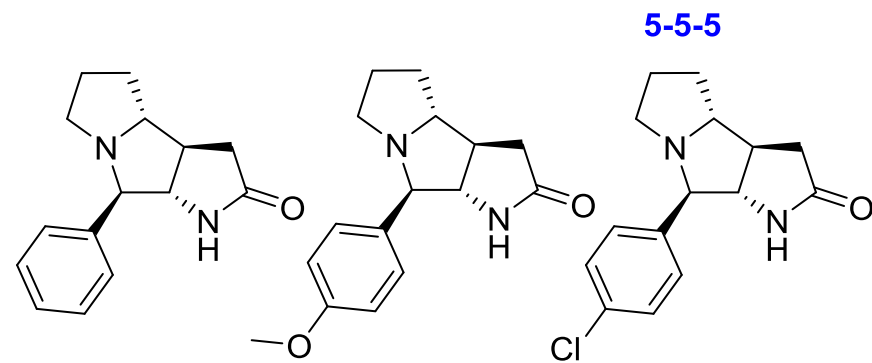

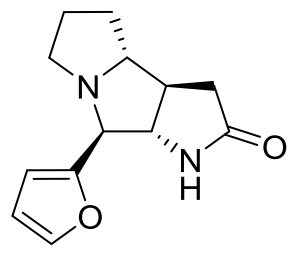

$2.5 \mathrm{ad}, 69 \%$

5-6-5

$2.5 \mathrm{ac}, 84 \%$

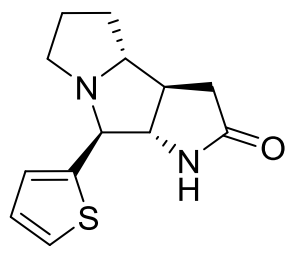

$2.5 \mathrm{ae}, 74 \%$

$2.5 \mathrm{aa}, 81 \%$

$2.5 \mathrm{ab}, 76 \%$

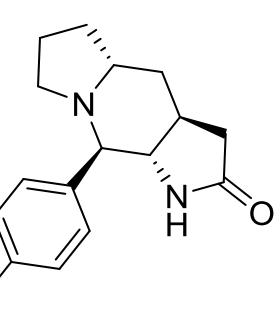<smiles>O=C1C[C@H]2C[C@H]3CCCN3[C@@H](c3ccco3)[C@H]2N1</smiles><smiles>O=C1C[C@H]2C[C@@H]3CCCN3[C@H](c3cccs3)[C@@H]2N1</smiles><smiles>O=C1C[C@H]2C[C@H]3CCCN3[C@@H](c3ccccc3)[C@H]2N1</smiles><smiles>COC</smiles>

$2.5 \mathrm{ba}, 84 \%$

$2.5 \mathrm{bb}, 76 \%$

$2.5 \mathrm{bc}, 89 \%$

6-5-5

$2.5 \mathrm{bd}, 84 \%$

$2.5 \mathrm{be}, 79 \%$

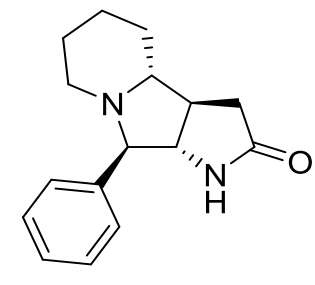

2.5ca, $81 \%$<smiles>COc1ccc([C@@H]2[C@H]3NC(=O)C[C@@H]3[C@H]3CCCCN32)cc1</smiles>

$2.5 \mathrm{cb}, 69 \%$

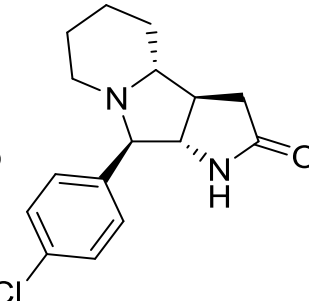<smiles>O=C1C[C@@H]2[C@H](N1)[C@H](c1ccco1)N1CCCC[C@@H]21</smiles><smiles>O=C1C[C@H]2[C@@H]3CCCCN3[C@@H](c3cccs3)[C@@H]2N1</smiles>

$2.5 \mathrm{cc}, 84 \%$

$2.5 \mathrm{~cd}, 64 \%$

$2.5 \mathrm{ce}, 69 \%$

${ }^{a}$ General reaction conditions: 2.3 ( $0.5 \mathrm{mmol}, 1.0$ equiv.), iron powder (5 mmol, 10 equiv.) in $\mathrm{AcOH}(5 \mathrm{~mL}) \mathrm{reflux}$ for $10 \mathrm{hr}$.

In case of $[6,6,5]$ aromatic nitro-ester, reductive cyclization not only provided lower yields but were also found unsuitable for the heteroaromatic system. $N$-ethyl substituted [6,5] reductive amidation process were also applicable with decent yield. In the case of $[5,5] \mathrm{N}$ methyl nitroester, a Hofmann degradation of so formed quaternary ammonium salt by $\beta$ elimination arrested our desired route. Since $p$-methoxy benzene ring has less reactive substituents, it promoted lactam formation for a moderate yield. 
6-6-5

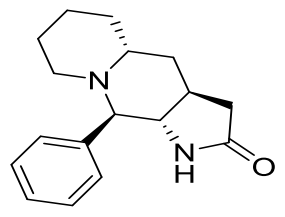

$2.5 d a, 69 \%$

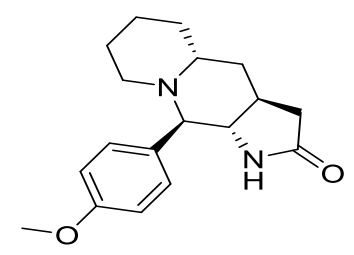

$2.5 d b, 63 \%$

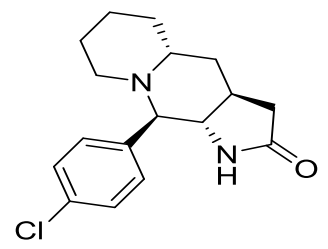

$2.5 d c, 73 \%$

6-5<smiles>CCN1CC[C@@H]2CC(=O)N[C@@H]2C1c1ccccc1C1[C@@H]2NC(=O)CC2CCN1CC</smiles>

$2.5 f a, 71 \%$

$2.5 \mathrm{fb}, 66 \%$

$2.5 \mathrm{fc}, 73 \%$

5-5

$2.5 f d, 61 \%$

$2.5 f e, 67 \%$

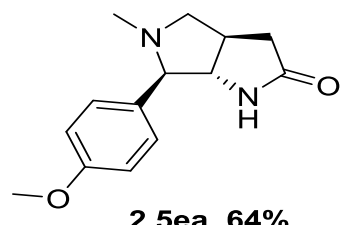

$2.5 e a, 64 \%$

${ }^{a}$ General reaction conditions: 2.3 ( 0.5 mmol, 1.0 equiv. $)$, iron powder $(5 \mathrm{mmol}, 10$ equiv. $)$ in $\mathrm{AcOH}(5 \mathrm{~mL})$ reflux for $10 \mathrm{hr}$.

This method is straightforward and applicable where additional rings are fused through vicinal carbons. The higher thermodynamic stability of amide is the major driving force for this cyclization. Apparently, during the course of lactamization, cyclization from five membered nitroester took precedence over the six membered nitroester rings, a behavior consistent with that encountered in other indole ring closures. ${ }^{34}$

\subsection{Asymmetric transformation}

With the very mild reaction conditions, this newly developed method could lead to an easy asymmetric synthesis of desired $N$-heterocycles from the readily available enantiomeric pure amino alcohol/acid. To confirm the stereochemistry retention, the enantiomerically pure amino alcohol 2.6 was used in our protocol for this transformation. As indicated in Scheme 32, through the coupling with (-) Mosher's acid, the single diastereomer was obtained, which confirmed the complete retention of stereochemistry throughout the overall operations. 
Further absolute stereochemistry was determined by optical rotation and chiral HPLC. Thus, the reported method can be readily applied for the asymmetric synthesis of $N$-heterocycles from readily available, enantiomerically pure amino-esters.

\section{Scheme 32: Retention of stereochemistry in overall transformation}
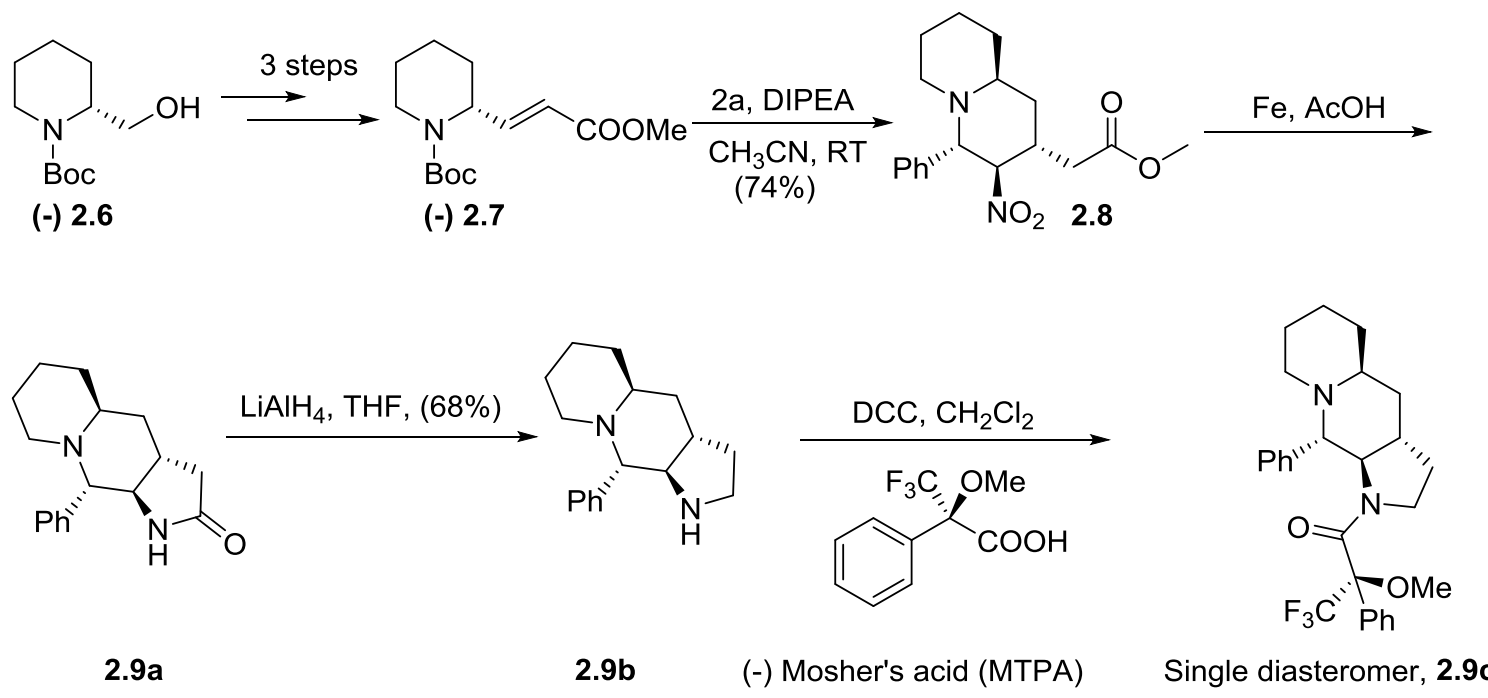

\subsection{Conclusion}

In short, a new, short and facile method for the direct synthesis of biologically relevant $N$ heterocyclic scaffolds was developed by utilizing cheap and easily available materials for the first time from the Aza-Michael conjugate addition of amino-pendant conjugated ester reaction with nitroalkene followed by reductive amidation. This highly convergent design is based on the conjugate amine addition to nitroalkene, which is different and new from literature reported general strategies. This strategy demonstrated excellent efficiency, giving complex $N$-heterocycles with good to excellent yields and a broad substrate scope. The incorporation of $\mathrm{CF}_{3}$ and excellent stereoselectivity further highlighted the promising potential of this powerful method in the preparation of complex polycyclic $N$-heterocycles under mild conditions with high atom economy and stereoselectivity. The strength of this process is that it provides ample opportunities for the quick and easy synthesis and design of pharmaceutically and medicinally active fluorinated scaffolds by the use of trifluoromethyl and ester substituted nitroalkene. 


\section{Chapter 3: Synthesis of Enantiopure Piperidines by Exocyclic Chirality Induction}

\subsection{Introduction}

\subsubsection{Literature reported asymmetric synthesis of piperidine synthesis}

Piperidines are very important structural moieties contained in a wide range of biologically active and medicinally significant compounds. This importance is directly reflected in the investigation of over 12000 piperidine varieties in clinical or preclinical studies over a 13year period because of their wide range of physiological activities (Scheme 33). ${ }^{35}$

Scheme 33: Biologically active piperidine moieties containing Natural products<smiles>CCCCCCCCCC(=O)O</smiles>

(+)-Carpamic acid<smiles>OC[C@H]1NC[C@@H](O)[C@H](O)[C@@H]1O</smiles>

(+)-Deoxynojirimycin<smiles>O[C@H](C[C@@H]1CCCCN1)c1ccccc1</smiles>

(+)-Sedamine<smiles>CC(=O)C1CC[C@@H](O)[C@@H](CO)N1</smiles>

(-)-Prosophyline<smiles>CCC[C@@H]1CCCCN1</smiles>

(+)-Coniine<smiles>OC(C[C@@H]1CCCCN1)c1ccccc1</smiles>

(+)-Norsedamine<smiles>CC(=O)C[C@@H]1CCCCN1</smiles>

(+)-Pelletierine<smiles>c1cncc([C@@H]2CCCCN2)c1</smiles>

(S)-Anabasine<smiles>O=C(O)[C@H]1CC=CCN1</smiles>

(S)-Baikiain<smiles>CC[C@H](O)[C@H]1CCCCN1</smiles>

(-)- $\beta$-Conhydrine

In the past few years a burgeoning interest in chiral compounds emanated in synthetic organic chemistry has been strengthened by the more demand from the pharmaceutical companies to produce enantiomerically pure drugs since unwanted enantiomer can have harmful and sometimes fatal effects. Several synthetic strategies for the synthesis of piperidine derivatives have been developed. ${ }^{36}$ Most of these strategies rely extensively on the chiral starting materials ${ }^{36 \mathrm{~b}}$ or use of chiral ligands, ${ }^{36 \mathrm{~d}}$ for the synthesis of a wide variety of heterocyclic compounds. Asymmetric syntheses to piperidines generally revolve around following four strategic categories. ${ }^{36 a}$ 
(a) Intramolecular $\mathrm{SN}_{2}$ reaction: it is the most useful and reliable method of preparation where ring formation occurs through amine attack to precursor containing better leaving group. As a result, pre-defined stereochemistry is established (Scheme 34).

\section{Scheme 34: Intramolecular $\mathrm{SN}_{2}$ reaction}<smiles>C=CC[C@H]1CC[C@@H](OCc2ccccc2)[C@H](CO[R5](=O)[O-])N1</smiles>

$$
X=\text { tosylate, triflate, mesylate }
$$

(-)-Prosophylline

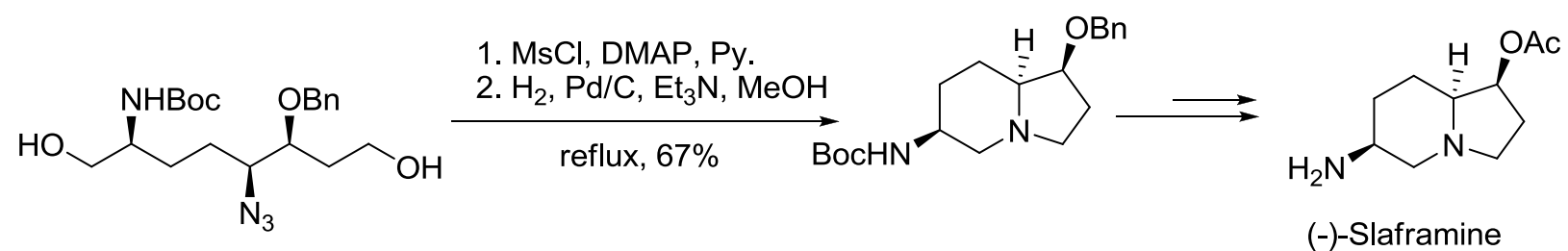

(b) Asymmetry generation in existing six- membered nitrogen heterocycle via lithiation.

The addition of an electrophile to an $\alpha$-lithiated 4-substituted piperidines could be the best way for the synthesis of substituted piperidines to occur. Depending upon the size of electrophile, cis or trans 2,4-disubstituted piperidines can be obtained (Scheme 35).

\section{Scheme 35: Asymmetry generation}
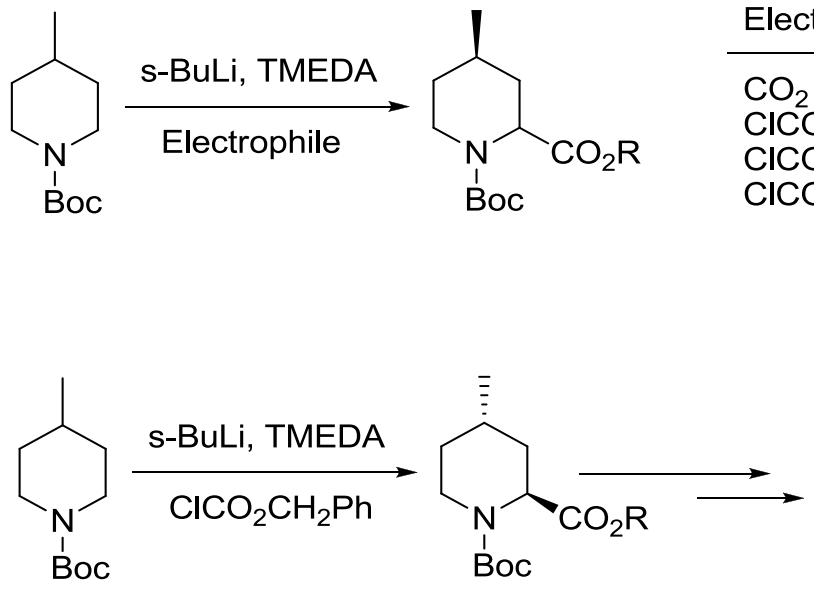

(c) Rearrangement reactions: Ring expansion of pyrrolidine derivatives

\begin{tabular}{llc} 
Electrophile & cis/trans & yield \% \\
\hline $\mathrm{CO}_{2}$ & $100 / 0$ & 60 \\
$\mathrm{ClCO}_{2} \mathrm{CH}_{3}$ & $35 / 65$ & 58 \\
$\mathrm{ClCO}_{2} \mathrm{Et}$ & $30 / 70$ & 60 \\
$\mathrm{ClCO}_{2} \mathrm{CH}_{2} \mathrm{Ph}$ & $5 / 95$ & 35
\end{tabular}


Rearrangement of optically active prolinols under basic conditions undergoes ring expansion to piperidine derivatives (Scheme 36).

\section{Scheme 36: Rearrangement of prolinols and their derivatives to piperidines}
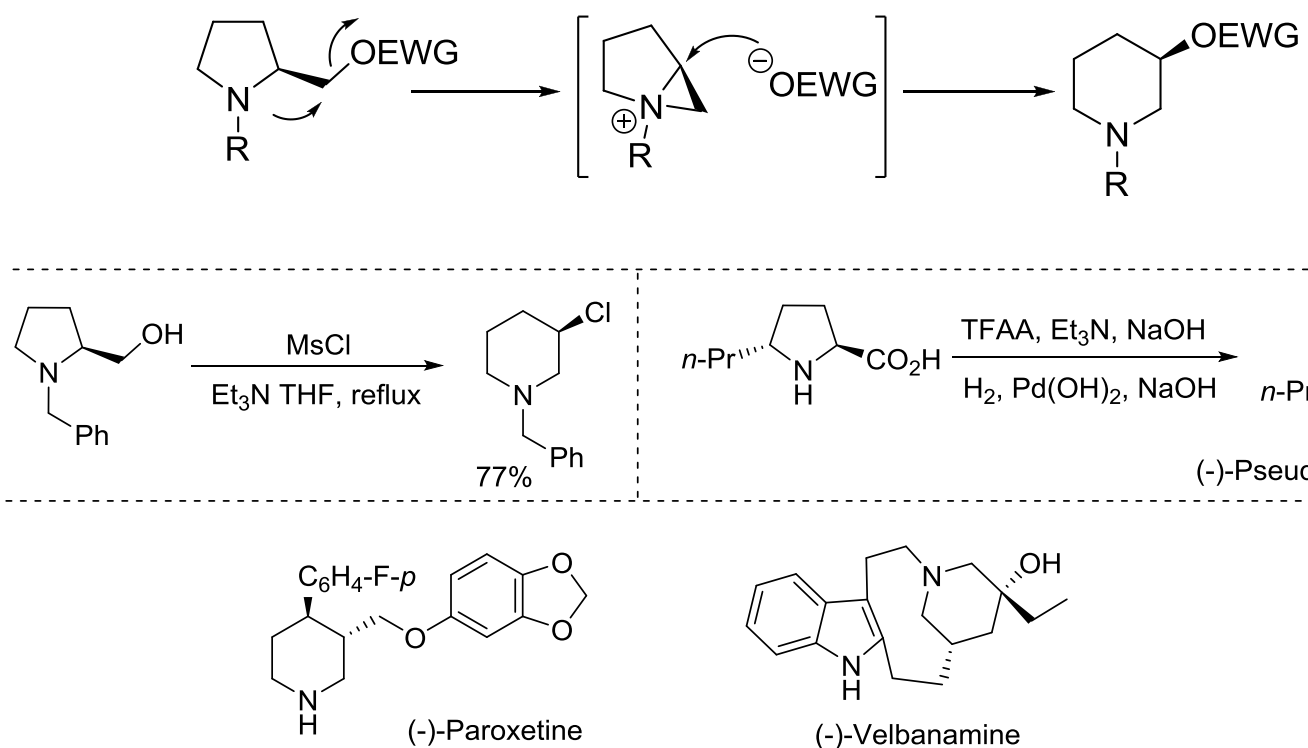

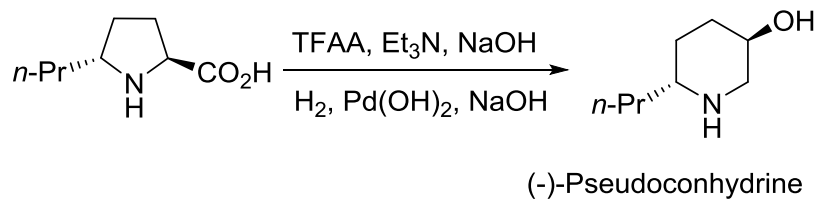

(d) Ring closing-metathesis (RCM) on dialkyl substituted nitrogen derivatives where each alkyl group contains an appropriately positioned alkene functional group.

$\mathrm{N}$-Boc or $\mathrm{N}$-tosyl-protected unsaturated amines undergo RCM to produce the desired piperidines in high yield. This methodology is particularly useful in producing piperidines from $N$-allyl and $N$-butenylamines. The resulting unsaturated piperidines can be functionalized to highly substituted piperidines (Scheme 37).

\section{Scheme 37: Ring closing metathesis for piperidine synthesis}
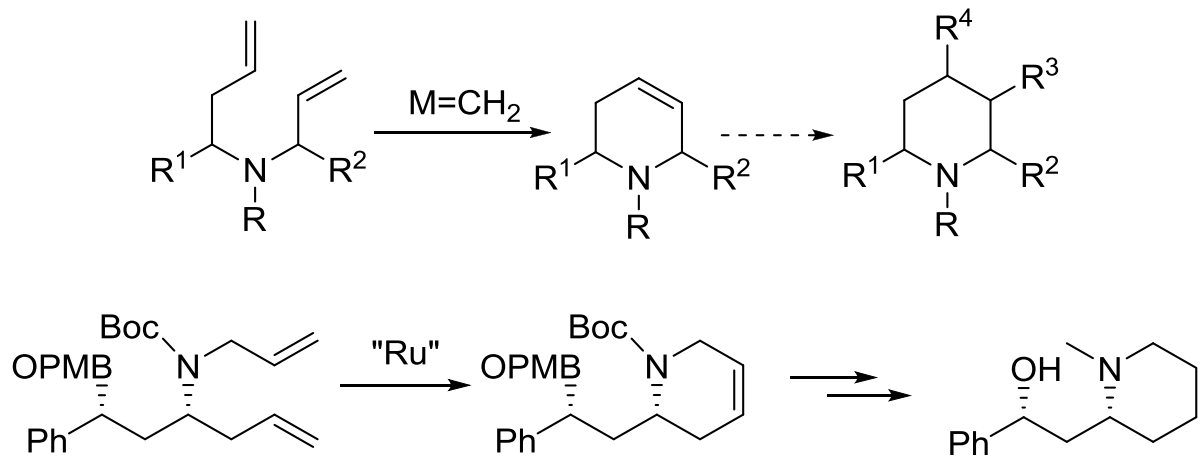

$(+)$-Sedamine 
Some other examples are:

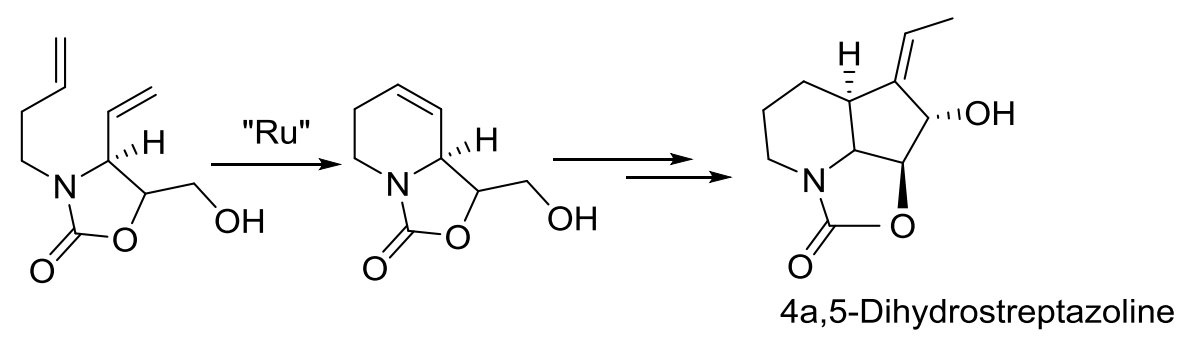

Although the literature describes plenty of methods to prepare these heterocyclic systems, short, direct, multi-substituted and diversity-oriented asymmetric piperidine syntheses are scarce. One explanation for this is the lack of practical methods that give access to optically pure materials. In pursuit of a general, cheap and scale up friendly method for the synthesis of piperidines, we undertook the synthesis of an enantiopure form.

\subsubsection{Rationale for enantiopure piperidine synthesis}

Our group developed a novel cascade approach for the stereoselective synthesis of the substituted and $\mathrm{N}$-protected piperidine moiety, based on the development of an intermolecular double-Michael addition between $\alpha, \beta$-unsaturated carbonyl compounds and nitroalkenes, facilitated by amines as Lewis bases. ${ }^{9,} 37$ The mechanistic hypothesis to this approach is that the amine reacts with nitro-alkene to form intermediate $\mathbf{A}$ in equilibrium which further reacts with electrophiles to nitro-substituted intermediate. Then, allylic nitro products are generated in this process via the $\beta$-elimination of the LB (Scheme 38).

\section{Scheme 38: Intermolecular cross-double-Michael addition by amines via $\beta$ - elimination}

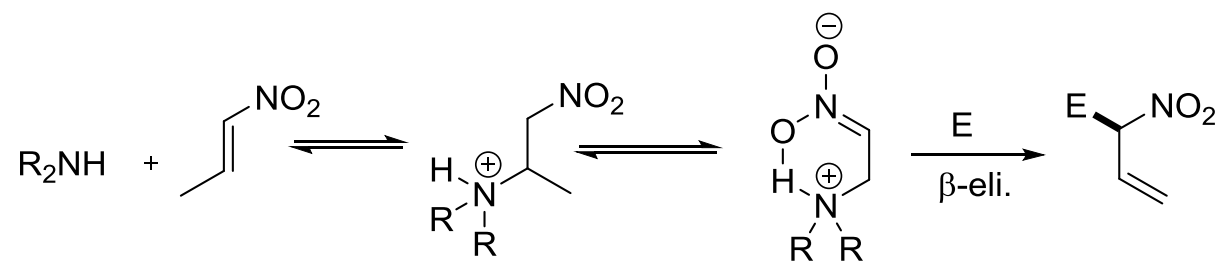

This phenomenon of formation of $\mathbf{A}$ encouraged us to apply this unique site for the construction of nitrogen heterocycles (Scheme 38). The reaction of primary amine with nitroalkene produces intermediate $\mathbf{A}^{\prime}$ which under reaction with the appropriate Michael 
acceptor generates adduct $\mathbf{B}^{\prime}$. Finally, nucleophilic addition to ring closure provided the substituted piperidine in one pot (Scheme 39).

\section{Scheme 39: One pot cascade piperidine synthesis}

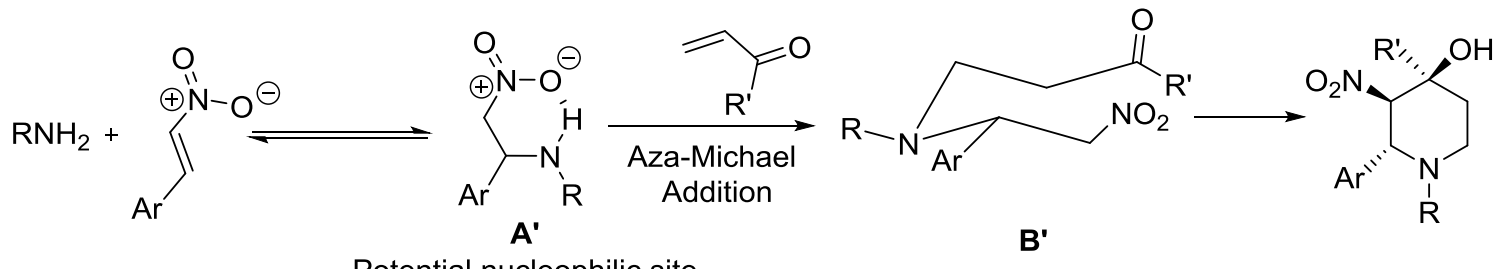

As proposed, varieties of substituted piperidines were synthesized with excellent yields and diastereoselectivities. Although three stereogenic centers were generated in piperidine only two C-4 diastereoisomers were obtained with the control of exocyclic chiral center, of which the cis isomer of C-3 nitro and C-4 hydroxy groups was the major product. Mechanistic investigation suggested that cyclization is rate determining step (RDS), which in turn confirmed diastereoselectivity of this reaction is controlled by the chair like transition state. Thus, it is possible to control stereochemistry of the piperidine by choosing an appropriate chiral amine (Scheme 40).

\section{Scheme 40: Asymmetric synthesis of substituted piperidine moiety}

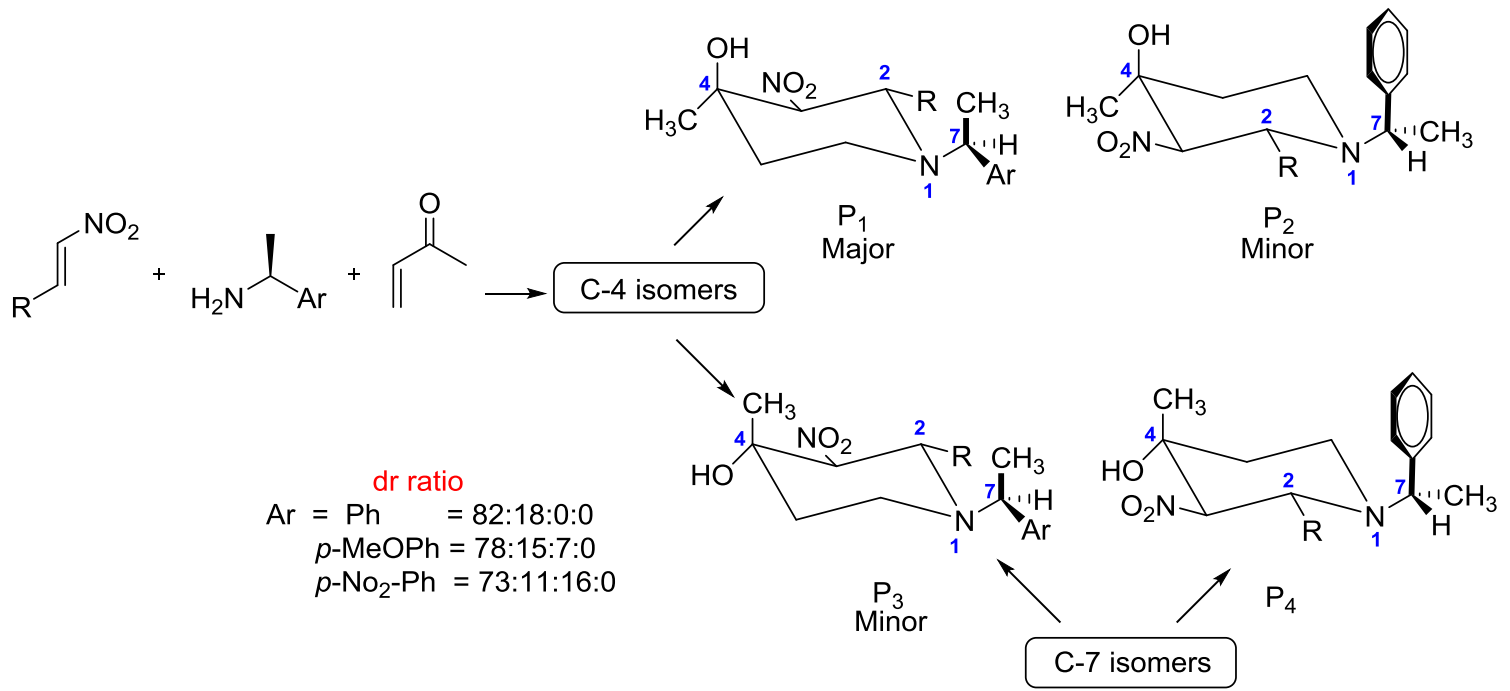

As expected, the reaction showed excellent yields and diastereoselectivity of the C-4 position in $\mathrm{dr}>10: 1$. In addition, modest chirality induction by the $\mathrm{C}-7$ position was observed with $\mathrm{dr}$ 
$=4: 1 . \mathrm{X}$-ray analysis of the piperidine crystals revealed that the exocyclic C-7 adopted a staggered conformation with respect to the ring. This data suggested that the N1-C7 $\sigma$-bond rotation was restricted. The $\mathrm{N}-1$ nitrogen lone pair electrons were placed in the axial position and the preferred staggered N1-C7 conformation could be achieved when the small group on C-7 was placed anti (axial orientation) to the N-1 nitrogen lone pair. Three syn-pentane interactions were relieved in this staggered conformation. Complete chirality induction was achieved through this control of exocyclic asymmetry. This new one-pot method will open the door for the asymmetric synthesis of several natural products that contain a piperidine moiety.

Although, we were successful in the synthesis substituted piperidines, the development of enantioselective route through proposed the chirality induction by exocyclic asymmetry as well as the cleavage or deprotection of $N$-substituted chiral moiety still remained a challenge to generate enantiopure piperidine.

\subsection{Research objectives}

Various substrates from chiral amines will be developed and then plausible deprotection pathways for the removal of exocyclic fragment to piperidines would be investigated. After the preparation of enantiopure piperidines, HPLC method would be developed to confirm enantioselectivity (Scheme 41).

\section{Scheme 41: Reaction hypothesis for enantiopure piperidine synthesis}

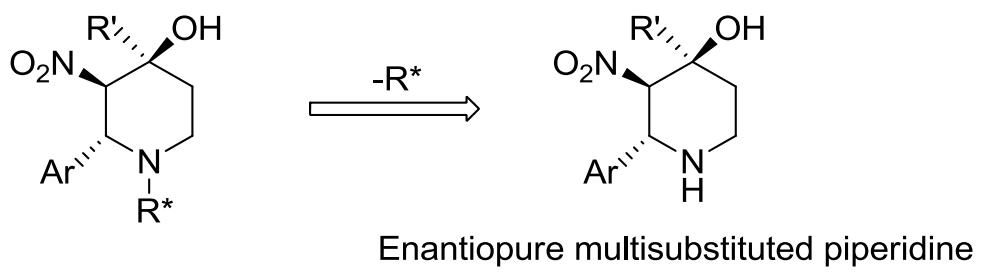

\subsection{Result and Discussion}

\subsubsection{Substrate Scope}

Based on our previous reaction methodology, various substrate scopes were developed starting with enantiopure amine. As summarized in Figure 8, a large group of substrates 
were suitable for this chiral transformation, including aromatic and heteroaromatic nitroalkenes. Good to excellent diastereoselectivity were observed in all cases with only C-4 isomers obtained. Aliphatic nitroalkene did not work under this condition. It could be due an electron-donating inductive effect of nitro-alkene. Similar observations were obtained when para-methoxy nitroalkene was used.

\section{Figure 8: Representative substrates}

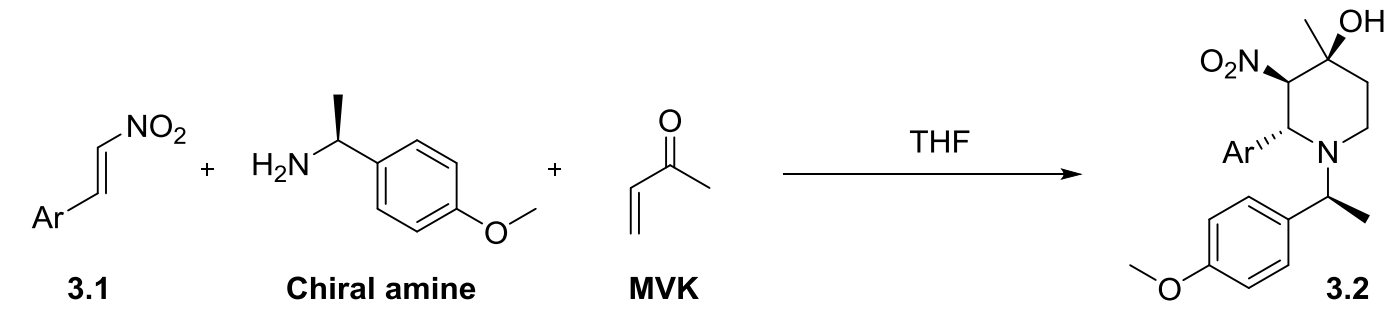

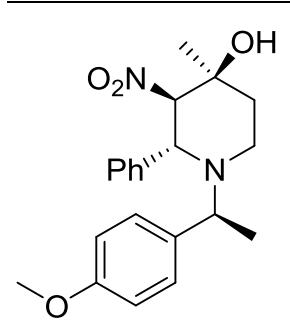

$3.2 \mathrm{a}, 72 \%$

$\mathrm{dr}=8: 1.5: .5: 0$

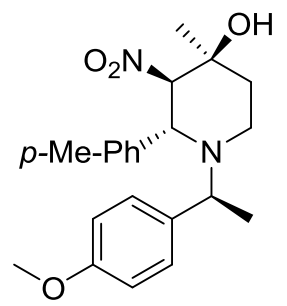

$3.2 e, 66 \%$

$\mathrm{dr}=7.8: 1 \cdot 4: .8: 0$

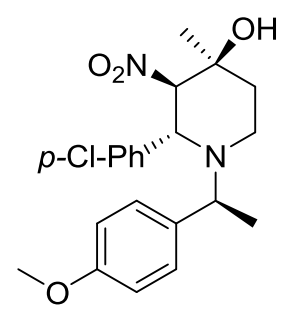

$3.2 b, 75 \%$

$\mathrm{dr}=7: 1: .3: 0$

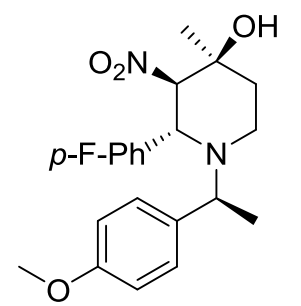

$3.2 c, 73 \%$

$\mathrm{dr}=9 \cdot 5: 1 \cdot 1: 1: 0$

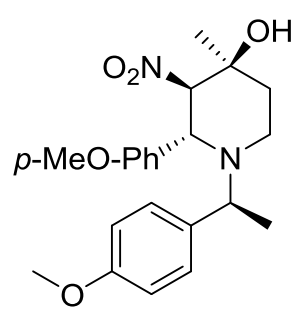

$3.2 d, 55 \%$

$\mathrm{dr}=7.6: 1.6: 1: 0$

General reaction conditions: Nitroalkene (1.0 eq.), Chiral amine (1.5 eq.), and MVK (3.0-4.0 eq.) mixed in THF ( $0.2 \mathrm{M})$. The reactions were monitored by TLC till nitroalkene was totally consume. Isolated yield of major diastereomer. dr and structure determined by NMR of crude reaction.

The reaction is extremely slow and a limited yield was produced even after increasing the reaction time. $p$-Chloro-substituted nitroalkene reacted faster and higher yield was obtained. Indole and protected indole nitroalkene also seemed to be unreactive under this condition. 
Aromatic vinyl ketones did not promote the reaction. It could be due an electron-withdrawing inductive effect of aromatic group. Neither electron releasing nor electron withdrawing groups in the $\beta$-position of the Michael acceptor tolerated this optimized reaction condition. There could be the plausible stereoelectronic effect during the chair like transition state formation (Scheme 42).

\section{Scheme 42: Unreactive nitroalkenes and Michael acceptor in cascade synthesis}

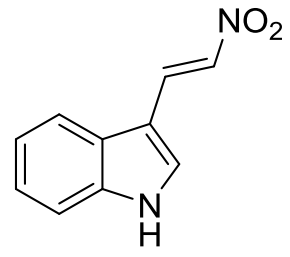

3.1d

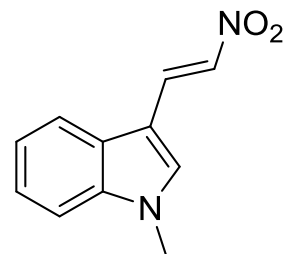

$3.1 \mathrm{e}$<smiles>CCCCCC=C[N+](=O)[O-]</smiles>

3.1f<smiles>C=CC(=O)Br</smiles>

$3.1 \mathrm{~g}$

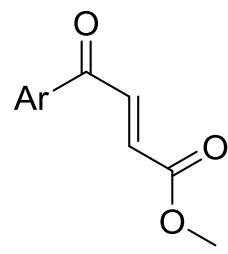

$3.1 \mathrm{~h}$

\subsubsection{N-Deprotection of exocyclic tethered chiral group}

With the successful development of diastereomeric substrate compounds, we set forth to find the best method of $\mathrm{N}$-deprotection reaction condition searching through suitable literature procedures (Table 7). ${ }^{38}$ While these approaches offer versatile routes for amines, there are certain limitations regarding the innate sensitive functionalities due to possible side reactions. In addition, we have to choose those reagents which do not change the stereochemistry of the product in presence of intact reactive functional groups like $-\mathrm{NO}_{2}$ and $-\mathrm{OH}$. With Raney nickel, hydrogenation of $-\mathrm{NO}_{2}$ became more prominent over debenzylation (entry 1). Similarly, palladium became a nonspecific catalyst under both basic and acidic condition (entry 2). We can, however, argue that acidic conditions gave some desired product. Reductive deprotection under the Birch condition gave byproducts as we observed the hydrogenation of aromatic systems. Silicon hydride under acidic conditions did not promote the reaction (entry 5). Most literature procedures described the deprotection with ceric ammonium nitrate (CAN) though it is expensive, but we got an $\alpha$-hydroxy unprotected molecule most of the time. In addition, it produced highly toxic waste during column work. DDQ proved to be non-effective reagent to promote asymmetric deprotection. Recently, a mild and efficient deprotection using $\mathrm{TMSCl}$ and hydrochloric acid was reported. It was found that, $\mathrm{HCl}$ improved our aimed route on comparing with $\mathrm{TMSCl}$ (entry 8, 9). In the 
pursuit of finding a very acidic organic reagent, TFA in $\mathrm{CH}_{2} \mathrm{Cl}_{2}$ stimulated our work. We got $90 \%$ yield with the retention of configuration. It could be the appropriate environmentally benign condition because it requires only acid/base extraction, leading to an overall reduction of costs. Since angular methyl group is increasingly being used near the nitrogen protecting group for amines, this acidic condition could be the rapid and versatile $N$-deprotection strategy to produce free secondary amine which will preserve the stereochemistry of presettled functional groups. Increasing the concentration of TFA decreased the yield of the piperidine product because of side reactions as caused by the elimination of tertiary alcohol group.

Table 7: $N$-deprotection of angular methyl PMB group<smiles>C[C@]1(O)CCN(Cc2ccccc2)[C@H](c2ccccc2)[C@@H]1[N+](=O)[O-]</smiles>

$3.2 h(A)$<smiles>C[C@H](c1ccccc1)N1CC[C@](C)(O)[C@H]([N+](=O)[O-])[C@H]1P</smiles>

3.2i(B)<smiles>CCCN1CC[C@](C)(O)[C@H]([N+](=O)[O-])[C@H]1P</smiles>

$3.2 \mathrm{j}(\mathrm{C})$

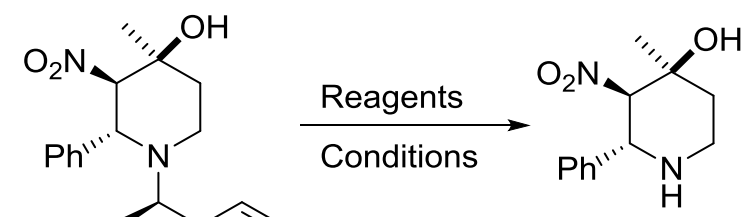

3.3a

\begin{tabular}{|c|c|c|c|c|c|}
\hline Entry & Conditions & $\mathbf{A}$ & $\mathbf{B}$ & C & D \\
\hline 1 & Raney $\mathrm{Ni}, \mathrm{H}_{2}, \mathrm{Ac}_{2} \mathrm{O}, \mathrm{MeOH}, 20-40 p s i$ & 5 & 5 & 5 & 5 \\
\hline 2 & $\mathrm{Pd}(\mathrm{OH})_{2}, \mathrm{H}_{2}, \mathrm{Boc}_{2} \mathrm{O}, \mathrm{MeOH}, 20-40 p s i$ & 5 & 5 & 5 & 5 \\
\hline 3 & $\mathrm{Pd} / \mathrm{C}, \mathrm{H}_{2}, \mathrm{AcOH}, \mathrm{MeOH}, 20-40 p s i$ & 20 & 10 & 15 & 10 \\
\hline 4 & $\mathrm{Na}, \mathrm{NH}_{3},-78^{\circ} \mathrm{C} \mathrm{THF}$ & 25 & 25 & 20 & 20 \\
\hline 5 & $\mathrm{Et}_{3} \mathrm{SiH}, \mathrm{HCOOH}, 12 \mathrm{hr} 90^{\circ} \mathrm{C}$ & 40 & 30 & 40 & 30 \\
\hline 6 & $\mathrm{CAN}, \mathrm{AcOH}: \mathrm{H}_{2} \mathrm{O}$ & 35 & 30 & 35 & 30 \\
\hline 7 & $\mathrm{DDQ}, \mathrm{DCM}: \mathrm{H}_{2} \mathrm{O}$ & 40 & 30 & 40 & 30 \\
\hline 8 & TMSCI, DCM & na & na & 25 & 30 \\
\hline 9 & $\mathrm{HCl}$, Dioxane, $\mathrm{RT}-70^{\circ} \mathrm{C}$ & na & na & 40 & 45 \\
\hline 10 & TFA:DCM (1:1) & na & na & 50 & 90 \\
\hline 11 & TFA & na & na & 30 & 50 \\
\hline
\end{tabular}

General reaction conditions: Piperidines 3.2 (1.0 eq.), reagents excess except entry 4, 5, 6 \& 7 (2.1eq.). The reactions were monitored by TLC/crude NMR till SM totally consumed. Isolated yield of product na $=$ not applicable/inert 


\subsubsection{Substrate scope of representative enantiopure piperidines}

With optimum reaction condition in hand, various enantiopure piperidines were prepared and their structures were confirmed by ${ }^{1} \mathrm{H}-\mathrm{NMR},{ }^{13} \mathrm{C}-\mathrm{NMR}$ and HRMS as well as their enantioselectivities were determined by chiral HPLC as shown in Figure 9.

As usual chloro and fluoro substituted piperidines performed excellently for this reaction. To our delight the enantioselectivity is $>99 \%$ in all cases. The electron donating group in piperidines like toluene and para methoxy benzene gave good yield. But, in the case of furan substituted piperidine the product yield is low whereas thiophene gave decent yield. This low yield of furan may be due to secondary rearrangement reaction under strongly acidic condition.

\section{Figure 9: Reaction substrate scope for the formation of enantiopure piperidine}

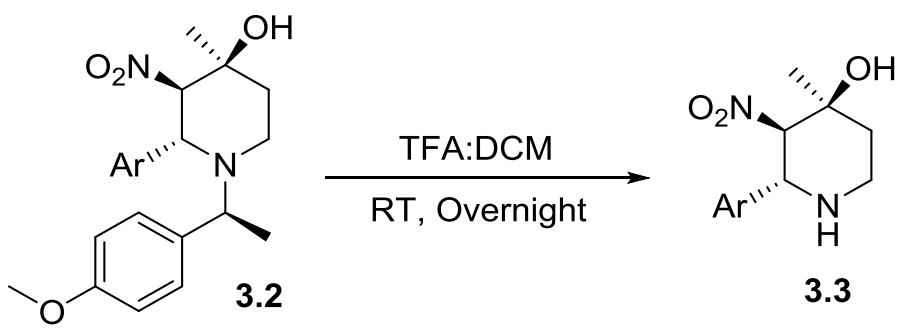

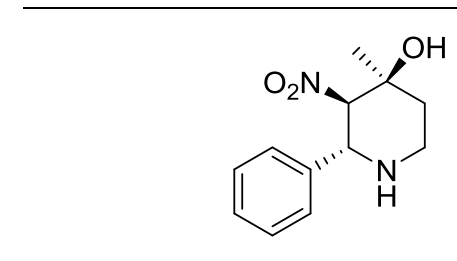

$3.3 a, 88 \%$ ee $>99 \%$<smiles>C[C@]1(O)CCN[C@H](c2ccc(Cl)cc2)[C@@H]1[N+](=O)[O-]</smiles>

3.3b, $92 \%$ ee $>99 \%$<smiles>C[C@]1(O)CCN[C@H](c2ccc(F)cc2)[C@@H]1[N+](=O)[O-]</smiles>

3.3c, $90 \%$ ee $>99$<smiles>Cc1ccc([C@@H]2NCC[C@](C)(O)[C@H]2[N+](=O)[O-])cc1</smiles>

3.3d, $77 \%$ ee $>99$

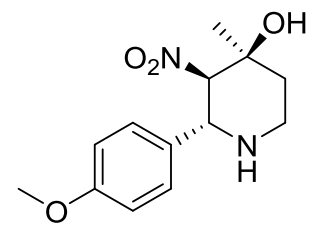

3.3e, $75 \%$ ee $>99$

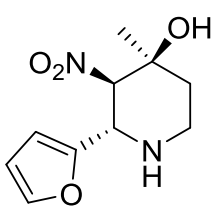

3.3f, $65 \%$ ee $>99$

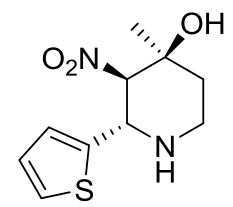

3.3g, $85 \%$ ee $>99$

General reaction conditions: Substrate 3.2 (1eq.), TFA:DCM (1:1) at RT, 12-18hr, The reactions were monitored by TLC, yield is both crude NMR/ isolated, ee determined by chiral HPLC 


\subsection{Application of piperidines towards the synthesis of chiral thiourea- based catalyst}

Remarkable advances have been realized by the use of small privileged organic molecules to catalyze asymmetric reactions. This development of organocatalysts in asymmetric reactions have attracted much attention in recent years because they are are generally non-toxic, highly efficient, selective, environmentally friendly and durable in aerobic and aqueous reaction conditions. $^{39}$

Encouraged by the decent yield and enantioselectivity of piperidine, we first moved towards the synthesis of catalyst $\mathbf{3 . 4 b}$. The chiral piperidine under zinc reduction produced amine 3.4A which upon treatment with 3,5-di-trifluromethyl-pheny thiocyanate resulted in the desired molecule 3.4b in over 95\% yield (Scheme 43). To run the reaction, we chose Michael addition between chalcone and nitroalkane as being one of the most efficient and powerful atom-economic carbon-carbon bond forming reactions in organic chemistry. Our hypothesis behind the chiral transformation could be the nitroalkane co-ordinated to tertiary protonated amine or alcohol group to furnish nucleophilic site while the diamine thiourea by the coordination through $\mathrm{H}$-bond provide electrophilic site and the reaction happened in linear fashion to produce the chiral product (Scheme 44). In addition, a solvent-free condition was found to be a very effective reaction due to the intimacy of the reactants.

As proposed, high yield (80\%) and enatioselectivity (ee 90\%) of 3.4d were observed from the conjugate reaction between chalcone and nitroalkane in the presence of our catalyst $\mathbf{3 . 4 b}$.

\section{Scheme 43: Short synthesis of thiourea based piperidine organocatalyst}

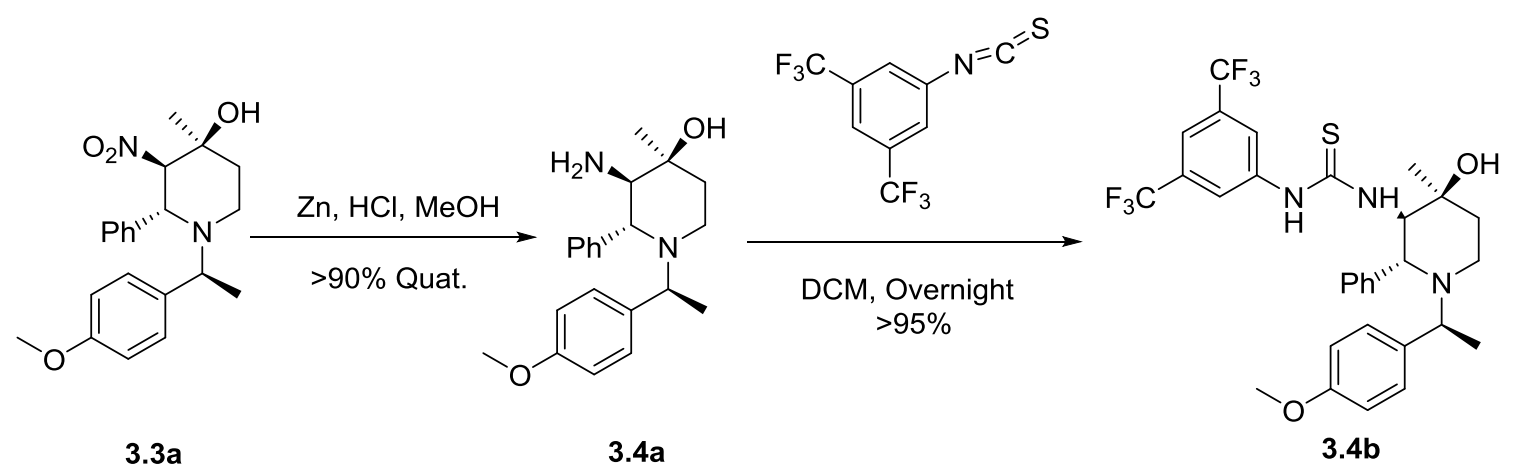


The design and synthesis of highly stereoselective, readily accessible and tunable catalysts are always desirable for asymmetric catalysis. In this direction, we have developed an efficient synthesis of piperidine based thiourea organocatalyst 3.4b (Table 8).

Scheme 44: Hypothetical proposition of transition state for the control of enantioselectivity

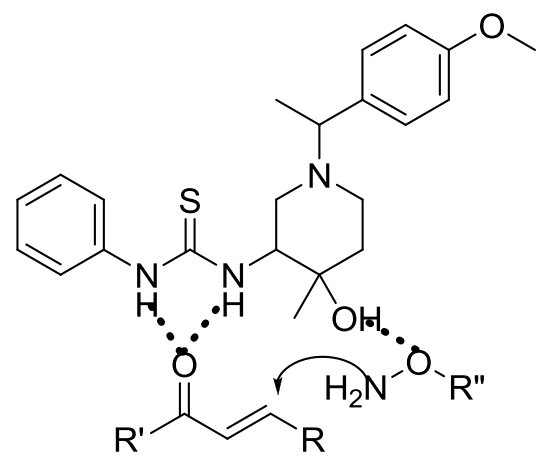

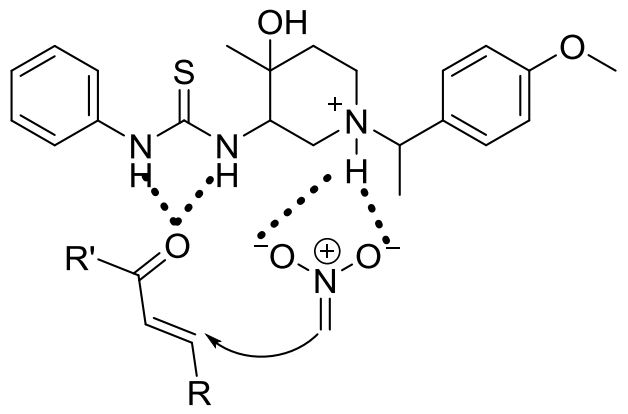

Table 8: Reaction of chalcone with nitroalkane under organocatalyst ${ }^{a}$<smiles>CN(O)C(=O)CC(C[N+](=O)[O-])c1ccccc1</smiles>

3.4c

3.4d

\begin{tabular}{ccccccc}
\hline Entry & Catalyst (3.4b, mol\%) & Solvent & Temp. $\left({ }^{\circ} \mathbf{C}\right)$ & Time & 3.4d, Yield $^{b}$ & ee $^{c}$ \\
\hline 1 & 20 & neat & 80 & 150 & 80 & 60 \\
2 & 20 & neat & 50 & 240 & 80 & 90 \\
\hline
\end{tabular}

${ }^{a}$ The reaction was conducted chalcone $3.4 \mathrm{c}(0.1 \mathrm{mmol})$ in excess nitroalkane. ${ }^{b}$ Isolated yield after silica gel chromatography. ${ }^{c}$ Determined by HPLC using Chiral HPLC method.

\subsection{Conclusion}

We have developed the novel method for the synthesis of enantiopure piperidine. The wide substrate scope, excellent yields and enantioselectivity showed it as a unique strategy. We have also demonstrated a practical synthesis and application of organocatalyst 3.4b for Michael additions of nitromethane to chalcone to produce a product with high to excellent 
chemical yields and high level of enantioselectivity under solvent-free conditions. This represents an alternative, attractive method for asymmetric Michael addition. Further studies of the newly developed catalyst in organocatalysis are currently underway. 


\section{Chapter 4: Unique Reactivity of Triazole gold towards Alkyne Activation to Allene and Enone: Chemoselectivity, Acidity and Ligand Economy}

\subsection{Introduction}

Homogeneous gold catalysis, being unique and versatile as evidenced by immense organic transformations and its use in total synthesis, has gained extensive popularity among synthetic and pharma-academia community. ${ }^{40}$ Out of the two oxidation states $\mathrm{Au}(\mathrm{I})$ and $\mathrm{Au}(\mathrm{III})$, the former is widely utilized in academic and industrial field due to its exclusive characteristics including: ease of preparation, better pre-catalytic stability, strong tuning with phosphine ligands (L), solubility, chemo and stereo selectivity, soft carbophillic nature towards the $\pi$-activation of $\mathrm{C}$-C multiple bonds, high oxidation potential of $\mathrm{Au}(\mathrm{I})$ and $\mathrm{Au}(\mathrm{III})$ and good catalytic turnover. It is currently accepted that the $\mathrm{Au}$ (I) complexes adopt one of the two co-ordination sites in $180^{\circ}$ linear geometry (Scheme 45). The actual catalyst in alkyne and alkene activation are of type $[\mathrm{L}-\mathrm{Au}]^{+}$, generated from stable precursors $\mathrm{L}-\mathrm{Au}-\mathrm{X}$ or $[\mathrm{L}-\mathrm{Au}-\mathrm{X}]^{+}$. A; , with the open co-ordination site on the opposite side of the ligand (L) for substrate binding. ${ }^{41}$ While the ligands (L) are certainly considered critical in gold catalysis, more and more attention is being paid to the evaluation of whether the choice of counter ligand " $X$ " can be used to adjust the overall catalyst reactivity.

\section{Scheme 45: The counter ligands and modes of reactivity in $\mathrm{Au}(\mathrm{I})$ catalysis}

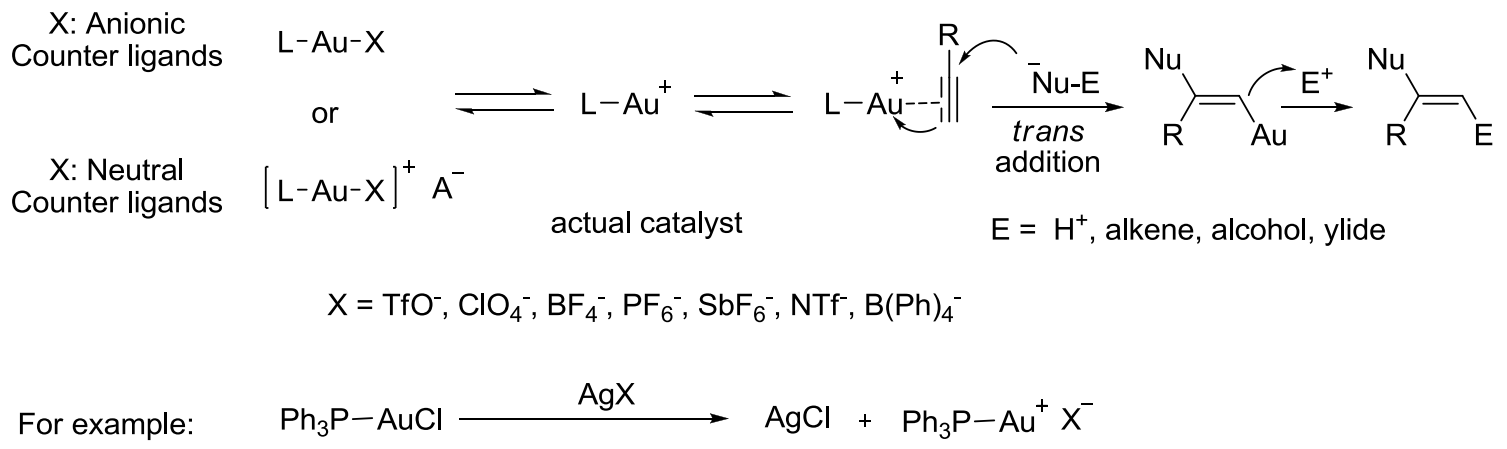

Generally, the triphenyl phosphine compounds can be applied as a ligand in Au (I) catalysis. The recent development of $\mathrm{N}$-heterocyclic carbene (NHC) derivatives commonly described as excellent $\sigma$-donors have significantly expanded the choice of ligands by improving the 
catalytic stability through metal-ligand backbonding (Figure 10). ${ }^{42}$ The cationic and carbene character of gold catalyst were confirmed separately by Fürstner et al. using alkyl gold complex and later by Toste $e t a l$. as a carbocation-carbenoid continuum. ${ }^{43}$

\section{Figure 10: Triphenyl phosphine and NHC gold (I) catalysts}

$$
\begin{gathered}
\mathrm{Ph}_{3} \mathrm{P}-\mathrm{Au}^{+} \mathrm{X}^{-} \\
\mathrm{X}=\mathrm{TfO}^{-}, \mathrm{ClO}_{4}^{-}, \mathrm{BF}_{4}^{-}, \mathrm{PF}_{6}^{-}, \mathrm{SbF}_{6}^{-}, \mathrm{NTf}_{2}^{-}, \mathrm{B}(\mathrm{Ph})_{4}^{-}
\end{gathered}
$$

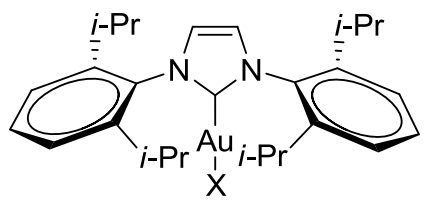

Cationic $\mathrm{Au}(\mathrm{I})$ catalysts wit improved stability

Even though there is a high efficiency when using phosphine gold (I) complexes the active catalysts are typically prepared by the addition of a silver activator to a gold halide precatalyst. This system has certain limitations: the hygroscopic nature of silver and the decreasing stability as well as catalytic activity of gold (I). ${ }^{44}$ As a result, researchers are constantly on the quest for excellent catalytic systems to accomplish the active gold (I) species. In this regard, we pursued towards the application of triazoles as ligands in $\mathrm{Au}$ (I) complexes. Since triazole possesses a strong dipole moment with nitrogen $\sigma$-donor and a lower LUMO aromatic antibonding orbital for potentially improved metal backbonding, we envisioned triazoles as good binding ligands to produce new cationic $\mathrm{Au}$ (I) catalysts with improved stability and effective reactivity, especially at high temperatures (Figure 11). ${ }^{45}$

\section{Figure 11: 1,2,3-triazole gold(I) catalysts}

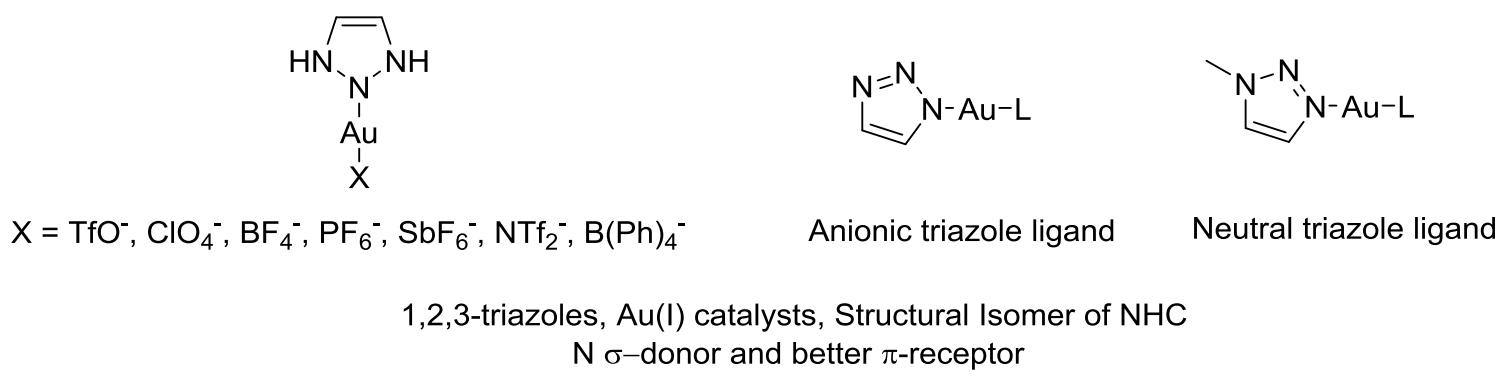

Our group systematically developed the new synthetic methods for the substituted 1,2,3triazole coordinated gold(I) complexes. ${ }^{13,46-50}$ X-ray crystal structures revealed (Figure 12) that both neutral and anionic triazoles can coordinate with an $\mathrm{Au}(\mathrm{I})$ cation, forming stable $\mathrm{TA}-\mathrm{Au}$ complexes. The preparation of these complexes was very straightforward. Simply 
treating the $\mathrm{NH}$-triazoles with $\mathrm{PPh}_{3} \mathrm{AuCl}$ in methanol under basic conditions $\left(\mathrm{K}_{2} \mathrm{CO}_{3}, 1\right.$ equiv) at room temperature gave the neutral TA-Au-1 in $>90 \%$ yield. The "cationic" complex TAAu-2 was prepared either from the addition of HOTf to TA-Au-1 or by the reaction between $\mathrm{PPh}_{3} \mathrm{Au}-\mathrm{OTf}$ (prepared from $\mathrm{PPh}_{3}-\mathrm{Au}-\mathrm{Cl}$ and $\mathrm{AgOTf}$ ) and benzotriazole. Both complexes were stable and could be further purified by recrystallization to ensure no extra $\mathrm{Ag}^{+}$or acid in the catalyst. The crystal structures revealed nearly identical $\mathrm{Au}-\mathrm{P}$ bond length for both the anionic and neutral triazole coordinated $\mathrm{Au}(\mathrm{I})$ complexes. The longer $\mathrm{Au}-\mathrm{N}$ bond in $\mathrm{TA}-$ Au-2 implies that the neutral triazole dissociates more easily to release the coordination site for substrate activation. This new class of NH-triazole $\mathrm{Au}$ compounds offer improved thermal stability and substrate stability as ligands in transition metal coordination. ${ }^{47}$ Preliminary studies have also shown that triazole-Rh(I) complexes provide much better stability while retaining good catalytic reactivity (Scheme 46). In comparison with the more expensive NHC ligands, simple triazole compounds possess $\sigma$-donor from nitrogen lone pair electrons and the $\pi$-receptor from highly electron deficient aromatic system.

\section{Figure 12: X-ray crystal structures of the two different types of 1,2,3 triazole-Au complexes}
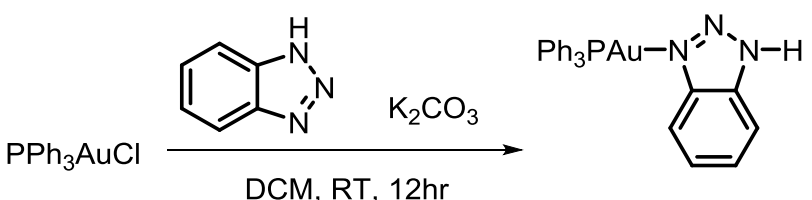

L-Au-TA

TA-Au-1

Au-P $=2.240 \mathrm{~A}^{\circ}$

4.1a
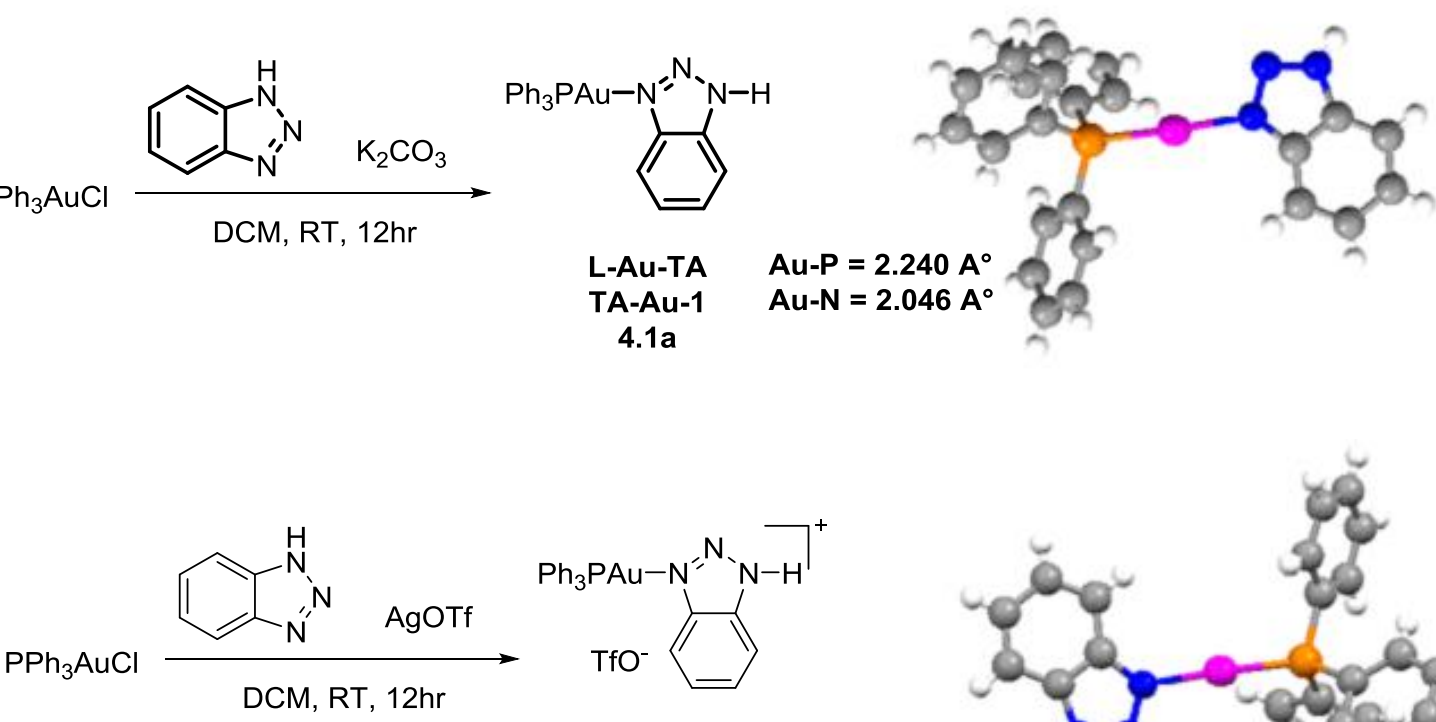

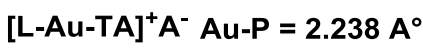

TA-Au-2 Au-N $=2.063 \mathrm{~A}^{\circ}$ 4.1b

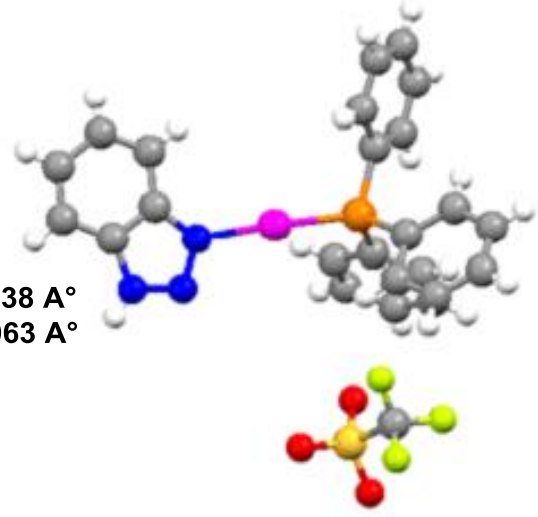




\section{Scheme 46: $R h(I)$ complexes and Pauson-Khand reaction}

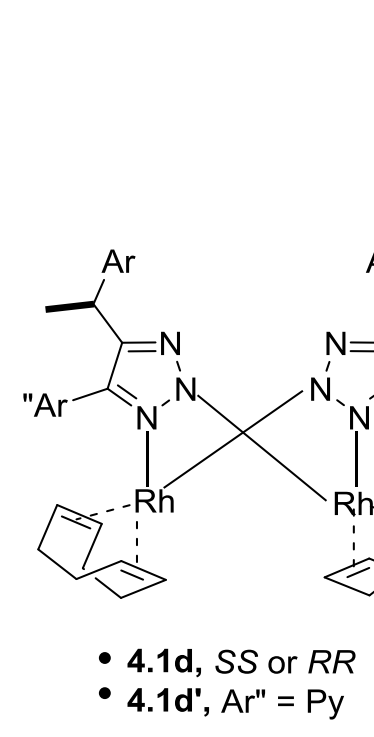

- 4.1d, $S S$ or $R R$
- 4.1d', $\mathrm{Ar}^{\prime \prime}=\mathrm{Py}$

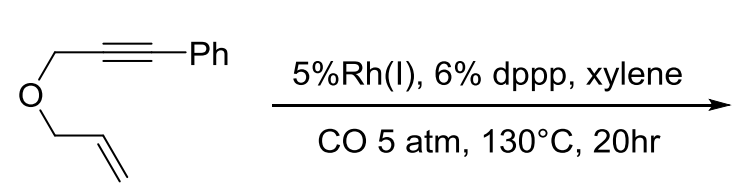

$4.1 \mathrm{e}$

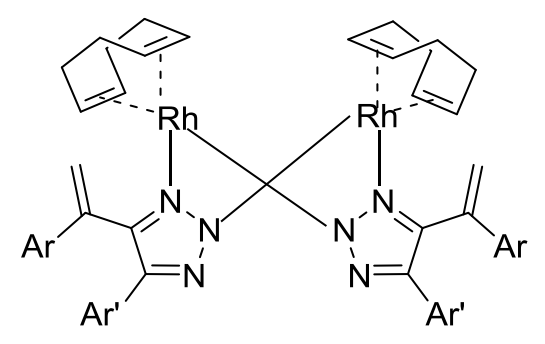

4.1c, $A r^{\prime}=\mathrm{Ph}, p-\mathrm{NO}_{2}-\mathrm{C}_{6} \mathrm{H}_{4}$

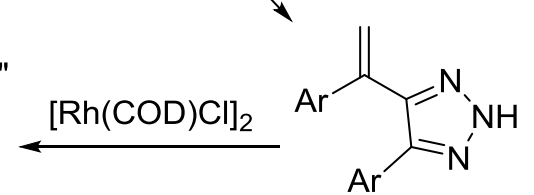

Air and Moisture stable Rh(I) Complexes

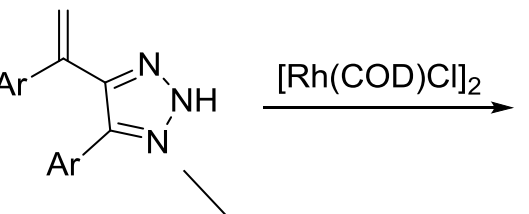

"."
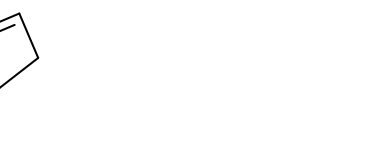
Early on, in 2010 Shi et al. reported the application of 1,2,3-triazole bound $\mathrm{Au}(\mathrm{I})$ complexes as effective precatalysts in promoting chemoselective intramolecular furan-alkyne cyclization, which provided (a) clear evidence for the $\mathrm{Au}(\mathrm{I})$ cation as a possible catalyst in this transformation and (b) a practical alternative solution that allows simple, inexpensive $\mathrm{PPh}_{3}$ as an effective ligand (Scheme 48). ${ }^{49}$

\section{Scheme 48: Au(I) complexes for Hashmi Phenol Synthesis}

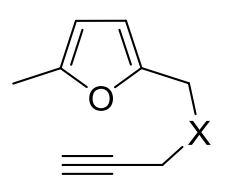

$4.1 \mathrm{i}$
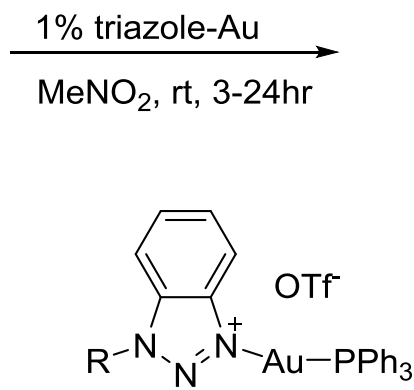

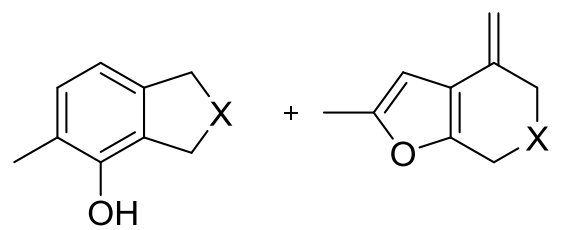

$4.1 \mathrm{j}$
$4.1 \mathrm{k}$

Yield up to $95 \%$ of phenol product selectivity $>20: 1$

Catalyst: $R=H(4.1 b), M e(4.1 b ')$

In the meantime, the triazole-gold complexes were discovered as precatalyst in promoting cascade vinyliodination reaction in propargyl acetate rearrangement in the presence of NXS. This transformation is unique mode which furnishes challenging kinetic $E$-isomers with good to excellent selectivity (Scheme 49). ${ }^{50}$

\section{Scheme 49: Chemoselective alkyne activation to trans $\alpha$-haloenones}

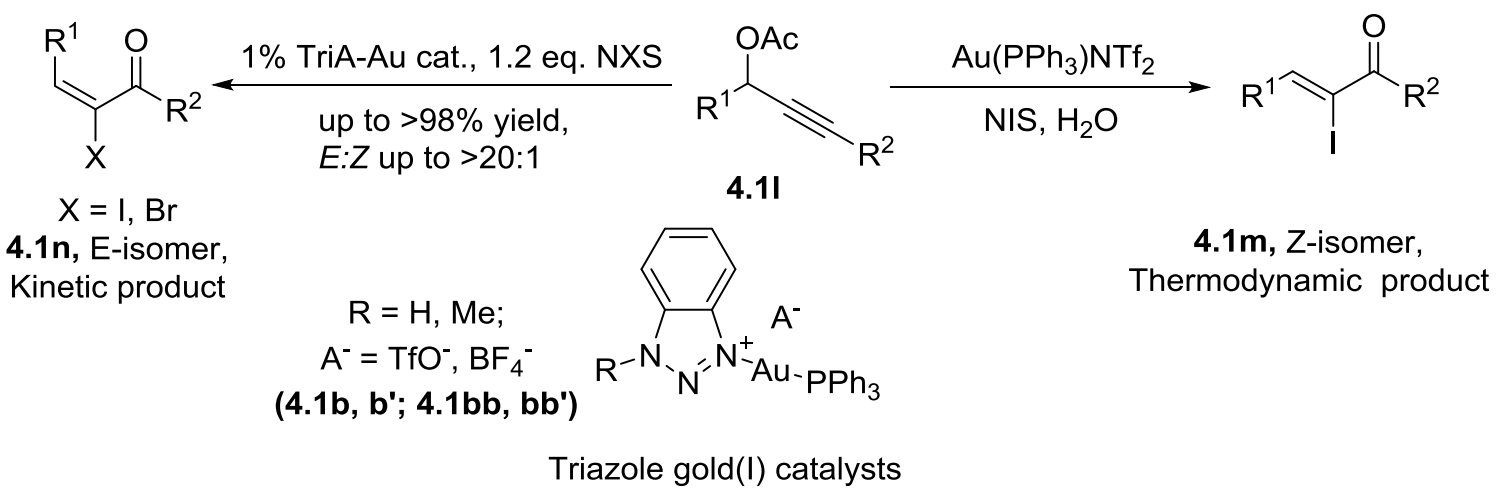

This new class of catalysts exhibited significantly improved thermal stability and substrate tolerance. These results opened up a new strategy in tuning gold reactivity through the 
counter ligand instead of the primary ligand. The TA-Au catalyst has a significantly lower cost than other ligands. In comparision, the combination of the $\mathrm{PPh}_{3}$ primary ligand and triazole counter ligand can be $>1000$ times cheaper than the NHC primary ligand.

\subsection{Research objectives}

In continuation of extension of application of 1,2,3-triazole, we wanted to study the following three aspects of the reaction in order to determine whether TA-Au could promote transformations that previously required the expensive NHC primary ligands which substantially improve the ligand economy of the overall reaction.

4.2.1 Propargylic ester rearrangement and sequential hydration to form enones.

4.2.2 Meyer-Schuster rearrangement of propargylic alcohols to enones.

4.2.3 Asymmetric synthesis of substituted allenes

\subsection{Results and Discussions}

\subsubsection{Optimization for Enone synthesis with TA-Au catalyst $\$$}

The gold catalyzed propargylic ester 3,3-rearrangement is a well-studied transformation. ${ }^{40,51}$ One application of this process was the synthesis of enones from sequential hydration of the allene-acetate intermediates (Scheme 50). Although this direct transformation provided one attractive strategy in preparing enones under mild conditions, it suffered from limited substrate scope due to the side reactions caused by the gold-promoted allene activation. One side reaction was the intramolecular Friedel-Crafts cyclization of allene (path B) giving the indene 4.3.3a. ${ }^{52}$ As a result, a simple $\mathrm{Au}(\mathrm{I})$ catalyst, such as $\mathrm{PPh}_{3} \mathrm{Au}^{+}$, gave poor overall yields of the desired enones $\left(5 \% \mathrm{Ph}_{3} \mathrm{PAuCl} / \mathrm{AgOTf},<40 \%\right.$ yields). To overcome this problem, Nolan and co-workers investigated different $N$-heterocyclic carbene ligands. ${ }^{53}$

\footnotetext{
${ }^{\S}$ Reproduced in parts with permission from Adv. Synth. Catal. 2011, 353, 2584-2588. Copyright 2011, with permission from Willey-VCH Verlag GmbH \& Co. KGaA, Weinheim.
} 


\section{Scheme 50: $\mathrm{Au}(\mathrm{I})$ catalysis for activation of both alkyne and allene}

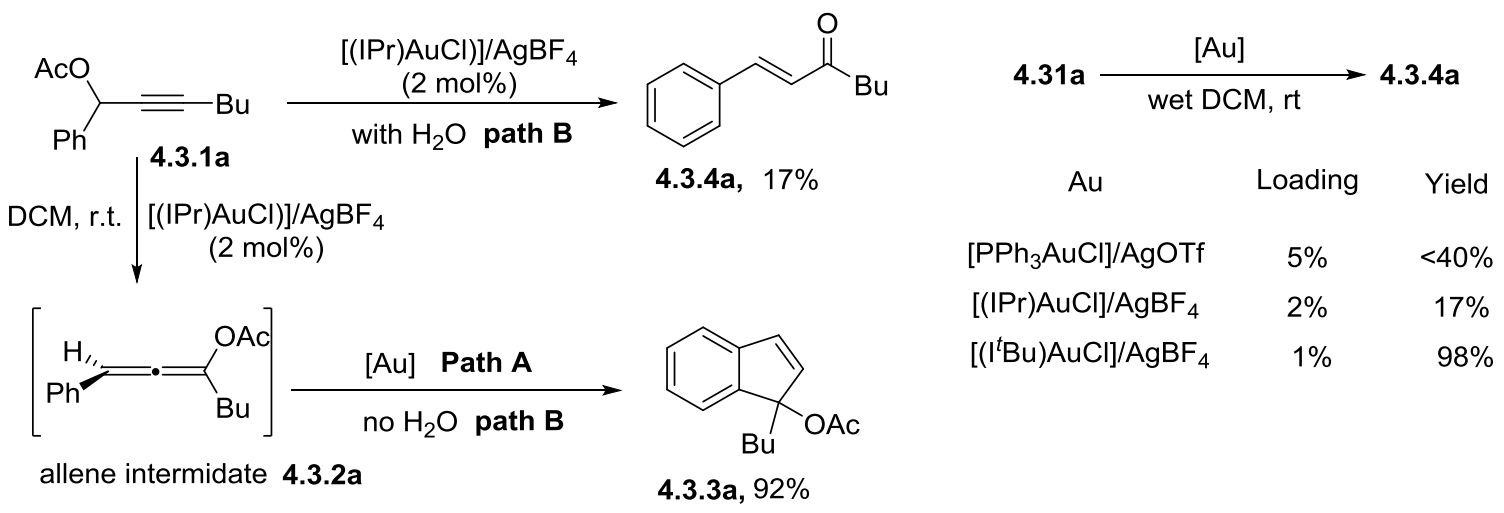

The more sterically hindered $\left[\left(I^{t} \mathrm{Bu}\right) \mathrm{Au}\right]^{+}$complex was revealed as the optimal catalyst for the formation of enones with high efficiency (1\% loading, up to $98 \%$ yields). The comprehensive mechanistic investigations, both through experimental and computational studies, showed that the $\mathrm{SN}_{2}{ }^{\prime}$ water addition to the gold activated alkyne was the mechanism by avoiding the formation of allene (Scheme 51A). Two experimental observations supported this mechanism: (i) no enone formation with $t$-Bu-substituted alkyne 4.3.1b (Scheme 51B), and (ii) treating an allene ester 4.3.2a with the NHC-Au catalyst did not give enone 4.3.4a (Scheme 51C).

\section{Scheme 51: Proposed $\mathrm{SN}_{2}{ }^{\prime}$ addition mechanism by Nolan}

\section{A}<smiles>O=C(Br)/C=C/c1ccccc1</smiles>

B

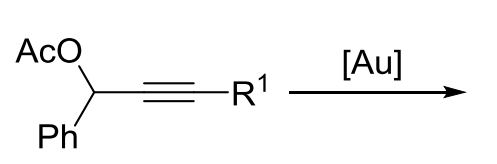

$$
\text { 4.3.1a, } R^{1}=B u
$$

4.3.1b, $R^{1}=t-B u$

C

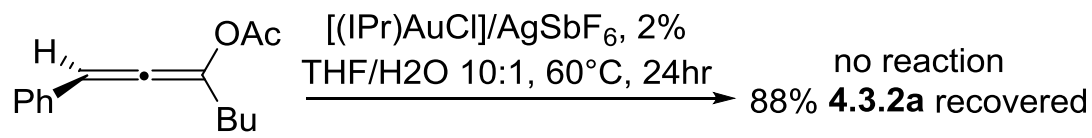

Conditions

[(IPr)AuCl] $/ \mathrm{AgSbF}_{6}, 2 \%$

THF/H2O 10:1, 60 ${ }^{\circ} \mathrm{C}, 8 \mathrm{hr}$

$98 \%$ yield

no reaction

4.3.2a 
Recently, our group reported the synthesis of E- $\alpha$-iodoenone from a propargylic ester 3,3rearrangement followed by the iodination of the allene ester. Interestingly, while all other [L$\mathrm{Au}]^{+}$catalysts $\left(\right.$such as $[\mathrm{NHC}-\mathrm{Au}]^{+}$and $\left[\mathrm{PPh}_{3}-\mathrm{Au}\right]^{+}$) gave only the thermodynamically stable Z-isomers, the application of the TA-Au led to the effective formation of the kinetically favored E-isomers. These results suggested that TA-Au was a chemo selective catalyst, which could effectively promote alkyne activation without interrupting the inherent reactivity of the allene intermediates. Moreover, as shown in Scheme 52A, although the allene ester 4.3.2a was rather stable even at elevated temperatures, treatment of this compound with a catalytic amount of acid could effectively convert the allene to the desired enone with excellent yields. Contrastingly, unlike the previously reported NHC-Au complexes (Scheme 52B), TA-Au could effectively catalyze the hydration of 4.3.2a at either room temperature or elevated temperature, giving the desired enone in excellent yields. This was likely caused by the equilibrium shown in Scheme 52B, where a catalytic amount of HOTf was released to serve as the Bronsted acid in promoting the hydration. We then postulated that TA-Au might be an effective catalyst for promoting propargylic ester rearrangement and hydration to give enones. Unlike the $\left[\left(\mathrm{I}^{t} \mathrm{Bu}\right) \mathrm{Au}\right]^{+}$catalyst, TA-Au promoted this reaction through a chemo selective rearrangement followed by an effective hydration with the same pre-catalysts, which therefore provides an alternative pathway to prepare enones compared with the $\mathrm{SN}_{2}{ }^{\prime}$ mechanism by the more expensive $\left[\left(\mathrm{I}^{t} \mathrm{Bu}\right) \mathrm{Au}\right]+$ catalysts.

\section{Scheme 52: Triazole-Gold Catalysis and acidic character}

A

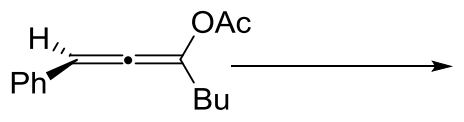

4.32a

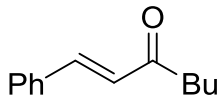

4.3.4a

Cat.
-
$5 \%$ TfOH
$5 \%$ TA-Au

4.1b
Conditions

$\mathrm{MeOH}, 60^{\circ} \mathrm{C}, 10 \mathrm{hr}$

$\mathrm{MeOH}, 60^{\circ} \mathrm{C}, 6 \mathrm{hr}$

$\mathrm{MeOH}, 60^{\circ} \mathrm{C}, 6 \mathrm{hr}$ 4.3.4a

n.r.

$99 \%$

$98 \%$

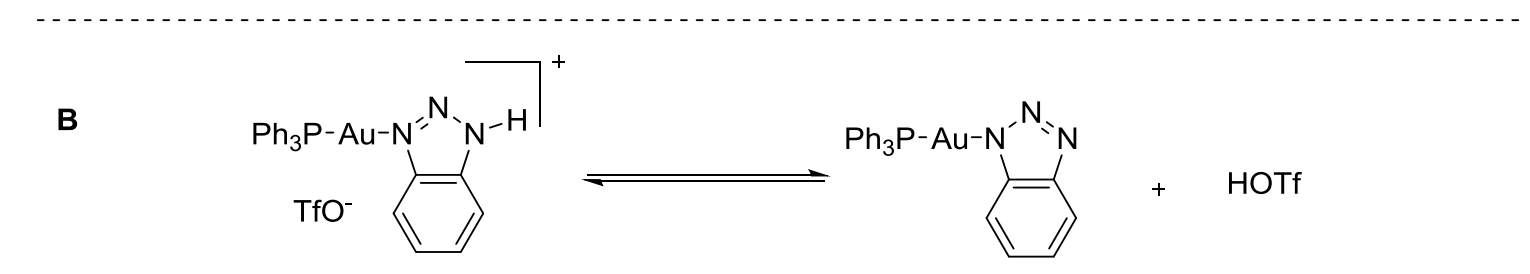




\subsubsection{Substrate Scope of Enone synthesis from the propargylic ester}

As expected, with the triazole gold catalyst, enone 4.3.4 was obtained in excellent yields as shown in Figure 13 below. No indene by-products were observed, which highlighted the chemoselective nature of the TA-Au catalyst. TfOH was not a suitable catalyst for this reaction since the 3,3-rearrangement did not occur with only TfOH. Screening of solvent revealed that $\mathrm{MeOH}$ was the optimal choice. The reaction worked smoothly at room temperature and gave the enone products in excellent yields over 24 hours. Raising the temperature decreased the reaction time to 3-6 hours. As a result, the enones 4.3.4 were obtained with near quantitative yields (>99\% NMR yields) at very low catalyst loading $(0.2 \%)$.

Figure 13: Substrate Scope of propargyl ester hydrolysis

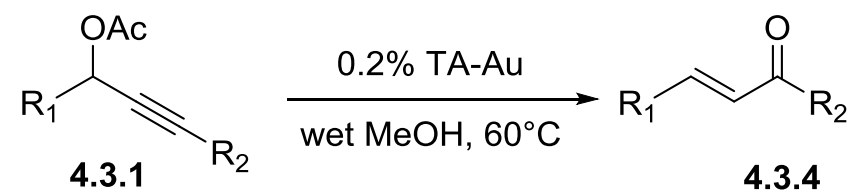

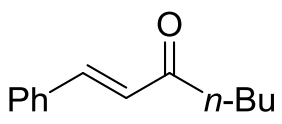

4.3.4a, $92 \%, E / Z=12: 1$<smiles></smiles>

4.3.4d, $91 \%, E / Z>8: 1$<smiles>CC=CC(=O)OCCC</smiles>

4.3.4g, $85 \%, E / Z>20: 1$<smiles>CCCCC(=O)C=CC[PH2+]</smiles>

4.3.4j, 93\%, E/Z > 20:1<smiles>CC(C)(C)C(=O)/C=C/c1ccccc1</smiles>

4.3.4b, 93\%, $E / Z=3: 1$<smiles>O=C(/C=C/c1ccccc1)C1CC1</smiles>

4.3.4e, $83 \%, E / Z=10: 1$<smiles>CC(C)(C)C(=O)/C=C/c1ccccc1</smiles>

4.3.4h, $95 \%, E / Z>20: 1$<smiles>CC(C)(C)C(=O)C=C1CCCCC1</smiles>

4.3.4k, $87 \%$<smiles>[3H]PCC=CC(=O)CCCC</smiles>

4.3.4c, $92 \%, E / Z>20: 1$<smiles>O=C(/C=C/[Pb]=P)c1ccccc1</smiles>

4.3.4f, $89 \%, E / Z>20: 1$<smiles>CCCCC(=O)C=C(C)C</smiles>

4.3.4i, $89 \%$<smiles>CCCCC(=O)C=C[Al]=CP</smiles>

4.3.4I, $97 \%, E / Z>20: 1$

\footnotetext{
${ }^{a}$ General reaction conditions: 4.3 .1 (1.0 equiv.) and 4.1b-TA-Au (0.2\%) in wet $\mathrm{MeOH}(0.25 \mathrm{M})$, the reaction were monitored by TLC $(3-6 \mathrm{hr}), 60^{\circ} \mathrm{C} ;{ }^{b}$ Isolated yields; $\mathrm{E} / \mathrm{Z}$ ratio determined by ${ }^{1} \mathrm{H}$ NMR
} 
As shown in Figure 13, the reaction tolerated variety of substrates, giving the desired enone in excellent yields with good double-bond selectivity (dominant trans-isomers). The $t$-Busubstituted alkyne which was not suitable with the NHC-Au catalyst due to the SN2' mechanism, proceeded smoothly under these alternative conditions although with slightly decreased Z/E selectivity (4.3.4b). The high efficiency makes TA-Au a very attractive and practical catalyst for this transformation: at least five times lower catalyst loading values than $\mathrm{NHC}-\mathrm{Au}^{+}$with much less expensive ligands.

\subsubsection{Meyer-Schuster rearrangement with TA-Au catalyst ${ }^{* *}$}

Heating the $[(\mathrm{IPr}) \mathrm{AuCl}] / \mathrm{AgBF}_{4}$ in wet $\mathrm{MeOH}$ at $60^{\circ} \mathrm{C}$ produced a black solution/precipitate within $30 \mathrm{~min}$, indicating the rapid decomposition of catalyst. TA-Au on the other hand, showed much improved stability, with no decomposition after more than $6 \mathrm{hr}$ under the same conditions. Considering the good thermal stability of TA-Au, we wondered whether this catalyst could also be used to promote the challenging Meyer-Schuster rearrangement of propargylic alcohols 4.3.5 at a high temperature. Impressively, the desired enone products were formed with excellent yields (Figure 14). The reaction tolerated a large group of substrates. Surprisingly, the bulky $t$-butyl substituted alkyne 4.3.5b was also suitable for this reaction, which suggested the effective water addition to the sterically hindered alkyne at a higher temperature. The terminal alkyne gave enals in modest yields which were likely produced by the longer reaction time required for the unfavored anti-Markovnikov addition. Continuous addition of catalysts could improve the overall yields.

\footnotetext{
** Reproduced in parts with permission from Adv. Synth. Catal. 2011, 353, 2584-2588. Copyright 2011, with permission from Willey-VCH Verlag GmbH \& Co. KGaA, Weinheim
} 
Figure 14: Substrate Scope of TA-Au catalyzed Meyer-Schuster rearrangement of propargyl alcohol

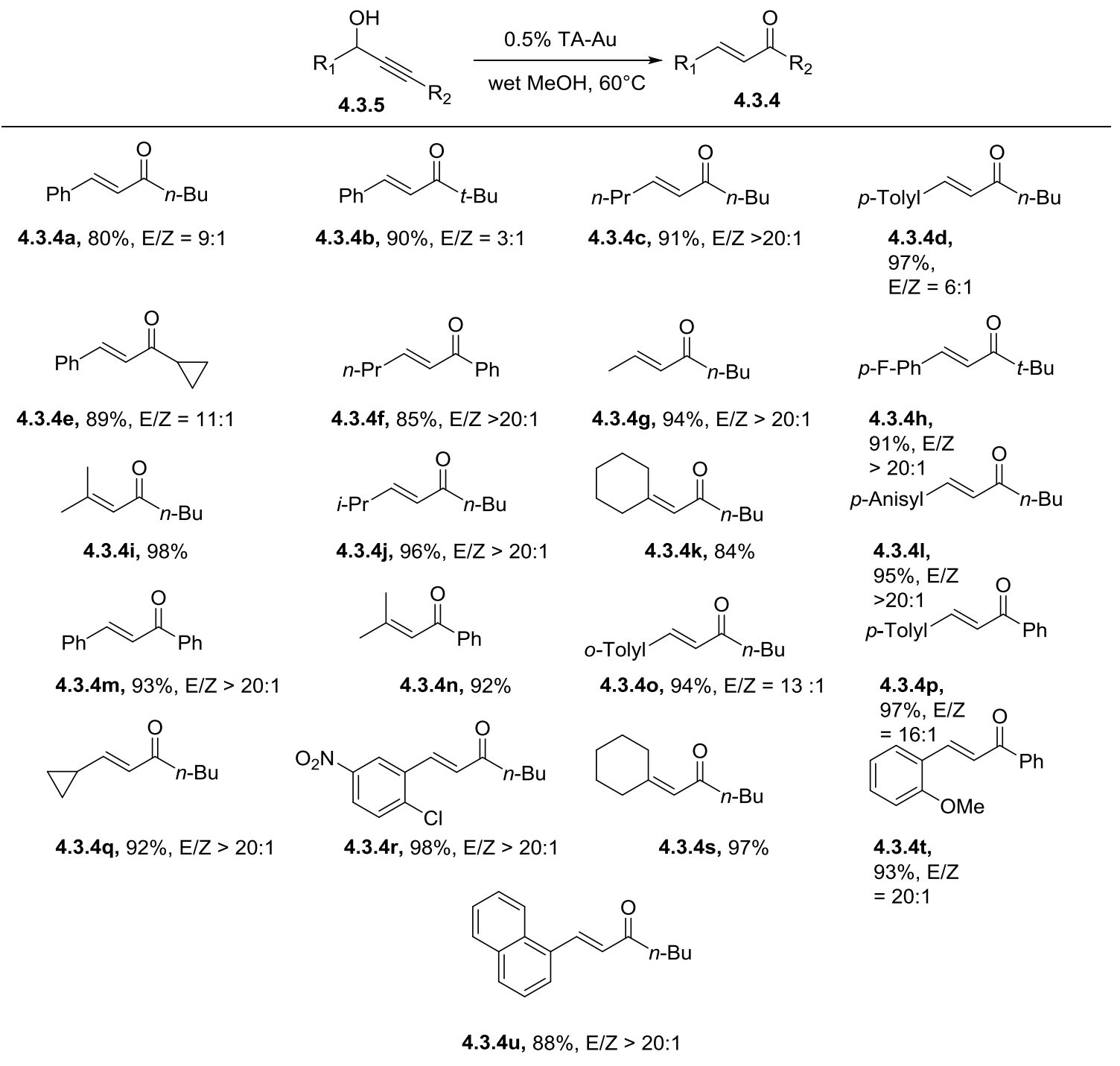

${ }^{\mathrm{a} G e n e r a l ~ r e a c t i o n ~ c o n d i t i o n s: ~} 4.3 .5$ (1.0 equiv.) and 4.1b-TA-Au (0.5\%) in wet $\mathrm{MeOH}(0.2 \mathrm{M})$, the reaction were monitored by TLC $(4-12 \mathrm{hr}), 60^{\circ} \mathrm{C}$; ${ }^{\mathrm{b}}$ Isolated yields; E/Z ratio determined by ${ }^{1} \mathrm{H}-\mathrm{NMR}$

Nevertheless, the feasibility of this challenging substrate highlighted the strength of the TA$\mathrm{Au}$ catalyst over the $[\mathrm{NHC}-\mathrm{Au}]^{+}$catalysts (Table 9) by tolerating the much harsher conditions. 
Table 9: Comparision with the best results obtained in the literature

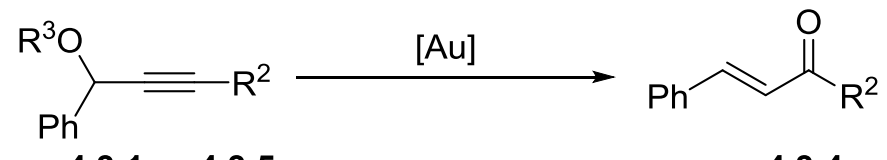

4.3.1 or 4.3 .5

4.3.4

TA-Au (4.1b)

\begin{tabular}{|c|c|c|}
\hline Substrates & Different Catalysts & Yields \\
\hline \multirow{3}{*}{$\begin{array}{l}\text { 4.3.1a: } \\
\mathrm{R}^{3}=\mathrm{Ac}, \mathrm{R}^{2}=n-\mathrm{Bu}\end{array}$} & {$[(\mathrm{IPr}) \mathrm{AuCl}] / \mathrm{AgSbF}_{6}, 2 \%$} & $98 \%$ \\
\hline & $(\mathrm{IPr}) \mathrm{AuOH}, 2 \%:$ & $91 \%$ \\
\hline & TA-Au $(0.2 \%)$ & $92 \%$ \\
\hline \multirow{2}{*}{$\begin{array}{l}\text { 4.3.1b: } \\
\mathrm{R}^{3}=\mathrm{Ac}, \mathrm{R}^{2}=t-\mathrm{Bu}\end{array}$} & {$[(\mathrm{IPr}) \mathrm{AuCl}] / \mathrm{AgSbF}_{6}, 2 \%$} & n.r. \\
\hline & TA-Au (0.2\%) & $93 \%$ \\
\hline \multirow{2}{*}{$\begin{array}{l}\text { 4.3.5a: } \\
\mathrm{R}^{3}=\mathrm{H}, \mathrm{R}^{2}=n-\mathrm{Bu}\end{array}$} & $(\mathrm{IPr}) \mathrm{AuOH}, 2 \%$ : & $97 \%$ \\
\hline & TA-Au (0.5\%) & $89 \%$ \\
\hline 4.3.5b: & (IPr)AuOH, 2\%: & $75 \%$ \\
\hline $\mathrm{R}^{3}=\mathrm{H}, \mathrm{R}^{2}=t-\mathrm{Bu}$ & TA-Au (0.5\%) & $90 \%$ \\
\hline
\end{tabular}

\subsubsection{Asymmetric Synthesis of Substituted allenes ${ }^{\dagger \dagger}+4$}

In homogeneous gold catalysis, both experimental and theoretical investigations confirmed the reversibility between allene and propargyl ester (Scheme 53) led to the considerable challenge of achieving chemoselective activation of alkyne over allene. ${ }^{51,54}$

\section{Scheme 53: Challenge in homogeneous gold catalysis for selective acitvation}
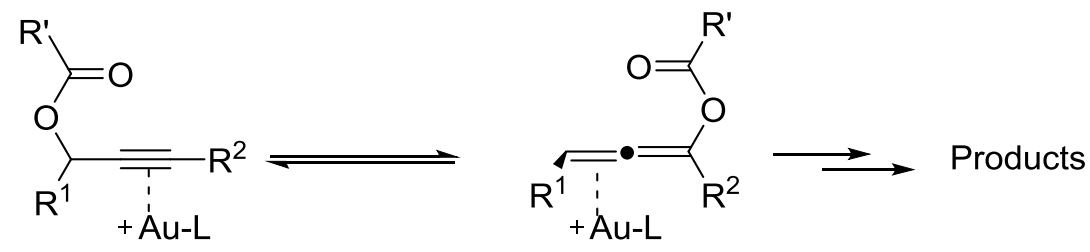

According to the literature, the current strategy was the introduction of proper reaction partners to trap the Au activated allene intermediates. The indene synthesis reported by

${ }^{\dagger}$ Reproduced in parts with permission from Org. Lett. 2011, 13, 2618-2621. Copyright 2011, with permission from American Chemical Society.

\#t This work was highlighted in Organic Chemistry Portal by Douglass F Taber. 
Nolan and co-workers along with the cyclopropanyl propargyl ester rearrangement reported by Toste and co-workers are two examples that highlight the power of this transformation in complex molecule synthesis (Scheme 54) ${ }^{55}$

\section{Scheme 54: Trapping the Allene by Proper Synthetic Partners}

A)<smiles>CC(=O)OC(C#CBr)c1ccccc1</smiles>

4.3.1a<smiles>CC(=O)OC1(Br)C=Cc2ccccc21</smiles>

4.3.4.3a<smiles>CC(=O)OC1C=C(Br)c2ccccc21</smiles>

4.3.4.3b

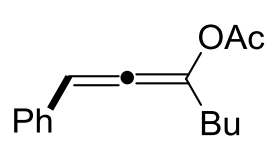

4.3.2a

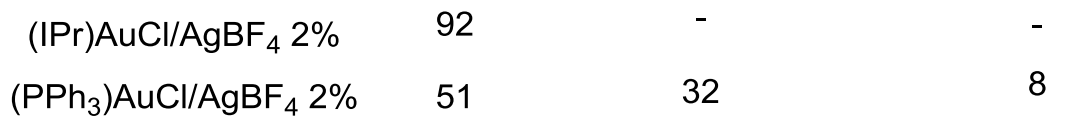

B)

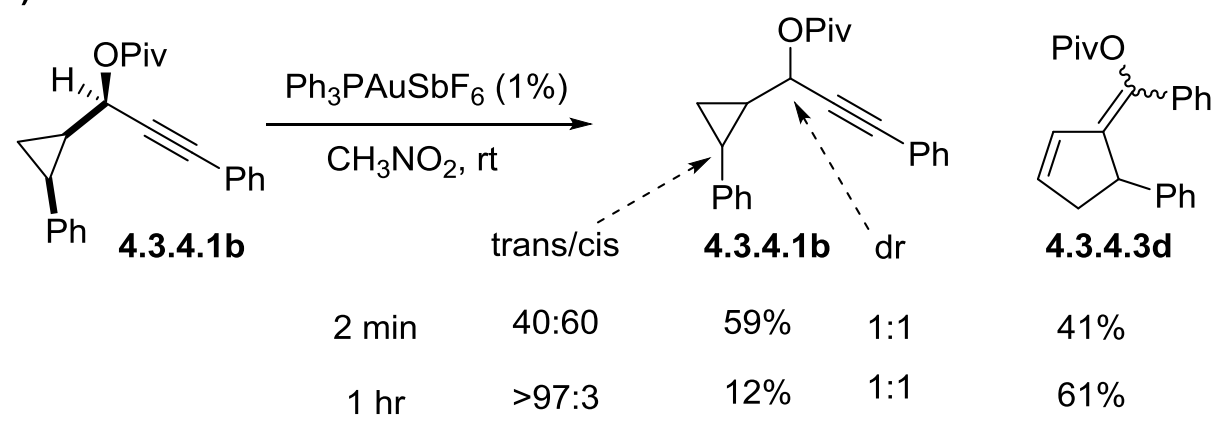

However, the lack of chemoselectivity by cationic Au catalysts generated significant limitations for this transformation: (a) the Au catalyzed 3,3-rearrangement was not considered as a practical approach for allene synthesis due to the good reactivity of the $\mathrm{Au}$ activated allene toward many other groups (even a simple benzene ring, Scheme 54A); (b) the rapid equilibrium between alkyne and allene under the reaction conditions caused poor stereoselectivity due to the rapid racemization on the propargyl stereogenic center (Scheme 54B; complete racemization at the propargyl position occurred in $2 \mathrm{~min}$ ). Therefore, effective new catalytic systems that can achieve selective alkyne activation over allene are highly desirable.

With the interest of 1,2,3-triazole-Au (TA-Au) complexes in finding new reaction modes and strategies, recently our group found that the TA-Au catalyzed synthesis of kinetically favored 
$E$ - $\alpha$-haloenones did not interrupt the allene reactivity. ${ }^{50}$ Encouraged by this result, we decided to investigate whether the triazole-Au complexes could be applied as effective chemoselective catalysts for propargyl ester 3,3-rearrangement. The reactions of 4.3.1a were set up with TA-Au as the catalysts. The results are shown in Scheme 55.

\section{Scheme 55: Proposed $\mathrm{SN}_{2}{ }^{\prime}$ Addition Mechanism by Nolan}

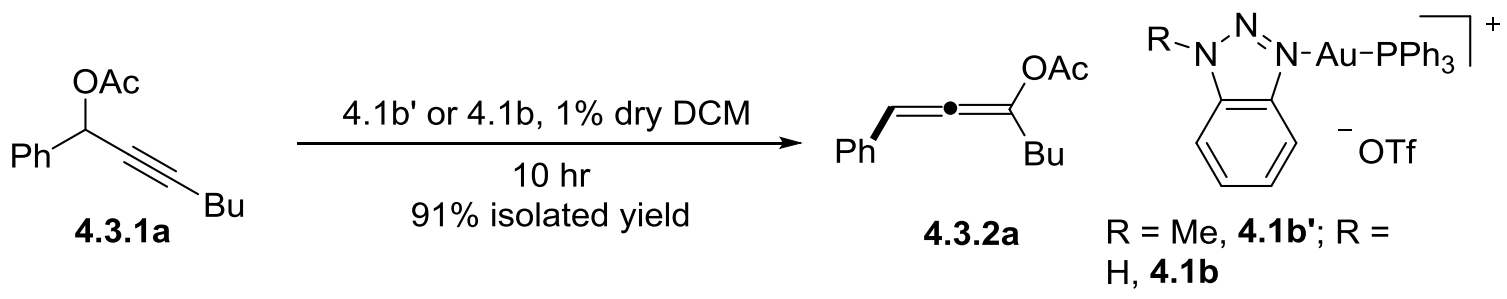

\begin{tabular}{lccc:cccc}
\hline time & Indene 4.3.4.3a & Indene 4.3.4.3b & $\mathbf{4 . 3 . 2 a}$ & time & Indene 4.3.4.3a & Indene & 4.3.2a \\
\hline $10 \mathrm{~min}$ & 0 & 0 & $15 \%$ & $20 \mathrm{hr}$ & 0 & $\mathbf{4 . 3 . 4 . 3}$ & $>98 \%$ \\
$4 \mathrm{hr}$ & 0 & 0 & $83 \%$ & $48 \mathrm{hr}$ & 0 & 0 & $>98 \%$ \\
$8 \mathrm{hr}$ & 0 & 0 & $95 \%$ & & & & \\
\hline
\end{tabular}

As shown in Figure 12, both $\mathbf{4 . 1 b}$ and $\mathbf{4 . 1 b ^ { \prime }}$ catalysts demonstrated good reactivity toward alkyne activation, promoting the 3,3-rearrangement with high efficiency (1\% loading). Impressively, excellent chemoselectivity was achieved, where no further reaction to enone proceeded, giving the desired allene product in excellent yields. This simple modification of catalysts (4.1b') provided one effective strategy in the preparation of functional allenes.

Encouraged by good chemoselectivity, we then wondered whether TA-Au could be used as an effective catalyst for the chiral transformation of propargyl alcohol/acetate by overcoming the rapid racemization associated with other reported cationic Au catalysts. The example shown in Scheme 54B highlighted the challenges for this proposed chirality transfer: rapid epimerization on the propargyl position $(2 \mathrm{~min})$ due to the Au activation of allene caused a loss of stereochemistry at the propargyl position. To investigate the chirality transfer, enantiomeric enriched 4.3.1a was first used to react with TA-Au 4.1b' (Scheme 56). 


\section{Scheme 56: Proposed SN2' Addition Mechanism by Nolan}

\begin{tabular}{|c|c|c|c|c|c|}
\hline OAc & 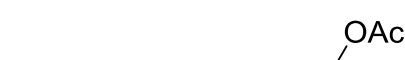 & Catalyst & time & $4.3 .1 \mathrm{a}$ & $4.3 .2 \mathrm{a}$ \\
\hline $\mathrm{Ph}^{-}$ & $\frac{\mathrm{Au} \text { Cat. }}{\mathrm{DCM}, \mathrm{rt}}$ & $4.1 b^{\prime}, 1 \%$ & $30 \mathrm{~min}$ & $\begin{array}{c}59 \% \\
90 \% \text { ee }\end{array}$ & $\begin{array}{c}41 \% \\
0 \% \text { ee }\end{array}$ \\
\hline 4.3.1a, $90 \%$ ee & 4.3.2a & 4.1b', $1 \%$ & $4 \mathrm{hr}$ & $\begin{array}{c}17 \% \\
90 \% \text { ee }\end{array}$ & $\begin{array}{r}83 \% \\
0 \% \mathrm{ee} \\
\end{array}$ \\
\hline
\end{tabular}

Unfortunately, allene 4.3.2a was obtained as racemic mixtures ( $0 \%$ ee) even with TA-Au as the catalyst at low temperature $\left(-40^{\circ} \mathrm{C}\right)$. However, a closer look of this reaction revealed a rather surprising observation: no epimerization of propargyl ester occurred during the reaction, which strongly suggested the lack of equilibrium between allene 4.3.2a and propargyl ester 4.3.1a while TA-Au catalysts were used. The loss of allene 4.3.2a stereochemistry was likely caused by the low energy barrier for the allene racemization process (no enantiomeric enriched allene acetates have ever been reported). This hypothesis was supported by the DFT computational studies, where the relative low energy barrier (5 $\mathrm{kcal} / \mathrm{mol}$ ) was revealed between the two resonance structures of allene acetate.

Later, we proposed that if the resulting allenes have a high epimerization barrier, asymmetric synthesis of allenes could be achieved. To verify this hypothesis, propargyl-vinyl-ether 4.5a was prepared. As expected, excellent chirality transfer was obtained with propargyl vinyl ether 4.5a while TA-Au was used (1\% catalyst, Scheme 57). It has been reported that goldoxo complex $\left[\left(\mathrm{Ph}_{3} \mathrm{PAu}\right)_{3}-\mathrm{O}\right] \mathrm{BF}_{4} \mathbf{4 c}$ could also promote this reaction with good to modest yields and good chirality transfer. ${ }^{55 f}$ However, this complex was not a chemoselective catalyst.

As demonstrated in Scheme 57, treating the allene 4.9a with the gold-oxo catalyst $\mathbf{4 c}$ resulted in significant racemization of the allenes over time. Overall, the gold-oxo complexes were the precatalysts, which could slowly release the $\mathrm{L}-\mathrm{Au}^{+}$and adopted catalysis. This lack of chemoselectivity with gold-oxo catalysts was further demonstrated by the synthesis of dihydropyran 4.7 from intramolecular trapping of gold activated allenes (Scheme 57A). ${ }^{16}$ Despite providing very attractive new synthetic methods, this reaction highlighted the strong desire for a "true" chemoselective gold catalyst. The TA-Au catalyst not only could effectively promote this transformation with excellent chirality transfer but also successfully 
avoid the undesired racemization of allene 4.9a over a long period of time (12 h, Scheme 57B). These results suggested $\mathrm{TA}-\mathrm{Au}$ as the first successful chemoselective catalyst, for selectively activating alkyne over allenes and promote chiral transformation.

\section{Scheme 57: Screening of gold catalysts to propargyl ethers and test of racemization}
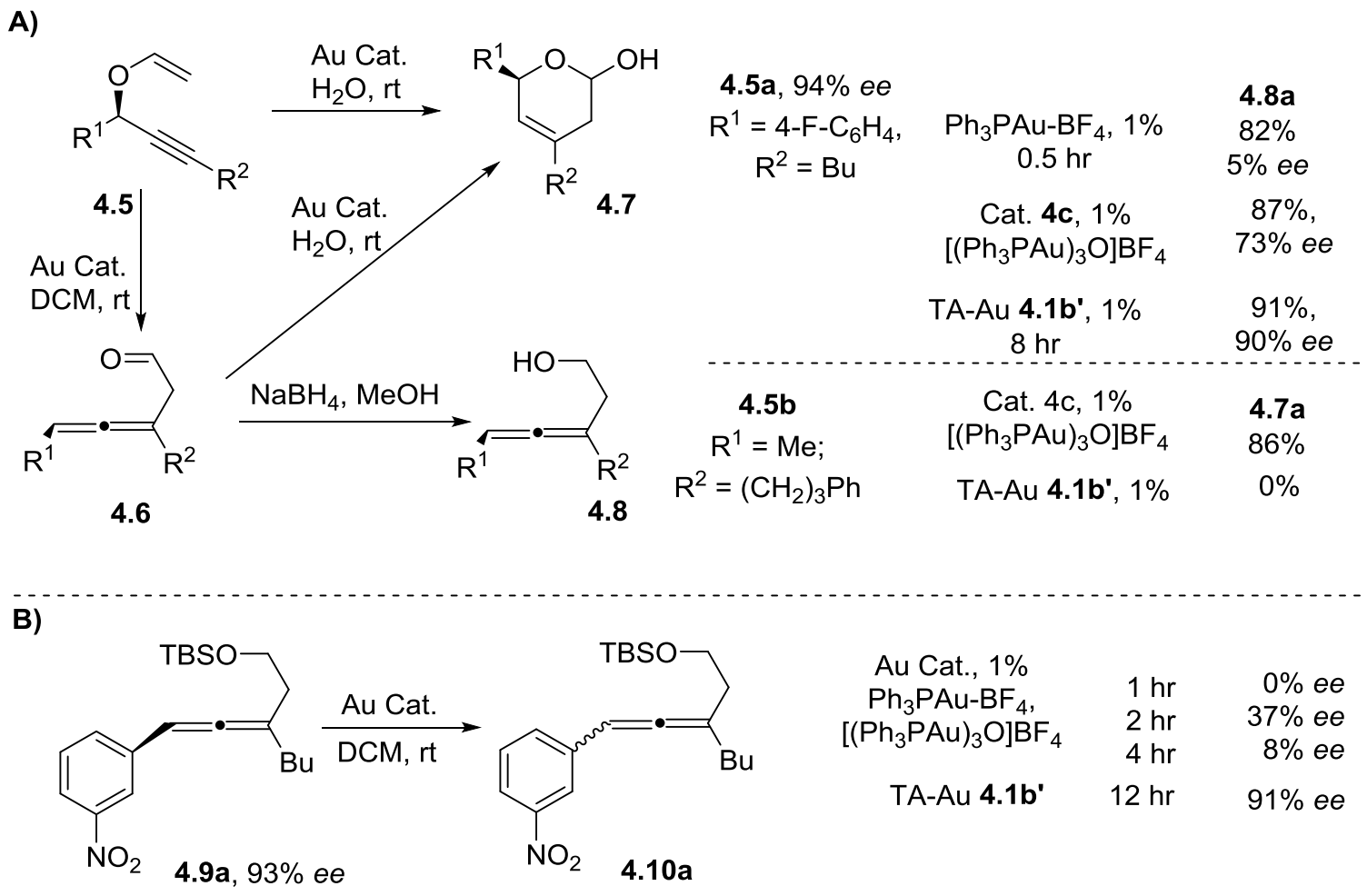

To explore the reaction substrate scope, various chiral/achiral propargyl vinyl ethers were prepared (Scheme 58). The results are summarized in Figure 15. The TA-Au was an effective catalyst for a large scope of substrates. Both terminal and internal alkynes were suitable for this transformation, giving the allene products in good to excellent yields. Effective chirality transfers were observed in terminal alkynes and alkyl substituted internal alkynes. 


\section{Scheme 58: Synthesis protocol of Chiral and Achiral propargyl vinyl ethers}

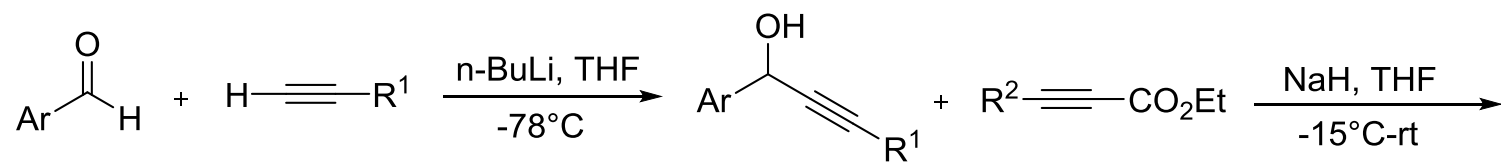
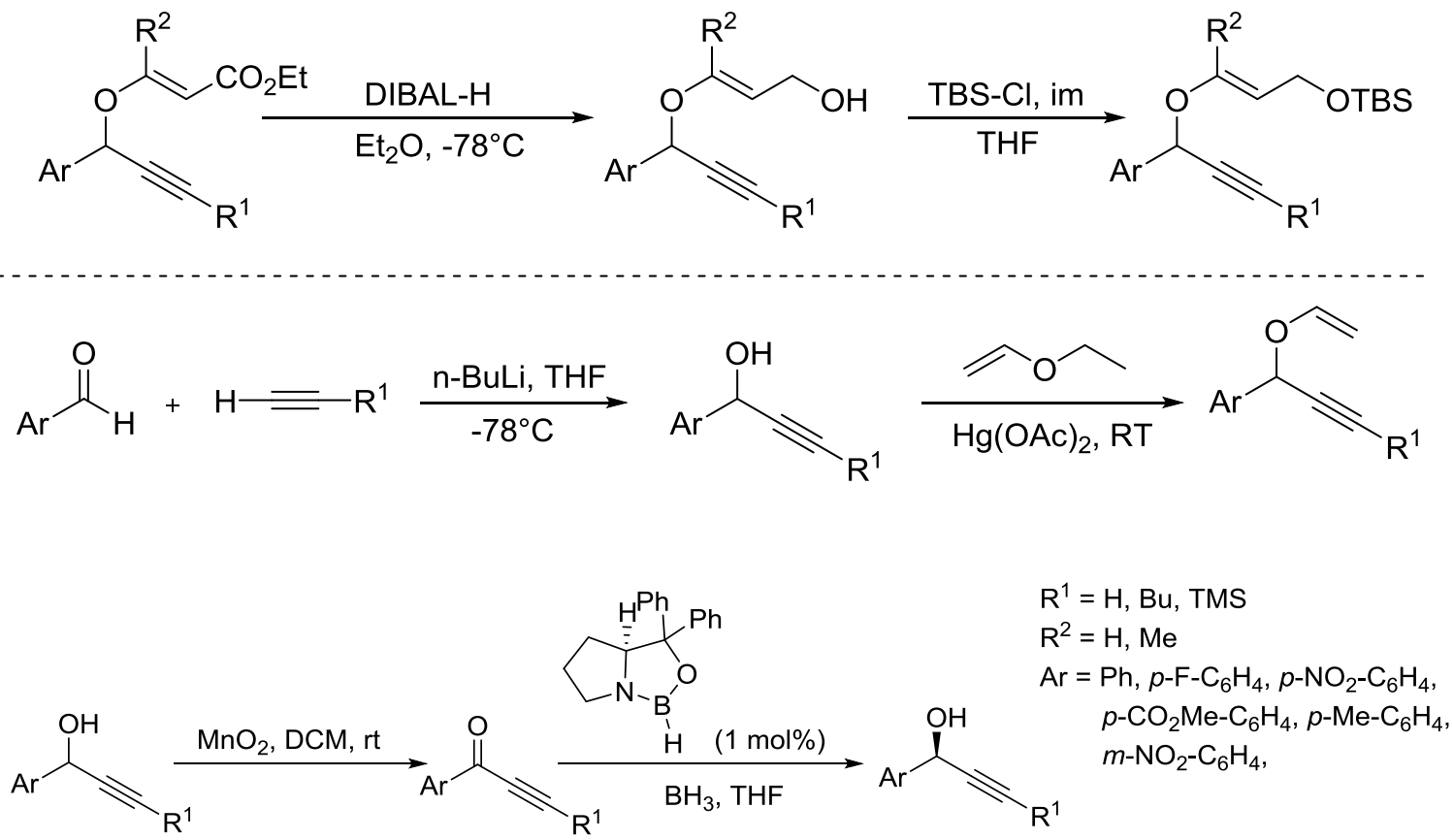

The excellent diastereoselectivity obtained in $\mathbf{4 . 1 0 b}$ suggested a chair like transition state in this rearrangement. ${ }^{55}$ Racemic allenes were obtained with phenyl substituted internal alkynes, which implied possible higher reactivity or a different mechanism ${ }^{56}$ for these substrates. Nevertheless, the high efficiency and good stereoselectivity made this strategy as one of a practical approach for the asymmetric synthesis of chiral allenes. These results opened the possibility for the development of new reactions that could take advantage of the good reactivity of a gold cation towards alkyne activation without suffering the undesired sequential allene activation by the same catalyst. 


\section{Figure 15: Reaction Substrate Scope of Chiral allenes}

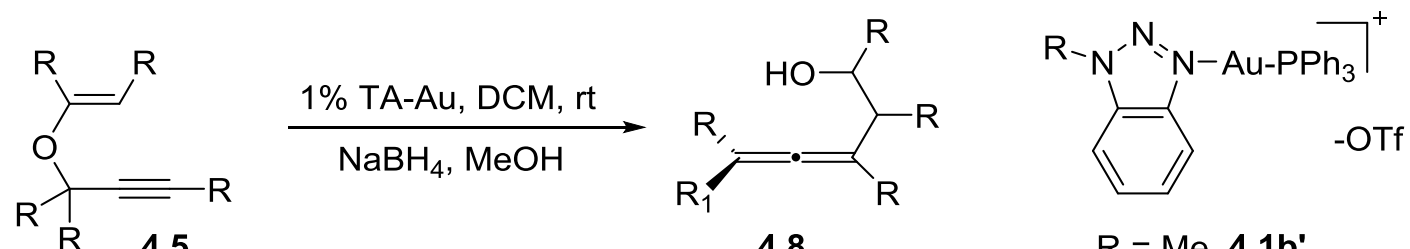

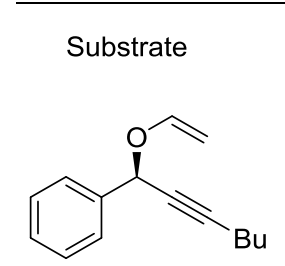

4.5a, $90 \%$ ee<smiles>C=CO[C@@H](C#CBr)c1ccc(F)cc1</smiles>

4.5b, $90 \%$ ee<smiles>C=CO[C@H](C#CCBr)c1ccc([N+](=O)[O-])cc1</smiles><smiles>C#C[C@@H](OC=C)c1cccc([N+](=O)[O-])c1</smiles>

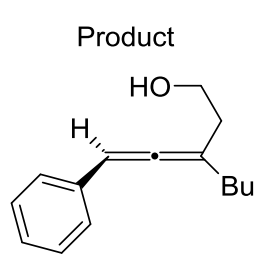

4.8a, $87 \%$ ee, $93 \%$

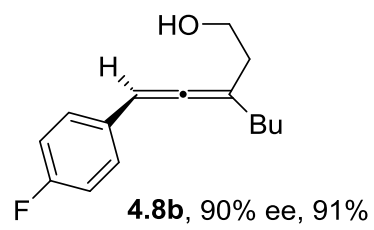

$4.8 b, 90 \%$ ee, $91 \%$
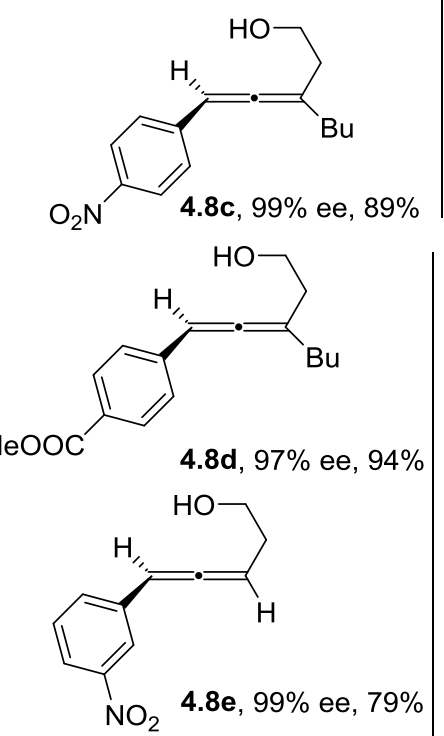

$\mathrm{R}=\mathrm{Me}, \mathbf{4 . 1 b ^ { \prime }}$

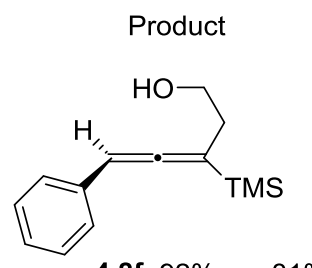

4.8f, $92 \%$ ee, $81 \%$<smiles>CC(C)(C)C(=C=Cc1cccc([N+](=O)[O-])c1)CCO</smiles>

$4.8 \mathrm{~g}, 93 \%$ ee, $95 \%$<smiles>O=[Po]([O-])[O-]</smiles><smiles>OCCC=Cc1ccc(F)cc1</smiles>

4.8i, $94 \%$ ee, $71 \%$<smiles>C=CO[C@H](C#CBr)c1ccc(C)cc1</smiles>

4.5j, 91\% ee

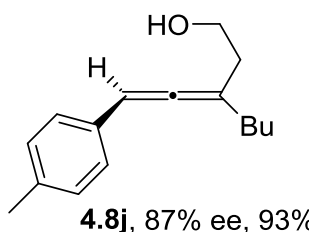

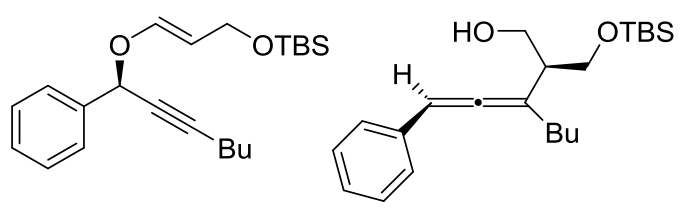

4.9b, $99 \%$ ee

4.10b, $99 \%$ ee, $83 \%$, dr $>20: 1$

General reaction conditions: $4.5(0.25 \mathrm{mmol})$, 4.1 b' (1.0\%), DCM $(2.5 \mathrm{~mL})$, The reactions were monitored by TLC (0.5 hr), rt; ee was determined by Chiral HPLC. For products $4.8 \mathrm{i}-\mathrm{j}$, 4.1 b' (3.0\%) was used. 


\subsection{Conclusion}

In conclusion, the application of 1,2,3-tri-azole coordinated $\mathrm{PPh}_{3}-\mathrm{Au}(\mathrm{TA}-\mathrm{Au})$ as an effective catalyst in promoting the propargylic ester rearrangement and sequential hydration to form the enone with high efficiency, mild reaction conditions with unique reactivity (combining the chemoselectivity and acidity), and improved ligand-economy. In addition, with the significantly improved thermal stability, TA-Au was further applied as the effective catalyst in promoting the propargylic alcohol Meyer-Schuster rearrangement to give the enones which highlighted the strength of this complex compared with other conventional $\mathrm{Au}$ (I) catalysts. Moreover, with the view of extension of application this catalyst was applied as chemoselective and asymmetric catalyst for propargyl ether rearrangements to chiral allenes. These aforementioned applications of triazole gold not only provided an efficient strategy for the synthesis of challenging enantio-enriched allenes, but also confirmed as a new class of mild catalyst in promoting alkyne activation with different reactivity than other Au catalysts, which could likely benefit the world in the discovery of new efficient organic transformations.

\section{Contributions}

Dr. Dawei Wang was the researcher who had first investigated this reaction. Lekh Nath S Gautam was responsible for the detailed reaction conditions, synthetic work, supervised the experimental work to others, interpreted the results, NMR studies, HPLC and for the completion of the manuscript and supporting information for the successful submission to Adv. Synth. \& Catal. as well as Org. Lett. 


\section{REFERENCES}

1. a) MacMillan, D. W. C. Nature, 2008, 455, 304-308. b) Nicolaou, K. C.; Montagnon, T.; Snyder, S. A. Chem. Commun. 2003, 551

2. Jones, S. B.; Simmons, B.; MacMillan, D. W. C. Nature, 2011, 475, 183-188

3. a) Simmons, B.; Walji, A. M.; MacMillan, D. W. C. Angew, Chem. Int. Ed. 2009, 48, 43494353. b) Jakubec, P.; Cockfield, D. M.; Dixon, D. J. J. Am. Chem. Soc. 2009, 131, 1663216633. c) Enantioselective Organocatalysis: Reactions and Experimental Procedures (Ed.: Dalko, P. I.), Wiley-VCH, Weinheim, 2007. d) Seayad, J.; List, B. Org. Biomol. Chem. 2005, $3,719-724$

4. a) Huang, Y.; Walji, A. M.; Larsen, C. H.; MacMillan, D. W. C. J. Am, Chem. Soc. 2005, 127, 15051-15053, b) Marigo, M.; Schulte, T.; Franzen, J.; Jorgensen, K. A. J. Am. Chem. Soc. 2005, 127, 15710-15711

5. a) Jang, H.; Hong, J.; MacMillan, D. W. C. J. Am. Chem. Soc. 2007, 129, 7004-7005. b) Reisman, S. E.; Doyle, A. G.; Jacobsen, E. N. J. Am. Chem. Soc. 2008, 130, 7198-7199. c) Corey, E. J.; Grogan, M. J. Org. Lett. 1999, 1, 157-160.

6. Bahmanyar, S.; Houk, K. N.; Martin, H. J.; List, B. J. Am. Chem. Soc. 2003, 125, 2475-2479.

7. a) Zhong, C.; Shi, X. Eur. J. Org. Chem. 2010, 2999-3025. b) Shao, Z.; Zhang, H. Chem. Soc. Rev. 2009, 38, 2745-2755.

8. a) Denmark, S. E.; Beutner, G. L. Angew. Chem. Int. Ed. 2008, 47, 1560-1638. b) Lewis acids in Organic Synthesis (Ed.: H. Yamamoto). Wiley-VCH, Weinheim, 2000. c) Robiette, R.; Aggarwal, V. K.; Harvey, J. N. J. Am. Chem. Soc. 2007, 129, 15513-15525.

9. a) Sun, X.; Sengupta, S.; Petersen, J. L.; Wang, H.; Lewis, J. P.; Shi, X. Org. Lett. 2007, 9, 4495-4498. b) Dadwal, M.; Mohan, R.; Panda, D.; Mobinc, S. M.; Namboo-thiri, I. N. N. Chem. Commun. 2006, 338-340.

10. Zhong, C.; Chen, Y.; Petersen, J. L.; Akhmedov, N. G.; Shi, X. Angew. Chem. Int. Ed. 2009, 48, 1279-1282.

11. Chen, Y.; Zhong, C.; Sun, X.; Akhmedov, N.; Petersen, J. L.; Shi, X. Chem. Commun. 2009, $5150-5152$

12. Pidathala, C.; Hoang, L.; Vignola, N.; List, B. Angew. Chem. 2003, 115, 2891-2894; Angew. Chem. Int. Ed. 2003, 42, 2785-2788. 
13. a) Zhong, C.; Liao, T.; Tuguldur, O.; Shi, X. Org. lett. 2010, 12, 2064-2067. b) Sengupta, S.; Duan, H.; Lu, W.; Petersen, J. L.; Shi, X. Org. lett. 2008, 10, 1493-1494.

14. a) Rostovtsev, V. V.; Green, L. G.; Fokin, V. V.; Sharpless, K. B. Angew. Chem. 2002, 114, 2708-2711; Angew. Chem. Int. Ed. 2002, 41, 2596-2599. b) Kolb, H. C.; Finn, M. G.; Sharpless, K. B. Angew. Chem. 2001, 113, 2056-2075; Angew. Chem. Int. Ed. 2001, 40, 2004-2021. c) Bock,V. D.; Hiemstra, H.; Van Maarseveen, J. H. Eur. J. Org. Chem. 2006, 51-68. d) Moses, J. E.; Moorhouse, A. D. Chem. Soc. Rev. 2007, 36, 1249-1262.

15. a) Liao, W.; Chen, Y.; Duan, H.; Liu, Y.; Petersen, J. L.; Shi, X. Chem. Commun. 2009, 6436-6438. b) Yan, W.; Wang, Q.; Lin, Q.; Li, M.; Petersen, J. L.; Shi, X. Chem. Eur. J. 2011, 17, 5011-5018. c) Chen, Y.; Wang, D.; Petersen, J. L.; Akhmedov, N.; Shi, X. Chem. Commun. 2010, 46, 6147-6149.

16. Duan, H.; Sun, X.; Liao, W.; Petersen, J. L.; Shi, X. Org. Lett. 2008, 10, 4113-4116

17. a) Zhu, C.; Deng, X.; Sun, X.; Zheng, J.; Tang, Y. Chem. Commun. 2008, 738-740. b) Zhu, C.; Sun, X.; Deng, X.; Zheng, J.; Tang, Y. Tetrahedron 2008, 64, 5583-5589. c) Jiang, H.; Elsner, P.; Jensen, K. L.; Falcicchio, A.; Marcos, V.; Jorgensen, K. A. Angew. Chem. 2009, 121, 6976-6980; Angew. Chem. Int. Ed. 2009, 48, 6844-6848.

18. a) Kano, T.; Yamamoto, A.; Song, S.; Maruoka, K. Chem. Commun. 2011, 47, 4358-4360. b) Guo, Z.; Xie, J.; Chen, C.; Zhu, W. Org. Biomol. Chem. 2012, 10, 8471-8477.

19. a) Wang, X. Y.; Zhang, J. T. J. Asian Nat. Prod. Res. 2003, 5, 1-4. b) Wang, X. Y.; Zhang, J. T. Acta Pharmacol. Sin. 2001, 22, 1099-1102. c) Xu, L.; Liu, S. L.; Zhang, J. T. Chirality 2005, 17, 239-244. For the synthesis of Clausenamide: d) Yang, L.; Deng, G.; Wang, C. X.; Huang, Z. T.; Zhu, J. P.; Wang, M. X. Org. Lett. 2007, 9, 1387 -1390; e) Yakura, T.; Matsumura, Y.; Ikeda, M. Synlett 1991, 343-344.

20. a) Michael, J. P. Nat. Prod. Rep. 2008, 25, 139-165. b) Bull, J. A.; Mousseau, J. J.; Pelletier, G.; Charette, A. B. Chem. Rev. 2012, 112, 2642-2713. c) Candeias, N. R.; Brancol, C.; Gois, P. M. P.; Afonso C. A. M.; Trindade, A. F. Chem. Rev. 2009, 109, 2703-2802. d) Aranda,M. T.; Perez, P.; Gonzalez, R.; Curr. Org. Synth. 2009, 6, 325-341. e) Patil, N. T.; Yamamoto, Y. Chem. Rev. 2008, 108, 3395-3442. f) Alcaide, B.; Almendros, P.; Aragoncillo, C. Chem. Rev. 2007, 107, 4437-4492.

21. a) Zhang, Y.; Yao, W.; Li, H.; Mu, Y. Organometallics, 2012, 31, 4670-4679. b) Badoiu, A.; Kundig, E. P. Org. Biomol. Chem. 2012, 10, 114-121. c) Martin, M.; Najera, C.; Sansano, J. 
M. Synlett. 2012, 23, 62-65. d) Noole, A.; Pehk, T.; Järving, I.; Lopp, M.; Kanger, T.; Tetrahedron: Asymmetry. 2012, 23, 188-198. e) Merino, P.; Tejero, T.; Diez, A.; Gultekin, Z. Eur. J. Org. Chem., 2011, 6567-6573. f ) Barco, A.; Benetti, S.; Casolari, A.; Pollini, G. P.; Spalluto, G. Tetrahedron Lett., 1990, 31, 3039-3042. g) Muller, T. E.; Hultzsch, K. C.; Yus, M.; Foubelo, F.; Tada, M Chem. Rev. 2008, 108, 3795-3892

22. a) Huisgen, R. Angew. Chem. Int. Ed. 1963, 2, 565-598. b) Rehn, S.; Bergman, J.; Stensland, B. Eur. J. Org. Chem. 2004, 2004, 413. c) Liu, G.; Li, W.; Wang, Y.; Ding, Z.; Li, Y. Tetrahedron Lett. 2012, 53, 4393-4396. d) Mukherjee, A.; Sen, T. K.; Ghorai, P. K.; Samuel, P. P.; Schulzke, C.; Mandal, S. K. Chem. Eur. J., 2012, 18, 10530-10545. e) Patil, N. T.; Pahadi, N. K.; Yamamoto, Y. Tetrahedron Lett., 2005, 46, 2101-2103.

23. a) Kaim, L. E.; Gizolme, M.; Grimaud, L.; Oble, J. Org. Lett. 2006, 8, 4019-4021. b) Domling, A.; Wang, W.; Wang, K. Chem. Rev., 2012, 112, 3083-3135. c) Yu, J.; Shi, F.; Gong, L. Acc. Chem. Res., 2011, 44, 1156-1171. d) Gilley, C. B.; Kobayashi, Y. Org. Lett., 2007, 9, 3631-3634. e) Domling, A. Chem. Rev., 2006, 106, 17-89.

24. a) Busacca, C. A.; Fandrick, D. R.; Song, J. J.; Senanayake, C. H. Adv. Synth. Catal., 2011, 353, 1825-1864. b) Marqués-López, E.; Herrera, R. P.; Christmann, M. Nat. Prod. Rep. 2010, 27, 1138-1167; (c) Dalko, P. I.; Moisan, L. Angew. Chem., Int. Ed., 2004, 43, 5138-5175.

25. a) Tsogoeva, S. B. Eur. J. Org. Chem., 2007, 1701-1716. b) Pellissier, H. Tetrahedron, 2007, 63, 9267-9331. c) Akiyama, T.; Itoh, J.; Fuchibe, K. Adv. Synth. Catal. 2006, 348, 999-1010. 26. a) Pellissier, H. Adv. Synth. Catal., 2012, 237-294. b) Barlaam, B.; Boivin, J.; Zard, S. Z. Tetrahedron Lett. 1990, 31, 7429-7432. c) Tamura, R.; Kai, Y.; Kakihana, M.; Hayashi, Tsuji, K. M.; Nakamura, T.; Oda, D. J. Org. Chem. 1986, 51, 4375-4385. d) Tamura, R.; Hegedus, L. S. J. Am. Chem. Soc. 1982, 104, 3727-3729.

27. Watson, R. T.; Gore, V. K.; Chandupatla, K. R.; Dieter, R. K.; Snyder, J. P. J. Org. Chem. 2004, 69, 6105-6114.

28. a) Poon, C. Y.; Chiu, P. Tetrahedron Lett. 2004, 45, 2985-2988. b) Bartoli, G., Bosco, M., Dalpozzo, R., Giuliani, A., Marcantoni, E., Mecozzi, T., Sambri, L., and Torregiani, E. J. Org. Chem. 2002, 67, 9111-9114. c) Bischofberger, N.; Waldmann, H.; Saito T., Simon, E. S.; Lees, W. J.; Bednarski, M. D.; Whitesides, G. M., J. Org. Chem. 1988, 53, 3457-3465. d) Reed, P. E.; Katzenellenbogen, J. A. J. Org. Chem. 1991, 56, 2624. e) Jung, M. E.; Mazurek, M. A.; Lim, R. M., Synthesis, 1978, 8, 588-589. f) Werkhoven, T.M.; van Nispen, 
R.; Lugtenburg, J. Eur. J. Org. Chem. 1999, 2909. g) Siegrist, R.; Baumgartner, C.; Seiler, P.; Diederich, F. Helv. Chim. Acta 2005, 88, 2250-2261. h) Grison, C.; Ge'neve, S.; Halbin, E.; Coutrot, P., Tetrahedron 2001, 57, 4903-4923.

29. a) Bowman, R. K.; Johnson, J. S. J. Org. Chem. 2004, 69, 8537-8540. b) Trost, B. M.; Mueller, C. J. Am. Chem. Soc. 2008, 130, 2438-2439.

30. a) Liu, M.; Sibi, M. P. Tetrahedron. 2002, 58, 7991. b) Vicario, J. L.; Badia, D.; Carrillo, L. Org. Prep. Proc. Int. 2005, 37, 513. c) Xu, L.-W.; Xia, C.-G. Eur. J. Org. Chem. 2005, 633. d) Sibi, M. P.; Shay, J. J.; Liu, M.; Jaspers, C. P. J. Am. Chem. Soc. 1998, 120, 6615.

31. a) Leslie, A. K.; Li, D.; Koide, K. J. Org. Chem. 2011, 76, 6680-6865. b) Wei, Y.; Shi, M. Chem. rev. 2013, 113, 6659-6690.

32. a) Campbell, M. M.; Kaye, A. D.; Sainsbury, M. Tetrahedron 1982, 38, 2783. (b)Itoh, K.; Kitoh, K.; Kishimoto, S. Can. J. Chem. 2006, 84, 392-406. b) Molteni, M.; Volonterio, A.; Zanda, M. Org. Lett. 2003, 5, 3887-3890. c) Klenz, O.; Evers, R.; Miethchen, R.; Michalik, M. J. Fluorine Chem. 1997, 81, 205-210 and references therein.

33. a) Photiadou, A. D.; Stathakis C. I.; Gallos, J. K. J. Heterocyclic Chem. 2008 45, 1251. b) Lee, K. Y.; Lee, Y. J.; Kim, J. N. Bull. Korean Chem. Soc. 2007, 28, 143-146

34. Taylor and Baker, Sidgwick's Organic Chemistry of Nitrogen 1937 Oxford University Press, Oxford, England, p. 497.

35. a) Baliah, V.; Jeyaraman, R.; Chandrasekaran, L. Chem. Rev. 1983, 83, 379. b) Kallstrom, S.; Leino, R. Bioorg. Med. Chem. 2008, 16, 601. c) Merino, P.; Tejero, T.; Greco, G.; Marca, E.; Delso, I.; Gomez-SanJuan, A.; Matute, R. Heterocycles 2012, 84, 75. d) Asano, N.; Nash, R. J.; Molyneux, R. J.; Fleet, G. W. J. Tetrahedron: Asymmetry 2000, 11, 1645-1680. e) Watson, P. S.; Jiang, B.; Scott, $\quad$ B. Org. Lett. 2000, 2, 3679-3681. f) Stinson, S. C. $C \& E N$ 2001, 79 (20), 45-57. i) Thayer, A. M. $C \& E N$ 2007, 85 (32), 11-19.

36. a) Cossy. J. Chem. Rec. 2005, 5, 70-80. b) Pearson, M. S. M.; Mathe A. M.; Fargeas, V.; Lebreton, J. Eur. J. Org. Chem 2005, 2159-2191. c) Buffat, M. G. P. Tetrahedron 2004, 60, 1701-1729. d) Zhou, P.; Chen, B. C.; Davis, F. A. Tetrahedron 2004, 60, 8003-8030. e) Weintraub, P. M.; Sabol, J. S.; Kane, J. M.; Borcherding, D. R. Tetrahedron 2003, 59, 29532989. f) Laschat, S.; Dickner, T. Synthesis 2000, 1781-1813. g) Bailey, P. D.; Millwood, P. A.; Smith, P. D. J. Chem. Commun. 1998, 633-640. h) Sebesta, R.; Pizzuti, M.; Boersma, A. J.; Minnaard, A. J.; Feringa, B. L. Chem. Commun. 2005, 1711-1713. i) Jagt, R. B. C.; de 
Vries, J. G.; Feringa, B. L.; Minnaard, A. J. Org. Lett. 2005, 7, 2433-2435.

37. a) Chen, Y.; Zhong, C.; Petersen, J.L.; Akhmedov, N.G.; Shi, X. Org. Lett. 2009, 11, 23332336. b) Wahba, A. E.; Hamann, M. T. Mar. Drugs 2010, 8, 2395-2416.

38. Davies, S. G.; Hughes, D. G.; Price, P. D.; Roberts, P. M.; Russell, A. J.; Smith, A. D.; Thomson, J. E.; Williams, O. M. H. Synlett 2010, 4, 567-570. b) Davies, S. G.; Fletcher, A. M.; Lee, J. A.; Roberts, P. M.; Russell, A. J.; Taylor, R. J.; A. D.; Thomson, A. D.; Thomson, J. E. Org. lett. 2012, 14, 1672-1675. c) Davies, S. G.; Lee, J. A.; Roberts, P. M.; Stonehouse, J. P.; Thomson, J. E. J. Org. Chem. 2012, 77, 7028-7045. d) Jarowicki, K.; Kocienski, P. J. Chem. Soc., Perkin Trans. 1, 1998, 4005-4037. e) Fernandes, R. A.; Nallasivam, J. L. Org. Biomol. Chem. 2012, 10, 7789-7800. f) Bull, S. D.; Davies, S. G.; Kelly, P. M.; Gianotti, M.; a; Smith, A. D. J. Chem. Soc., Perkin Trans. 1, 2001, 3106-3111. g) Davies, S. G.; Fletcher, A. M.; Hughes, D. G.; Lee, J. A.; Price, P. D.; Roberts, P. M.; Russell, A. J.; Smith, A. D.; Thomson, J. E.; Williams, O. M. H. Tetrahedron 2011, 67, 9975-9992. h) Yonemura, I.; Yasuda, N.; Kawanami, T.; Furono, H.; Inanaga, J. Heterocycles, 2005, 67, 433-436.

39. a) List, B. Tetrahedron 2002, 58, 5573-5590. b) Dondoni, A.; Massi, A. Angew. Chem. 2008, 120, 4716-4739; Angew. Chem. Int. Ed. 2008, 47, 4638-4660. c) Chem. Rev. 2007, 107, 12. f) Acc.Chem. Res. 2004, 37, 8. d) Adv. Synth. Catal. 2004, 346, 9-10. e) Dalko, P. I. Enantioselective Organoctalysis, Wiley-VCH, Weinheim, 2007. f) Berkessel, A.; Grcger, H. Asymmetric Organocatalysis: From Biomimetic Concepts to Applications in Asymmetric Synthesis Wiley-VCH, Weinheim, 2005.

40. a) Gorin, D. J.; Sherry, B. D.; Toste, F. D. Chem. Rev. 2008, 108, 3351. b) Hashmi, A. S. K.; Rudolph, M. Chem. Soc. Rev. 2008, 37, 1766-1775. c) Jiménez-Núñez, E.; Echavarren, A. M. Chem. Rev. 2008, 108, 3326-3350. d) Soriano, E.; Marco-Contelles, J. Acc. Chem. Res. 2009, 42, 1026. e) Arcadi, A. Chem. Rev. 2008, 108, 3266-3325. f) Diez-Gonzalez, S.; Marion, N.; Nolan, S. P. Chem. Rev. 2009, 109, 3612-3676. g) Jimenez-Nunez, E.; Echavarren, A. M. Chem. Commun. 2007, 333-346.

41. a) Hashmi, A. S. K. Chem. Rev. 2007, 107, 3180-3211. b) Fürstner, A.; Davies, P. W. Angew. Chem., Int. Ed. 2007, 46, 3410-3449. c) Shapiro, N. D.; Toste, F. D. Proc. Natl. Acad. Sci. U. S. A. 2008, 105, 2779-2782. 
42. a) Shapiro, N. D.; Toste, F. D. Synlett., 2010, 5, 675-691. b) de Frémont, P.; Scott, N. M.; Stevens, E. D.; Nolan, S. P. Organometallics 2005, 24, 2411-2418. d) Marion, N.; Nolan, S. P. Acc. Chem. Res. 2008, 41, 1440-1449.

43. a) Fürstner, A.; Morency, L. Angew. Chem., Int. Ed. 2008, 47, 5030-5033. b) Seidel, G.; Mynott, R.; Fürstner, A. Angew. Chem., Int. Ed. 2009, 48, 2510-2513. c) Benitez, D.; Shapiro, N.; Tkatchouk, E.; Wang, Y.; Goddard, W.; Toste, F. D. Nature Chem. 2009, 1, 482-486. d) Horino, Y.; Yamamoto, T.; Ueda, K.; Kuroda, S.; Toste, F. D. J. Am. Chem. Soc. 2009, 131, 2809-2811.

44. a) Raabe, I.; Krossing, I. Angew. Chem., Int. Ed. 2004, 43, 2066-2090. b) Nieto-oberhuber, C.; Lopez, S.; Munoz, M. P.; Cardenas, D. J.; Bunuel, E.; Nevado, C.; Echavarren, A. M. Angew. Chem., Int. Ed. 2005, 44, 6146-6148. c) Ferrer, C.; Echavarren, A. M.; Angew. Chem., Int. Ed. 2006, 45, 1105-1109. d) Nieto-oberhuber, C.; Munoz, M. P.; Lopez, S.; Jimenez-Nunez, E; Nevado, C.; Herrero-Gomez, E.; Raducan, M.; Echavarren, A. M. Chem. Eur. J. 2006, 12, 1677-1693.

45. a) Partyka, D. V.; Robilotto, T. J.; Zeller, M.; Hunter, A. D.; Gray, T. G. Proc. Natl. Acad. Sci. U.S.A. 2008, 105, 14293. b) Nomiya, K.; Noguchi, R.; Oda, M. Inorg. Chim. Acta 2000, 298, 24. c) Kieft, R. L.; Petersen, W. M.; Blundell, G. L.; Horton, S.; Henry, R. A.; Jonassen, H. B. Inorg. Chem. 1976, 15, 1721.

46. a) Liu, Y.; Yan, W.; Chen, Y.; Petersen, J. L.; Shi, X. Org.Lett. 2008, 10, 5389. b) Chen, Y.; Liu, Y.; Petersen, J. L.; Shi, X. Chem.Commun. 2008, 3254.

47. Duan, H.; Sengupta, S.; Petersen, J. L.; Shi, X. Organometallics 2009, 28, 2352-2355.

48. Duan, H.; Sengupta, S.; Petersen, J. L.; Akhmedov, N. G.; Shi, X. J. Am. Chem. Soc. 2009, $131,12100-12102$.

49. Chen, Y.; Yan, W.; Akhmedov, N. G.; Shi, X. Org. Lett., 2010, 12, 344-347.

50. Wang, D.; Ye, X.; Shi, X. Org. Lett., 2010, 12, 2088-2091.

51. a) Zhang, L. J. Am. Chem. Soc., 2005, 127, 16804. b) Wang, S.; Zhang, G.; Zhang, L. Synlett, 2010, 692. b) Marion, N.; Nolan, S. P. Angew. Chem., Int. Ed., 2007, 46, 2750. c) MarcoContelles, J.; Soriano, E. Chem. Eur. J., 2007, 13, 1350. d) Li, Z.; Brouwer, C.; He, C. Chem. Rev. 2008, 108, 3239.

52. a) Marion, N.; Diez-Gonzalez, S.; Fremont, P.; Noble, A. R.; Nolan, S. P. Angew. Chem. 2006, 118, 3729. b) Angew. Chem. Int. Ed. 2006, 45, 3647-3650. 
53. Ramon, R. S.; Gaillard, S.; Slawin, A. M.Z.; Porta, A.; DAlfonso, A.; Zanoni, G.; Nolan, S.P. Orgnometallics 2010, 29, 3665-3668.

54. a) Boogaerts, I. I. F.; Nolan, S. P. J. Am. Chem. Soc. 2010, 132, 8858-8859. b) Boogaerts, I. I. F.; Fortman, G. C.; Furst, M. R. L.; Cazin, C. S. J.; Nolan, S. P. Angew. Chem., Int. Ed. 2010, 49, 8674-8679. c) Zhang, Z.; Lee, S. D.; Widenhoefer, R. A. J. Am. Chem. Soc. 2009, 131, 5372-5373. d) Brown, T. J.; Dickens, M. G.; Widenhoefer, R. A. J. Am. Chem. Soc. 2009, $131,6350-6351$.

55. a) Marion, N.; Carlqvist, P.; Gealageas, R.; Fremont, P.; Maseras, F.; Nolan, S. P. Chem.;Eur. J. 2007, 13, 6437-6451. b) Castro, A. M. M. Chem. Rev. 2004, 104, 2939-3002. c) Ito, H.; Taguchi, T. Chem. Soc. Rev. 1999, 28, 43-50. d) Hiersemann, M.; Abraham., L. Eur. J. Org. Chem. 2002, 1461-1471. e) Grissom, J. W.; Kilingberg, D.; Huang, D.; Slattery, B. J. Org. Chem. 1997, 62, 603-626. f) Sherry, B. D.; Toste, F. D. J. Am. Chem. Soc. 2004, 126, 1597815979. g) Sherry, B. D.; Maus, L.; Laforteza, B. N.; Toste, F. D. J. Am. Chem. Soc. 2006, 128, 8132-8133. h) Mauleon, P.; Krinsky, J. L.; Toste, F. D. J. Am. Chem. Soc. 2009, 131, 4513-4520.

56. Shi, X.; Gorin, D. J.; Toste, F. D. J. Am. Chem. Soc. 2005, 127, 5802-5803. 


\section{APPENDIX: EXPERIMENTAL SECTION}

\section{Appendix 1}

\section{A1.1: General Methods and materials}

All of the reactions dealing with air and/or moisture-sensitive reactions were carried out under an atmosphere of nitrogen using oven/flame-dried glassware and standard syringe/septa techniques. Unless otherwise noted, all commercial reagents and solvents were obtained from the commercial provider and used without further purification. ${ }^{1} \mathrm{H}$ NMR and ${ }^{13} \mathrm{C}$-NMR spectra were recorded on Varian $600 \mathrm{MHz}$ spectrometers. Chemical shifts were reported relative to internal tetramethylsilane $(\delta 0.00 \mathrm{ppm})$ or $\mathrm{CDCl}_{3}(\delta 7.26$ ppm) for ${ }^{1} \mathrm{H}$ and $\mathrm{CDCl}_{3}(\delta 77.0 \mathrm{ppm})$ for ${ }^{13} \mathrm{C}$. Flash column chromatography was performed on 230-430 mesh silica gels. Analytical thin layer chromatography was performed with precoated glass baked plates $(250 \mu)$ and visualized by fluorescence and by charring after treatment with potassium permanganate stain. $\mathbf{R}_{f}$ values were obtained by elution in the stated solvent ratios. Optical rotations were measured on a commercial automatic polarimeter and reported as follows: $[\alpha]^{T} \mathrm{D}(\mathrm{c}=\mathrm{mg} / \mathrm{mL}$, solvent $)$. Melting points were measured on a Mel-Temp 1001D apparatus and uncorrected. HRMS were recorded on LTQ-FTUHRA spectrometer. Anhydrous hexane, tetrahydrofuran (THF), toulene, EtOAc, Acetonitrile and methanol were purchased from Acros and distilled with sodium, immediately before use. Anhydrous dichlomethane $\left(\mathrm{CH}_{2} \mathrm{Cl}_{2}\right)$ was distilled with $\mathrm{CaH}_{2}$. High Pressure Liquid chromatography (HPLC) was performed on a SHIMADZU SPD-M20A (LC-20AB) chromatographs using a chiral column $(50 \mathrm{~cm})$ and guard column $(5 \mathrm{~cm})$ as noted for each compound. Enantiomeric excess was determined by HPLC analysis, described below in detail. The configuration of products was determined by comparison of rotation sign with the literature data or by analogue.

The nitroalkene starting materials were prepared according to the following reported procedures: a) Ohta, H.; Kobayashi, N.; Ozaki, K. J. Org. Chem. 1989, 54, 1802-1804. b) Lucet, D.; Sabelle, S.; Kostelitz, O.; Gall, T. L.; Mioskowski, C. Eur. J. Org. Chem. 1999, 2583-2591. c) Jang, Y. J.; Lin, W. W.; Shih, Y. K.; Liu, J. T.; Hwang, M. H.; Yao, C. F. 
Tetrahedron, 2003, 59, 4979-4992. Substrates 4.3.1 and 4.3.5 were synthesized according to the literature as below: (Propargyl acetate and alcohol): a) M. Yu, G. Zhang, L. Zhang Org. Lett. 2007, 9, 2147-2150. b) N. Marion, P. Carlqvist, R. Gealageas, P. Fremont, F. Maseras, S. P. Nolan, Chem. Eur. J. 2007, 13, 6437-6451. c) Nonoshita, K.; Banno, H.; Maruoka, K.; Yamamoto, H. J. Am. Chem. Soc. 1990, 112, 316-322. d) Sherry, B. D.; Toste, F. D. J. Am. Chem. Soc. 2004, 126, 15978-15979. e) Sherry, B. D.; Maus, L.; Laforteza, B. N.; Toste, F. D. J. Am. Chem. Soc. 2006, 128, 8132-8133. f) Mauleon, P.; Krinsky, J. L.; Toste, F. D. J. Am. Chem. Soc. 2009, 131, 4513-4520.

\section{A1.2: General Experimental Procedures}

\section{A1.2.1: General Procedure for preparation of homo-isoxazoline- $N$-oxide (1.4.3)}

The nitroalkene 1.2.1a' (1.1 mmol, 1.1 eq.) was added to aldehyde 1.2.4b' (0.5 mmol, 0.5 eq.), in DMSO solution followed by L-proline ( $25 \mathrm{mg}, 0.22 \mathrm{mmol}, 0.2$ eq.), and $\mathrm{K}_{2} \mathrm{CO}_{3}$ (35 mg, $0.25 \mathrm{mmol}, 0.5 \mathrm{eq}$.), with a concentration of $0.1 \mathrm{M}$ for aldehyde. The resulting reaction mixture was stirred at room temperature and monitored by TLC. Then, the mixture was diluted with EtOAc $(100 \mathrm{~mL})$. The organic phase was washed by $\mathrm{HCl}$ solution (1.0 M), saturated $\mathrm{NaHCO}_{3}$ (aq.) and brine and then dried over anhydrous $\mathrm{Na}_{2} \mathrm{SO}_{4}$. The solvent was removed under reduced pressure to give a residue. Flash column was then applied to give the product 1.4.3.

\section{A1.2.2: General Procedure for preparation of isoxazoline- $N$-oxide)}

\section{A1.2.2.1: Racemic N-oxide preparation 1.4.4.3}

The nitroalkene 1.2.1a' ( $0.6 \mathrm{mmol}, 1.2$ eq.) was added to a solution of the corresponding sulfur ylide 1.4.4.2f ( $0.55 \mathrm{mmol}, 1.1$ eq.) in DMSO ( $0.2 \mathrm{M}$ for nitroalkene) solution, till the ylide is all dissolved. L-Proline (12 mg, $0.1 \mathrm{mmol}, 0.2$ eq.) and $\mathrm{K}_{2} \mathrm{CO}_{3}(35 \mathrm{mg}, 0.25$ mmol, 0.5 eq.) were then added in and stir for 5 minutes. The aldehyde 1.2.4b' $(0.5 \mathrm{mmol}$, 1.0 eq.) in DMSO solution (0.2 M) was added drop wise and stirred at RT until TLC showed all consumed, the mixture was diluted with EtOAc $(100 \mathrm{~mL})$. The organic phase was washed by $\mathrm{HCl}$ solution $(1.0 \mathrm{M})$, saturated $\mathrm{NaHCO}_{3}$ (aq.) and brine and then dried 
under anhydrous $\mathrm{Na}_{2} \mathrm{SO}_{4}$. The solvent was removed under reduced pressure to give a residue. Flash silica gel chromatography was then applied to give the product 1.4.4.3.

\section{A1.2.2.2: Optical sample preparation 1.4.5}

The nitroalkene 1.2.19' $(0.7 \mathrm{mmol}, 1.4$ eq. $)$ was added to a solution of the sulfur ylide aux-d (0.6 mmol, 1.2 eq.) $\mathrm{MeOH}$ solution (0.4 M for nitroalkene), till the ylide is all dissolved. The mixture was cooled down to $-25^{\circ} \mathrm{C}$. Pyrrolidine $(7 \mathrm{mg}, 0.1 \mathrm{mmol}, 0.2$ eq. $)$ and $\mathrm{K}_{2} \mathrm{CO}_{3}$ (35 mg, $0.25 \mathrm{mmol}, 0.5$ eq.) were then added in and stir for 30 minutes. The aldehyde (0.5 mmol, 1.0 eq.) $\mathrm{MeOH}$ solution (0.4 M) was added drop wise. The resulting reaction mixture was stirred at $-25^{\circ} \mathrm{C}$ for 2 days and monitored by TLC. EtOAc extraction followed by drying over anhydrous $\mathrm{Na}_{2} \mathrm{SO}_{4}$. The solvent was removed under reduced pressure to give a residue. Flash silica gel chromatography furnished the product, which were then examined for e.e values.

\section{A1.2.2.3: Procedure for Synthesis of 1.5c}

The isozaxoline-N-oxide $\mathbf{1 . 4 . 5 a}$ (323 mg, $1.0 \mathrm{mmol}, 1.0$ equiv.) was dissolved in $\mathrm{MeOH}$ $(20 \mathrm{ml})$ at $-15^{\circ} \mathrm{C}$ and keep stirring for $10 \mathrm{~min}$. Zn dust (975 mg, $15 \mathrm{mmol}, 15$ equiv., activated) was and $5 \mathrm{M} \mathrm{HCl}$ in $\mathrm{MeOH}(5 \mathrm{ml}, 25 \mathrm{mmol}, 25$ equiv.) added and stirred for 6 hrs. $\mathrm{Et}_{3} \mathrm{~N}$ ( $2500 \mathrm{mg}, 25 \mathrm{mmol}, 25$ equiv.) was then added and stirred to another 5 hours. Extraction, work-up and vacuum furnished a residue. Flash silica gel chromatography was then applied to give the product lactam 1.5a as white solid $160 \mathrm{mg}$, in $57 \%$ yield. Then, 1.5a (160 mg, $0.57 \mathrm{mmol}, 1.0$ equiv.) in acetone at $0^{\circ} \mathrm{C}$ added $t$ - $\mathrm{BuONa}(55 \mathrm{mg}$, $0.57 \mathrm{mmol}, 1.0$ equiv.) and $\mathrm{MeI}(81 \mathrm{mg}, 0.58 \mathrm{mmol}, 1.0$ equiv.) The reaction was monitored by TLC and quenched by adding $\mathrm{H}_{2} \mathrm{O}$. Carefully vacuumed out acetone and dilute the mixture with EtOAc $20 \mathrm{ml}$ for extraction. The water phase was extracted with EtOAc $(20 \mathrm{~mL}$ x 3). Acid-base work up and vacuum gave the crude product which then dissolved in THF and $\mathrm{H}_{2} \mathrm{O}(1: 1)$ solution (10 $\mathrm{ml}$ in total). At room temperature, NaIO4 (487 mg, $2.28 \mathrm{mmol}, 4.0$ equiv.) and $\mathrm{OsO}_{4}$ (8 mg, $0.029 \mathrm{mmol}, 0.05$ equiv.) was added in the reaction mixture. Monitored by TLC, the reaction was quenched by $\mathrm{Na}_{2} \mathrm{~S}_{2} \mathrm{O}_{3}$ saturated solution after 4 hours. Brine addition, extraction with EtOAc (20 mL x 3), dry 
out over anhydrous $\mathrm{Na}_{2} \mathrm{SO}_{4}$ and solvent evaporation under reduced pressure to give a residue. Flash silica gel chromatography gave $79 \%(132 \mathrm{mg})$ of the product $\mathbf{1 . 5} \mathbf{b}$ as white solid. To ketone $\mathbf{1 . 5 b}$ (132 mg, $0.45 \mathrm{mmol}, 1.0$ equiv.) in $5 \mathrm{ml}$ of MeOH/DCM (1:1) at $0^{\circ} \mathrm{C}$ added $\mathrm{NaBH}_{4}(20 \mathrm{mg}, 0.52 \mathrm{mmol}, 1.1$ equiv.). Five hours later, TLC indicated the ketone 9d all consumed, warmed up and added EtOAc $(50 \mathrm{ml})$ then $50 \mathrm{ml}$ of brine. Complete work up gives a residue. Flash silica gel chromatography was then applied to give $1.5 c$ (132 mg, >98\% yield) as white crystals.

\section{A1.2.3: Representative procedure of stereoselective synthesis of $N$ - heterocycles}

\section{A1.2.3.1: Experimental Procedure for Aza-Michael addition}

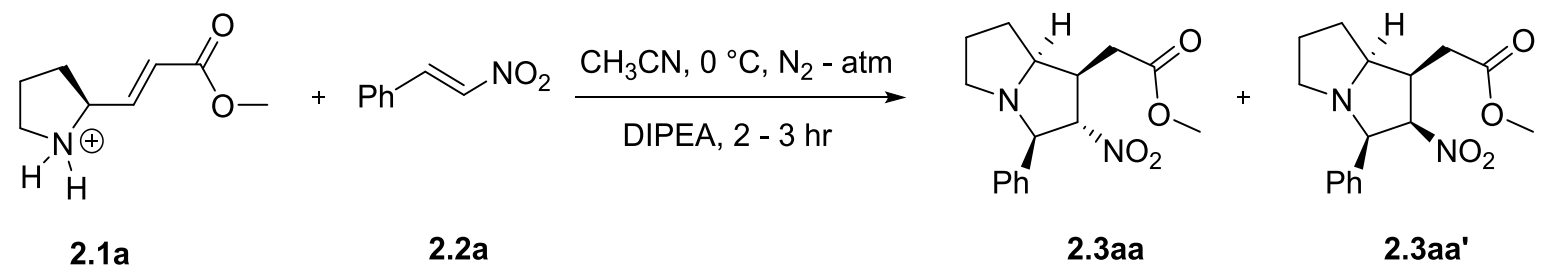

To a well-stirred solution of aminoester salt $\mathbf{2 . 1 a}(300 \mathrm{mg}, 1.57 \mathrm{mmol}, 1$ equiv.) in dry acetonitrile were added nitro-alkene 2.2a (306 mg, $2 \mathrm{mmol}, 1.3$ equiv.) pre-cooled to $0^{\circ} \mathrm{C}$ and kept stirring until the solution became clear. Then, appropriate amount of DIPEA (1.15 ml, $6.28 \mathrm{mmol}, 4$ equiv.) was added slowly over 5 minute time period. Stirring was maintained for $5 \mathrm{hr}$, meanwhile rose temperature from $0^{\circ} \mathrm{C}$ to $\mathrm{RT}$ until complete consumption of 2.1a. Then, let the reaction mixture and residue passed through the pad of cotton plug, sand and silica gel and washed with EtOAc, concentrated under vacuum. Column chromatography (Hexane/EtOAc, 15:1 to 5:1) of the crude product over $\mathrm{SiO}_{2}$ afforded pure $430 \mathrm{mg}$ aza-Michael adducts 2.3aa/2.3aa' as solid (91\%). 


\section{A1.2.3.2: Representative procedure for the synthesis of $\gamma$-lactam}<smiles>COC(=O)C[C@@H]1C2CCCN2C(c2ccccc2)[C@H]1[N+](=O)[O-]</smiles>

2.3aa

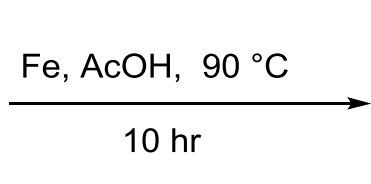

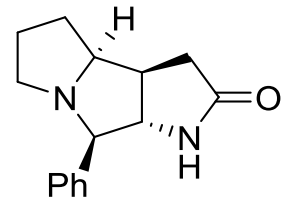

2.5aa

A diastereomeric mixture of bicyclic nitroester 2.3aa/2.3aa' (500 mg, 1.64 mmol, 1 equiv.) and iron powder (921 mg, $16.4 \mathrm{mmol}, 10$ equiv.) in acetic acid (5 mL) was heated to $90{ }^{\circ} \mathrm{C}$ and stirred for $12 \mathrm{hr}$. After complete consumption of 2.3aa/2.3aa', celite filtration was performed to filter off the solid impurities, followed by washing with THF. A residue was obtained after the removal of solvent under vacuum. Then, silica gel flash column chromatography was employed $\left(\mathrm{CH}_{2} \mathrm{Cl}_{2} / \mathrm{MeOH}=20: 1\right.$, v/v) to afford single $\gamma$ lactam 5aa as solid (320 mg, $80 \%$ based on the amount of 2.3aa/2.3aa' mixture, $\mathbf{R}_{f}=0.30$, $\left.\mathrm{CH}_{2} \mathrm{Cl}_{2} / \mathrm{MeOH}=9: 1\right)$.

\section{A1.2.3.3: Typical Procedure for Asymmetric Synthesis of N-Heterocycles}

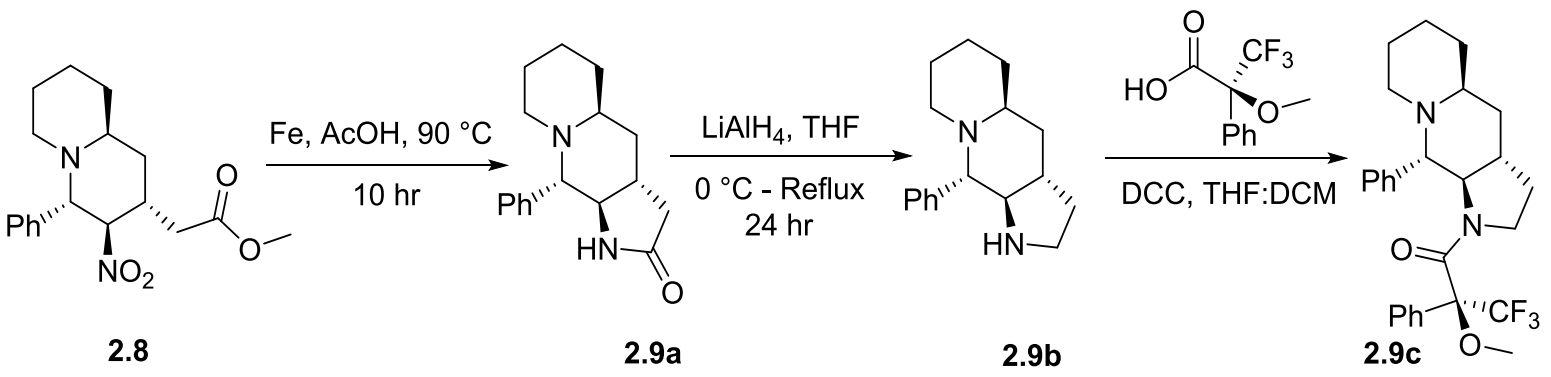

The compounds $\mathbf{2 . 8}$ and 2.9a were prepared according to the procedures described as above (Yield of $\mathbf{2 . 8}=74 \%$; Yield of 2.9a $=71 \%)$. A solution of $\gamma$-lactam 2.9a $(200 \mathrm{mg}$, $0.7 \mathrm{mmol}, 1.0$ equiv. $)$ in tetrahydrofuran $(10 \mathrm{~mL})$ was cooled to $0{ }^{\circ} \mathrm{C}$ under nitrogen atmosphere. Lithium aluminum hydride powder (150 mg, $3.7 \mathrm{mmol}, 5.3$ equiv.) was added slowly while continuously stirring. Contents of the reaction flask were first warmed to RT for $1 \mathrm{hr}$ then heated to $65^{\circ} \mathrm{C}$ for $24 \mathrm{hr}$. Then, the reaction was cooled to $0{ }^{\circ} \mathrm{C}$ and quenched by drop wise addition of $2 \mathrm{~N}$ sodium hydroxide $(3 \mathrm{~mL})$, and water (1 $\mathrm{mL})$. Content of the reaction flask was warmed to room temperature, filtered by filter 
paper, and the filtrate dried with anhydrous magnesium sulfate. After removal of the magnesium sulfate, concentration was taken under reduced pressure and flash column chromatography $\left(\mathrm{CH}_{2} \mathrm{Cl}_{2} / \mathrm{MeOH}=9: 1, \mathrm{v} / \mathrm{v}\right)$ afforded the diamine $\mathbf{2 . 9 b}$ as colorless oil, $130 \mathrm{mg}$ (68\% yield).

To a flame-dried flask was added N, N'-dicyclohexylcarbodiimide, $57 \mathrm{mg}(0.30 \mathrm{mmol}$, 1.1 equiv.) in equimolar solution of tetrahedron furan and dichloromethane $(5.0 \mathrm{ml}, \mathrm{v} / \mathrm{v}=$ 1/1). Diamine 2.9b (70 mg, $0.27 \mathrm{mmol}, 1.0$ equiv.) was added in one portion at room temperature. Then, Chiral (R)-(+)- $\alpha$-methoxy- $\alpha$-(trifluoromethyl)phenylacetic acid (64 $\mathrm{mg}, 0.27 \mathrm{mmol}, 1.0$ equiv.) was added in one portion. It caused immediate turbidity. The reaction was stirred at room temperature for $24 \mathrm{hr}$. The reaction mixture was then diluted with $15 \mathrm{ml} \mathrm{CH}_{2} \mathrm{Cl}_{2}$ and washed with $20 \mathrm{ml} 1.0 \mathrm{M} \mathrm{HCl}, 20 \mathrm{ml}$ saturated aqueous sodium bicarbonate and $20 \mathrm{ml}$ of brine. The $\mathrm{CH}_{2} \mathrm{Cl}_{2}$ layer was dried over anhydrous magnesium sulfate, filtered through a fine sintered glass funnel, and the solvent was removed under vacuum. The crude product was redissolved in hexanes and filtered again to remove dicyclohexylurea. The hexanes were removed under vacuum to afford chiral amide 2.9c (105 mg, $0.22 \mathrm{mmol}, 80 \%$ yield) of a glassy solid. NMR and Mass analysis was performed on the pure product $2.9 \mathrm{c}$ after column chromatography $\left(\mathrm{CH}_{2} \mathrm{Cl}_{2} / \mathrm{MeOH}=15: 1\right.$, $\mathrm{v} / \mathrm{v})$.

\section{A1.2.4: Experimental procedures for enantioselective synthesis of piperidine}

\section{A1.2.4.1: Procedure for Synthesis of Substituted Racemic and Chiral $N$-protected piperidine}

\section{Chiral Synthesis:}

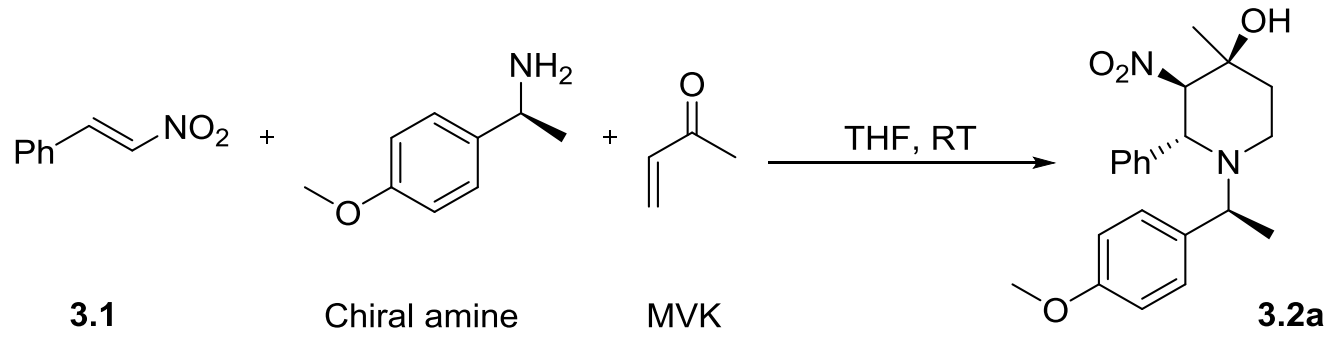


Racemic Synthesis:

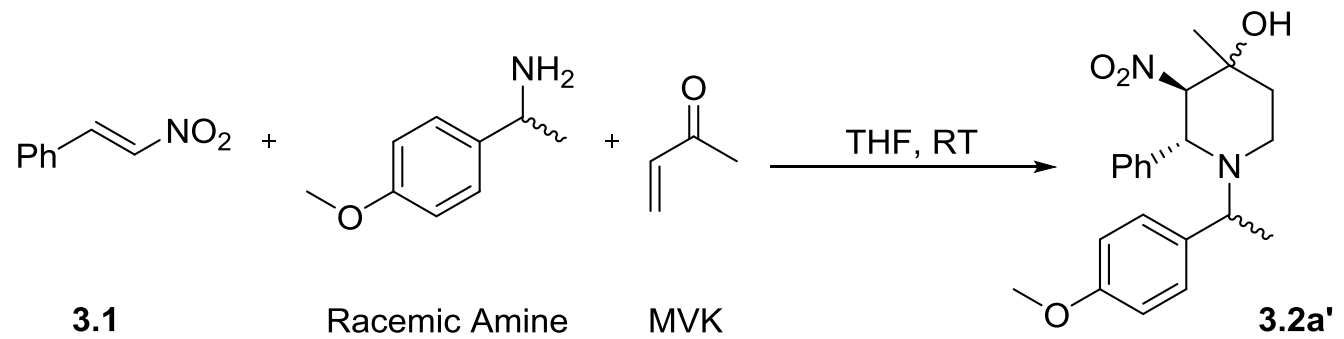

To a solution of nitroalkene 3.1 (149 mg, $1 \mathrm{mmol}, 1$ eq.) in dry THF (5 mL), was added successively Chiral 4-methoxy-phenylethanamine (158 mg, $1.5 \mathrm{mmol}, 1.5$ eq.) and MVK (140 mg, $2.0 \mathrm{mmol}, 2.0$ eq.) under $\mathrm{N}_{2}$ atmosphere. The mixture was stirred at room temperature for $36 \mathrm{hr}$ and monitored by TLC. After removing the solvent, the residue was purified by flash silica gel chromatography (Hexane-EtOAc v/v 8:1) gave a major diastereomeric piperidine (266 mg, $0.97 \mathrm{mmol}$, yield: $71 \%$ ) as white solids. Racemic sample 3.2a' was also prepared using racemic amine following same procedure.

\section{A1.2.4.2: Experiment for $N$-deprotection to piperidine (both chiral and racemic)}

TFA was added drop wise to a stirred solution of the substrate 3.2a (266 mg, $0.97 \mathrm{mmol})$ in minimum amount of DCM and stirred at room temperature 24hr (TFA:DCM, 1:1). After concentration in rotary evaporator, the residue was partitioned between saturated aquous sodium bicarbonate solution $(8 \mathrm{ml})$ and Dichloromethane $(8 \mathrm{ml})$.
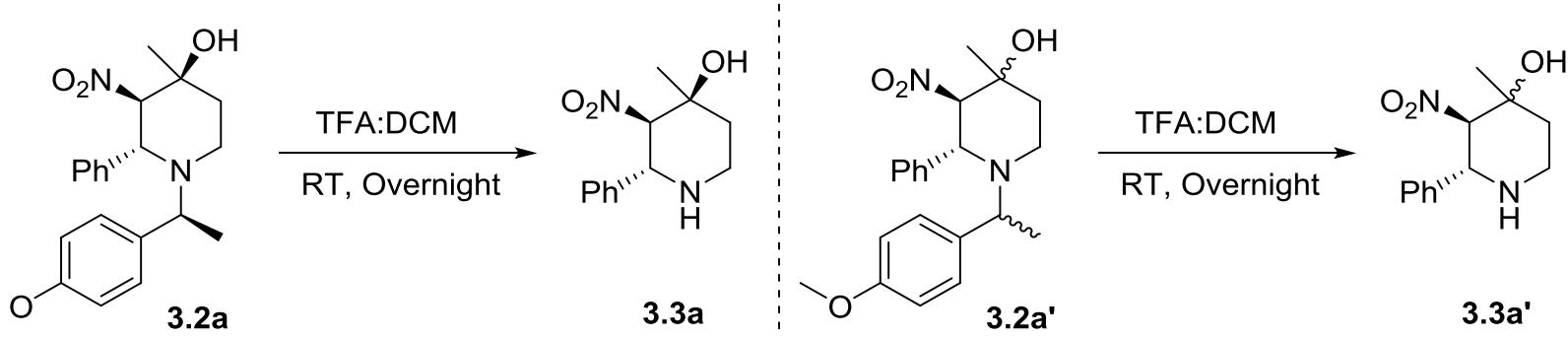

The separted aqueous phase was extracted with Dichloromethane $(3 \times 8 \mathrm{ml})$, and the combined organic extracts dried over sodium or magnesium sulfate for $2 \mathrm{hr}$ then filtered through the cotton plug. Finally, the dilute solution is concentrated in rotavapor and the 
residue was purified by column chromatography using solvent system (Dichloromethane: Methanol; 200:1 to 50:1) to afford racemic piperidine 3.3a for \% ee measurement. Using the same mentioned procedure 3.3a' was prepared from 3.2a'.

\section{A1.2.4.3: Representative Procedure for the synthesis of thioureabased piperidine}

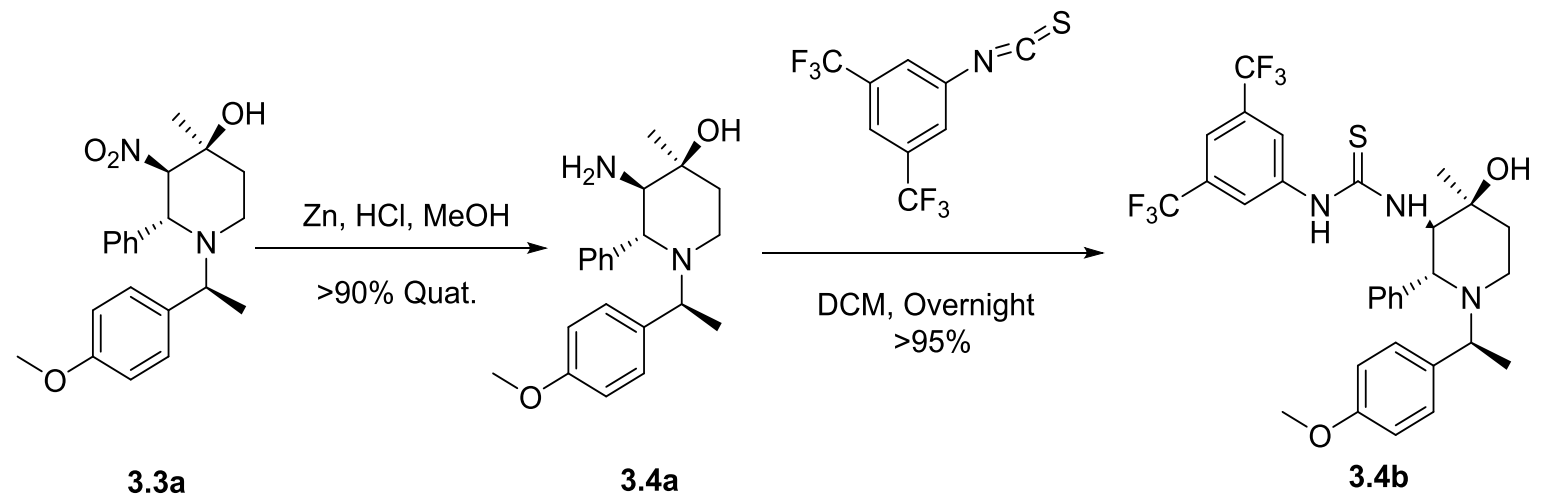

To a solution of 3.3a (major) $(800 \mathrm{mg}, 2.16 \mathrm{mmol}$, 1eq) added $1 \mathrm{~N} \mathrm{HCl}$ in $\mathrm{MeOH}(25$ $\mathrm{mL},>10$ eq.) and $\mathrm{Zn}$ powder (2.10 gm, $7.5 \mathrm{mmol}, 15$ eq. $)$ were added at .The mixture was then stirred at room temperature and monitored by TLC. After the complete consumption of 3.3a, $\mathrm{MeOH}$ was completely evaporated followed by treatment with $\mathrm{NaHCO}_{3}(\mathrm{aq})$ was added until $\mathrm{pH}>10$, and $\mathrm{CH}_{2} \mathrm{Cl}_{2}$. Organic layer was extracted with $\mathrm{CH}_{2} \mathrm{Cl}_{2}(30 \mathrm{~mL} \times 5)$. The combined organic layer was washed with brine and then dried over anhydrous $\mathrm{Na}_{2} \mathrm{SO}_{4}$. After filtration and evaporation, the residue was dissolved in minimum $\mathrm{CH}_{2} \mathrm{Cl}_{2}(25 \mathrm{~mL})$ and purified by flash silica gel chromatography $\left(\mathrm{CH}_{2} \mathrm{Cl}_{2}-\right.$ $\mathrm{MeOH}$ v/v 100:1) gave almost quantitative amount of $\mathbf{3 . 4 a}$ (700 mg, 2.0 mmol, yield: $95 \%)$.

To a solution of amine $\mathbf{3 . 4 a}(700 \mathrm{mg}, 2.0 \mathrm{mmol})$ in $25 \mathrm{ml}$ dichloromethane added 3,5 ditrifluoromethyl-phenyl isothiocyanate $(557 \mathrm{mg}, 2.0 \mathrm{mmol}, 1 \mathrm{eq}$.$) and stirred it overnight.$ After, TLC showed the disappearance of $3.4 \mathrm{a}$, the solution was evaporated and the residue was chromatographed in solvent system (EtoAc: Hexane, v/v 5:1 to 1:1) to afford white solid 3.4b (1.092 mg, $1.78 \mathrm{mmol}$, yield: 86\%). 


\section{A1.2.4.4: Procedure for Racemic product 3.4d synthesis}

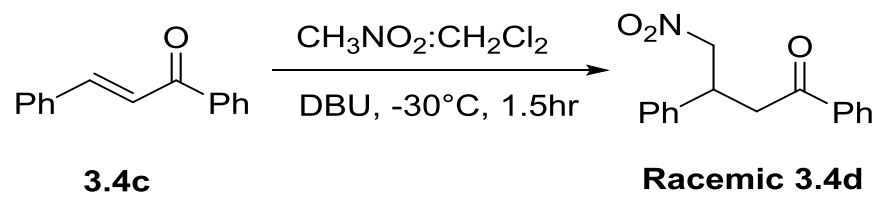

To a $50 \mathrm{~mL}$ Pyrex flask, chalcone (500mg, 2.4mmol, 1eq.) in $\mathrm{CH}_{3} \mathrm{NO}_{2}: \mathrm{CH}_{2} \mathrm{CL}_{2}$ (6ml:14ml, excess), was added followed by DBU (365mg/0.36ml, 2.4mmol, 1eq.). The mixture was stirred at the temperature $-30^{\circ} \mathrm{C}$ for the period of $1.5 \mathrm{hr}$. TLC monitored until chalcone was disappeared indicated by TLC. After warming upto RT, the mixture was quenched with water to neutral, dried, and evaporated to form a residue. After purification by flash chromatography on silica gel using $15 \%$ ethyl acetate in petroleum ether, the Michael adduct was obtained. The authenticity of the products was established by comparison of NMR and melting points with literature value.

\section{A1.2.4.5: Asymmetric Michael addition of nitromethane to chalcone for Chiral 3.4d}

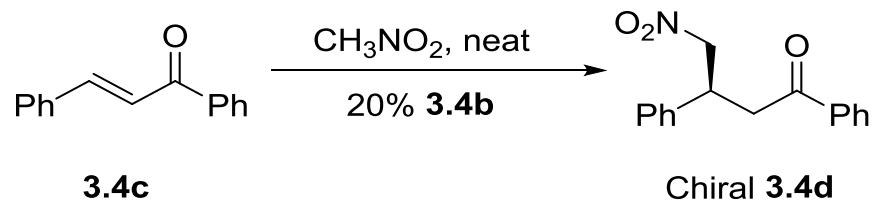

To a solution of chalcones 3.4c ( $1 \mathrm{mmol}, 1.0$ equiv) and nitromethane $(915 \mathrm{mg} / 0.80 \mathrm{ml}, 15$ mmol, 15.0 equiv) added thiourea-catalyst 3.4b (122mg, $0.2 \mathrm{mmol}, 20 \mathrm{~mol} \%)$. The reaction mixture was stirred in capped vial for $240 \mathrm{~h}$ at $50^{\circ} \mathrm{C}$. Then the volatiles was removed by concentration and the residue purified by silica gel flash column chromatography (ethyl acetate-petroleum ether $1: 15 \mathrm{~V} / \mathrm{V}$ ) to afford the product $3.4 \mathrm{~d}$ as white solid (63.1 mg, 94\% yield). Enantiomeric excess was determined by HPLC on Chiralpak AS-H column (n-hexane-isopropanol 90:10 V/V, flow rate $1.0 \mathrm{~mL} / \mathrm{min}, 220$ $\mathrm{nm}$ ), major enantiomer $t_{r}=10.3 \mathrm{~min}$, minor enantiomer $t_{r}=13.6 \mathrm{~min},>90 \%$ ee. 


\section{A1.2.5: Representative procedures for Triazole-Gold(I) Catalysis}

\section{A1.2.5.1: Representative procedure for $\alpha, \beta$-unsatured ketone 4.3.4a from 4.3 .1}

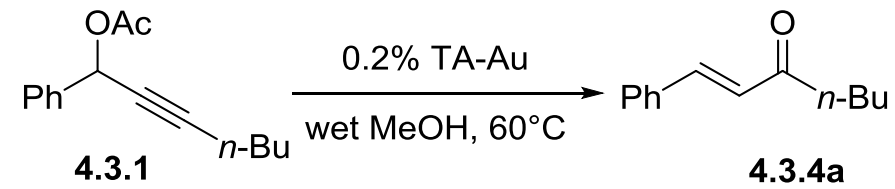

To a solution of 4.3.1a (288 mg, $1.25 \mathrm{mmol})$ in wet $\mathrm{MeOH}\left(5 \mathrm{~mL}, 0.25 \mathrm{M}, \mathrm{MeOH}: \mathrm{H}_{2} \mathrm{O}=\right.$ 100:1), was added $\mathrm{Au}(\mathrm{I})$ catalyst $(1.8 \mathrm{mg}, 0.0025 \mathrm{~mol}, 0.2 \mathrm{~mol} \%)$ at $60^{\circ} \mathrm{C}$. The reaction mixture was stirred at $60^{\circ} \mathrm{C}$ and monitored by TLC. After the reaction was completed (4h), the solvent was removed under reduced pressure and the residue was purified by flash chromatography on silica gel (ethyl acetate/hexane $=1: 20, \mathrm{~V} / \mathrm{V})$ to give $\mathbf{4 . 3 . 4 a}(92 \%$ yield) as colorless oil.

\section{A1.2.5.2: Representative procedure for $\alpha, \beta$-unsatured ketone 4.3.4a from 4.3 .5}

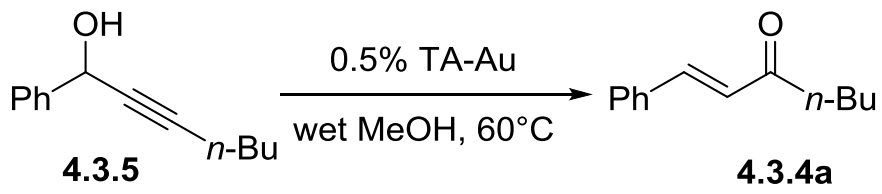

To a solution of 4.3 .5 (94 mg, $0.5 \mathrm{mmol})$ in wet $\mathrm{MeOH}\left(2.5 \mathrm{~mL}, \mathrm{MeOH}: \mathrm{H}_{2} \mathrm{O}=100: 1\right)$, was added $\mathrm{Au}(\mathrm{I})$ catalyst $(1.8 \mathrm{mg}, 0.0025 \mathrm{~mol}, 0.5 \mathrm{~mol} \%)$ at $60^{\circ} \mathrm{C}$. The reaction mixture was stirred at $60^{\circ} \mathrm{C}$ and monitored by TLC. After the reaction was completed $(3 \mathrm{~h})$, the solvent was removed under reduced pressure and the residue was purified by flash chromatography on silica gel (ethyl acetate/hexane $=1: 20, \mathrm{~V} / \mathrm{V})$ to give $4.3 .4 \mathrm{a}(89 \%$ yield) as colorless oil. 


\section{A1.2.5.3: Representative procedure for the preparation of Allene 4.3.2a from 4.3.1a}

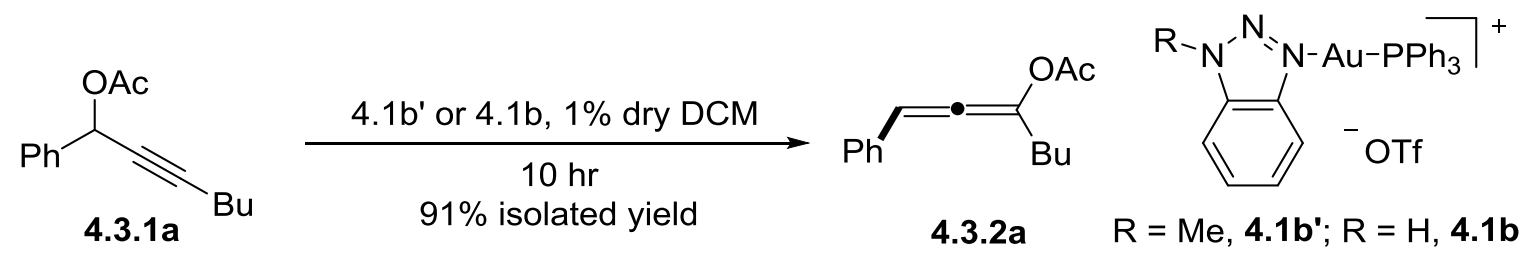

To a solution of 4.3.1a (58 mg, $0.25 \mathrm{mmol})$ in dry $\mathrm{CH}_{2} \mathrm{Cl}_{2}(2.5 \mathrm{~mL}, 0.1 \mathrm{M})$, was added $\mathrm{Au}(\mathrm{I})$ catalyst $(1.9 \mathrm{mg}, 0.0025 \mathrm{~mol}, 1.0 \mathrm{~mol} \%)$ at RT. The reaction mixture was stirred at RT and monitored by TLC. After the reaction was completed (2-10 h), the solvent was removed under reduced pressure and the residue was purified by flash chromatography on silica gel (ethyl acetate/hexane $=20: 1, \mathrm{~V} / \mathrm{V})$ to give 4.3.2a (91\% yield) as colorless oil.

\section{A1.2.5.4: Representative procedure for the preparation of Chiral Allene 4.8a from}

\section{5a}
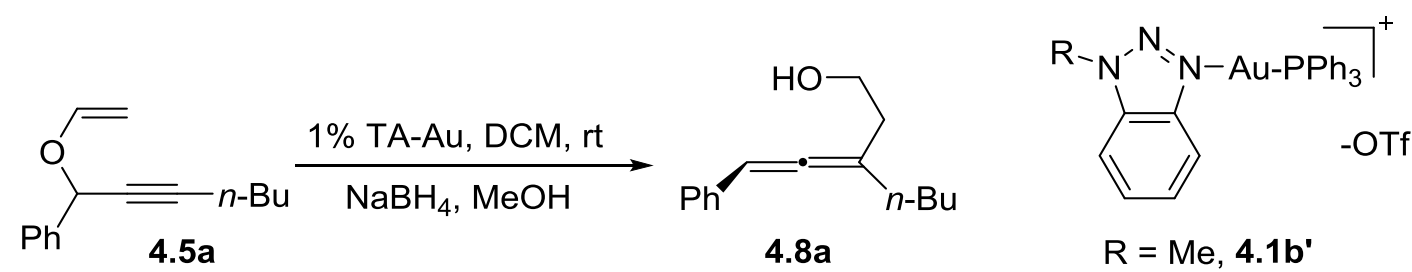

To a solution of $4.5 \mathrm{a}(54 \mathrm{mg}, 0.25 \mathrm{mmol})$ in dry $\mathrm{CH}_{2} \mathrm{Cl}_{2}(2.5 \mathrm{~mL}, 0.1 \mathrm{M})$, was added $\mathrm{Au}(\mathrm{I})$ catalyst (1.9 mg, $0.0025 \mathrm{~mol}, 1.0 \mathrm{~mol} \%)$ at RT. The reaction mixture was stirred at RT and monitored by TLC. After the reaction was completed (0.5-10 h), $\mathrm{NaBH}_{4}(10 \mathrm{mg}$, $0.25 \mathrm{mmol})$ was added to the reaction at $\mathrm{RT}$. Then $\mathrm{MeOH}(1 \mathrm{~mL})$ was added to dilute the mixture. The reaction mixture was stirred at RT and monitored by TLC (10 min). Then the solvent was removed under reduced pressure and the residue was purified by flash chromatography on silica gel (ethyl acetate/hexane $=5: 1, \mathrm{~V} / \mathrm{V}$ ) to give 4.8a (93\% yield) as colorless oil. 


\section{Appendix 2: Compound Characterization $\left({ }^{1} \mathrm{H}-\mathrm{NMR},{ }^{13} \mathrm{C}-\mathrm{NMR}\right.$, HRMS)}

\section{A2.1: Stereoselective $N$-heterocycles synthesis}

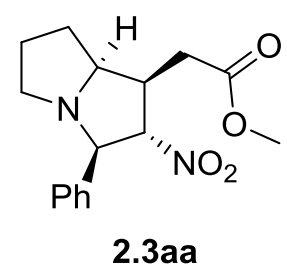

Methyl 2-((1R, 2S, 3R, 7aS)-2-nitro-3-phenylhexahydro-1H-pyrrolizin-1-yl) acetate (2.3aa) was purified by flash chromatography (Hexane/EtOAc $=7: 1$, v/v) as light yellow liquid. Reaction time $3 \mathrm{hr}$; Isolated yield 91\%, dr = 9:1; ${ }^{1} \mathrm{H}-\mathrm{NMR}\left(600 \mathrm{MHz}, \mathrm{CDCl}_{3}\right) \delta$ 7.37-7.25 (m, 5H), 5.47-5.44 (dd, $J=9.07 \mathrm{~Hz}, 6.59 \mathrm{~Hz}, 1 \mathrm{H}), 4.73(\mathrm{~d}, J=6.89 \mathrm{~Hz}, 1 \mathrm{H})$, $3.68(\mathrm{~s}, 3 \mathrm{H}), 3.40-3.37(\mathrm{~m}, 1 \mathrm{H}), 2.83-2.78(\mathrm{~m}, 1 \mathrm{H}), 2.59-2.53(\mathrm{~m}, 1 \mathrm{H}), 2.50(\mathrm{~d}, J=7.6$ $\mathrm{Hz}, 1 \mathrm{H}), 2.48-2.44(\mathrm{~m}, 1 \mathrm{H}), 2.41-2.38(\mathrm{~m}, 1 \mathrm{H}), 2.08-2.02(\mathrm{~m}, 1 \mathrm{H}), 1.99-1.88(\mathrm{~m}, 2 \mathrm{H})$, 1.62-1.56 (m, 1H); ${ }^{13} \mathrm{C}-\mathrm{NMR}\left(150 \mathrm{MHz}, \mathrm{CDCl}_{3}\right) \delta 171.98,136.91,129.06,128.62$, 127.93, 94.38, 70.62, 69.75, 52.20, 47.49, 43.90, 32.71, 28.88, 26.35; HRMS Calculated for $\mathrm{C}_{16} \mathrm{H}_{20} \mathrm{~N}_{2} \mathrm{O}_{4}[\mathrm{M}+\mathrm{H}]^{+}:$305.1457, Found: 305.1495 .

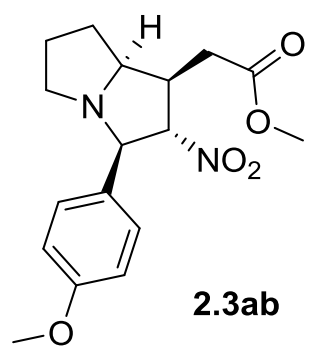

Methyl 2-((1R, 2S, 3R, 7aS)-3-(4-methoxyphenyl)-2-nitrohexahydro-1H-pyrrolizin1-yl) acetate (2.3ab) was purified by flash chromatography $($ Hexane/EtOAc $=5: 1$, v/v) as yellow liquid. Reaction time $4 \mathrm{hr}$; Isolated yield 79\%, dr = 3:1; ${ }^{1} \mathrm{H}-\mathrm{NMR}(600 \mathrm{MHz}$, $\left.\mathrm{CDCl}_{3}\right) \delta 7.28(\mathrm{~d}, J=8.64 \mathrm{~Hz}, 2 \mathrm{H}), 6.87(\mathrm{~d}, J=8.64 \mathrm{~Hz}, 2 \mathrm{H}), 4.67(\mathrm{t}, J=8.05 \mathrm{~Hz}, 1 \mathrm{H})$, $4.20(\mathrm{~d}, J=5.85 \mathrm{~Hz}, 1 \mathrm{H}), 3.79$ (s, 3H), 3.67 (s, 3H), 3.44-3.40 (m, 1H), 2.97-2.94 (m, $1 \mathrm{H}), 2.85-2.81(\mathrm{~m}, 1 \mathrm{H}), 2.69-2.65(\mathrm{~m}, 1 \mathrm{H}), 2.59-2.53(\mathrm{~m}, 2 \mathrm{H}), 2.09-2.01(\mathrm{~m}, 2 \mathrm{H}), 1.85-$ $1.80(\mathrm{~m}, 2 \mathrm{H}) ;{ }^{13} \mathrm{C}-\mathrm{NMR}\left(150 \mathrm{MHz}, \mathrm{CDCl}_{3}\right) \delta 176.68,159.74,129.55,114.45,77.55$, 60.61, 51.88, 42.66, 37.96, 31.59, 24.88, 21.19, 14.14; HRMS Calculated for $\mathrm{C}_{17} \mathrm{H}_{22} \mathrm{~N}_{2} \mathrm{O}_{5}$ $[\mathrm{M}+\mathrm{H}]^{+}:$335.1562, Found: 335.1601. 


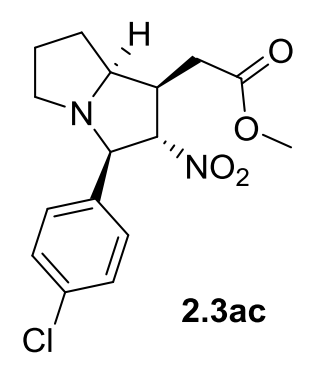

Methyl 2-((1R, 2S, 3R, 7aS)-3-(4-chlorophenyl)-2-nitrohexahydro-1H-pyrrolizin-1-yl) acetate (2.3ac) was purified by flash chromatography (Hexane/EtOAc $=7: 1$, v/v) as yellow liquid. Reaction time $2.5 \mathrm{hr}$; Isolated yield 94\%, dr = 7:1; ${ }^{1} \mathrm{H}-\mathrm{NMR}(600 \mathrm{MHz}$, $\left.\mathrm{CDCl}_{3}\right) \delta$ 7.37-7.28 (m, 4H), $4.65(\mathrm{t}, J=10.39 \mathrm{~Hz}, 1 \mathrm{H}), 4.25(\mathrm{~d}, J=9.66 \mathrm{~Hz}, 1 \mathrm{H}), 3.66(\mathrm{~s}$, $3 \mathrm{H}), 3.46-3.41(\mathrm{~m}, 1 \mathrm{H}), 2.98-2.93(\mathrm{~m}, 1 \mathrm{H}), 2.87-2.82(\mathrm{~m}, 1 \mathrm{H}), 2.66-2.61(\mathrm{~m}, 2 \mathrm{H}), 2.56-$ $2.53(\mathrm{~m}, 1 \mathrm{H}), 2.10-1.99(\mathrm{~m}, 2 \mathrm{H}), 1.86-1.78(\mathrm{~m}, 2 \mathrm{H}) ;{ }^{13} \mathrm{C}-\mathrm{NMR}\left(150 \mathrm{MHz}, \mathrm{CDCl}_{3}\right) \delta$ 171.36, 138.06, 134.43, 129.15, 128.71, 96.74, 72.36, 68.46, 53.40, 52.10, 46.83, 36.19, 32.52, 25.77; HRMS Calculated for $\mathrm{C}_{16} \mathrm{H}_{19} \mathrm{ClN}_{2} \mathrm{O}_{4}[\mathrm{M}+\mathrm{H}]^{+}: 340.1004$, Found: 339.1106 .

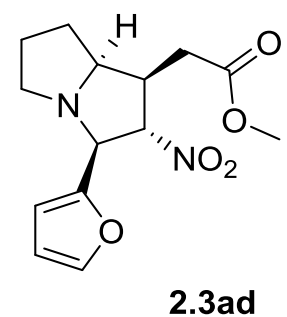

Methyl 2-((1R, 2S, 3S, 7aS)-3-(furan-2-yl)-2-nitrohexahydro-1H-pyrrolizin-1-yl) acetate (2.3ad) was purified by flash chromatography (Hexane/EtOAc $=4: 1, \mathrm{v} / \mathrm{v})$ as yellow liquid. Reaction time $3.5 \mathrm{hr}$; Isolated yield $87 \%$, dr $=7: 1 ;{ }^{1} \mathrm{H}-\mathrm{NMR}(600 \mathrm{MHz}$, $\left.\mathrm{CDCl}_{3}\right) \delta 7.39(\mathrm{t}, J=3.6 \mathrm{~Hz}, 1 \mathrm{H}), 6.32-6.29(\mathrm{~m}, 2 \mathrm{H}), 4.95(\mathrm{t}, J=7.06 \mathrm{~Hz}, 1 \mathrm{H}), 4.56(\mathrm{~d}, J$ $=4.54 \mathrm{~Hz}, 1 \mathrm{H}), 3.67(\mathrm{~s}, 3 \mathrm{H}), 3.45-3.42(\mathrm{~m}, 1 \mathrm{H}), 3.26-3.23(\mathrm{~m}, 1 \mathrm{H}), 2.96-2.92(\mathrm{~m}, 1 \mathrm{H})$, 2.69-2.65 (m, 2H), 2.61-2.54 (m, 1H), 2.53-1.49 (m, 1H), 2.10-2.01 (m, 1H), 2.00-1.97 $(\mathrm{m}, 1 \mathrm{H}), 1.88-1.78(\mathrm{~m}, 1 \mathrm{H}) ;{ }^{13} \mathrm{C}-\mathrm{NMR}\left(150 \mathrm{MHz}, \mathrm{CDCl}_{3}\right) \delta 171.73,138.02,134.59$, 129.19, 128.70, 96.81, 72.28, 68.52, 53.42, 52.02, 46.82, 36.24, 32.44, 25.85; HRMS Calculated for $\mathrm{C}_{14} \mathrm{H}_{18} \mathrm{~N}_{2} \mathrm{O}_{5}[\mathrm{M}+\mathrm{H}]^{+}: 295.1249$, Found: 295.1288. 


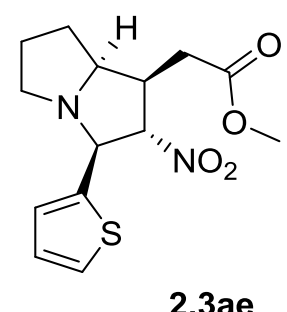

Methyl 2-((1R, 2S, 3S, 7aS)-2-nitro-3-(thiophen-2-yl) hexahydro-1H-pyrrolizin-1-yl) acetate (2.3ae) was purified by flash chromatography (Hexane/EtOAc $=4: 1$, v/v) as yellow liquid. Reaction time $3.0 \mathrm{hr}$; Isolated yield 78\%, dr = 9:1; ${ }^{1} \mathrm{H}-\mathrm{NMR}(600 \mathrm{MHz}$, $\left.\mathrm{CDCl}_{3}\right) \delta 7.24(\mathrm{~d}, J=5.12 \mathrm{~Hz}, 1 \mathrm{H}), 6.93-6.91(\mathrm{~m}, 2 \mathrm{H}), 4.69(\mathrm{t}, J=9.37 \mathrm{~Hz}, 1 \mathrm{H}), 4.57(\mathrm{~d}$, $\mathrm{J}=8.78 \mathrm{~Hz}, 1 \mathrm{H}), 3.65(\mathrm{~s}, 3 \mathrm{H}), 3.46-3.42(\mathrm{~m}, 1 \mathrm{H}), 2.96-2.91(\mathrm{~m}, 2 \mathrm{H}), 2.79-2.75(\mathrm{~m}, 1 \mathrm{H})$, 2.65-2.61 (m, 1H), 2.58-1.51 (m, 1H), 2.08-2.04 (m, 1H), 2.01-1.97 (m, 1H), 1.86-1.77 $(\mathrm{m}, 2 \mathrm{H}) ;{ }^{13} \mathrm{C}-\mathrm{NMR}\left(150 \mathrm{MHz}, \mathrm{CDCl}_{3}\right) \delta 171.32,127.42,125.66,125.52,125.43,96.73$, $68.65,68.34,53.53,52.07,46.72,36.40,32.48,25.55$; HRMS Calculated for $\mathrm{C}_{14} \mathrm{H}_{18} \mathrm{~N}_{2} \mathrm{O}_{4} \mathrm{~S}[\mathrm{M}+\mathrm{H}]^{+}: 311.1021$, Found: 311.1060.

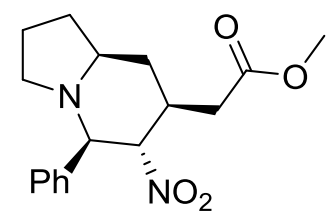

2.3ba

\section{Methyl 2-((5R, 6S, 7S, 8aS)-6-nitro-5-phenyloctahydroindolizin-7-yl) acetate (2.3ba)} was purified by flash chromatography (Hexane/EtOAc $=6: 1$, v/v) as light yellow liquid. Reaction time $4 \mathrm{hr}$; Isolated yield $88 \%, \mathrm{dr}=3: 1 ;{ }^{1} \mathrm{H}-\mathrm{NMR}\left(600 \mathrm{MHz}, \mathrm{CDCl}_{3}\right) \delta 7.40$ $7.25(\mathrm{~m}, 5 \mathrm{H}), 5.49$ (t, $J=9.51 \mathrm{~Hz}, 1 \mathrm{H}), 3.66(\mathrm{~s}, 3 \mathrm{H}), 3.52(\mathrm{~d}, J=8.93 \mathrm{~Hz}, 1 \mathrm{H}), 2.68-2.60$ (m, $2 \mathrm{H}), 2.41-2.38(\mathrm{~m}, 1 \mathrm{H}), 2.29-2.24(\mathrm{~m}, 1 \mathrm{H}), 2.18-2.16(\mathrm{~m}, 1 \mathrm{H}), 1.98-1.91(\mathrm{~m}, 2 \mathrm{H})$, 1.68-1.62 (m, 3H), 1.47-1.44 (m, 1H), 1.29-1.27 (m, 1H); ${ }^{13} \mathrm{C}-\mathrm{NMR}\left(150 \mathrm{MHz}, \mathrm{CDCl}_{3}\right) \delta$ $171.45,137.78,128.90,128.75,128.15,95.06,71.20,65.49,63.40,52.16,38.21,36.99$, 34.48, 30.31, 21.24; HRMS Calculated for $\mathrm{C}_{17} \mathrm{H}_{22} \mathrm{~N}_{2} \mathrm{O}_{4}[\mathrm{M}+\mathrm{H}]^{+}$: 319.1613, Found: 319.1652 . 


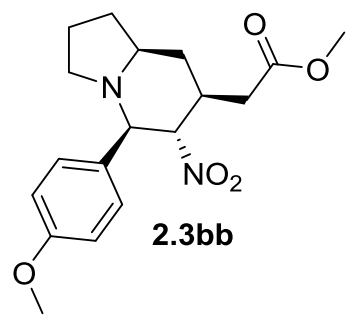

\section{Methyl 2-((5R, 6S, 7S, 8aS)-5-(4-methoxyphenyl)-6-nitrooctahydroindolizin-7-yl)} acetate (2.3bb) was purified by flash chromatography (Hexane/EtOAc $=4: 1, \mathrm{v} / \mathrm{v})$ as yellow liquid. Reaction time $4 \mathrm{hr}$; Isolated yield $79 \%$, dr $=6: 1 ;{ }^{1} \mathrm{H}-\mathrm{NMR}(600 \mathrm{MHz}$, $\left.\mathrm{CDCl}_{3}\right) \delta 7.22(\mathrm{~d}, J=7.96 \mathrm{~Hz}, 2 \mathrm{H}), 6.80(\mathrm{~d}, J=7.76 \mathrm{~Hz}, 2 \mathrm{H}), 4.45(\mathrm{t}, J=9.08 \mathrm{~Hz}, 1 \mathrm{H})$, $3.46(\mathrm{~d}, \mathrm{~J}=8.93 \mathrm{~Hz}, 1 \mathrm{H}), 3.74(\mathrm{~s}, 3 \mathrm{H}), 3.64(\mathrm{~s}, 3 \mathrm{H}), 2.66-2.59(\mathrm{~m}, 2 \mathrm{H}), 2.39-2.35$ (m, $1 \mathrm{H}), 2.27-2.23(\mathrm{~m}, 2 \mathrm{H}), 2.15(\mathrm{~d}, J=5.12 \mathrm{~Hz}, 1 \mathrm{H}), 2.00-1.80(\mathrm{~m}, 2 \mathrm{H}), 1.68-1.61(\mathrm{~m}, 2 \mathrm{H})$, 1.45-1.44 (m, 1H), 1.26-1.24 (m, 1H); ${ }^{13} \mathrm{C}-\mathrm{NMR}\left(150 \mathrm{MHz}, \mathrm{CDCl}_{3}\right) \delta 171.45,159.91$, 130.11, 129.21, 114.21, 95.13, 70.58, 64.83, 63.42, 55.37, 52.13, 38.21, 37.01, 34.27, 30.50, 21.20; HRMS Calculated for $\mathrm{C}_{18} \mathrm{H}_{24} \mathrm{~N}_{2} \mathrm{O}_{5}[\mathrm{M}+\mathrm{H}]^{+}: 349.1719$, Found: 349.1757 .

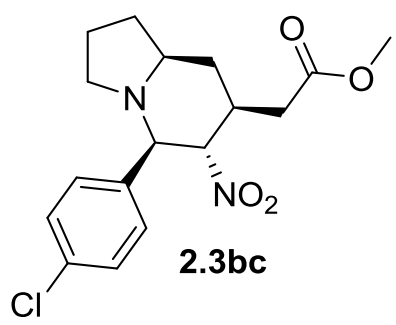

\footnotetext{
Methyl 2-((5R，6S，7S， 8aS)-5-(4-chlorophenyl)-6-nitrooctahydroindolizin-7-yl) acetate (2.3bc) was purified by flash chromatography (Hexane/EtOAc $=7: 1, \mathrm{v} / \mathrm{v})$ as yellow liquid. Reaction time $2.5 \mathrm{hr}$; Isolated yield $93 \%, \mathrm{dr}=6: 1 ;{ }^{1} \mathrm{H}-\mathrm{NMR}(600 \mathrm{MHz}$, $\left.\mathrm{CDCl}_{3}\right) \delta$ 7.28-7.23 (m, 4H), $4.42(\mathrm{t}, J=10.10 \mathrm{~Hz}, 1 \mathrm{H}), 3.65(\mathrm{~s}, 3 \mathrm{H}), 3.50(\mathrm{~d}, J=9.37 \mathrm{~Hz}$, $1 \mathrm{H}), 2.65-2.58(\mathrm{~m}, 2 \mathrm{H}), 2.39-2.36(\mathrm{~m}, 1 \mathrm{H}), 2.27-2.23(\mathrm{~m}, 2 \mathrm{H}), 2.15(\mathrm{~d}, J=9.37 \mathrm{~Hz}, 1 \mathrm{H})$, 1.92-1.88 (m, 2H), 1.69-1.62 (m, 2H), 1.45-1.41 (m, 1H), 1.29-1.23 (m, 1H); ${ }^{13} \mathrm{C}-\mathrm{NMR}$ $\left(150 \mathrm{MHz}, \mathrm{CDCl}_{3}\right) \delta 171.35,136.40,134.60,129.17,129.00,94.93,70.43,63.36,52.11$, 52.04, 38.15, 36.87, 34.27, 30.40, 21.23; HRMS Calculated for $\mathrm{C}_{17} \mathrm{H}_{21} \mathrm{ClN}_{2} \mathrm{O}_{4}[\mathrm{M}+\mathrm{H}]^{+}$: 354.1160 , Found: 353.1262.
} 


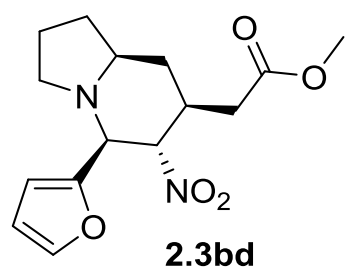

Methyl 2-((5S, 6S, 7S, 8aS)-5-(furan-2-yl)-6-nitrooctahydroindolizin-7-yl) acetate (2.3bd) was purified by flash chromatography (Hexane/EtOAc $=4: 1, \mathrm{v} / \mathrm{v}$ ) as yellow liquid. Reaction time $4 \mathrm{hr}$; Isolated yield $89 \%, \mathrm{dr}=7: 1 ;{ }^{1} \mathrm{H}-\mathrm{NMR}\left(600 \mathrm{MHz}, \mathrm{CDCl}_{3}\right) \delta$ 7.40-7.30 (m, 1H), 6.32-6.20 (m, 2H), $4.72(\mathrm{t}, J=9.95 \mathrm{~Hz}, 1 \mathrm{H}), 3.68(\mathrm{~d}, J=9.95 \mathrm{~Hz}, 1 \mathrm{H})$, $3.64(\mathrm{~s}, 3 \mathrm{H}), 2.66-2.61(\mathrm{~m}, 2 \mathrm{H}), 2.41-2.38(\mathrm{~m}, 1 \mathrm{H}), 2.29-2.25(\mathrm{~m}, 2 \mathrm{H}), 2.17-2.09(\mathrm{~m}, 2 \mathrm{H})$, $1.92-1.88(\mathrm{~m}, 1 \mathrm{H}), 1.76-1.65(\mathrm{~m}, 2 \mathrm{H}), 1.50-1.47(\mathrm{~m}, 1 \mathrm{H}), 1.27-1.21(\mathrm{~m}, 1 \mathrm{H}) ;{ }^{13} \mathrm{C}-\mathrm{NMR}$ $\left(150 \mathrm{MHz}, \mathrm{CDCl}_{3}\right) \delta 171.30,149.91,143.43,110.32,110.01,91.74,63.96,63.31,52.14$, 52.05, 38.01, 37.04, 34.17, 30.09, 21.13; HRMS Calculated for $\mathrm{C}_{15} \mathrm{H}_{20} \mathrm{~N}_{2} \mathrm{O}_{5}[\mathrm{M}+\mathrm{H}]^{+}$: 309.1406, Found: 309.1444.

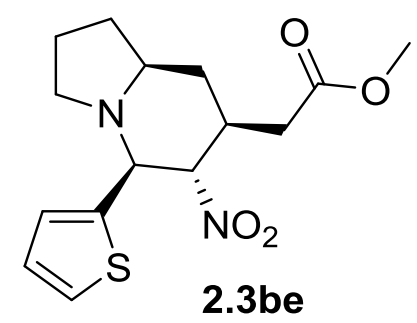

Methyl 2-((5S, 6S, 7S, 8aS)-6-nitro-5-(thiophen-2-yl)octahydroindolizin-7-yl) acetate (2.3be) was purified by flash chromatography (Hexane/EtOAc $=4: 1, \mathrm{v} / \mathrm{v}$ ) as yellow liquid. Reaction time $3.0 \mathrm{hr}$; Isolated yield $84 \%, \mathrm{dr}=4: 1 ;{ }^{1} \mathrm{H}-\mathrm{NMR}\left(600 \mathrm{MHz}, \mathrm{CDCl}_{3}\right) \delta$ $7.26(\mathrm{~d}, J=4.98 \mathrm{~Hz}, 1 \mathrm{H}), 6.85(\mathrm{t}, J=4.25 \mathrm{~Hz}, 1 \mathrm{H}), 6.94-6.88($ br s, $1 \mathrm{H}), 4.49-4.45$ (t, J = $10.25 \mathrm{~Hz}, 1 \mathrm{H}), 3.89$ (d, $J=9.22 \mathrm{~Hz}, 1 \mathrm{H}), 3.65$ (s, 3H), $2.84(\mathrm{t}, J=8.20 \mathrm{~Hz}, 1 \mathrm{H}), 2.66-$ $2.63(\mathrm{~m}, 1 \mathrm{H}), 2.37(\mathrm{~d}, J=3.37 \mathrm{~Hz}, 2 \mathrm{H}), 2.28-2.24(\mathrm{~m}, 2 \mathrm{H}), 2.02-1.99$ (m, 2H), 1.73-1.63 $(\mathrm{m}, 2 \mathrm{H}), 1.48-1.45(\mathrm{~m}, 1 \mathrm{H}), 1.27-1.22(\mathrm{~m}, 1 \mathrm{H}) ;{ }^{13} \mathrm{C}-\mathrm{NMR}\left(150 \mathrm{MHz}, \mathrm{CDCl}_{3}\right) \delta 171.34$, $141.17,127.04,126.50,126.37,95.98,66.55,63.52,52.36,52.05,38.20,36.47,34.31$, 30.27, 21.10; HRMS Calculated for $\mathrm{C}_{15} \mathrm{H}_{20} \mathrm{~N}_{2} \mathrm{O}_{4} \mathrm{~S}[\mathrm{M}+\mathrm{H}]^{+}:$325.1177, Found: 325.1216 . 


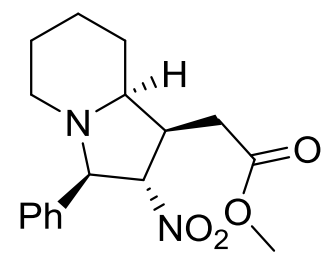

$2.3 \mathrm{ca}$

\section{Methyl 2-((1R, 2S, 3R, 8aS)-2-nitro-3-phenyloctahydroindolizin-1-yl) acetate (2.3ca)} was purified by flash chromatography (Hexane/EtOAc $=7: 1, \mathrm{v} / \mathrm{v})$ as light yellow liquid. Reaction time $4 \mathrm{hr}$; Isolated yield $77 \%$, dr > 99:1; ${ }^{1} \mathrm{H}-\mathrm{NMR}\left(600 \mathrm{MHz}, \mathrm{CDCl}_{3}\right) \delta 7.30$ $7.26(\mathrm{~m}, 5 \mathrm{H}), 5.04-5.02(\mathrm{dd}, J=8.49 \mathrm{~Hz}, 5.85 \mathrm{~Hz}, 1 \mathrm{H}), 3.76(\mathrm{~d}, J=8.64 \mathrm{~Hz}, 1 \mathrm{H}), 3.64$ (s, $3 \mathrm{H}), 3.05(\mathrm{~d}, J=8.64 \mathrm{~Hz}, 1 \mathrm{H}), 2.83(\mathrm{~d}, J=10.83 \mathrm{~Hz}, 1 \mathrm{H}), 2.66-2.63(\mathrm{dd}, J=16.54 \mathrm{~Hz}$, $4.24 \mathrm{~Hz}, 1 \mathrm{H}), 2.45-2.41$ (dd, $J=16.54 \mathrm{~Hz}, 9.59 \mathrm{~Hz}, 1 \mathrm{H}), 1.93-1.87$ (m, 3H), 1.77-1.72 (m, $1 \mathrm{H}), 1.61-1.46(\mathrm{~m}, 3 \mathrm{H}), 1.29-1.21(\mathrm{~m}, 1 \mathrm{H}) ;{ }^{13} \mathrm{C}-\mathrm{NMR}\left(150 \mathrm{MHz}, \mathrm{CDCl}_{3}\right) \delta 171.99$, $135.19,128.76,128.57,94.34,73.02,67.83,52.65,51.42,44.75,34.69$, 29.89, 25.09, 24.26; HRMS Calculated for $\mathrm{C}_{17} \mathrm{H}_{22} \mathrm{~N}_{2} \mathrm{O}_{4}[\mathrm{M}+\mathrm{H}]+:$ 319.1613, Found: 319.1652 .

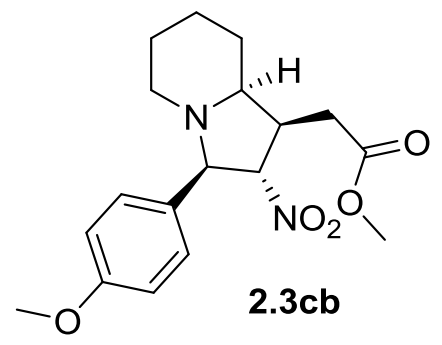

Methyl 2-((1R, 2S, 3R, 8aS)-3-(4-methoxyphenyl)-2-nitrooctahydroindolizin-1-yl) acetate $(2.3 \mathbf{c b})$ was purified by flash chromatography (Hexane/EtOAc $=6: 1, \mathrm{v} / \mathrm{v})$ as light yellow liquid. Reaction time 4 hr; Isolated yield $69 \%$ dr > 99:1; ${ }^{1} \mathrm{H}-\mathrm{NMR}$ (600 $\left.\mathrm{MHz} \mathrm{CDCl}_{3}\right) \delta 7.21(\mathrm{~d}, J=8.05 \mathrm{~Hz}, 2 \mathrm{H}), 6.82(\mathrm{~d}, J=8.78 \mathrm{~Hz}, 2 \mathrm{H}), 4.99-4.97$ (dd, $J=$ $8.64 \mathrm{~Hz}, 5.85 \mathrm{~Hz}, 1 \mathrm{H}), 3.76$ (s, 3H), 3.70 (d, J = 8.49 Hz, 1H), 3.63 (s, 3H), 3.02-3.01 (m, $1 \mathrm{H}), 2.80-2.79$ (br d, 1H), 2.65-2.61 (dd, $J=16.54 \mathrm{~Hz}, 4.24 \mathrm{~Hz}, 1 \mathrm{H}), 2.43-2.39$ (dd $J=$ $16.54 \mathrm{~Hz}, 9.95 \mathrm{~Hz}, 1 \mathrm{H}), 1.88$ (t, $J=9.66 \mathrm{~Hz}, 3 \mathrm{H}), 1.72$ (t, $J=12.88 \mathrm{~Hz}, 1 \mathrm{H}), 1.58-1.40$ $(\mathrm{m}, 3 \mathrm{H}), 1.31-1.17(\mathrm{~m}, 1 \mathrm{H}) ;{ }^{13} \mathrm{C}-\mathrm{NMR}\left(150 \mathrm{MHz}, \mathrm{CDCl}_{3}\right) \delta 172.03,159.89,129.58$, 127.08, 113.99, 94.35, 72.53, 67.77, 55.34, 51.35, 44.68, 34.72, 29.89, 25.11, 24.27; HRMS Calculated for $\mathrm{C}_{18} \mathrm{H}_{24} \mathrm{~N}_{2} \mathrm{O}_{4}[\mathrm{M}+\mathrm{H}]+:$ 349.1719, Found: 349.1735. 


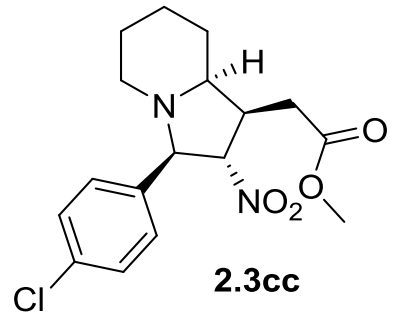

\section{Methyl 2-((1R，2S，3R， 8aS)-3-(4-chlorophenyl)-2-nitrooctahydroindolizin-1-yl)} acetate (2.3cc) was purified by flash chromatography (Hexane/EtOAc $=7: 1, \mathrm{v} / \mathrm{v})$ as light yellow liquid. Reaction time $4 \mathrm{hr}$; Isolated yield $78 \%$, dr > 99:1; ${ }^{1} \mathrm{H}-\mathrm{NMR}$ (600 $\left.\mathrm{MHz}, \mathrm{CDCl}_{3}\right) \delta$ 7.28-7.23 (m, 4H), 5.03-5.01 (dd, $\left.J=8.64 \mathrm{~Hz}, 6.00 \mathrm{~Hz}, 1 \mathrm{H}\right), 3.73(\mathrm{~d}, J=$ $8.64 \mathrm{~Hz}, 1 \mathrm{H}), 3.64$ (s, 3H), 3.03-3.01 (m, 1H), 2.76 (d, J = 10.83 Hz, 1H), 2.66-2.62 (dd, $J=16.54 \mathrm{~Hz}, 4.24 \mathrm{~Hz}, 1 \mathrm{H}), 2.40-2.44(\mathrm{td}, J=16.54 \mathrm{~Hz}, 9.81 \mathrm{~Hz}, 1 \mathrm{H}), 1.94-1.87$ (m, 3H), $1.75(\mathrm{t}, J=4.83 \mathrm{~Hz}, 1 \mathrm{H}), 1.60-1.48(\mathrm{~m}, 3 \mathrm{H}), 1.26-1.23(\mathrm{~m}, 1 \mathrm{H}) ;{ }^{13} \mathrm{C}-\mathrm{NMR}(150 \mathrm{MHz}$, $\left.\mathrm{CDCl}_{3}\right) \delta 171.94,134.56,133.82,129.90,128.85,94.13,72.18,67.67,52.10,51.34$, 44.70, 34.54, 29.86, 25.06, 24.17; HRMS Calculated for $\mathrm{C}_{17} \mathrm{H}_{21} \mathrm{ClN}_{2} \mathrm{O}_{4}[\mathrm{M}+\mathrm{H}]+$ : 354.1160, Found: 353.1265.

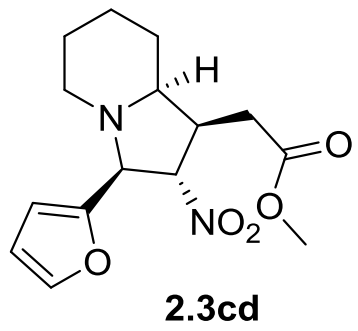

Methyl 2-((1R, 2S, 3S, 8aS)-3-(furan-2-yl)-2-nitrooctahydroindolizin-1-yl) acetate (2.3cd) was purified by flash chromatography (Hexane/EtOAc $=5: 1$, v/v) as light yellow liquid. Reaction time $4 \mathrm{hr}$; Isolated yield $68 \%$, dr > 99:1; ${ }^{1} \mathrm{H}-\mathrm{NMR}(600 \mathrm{MHz}$, $\left.\mathrm{CDCl}_{3}\right) \delta 7.34(\mathrm{~d}, J=4.98 \mathrm{~Hz}, 1 \mathrm{H}), 6.30-6.29(\mathrm{~m}, 2 \mathrm{H}), 5.02-4.99(\mathrm{dd}, J=8.34 \mathrm{~Hz}, 5.71$ $\mathrm{Hz}, 1 \mathrm{H}), 3.86(\mathrm{~d}, J=8.34 \mathrm{~Hz}, 1 \mathrm{H}), 3.62(\mathrm{~s}, 3 \mathrm{H}), 3.06-3.01(\mathrm{~m}, 1 \mathrm{H}), 2.86(\mathrm{~d}, J=10.83 \mathrm{~Hz}$, $1 \mathrm{H}), 2.63-2.59(\mathrm{dd}, J=16.54 \mathrm{~Hz}, 4.24 \mathrm{~Hz}, 1 \mathrm{H}), 2.42-2.37(\mathrm{~m}, 1 \mathrm{H}), 1.86-1.76(\mathrm{~m}, 4 \mathrm{H})$, 1.60-1.56 (m, 2H), 1.50-1.44 (m, 1H), 1.24-1.19 (m, 1H); ${ }^{13} \mathrm{C}-\mathrm{NMR}\left(150 \mathrm{MHz}, \mathrm{CDCl}_{3}\right) \delta$ 171.61, 148.81, 143.01, 110.53, 109.37, 91.94, 67.47, 66.76, 51.81, 51.33, 44.11, 34.17, 29.33, 24.61, 23.86; HRMS Calculated for $\mathrm{C}_{15} \mathrm{H}_{20} \mathrm{~N}_{2} \mathrm{O}_{5}[\mathrm{M}+\mathrm{H}]+$ : 309.1406, Found: 309.1444 . 


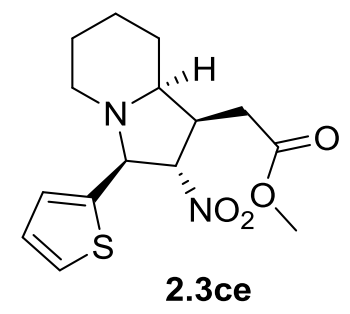

\section{Methyl 2-((1R, 2S, 3S, 8aS)-2-nitro-3-(thiophen-2-yl)octahydroindolizin-1-yl) acetate} (2.3ce) was purified by flash chromatography (Hexane/EtOAc $=5: 1, \mathrm{v} / \mathrm{v})$ as light yellow liquid. Reaction time $4 \mathrm{hr}$; Isolated yield 64\%, dr > 99:1; ${ }^{1} \mathrm{H}-\mathrm{NMR}(600 \mathrm{MHz}$, $\left.\mathrm{CDCl}_{3}\right) \delta 7.24(\mathrm{~d}, J=4.10 \mathrm{~Hz}, 1 \mathrm{H}), 7.00(\mathrm{~d}, J=3.22 \mathrm{~Hz}, 1 \mathrm{H}), 6.94(\mathrm{t}, J=3.66 \mathrm{~Hz}, 1 \mathrm{H})$, 5.03-5.01 (dd, $J=8.64 \mathrm{~Hz}, 6.29 \mathrm{~Hz}, 1 \mathrm{H}), 4.09$ (d, $J=8.64 \mathrm{~Hz}, 1 \mathrm{H}), 3.63(\mathrm{~s}, 3 \mathrm{H}), 3.07-$ $3.02(\mathrm{~m}, 1 \mathrm{H}), 2.95(\mathrm{~d}, J=10.83 \mathrm{~Hz}, 1 \mathrm{H}), 2.63-2.60(\mathrm{dd}, J=16.54 \mathrm{~Hz}, 12.30 \mathrm{~Hz}, 1 \mathrm{H})$, 2.42-2.36 (m, $1 \mathrm{H}), 1.93-1.79(\mathrm{~m}, 4 \mathrm{H}), 1.61-1.45(\mathrm{~m}, 3 \mathrm{H}), 1.24-1.21(\mathrm{~m}, 1 \mathrm{H}) ;{ }^{13} \mathrm{C}-\mathrm{NMR}$ $\left(150 \mathrm{MHz}, \mathrm{CDCl}_{3}\right) \delta 171.90,138.75,127.05,126.96,126.30,93.76,68.07,67.51,52.07$, 51.75, 44.47, 34.44, 29.79, 25.05, 24.19; HRMS Calculated for $\mathrm{C}_{15} \mathrm{H}_{20} \mathrm{~N}_{2} \mathrm{O}_{4} \mathrm{~S}[\mathrm{M}+\mathrm{H}]+$ : 325.1177, Found: 325.11216 .

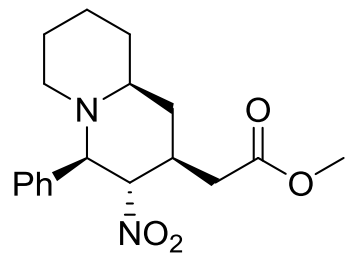

2.3da

Methyl 2-((2S, 3S, 4R, 9aS)-3-nitro-4-phenyloctahydro-1H-quinolizin-2-yl) acetate (2.3da) was purified by flash chromatography (Hexane/EtOAc $=8: 1, \mathrm{v} / \mathrm{v})$ as light yellow liquid. Reaction time $4 \mathrm{hr}$; Isolated yield $66 \%, \mathrm{dr}=3: 2 ;{ }^{1} \mathrm{H}-\mathrm{NMR}(600 \mathrm{MHz}$, $\left.\mathrm{CDCl}_{3}\right) \delta$ 7.40-7.26 (m, 5H), $4.46(\mathrm{t}, J=10.39 \mathrm{~Hz}, 1 \mathrm{H}), 3.68(\mathrm{~s}, 3 \mathrm{H}), 3.46(\mathrm{~d}, J=10.69$ $\mathrm{Hz}, 1 \mathrm{H}), 2.68(\mathrm{~d}, J=7.32 \mathrm{~Hz}, 1 \mathrm{H}), 2.56(\mathrm{~d}, J=10.83 \mathrm{~Hz}, 1 \mathrm{H}), 2.37-2.33(\mathrm{dd}, J=16.54$ $\mathrm{Hz}, 12.30 \mathrm{~Hz}, 1 \mathrm{H}), 2.23-2.16(\mathrm{~m}, 1 \mathrm{H}), 1.79-1.72(\mathrm{~m}, 1 \mathrm{H}), 1.70-1.63(\mathrm{~m}, 2 \mathrm{H}), 1.47$ (t, $J=$ $12.15 \mathrm{~Hz}, 1 \mathrm{H}), 1.36-1.23(\mathrm{~m}, 6 \mathrm{H}) ;{ }^{13} \mathrm{C}-\mathrm{NMR}\left(150 \mathrm{MHz}, \mathrm{CDCl}_{3}\right) \delta 171.79,137.91$, 129.01, 128.49, 125.90, 94.99, 71.89, 61.41, 55.84, 52.64, 51.86, 36.94, 36.71, 33.10, 25.73, 24.22; HRMS Calculated for $\mathrm{C}_{18} \mathrm{H}_{24} \mathrm{~N}_{2} \mathrm{O}_{4}[\mathrm{M}+\mathrm{H}]+$ : 333.1770 , Found: 333.1808 . 


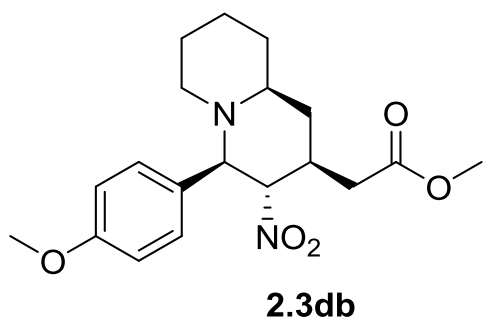

Methyl 2-((2S, 3S, 4R, 9aS)-4-(4-methoxyphenyl)-3-nitrooctahydro-1H-quinolizin-2yl) acetate (2.3db) was purified by flash chromatography (Hexane/EtOAc $=8: 1, \mathrm{v} / \mathrm{v}$ ) as light yellow liquid. Reaction time $4 \mathrm{hr}$; Isolated yield $61 \%$, dr $=2: 1 ;{ }^{1} \mathrm{H}-\mathrm{NMR}(600 \mathrm{MHz}$, $\left.\mathrm{CDCl}_{3}\right) \delta$ 7.50-7.15 (m, 2H), $6.81(\mathrm{~d}, J=7.03 \mathrm{~Hz}, 2 \mathrm{H}), 4.32(\mathrm{t}, J=10.10 \mathrm{~Hz}, 1 \mathrm{H}), 3.77(\mathrm{~s}$, $3 \mathrm{H}), 3.67(\mathrm{~s}, 3 \mathrm{H}), 3.40(\mathrm{~d}, J=9.37 \mathrm{~Hz}, 1 \mathrm{H}), 2.67(\mathrm{~d}, J=10.83 \mathrm{~Hz}, 1 \mathrm{H}), 2.56(\mathrm{~d}, 1 \mathrm{H})$, 2.36-2.33 (dd, $J=16.52 \mathrm{~Hz}, 12.28 \mathrm{~Hz}, 1 \mathrm{H}), 2.15(\mathrm{~m}, 1 \mathrm{H}), 1.93(\mathrm{~d}, J=10.10 \mathrm{~Hz}, 1 \mathrm{H})$, 1.69-1.63 (m, 4H), 1.49-1.46 (m, 1H), 1.34-1.23 (m, 4H); ${ }^{13} \mathrm{C}-\mathrm{NMR}\left(150 \mathrm{MHz}, \mathrm{CDCl}_{3}\right) \delta$ 171.14, 159.61, 159.56, 129.97, 129.71, 95.04, 71.27, 61.48, 55.14, 52.72, 51.77, 36.95, 36.24, 33.08, 33.06, 25.75, 24.23; HRMS Calculated for $\mathrm{C}_{19} \mathrm{H}_{26} \mathrm{~N}_{2} \mathrm{O}_{5}[\mathrm{M}+\mathrm{H}]+:$ 363.1875, Found: 363.1914 .

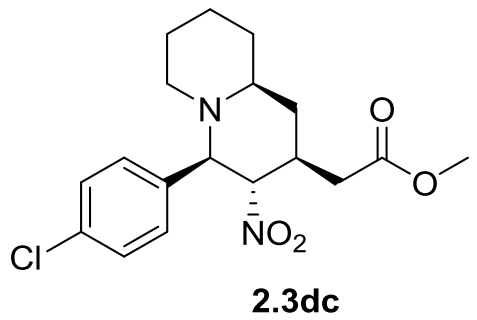

\section{Methyl 2-((2S, 3S, 4R, 9aS)-4-(4-chlorophenyl)-3-nitrooctahydro-1H-quinolizin-2-yl)} acetate (2.3dc) was purified by flash chromatography (Hexane/EtOAc $=8: 1, \mathrm{v} / \mathrm{v})$ as light yellow liquid. Reaction time $4 \mathrm{hr}$; Isolated yield 66\%, dr =3:2; ${ }^{1} \mathrm{H}-\mathrm{NMR}(600 \mathrm{MHz}$, $\left.\mathrm{CDCl}_{3}\right) \delta$ 7.80-7.60 (m, 4H), 4.39 (t, $\left.J=10.25 \mathrm{~Hz}, 1 \mathrm{H}\right), 3.66$ (s, 3H), 3.43 (d, $J=9.66 \mathrm{~Hz}$, $1 \mathrm{H}), 2.64(\mathrm{~d}, J=7.61 \mathrm{~Hz}, 1 \mathrm{H}), 2.51-2.44(\mathrm{dd}, J=28.10 \mathrm{~Hz}, 11.71 \mathrm{~Hz}, 1 \mathrm{H}), 2.24-2.11(\mathrm{~m}$, $2 \mathrm{H}), 1.91(\mathrm{~d}, J=13.32 \mathrm{~Hz}, 1 \mathrm{H}), 1.75-1.64(\mathrm{~m}, 4 \mathrm{H}), 1.45(\mathrm{t}, J=10.83 \mathrm{~Hz}, 3 \mathrm{H}), 1.32-1.22$ $(\mathrm{m}, 2 \mathrm{H}) ;{ }^{13} \mathrm{C}-\mathrm{NMR}\left(150 \mathrm{MHz}, \mathrm{CDCl}_{3}\right) \delta 171.31,162.50,137.34,134.58,134.26,95.09$, 71.34, 61.61, 56.02, 53.14, 52.08, 37.10, 36.81, 33.50, 32.54, 25.92, 24.40; HRMS Calculated for $\mathrm{C}_{18} \mathrm{H}_{23} \mathrm{ClN}_{2} \mathrm{O}_{4}[\mathrm{M}+\mathrm{H}]+:$ 368.1317, Found: 363.1419 . 


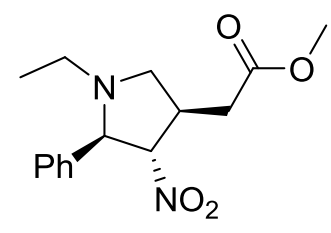

2.3ea

Methyl 2-((3R, 4S, 5R)-1-ethyl-4-nitro-5-phenylpyrrolidin-3-yl) acetate (2.3ea) was purified by flash chromatography (Hexane/EtOAc $=7: 1, \mathrm{v} / \mathrm{v})$ as light yellow liquid. Reaction time $4 \mathrm{hr}$; Isolated yield 86\%, dr > 99:1; ${ }^{1} \mathrm{H}-\mathrm{NMR}\left(600 \mathrm{MHz}, \mathrm{CDCl}_{3}\right) \delta 7.41$ 7.26 (m, 5H), 4.93-4.90 (dd, $J=8.34 \mathrm{~Hz}, 4.39 \mathrm{~Hz}, 1 \mathrm{H}), 4.16$ (d, $J=4.25 \mathrm{~Hz}, 1 \mathrm{H}), 3.68$ (s, $3 \mathrm{H}), 3.50-3.48(\mathrm{dd}, J=8.78 \mathrm{~Hz}, 6.44 \mathrm{~Hz}, 1 \mathrm{H}), 3.12-3.08(\mathrm{~m}, 1 \mathrm{H}), 2.71-2.65(\mathrm{~m}, 1 \mathrm{H})$, 2.57-2.54 (dd, $J=10.98 \mathrm{~Hz}, 8.78 \mathrm{~Hz}, 1 \mathrm{H}), 2.46-2.41$ (m, 3H), 1.03 (t, $J=7.17 \mathrm{~Hz}, 3 \mathrm{H})$; ${ }^{13} \mathrm{C}-\mathrm{NMR}\left(150 \mathrm{MHz}, \mathrm{CDCl}_{3}\right) \delta 171.54,140.44,128.77,128.16,127.17,95.49,73.10$, 56.35, 51.95, 47.50, 37.63, 32.13, 13.45; HRMS Calculated for $\mathrm{C}_{15} \mathrm{H}_{20} \mathrm{~N}_{2} \mathrm{O}_{4}[\mathrm{M}+\mathrm{H}]^{+}$: 293.1457, Found: 293.1339.

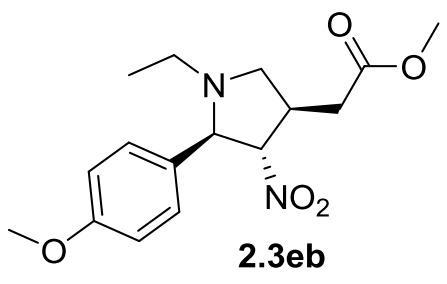

\section{Methyl 2-((3R, 4S, 5R)-1-ethyl-5-(4-methoxyphenyl)-4-nitropyrrolidin-3-yl) acetate} (2.3eb) was purified by flash chromatography (Hexane/EtOAc $=7: 1$, v/v) as light yellow liquid. Reaction time $4 \mathrm{hr}$; Isolated yield 76\%, dr > 99:1; ${ }^{1} \mathrm{H}-\mathrm{NMR}(600 \mathrm{MHz}$, $\left.\mathrm{CDCl}_{3}\right) \delta 7.25(\mathrm{~d}, J=8.64 \mathrm{~Hz}, 2 \mathrm{H}), 6.85(\mathrm{~d}, J=8.74 \mathrm{~Hz}, 2 \mathrm{H}), 4.88-4.86(\mathrm{dd}, J=8.49 \mathrm{~Hz}$, $4.68 \mathrm{~Hz}, 1 \mathrm{H}), 4.06(\mathrm{~d}, J=4.68 \mathrm{~Hz}, 1 \mathrm{H}), 3.78(\mathrm{~s}, 3 \mathrm{H}), 3.66(\mathrm{~s}, 3 \mathrm{H}), 3.47-3.45$ (dd, $J=$ $8.64 \mathrm{~Hz}, 6.44 \mathrm{~Hz}, 1 \mathrm{H}), 3.09-3.07$ (m, 1H), 2.66-2.61 (m, 1H), 2.51-2.48 (dd, $J=10.98 \mathrm{~Hz}$, $8.78 \mathrm{~Hz}, 1 \mathrm{H}), 2.44-2.40(\mathrm{dd}, J=7.32 \mathrm{~Hz}, 3.51 \mathrm{~Hz}, 2 \mathrm{H}), 2.39-2.35(\mathrm{~m}, 1 \mathrm{H}), 1.01(\mathrm{t}, J$ $=7.17 \mathrm{~Hz}, 3 \mathrm{H}) ;{ }^{13} \mathrm{C}-\mathrm{NMR}\left(150 \mathrm{MHz}, \mathrm{CDCl}_{3}\right) \delta 171.58,159.52,132.28,128.33,114.14$, 95.54, 72.76, 56.42, 55.27, 51.93, 47.34, 37.45, 32.22, 13.39; HRMS Calculated for $\mathrm{C}_{16} \mathrm{H}_{22} \mathrm{~N}_{2} \mathrm{O}_{5}[\mathrm{M}+\mathrm{H}]^{+}:$323.1562, Found: 323.1444. 


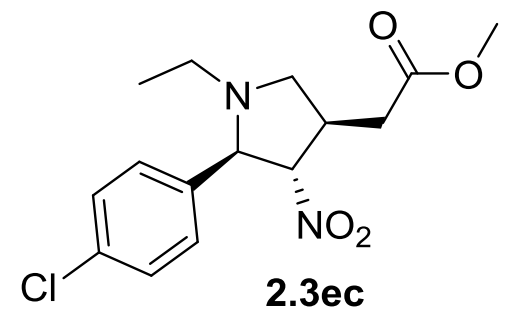

Methyl 2-((3R，4S，5R)-5-(4-chlorophenyl)-1-ethyl-4-nitropyrrolidin-3-yl) acetate (2.3ec) was purified by flash chromatography (Hexane/EtOAc $=6: 1, \mathrm{v} / \mathrm{v})$ as light yellow liquid. Reaction time $4 \mathrm{hr}$; Isolated yield $81 \%$, dr > 99:1; ${ }^{1} \mathrm{H}-\mathrm{NMR}(600 \mathrm{MHz}$, $\left.\mathrm{CDCl}_{3}\right) \delta$ 7.30-7.23 (m, 4H), 4.95-4.98 (dd, $\left.J=8.64 \mathrm{~Hz}, 5.85 \mathrm{~Hz}, 1 \mathrm{H}\right), 4.25(\mathrm{~d}, J=8.64$ $\mathrm{Hz}, 1 \mathrm{H}), 3.81(\mathrm{~d}, J=9.08 \mathrm{~Hz}, 1 \mathrm{H}), 3.65(\mathrm{~s}, 3 \mathrm{H}), 3.49-3.46(\mathrm{~m}, 1 \mathrm{H}), 2.61-2.50(\mathrm{~m}, 3 \mathrm{H})$, 2.05-1.99 (m, 2H), $1.03(\mathrm{t}, J=7.17 \mathrm{~Hz}, 3 \mathrm{H}) ;{ }^{13} \mathrm{C}-\mathrm{NMR}\left(150 \mathrm{MHz}, \mathrm{CDCl}_{3}\right) \delta 171.48$, 134.40, 134.11, 129.49, 128.68, 94.75, 72.05, 56.75, 51.92, 47.63, 38.01, 35.73, 12.94; HRMS Calculated for $\mathrm{C}_{15} \mathrm{H}_{19} \mathrm{ClN}_{2} \mathrm{O}_{4}[\mathrm{M}+\mathrm{H}]^{+}$: 328.1004, Found: 327.0949 .

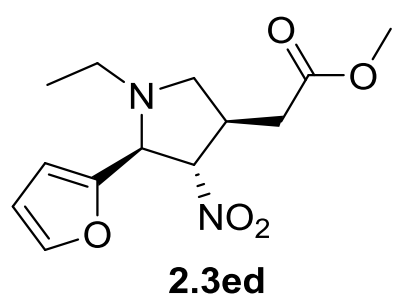

Methyl 2-((3R, 4S, 5S)-1-ethyl-5-(furan-2-yl)-4-nitropyrrolidin-3-yl) acetate (2.3ed) was purified by flash chromatography $(\mathrm{Hexane} / \mathrm{EtOAc}=6: 1$, v/v) as light yellow liquid. Reaction time $4 \mathrm{hr}$; Isolated yield 76\%, dr > 99:1; ${ }^{1} \mathrm{H}-\mathrm{NMR}\left(600 \mathrm{MHz}, \mathrm{CDCl}_{3}\right) \delta 7.37$ (d, $J=3.07 \mathrm{~Hz}, 1 \mathrm{H}), 6.30-6.28(\mathrm{~m}, 2 \mathrm{H}), 5.16-5.14(\mathrm{dd}, J=8.05 \mathrm{~Hz}, 3.66 \mathrm{~Hz}, 1 \mathrm{H}), 4.26(\mathrm{~d}, J$ $=3.66 \mathrm{~Hz}, 1 \mathrm{H}), 3.67(\mathrm{~s}, 3 \mathrm{H}), 3.41-3.39(\mathrm{dd}, J=8.78 \mathrm{~Hz}, 6.44 \mathrm{~Hz}, 1 \mathrm{H}), 3.17-3.13(\mathrm{~m}, 1 \mathrm{H})$, 2.80-2.77 (m, 1H), 2.55-2.49 (m, 2H), $2.40(\mathrm{t}, J=5.56 \mathrm{~Hz}, 2 \mathrm{H}), 2.03(\mathrm{t}, J=7.32 \mathrm{~Hz}, 3 \mathrm{H})$; ${ }^{13} \mathrm{C}-\mathrm{NMR}\left(150 \mathrm{MHz}, \mathrm{CDCl}_{3}\right) \delta 171.34,152.43,142.96,110.24,108.34,92.15,66.17$, 55.98, 51.97, 47.91, 37.94, 32.01, 13.31; HRMS Calculated for $\mathrm{C}_{13} \mathrm{H}_{18} \mathrm{~N}_{2} \mathrm{O}_{5}[\mathrm{M}+\mathrm{H}]^{+}$: 283.1249, Found: 283.4311. 


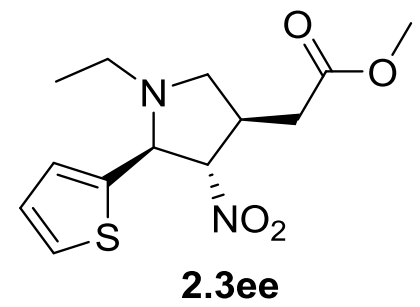

Methyl 2-((3R, 4S, 5S)-1-ethyl-4-nitro-5-(thiophen-2-yl)pyrrolidin-3-yl) acetate (2.3ee) was purified by flash chromatography (Hexane/EtOAc $=6: 1$, v/v) as light yellow liquid. Reaction time $4 \mathrm{hr}$; Isolated yield 76\%, dr > 99:1; ${ }^{1} \mathrm{H}-\mathrm{NMR}(600 \mathrm{MHz}$, $\left.\mathrm{CDCl}_{3}\right) \delta 7.24(\mathrm{t}, J=3.66 \mathrm{~Hz}, 1 \mathrm{H}), 6.99(\mathrm{~d}, J=3.51 \mathrm{~Hz}, 1 \mathrm{H}), 6.93(\mathrm{~d}, J=3.56 \mathrm{~Hz}, 1 \mathrm{H})$, 5.02-4.99 (dd, $J=8.64 \mathrm{~Hz}, 6.44 \mathrm{~Hz}, 1 \mathrm{H}), 4.25(\mathrm{~d}, J=8.78 \mathrm{~Hz}, 1 \mathrm{H}), 3.66$ (s, 3H), 3.62 (t, $J=8.64 \mathrm{~Hz}, 1 \mathrm{H}), 3.52-3.50(\mathrm{~m}, 1 \mathrm{H}), 2.76-2.73(\mathrm{~m}, 1 \mathrm{H}), 2.56-2.54(\mathrm{~m}, 2 \mathrm{H}), 2.16-2.08(\mathrm{~m}$, 2H), $1.06(\mathrm{t}, J=7.17 \mathrm{~Hz}, 3 \mathrm{H}) ;{ }^{13} \mathrm{C}-\mathrm{NMR}\left(150 \mathrm{MHz}, \mathrm{CDCl}_{3}\right) \delta 171.46,139.34,135.00$, 126.82, 126.10, 94.01, 67.46, 56.35, 51.92, 47.91, 37.64, 35.66, 12.85; HRMS Calculated for $\mathrm{C}_{13} \mathrm{H}_{18} \mathrm{~N}_{2} \mathrm{O}_{4} \mathrm{~S}[\mathrm{M}+\mathrm{H}]^{+}: 299.1021$, Found: 299.0903 .

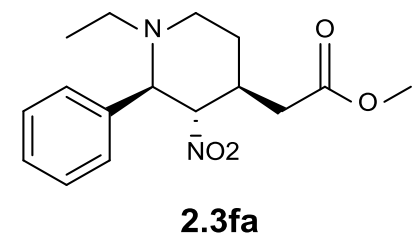

Methyl 2-((2R, 3S, 4S)-1-ethyl-3-nitro-2-phenylpiperidin-4-yl) acetate (2.3fa) was purified by flash chromatography (Hexane/EtOAc $=10: 1, \mathrm{v} / \mathrm{v})$ as light yellow liquid. Reaction time $4 \mathrm{hr}$; Isolated yield 74\%, $\mathrm{dr}=3: 1 ;{ }^{1} \mathrm{H}-\mathrm{NMR}\left(600 \mathrm{MHz}, \mathrm{CDCl}_{3}\right) \delta 7.36-$ $7.26(\mathrm{~m}, 5 \mathrm{H}), 4.44(\mathrm{t}, J=9.95 \mathrm{~Hz}, 1 \mathrm{H}), 3.68(\mathrm{~s}, 3 \mathrm{H}), 3.60(\mathrm{~d}, J=9.66 \mathrm{~Hz}, 1 \mathrm{H}), 3.20-3.06$ (br m, 1H), 2.52-2.42 (m, 2H), 2.38-2.35 (m, 3H), 2.11-2.05 (m, 3H), $0.91(\mathrm{t}, J=7.03 \mathrm{~Hz}$, $3 \mathrm{H}) ;{ }^{13} \mathrm{C}-\mathrm{NMR}\left(150 \mathrm{MHz}, \mathrm{CDCl}_{3}\right) \delta 171.16,138.00,128.79,128.59,128.18,95.32$, 70.12, 63.76, 51.81, 50.54, 48.01, 37.64, 36.77, 31.79, 10.54; HRMS Calculated for $\mathrm{C}_{16} \mathrm{H}_{22} \mathrm{~N}_{2} \mathrm{O}_{4}[\mathrm{M}+\mathrm{H}]^{+}:$307.1613, Found: 307.1652 .

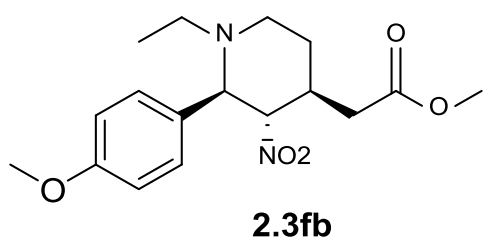


Methyl 2-((2R, 3S, 4S)-1-ethyl-2-(4-methoxyphenyl)-3-nitropiperidin-4-yl) acetate (2.3fb) was purified by flash chromatography (Hexane/EtOAc $=10: 1$, v/v) as light yellow liquid. Reaction time $4 \mathrm{hr}$; Isolated yield 68\%, dr $=3: 1 ;{ }^{1} \mathrm{H}-\mathrm{NMR}(600 \mathrm{MHz}$, $\left.\mathrm{CDCl}_{3}\right) \delta 7.14(\mathrm{~d}, J=8.78 \mathrm{~Hz}, 2 \mathrm{H}), 6.85(\mathrm{~d}, J=7.32 \mathrm{~Hz}, 2 \mathrm{H}), 4.45-4.36(\mathrm{~m}, 1 \mathrm{H}), 3.78(\mathrm{~s}$, $3 \mathrm{H}), 3.67$ (s, 3H), 3.58-3.50 (m, 1H), 3.12-3.08 (m, 1H), 2.63-2.40 (m, 3H), 2.38-2.20 (m, $3 \mathrm{H}), 2.11-2.06(\mathrm{~m}, 2 \mathrm{H}), 0.88(\mathrm{t}, J=6.59 \mathrm{~Hz}, 3 \mathrm{H}) ;{ }^{13} \mathrm{C}-\mathrm{NMR}\left(150 \mathrm{MHz}, \mathrm{CDCl}_{3}\right) \delta 171.17$, 129.82 , 129.24, 114.15, 112.92, 95.40, 69.48, 63.09, 55.18, 51.80, 50.60, 47.83, 37.40, 36.82, 29.23; HRMS Calculated for $\mathrm{C}_{17} \mathrm{H}_{24} \mathrm{~N}_{2} \mathrm{O}_{5}[\mathrm{M}+\mathrm{H}]^{+}: 337.1719$, Found: 337.1757.

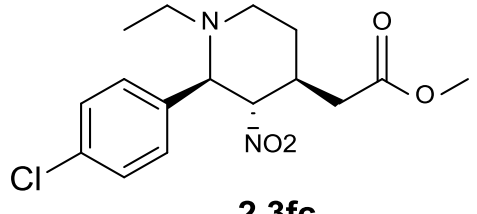

2.3fc

Methyl 2-((2R，3S，4S)-2-(4-chlorophenyl)-1-ethyl-3-nitropiperidin-4-yl) acetate (2.3fc) was purified by flash chromatography (Hexane/EtOAc $=10: 1$, v/v) as light yellow liquid. Reaction time $4 \mathrm{hr}$; Isolated yield 73\%, dr $=3: 1 ;{ }^{1} \mathrm{H}-\mathrm{NMR}(600 \mathrm{MHz}$, $\left.\mathrm{CDCl}_{3}\right) \delta 7.29(\mathrm{~d}, J=6.73 \mathrm{~Hz}, 2 \mathrm{H}), 7.24(\mathrm{~d}, J=8.05 \mathrm{~Hz}, 2 \mathrm{H}), 4.38(\mathrm{t}, J=9.95 \mathrm{~Hz}, 1 \mathrm{H})$, 3.68 (s, 3H), 3.58 (d, $J=8.78 \mathrm{~Hz}, 1 \mathrm{H}), 3.11$ (d, $J=10.10 \mathrm{~Hz}, 1 \mathrm{H}), 2.58-2.50(\mathrm{~m}, 2 \mathrm{H})$, 2.45-2.22 (m, 3H), 2.11-2.04 (m, 2H), $1.84(\mathrm{~d}, J=13.76 \mathrm{~Hz}, 1 \mathrm{H}), 0.88(\mathrm{t}, J=7.06 \mathrm{~Hz}$, $3 \mathrm{H}) ;{ }^{13} \mathrm{C}-\mathrm{NMR}\left(150 \mathrm{MHz}, \mathrm{CDCl}_{3}\right) \delta 171.07,136.21,134.36,129.47,129.09,95.17$, 69.39, 51.84, 50.48, 48.00, 37.58, 36.66, 29.11, 10.58; HRMS Calculated for $\mathrm{C}_{16} \mathrm{H}_{21} \mathrm{ClN}_{2} \mathrm{O}_{4}[\mathrm{M}+\mathrm{H}]^{+}:$342.1160, Found: 341.1262 .

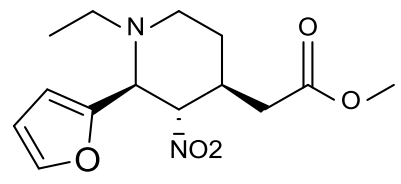

2.3fd

\section{Methyl 2-((2S, 3S, 4S)-1-ethyl-2-(furan-2-yl)-3-nitropiperidin-4-yl) acetate (2.3fd)} was purified by flash chromatography (Hexane/EtOAc $=10: 1, \mathrm{v} / \mathrm{v}$ ) as light yellow liquid. Reaction time $4 \mathrm{hr}$; Isolated yield 72\%, dr $=3: 1 ;{ }^{1} \mathrm{H}-\mathrm{NMR}\left(600 \mathrm{MHz}, \mathrm{CDCl}_{3}\right) \delta$ $7.27(\mathrm{~d}, J=5.50 \mathrm{~Hz}, 1 \mathrm{H}), 7.05(\mathrm{~d}, J=5.70 \mathrm{~Hz}, 1 \mathrm{H}), 6.90(\mathrm{t}, J=1.02 \mathrm{~Hz}, 1 \mathrm{H}), 4.43(\mathrm{t}, J=$ $8.34 \mathrm{~Hz}, 1 \mathrm{H}), 3.66$ (s, 3H), 3.12 (d, $J=7.76 \mathrm{~Hz}, 1 \mathrm{H}), 2.65-2.55$ (m, 1H), 2.37-2.32 (m, 
3H), 2.25-2.19 (m, 4H), $2.04(\mathrm{~m}, 1 \mathrm{H}), 0.94(\mathrm{t}, J=7.17 \mathrm{~Hz}, 3 \mathrm{H}) ;{ }^{13} \mathrm{C}-\mathrm{NMR}(150 \mathrm{MHz}$, $\left.\mathrm{CDCl}_{3}\right) \delta 178.06,144.40,126.60,126.04,125.84,89.68,66.87,60.80,52.43,48.15$, 43.34, 38.35, 28.18, 11.43; HRMS Calculated for $\mathrm{C}_{14} \mathrm{H}_{20} \mathrm{~N}_{2} \mathrm{O}_{5}[\mathrm{M}+\mathrm{H}]^{+}$: 297.1406, Found: 297.1444 .

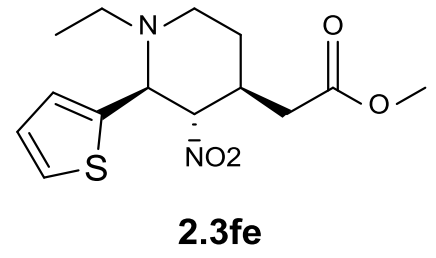

Methyl 2-((2S, 3S, 4S)-1-ethyl-3-nitro-2-(thiophen-2-yl)piperidin-4-yl) acetate (2.3fe) was purified by flash chromatography (Hexane/EtOAc $=10: 1, \mathrm{v} / \mathrm{v})$ as light yellow liquid. Reaction time $4 \mathrm{hr}$; Isolated yield $69 \%, \mathrm{dr}=3: 1 ;{ }^{1} \mathrm{H}-\mathrm{NMR}\left(600 \mathrm{MHz}, \mathrm{CDCl}_{3}\right) \delta$ 7.29 (d, $J=4.42 \mathrm{~Hz}, 1 \mathrm{H}), 7.25$ (t, $J=3.84 \mathrm{~Hz}, 1 \mathrm{H}), 6.99(\mathrm{~d}, J=5.12 \mathrm{~Hz}, 1 \mathrm{H}), 4.43$ (t, $J=$ $8.24 \mathrm{~Hz}, 1 \mathrm{H}), 3.96(\mathrm{~d}, J=6.73 \mathrm{~Hz}, 1 \mathrm{H}), 3.65$ (s, 3H), 3.13-3.11 (m, 1H), 2.66-2.62 (m, $1 \mathrm{H}), 2.57-2.53(\mathrm{~m}, 1 \mathrm{H}), 2.37-2.30(\mathrm{~m}, 2 \mathrm{H}), 2.26-2.16(\mathrm{~m}, 2 \mathrm{H}), 2.06-2.02(\mathrm{~m}, 2 \mathrm{H}), 0.94(\mathrm{t}$, $J=6.74 \mathrm{~Hz}, 3 \mathrm{H}) ;{ }^{13} \mathrm{C}-\mathrm{NMR}\left(150 \mathrm{MHz}, \mathrm{CDCl}_{3}\right) \delta 171.28,135.06,128.66,127.88,126.68$, 94.85, 65.65, 52.06, 50.82, 48.46, 41.61, 37.79, 29.18, 11.02; HRMS Calculated for $\mathrm{C}_{14} \mathrm{H}_{20} \mathrm{~N}_{2} \mathrm{O}_{4} \mathrm{~S}[\mathrm{M}+\mathrm{H}]^{+}:$313.1177, Found: 313.1216.

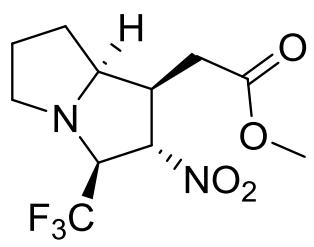

2.4aa

Methyl 2-((1R, 2S, 3S, 7aS)-2-nitro-3-(trifluoromethyl)hexahydro-1H-pyrrolizin-1-yl) acetate (2.4aa) was purified by flash chromatography (Hexane/EtOAc $=7: 1, \mathrm{v} / \mathrm{v}$ ) as light yellow liquid. Reaction time $4 \mathrm{hr}$; Isolated yield $86 \%$, $\mathrm{dr}=17: 1 ;{ }^{1} \mathrm{H}-\mathrm{NMR}(600$ $\left.\mathrm{MHz}, \mathrm{CDCl}_{3}\right) \delta 5.01-4.98(\mathrm{dd}, J=9.51 \mathrm{~Hz}, 6.73 \mathrm{~Hz}, 1 \mathrm{H}), 4.07-4.01(\mathrm{~m}, 1 \mathrm{H}), 3.67(\mathrm{~s}, 3 \mathrm{H})$, 3.43-3.41 (m, 1H), 3.23-3.21 (m, 1H), 2.92-2.90 (m, 1H), 2.82-2.79 (m, 1H), 2.62-2.53 (m, 2H), 2.01-2.00 (m, 2H), 1.94-1.91 (m, 1H), 1.78-1.70 (m, 1H); ${ }^{13} \mathrm{C}-\mathrm{NMR}(150 \mathrm{MHz}$, $\left.\mathrm{CDCl}_{3}\right) \delta 170.90,124.23,91.26,70.64,69.25,55.96,52.20,48.15,35.00,30.18,26.01$; HRMS Calculated for $\mathrm{C}_{11} \mathrm{H}_{15} \mathrm{~F}_{3} \mathrm{~N}_{2} \mathrm{O}_{4}[\mathrm{M}+\mathrm{H}]^{+}:$297.1017, Found: 297.1056. 


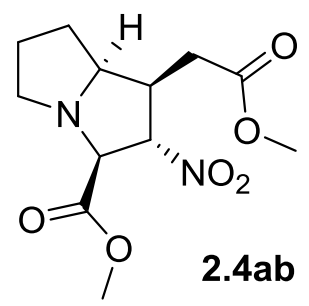

(1R, 2S, 3S, 7aS)-methyl 1-(2-methoxy-2-oxoethyl)-2-nitrohexahydro-1H-pyrrolizine -3-carboxylate (2.4ab) was purified by flash chromatography (Hexane/EtOAc $=15: 1$, $\mathrm{v} / \mathrm{v})$ as light yellow liquid. Reaction time $4 \mathrm{hr}$; Isolated yield 71\%, dr > 99:1; ${ }^{1} \mathrm{H}-\mathrm{NMR}$ $\left(600 \mathrm{MHz}, \mathrm{CDCl}_{3}\right) \delta 3.77(\mathrm{~s}, 3 \mathrm{H}), 3.70-3.66(\mathrm{~m}, 1 \mathrm{H}), 3.63(\mathrm{~s}, 3 \mathrm{H}), 3.63-3.62(\mathrm{~m}, 2 \mathrm{H})$, $4.55(\mathrm{~d}, J=7.03 \mathrm{~Hz}, 1 \mathrm{H}), 2.60-2.58(\mathrm{~m}, 1 \mathrm{H}), 2.56-2.48$ (m, 1H), 1.88-1.80 (m, 1H), 1.80 $1.72(\mathrm{~m}, 1 \mathrm{H}), 1.62-1.52(\mathrm{~m}, 2 \mathrm{H}), 1.42-1.36(\mathrm{~m}, 2 \mathrm{H}) ;{ }^{13} \mathrm{C}-\mathrm{NMR}\left(150 \mathrm{MHz}, \mathrm{CDCl}_{3}\right) \delta$ $172.73,165.72,89.87,77.60,76.89,53.81,52.64,52.48,52.09,50.47,34.39,23.50$; HRMS Calculated for $\mathrm{C}_{12} \mathrm{H}_{18} \mathrm{~N}_{2} \mathrm{O}_{6}[\mathrm{M}+\mathrm{H}]^{+}:$287.1198, Found: 287.1237.

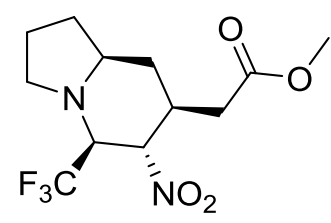

2.4ba

Methyl 2-((5S, 6S, 7S, 8aS)-6-nitro-5-(trifluoromethyl) octahydroindolizin-7-yl) acetate $(2.4 b a)$ was purified by flash chromatography (Hexane/EtOAc $=8: 1, \mathrm{v} / \mathrm{v})$ as light yellow liquid. Reaction time $4 \mathrm{hr}$; Isolated yield 84\%, dr > 99:1; ${ }^{1} \mathrm{H}-\mathrm{NMR}$ (600 $\left.\mathrm{MHz} \mathrm{CDCl}_{3}\right) \delta 4.97(\mathrm{~d}, J=2.78 \mathrm{~Hz}, 1 \mathrm{H}), 4.27-4.23(\mathrm{dd}, J=18.00 \mathrm{~Hz}, 8.93 \mathrm{~Hz}, 1 \mathrm{H})$, $3.68(\mathrm{~s}, 3 \mathrm{H}), 3.18-3.16(\mathrm{~m}, 1 \mathrm{H}), 3.09-3.04(\mathrm{~m}, 1 \mathrm{H}), 2.62-2.58(\mathrm{~m}, 1 \mathrm{H}), 2.46-2.42(\mathrm{~m}, 1 \mathrm{H})$, 2.03-1.98 (m, 1H), 1.80-1.76 (m, 1H), 1.76-1.68 (m, 2H), 1.64-1.59 (m, 2H), 1.51-1.47 $(\mathrm{m}, 1 \mathrm{H}), 1.43-1.39(\mathrm{~m}, 1 \mathrm{H}) ;{ }^{13} \mathrm{C}-\mathrm{NMR}\left(150 \mathrm{MHz}, \mathrm{CDCl}_{3}\right) \delta 172.5,126.91,80.78,60.72$, 54.34, 52.09, 51.44, 36.95, 32.40, 32.10, 31.46, 22.73; HRMS Calculated for $\mathrm{C}_{12} \mathrm{H}_{17} \mathrm{~F}_{3} \mathrm{~N}_{2} \mathrm{O}_{4}[\mathrm{M}+\mathrm{H}]^{+}:$311.1174, Found: 311.1213 . 


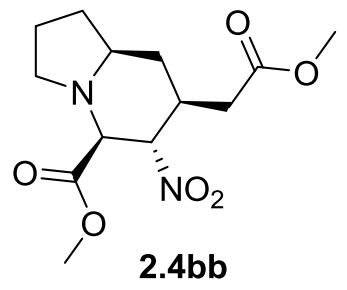

(5S, 6S, 7S, 8aS) -methyl 7-(2-methoxy-2-oxoethyl)-6-nitrooctahydroindolizine-5carboxylate $(\mathbf{2 . 4 b b})$ was purified by flash chromatography (Hexane/EtOAc $=8: 1$, v/v) as light yellow liquid. Reaction time $4 \mathrm{hr}$; Isolated yield 79\%, dr =6:1; ${ }^{1} \mathrm{H}-\mathrm{NMR}(600$ $\left.\mathrm{MHz} \mathrm{CDCl}_{3}\right) \delta$ 4.65-4.62 (dd, $\left.J=11.42 \mathrm{~Hz}, 9.66 \mathrm{~Hz}, 1 \mathrm{H}\right), 3.72$ (s, 3H), 3.67 (s, 3H), $3.37(\mathrm{~d}, J=9.66 \mathrm{~Hz}, 1 \mathrm{H}), 2.96-3.02(\mathrm{td}, J=8.78,2.44 \mathrm{~Hz}, 1 \mathrm{H}), 2.64-2.56(\mathrm{~m}, 1 \mathrm{H}), 2.47-$ $2.43(\mathrm{~m}, 1 \mathrm{H}), 2.30-2.21(\mathrm{~m}, 3 \mathrm{H}), 2.12-2.08(\mathrm{~m}, 1 \mathrm{H}), 1.90-1.73(\mathrm{~m}, 3 \mathrm{H}), 1.46-1.44(\mathrm{~m}$, $1 \mathrm{H}), 1.25-1.19(\mathrm{~m}, 1 \mathrm{H}) ;{ }^{13} \mathrm{C}-\mathrm{NMR}\left(150 \mathrm{MHz}, \mathrm{CDCl}_{3}\right) \delta 171.23,169.65,89.25,86.70$, 62.75, 59.12, 52.98, 52.12, 37.19, 36.92, 33.95, 29.56, 21.42; HRMS Calculated for $\mathrm{C}_{13} \mathrm{H}_{20} \mathrm{~N}_{2} \mathrm{O}_{6}[\mathrm{M}+\mathrm{H}]^{+}:$301.1355, Found: 301.1394 .

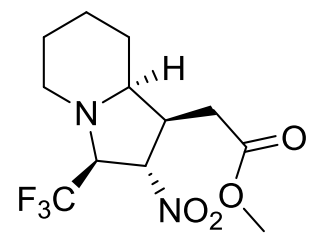

2.4ca

\begin{abstract}
Methyl 2-((1R，2S，3S，8aS)-2-nitro-3-(trifluoromethyl) octahydroindolizin-1-yl) acetate (2.4ca) was purified by flash chromatography (Hexane/EtOAc $=8: 1$, v/v) as light yellow liquid. Reaction time $4 \mathrm{hr}$; Isolated yield 91\%, dr =6:1; ${ }^{1} \mathrm{H}-\mathrm{NMR}(600 \mathrm{MHz}$, $\left.\mathrm{CDCl}_{3}\right) \delta 5.12-5.10(\mathrm{dd}, J=8.78 \mathrm{~Hz}, 3.22 \mathrm{~Hz}, 1 \mathrm{H}), 4.47-4.43(\mathrm{~m}, 1 \mathrm{H}), 3.71(\mathrm{~s}, 3 \mathrm{H}), 3.30-$ 3.26 (m, 1H), 3.24-3.17 (m, 2H), 2.93-2.85 (td, $J=16.10 \mathrm{~Hz}, 2.78 \mathrm{~Hz}, 1 \mathrm{H}), 2.47-2.38$ (m, 2H), 1.87-1.84 (m, 2H), 1.57-1.51 (m, 1H), 1.43 (d, J=13.47 Hz, 1H), 1.37-1.28 (m, 1H), 1.24-1.15 (m, 1H); ${ }^{13} \mathrm{C}-\mathrm{NMR}\left(150 \mathrm{MHz}, \mathrm{CDCl}_{3}\right) \delta$ 171.66, 87.50, 64.36, 64.16, 61.67, 52.29, 47.35, 41.27, 30.06, 24.81, 23.77, 21.72; HRMS Calculated for $\mathrm{C}_{12} \mathrm{H}_{17} \mathrm{~F}_{3} \mathrm{~N}_{2} \mathrm{O}_{4}$ $[\mathrm{M}+\mathrm{H}]^{+}:$311.1174, Found: 311.1213 .
\end{abstract}




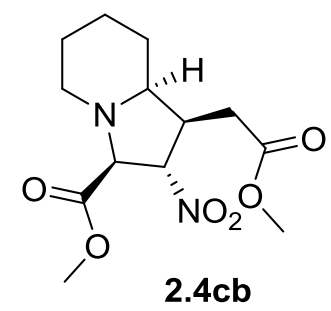

(1R, 2S, 3S, 8aS)-methyl 1-(2-methoxy-2-oxoethyl) - 2 - nitrooctahydroindolizine-3carboxylate $\mathbf{( 2 . 4 c b )}$ was purified by flash chromatography $($ Hexane/EtOAc $=14: 1, \mathrm{v} / \mathrm{v})$ as light yellow liquid. Reaction time $4 \mathrm{hr}$; Isolated yield 78\%, dr > 99:1; ${ }^{1} \mathrm{H}-\mathrm{NMR}$ (600 $\left.\mathrm{MHz}, \mathrm{CDCl}_{3}\right) \delta 4.92-4.91$ (dd, $\left.J=5.56 \mathrm{~Hz}, 1.90 \mathrm{~Hz}, 1 \mathrm{H}\right), 4.28-4.27$ (m, 1H), 3.73 (s, 3H), 3.65 (s, 3H), 2.96-2.94 (m, 1H), 2.83-2.78 (m, 1H), 2.62-2.55 (m, 2H), 2.44 (t, J = 10.39 $\mathrm{Hz}, 1 \mathrm{H}), 2.22$ (t, $J=11.56 \mathrm{~Hz}, 1 \mathrm{H}), 2.79(\mathrm{q}, J=7.46 \mathrm{~Hz}, 2 \mathrm{H}), 1.61-1.58(\mathrm{~m}, 1 \mathrm{H}), 1.53-$ $1.46(\mathrm{~m}, 1 \mathrm{H}), 1.26-1.12(\mathrm{~m}, 2 \mathrm{H}) ;{ }^{13} \mathrm{C}-\mathrm{NMR}\left(150 \mathrm{MHz}, \mathrm{CDCl}_{3}\right) \delta 171.98,170.21,90.12$, 68.83, 64.26, 52.10, 48.04, 46.48, 35.24, 30.50, 25.07, 23.59; HRMS Calculated for $\mathrm{C}_{13} \mathrm{H}_{20} \mathrm{~N}_{2} \mathrm{O}_{6}[\mathrm{M}+\mathrm{H}]^{+}:$301.1355, Found: 301.1394 .

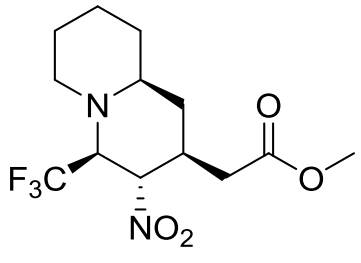

2.4da

\section{Methyl 2-((2S, 3S, 4S, 9aS)-3-nitro-4-(trifluoromethyl)octahydro-1H-quinolizin-2-yl)} acetate (2.4da) was purified by flash chromatography (Hexane/EtOAc $=10: 1, \mathrm{v} / \mathrm{v})$ as light yellow liquid. Reaction time $4 \mathrm{hr}$; Isolated yield 86\%, dr $=15: 1 ;{ }^{1} \mathrm{H}-\mathrm{NMR}(600$ $\left.\mathrm{MHz}, \mathrm{CDCl}_{3}\right) \delta 5.02-4.98(\mathrm{~m}, 1 \mathrm{H}), 4.19-4.12(\mathrm{~m}, 1 \mathrm{H}), 3.69(\mathrm{~s}, 3 \mathrm{H}), 2.92$ (t, $J=10.54 \mathrm{~Hz}$, $1 \mathrm{H}), 2.80(\mathrm{~d}, J=11.86 \mathrm{~Hz}, 1 \mathrm{H}), 2.75-2.69(\mathrm{~m}, 3 \mathrm{H}), 2.60-2.53(\mathrm{~m}, 2 \mathrm{H}), 1.71-1.57(\mathrm{~m}, 2 \mathrm{H})$, 1.44-1.39 (m, 2H), 1.27-1.22 (m, 2H), 1.14-1.06 (m, 1H); ${ }^{13} \mathrm{C}-\mathrm{NMR}\left(150 \mathrm{MHz}, \mathrm{CDCl}_{3}\right) \delta$ $172.38,126.04,81.92,77.49,65.23,61.02,53.21,52.68,52.06,36.76,34.75,33.35$, 30.37, 26.59, 23.99; HRMS Calculated for $\mathrm{C}_{13} \mathrm{H}_{19} \mathrm{~F}_{3} \mathrm{~N}_{2} \mathrm{O}_{4}[\mathrm{M}+\mathrm{H}]^{+}$: 325.1330, Found: 325.1369 . 


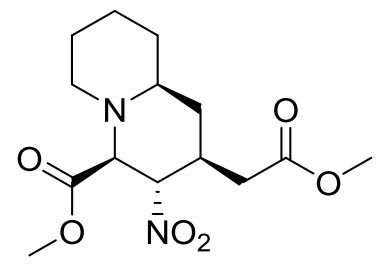

2.4db

(2S, 3S, 4S, 9aS)-methyl 2-(2-methoxy-2-oxoethyl)-3-nitrooctahydro-1H-quinolizine4-carboxylate $\mathbf{( 2 . 4 d b )}$ was purified by flash chromatography (Hexane/EtOAc = $16: 1$, v/v) as light yellow liquid. Reaction time $4 \mathrm{hr}$; Isolated yield 84\%, dr = 17:1; ${ }^{1} \mathrm{H}-\mathrm{NMR}$ $\left(600 \mathrm{MHz}, \mathrm{CDCl}_{3}\right) \delta 4.75-4.72(\mathrm{dd}, J=11.86 \mathrm{~Hz}, 4.98 \mathrm{~Hz}, 1 \mathrm{H}), 4.02(\mathrm{~d}, J=5.12 \mathrm{~Hz}, 1 \mathrm{H})$, $3.66(\mathrm{~s}, 3 \mathrm{H}), 3.65(\mathrm{~s}, 3 \mathrm{H}), 3.10-3.07(\mathrm{~m}, 1 \mathrm{H}), 2.73-2.71(\mathrm{~m}, 1 \mathrm{H}), 2.43(\mathrm{~d}, J=15.52 \mathrm{~Hz}$, 1H), 2.34 (t, $J=11.71 \mathrm{~Hz}, 1 \mathrm{H}), 2.19$ (q, $J=8.49 \mathrm{~Hz}, 1 \mathrm{H}), 1.91(\mathrm{~m}, 1 \mathrm{H}), 1.68-1.45$ (m, $6 \mathrm{H}), 1.27-1.22$ (br m, 1H), 1.08-1.02 (m, 1H); ${ }^{13} \mathrm{C}-\mathrm{NMR}\left(150 \mathrm{MHz}, \mathrm{CDCl}_{3}\right) \delta 171.44$, $169.30,88.26,65.10,52.89,25.66,51.98,51.82,37.07,33.50,31.15,26.06,24.02$; HRMS Calculated for $\mathrm{C}_{14} \mathrm{H}_{22} \mathrm{~N}_{2} \mathrm{O}_{6}[\mathrm{M}+\mathrm{H}]^{+}:$315.1511, Found: 315.1550.

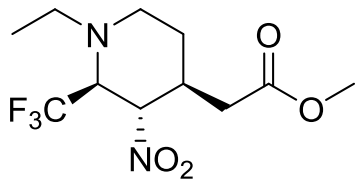

2.4ea

Methyl 2-((2S，3S，4S)-1-ethyl-3-nitro-2-(trifluoromethyl)piperidin-4-yl) acetate (2.4ea) was purified by flash chromatography (Hexane/EtOAc $=11: 1, \mathrm{v} / \mathrm{v})$ as light yellow liquid. Reaction time $4 \mathrm{hr}$; Isolated yield 86\%, dr > 99:1; ${ }^{1} \mathrm{H}-\mathrm{NMR}(600 \mathrm{MHz}$, $\left.\mathrm{CDCl}_{3}\right) \delta 5.00-4.96(\mathrm{~m}, 1 \mathrm{H}), 4.20-4.10(\mathrm{dd}, J=18.00 \mathrm{~Hz}, 8.93 \mathrm{~Hz}, 1 \mathrm{H}), 3.68(\mathrm{~s}, 3 \mathrm{H})$, $2.96(\mathrm{t}, J=12.30 \mathrm{~Hz}, 1 \mathrm{H}), 2.85-2.81(\mathrm{~m}, 2 \mathrm{H}), 2.75-2.72(\mathrm{~m}, 1 \mathrm{H}), 2.68-2.64(\mathrm{~m}, 1 \mathrm{H})$, 2.57-2.51 (m, 2H), 2.01-1.98 (m, 1H), $1.54(\mathrm{~d}, J=13.17 \mathrm{~Hz}, 1 \mathrm{H}), 1.03(\mathrm{t}, J=7.18 \mathrm{~Hz}$, $3 \mathrm{H}) ;{ }^{13} \mathrm{C}-\mathrm{NMR}\left(150 \mathrm{MHz}, \mathrm{CDCl}_{3}\right) \delta 172.20,125.28,81.65,61.98,61.80,52.04,49.46$, 45.10, 36.82, 31.38, 25.23, 13.55; HRMS Calculated for $\mathrm{C}_{11} \mathrm{H}_{17} \mathrm{~F}_{3} \mathrm{~N}_{2} \mathrm{O}_{4}[\mathrm{M}+\mathrm{H}]^{+}$: 299.1174, Found: 299.1213. 


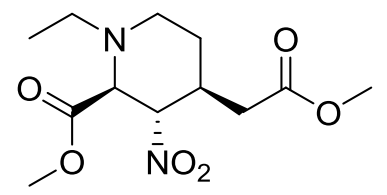

2.4eb

(2S, 3S, 4S)-methyl 1-ethyl-4-(2-methoxy-2-oxoethyl) - 3 - nitropiperidine - 2 carboxylate (2.4eb) was purified by flash chromatography $($ Hexane/EtOAc $=15: 1, \mathrm{v} / \mathrm{v})$ as light yellow liquid. Reaction time $4 \mathrm{hr}$; Isolated yield 71\%, dr > 99:1; ${ }^{1} \mathrm{H}-\mathrm{NMR}$ (600 $\left.\mathrm{MHz} \mathrm{CDCl}_{3}\right) \delta 5.04(\mathrm{t}, J=3.66 \mathrm{~Hz}, 1 \mathrm{H}), 4.31(\mathrm{~d}, J=3.51 \mathrm{~Hz}, 1 \mathrm{H}), 3.75(\mathrm{~s}, 3 \mathrm{H}), 3.67(\mathrm{~s}$, $3 \mathrm{H}), 3.10-2.85(\mathrm{~m}, 2 \mathrm{H}), 2.70-2.58(\mathrm{~m}, 3 \mathrm{H}), 2.50-2.40(\mathrm{~m}, 1 \mathrm{H}), 2.10-1.90(\mathrm{~m}, 1 \mathrm{H}), 1.24-$ $1.23(\mathrm{~m}, 2 \mathrm{H}), 0.99(\mathrm{t}, J=7.17 \mathrm{~Hz}, 3 \mathrm{H}) ;{ }^{13} \mathrm{C}-\mathrm{NMR}\left(150 \mathrm{MHz}, \mathrm{CDCl}_{3}\right) \delta 172.40,170.22$, 84.69, 63.62, 52.01, 49.16, 46.24, 36.20, 32.29, 26.64, 12.95; HRMS Calculated for $\mathrm{C}_{12} \mathrm{H}_{20} \mathrm{~N}_{2} \mathrm{O}_{6}[\mathrm{M}+\mathrm{H}]^{+}:$289.1355, Found: 289.1394.

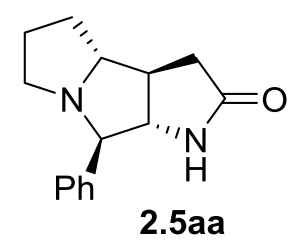

(3aS, 3bR, 8R, 8aS)-8-phenyloctahydropyrrolo[3,2-a]pyrrolizin-2(1H)-one (2.5aa) was purified by flash chromatography $\left(\mathrm{CH}_{2} \mathrm{Cl}_{2} / \mathrm{MeOH}=25: 1\right.$, v/v) as white semisolid. Reaction time $8 \mathrm{hr}$; Isolated yield 81\%; ${ }^{1} \mathrm{H}-\mathrm{NMR}\left(600 \mathrm{MHz}, \mathrm{CDCl}_{3}\right) \delta 7.36-7.33(\mathrm{~m}, 4 \mathrm{H})$, 7.29-7.24 (m, 1H), $6.83(\mathrm{~s}, 1 \mathrm{H}), 4.35-4.32$ (dd, $J=8.64 \mathrm{~Hz}, 6.15 \mathrm{~Hz}, 1 \mathrm{H}), 3.79$ (d, $J=$ $6.15 \mathrm{~Hz}, 1 \mathrm{H}), 3.12$ (q, $J=7.03 \mathrm{~Hz}, 1 \mathrm{H}), 2.72-2.67$ (m, 1H), 2.56-2.51 (m, 2H), 2.30-2.25 (m, 2H), 2.08-2.04 (m, 1H), 2.00-1.97 (m, 1H), 1.93-1.89 (m, 1H), 1.60-1.59 (m, 1H); ${ }^{13} \mathrm{C}-\mathrm{NMR}\left(150 \mathrm{MHz}, \mathrm{CDCl}_{3}\right) \delta 177.76,138.23,129.02,128.28,128.01,73.62,72.92$, 67.04, 47.03, 42.11, 34.46, 28.54, 26.20; HRMS Calculated for $\mathrm{C}_{15} \mathrm{H}_{18} \mathrm{~N}_{2} \mathrm{O}[\mathrm{M}+\mathrm{H}]^{+}$: 243.1453, Found: 243.1491.

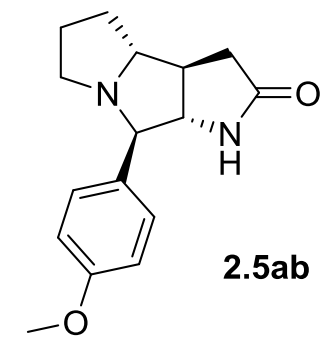


(3aS, 3bR, 8R, 8aS)-8-(4-methoxyphenyl)octahydropyrrolo[3,2-a]pyrrolizin-2(1H)one (2.5ab) was purified by flash chromatography $\left(\mathrm{CH}_{2} \mathrm{Cl}_{2} / \mathrm{MeOH}=20: 1, \mathrm{v} / \mathrm{v}\right)$ as white semisolid. Reaction time $8 \mathrm{hr}$; Isolated yield 76\%; ${ }^{1} \mathrm{H}-\mathrm{NMR}\left(600 \mathrm{MHz}, \mathrm{CDCl}_{3}\right) \delta 7.32(\mathrm{~d}$, $J=8.64 \mathrm{~Hz}, 2 \mathrm{H}), 6.89$ (d, $J=8.64 \mathrm{~Hz}, 1 \mathrm{H}), 4.93(\mathrm{~s}, 1 \mathrm{H}), 4.23-4.21$ (dd, $J=6.59 \mathrm{~Hz}, 5.12$ $\mathrm{Hz}, 1 \mathrm{H}), 3.79$ (s, 3H), 3.39 (t, J = 7.46 Hz, 1H), 2.97-2.91 (m, 1H), 2.88-2.83 (m, 1H), 2.69-2.64 (m, 2H), 2.38-2.35 (dd, $J=17.42 \mathrm{~Hz}, 15.52 \mathrm{~Hz}, 1 \mathrm{H}), 2.08-2.03(\mathrm{~m}, 1 \mathrm{H}), 2.01$ $1.94(\mathrm{~m}, 2 \mathrm{H}), 1.79-1.73(\mathrm{~m}, 1 \mathrm{H}), 1.62-1.56(\mathrm{~m}, 2 \mathrm{H}) ;{ }^{13} \mathrm{C}-\mathrm{NMR}\left(150 \mathrm{MHz}, \mathrm{CDCl}_{3}\right) \delta$ 176.67, 171.32, 159.73, 129.43, 114.46, 73.64, 64.90, 60.63, 55.64, 51.89, 42.62, 37.99, 31.57, 24.98; HRMS Calculated for $\mathrm{C}_{16} \mathrm{H}_{20} \mathrm{~N}_{2} \mathrm{O}_{2}[\mathrm{M}+\mathrm{H}]^{+}: 273.1558$, Found: 273.1593 .

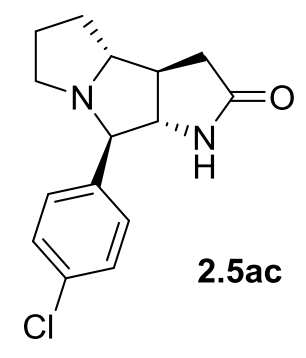

(3aS, 3bR, 8R, 8aS)-8-(4-chlorophenyl)octahydropyrrolo[3,2-a]pyrrolizin-2(1H)-one (2.5ac) was purified by flash chromatography $\left(\mathrm{CH}_{2} \mathrm{Cl}_{2} / \mathrm{MeOH}=25: 1\right.$, v/v) as white semisolid. Reaction time $8 \mathrm{hr}$; Isolated yield $84 \%$; ${ }^{1} \mathrm{H}-\mathrm{NMR}\left(600 \mathrm{MHz}, \mathrm{CDCl}_{3}\right) \delta$ 7.337.29 (m, 4H), $6.82(\mathrm{~s}, 1 \mathrm{H}), 4.24-4.21(\mathrm{dd}, J=8.78 \mathrm{~Hz}, 6.00 \mathrm{~Hz}, 1 \mathrm{H}), 3.60(\mathrm{~d}, J=5.27 \mathrm{~Hz}$, $1 \mathrm{H}), 2.97(\mathrm{~d}, J=6.73 \mathrm{~Hz}, 1 \mathrm{H}), 2.69-2.64(\mathrm{~m}, 1 \mathrm{H}), 2.56-2.51(\mathrm{~m}, 2 \mathrm{H}), 2.25-2.18(\mathrm{~m}, 2 \mathrm{H})$, 2.05-2.00 (m, 2H), 1.97-1.92 (m, 1H), 1.60-1.56 (m, 1H); ${ }^{13} \mathrm{C}-\mathrm{NMR}\left(150 \mathrm{MHz}, \mathrm{CDCl}_{3}\right) \delta$ 177.82, 137.57, 133.96, 129.17, 129.15, 74.27, 72.62, 68.32, 46.73, 41.45, 34.20, 27.99, 26.50; HRMS Calculated for $\mathrm{C}_{15} \mathrm{H}_{17} \mathrm{ClN}_{2} \mathrm{O}[\mathrm{M}+\mathrm{H}]^{+}: 278.1000$, Found: 277.1102 .

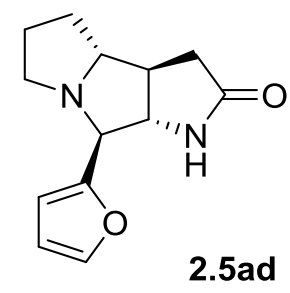

(3aS, 3bR， 8S， 8aS)-8-(furan-2-yl)octahydropyrrolo[3,2-a]pyrrolizin-2(1H)-one (2.5ad) was purified by flash chromatography $\left(\mathrm{CH}_{2} \mathrm{Cl}_{2} / \mathrm{MeOH}=20: 1\right.$, v/v $)$ as yellow semisolid. Reaction time $8 \mathrm{hr}$; Isolated yield 69\%; ${ }^{1} \mathrm{H}-\mathrm{NMR}\left(600 \mathrm{MHz}, \mathrm{CDCl}_{3}\right) \delta 7.41$ (d, 
$J=0.88 \mathrm{~Hz}, 1 \mathrm{H}), 6.45(\mathrm{~s}, 1 \mathrm{H}), 6.36-6.34(\mathrm{~m}, 1 \mathrm{H}), 4.48-4.46(\mathrm{dd}, J=8.20 \mathrm{~Hz}, 5.12 \mathrm{~Hz}$, $1 \mathrm{H}), 4.20(\mathrm{~d}, J=5.12 \mathrm{~Hz}, 1 \mathrm{H}), 3.38-3.34(\mathrm{dd}, J=12.88 \mathrm{~Hz}, 6.15 \mathrm{~Hz}, 1 \mathrm{H}), 2.84-2.82(\mathrm{~m}$, $1 \mathrm{H}), 2.62-2.52(\mathrm{~m}, 3 \mathrm{H}), 2.29-2.26(\mathrm{dd}, J=17.56 \mathrm{~Hz}, 14.04 \mathrm{~Hz}, 1 \mathrm{H}), 2.15-2.10(\mathrm{~m}, 1 \mathrm{H})$, 1.87-1.82 (m, 2H), 1.71-1.67 (m, 2H); ${ }^{13} \mathrm{C}-\mathrm{NMR}\left(150 \mathrm{MHz}, \mathrm{CDCl}_{3}\right) \delta 177.35,151.50$, 143.05, 110.65, 109.50, 73.01, 66.48, 64.35, 48.12, 43.62, 35.26, 30.06, 25.98; HRMS Calculated for $\mathrm{C}_{13} \mathrm{H}_{16} \mathrm{~N}_{2} \mathrm{O}_{2}[\mathrm{M}+\mathrm{H}]^{+}: 233.1245$, Found: 233.1284.

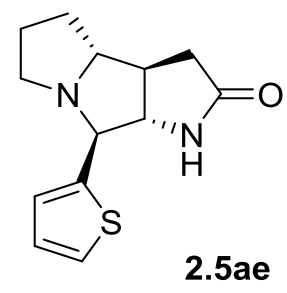

(3aS, 3bR, 8S, 8aS)-8-(thiophen-2-yl)octahydropyrrolo[3,2-a]pyrrolizin-2(1H)-one (2.5ae) was purified by flash chromatography $\left(\mathrm{CH}_{2} \mathrm{Cl}_{2} / \mathrm{MeOH}=20: 1\right.$, v/v) as brown semisolid. Reaction time $8 \mathrm{hr}$; Isolated yield 74\%; ${ }^{1} \mathrm{H}-\mathrm{NMR}\left(600 \mathrm{MHz}, \mathrm{CDCl}_{3}\right) \delta 7.29$ (d, $J=5.12 \mathrm{~Hz}, 1 \mathrm{H}), 7.05(\mathrm{~d}, J=2.93 \mathrm{~Hz}, 1 \mathrm{H}), 6.99$ (s, 1H), 6.51 (s, 1H), 4.38-4.36 (dd, $J=$ $8.64 \mathrm{~Hz}, 6.15 \mathrm{~Hz}, 1 \mathrm{H}), 4.17$ (d, $J=6.15 \mathrm{~Hz}, 1 \mathrm{H}), 3.21(\mathrm{q}, J=13.32 \mathrm{~Hz}, 6.59 \mathrm{~Hz}, 1 \mathrm{H})$, 2.97-2.75 (m, $1 \mathrm{H}), 2.63-2.55(\mathrm{~m}, 2 \mathrm{H}), 2.50-2.46(\mathrm{~m}, 1 \mathrm{H}), 2.29-2.25(\mathrm{dd}, J=17.56 \mathrm{~Hz}$, 13.47 Hz, 1H), 2.14-2.09 (m, 1H), 2.00-1.90 (m, 2H), 1.70-1.65 (m, 1H); ${ }^{13} \mathrm{C}-\mathrm{NMR}(150$ $\left.\mathrm{MHz}, \mathrm{CDCl}_{3}\right) \delta 177.56,141.71,127.20,126.14,125.82,73.44,68.83,67.53,47.41$, 42.76, 34.70, 29.22, 25.89; HRMS Calculated for $\mathrm{C}_{13} \mathrm{H}_{16} \mathrm{~N}_{2} \mathrm{OS}[\mathrm{M}+\mathrm{H}]^{+}: 249.1017$, Found: 249.1056 .

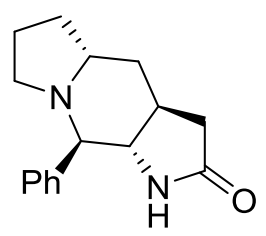

$2.5 \mathrm{ba}$

(3aS, 4aR, 9R, 9aS)-9-phenyloctahydro-1H-pyrrolo[2,3-f]indolizin-2(3H)-one (2.5ba) was purified by flash chromatography $\left(\mathrm{CH}_{2} \mathrm{Cl}_{2} / \mathrm{MeOH}=20: 1\right.$, v/v) as brown semisolid. Reaction time $8 \mathrm{hr}$; Isolated yield $84 \% ;{ }^{1} \mathrm{H}-\mathrm{NMR}\left(600 \mathrm{MHz}, \mathrm{CDCl}_{3}\right) \delta 7.30-7.24(\mathrm{~m}, 5 \mathrm{H})$, 5.38 (s, 1H), 3.31 (t, $J=8.78 \mathrm{~Hz}, 1 \mathrm{H}), 3.02(\mathrm{~d}, J=9.07 \mathrm{~Hz}, 1 \mathrm{H}), 2.73(\mathrm{t}, J=8.64 \mathrm{~Hz}$, $1 \mathrm{H}), 2.40-2.37(\mathrm{dd}, J=14.71 \mathrm{~Hz}, 5.51 \mathrm{~Hz}, 1 \mathrm{H}), 2.36-2.28(\mathrm{~m}, 1 \mathrm{H}), 2.15-2.02(\mathrm{~m}, 3 \mathrm{H})$, 
1.99-1.85 (m, 2H), 1.73-1.67 (m, 1H), 1.65-1.59 (m, 1H), 1.55-1.50 (m, 1H), 1.47-1.41 (m, 1H); ${ }^{13} \mathrm{C}-\mathrm{NMR}\left(150 \mathrm{MHz}, \mathrm{CDCl}_{3}\right) \delta 178.94,139.61,129.04,128.38,127.67,71.36$, 65.55, 65.40, 50.73, 44.07, 37.94, 32.93, 29.92, 21.33; HRMS Calculated for $\mathrm{C}_{16} \mathrm{H}_{20} \mathrm{~N}_{2} \mathrm{O}$ $[\mathrm{M}+\mathrm{H}]^{+}: 257.1609$, Found: 257.1648.

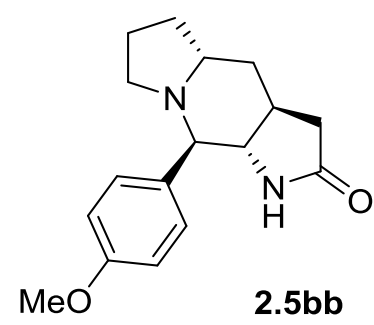

(3aS，4aR，9R，9aS)-9-(4-methoxyphenyl) octahydro-1H-pyrrolo[2,3-f]indolizin2(3H)-one (2.5bb) was purified by flash chromatography $\left(\mathrm{CH}_{2} \mathrm{Cl}_{2} / \mathrm{MeOH}=20: 1\right.$, v/v) as brown semisolid. Reaction time $8 \mathrm{hr}$; Isolated yield $76 \%$; ${ }^{1} \mathrm{H}-\mathrm{NMR}\left(600 \mathrm{MHz}, \mathrm{CDCl}_{3}\right) \delta$ $7.22(\mathrm{~d}, J=8.34 \mathrm{~Hz}, 2 \mathrm{H}), 6.85(\mathrm{~d}, J=8.34 \mathrm{~Hz}, 2 \mathrm{H}), 5.20(\mathrm{~s}, 1 \mathrm{H}), 3.77$ (s, 3H), 3.28 (t, $J$ $=6.44 \mathrm{~Hz}, 1 \mathrm{H}), 2.96(\mathrm{~d}, J=6.88 \mathrm{~Hz}, 1 \mathrm{H}), 2.71(\mathrm{t}, J=6.44 \mathrm{~Hz}, 1 \mathrm{H}), 2.39-2.36(\mathrm{dd}, J=$ $14.93 \mathrm{~Hz}, 9.07 \mathrm{~Hz}, 1 \mathrm{H}), 2.32-2.24$ (m, 1H), 2.14-2.01 (m, 3H), 1.93-1.86 (m, 3H), 1.72$1.56(\mathrm{~m}, 1 \mathrm{H}), 1.54-1.36(\mathrm{~m}, 2 \mathrm{H}) ;{ }^{13} \mathrm{C}-\mathrm{NMR}\left(150 \mathrm{MHz}, \mathrm{CDCl}_{3}\right) \delta 178.65,159.61,131.75$, $128.70,114.38,70.69,65.51,65.34,55.49,50.71,44.05,37.49,33.03,30.00,21.29$; HRMS Calculated for $\mathrm{C}_{17} \mathrm{H}_{22} \mathrm{~N}_{2} \mathrm{O}_{2}[\mathrm{M}+\mathrm{H}]^{+}:$287.1715, Found: 287.1754.

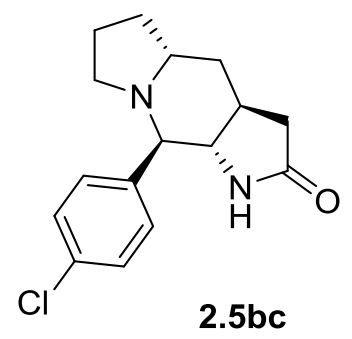

(3aS, 4aR, 9R, 9aS)-9-(4-chlorophenyl) octahydro-1H-pyrrolo[2,3-f]indolizin-2(3H)one (2.5bc) was purified by flash chromatography $\left(\mathrm{CH}_{2} \mathrm{Cl}_{2} / \mathrm{MeOH}=20: 1\right.$, v/v) as brown semisolid. Reaction time $8 \mathrm{hr}$; Isolated yield 89\%; ${ }^{1} \mathrm{H}-\mathrm{NMR}\left(600 \mathrm{MHz}, \mathrm{CDCl}_{3}\right) \delta 7.29$ (d, $J=8.64 \mathrm{~Hz}, 2 \mathrm{H}), 7.25(\mathrm{~d}, J=8.64 \mathrm{~Hz}, 2 \mathrm{H}), 5.26(\mathrm{br} \mathrm{s}, 1 \mathrm{H}), 3.21(\mathrm{t}, J=8.78 \mathrm{~Hz}, 1 \mathrm{H})$, $2.98(\mathrm{~d}, J=8.93 \mathrm{~Hz}, 1 \mathrm{H}), 2.67(\mathrm{t}, J=8.05 \mathrm{~Hz}, 1 \mathrm{H}), 2.37-2.34(\mathrm{dd}, J=14.64 \mathrm{~Hz}, 9.22 \mathrm{~Hz}$, $1 \mathrm{H}), 2.29-2.28$ (br d, 1H), 2.11-2.00 (m, 3H), 1.93-1.83 (m, 2H), 1.70-1.59 (m, 2H), 1.50- 
$1.38(\mathrm{~m}, 2 \mathrm{H}) ;{ }^{13} \mathrm{C}-\mathrm{NMR}\left(150 \mathrm{MHz}, \mathrm{CDCl}_{3}\right) \delta 178.64,138.40,133.94,129.22,129.00$, 70.63, 65.56, 65.24, 50.66, 43.95, 37.83, 32.95, 29.93, 21.33; HRMS Calculated for $\mathrm{C}_{16} \mathrm{H}_{19} \mathrm{ClN}_{2} \mathrm{O}[\mathrm{M}+\mathrm{H}]^{+}: 292.1156$, Found: 291.1288.

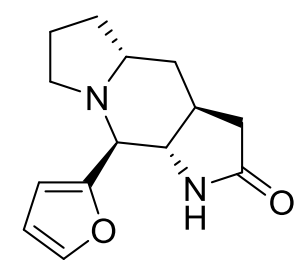

2.5bd

(3aS, 4aR, 9S, 9aS)-9-(furan-2-yl) octahydro-1H-pyrrolo[2,3-f]indolizin-2(3H)-one (2.5bd) was purified by flash chromatography $\left(\mathrm{CH}_{2} \mathrm{Cl}_{2} / \mathrm{MeOH}=20: 1\right.$, v/v) as brown semisolid. Reaction time $8 \mathrm{hr}$; Isolated yield 84\%; ${ }^{1} \mathrm{H}-\mathrm{NMR}\left(600 \mathrm{MHz}, \mathrm{CDCl}_{3}\right) \delta 7.37(\mathrm{~d}$, $J=1.32, \mathrm{~Hz}, 1 \mathrm{H}), 6.32-6.28(\mathrm{~m}, 2 \mathrm{H}), 5.47$ (s, $1 \mathrm{H}), 3.60-3.52$ (s, $1 \mathrm{H}), 3.18(\mathrm{~d}, J=8.93$ $\mathrm{Hz}, 1 \mathrm{H}), 2.76$ (br t, 1H), 2.41-2.37 (dd, $J=15.66 \mathrm{~Hz}, 9.22 \mathrm{~Hz}, 1 \mathrm{H}), 2.34-2.28(\mathrm{~m}, 1 \mathrm{H})$, $2.15(\mathrm{t}, J=12.88 \mathrm{~Hz}, 2 \mathrm{H}), 2.05-2.01(\mathrm{~m}, 2 \mathrm{H}), 1.92-1.86(\mathrm{~m}, 1 \mathrm{H}), 1.80-1.74(\mathrm{~m}, 1 \mathrm{H})$, 1.70-1.64 (m, 1H), 1.60-1.54 (m, $1 \mathrm{H}), 1.50-1.40(\mathrm{~m}, 1 \mathrm{H}) ;{ }^{13} \mathrm{C}-\mathrm{NMR}\left(150 \mathrm{MHz}, \mathrm{CDCl}_{3}\right) \delta$ 178.53, 152.22, 142.90, 110.40, 108.45, 65.41, 64.20, 62.17, 50.95, 44.14, 37.75, 32.76, 29.72, 21.17; HRMS Calculated for $\mathrm{C}_{14} \mathrm{H}_{18} \mathrm{~N}_{2} \mathrm{O}_{2}[\mathrm{M}+\mathrm{H}]^{+}$: 247.1402, Found: 247.1441.

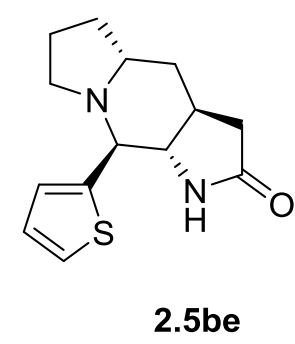

(3aS, 4aR, 9S, 9aS)-9-(thiophen-2-yl) octahydro-1H-pyrrolo[2,3-f]indolizin-2(3H)one (2.5be) was purified by flash chromatography $\left(\mathrm{CH}_{2} \mathrm{Cl}_{2} / \mathrm{MeOH}=20: 1\right.$, v/v) as brown semisolid. Reaction time $8 \mathrm{hr}$; Isolated yield 79\%; ${ }^{1} \mathrm{H}-\mathrm{NMR}\left(600 \mathrm{MHz}, \mathrm{CDCl}_{3}\right) \delta 7.23(\mathrm{~d}$, $J=5.12 \mathrm{~Hz}, 1 \mathrm{H}), 6.95(\mathrm{~d}, J=5.12 \mathrm{~Hz}, 1 \mathrm{H}), 6.90-6.88(\mathrm{dd}, J=5.12 \mathrm{~Hz}, 3.51 \mathrm{~Hz}, 1 \mathrm{H})$, $5.77(\mathrm{~s}, 1 \mathrm{H}), 3.35-3.30(\mathrm{~m}, 1 \mathrm{H}), 2.85(\mathrm{t}, J=8.93 \mathrm{~Hz}, 1 \mathrm{H}), 2.38-2.34(\mathrm{dd}, J=15.37 \mathrm{~Hz}$, $6.99 \mathrm{~Hz}, 1 \mathrm{H}), 2.29-2.28(\mathrm{~m}, 1 \mathrm{H}), 2.12(\mathrm{t}, J=12.88 \mathrm{~Hz}, 1 \mathrm{H}), 2.05-1.96(\mathrm{~m}, 3 \mathrm{H}), 1.87-1.81$ $(\mathrm{m}, 1 \mathrm{H}), 1.71-1.67(\mathrm{~m}, 1 \mathrm{H}), 1.63-1.59(\mathrm{~m}, 1 \mathrm{H}), 1.52-1.42(\mathrm{~m}, 2 \mathrm{H}) ;{ }^{13} \mathrm{C}-\mathrm{NMR}(150 \mathrm{MHz}$, 
$\left.\mathrm{CDCl}_{3}\right) \delta 179.04,143.34,126.65,125.70,125.53,66.69,66.33,65.57,50.90,43.97$, 37.91, 32.61, 29.87, 21.23; HRMS Calculated for $\mathrm{C}_{14} \mathrm{H}_{18} \mathrm{~N}_{2} \mathrm{OS}[\mathrm{M}+\mathrm{H}]^{+}: 263.1173$, Found: 263.1212 .

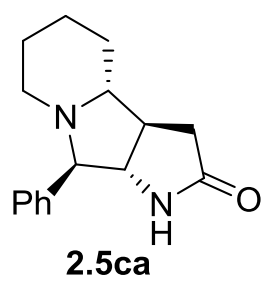

(3aS，3bR，9R，9aS)-9-phenyloctahydro-1H-pyrrolo[3,2-a]indolizin-2(3bH)-one (2.5ca) was purified by flash chromatography $\left(\mathrm{CH}_{2} \mathrm{Cl}_{2} / \mathrm{MeOH}=20: 1\right.$, v/v) as brown semisolid. Reaction time $8 \mathrm{hr}$; Isolated yield $81 \%$; ${ }^{1} \mathrm{H}-\mathrm{NMR}\left(600 \mathrm{MHz}, \mathrm{CDCl}_{3}\right) \delta$ 7.33$7.24(\mathrm{~m}, 5 \mathrm{H}), 6.30(\mathrm{~s}, 1 \mathrm{H}), 3.78-3.76(\mathrm{dd}, J=8.64 \mathrm{~Hz}, 5.12 \mathrm{~Hz}, 1 \mathrm{H}), 3.02(\mathrm{~d}, J=5.42 \mathrm{~Hz}$, $1 \mathrm{H}), 2.67(\mathrm{~d}, J=8.93 \mathrm{~Hz}, 1 \mathrm{H}), 2.58-2.46(\mathrm{~m}, 1 \mathrm{H}), 2.17-2.13(\mathrm{dd}, J=16.98 \mathrm{~Hz}, 2.20 \mathrm{~Hz}$, $1 \mathrm{H}), 1.97(\mathrm{t}, J=10.98 \mathrm{~Hz}, 1 \mathrm{H}), 1.91-1.88(\mathrm{~m}, 2 \mathrm{H}), 1.82-1.78(\mathrm{~m}, 2 \mathrm{H}), 1.55-1.53(\mathrm{~m}, 1 \mathrm{H})$, $1.45-1.40(\mathrm{~m}, 1 \mathrm{H}), 1.34-1.31(\mathrm{~m}, 1 \mathrm{H}), 1.25-1.20(\mathrm{~m}, 1 \mathrm{H}) ;{ }^{13} \mathrm{C}-\mathrm{NMR}\left(150 \mathrm{MHz}, \mathrm{CDCl}_{3}\right) \delta$ 177.70, 140.82, 128.93, 127.96, 127.80, 70.66, 65.56, 51.50, 50.93, 42.64, 33.50, 30.36, 25.43, 24.30, 22.92; HRMS Calculated for $\mathrm{C}_{16} \mathrm{H}_{20} \mathrm{~N}_{2} \mathrm{O}[\mathrm{M}+\mathrm{H}]^{+}$: 257.1609, Found: 257.1648 .

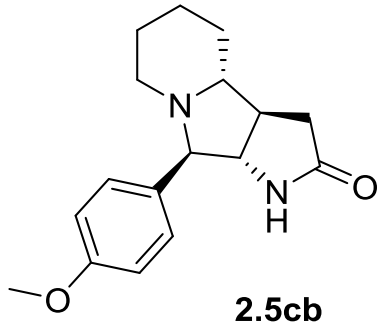

(3aS，3bR，9R，9aS)-9-(4-methoxyphenyl) octahydro-1H-pyrrolo[3,2-a]indolizin2(3bH)-one (2.5cb) was purified by flash chromatography $\left(\mathrm{CH}_{2} \mathrm{Cl}_{2} / \mathrm{MeOH}=17: 1, \mathrm{v} / \mathrm{v}\right)$ as brown semisolid. Reaction time $8 \mathrm{hr}$; Isolated yield 69\%; ${ }^{1} \mathrm{H}-\mathrm{NMR}\left(600 \mathrm{MHz}, \mathrm{CDCl}_{3}\right.$ ) $\delta 7.21(\mathrm{~d}, J=8.20 \mathrm{~Hz}, 2 \mathrm{H}), 6.90(\mathrm{~s}, 1 \mathrm{H}), 6.85(\mathrm{~d}, J=8.20 \mathrm{~Hz}, 2 \mathrm{H}), 3.76(\mathrm{~s}, 3 \mathrm{H}), 2.96(\mathrm{~d}$, $J=4.98 \mathrm{~Hz}, 1 \mathrm{H}), 2.65(\mathrm{~d}, J=9.66 \mathrm{~Hz}, 1 \mathrm{H}), 2.51-2.47(\mathrm{~m}, 2 \mathrm{H}), 2.15(\mathrm{~d}, J=14.78 \mathrm{~Hz}$, $1 \mathrm{H}), 2.10-1.86(\mathrm{~m}, 2 \mathrm{H}), 1.78-1.74(\mathrm{~m}, 2 \mathrm{H}), 1.54-1.52(\mathrm{~m}, 2 \mathrm{H}), 1.45-1.11(\mathrm{~m}, 3 \mathrm{H}) ;{ }^{13} \mathrm{C}-$ NMR (150 MHz, $\left.\mathrm{CDCl}_{3}\right) \delta 178.35,159.43,132.63,128.86,114.29,78.12,70.60,65.80$, 
55.47, 50.86, 42.40, 33.08, 30.30, 25.39, 24.30; HRMS Calculated for $\mathrm{C}_{17} \mathrm{H}_{22} \mathrm{~N}_{2} \mathrm{O}_{2}$ $[\mathrm{M}+\mathrm{H}]^{+}:$287.1715, Found: 287.1754 .

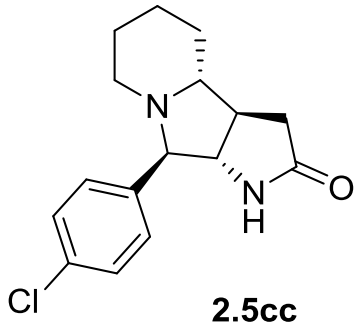

(3aS，3bR，9R，9aS)-9-(4-chlorophenyl) octahydro-1H-pyrrolo[3,2-a]indolizin2(3bH)-one (2.5cc) was purified by flash chromatography $\left(\mathrm{CH}_{2} \mathrm{Cl}_{2} / \mathrm{MeOH}=25: 1, \mathrm{v} / \mathrm{v}\right)$ as brown semisolid. Reaction time $8 \mathrm{hr}$; Isolated yield $84 \%$; ${ }^{1} \mathrm{H}-\mathrm{NMR}\left(600 \mathrm{MHz}, \mathrm{CDCl}_{3}\right.$ ) $\delta 7.47(\mathrm{~s}, 1 \mathrm{H}), 7.27-7.22(\mathrm{~m}, 4 \mathrm{H}), 3.66(\mathrm{t}, J=8.78 \mathrm{~Hz}, 1 \mathrm{H}), 3.00(\mathrm{~d}, J=5.27 \mathrm{~Hz}, 1 \mathrm{H})$, $2.63(\mathrm{~d}, J=5.27 \mathrm{~Hz}, 1 \mathrm{H}), 2.50-2.44(\mathrm{~m}, 2 \mathrm{H}), 2.16-2.13(\mathrm{~m}, 1 \mathrm{H}), 1.94(\mathrm{t}, J=8.78 \mathrm{~Hz}, 1 \mathrm{H})$, 1.87 (d, $J=10.63 \mathrm{~Hz}, 1 \mathrm{H}), 1.78$ (t, $J=8.78 \mathrm{~Hz}, 2 \mathrm{H}), 1.53-1.50(\mathrm{~m}, 1 \mathrm{H}), 1.45-1.16$ (m, $3 \mathrm{H}) ;{ }^{13} \mathrm{C}-\mathrm{NMR}\left(150 \mathrm{MHz}, \mathrm{CDCl}_{3}\right) \delta 178.63,139.41,133.51,130.23,129.07,128.40$, 77.78, 70.37, 65.98, 50.87, 42.46, 33.65, 30.27, 25.36, 24.21; HRMS Calculated for $\mathrm{C}_{16} \mathrm{H}_{19} \mathrm{ClN}_{2} \mathrm{O}[\mathrm{M}+\mathrm{H}]^{+}:$292.1156, Found: 291.1258.

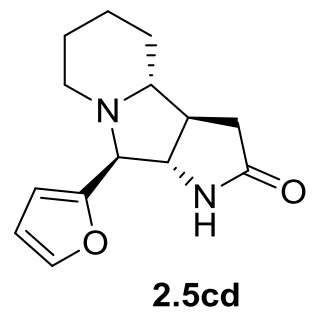

(3aS, 3bR, 9S, 9aS)-9-(furan-2-yl) octahydro-1H-pyrrolo[3,2-a]indolizin-2(3bH)-one (2.5cd) was purified by flash chromatography $\left(\mathrm{CH}_{2} \mathrm{Cl}_{2} / \mathrm{MeOH}=12: 1\right.$, v/v) as brown semisolid. Reaction time $8 \mathrm{hr}$; Isolated yield 64\%; ${ }^{1} \mathrm{H}-\mathrm{NMR}\left(600 \mathrm{MHz}, \mathrm{CDCl}_{3}\right) \delta 7.36(\mathrm{~d}$, $J=3.22 \mathrm{~Hz}, 1 \mathrm{H}), 6.60(\mathrm{~s}, 1 \mathrm{H}), 6.29-6.28(\mathrm{~m}, 1 \mathrm{H}), 6.23(\mathrm{~d}, J=3.22 \mathrm{~Hz}, 1 \mathrm{H}), 4.13-4.10$ (dd, $J=8.93 \mathrm{~Hz}, 5.56 \mathrm{~Hz}, 1 \mathrm{H}), 3.10(\mathrm{~d}, J=5.42 \mathrm{~Hz}, 1 \mathrm{H}), 2.81(\mathrm{~d}, J=10.98 \mathrm{~Hz}, 1 \mathrm{H})$, $2.56(\mathrm{q}, J=9.07 \mathrm{~Hz}, 1 \mathrm{H}), 2.50-2.47(\mathrm{~m}, 1 \mathrm{H}), 2.13-2.10(\mathrm{dd}, J=17.27 \mathrm{~Hz}, 2.34 \mathrm{~Hz}, 1 \mathrm{H})$, $1.90-1.83(\mathrm{~m}, 2 \mathrm{H}), 1.79-1.76(\mathrm{~m}, 2 \mathrm{H}), 1.58-1.50(\mathrm{~m}, 1 \mathrm{H}), 1.50-1.40(\mathrm{~m}, 1 \mathrm{H}), 1.40-4.30$ $(\mathrm{m}, 1 \mathrm{H}), 1.24-1.14(\mathrm{~m}, 1 \mathrm{H}) ;{ }^{13} \mathrm{C}-\mathrm{NMR}\left(150 \mathrm{MHz}, \mathrm{CDCl}_{3}\right) \delta 177.84,152.32,143.00$, 
$110.35,108.69,71.82,70.77,61.61,51.37,42.15,33.39,29.92,25.11,24.18$; HRMS Calculated for $\mathrm{C}_{14} \mathrm{H}_{18} \mathrm{~N}_{2} \mathrm{O}_{2}[\mathrm{M}+\mathrm{H}]^{+}: 247.1402$, Found: 247.1441.

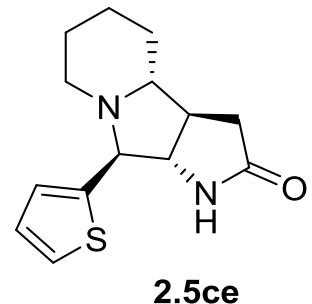

(3aS, 3bR, 9S, 9aS)-9-(thiophen-2-yl) octahydro-1H-pyrrolo[3,2-a]indolizin-2(3bH)one (2.5ce) was purified by flash chromatography $\left(\mathrm{CH}_{2} \mathrm{Cl}_{2} / \mathrm{MeOH}=15: 1\right.$, v/v) as brown semisolid. Reaction time $8 \mathrm{hr}$; Isolated yield 69\%; ${ }^{1} \mathrm{H}-\mathrm{NMR}\left(600 \mathrm{MHz}, \mathrm{CDCl}_{3}\right) \delta 7.12(\mathrm{~d}$, $J=4.98 \mathrm{~Hz}, 1 \mathrm{H}), 7.05(\mathrm{~s}, 1 \mathrm{H}), 6.95-6.89(\mathrm{~m}, 2 \mathrm{H}), 3.84-3.81(\mathrm{~m}, 1 \mathrm{H}), 3.36(\mathrm{~d}, J=3.12$ $\mathrm{Hz}, 1 \mathrm{H}), 2.84(\mathrm{~d}, J=10.83 \mathrm{~Hz}, 1 \mathrm{H}), 2.54-2.42(\mathrm{~m}, 2 \mathrm{H}), 2.13(\mathrm{~d}, J=10.84 \mathrm{~Hz}, 1 \mathrm{H}), 1.94$ (t, $J=8.78 \mathrm{~Hz}, 1 \mathrm{H}), 1.83$ (t, $J=11.86 \mathrm{~Hz}, 1 \mathrm{H}), 1.80-1.70(\mathrm{~m}, 2 \mathrm{H}), 1.54(\mathrm{t}, J=13.17 \mathrm{~Hz}$, $1 \mathrm{H}), 1.43-1.40(\mathrm{~m}, 1 \mathrm{H}), 1.31-1.29(\mathrm{~m}, 1 \mathrm{H}), 1.22-1.17(\mathrm{~m}, 1 \mathrm{H}) ;{ }^{13} \mathrm{C}-\mathrm{NMR}(150 \mathrm{MHz}$, $\left.\mathrm{CDCl}_{3}\right) \delta 178.53,145.48,127.25,126.93,125.42,73.85,70.62,66.32,51.12,42.13$, 33.66, 30.23, 25.32, 24.22; HRMS Calculated for $\mathrm{C}_{14} \mathrm{H}_{18} \mathrm{~N}_{2} \mathrm{OS}[\mathrm{M}+\mathrm{H}]^{+}: 263.1173$, Found: 263.1212 .

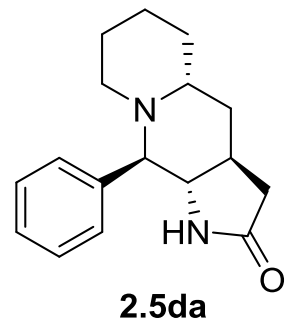

(3aS, 4aR, 10R, 10aS)-10-phenyldecahydropyrrolo[3,2-b]quinolizin-2(1H)-one (2.5da) was purified by flash chromatography $\left(\mathrm{CH}_{2} \mathrm{Cl}_{2} / \mathrm{MeOH}=20: 1\right.$, v/v) as brown semisolid. Reaction time $8 \mathrm{hr}$; Isolated yield $69 \%$; ${ }^{1} \mathrm{H}-\mathrm{NMR}\left(600 \mathrm{MHz}, \mathrm{CDCl}_{3}\right) \delta$ 7.487.09 (m, 5H), $4.94(\mathrm{~s}, 1 \mathrm{H}), 3.15(\mathrm{t}, J=9.51 \mathrm{~Hz}, 1 \mathrm{H}), 2.95(\mathrm{~d}, J=9.51 \mathrm{~Hz}, 1 \mathrm{H}), 2.69(\mathrm{~d}, J$ $=11.42 \mathrm{~Hz}, 1 \mathrm{H}), 2.38-2.34(\mathrm{dd}, J=14.05 \mathrm{~Hz}, 4.98 \mathrm{~Hz}, 1 \mathrm{H}), 2.20(\mathrm{t}, J=10.54 \mathrm{~Hz}, 1 \mathrm{H})$, 2.09-1.97 (m, 2H), 1.82 (d, $J=12.73 \mathrm{~Hz}, 1 \mathrm{H}), 1.75$ (t, $J=12.00 \mathrm{~Hz}, 1 \mathrm{H}), 1.67$ (t, $J=$ $16.83 \mathrm{~Hz}, 2 \mathrm{H}), 1.51-1.36(\mathrm{~m}, 4 \mathrm{H}), 1.29-1.23(\mathrm{~m}, 1 \mathrm{H}) ;{ }^{13} \mathrm{C}-\mathrm{NMR}\left(150 \mathrm{MHz}, \mathrm{CDCl}_{3}\right) \delta$ 
$178.25,140.66,129.75,128.55,128.20,126.22,72.91,65.60,63.76,52.88,42.63,38.08$, $36.19,33.93,26.31,25.03$; HRMS Calculated for $\mathrm{C}_{17} \mathrm{H}_{22} \mathrm{~N}_{2} \mathrm{O}[\mathrm{M}+\mathrm{H}]^{+}: 271.1766$, Found: 271.1804 .

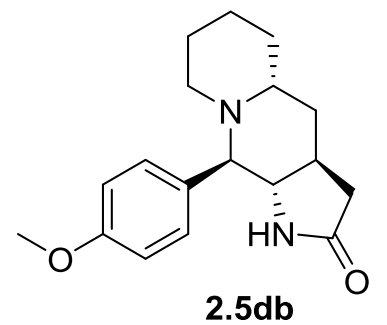

(3aS，4aR，10R，10aS)-10-(4-methoxyphenyl) decahydropyrrolo[3,2-b]quinolizin2(1H)-one (2.5db) was purified by flash chromatography $\left(\mathrm{CH}_{2} \mathrm{Cl}_{2} / \mathrm{MeOH}=10: 1\right.$, v/v) as brown semisolid. Reaction time $8 \mathrm{hr}$; Isolated yield $63 \%$; ${ }^{1} \mathrm{H}-\mathrm{NMR}\left(600 \mathrm{MHz}, \mathrm{CDCl}_{3}\right) \delta$ 7.38 (br s, 1H), 7.04-6.79 (m, 3H), $4.94(\mathrm{~s}, 1 \mathrm{H}), 3.78(\mathrm{~s}, 3 \mathrm{H}), 3.14(\mathrm{t}, J=9.51 \mathrm{~Hz}, 1 \mathrm{H})$, $2.89(\mathrm{~d}, J=9.51 \mathrm{~Hz}, 1 \mathrm{H}), 2.69(\mathrm{~d}, J=11.42 \mathrm{~Hz}, 1 \mathrm{H}), 2.38-2.34(\mathrm{dd}, J=15.08 \mathrm{~Hz}, 5.85$ $\mathrm{Hz}, 1 \mathrm{H}), 2.18(\mathrm{t}, J=10.10 \mathrm{~Hz}, 1 \mathrm{H}), 2.09-2.01(\mathrm{~m}, 2 \mathrm{H}), 1.82(\mathrm{~d}, J=12.73 \mathrm{~Hz}, 1 \mathrm{H}), 1.75-$ $1.64(\mathrm{~m}, 3 \mathrm{H}), 1.48(\mathrm{t}, J=11.56 \mathrm{~Hz}, 2 \mathrm{H}), 1.42-1.35(\mathrm{~m}, 2 \mathrm{H}), 1.27-1.23(\mathrm{~m}, 1 \mathrm{H}) ;{ }^{13} \mathrm{C}-\mathrm{NMR}$ $\left(150 \mathrm{MHz}, \mathrm{CDCl}_{3}\right) \delta 178.27,159.89,132.52,130.42,127.26,115.83,113.17,72.23$, $65.57,63.85,60.60,55.51,52.69,42.65,38.14,36.20,33.42,26.33,25.03$; HRMS Calculated for $\mathrm{C}_{18} \mathrm{H}_{24} \mathrm{~N}_{2} \mathrm{O}_{2}[\mathrm{M}+\mathrm{H}]^{+}$: 301.1871, Found: 301.1910 .

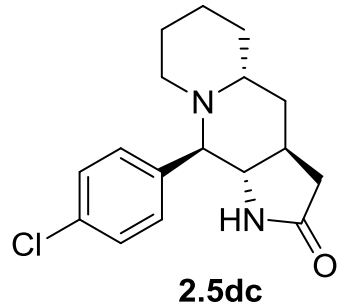

(3aS，4aR，10R，10aS)-10-(4-chlorophenyl) decahydropyrrolo[3,2-b]quinolizin2(1H)-one (2.5dc) was purified by flash chromatography $\left(\mathrm{CH}_{2} \mathrm{Cl}_{2} / \mathrm{MeOH}=15: 1\right.$, v/v) as brown semisolid. Reaction time $8 \mathrm{hr}$; Isolated yield $73 \%$; ${ }^{1} \mathrm{H}-\mathrm{NMR}\left(600 \mathrm{MHz}, \mathrm{CDCl}_{3}\right) \delta$ 7.44-7.04 (m, 4H), 4.99 (s, 1H), 3.10 (t, $J=9.51 \mathrm{~Hz}, 1 \mathrm{H}), 2.94(\mathrm{~d}, J=9.37 \mathrm{~Hz}, 1 \mathrm{H}), 2.62$ (d, $J=11.42 \mathrm{~Hz}, 1 \mathrm{H}), 2.37-2.34(\mathrm{dd}, J=14.64 \mathrm{~Hz}, 5.56 \mathrm{~Hz}, 1 \mathrm{H}), 2.20(\mathrm{t}, J=10.68 \mathrm{~Hz}$, 1H), 2.07-2.02 (m, 2H), 1.82 (d, $J=12.73 \mathrm{~Hz}, 1 \mathrm{H}), 1.79-1.72(\mathrm{td}, J=11.86 \mathrm{~Hz}, 14.34 \mathrm{~Hz}$, $2.49 \mathrm{~Hz}, 1 \mathrm{H}), 1.67(\mathrm{t}, J=17.71 \mathrm{~Hz}, 2 \mathrm{H}), 1.47-1.43(\mathrm{~m}, 2 \mathrm{H}), 1.41-1.34(\mathrm{~m}, 2 \mathrm{H}), 1.28-1.23$ 
$(\mathrm{m}, 1 \mathrm{H}) ;{ }^{13} \mathrm{C}-\mathrm{NMR}\left(150 \mathrm{MHz}, \mathrm{CDCl}_{3}\right) \delta 178.28,139.31,133.82,130.49,130.09,128.60$, $127.73,72.20,65.51,63.70,52.86,42.50,37.96,36.08,33.90,26.28,24.96$; HRMS Calculated for $\mathrm{C}_{17} \mathrm{H}_{21} \mathrm{ClN}_{2} \mathrm{O}[\mathrm{M}+\mathrm{H}]^{+}$: 306.1313, Found: 305.1415 .

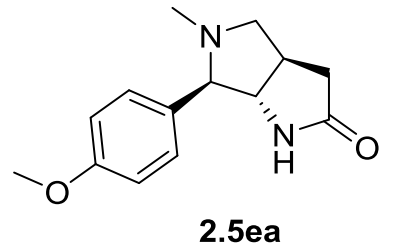

(3aR, 6R, 6aS)-6-(4-methoxyphenyl)-5-methylhexahydropyrrolo[3,4-b]pyrrol-2(1H)one (2.5ea) was purified by flash chromatography $\left(\mathrm{CH}_{2} \mathrm{Cl}_{2} / \mathrm{MeOH}=20: 1\right.$, v/v) as brown semisolid. Reaction time $8 \mathrm{hr}$; Isolated yield 64\%; ${ }^{1} \mathrm{H}-\mathrm{NMR}\left(600 \mathrm{MHz}, \mathrm{CDCl}_{3}\right) \delta 7.21(\mathrm{~d}$, $J=8.64 \mathrm{~Hz}, 2 \mathrm{H}), 6.89(\mathrm{~d}, J=8.64 \mathrm{~Hz}, 2 \mathrm{H}), 5.85(\mathrm{~s}, 1 \mathrm{H}), 3.86(\mathrm{t}, J=7.61 \mathrm{~Hz}, 1 \mathrm{H}), 3.79$ (s, 3H), $3.55(\mathrm{t}, J=8.64 \mathrm{~Hz}, 1 \mathrm{H}), 3.14-3.06(\mathrm{~m}, 1 \mathrm{H}), 2.86(\mathrm{~d}, J=5.71 \mathrm{~Hz}, 1 \mathrm{H}), 2.59-2.54$ $(\mathrm{dd}, J=17.86 \mathrm{~Hz}, 10.39 \mathrm{~Hz}, 1 \mathrm{H}), 2.22-2.18(\mathrm{~m}, 2 \mathrm{H}), 2.10$ (s, 3H); ${ }^{13} \mathrm{C}-\mathrm{NMR}(150 \mathrm{MHz}$, $\left.\mathrm{CDCl}_{3}\right) \delta 177.40,163.25,159.70,128.85,114.49,79.29,66.97,63.91,55.52,39.85$, 35.50, 35.18; HRMS Calculated for $\mathrm{C}_{14} \mathrm{H}_{18} \mathrm{~N}_{2} \mathrm{O}_{2}[\mathrm{M}+\mathrm{H}]^{+}:$247.1402, Found: 247.1441.

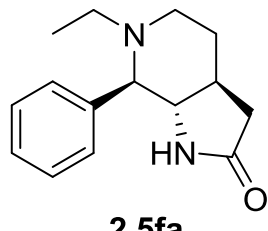

(3aS，7R，7aS)-6-ethyl-7-phenylhexahydro-1H-pyrrolo[2,3-c]pyridin-2(3H)-one (2.5fa) was purified by flash chromatography $\left(\mathrm{CH}_{2} \mathrm{Cl}_{2} / \mathrm{MeOH}=20: 1\right.$, v/v) as brown semisolid. Reaction time $8 \mathrm{hr}$; Isolated yield 71\%; ${ }^{1} \mathrm{H}-\mathrm{NMR}\left(600 \mathrm{MHz}, \mathrm{CDCl}_{3}\right) \delta 7.34-$ $7.24(\mathrm{~m}, 5 \mathrm{H}), 4.93$ (s, 1H), 3.24 (d, J=11.71 Hz, 1H), 3.17 (t, $J=9.51 \mathrm{~Hz}, 1 \mathrm{H}), 3.08$ (d, $J=9.22 \mathrm{~Hz}, 1 \mathrm{H}), 2.54$ (hex, 1H), 2.40-2.32 (m, 2H), 2.16-2.07 (m, 2H), 1.98-1.95 (m, $1 \mathrm{H}), 1.90(\mathrm{~d}, J=12.73 \mathrm{~Hz}, 1 \mathrm{H}), 1.80-1.70(\mathrm{~m}, 1 \mathrm{H}), 0.90(\mathrm{t}, J=7.03 \mathrm{~Hz}, 3 \mathrm{H}) ;{ }^{13} \mathrm{C}-\mathrm{NMR}$ $\left(150 \mathrm{MHz}, \mathrm{CDCl}_{3}\right) \delta 178.23,140.10,129.11,128.34,127.81,71.25,65.80,52.28,47.91$, 43.53, 38.10, 28.46, 11.33; HRMS Calculated for $\mathrm{C}_{15} \mathrm{H}_{20} \mathrm{~N}_{2} \mathrm{O}[\mathrm{M}+\mathrm{H}]^{+}$: 245.1609, Found: 245.1648 . 


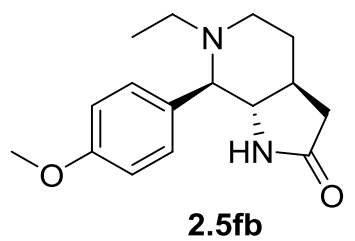

(3aS, 7R，7aS)-6-ethyl-7-(4-methoxyphenyl) hexahydro-1H-pyrrolo[2,3-c]pyridin2(3H)-one (2.5fb) was purified by flash chromatography $\left(\mathrm{CH}_{2} \mathrm{Cl}_{2} / \mathrm{MeOH}=20: 1\right.$, v/v) as brown semisolid. Reaction time $8 \mathrm{hr}$; Isolated yield $66 \%$; ${ }^{1} \mathrm{H}-\mathrm{NMR}\left(600 \mathrm{MHz}, \mathrm{CDCl}_{3}\right) \delta$ 7.21 (d, $J=8.05 \mathrm{~Hz}, 2 \mathrm{H}), 6.86$ (d, $J=8.64 \mathrm{~Hz}, 2 \mathrm{H}), 4.94-4.93($ br s, $1 \mathrm{H}), 3.79$ (s, 3H), $3.22(\mathrm{~d}, J=11.12 \mathrm{~Hz}, 1 \mathrm{H}), 3.16(\mathrm{t}, J=9.22 \mathrm{~Hz}, 1 \mathrm{H}), 3.03(\mathrm{~d}, J=8.93 \mathrm{~Hz}, 1 \mathrm{H}), 2.56-2.53$ (m, 1H), 2.40-2.32 (m, 2H), 2.15-2.07 (m, 2H), 2.01-1.89 (m, 2H), 1.73-1.72 (m, 1H), $0.89(\mathrm{t}, J=6.88 \mathrm{~Hz}, 3 \mathrm{H}) ;{ }^{13} \mathrm{C}-\mathrm{NMR}\left(150 \mathrm{MHz}, \mathrm{CDCl}_{3}\right) \delta 177.24,159.62,131.92,128.86$, 114.54, 70.48, 65.78, 55.51, 52.33, 47.70, 43.56, 38.16, 28.47, 11.28; HRMS Calculated for $\mathrm{C}_{16} \mathrm{H}_{22} \mathrm{~N}_{2} \mathrm{O}_{2}[\mathrm{M}+\mathrm{H}]^{+}:$275.1715, Found: 275.1754.

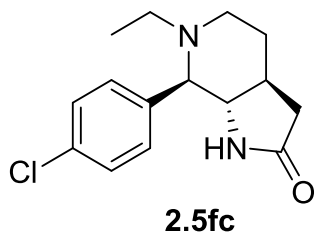

(3aS，7R，7aS)-7-(4-chlorophenyl)-6-ethylhexahydro-1H-pyrrolo[2,3-c]pyridin2(3H)-one (2.5fc) was purified by flash chromatography $\left(\mathrm{CH}_{2} \mathrm{Cl}_{2} / \mathrm{MeOH}=15: 1\right.$, v/v) as brown semisolid. Reaction time $8 \mathrm{hr}$; Isolated yield $73 \%$; ${ }^{1} \mathrm{H}-\mathrm{NMR}\left(600 \mathrm{MHz}, \mathrm{CDCl}_{3}\right) \delta$ $7.32(\mathrm{~d}, J=8.64 \mathrm{~Hz}, 2 \mathrm{H}), 7.25(\mathrm{~d}, J=7.40 \mathrm{~Hz}, 2 \mathrm{H}), 4.90(\mathrm{~s}, 1 \mathrm{H}), 3.22(\mathrm{~d}, J=12.59 \mathrm{~Hz}$, $1 \mathrm{H}), 3.12(\mathrm{t}, J=9.37 \mathrm{~Hz}, 1 \mathrm{H}), 3.06(\mathrm{~d}, J=9.22 \mathrm{~Hz}, 1 \mathrm{H}), 2.50(\mathrm{Hex}, 1 \mathrm{H}), 2.40-2.30(\mathrm{~m}$, $2 \mathrm{H}), 2.15-2.06(\mathrm{~m}, 2 \mathrm{H}), 2.00-1.89(\mathrm{~m}, 2 \mathrm{H}), 1.75-1.68(\mathrm{~m}, 1 \mathrm{H}), 0.89(\mathrm{t}, J=7.03 \mathrm{~Hz}, 3 \mathrm{H})$; ${ }^{13} \mathrm{C}-\mathrm{NMR}\left(150 \mathrm{MHz}, \mathrm{CDCl}_{3}\right) \delta 178.20,138.79,133.99,129.41,129.12,70.56,65.74$, 52.21, 47.90, 43.41, 37.99, 28.41, 11.37; HRMS Calculated for $\mathrm{C}_{15} \mathrm{H}_{19} \mathrm{ClN}_{2} \mathrm{O}[\mathrm{M}+\mathrm{H}]^{+}$: 280.1156, Found: 279.1258 .

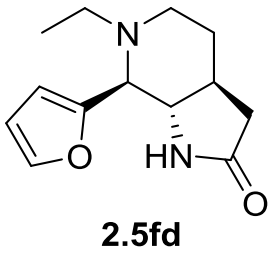


(3aS, 7S, 7aS)-6-ethyl-7-(furan-2-yl) hexahydro-1H-pyrrolo[2,3-c]pyridin-2(3H)-one (2.5fd) was purified by flash chromatography $\left(\mathrm{CH}_{2} \mathrm{Cl}_{2} / \mathrm{MeOH}=10: 1\right.$, v/v) as yellow semisolid. Reaction time $8 \mathrm{hr}$; Isolated yield $61 \%$; ${ }^{1} \mathrm{H}-\mathrm{NMR}\left(600 \mathrm{MHz}, \mathrm{CDCl}_{3}\right) \delta$ 7.327.28 (br m, 1H), 7.04 (d, $J=4.88 \mathrm{~Hz}, 1 \mathrm{H}), 6.89$ (d, $J=4.88 \mathrm{~Hz}, 1 \mathrm{H}), 4.85$ (s, 1H), 4.414.44 (br s, 1H), 3.95-3.97 (br s, $J=9.32 \mathrm{~Hz}, 1 \mathrm{H}$ ), 3.67-3.65 (br m, 3H), 3.06 (d, 1H), 2.70-2.43 (m, 1H), 2.40-2.28 (m, 1H), 2.26-1.15 (m, 1H), $2.04(\mathrm{~d}, J=10.73 \mathrm{~Hz}, 1 \mathrm{H})$, 1.92-1.90 (m, $1 \mathrm{H}), 0.95(\mathrm{t}, J=7.03 \mathrm{~Hz}, 3 \mathrm{H}) ;{ }^{13} \mathrm{C}-\mathrm{NMR}\left(150 \mathrm{MHz}, \mathrm{CDCl}_{3}\right) \delta 171.42$, $141.48,128.47,127.88,126.70,65.62,52.03,50.85,48.48,41.59,37.84,29.17,11.44$; HRMS Calculated for $\mathrm{C}_{13} \mathrm{H}_{18} \mathrm{~N}_{2} \mathrm{O}_{2}[\mathrm{M}+\mathrm{H}]^{+}:$235.1402, Found: 235.1464 .

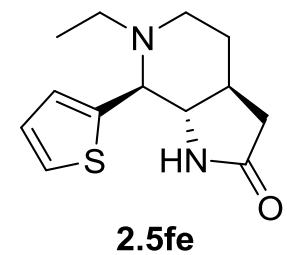

(3aS, 7S, 7aS)-6-ethyl-7-(thiophen-2-yl) hexahydro-1H-pyrrolo[2,3-c]pyridin-2(3H)one (2.5fe) was purified by flash chromatography $\left(\mathrm{CH}_{2} \mathrm{Cl}_{2} / \mathrm{MeOH}=10: 1\right.$, v/v) as yellow semisolid. Reaction time $8 \mathrm{hr}$; Isolated yield 67\%; ${ }^{1} \mathrm{H}-\mathrm{NMR}\left(600 \mathrm{MHz}, \mathrm{CDCl}_{3}\right) \delta 7.29$ (d, $J=4.98 \mathrm{~Hz}, 2 \mathrm{H}), 6.96-6.92(\mathrm{~m}, 1 \mathrm{H}), 5.08(\mathrm{~s}, 1 \mathrm{H}), 3.44(\mathrm{~d}, J=9.22 \mathrm{~Hz}, 1 \mathrm{H}), 3.25-3.20$ (m, 2H), 2.71-2.67 (m, 1H), 2.42-2.31 (m, 2H), 2.23-2.20 (m, 1H), $2.12(\mathrm{t}, J=12.73 \mathrm{~Hz}$, $1 \mathrm{H}), 1.97-1.88(\mathrm{~m}, 2 \mathrm{H}), 1.75-1.73(\mathrm{~m}, 1 \mathrm{H}), 0.95(\mathrm{t}, J=7.03 \mathrm{~Hz}, 3 \mathrm{H}) ;{ }^{13} \mathrm{C}-\mathrm{NMR}(150$ $\left.\mathrm{MHz}, \mathrm{CDCl}_{3}\right) \delta 178.05,144.49,126.60,126.01,125.82,66.64,52.42,48.08,43.29$, 38.14, 28.27, 11.43; HRMS Calculated for $\mathrm{C}_{13} \mathrm{H}_{18} \mathrm{~N}_{2} \mathrm{OS}[\mathrm{M}+\mathrm{H}]^{+}$: 251.1173, Found: 251.1212 .

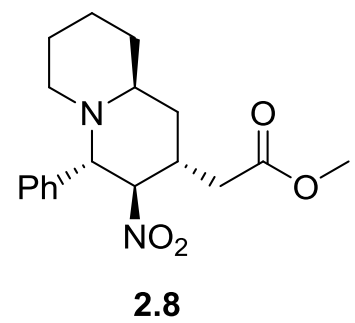

Methyl 2-((2R,3R,4S,9aS)-3-nitro-4-phenyloctahydro-1H-quinolizin-2-yl)acetate (2.8) was purified by flash chromatography (Hexane/EtOAc $=8: 1$, v/v) as light yellow liquid. Reaction time $4 \mathrm{hr}$; Isolated yield $74 \%$, dr > 99:1; ${ }^{1} \mathrm{H}-\mathrm{NMR}\left(600 \mathrm{MHz}, \mathrm{CDCl}_{3}\right) \delta$ 7.42- 
$7.18(\mathrm{~m}, 5 \mathrm{H}), 4.45(\mathrm{t}, J=10.39 \mathrm{~Hz}, 1 \mathrm{H}), 3.68(\mathrm{~s}, 3 \mathrm{H}), 3.45(\mathrm{~d}, J=10.69 \mathrm{~Hz}, 1 \mathrm{H}), 3.06(\mathrm{br}$ $\mathrm{m}, 1 \mathrm{H}) ; 2.66(\mathrm{~d}, J=7.32 \mathrm{~Hz}, 1 \mathrm{H}), 2.53(\mathrm{~d}, J=10.83 \mathrm{~Hz}, 1 \mathrm{H}), 2.36-2.33(\mathrm{dd}, J=16.54 \mathrm{~Hz}$, $12.30 \mathrm{~Hz}, 1 \mathrm{H}), 2.26-2.16(\mathrm{~m}, 1 \mathrm{H}), 1.93(\mathrm{~d}, J=11.71 \mathrm{~Hz}, 1 \mathrm{H}), 1.78-1.64(\mathrm{~m}, 2 \mathrm{H}), 1.45$ (t, $J=12.15 \mathrm{~Hz}, 1 \mathrm{H}), 1.31-1.21(\mathrm{~m}, 5 \mathrm{H}) ;{ }^{13} \mathrm{C}-\mathrm{NMR}\left(150 \mathrm{MHz}, \mathrm{CDCl}_{3}\right) \delta 171.40,143.39$, 138.64, 138.17, 128.72, 128.52, 95.24, 72.12, 61.64, 56.08, 53.13, 52.02, 37.18, 33.34, 32.64, 25.97, 24.59; HRMS Calculated for $\mathrm{C}_{18} \mathrm{H}_{24} \mathrm{~N}_{2} \mathrm{O}_{4}[\mathrm{M}+\mathrm{H}]+$ : 333.1770, Found: 333.1808 .

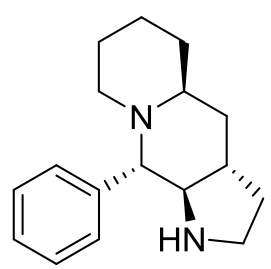

$2.9 b$

(3aS, 4aS, 10S, 10aR)-10-phenyl dodecahydropyrrolo[3,2-b]quinolizine (2.9b) was purified by flash chromatography $\left(\mathrm{CH}_{2} \mathrm{Cl}_{2} / \mathrm{MeOH}=5: 1, \mathrm{v} / \mathrm{v}\right)$ as yellow liquid. Reaction time $24 \mathrm{hr}$; Isolated yield 68\%; ${ }^{1} \mathrm{H}-\mathrm{NMR}\left(600 \mathrm{MHz}, \mathrm{CDCl}_{3}\right) \delta$ 7.50-7.11 (m, 5H), $3.18(\mathrm{t}$, $J=9.78 \mathrm{~Hz}, 1 \mathrm{H}), 2.97(\mathrm{~d}, J=10.51 \mathrm{~Hz}, 1 \mathrm{H}), 2.71(\mathrm{~d}, J=8.84 \mathrm{~Hz}, 1 \mathrm{H}), 2.40-2.36(\mathrm{dd}, J$ $=14.25 \mathrm{~Hz}, 5.45 \mathrm{~Hz}, 1 \mathrm{H}), 2.22(\mathrm{t}, J=10.28 \mathrm{~Hz}, 1 \mathrm{H}), 2.11-1.85(\mathrm{~m}, 3 \mathrm{H}), 1.84(\mathrm{~d}, J=$ $11.48 \mathrm{~Hz}, 1 \mathrm{H}), 1.78(\mathrm{t}, J=12.78 \mathrm{~Hz}, 1 \mathrm{H}), 1.69(\mathrm{t}, J=11.78 \mathrm{~Hz}, 3 \mathrm{H}), 1.53-1.37(\mathrm{~m}, 5 \mathrm{H})$, $1.30-1.24(\mathrm{~m}, 1 \mathrm{H}) ;{ }^{13} \mathrm{C}-\mathrm{NMR}\left(150 \mathrm{MHz}, \mathrm{CDCl}_{3}\right) \delta 139.06,128.56,128.55,127.97$, 123.96, 69.97, 66.83, 62.42, 55.08, 52.59, 43.92, 41.52, 36.53, 33.67, 29.07, 24.64; HRMS Calculated for $\mathrm{C}_{17} \mathrm{H}_{24} \mathrm{~N}_{2}[\mathrm{M}+\mathrm{H}]^{+}$: 257.1973, Found: 257.1993.

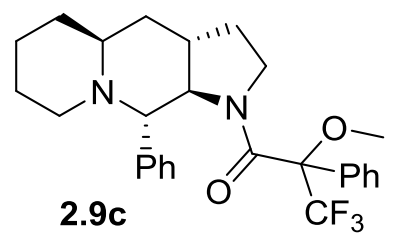

3,3,3-trifluoro-2-methoxy-2-phenyl-1-((3aS, 4aS, 10S, 10aR)-10-phenyl decahydro pyrrolo[3,2-b]quinolizin-1(2H)-yl)propan-1-one $\mathbf{( 2 . 9 c )}$ was purified by flash chromatography $\left(\mathrm{CH}_{2} \mathrm{Cl}_{2} / \mathrm{MeOH}=12: 1, \mathrm{v} / \mathrm{v}\right)$ as solid residue. Reaction time $24 \mathrm{hr}$; Isolated yield 80\%; ${ }^{1} \mathrm{H}-\mathrm{NMR}\left(600 \mathrm{MHz}, \mathrm{CDCl}_{3}\right) \delta 7.58-7.19(\mathrm{~m}, 10 \mathrm{H}), 3.41(\mathrm{~s}, 3 \mathrm{H}), 3.32$ (d, $J=8.78 \mathrm{~Hz}, 1 \mathrm{H}), 2.86-2.84(\mathrm{~m}, 2 \mathrm{H}), 2.78(\mathrm{t}, J=10.5 \mathrm{~Hz}, 1 \mathrm{H}), 2.57(\mathrm{~d}, J=11.27 \mathrm{~Hz}$, 
$1 \mathrm{H}), 2.08(\mathrm{t}, J=9.58 \mathrm{~Hz}, 1 \mathrm{H}), 1.84(\mathrm{t}, J=11.56 \mathrm{~Hz}, 2 \mathrm{H}), 1.71(\mathrm{t}, J=12.78 \mathrm{~Hz}, 2 \mathrm{H}), 1.65$ (t, $J=16.25 \mathrm{~Hz}, 2 \mathrm{H}), 1.41(\mathrm{t}, J=12.44 \mathrm{~Hz}, 2 \mathrm{H}), 1.33(\mathrm{q}, J=12.15 \mathrm{~Hz}, 3 \mathrm{H}), 1.26-1.21(\mathrm{~m}$, 1H); ${ }^{13} \mathrm{C}-\mathrm{NMR}\left(150 \mathrm{MHz}, \mathrm{CDCl}_{3}\right) \delta 170.31,139.05,135.53,129.33,128.55,128.21$, $128.00,127.92,127.39,125.89,123.96,85.25,69.97,66.83,62.42,55.08,52.59,43.92$, 41.52, 36.53, 33.67, 29.67, 25.99, 24.64;-70.30 (br s, $\mathrm{CF}_{3}$ ), HRMS Calculated for $\mathrm{C}_{27} \mathrm{H}_{31} \mathrm{~F}_{3} \mathrm{~N}_{2} \mathrm{O}_{2}[\mathrm{M}+\mathrm{H}]^{+}:$473.2371, Found: 473.2391, Also found as $\left[\mathrm{M}+\mathrm{H}_{2} \mathrm{O}+\mathrm{Na}\right]^{+}$: 513.3951 .

\section{A2.2: Enantioselective piperidine synthesis}

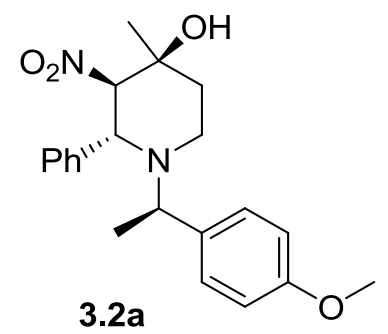

(2S,3S,4R)-1-((S)-1-(4-methoxyphenyl)ethyl)-4-methyl-3-nitro-2-phenylpiperidin-4-

ol (3.2a major) was purified by flash silica gel chromatography (Hexane- EtOAc, v/v 8/1) as white solid, yield: $72 \% .{ }^{1} \mathrm{H} \mathrm{NMR}\left(600 \mathrm{MHz}, \mathrm{CDCl}_{3}\right): \delta 7.19-7.40(\mathrm{~m}, 7 \mathrm{H}), 6.76(\mathrm{~d}, J=$ $8.20 \mathrm{~Hz}, 2 \mathrm{H}), 4.64(\mathrm{~d}, J=10.10 \mathrm{~Hz}, 1 \mathrm{H}), 4.27(\mathrm{~d}, J=10.10 \mathrm{~Hz}, 1 \mathrm{H}), 3.72(\mathrm{~s}, 3 \mathrm{H}), 3.66(\mathrm{q}, J$ $=6.15 \mathrm{~Hz}, 1 \mathrm{H}), 2.96(\mathrm{~s}, 1 \mathrm{H}), 2.77(\mathrm{t}, J=11.71 \mathrm{~Hz}, 1 \mathrm{H}), 2.30(\mathrm{~d}, J=13.61 \mathrm{~Hz}, 1 \mathrm{H}), 1.71(\mathrm{~d}$, $J=13.91 \mathrm{~Hz}, 1 \mathrm{H}), 1.51(\mathrm{t}, J=13.17 \mathrm{~Hz}, 1 \mathrm{H}), 1.22(\mathrm{~s}, 3 \mathrm{H}), 1.15(\mathrm{~d}, J=6.73 \mathrm{~Hz}, 3 \mathrm{H}) \cdot{ }^{13} \mathrm{C}$ NMR (600 MHz, $\left.\mathrm{CDCl}_{3}\right): \delta 158.5,137.2,135.5,129.2,129.0,128.6,113.5,98.5,69.5$, 63.9, 55.4, 54.5, 38.7, 37.1, 27.5, 8.9. HRMS Calculated for $\mathrm{C}_{21} \mathrm{H}_{27} \mathrm{~N}_{2} \mathrm{O}_{4}[\mathrm{M}+\mathrm{H}]^{+}$: 371.19453, Found: 371.19475.

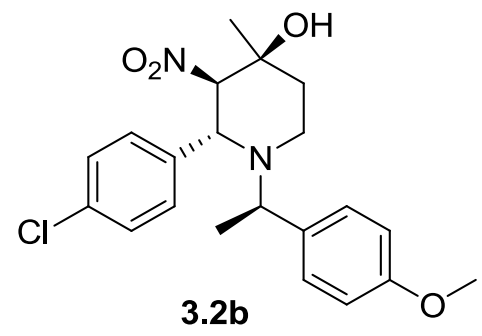

(2R,3R,4S)-2-(4-chlorophenyl)-1-((R)-1-(4-methoxyphenyl)ethyl)-4-methyl-3-nitropiperidin-4-ol (3.2b major) was purified by flash silica gel chromatography (Hexane- 
EtOAc, v/v 8/1) as white solid, yield: $75 \% .{ }^{1} \mathrm{H}$ NMR $\left(600 \mathrm{MHz}, \mathrm{CDCl}_{3}\right): \delta 7.43-7.33(\mathrm{~m}$, $4 \mathrm{H}), 7.22(\mathrm{~d}, J=8.64 \mathrm{~Hz}, 2 \mathrm{H}), 6.82(\mathrm{~d}, J=8.78 \mathrm{~Hz}, 2 \mathrm{H}), 4.64(\mathrm{~d}, J=10.10 \mathrm{~Hz}, 1 \mathrm{H}), 4.32(\mathrm{~d}$, $J=10.10 \mathrm{~Hz}, 1 \mathrm{H}), 3.78(\mathrm{~s}, 3 \mathrm{H}), 3.66(\mathrm{q}, J=6.88 \mathrm{~Hz}, 1 \mathrm{H}), 2.94(\mathrm{~s}, 1 \mathrm{H}), 2.81(\mathrm{td}, J=12.15$, $\mathrm{Hz}, J=2.49 \mathrm{~Hz}, 1 \mathrm{H}), 2.36(\mathrm{dt}, J=11.86 \mathrm{~Hz}, J=4.24 \mathrm{~Hz}, 1 \mathrm{H}), 1.76(\mathrm{dt}, J=13.76 \mathrm{~Hz}, J=$ $2.49 \mathrm{~Hz}, 1 \mathrm{H}), 1.57(\mathrm{~d}, J=6.74 \mathrm{~Hz}, 1 \mathrm{H}), 1.22(\mathrm{~s}, 3 \mathrm{H}), 1.20(\mathrm{~d}, J=6.88 \mathrm{~Hz}, 3 \mathrm{H}) .{ }^{13} \mathrm{C} \mathrm{NMR}$ $\left(600 \mathrm{MHz}, \mathrm{CDCl}_{3}\right): \delta 158.5,136.7,135.8,135.1,134.7,129.5,128.6,127.5,113.5,98.3$, 69.5, 63.2, 55.4, 54.7, 38.7, 37.1, 27.5, 8.9. HRMS Calculated for $\mathrm{C}_{21} \mathrm{H}_{25} \mathrm{ClN}_{2} \mathrm{O}_{4}[\mathrm{M}+\mathrm{H}]^{+}$: 405.15029, Found: 405.15120.

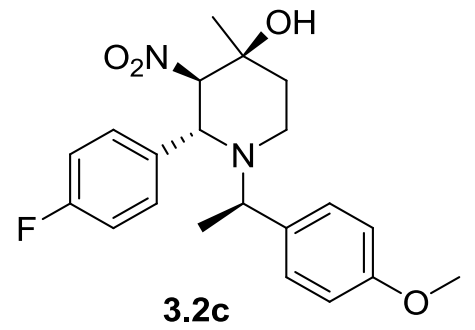

\section{(2R,3R,4S)-2-(4-fluorophenyl)-1-((R)-1-(4-methoxyphenyl)ethyl)-4-methyl-3-nitro}

piperidin-4-ol(3.2c major) was purified by flash silica gel chromatography (HexaneEtOAc, v/v 9/1) as white solid, yield: $73 \% .{ }^{1} \mathrm{H}$ NMR $\left(600 \mathrm{MHz}, \mathrm{CDCl}_{3}\right): \delta$ 7.46-7.38(m, $2 \mathrm{H}), 7.25-7.23(\mathrm{~m}, 2 \mathrm{H}), 7.05(\mathrm{~d}, J=7.90 \mathrm{~Hz}, 2 \mathrm{H}), 6.82(\mathrm{~d}, J=8.64 \mathrm{~Hz}, 2 \mathrm{H}), 4.64(\mathrm{~d}, J=$ $7.76 \mathrm{~Hz}, 1 \mathrm{H}), 4.33(\mathrm{~d}, J=10.10 \mathrm{~Hz}, 1 \mathrm{H}), 3.78(\mathrm{~s}, 3 \mathrm{H}), 3.67(\mathrm{~d}, J=6.59 \mathrm{~Hz}, 3 \mathrm{H}), 2.97(\mathrm{~s}$, $1 \mathrm{H}), 2.81(\mathrm{t}, J=11.12 \mathrm{~Hz}, 1 \mathrm{H}), 2.36(\mathrm{~d}, J=7.17 \mathrm{~Hz}, 1 \mathrm{H}), 1.76(\mathrm{~d}, J=15.37 \mathrm{~Hz}, 1 \mathrm{H})$, $1.50(\mathrm{~m}, 1 \mathrm{H}), 1.27(\mathrm{~s}, 3 \mathrm{H}), 1.20(\mathrm{~d}, J=6.44 \mathrm{~Hz}, 3 \mathrm{H}) .{ }^{13} \mathrm{C} \mathrm{NMR}\left(600 \mathrm{MHz}, \mathrm{CDCl}_{3}\right): \delta$ 163.0, 158.3, 136.5, 135.6, 134.9, 134.5, 129.3, 129.2, 128.3, 127.3, 113.3, 98.1, 69.2, 63.0, 55.2, 54.4, 38.4, 36.8, 27.2, 8.7. HRMS Calculated for $\mathrm{C}_{21} \mathrm{H}_{25} \mathrm{FN}_{2} \mathrm{O}_{5}[\mathrm{M}+\mathrm{H}]^{+}$: 389.18319, Found: 385.18361 .

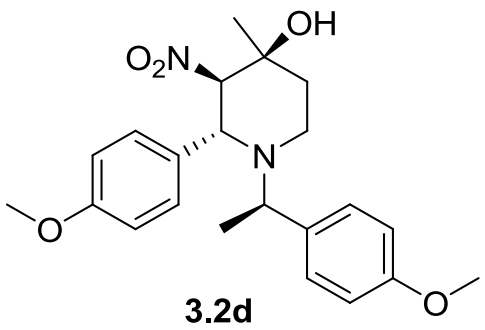


(2R,3R,4S)-2-(4-methoxyphenyl)-1-((R)-1-(4-methoxyphenyl)ethyl)-4-methyl-3-

nitropiperidin-4-ol(3.2d major) was purified by flash silica gel chromatography (Hexane- EtOAc, v/v 8/1) as white solid, yield: $55 \% .{ }^{1} \mathrm{H} \mathrm{NMR}\left(600 \mathrm{MHz}, \mathrm{CDCl}_{3}\right): \delta$ 7.40-7.35(m, 4H), 6.88(d, $J=8.05 \mathrm{~Hz}, 2 \mathrm{H}), 6.81(\mathrm{~d}, J=8.64 \mathrm{~Hz}, 2 \mathrm{H}), 4.67(\mathrm{~d}, J=9.95 \mathrm{~Hz}$, $1 \mathrm{H}), 4.28(\mathrm{~d}, J=10.10 \mathrm{~Hz}, 1 \mathrm{H}), 3.78(\mathrm{~s}, 3 \mathrm{H}), 3.77(\mathrm{~s}, 3 \mathrm{H}), 3.73(\mathrm{~d}, J=6.88 \mathrm{~Hz}, 1 \mathrm{H}), 3.02(\mathrm{~s}$, $1 \mathrm{H}), 2.80(\mathrm{t}, J=10.10, \mathrm{~Hz}, 1 \mathrm{H}), 2.35(\mathrm{~d}, J=15.37 \mathrm{~Hz}, 1 \mathrm{H}), 1.76(\mathrm{~d}, J=13.76 \mathrm{~Hz}, 1 \mathrm{H})$, $1.56(\mathrm{~d}, J=11.27 \mathrm{~Hz}, 1 \mathrm{H}), 1.27(\mathrm{~s}, 3 \mathrm{H}), 1.20(\mathrm{~d}, J=6.73 \mathrm{~Hz}, 3 \mathrm{H}) .{ }^{13} \mathrm{C} \mathrm{NMR}(600 \mathrm{MHz}$, $\left.\mathrm{CDCl}_{3}\right): \delta 159.9,158.4,135.6,128.9,128.6,114.6,113.5,98.6,69.5,63.3,55.4,38.8$, 37.1, 27.5, 8.90. HRMS Calculated for $\mathrm{C}_{22} \mathrm{H}_{28} \mathrm{~N}_{2} \mathrm{O}_{5}[\mathrm{M}+\mathrm{H}]^{+}:$401.20318, Found: 405.20352 .

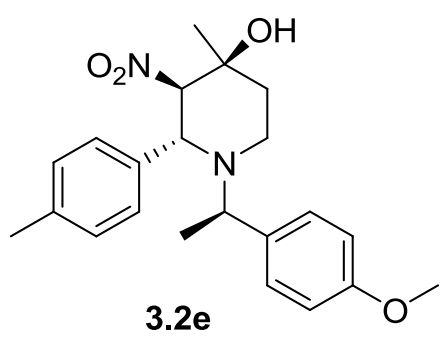

(2R,3R,4S)-1-((R)-1-(4-methoxyphenyl)ethyl)-4-methyl-3-nitro-2-p-tolylpiperidin-4ol (3.2e major) was purified by flash silica gel chromatography (Hexane- EtOAc, v/v 9/1) as white solid, yield: $66 \% .{ }^{1} \mathrm{H} \mathrm{NMR}\left(600 \mathrm{MHz}, \mathrm{CDCl}_{3}\right): \delta 7.39-7.24(\mathrm{~m}, 4 \mathrm{H}), 7.16(\mathrm{~d}, J=$ $7.90 \mathrm{~Hz}, 2 \mathrm{H}), 6.83(\mathrm{~d}, J=8.64 \mathrm{~Hz}, 2 \mathrm{H}), 4.71(\mathrm{~d}, J=10.10 \mathrm{~Hz}, 1 \mathrm{H}), 4.31(\mathrm{~d}, J=9.95 \mathrm{~Hz}$, $1 \mathrm{H}), 3.79(\mathrm{~s}, 3 \mathrm{H}), 3.74(\mathrm{q}, J=6.73 \mathrm{~Hz}, 3 \mathrm{H}), 3.05(\mathrm{~s}, 1 \mathrm{H}), 2.82(\mathrm{td}, J=12.29 \mathrm{~Hz}, J=2.34 \mathrm{~Hz}$, $1 \mathrm{H}), 2.36(\mathrm{~d}, J=4.39 \mathrm{~Hz}, 1 \mathrm{H}), 2.32(\mathrm{~s}, 3 \mathrm{H}), 1.76(\mathrm{~d}, J=13.76 \mathrm{~Hz}, 1 \mathrm{H}), 1.57(\mathrm{td}, J=12.88$ $\mathrm{Hz}, \quad J=3.81 \mathrm{~Hz}, 1 \mathrm{H}), 1.28(\mathrm{~s}, 3 \mathrm{H}), 1.21(\mathrm{~d}, J=6.73 \mathrm{~Hz}, 3 \mathrm{H}) .{ }^{13} \mathrm{C} \mathrm{NMR}(600 \mathrm{MHz}$, $\left.\mathrm{CDCl}_{3}\right): \delta 158.4,138.7,135.6,134.0,129.9,128.6,126.0,113.5,98.5,69.5,63.7,55.4$, 54.4, 38.7, 37.2, 27.5, 21.4, 8.9. HRMS Calculated for $\mathrm{C}_{22} \mathrm{H}_{28} \mathrm{~N}_{2} \mathrm{O}_{4}[\mathrm{M}+\mathrm{H}]^{+}: 385.20826$, Found: 385.20491 . 


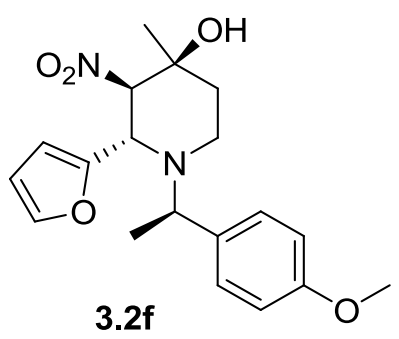

\section{(2S,3R,4S)-2-(furan-2-yl)-1-((R)-1-(4-methoxyphenyl)ethyl)-4-methyl-3-nitro}

piperidin-4-ol (3.2g major) was purified by flash silica gel chromatography (HexaneEtOAc, v/v 9/1) as white solid, yield: $73 \%$. ${ }^{1} \mathrm{H}$ NMR (600 MHz, $\left.\mathrm{CDCl}_{3}\right): \delta$ 7.34-7.33(m, $3 \mathrm{H}), 7.05(\mathrm{~m}, 1 \mathrm{H}), 6.91(\mathrm{~m}, 1 \mathrm{H}), 6.84(\mathrm{~d}, J=8.38 \mathrm{~Hz}, 1 \mathrm{H}), 4.71(\mathrm{~d}, J=10.10 \mathrm{~Hz}, 1 \mathrm{H})$, $4.34(\mathrm{~d}, J=10.10 \mathrm{~Hz}, 1 \mathrm{H}), 3.78(\mathrm{~s}, 3 \mathrm{H}), 3.72(\mathrm{~m}, 1 \mathrm{H}), 3.64(\mathrm{~s}, 1 \mathrm{H}), 2.82(\mathrm{t}, J=9.95 \mathrm{~Hz}, 1 \mathrm{H})$, $2.35(\mathrm{~d}, J=14.20 \mathrm{~Hz}, 1 \mathrm{H}), 1.76(\mathrm{~d}, J=13.76 \mathrm{~Hz}, 1 \mathrm{H}), 1.59(\mathrm{~m}, 1 \mathrm{H}), 1.27$ (s, 3H), $1.21(\mathrm{~d}, J$ $=6.6 .88 \mathrm{~Hz}, 3 \mathrm{H}) .{ }^{13} \mathrm{C} \mathrm{NMR}\left(600 \mathrm{MHz}, \mathrm{CDCl}_{3}\right): \delta 158.2,136.9,135.3,129.0,128.4$, 125.9, 132.0, 98.3, 69.2, 63.7, 55.2, 54.3, 38.5, 36.9, 27.3, 8.6. HRMS Calculated for $\mathrm{C}_{19} \mathrm{H}_{24} \mathrm{~N}_{2} \mathrm{O}_{4} \mathrm{~S}[\mathrm{M}+\mathrm{H}]^{+}: 361.17188$, Found: 361.17156 .

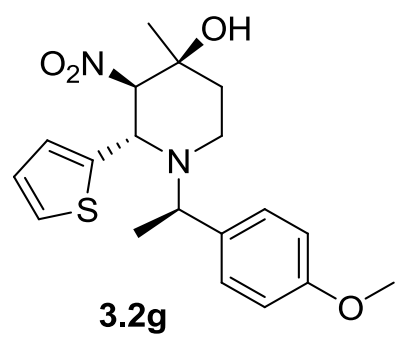

(2S,3R,4S)-1-((R)-1-(4-methoxyphenyl)ethyl)-4-methyl-3-nitro-2-(thiophen-2-yl)

piperidin-4-ol(3.2g major) was purified by flash silica gel chromatography (HexaneEtOAc, v/v 9/1) as white solid, yield: $72 \% .{ }^{1} \mathrm{H}$ NMR (600 MHz, $\left.\mathrm{CDCl}_{3}\right): \delta$ 7.33-7.31(m, $3 \mathrm{H}), 7.04(\mathrm{~m}, 1 \mathrm{H}), 6.90(\mathrm{t}, J=4.39 \mathrm{~Hz}, 1 \mathrm{H}), 6.83(\mathrm{~d}, J=8.64 \mathrm{~Hz}, 1 \mathrm{H}), 4.70(\mathrm{~m}, 2 \mathrm{H}), 3.78(\mathrm{~s}$, $3 \mathrm{H}), 2.97(\mathrm{~m}, 1 \mathrm{H}), 2.83(\mathrm{td}, J=12.44 \mathrm{~Hz}, J=2.49 \mathrm{~Hz}, 1 \mathrm{H}), 2.32(\mathrm{~d}, J=10.54 \mathrm{~Hz}, 1 \mathrm{H})$, $1.75(\mathrm{~d}, J=13.76 \mathrm{~Hz}, 1 \mathrm{H}), 1.56(\mathrm{~m}, 1 \mathrm{H}), 1.27(\mathrm{~s}, 3 \mathrm{H}), 1.25(\mathrm{~d}, J=6.73 \mathrm{~Hz}, 3 \mathrm{H}) .{ }^{13} \mathrm{C} \mathrm{NMR}$ $\left(600 \mathrm{MHz}, \mathrm{CDCl}_{3}\right): \delta 158.4,137.2,135.5,129.2,128.6,113.5,98.5,69.5,63.9,55.4$, 54.5, 38.7, 37.1, 27.5, 8.9. HRMS Calculated for $\mathrm{C}_{19} \mathrm{H}_{24} \mathrm{~N}_{2} \mathrm{O}_{4} \mathrm{~S}[\mathrm{M}+\mathrm{H}]^{+}$: 377.14903, Found: 377.14956. 


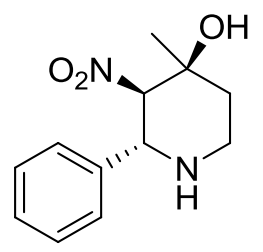

3.3a

(2R,3R,4S)-4-methyl-3-nitro-2-phenylpiperidin-4-ol (3.3a) was purified by flash silica gel chromatography $\left(\mathrm{CH}_{2} \mathrm{Cl}_{2}-\mathrm{MeOH}, \mathrm{v} / \mathrm{v} 100 / 1\right)$ as solid, yield: $88 \%$. ${ }^{1} \mathrm{H} \mathrm{NMR}(600 \mathrm{MHz}$, $\left.\mathrm{CDCl}_{3}\right): \delta 7.37-7.28(\mathrm{~m}, 5 \mathrm{H}), 4.56(\mathrm{~d}, J=10.25 \mathrm{~Hz}, 1 \mathrm{H}), 4.45(\mathrm{~d}, J=10.25 \mathrm{~Hz}, 1 \mathrm{H})$, $3.29(\mathrm{td}, J=12.29 \mathrm{~Hz}, J=2.93 \mathrm{~Hz}, 1 \mathrm{H}), 2.92(\mathrm{ddd}, J=12.07 \mathrm{~Hz}, J=4.83 \mathrm{~Hz}, J=2.20 \mathrm{~Hz}$, $1 \mathrm{H}), 1.89(\mathrm{dt}, J=13.76 \mathrm{~Hz}, J=2.49 \mathrm{~Hz}, 1 \mathrm{H}), 1.71(\mathrm{td}, J=12.59 \mathrm{~Hz}, J=4.83 \mathrm{~Hz}, 1 \mathrm{H})$, $1.31(\mathrm{~s}, 3 \mathrm{H}){ }^{13} \mathrm{C}$ NMR $\left(600 \mathrm{MHz}, \mathrm{CDCl}_{3}\right): \delta 138.2,129.1,129.0,127.7,96.9,69.9,60.4$, 41.5, 38.1, 27.7 HRMS Calculated for $\mathrm{C}_{12} \mathrm{H}_{16} \mathrm{~N}_{2} \mathrm{O}_{3}[\mathrm{M}+\mathrm{H}]^{+}:$237.11945, Found: 237.11933. Enantiomeric excess of the piperidine was determined by HPLC analysis with a Chiralcel OD-H column (90:10 hexane: isopropanol, $0.9 \mathrm{~mL} / \mathrm{min}, 220 \mathrm{~nm}$ ); Racemic mixture $\mathrm{tR}_{1}=13.8 \mathrm{~min}, \mathrm{tR}_{2}=17.8 \mathrm{~min}$; Enantiopure isomer: $99 \%$ ee, $\mathrm{tR}=19.2 \mathrm{~min}$ and $[\alpha]_{\mathrm{D}}^{20}-25.6\left(\mathrm{c}=0.1, \mathrm{CH}_{2} \mathrm{Cl}_{2}\right)$.

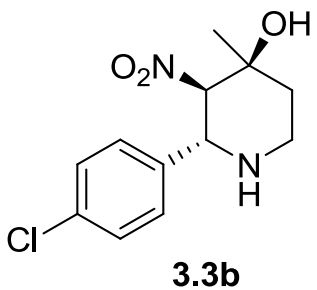

(2R,3R,4S)-2-(4-chlorophenyl)-4-methyl-3-nitropiperidin-4-ol(3.3b) was purified by flash silica gel chromatography $\left(\mathrm{CH}_{2} \mathrm{Cl}_{2}-\mathrm{MeOH}\right.$, v/v 100/1) as solid, yield: $92 \%$. ${ }^{1} \mathrm{H}$ NMR (600 MHz, $\left.\mathrm{CDCl}_{3}\right): \delta 7.32-7.24(\mathrm{~m}, 4 \mathrm{H}), 4.47(\mathrm{~d}, J=10.17 \mathrm{~Hz}, 1 \mathrm{H}), 4.43(\mathrm{~d}, J=$ $10.17 \mathrm{~Hz}, 1 \mathrm{H}), 3.28(\mathrm{td}, J=12.52 \mathrm{~Hz}, J=2.74 \mathrm{~Hz}, 1 \mathrm{H}), 2.90(\mathrm{dd}, J=11.74 \mathrm{~Hz}, J=4.70$ $\mathrm{Hz}, 1 \mathrm{H}), 1.86(\mathrm{dt}, J=13.69 \mathrm{~Hz}, J=2.74 \mathrm{~Hz}, 1 \mathrm{H}), 1.68(\mathrm{td}, J=12.52 \mathrm{~Hz}, J=5.09 \mathrm{~Hz}, 1 \mathrm{H})$, $1.31(\mathrm{~s}, 3 \mathrm{H}){ }^{13} \mathrm{C}$ NMR $\left(600 \mathrm{MHz}, \mathrm{CDCl}_{3}\right): \delta 136.7,134.6,129.0,128.9,96.7,69.7,59.6$, 41.3, 37.8, 27.4 HRMS Calculated for $\mathrm{C}_{12} \mathrm{H}_{15} \mathrm{ClN}_{2} \mathrm{O}_{3}[\mathrm{M}+\mathrm{H}]^{+}$: 272.07417, Found: 272.07327. Enantiomeric excess of the piperidine was determined by HPLC analysis with a Chiralcel OD-H column (90:10 hexane: isopropanol, $0.9 \mathrm{~mL} / \mathrm{min}, 220 \mathrm{~nm}$ ); Racemic 
mixture $\mathrm{tR}_{1}=16.5 \mathrm{~min}, \mathrm{tR}_{2}=19.1 \mathrm{~min}$; Enantiopure isomer: $99 \%$ ee, $\mathrm{tR}=16.4 \mathrm{~min}$ and $[\alpha]_{D}{ }^{20}-34.4\left(\mathrm{c}=0.1, \mathrm{CH}_{2} \mathrm{Cl}_{2}\right)$.

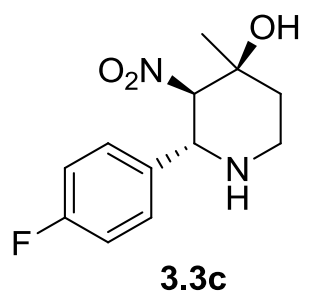

(2R,3R,4S)-2-(4-fluorophenyl)-4-methyl-3-nitropiperidin-4-ol (3.3c) was purified by flash silica gel chromatography $\left(\mathrm{CH}_{2} \mathrm{Cl}_{2}-\mathrm{MeOH}, \mathrm{v} / \mathrm{v} 100 / 1\right)$ as solid, yield: $90 \%$. ${ }^{1} \mathrm{H}$ NMR (600 MHz, $\left.\mathrm{CDCl}_{3}\right): \delta 7.33(\mathrm{t}, J=6.65 \mathrm{~Hz}, 2 \mathrm{H}), 6.99(\mathrm{~d}, J=6.65 \mathrm{~Hz}, 2 \mathrm{H}), 4.48(\mathrm{~d}, J$ $=10.17 \mathrm{~Hz}, 1 \mathrm{H}), 4.43(\mathrm{~d}, J=10.17 \mathrm{~Hz}, 1 \mathrm{H}), 3.28(\mathrm{td}, J=12.13 \mathrm{~Hz}, J=2.74 \mathrm{~Hz}, 1 \mathrm{H})$, $2.90(\mathrm{dq}, J=11.74 \mathrm{~Hz}, J=1.96 \mathrm{~Hz}, 1 \mathrm{H}), 1.87(\mathrm{dt}, J=13.69 \mathrm{~Hz}, J=2.35 \mathrm{~Hz}, 1 \mathrm{H}), 1.69(\mathrm{td}$, $J=13.69 \mathrm{~Hz}, J=4.70 \mathrm{~Hz}, 1 \mathrm{H}), 1.31(\mathrm{~s}, 3 \mathrm{H}){ }^{13} \mathrm{C} \mathrm{NMR}\left(600 \mathrm{MHz}, \mathrm{CDCl}_{3}\right): \delta 164.3,161.9$, 134.3, 129.5, 129.4, 116.1, 115.9, 97.2, 70.0, 59.8, 41.6, 38.1, 27.7 HRMS Calculated for $\mathrm{C}_{12} \mathrm{H}_{15} \mathrm{FN}_{2} \mathrm{O}_{3}[\mathrm{M}+\mathrm{H}]^{+}:$255.1103, Found: 255.1133. Enantiomeric excess of the piperidine was determined by HPLC analysis with a Chiralcel OD-H column (90:10 hexane: isopropanol, $0.9 \mathrm{~mL} / \mathrm{min}, 220 \mathrm{~nm}$ ); Racemic mixture $\mathrm{tR}_{1}=16.6 \mathrm{~min}, \mathrm{tR}_{2}=21.4$ min; Enantiopure isomer: 99\% ee, $\mathrm{tR}=16.2 \mathrm{~min}$ and $[\alpha]_{\mathrm{D}}{ }^{20}-39.5\left(\mathrm{c}=0.1, \mathrm{CH}_{2} \mathrm{Cl}_{2}\right)$.

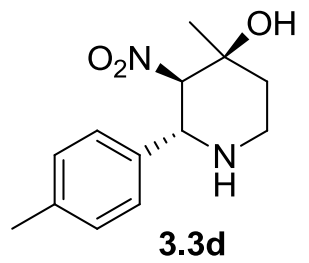

(2R,3R,4S)-4-methyl-3-nitro-2-p-tolylpiperidin-4-ol (3.3d) was purified by flash silica gel chromatography $\left(\mathrm{CH}_{2} \mathrm{Cl}_{2}-\mathrm{MeOH}, \mathrm{v} / \mathrm{v} 100 / 1\right)$ as solid, yield: $77 \% .{ }^{1} \mathrm{H} \mathrm{NMR}(600 \mathrm{MHz}$, $\left.\mathrm{CDCl}_{3}\right): \delta 7.23(\mathrm{~d}, J=8.22 \mathrm{~Hz}, 1 \mathrm{H}), 7.11(\mathrm{~d}, J=8.22 \mathrm{~Hz}, 1 \mathrm{H}), 4.52(\mathrm{~d}, J=10.17 \mathrm{~Hz}, 1 \mathrm{H})$, $4.41(\mathrm{~d}, J=10.17 \mathrm{~Hz}, 1 \mathrm{H}), 3.28(\mathrm{td}, J=12.52 \mathrm{~Hz}, J=2.74 \mathrm{~Hz}, 1 \mathrm{H}), 2.91(\mathrm{dd}, J=11.74$ $\mathrm{Hz}, J=2.34 \mathrm{~Hz}, 1 \mathrm{H}), 2.30(\mathrm{~s}, 3 \mathrm{H}), 1.88(\mathrm{~d}, J=11.74 \mathrm{~Hz}, 1 \mathrm{H}), 1.66(\mathrm{td}, J=13.30 \mathrm{~Hz}, J=$ $4.70 \mathrm{~Hz}, 1 \mathrm{H}), 1.31(\mathrm{~s}, 3 \mathrm{H}){ }^{13} \mathrm{C} \mathrm{NMR}\left(600 \mathrm{MHz}, \mathrm{CDCl}_{3}\right): \delta 138.6,135.0,129.4,127.3$, 96.8, 69.7, 60.0, 41.3, 37.9, 27.4, 21.1 HRMS Calculated for $\mathrm{C}_{13} \mathrm{H}_{18} \mathrm{~N}_{2} \mathrm{O}_{3}[\mathrm{M}+\mathrm{H}]^{+}$: 251.13510, Found: 151.13531. Enantiomeric excess of the piperidine was determined by 
HPLC analysis with a Chiralcel OD-H column (90:10 hexane: isopropanol, $0.9 \mathrm{~mL} / \mathrm{min}$, $220 \mathrm{~nm}$ ); Racemic mixture $\mathrm{tR}_{1}=15.9 \mathrm{~min}, \mathrm{tR}_{2}=18.4 \mathrm{~min}$; Enantiopure isomer: $99 \%$ ee, $\mathrm{tR}=16.4 \mathrm{~min}$ and $[\alpha]_{\mathrm{D}}^{20}-29.3\left(\mathrm{c}=0.1, \mathrm{CH}_{2} \mathrm{Cl}_{2}\right)$.

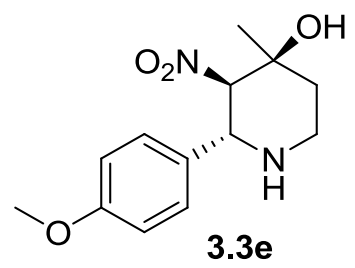

(2R,3R,4S)-2-(4-methoxyphenyl)-4-methyl-3-nitropiperidin-4-ol (3.3e) was purified by flash silica gel chromatography $\left(\mathrm{CH}_{2} \mathrm{Cl}_{2}-\mathrm{MeOH}, \mathrm{v} / \mathrm{v} 100 / 1\right)$ as solid, yield: $75 \% .{ }^{1} \mathrm{H}$ NMR (600 MHz, $\left.\mathrm{CDCl}_{3}\right): \delta 7.27(\mathrm{~d}, J=9.00 \mathrm{~Hz}, 1 \mathrm{H}), 6.82(\mathrm{~d}, J=9.00 \mathrm{~Hz}, 1 \mathrm{H}), 4.51(\mathrm{~d}, J$ $=10.17 \mathrm{~Hz}, 1 \mathrm{H}), 4.39(\mathrm{~d}, J=10.17 \mathrm{~Hz}, 1 \mathrm{H}), 3.76(\mathrm{~s}, 3 \mathrm{H}), 3.33(\mathrm{~s}, 1 \mathrm{H}), 2.82(\mathrm{td}, J=12.13$ $\mathrm{Hz}, J=2.74 \mathrm{~Hz}, 1 \mathrm{H}), 2.90(\mathrm{dd}, J=11.74 \mathrm{~Hz}, J=1.96 \mathrm{~Hz}, 1 \mathrm{H}), 1.86(\mathrm{dt}, J=13.69 \mathrm{~Hz}, 1 \mathrm{H})$, 1.68(m, 1H), $1.31(\mathrm{~s}, 3 \mathrm{H}){ }^{13} \mathrm{C}$ NMR $\left(600 \mathrm{MHz}, \mathrm{CDCl}_{3}\right): \delta 159.8,130.1,128.6,114.1$, 96.9, 69.7, 59.7, 55.2, 41.4, 37.8, 27.4 HRMS Calculated for $\mathrm{C}_{13} \mathrm{H}_{18} \mathrm{~N}_{2} \mathrm{O}_{4}[\mathrm{M}+\mathrm{H}]^{+}$: 267.13001, Found: 267.13054. Enantiomeric excess of the piperidine was determined by HPLC analysis with a Chiralcel OD-H column (95:5 hexane: isopropanol, $0.5 \mathrm{~mL} / \mathrm{min}$, $220 \mathrm{~nm}$ ); Racemic mixture $\mathrm{tR}_{1}=27.1 \mathrm{~min}, \mathrm{tR}_{2}=34.4 \mathrm{~min}$; Enantiopure isomer: $99 \%$ ee, $\mathrm{tR}=35.5 \mathrm{~min}$ and $[\alpha]_{\mathrm{D}}{ }^{20}-42.7\left(\mathrm{c}=0.1, \mathrm{CH}_{2} \mathrm{Cl}_{2}\right)$.

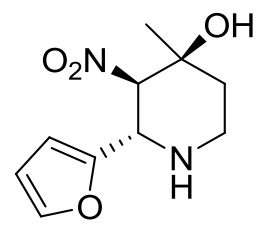

3.3f

(2S,3R,4S)-2-(furan-2-yl)-4-methyl-3-nitropiperidin-4-ol(3.3f) was purified by flash silica gel chromatography $\left(\mathrm{CH}_{2} \mathrm{Cl}_{2}-\mathrm{MeOH}, \mathrm{v} / \mathrm{v} 100 / 1\right)$ as solid, yield: $65 \% .{ }^{1} \mathrm{H}$ NMR $\left(600 \mathrm{MHz}, \mathrm{CDCl}_{3}\right): \delta 7.35(\mathrm{~m}, 1 \mathrm{H}), 6.27(\mathrm{~m}, 2 \mathrm{H}), 4.67(\mathrm{~d}, J=10.17 \mathrm{~Hz}, 1 \mathrm{H}), 4.62(\mathrm{~d}, J=$ $10.17 \mathrm{~Hz}, 1 \mathrm{H}), 3.33(\mathrm{~s}, 1 \mathrm{H}), 3.26(\mathrm{td}, J=12.52 \mathrm{~Hz}, J=2.74 \mathrm{~Hz}, 1 \mathrm{H}), 2.93(\mathrm{dd}, J=12.52$ $\mathrm{Hz}, J=1.96 \mathrm{~Hz}, 1 \mathrm{H}), 1.88(\mathrm{~d}, J=14.09 \mathrm{~Hz}, 1 \mathrm{H}), 1.33(\mathrm{~s} 3 \mathrm{H}),{ }^{13} \mathrm{C} \mathrm{NMR}(600 \mathrm{MHz}$, $\left.\mathrm{CDCl}_{3}\right): \delta 143.2,110.5,108.6,94.6,69.8,53.8,41.1,38.5,29.9,27.7$ HRMS Calculated for $\mathrm{C}_{10} \mathrm{H}_{14} \mathrm{~N}_{2} \mathrm{O}_{4}[\mathrm{M}+\mathrm{H}]^{+}$: 227.09871, Found: 227.09851. 
Enantiomeric excess of the piperidine was determined by HPLC analysis with a Chiralcel OD-H column (90:10 hexane: isopropanol, $1 \mathrm{~mL} / \mathrm{min}, 220 \mathrm{~nm}$ ); Racemic mixture $\mathrm{tR}_{1}=$ $19.1 \mathrm{~min}, \mathrm{tR}_{2}=25.1 \mathrm{~min}$; Enantiopure isomer: $99 \% \mathrm{ee}, \mathrm{tR}=18.4 \mathrm{~min}$ and $[\alpha]_{\mathrm{D}}{ }^{20}+57.2(\mathrm{c}$ $=0.1, \mathrm{CH}_{2} \mathrm{Cl}_{2}$ ).

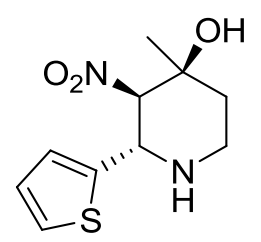

$3.3 \mathrm{~g}$

(2S,3R,4S)-4-methyl-3-nitro-2-(thiophen-2-yl)piperidin-4-ol(3.3g) was purified by flash silica gel chromatography $\left(\mathrm{CH}_{2} \mathrm{Cl}_{2}-\mathrm{MeOH}\right.$, v/v 100/1) as solid, yield: $85 \%$. ${ }^{1} \mathrm{H}$ NMR (600 MHz, $\left.\mathrm{CDCl}_{3}\right): \delta 7.24(\mathrm{~d}, J=4.70 \mathrm{~Hz}, 1 \mathrm{H}), 6.94(\mathrm{~d}, J=3.52 \mathrm{~Hz}, 2 \mathrm{H}), 6.90(\mathrm{t}, J$ $=5.09 \mathrm{~Hz}, 1 \mathrm{H}), 4.81(\mathrm{~d}, J=10.17 \mathrm{~Hz}, 1 \mathrm{H}), 4.47(\mathrm{~d}, J=10.17 \mathrm{~Hz}, 1 \mathrm{H}), 3.28(\mathrm{td}, J=12.13$ $\mathrm{Hz}, J=2.24 \mathrm{~Hz}, 1 \mathrm{H}), 2.90(\mathrm{dq}, J=11.74 \mathrm{~Hz}, J=2.34 \mathrm{~Hz}, 1 \mathrm{H}), 1.87(\mathrm{dt}, J=13.69 \mathrm{~Hz}, J=$ $2.74 \mathrm{~Hz}, 1 \mathrm{H}), 1.69(\mathrm{td}, J=12.52 \mathrm{~Hz}, J=5.09 \mathrm{~Hz}, 1 \mathrm{H}), 1.30(\mathrm{~s} 3 \mathrm{H}),{ }^{13} \mathrm{C} \mathrm{NMR}(600 \mathrm{MHz}$, $\left.\mathrm{CDCl}_{3}\right): \delta$ 132.2, 126.3, 126.0, 125.9, 97.2, 69.3, 61.2, 42.2. 38.3, 27.4 HRMS Calculated for $\mathrm{C}_{10} \mathrm{H}_{14} \mathrm{~N}_{2} \mathrm{O}_{3} \mathrm{~S}[\mathrm{M}+\mathrm{H}]^{+}:$243.07587, Found: 243.07551. Enantiomeric excess of the piperidine was determined by HPLC analysis with a Chiralcel OD-H column (90:10 hexane: isopropanol, $1 \mathrm{~mL} / \mathrm{min}, 220 \mathrm{~nm}$ ); Racemic mixture $\mathrm{tR}_{1}=20.1 \mathrm{~min}, \mathrm{tR}_{2}=26.7$ min; Enantiopure isomer: 99\% ee, $\mathrm{tR}=26.3 \mathrm{~min}$ and $[\alpha]_{\mathrm{D}}{ }^{20}+51.8\left(\mathrm{c}=0.1, \mathrm{CH}_{2} \mathrm{Cl}_{2}\right)$.

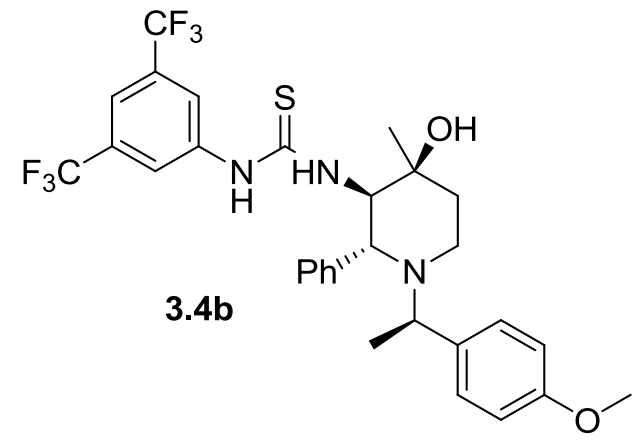

\section{1-(3,5-bis(trifluoromethyl)phenyl)-3-((2R,3R,4S)-4-hydroxy-1-((R)-1-(4-methoxy phenyl) ethyl) -4-methyl-2-phenylpiperidin-3-yl)thiourea (3.4b) was purified by flash} silica gel chromatography (Hexane/EtOAc, v/v 5/1 to 1/1) as solid, yield: $92 \% .{ }^{1} \mathrm{H}$ NMR 
(600 MHz, $\left.\mathrm{CDCl}_{3}\right): \delta 8.09(\mathrm{~s}, 2 \mathrm{H}), 7.73(\mathrm{t}, J=9.98 \mathrm{~Hz}, 1 \mathrm{H}), 7.65(\mathrm{~s}, 1 \mathrm{H}), 7.49(\mathrm{~m}, 2 \mathrm{H})$ $7.31(\mathrm{~d}, J=8.80 \mathrm{~Hz}, 2 \mathrm{H}), 7.25(\mathrm{t}, J=7.24 \mathrm{~Hz}, 1 \mathrm{H}), 7.16(\mathrm{t}, J=7.24 \mathrm{~Hz}, 1 \mathrm{H}), 6.87(\mathrm{~d}, J=$ $8.41 \mathrm{~Hz}, 2 \mathrm{H}), 4.93(\mathrm{~s}, 1 \mathrm{H}), 4.73(\mathrm{~s}, 2 \mathrm{H}), 4.65(\mathrm{t}, J=9.98 \mathrm{~Hz}, 1 \mathrm{H}), 3.73(\mathrm{~s}, 3 \mathrm{H}), 3.70(\mathrm{~m}$, $1 \mathrm{H}), 3.60(\mathrm{q}, J=6.85 \mathrm{~Hz}, 1 \mathrm{H}), 2.66(\mathrm{~m}, 2 \mathrm{H}), 2.19(\mathrm{~m}, 1 \mathrm{H}), 1.62(\mathrm{~m}, 1 \mathrm{H}), 1.14(\mathrm{~s}, 3 \mathrm{H})$, $1.13(\mathrm{~s}, 3 \mathrm{H}){ }^{13} \mathrm{C}$ NMR (600 MHz, CDCl3): $\delta$ 185.7, 162.8, 147.2, 145.2, 140.8, 135.7, 135.3, 135.0, 134.7, 133.4, 132.1, 129.7, 127.0, 126.3, 120.8, 118.4, 74.9, 70.3, 68.1, 60.1, 58.9, 43.4, 43.0, 32.9, 13.3 HRMS Calculated for $\mathrm{C}_{30} \mathrm{H}_{31} \mathrm{~F}_{6} \mathrm{~N}_{3} \mathrm{O}_{2} \mathrm{~S}[\mathrm{M}+\mathrm{H}]^{+}$: 612.20747, Found: 612.20711.

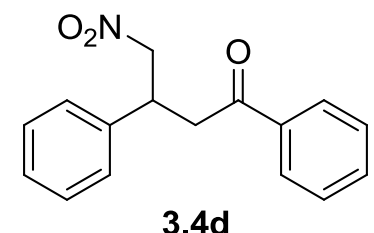

(R)-4-Nitro-1,3-diphenylbutan-1-one (3.4d): White solid; $[\alpha]_{\mathrm{D}}{ }^{20}=+21.0 \quad(\mathrm{c}=0.1$ in $\mathrm{CH}_{2} \mathrm{Cl}_{2}, 90: 10$ e.r.); ${ }^{1} \mathrm{H}$ NMR (400 MHz, $\mathrm{CDCl}_{3}$ ): $\delta=7.91-7.89$ (m, $2 \mathrm{H}$ ), 7.57-7.54 (m, 1 H), 7.46-7.42 (m, 2H), 7.32-7.27 (m, 5H), $4.81(\mathrm{dd}, \mathrm{J}=12.5,6.6 \mathrm{~Hz}, 1 \mathrm{H}), 4.68(\mathrm{dd}, \mathrm{J}=12.5$, $8.0 \mathrm{~Hz}, 1 \mathrm{H}), 4.22$ (ps quint, J=7.1 Hz, 1H), 3.50-3.37 (m, $2 \mathrm{H}) ;{ }^{13} \mathrm{C} \mathrm{NMR}(400 \mathrm{MHz}$, $\left.\mathrm{CDCl}_{3}\right): \delta=196.8,139.1,136.3,133.5,129.0,128.7,127.4,79.5,41.5,39.2 ;$ HPLC (Chiralpak AS-H, hexane/isopropanol 90:10, $1.0 \mathrm{~mL} / \mathrm{min}, 220 \mathrm{~nm}$ ): $\mathrm{tR}_{1}=10.3 \mathrm{~min}, \mathrm{tR}_{2}=$ 13.6 min; Enantiopure isomer: ee 94:6 (en1), ee 92:8 (en2); HRMS: m/z: calcd for $\mathrm{C}_{16} \mathrm{H}_{15} \mathrm{NO}_{3}[\mathrm{M}+\mathrm{H}]^{+}: 270.10519$; found: 270.10855 .

\section{A2.3: Triazole gold(I) catalysis}

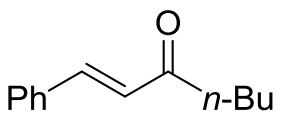

4.3.4a, $92 \%, E / Z=12: 1$

(E)-1-phenylhept-1-en-3-one $(\boldsymbol{E}$-4.3.4a): (Known compound, See: N. Marion, P. Carlqvist, R. Gealageas, P. Fremont, F. Maseras, S. P. Nolan, Chem. Eur. J. 2007, 13, 6437-6451) ${ }^{1} \mathrm{H}$ NMR (600 MHz, $\left.\mathrm{CDCl}_{3}\right): \delta$ 7.53-7.56 (m, 3H), 7.38-7.40 (m, 3H), $6.73(\mathrm{t}$, $J=16.2 \mathrm{~Hz}, 1 \mathrm{H}$ ), 2.66 (t, $J=7.5 \mathrm{~Hz}, 2 \mathrm{H}$ ), 1.66 (quintet, $J=7.5 \mathrm{~Hz}, 2 \mathrm{H}$ ), 1.37 (sextet, $J=$ 
$7.4 \mathrm{~Hz}, 2 \mathrm{H}), 0.94(\mathrm{t}, J=7.5 \mathrm{~Hz}, 3 \mathrm{H}) ;{ }^{13} \mathrm{C} \mathrm{NMR}\left(150 \mathrm{MHz}, \mathrm{CDCl}_{3}\right): \delta 200.8,142.5,134.8$, 130.6, 129.1, 128.4, 126.5, 40.9, 26.7, 22.7, 14.1.<smiles>CC(C)(C)C(=O)/C=C/c1ccccc1</smiles>

4.3.4b, $93 \%, E / Z=3: 1$

(E)-4,4-dimethyl-1-phenylpent-1-en-3-one $(\boldsymbol{E}$-4.3.4b): (Known compound, See: R. S. Ramon, S. Gaillard, A. M. Z. Slawin, A. Porta, A. D'Alfonso, G. Zanoni, S. P. Nolan, Organometallics 2010, 29, 3665-3668) ${ }^{1} \mathrm{H}$ NMR (600 MHz, $\left.\mathrm{CDCl}_{3}\right): \delta 7.69(\mathrm{~d}, J=16.2$ $\mathrm{Hz}, 1 \mathrm{H}, E), 7.56-7.58$ (m, 2H, E), 7.53-7.54 (m, 2H, Z), 7.37-7.40 (m, 3H, E), 7.29-7.33 (m, 3H, Z), 7.13 (d, $J=15.6 \mathrm{~Hz}, 1 \mathrm{H}, E), 6.78$ (d, $J=13.0 \mathrm{~Hz}, 1 \mathrm{H}, Z), 6.45$ (d, $J=13.0$ $\mathrm{Hz}, 1 \mathrm{H}, Z$ ) 1.23 (s, 9H, E), 1.20 (s, 9H, Z). ${ }^{13} \mathrm{C}$ NMR (150 MHz, CDCl $): \delta 204.2,142.9$, 140.1, 134.9, 130.2, 129.5, 128.8, 128.3, 128.1, 124.3, 120.8, 43.2, 26.3, 26.2 (Z+E).

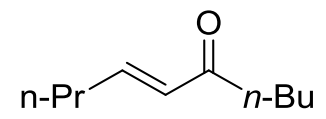

4.3.4c, $92 \%, E / Z>20: 1$

(E)-dec-6-en-5-one $(\boldsymbol{E}-4.3 .4 c)$ : (Known compound, See: M. N. Pennell, M. G. Unthank, P. Turner, T. D. Sheppard, J. Org. Chem. 2011, 76, 1479-1482) ${ }^{1} \mathrm{H}$ NMR (600 MHz, $\left.\mathrm{CDCl}_{3}\right): \delta 6.82(\mathrm{dt}, J=16.2,6.6 \mathrm{~Hz}, 1 \mathrm{H}), 6.10(\mathrm{dt}, J=15.6,3.6 \mathrm{~Hz}, 1 \mathrm{H}), 2.53(\mathrm{t}, J=7.8$ $\mathrm{Hz}, 2 \mathrm{H}$ ), 2.20 (qd, $J=7.2,1.2 \mathrm{~Hz}, 2 \mathrm{H}$ ), 1.60 (quintet, $J=7.7 \mathrm{~Hz}, 2 \mathrm{H}$ ), 1.50 (sextet, $J=$ $7.4 \mathrm{~Hz}, 2 \mathrm{H}$ ), 1.34 (sextet, $J=7.4 \mathrm{~Hz}, 2 \mathrm{H}$ ), 0.95 (t, $J=7.2 \mathrm{~Hz}, 3 \mathrm{H}$ ), 0.92 (t, $J=7.2 \mathrm{~Hz}$, $3 \mathrm{H}) ;{ }^{13} \mathrm{C}$ NMR $\left(150 \mathrm{MHz}, \mathrm{CDCl}_{3}\right): \delta 200.9,146.9,130.5,39.8,34.4,26.4,22.4,21.3$, 13.8, 13.6.

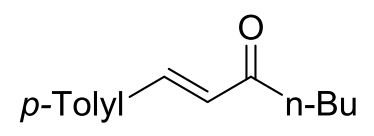

4.3.4d, $91 \%, E / Z>8: 1$

(E)-1-p-tolylhept-1-en-3-one $(\boldsymbol{E}$-4.3.4d): (Known compound, See: N. Marion, P. Carlqvist, R. Gealageas, P. Fremont, F. Maseras, S. P. Nolan, Chem. Eur. J. 2007, 13, 6437-6451) ${ }^{1} \mathrm{H}$ NMR (600 MHz, $\left.\mathrm{CDCl}_{3}\right): \delta 7.51(\mathrm{~d}, J=16.2, \mathrm{~Hz}, 1 \mathrm{H}), 7.43(\mathrm{~d}, J=7.8 \mathrm{~Hz}$, 
2H), $7.19(\mathrm{~d}, J=8.4 \mathrm{~Hz}, 2 \mathrm{H}), 6.71(\mathrm{~d}, J=15.6 \mathrm{~Hz}, 1 \mathrm{H}), 2.64(\mathrm{t}, J=7.5 \mathrm{~Hz}, 2 \mathrm{H}), 2.37(\mathrm{~s}$, $3 \mathrm{H}$ ), 1.66 (quintet, $J=7.7 \mathrm{~Hz}, 2 \mathrm{H}$ ), 1.37 (sextet, $J=7.4 \mathrm{~Hz}, 2 \mathrm{H}$ ), 0.92 (t, $J=7.5 \mathrm{~Hz}, 3 \mathrm{H}$ ); ${ }^{13} \mathrm{C}$ NMR (150 MHz, $\left.\mathrm{CDCl}_{3}\right): \delta .200 .6,142.3,140.8,131.8,129.6,128.2,125.3,40.5$, 26.5, 22.4, 21.4, 13.8 .

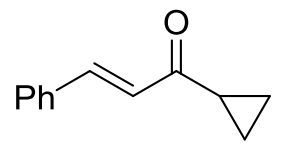

4.3.4e, $83 \%, E / Z=10: 1$

(E)-1-cyclopropyl-3-phenylprop-2-en-1-one $(\boldsymbol{E}$-4.3.4e): (Known compound, See: G. V. Kryshtal, G. M. Zhdankina, S. G. Zlotin, Eur. J. Org. Chem. 2005, 13, 2822-2827) ${ }^{1} \mathrm{H}$ NMR (600 MHz, $\left.\mathrm{CDCl}_{3}\right): \delta 7.63(\mathrm{~d}, J=16.2 \mathrm{~Hz}, 1 \mathrm{H}), \square 7.55-7.57(\mathrm{~m}, 2 \mathrm{H}), 7.38-7.40(\mathrm{~m}$, $3 \mathrm{H}), 6.86(\mathrm{~d}, J=16.2 \mathrm{~Hz}, 1 \mathrm{H}), 2.22-2.27(\mathrm{~m}, 1 \mathrm{H}), 1.15-1.17(\mathrm{~m}, 2 \mathrm{H}), 0.95-0.99(\mathrm{~m}, 2 \mathrm{H})$; ${ }^{13} \mathrm{C}$ NMR $\left(150 \mathrm{MHz}, \mathrm{CDCl}_{3}\right): \delta 199.9,141.9,134.6,130.2,128.8,128.2,126.4,19.6$, 11.3.

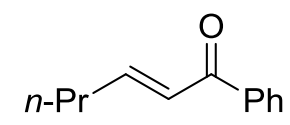

4.3.4f, $89 \%, E / Z>20: 1$

(E)-1-phenylhex-2-en-1-one (E-4.3.4f): (Known compound, See: N. Marion, P. Carlqvist, R. Gealageas, P. Fremont, F. Maseras, S. P. Nolan, Chem. Eur. J. 2007, 13, 6437-6451) ${ }^{1} \mathrm{H}$ NMR (600 MHz, $\left.\mathrm{CDCl}_{3}\right): \delta$ 7.91-7.93 (m, 2H), 7.52-7.54 (m, 1H), $7.45(\mathrm{t}$, $J=7.5 \mathrm{~Hz}, 2 \mathrm{H}), 7.05(\mathrm{dt}, J=15.6,7.8 \mathrm{~Hz}, 1 \mathrm{H}), 6.86(\mathrm{dt}, J=15.0,1.5 \mathrm{~Hz}, 1 \mathrm{H}), 2.28(\mathrm{~m}$, $2 \mathrm{H}), 1.54$ (sextet, $J=7.3 \mathrm{~Hz}, 2 \mathrm{H}), 0.97(\mathrm{t}, J=7.2 \mathrm{~Hz}, 3 \mathrm{H}) ;{ }^{13} \mathrm{C} \mathrm{NMR}\left(150 \mathrm{MHz}, \mathrm{CDCl}_{3}\right)$ : $\delta 190.8,149.6,137.9,132.4,128.4,128.3,125.9,34.7,21.3,13.6$.

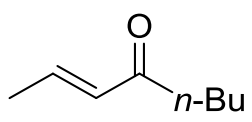

4.3.4g, $85 \%, E / Z>20: 1$

(E)-oct-2-en-4-one $(\boldsymbol{E}-\mathbf{4 . 3 . 4 g})$ : (Known compound, See: A. R. Katritzky, D. C. Oniciu, I. Ghiviriga, F. Soti, J. Org. Chem. 1998, 63, 2110-2115) ${ }^{1} \mathrm{H}$ NMR (600 MHz, $\left.\mathrm{CDCl}_{3}\right): \delta$ $6.85(\mathrm{dq}, J=16.2,6.8 \mathrm{~Hz}, 1 \mathrm{H}), 6.11(\mathrm{dq}, J=15.6,1.6 \mathrm{~Hz}, 1 \mathrm{H}), 2.52(\mathrm{t}, J=7.5 \mathrm{~Hz}, 2 \mathrm{H})$, 
1.90 (dd, $J=6.6,1.8 \mathrm{~Hz}, 3 \mathrm{H}$ ), 1.59 (quintet, $J=7.5 \mathrm{~Hz}, 2 \mathrm{H}$ ), 1.33 (sextet, $J=7.6 \mathrm{~Hz}$, 2H), $0.91(\mathrm{t}, J=7.2 \mathrm{~Hz}, 3 \mathrm{H}) ;{ }^{13} \mathrm{C} \mathrm{NMR}\left(150 \mathrm{MHz}, \mathrm{CDCl}_{3}\right): \delta 200.7,142.2,131.9,39.8$, $26.4,22.4,18.2,13.8$.

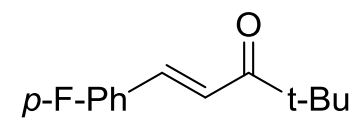

4.3.4h, $95 \%, E / Z>20: 1$

(E)-1-(4-fluorophenyl)hept-1-en-3-one $(\boldsymbol{E}$-4.3.4h): (Known compound, See: N. Marion, P. Carlqvist, R. Gealageas, P. Fremont, F. Maseras, S. P. Nolan, Chem. Eur. J. 2007, 13, 6437-6451) ${ }^{1} \mathrm{H}$ NMR (600 MHz, $\left.\mathrm{CDCl}_{3}\right): \delta 7.50-7.54(\mathrm{~m}, 3 \mathrm{H}), 7.08(\mathrm{t}, J=8.4 \mathrm{~Hz}, 2 \mathrm{H})$, $6.66(\mathrm{~d}, J=16.2 \mathrm{~Hz}, 1 \mathrm{H}), 2.65(\mathrm{t}, J=7.5 \mathrm{~Hz}, 2 \mathrm{H}), 1.66$ (quintet, $J=7.4 \mathrm{~Hz}, 2 \mathrm{H}), 1.38$ (sextet, $J=7.5 \mathrm{~Hz}, 2 \mathrm{H}), 0.94(\mathrm{t}, J=7.5 \mathrm{~Hz}, 3 \mathrm{H}) ;{ }^{13} \mathrm{C}$ NMR $\left(150 \mathrm{MHz}, \mathrm{CDCl}_{3}\right): \delta 200.3$, $163.0(\mathrm{~d}, J=249.8 \mathrm{~Hz}), 140.8,130.8(\mathrm{~d}, J=1.8 \mathrm{~Hz}), 130.0(\mathrm{~d}, J=8.3 \mathrm{~Hz}), 125.9,116.0$ $(\mathrm{d}, J=21.8 \mathrm{~Hz}), 40.7,26.4,22.3,13.8$.

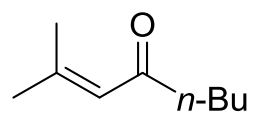

4.3.4i, $89 \%$

2-methyloct-2-en-4-one (4.3.4i): (Known compound, See: M. Yu, G. Li, S. Wang, L. Zhang, Adv. Synth. Catal. 2007, 349, 871-875) ${ }^{1} \mathrm{H}$ NMR (600 MHz, $\left.\mathrm{CDCl}_{3}\right)$ : $\delta$ 6.06-6.08 $(\mathrm{m}, 1 \mathrm{H}), 2.40(\mathrm{t}, J=7.5 \mathrm{~Hz}, 2 \mathrm{H}), 2.14(\mathrm{~d}, J=1.2 \mathrm{~Hz}, 3 \mathrm{H}), 1.88(\mathrm{~d}, J=1.2 \mathrm{~Hz}, 3 \mathrm{H}), 1.57$ (quintet, $J=7.5 \mathrm{~Hz}, 2 \mathrm{H}), 1.32$ (sextet, $J=7.4 \mathrm{~Hz}, 2 \mathrm{H}), 0.91(\mathrm{t}, J=7.2 \mathrm{~Hz}, 3 \mathrm{H}) ;{ }^{13} \mathrm{C} \mathrm{NMR}$ $\left(150 \mathrm{MHz}, \mathrm{CDCl}_{3}\right): \delta 201.2,154.5,123.8,43.9,27.5,26.4,22.4,20.6,13.8$.

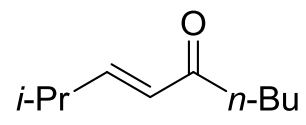

4.3.4j, 93\%, E/Z > 20:1

(E)-2-methylnon-3-en-5-one $(\boldsymbol{E}-4.3 .4 j)$ : (Known compound, See: M. Yu, G. Li, S. Wang, L. Zhang, Adv. Synth. Catal. 2007, 349, 871-875) ${ }^{1} \mathrm{H}$ NMR (600 $\left.\mathrm{MHz}, \mathrm{CDCl}_{3}\right): \delta$ $6.78(\mathrm{dd}, J=16.2,6.6 \mathrm{~Hz}, 1 \mathrm{H}), 6.03(\mathrm{dd}, J=16.2,1.8 \mathrm{~Hz}, 1 \mathrm{H}), 2.53(\mathrm{t}, J=7.5 \mathrm{~Hz}, 2 \mathrm{H})$, 2.41-2.48 (m, 1H), 1.59 (quintet, $J=7.4 \mathrm{~Hz}, 2 \mathrm{H}), 1.32$ (sextet, $J=7.4 \mathrm{~Hz}, 2 \mathrm{H}$ ), 1.07 (d, $J$ 
$=6.6 \mathrm{~Hz}, 6 \mathrm{H}), 0.91(\mathrm{t}, J=7.2 \mathrm{~Hz}, 3 \mathrm{H}) ;{ }^{13} \mathrm{C} \mathrm{NMR}\left(150 \mathrm{MHz}, \mathrm{CDCl}_{3}\right): \delta 201.2,153.1$, $127.5,39.8,31.0,26.4,22.4,21.3,13.8$.

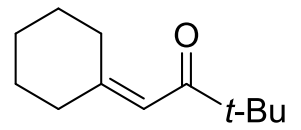

4.3.4k, $87 \%$

2-cyclohexylidene-1-phenylethanone (4.3.4k): (Known compound, See: B. Lu, C. Li, L. Zhang, J. Am. Chem. Soc. 2005, 127, 14180-14181) ${ }^{1} \mathrm{H}$ NMR (600 MHz, $\left.\mathrm{CDCl}_{3}\right)$ : $\delta$ 7.93$7.95(\mathrm{~m}, 2 \mathrm{H}), 7.51-7.54(\mathrm{~m}, 1 \mathrm{H}), 7.43-7.46(\mathrm{~m}, 2 \mathrm{H}), 6.60-6.61(\mathrm{~m}, 1 \mathrm{H})$, 2.76-2.78 (m, $2 \mathrm{H}), 2.31(\mathrm{td}, J=6.3,0.6 \mathrm{~Hz}, 2 \mathrm{H}), 1.71-1.75(\mathrm{~m}, 2 \mathrm{H}), 1.62-1.66(\mathrm{~m}, 4 \mathrm{H}) ;{ }^{13} \mathrm{C}$ NMR $(150$ $\left.\mathrm{MHz}, \mathrm{CDCl}_{3}\right): \delta 192.3,162.7,139.3,132.3,128.4,128.3,118.7,38.4,30.6,28.9,28.0$, 26.3.

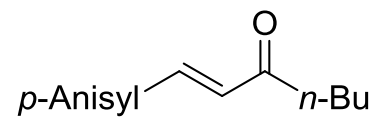

4.3.4I, $97 \%, E / Z>20: 1$

(E)-1-(4-methoxyphenyl)hept-1-en-3-one (E-4.3.4I): (Known compound, See: N. Marion, P. Carlqvist, R. Gealageas, P. Fremont, F. Maseras, S. P. Nolan, Chem. Eur. J. 2007, 13, 6437-6451) 1H NMR (600 MHz, $\left.\mathrm{CDCl}_{3}\right): \delta 7.51$ (d, $\left.J=15.6 \mathrm{~Hz}, 1 \mathrm{H}\right), 7.49$ (d, $J=8.4 \mathrm{~Hz}, 2 \mathrm{H}), 6.90(\mathrm{~d}, J=8.4 \mathrm{~Hz}, 2 \mathrm{H}), 6.63(\mathrm{~d}, J=16.2 \mathrm{~Hz}, 1 \mathrm{H}), 3.83(\mathrm{~s}, 3 \mathrm{H}), 2.63(\mathrm{t}$, $J=7.5 \mathrm{~Hz}, 2 \mathrm{H}$ ), 1.66 (quintet, $J=7.5 \mathrm{~Hz}, 2 \mathrm{H}$ ), 1.38 (sextet, $J=7.4 \mathrm{~Hz}, 2 \mathrm{H}$ ), 0.94 (t, $J=$ $7.2 \mathrm{~Hz}, 3 \mathrm{H}) ; 13 \mathrm{C} \mathrm{NMR}\left(150 \mathrm{MHz}, \mathrm{CDCl}_{3}\right): \delta 200.6,161.5,142.0,129.9,127.2,124.1$, 114.3, 55.3, 40.5, 26.6, 22.4, 13.9 .

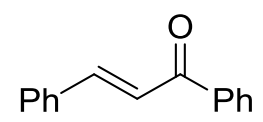

4.3.4m, $93 \%, E / Z>20: 1$

(E)-chalcone $(\boldsymbol{E}-\mathbf{4 . 3 . 4 m})$ : (Known compound, See: N. Marion, P. Carlqvist, R. Gealageas, P. Fremont, F. Maseras, S. P. Nolan, Chem. Eur. J. 2007, 13, 6437-6451) ${ }^{1} \mathrm{H}$ NMR (600 MHz, $\left.\mathrm{CDCl}_{3}\right): \delta 8.00-8.02(\mathrm{~m}, 2 \mathrm{H}), 7.80(\mathrm{~d}, J=15.6 \mathrm{~Hz}, 1 \mathrm{H}), 7.62-7.63(\mathrm{~m}$, $2 \mathrm{H}), 7.55-7.58(\mathrm{~m}, 1 \mathrm{H}), 7.52(\mathrm{~d}, J=15.6 \mathrm{~Hz}, 1 \mathrm{H}), 7.49(\mathrm{t}, J=7.5 \mathrm{~Hz}, 2 \mathrm{H}), 7.38-7.41(\mathrm{~m}$, 
$3 \mathrm{H}) ;{ }^{13} \mathrm{C}$ NMR $\left(150 \mathrm{MHz}, \mathrm{CDCl}_{3}\right): \delta 190.4,144.7,138.2,134.8,132.7,130.5,128.9$, $128.6,128.4,128.4,122.1$.

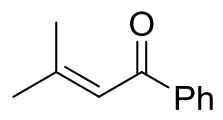

4.3.4n, $92 \%$

3-methyl-1-phenylbut-2-en-1-one (4.3.4n): (Known compound, See: P. N. Chatterjee, S. Roy, J. Org. Chem. 2010, 75, 4413-4423) ${ }^{1} \mathrm{H}$ NMR (600 MHz, $\left.\mathrm{CDCl}_{3}\right): \delta$ 7.92-7.94 (m, 2H), 7.50-7.53 (m, 1H), 7.42-7.45 (m, 2H), 6.74-6.75 (m, 1H), 2.21 (d, J=1.2 Hz, 3H), $2.01(\mathrm{~d}, J=1.2 \mathrm{~Hz}, 3 \mathrm{H}) ;{ }^{13} \mathrm{C}$ NMR $\left(150 \mathrm{MHz}, \mathrm{CDCl}_{3}\right): \delta 191.8,156.6,139.2,132.2$, 128.4, 128.1, 121.1, 27.9, 21.1.

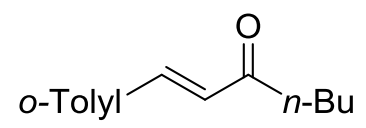

4.3.4o, $94 \%, E / Z=13: 1$

(E)-1-o-tolylhept-1-en-3-one $(\boldsymbol{E}$-4.3.40): (Known compound, See: N. Marion, P. Carlqvist, R. Gealageas, P. Fremont, F. Maseras, S. P. Nolan, Chem. Eur. J. 2007, 13, 6437-6451) 1H NMR (600 MHz, CDCl3): $\delta 7.85$ (d, $J=16.2 \mathrm{~Hz}, 1 \mathrm{H}), 7.56(\mathrm{~d}, J=7.8$ $\mathrm{Hz}, 1 \mathrm{H}), 7.25$ (t, $J=7.2 \mathrm{~Hz}, 1 \mathrm{H}), 7.20$ (t, $J=7.5 \mathrm{~Hz}, 2 \mathrm{H}), 6.66$ (d, $J=16.2 \mathrm{~Hz}, 1 \mathrm{H}), 2.65$ (t, $J=7.2 \mathrm{~Hz}, 2 \mathrm{H}$ ), 2.43 (s, 3H), 1.67 (quintet, $J=7.5 \mathrm{~Hz}, 2 \mathrm{H}$ ), 1.39 (sextet, $J=7.4 \mathrm{~Hz}$, 2H), 0.95 (t, $J=7.2 \mathrm{~Hz}, 3 \mathrm{H}) ; 13 \mathrm{C}$ NMR (150 MHz, CDCl3): $\delta$ 200.4, 139.6, 137.8, 133.5, $130.7,129.9,127.1,126.3,126.2,40.9,26.4,22.4,19.6,13.8$.

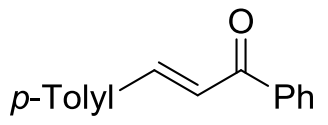

4.3.4p, $97 \%, E / Z=16: 1$

(E)-1-phenyl-3-p-tolylprop-2-en-1-one $(\boldsymbol{E}-4 \mathrm{p})$ : (Known compound, See: Y. Zhang, Y.L. Shao, H.-S. Xu, W. Wang, J. Org. Chem. 2011, 76, 1472-1474) ${ }^{1}$ H NMR (600 MHz, $\left.\mathrm{CDCl}_{3}\right): \delta 8.00-8.01(\mathrm{~m}, 2 \mathrm{H}), 7.79(\mathrm{~d}, J=15.6 \mathrm{~Hz}, 1 \mathrm{H}), 7.53-7.57(\mathrm{~m}, 3 \mathrm{H}), 7.47-7.50(\mathrm{~m}$, $3 \mathrm{H}), 7.22(\mathrm{~d}, J=7.8 \mathrm{~Hz}, 2 \mathrm{H}), 2.38(\mathrm{~s}, 3 \mathrm{H}) ;{ }^{13} \mathrm{C} \mathrm{NMR}\left(150 \mathrm{MHz}, \mathrm{CDCl}_{3}\right): \delta 190.6,144.9$, 141.0, 138.4, 132.6, 132.2, 129.7, 128.5, 128.4, 121.1, 21.5. 


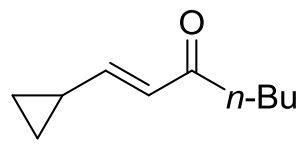

4.3.4q, $92 \%, E / Z>20: 1$

(E)-1-cyclopropylhept-1-en-3-one $(\boldsymbol{E}$-4.3.4q): (Known compound, See: M. N. Pennell, M. G. Unthank, P. Turner, T. D. Sheppard, J. Org. Chem. 2011, 76, 1479-1482) ${ }^{1}$ H NMR $\left(600 \mathrm{MHz}, \mathrm{CDCl}_{3}\right): \delta 6.31(\mathrm{dd}, J=15.6 \mathrm{~Hz}, 9.6 \mathrm{~Hz}, 1 \mathrm{H}), 6.21(\mathrm{~d}, J=15.6 \mathrm{~Hz}, 1 \mathrm{H}), 2.48$ (t, $J=7.5 \mathrm{~Hz}, 2 \mathrm{H}), 1.53-1.61(\mathrm{~m}, 3 \mathrm{H}), 1.34$ (sextet, $J=7.4 \mathrm{~Hz}, 2 \mathrm{H}), 0.95-0.99$ (m, 2H), $0.91(\mathrm{t}, J=7.5 \mathrm{~Hz}, 3 \mathrm{H}), 0.64-0.66(\mathrm{~m}, 2 \mathrm{H}) ;{ }^{13} \mathrm{C} \mathrm{NMR}\left(150 \mathrm{MHz}, \mathrm{CDCl}_{3}\right): \delta 199.8,152.0$, $127.2,40.0,26.5,22.4,14.5,13.8,8.8$.

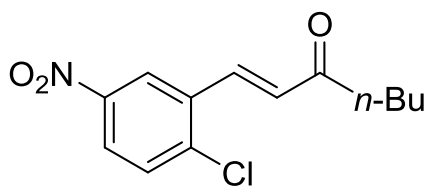

4.3.4r, $98 \%, E / Z>20: 1$

(E)-1-(2-chloro-5-nitrophenyl)hept-1-en-3-one $\left(\boldsymbol{E}\right.$-4.3.4r): ${ }^{1} \mathrm{H} \mathrm{NMR}\left(600 \mathrm{MHz}, \mathrm{CDCl}_{3}\right)$ : $\delta 8.04(\mathrm{~d}, J=1.8 \mathrm{~Hz}, 1 \mathrm{H}), 7.67(\mathrm{dd}, J=7.8 \mathrm{~Hz}, 1.8 \mathrm{~Hz}, 1 \mathrm{H}), 7.58(\mathrm{~d}, J=8.4 \mathrm{~Hz}, 1 \mathrm{H})$, $7.50(\mathrm{~d}, J=16.2 \mathrm{~Hz}, 1 \mathrm{H}), 6.80(\mathrm{~d}, J=15.6 \mathrm{~Hz}, 1 \mathrm{H}), 2.67(\mathrm{t}, J=7.5 \mathrm{~Hz}, 2 \mathrm{H}), 1.67$ (quintet, $J=7.5 \mathrm{~Hz}, 2 \mathrm{H}), 1.38$ (sextet, $J=7.4 \mathrm{~Hz}, 2 \mathrm{H}), 0.95\left(\mathrm{t}, J=7.2 \mathrm{~Hz}, 3 \mathrm{H}\right.$ ); ${ }^{13} \mathrm{C} \mathrm{NMR}$ (150 MHz, CDCl3): $\delta$ 199.5, 148.3, 137.8, 134.8, 132.4, 132.0, 128.8, 128.2, 124.5, 41.3, 26.1, 22.3, 13.8; HRMS Calculated for $\left[\mathrm{C}_{13} \mathrm{H}_{14} \mathrm{ClNO}_{3}+\mathrm{Na}\right]+$ : 290.05599, Found: 290.05585 .

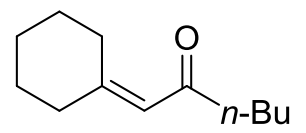

4.3.4s, $97 \%$

1-cyclohexylidenehexan-2-one (4.3.4s): (Known compound, See: M. Yu, G. Li, S. Wang, L. Zhang, Adv. Synth. Catal. 2007, 349, 871-875) ${ }^{1} \mathrm{H}$ NMR (600 MHz, $\left.\mathrm{CDCl}_{3}\right): \delta 5.97$ (s, $1 \mathrm{H}), 2.79(\mathrm{t}, J=5.4 \mathrm{~Hz}, 2 \mathrm{H}), 2.40(\mathrm{t}, J=7.2 \mathrm{~Hz}, 2 \mathrm{H}), 2.16(\mathrm{t}, J=6.3 \mathrm{~Hz}, 2 \mathrm{H}), 1.54-1.69$ $(\mathrm{m}, 8 \mathrm{H}), 1.32$ (sextet, $J=7.4 \mathrm{~Hz}, 2 \mathrm{H}), 0.91(\mathrm{t}, J=7.5 \mathrm{~Hz}, 3 \mathrm{H}) ;{ }^{13} \mathrm{C} \mathrm{NMR}(150 \mathrm{MHz}$, $\left.\mathrm{CDCl}_{3}\right): \delta 202.1,161.4,121.0,44.2,38.1,29.9,28.8,27.9,26.4,26.3,22.4,13.9$. 


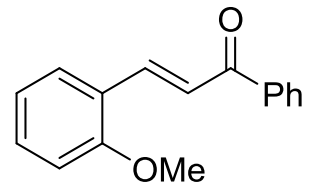

4.3.4t, $93 \%, E / Z=20: 1$

(E)-1-(2-methoxyphenyl)hept-1-en-3-one $\left(\boldsymbol{E}\right.$-4.3.4t): ${ }^{1} \mathrm{H}$ NMR $\left(600 \mathrm{MHz}, \mathrm{CDCl}_{3}\right)$ : $\delta$ $7.91(\mathrm{~d}, J=16.8 \mathrm{~Hz}, 1 \mathrm{H}), 7.53(\mathrm{~d}, J=7.8 \mathrm{~Hz}, 1 \mathrm{H}), 7.35(\mathrm{t}, J=8.1 \mathrm{~Hz}, 1 \mathrm{H}), 6.96(\mathrm{t}, J=$ $7.5 \mathrm{~Hz}, 1 \mathrm{H}), 6.91(\mathrm{~d}, J=8.4 \mathrm{~Hz}, 1 \mathrm{H}), 6.78(\mathrm{~d}, J=16.2 \mathrm{~Hz}, 1 \mathrm{H}), 3.89$ (s, 3H), 2.67 (t, $J=$ $7.5 \mathrm{~Hz}, 2 \mathrm{H}$ ), 1.66 (quintet, $J=7.5 \mathrm{~Hz}, 2 \mathrm{H}$ ), 1.38 (sextet, $J=7.4 \mathrm{~Hz}, 2 \mathrm{H}$ ), 0.94 (t, $J=7.5$ $\mathrm{Hz}, 3 \mathrm{H}) ;{ }^{13} \mathrm{C} \mathrm{NMR}\left(150 \mathrm{MHz}, \mathrm{CDCl}_{3}\right): \delta 201.2,158.3,137.5,131.5,128.3,126.9,123.5$, $120.7,111.1,55.4,40.1,26.6,22.4,13.9$.

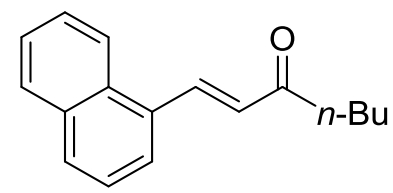

4.3.4u, $88 \%, E / Z>20: 1$

(E)-1-(naphthalen-4-yl)hept-1-en-3-one $(\boldsymbol{E}$-4.3.4u): (Known compound, See: R. S. Ramón, N. Marion, S. P. Nolan, Tetrahedron, 2009, 65, 1767-1773) ${ }^{1} \mathrm{H}$ NMR (600 MHz, $\left.\mathrm{CDCl}_{3}\right): \delta 8.40(\mathrm{~d}, J=16.2 \mathrm{~Hz}, 1 \mathrm{H}), 8.17(\mathrm{~d}, J=8.4 \mathrm{~Hz}, 1 \mathrm{H}), 7.88(\mathrm{t}, J=9.0 \mathrm{~Hz}, 2 \mathrm{H})$, $7.76(\mathrm{~d}, J=7.2 \mathrm{~Hz}, 1 \mathrm{H}), 7.57(\mathrm{t}, J=7.5 \mathrm{~Hz}, 1 \mathrm{H}), 7.52(\mathrm{t}, J=7.5 \mathrm{~Hz}, 1 \mathrm{H}), 7.48(\mathrm{t}, J=7.8$ $\mathrm{Hz}, 1 \mathrm{H}), 6.83(\mathrm{~d}, J=16.2 \mathrm{~Hz}, 1 \mathrm{H}), 2.73(\mathrm{t}, J=7.5 \mathrm{~Hz}, 2 \mathrm{H}), 1.72$ (quintet, $J=7.5 \mathrm{~Hz}, 2 \mathrm{H}$ ), 1.42 (sextet, $J=7.4 \mathrm{~Hz}, 2 \mathrm{H}), 0.97(\mathrm{t}, J=7.5 \mathrm{~Hz}, 3 \mathrm{H}) ;{ }^{13} \mathrm{C} \mathrm{NMR}\left(150 \mathrm{MHz}, \mathrm{CDCl}_{3}\right): \delta$ 200.4, 139.1, 133.7, 132.0, 131.6, 130.6, 128.8, 128.7, 126.8, 126.2, 125.4, 125.0, 123.3, $41.1,26.5,22.5,13.9$.

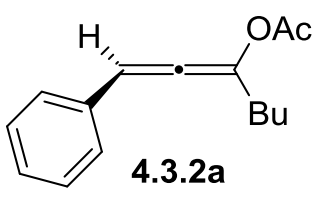

1-Phenylhepta-1,2-dien-3-yl acetate (4.3.2a) (Known compound, see: Sherry, B. D.; Toste, F. D. J. Am. Chem. Soc. 2004, 126, 15978-15979). ${ }^{1} \mathrm{H}$ NMR (600 MHz, $\left.\mathrm{CDCl}_{3}\right): \delta$ 7.43-7.44 (m, 2H), 7.32-7.35 (m, 2H), 7.25-7.27 (m, 1H), 6.59 (t, $J=3.0 \mathrm{~Hz}, 1 \mathrm{H}), 2.33-$ 
2.37 (m, 2H), 2.15 (s, 3H), 1.46-1.51 (m, 2H), 1.38-1.43 (m, 2H), 0.90 (t, $J=7.2 \mathrm{~Hz}, 3 \mathrm{H})$;

${ }^{13} \mathrm{C}$ NMR $\left(150 \mathrm{MHz}, \mathrm{CDCl}_{3}\right): \delta 196.7,168.6,133.9,129.2,128.6,127.9,127.0,104.5$, $31.5,28.3,22.1,21.0,13.8$.

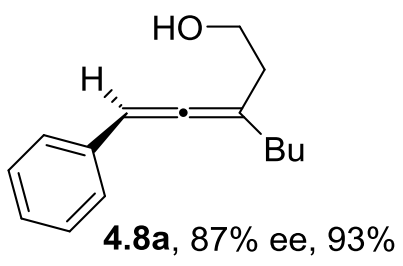

3-(2-Phenylvinylidene)heptan-1-ol (4.8a): (Known compound, see: Sherry, B. D.; Toste, F. D. J. Am. Chem. Soc. 2004, 126, 15978-15979). ${ }^{1} \mathrm{H}$ NMR (600 MHz, $\left.\mathrm{CDCl}_{3}\right): \delta$ 7.28$7.31(\mathrm{~m}, 4 \mathrm{H}), 7.17-7.20(\mathrm{~m}, 1 \mathrm{H}), 6.20$ (quintet, $J=2.9 \mathrm{~Hz}, 1 \mathrm{H}), 3.78(\mathrm{t}, J=6.3 \mathrm{~Hz}, 2 \mathrm{H}$ ), 2.32-3.39 (m, 2H), 2.10-2.14 (m, 2H), 1.63 (br s, 1H), 1.46-1.50 (m, 2H), 1.34-1.40 (m, $2 \mathrm{H}), 0.90(\mathrm{t}, J=7.5 \mathrm{~Hz}, 3 \mathrm{H}) .{ }^{13} \mathrm{C} \mathrm{NMR}\left(150 \mathrm{MHz}, \mathrm{CDCl}_{3}\right): \delta 201.9,135.4,128.6,126.7$, $126.4,105.8,96.1,60.9,35.9,32.7,29.7,22.4,13.9$. Enantiomeric excess was determined by HPLC with a Chiralcel OD-H column; $\lambda=254 \mathrm{~nm}$; eluent: Hexane/Isopropanol $=95 / 5$; Flow rate: $1.0 \mathrm{~mL} / \mathrm{min} ; \mathrm{t}_{\mathrm{R}}=6.8 \mathrm{~min}, \mathrm{t}_{\mathrm{R}}=11.4 \mathrm{~min} ; 87 \%$ ee .

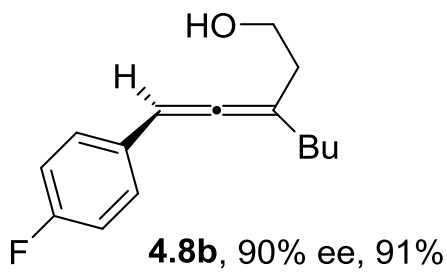

3-(2-(4-Fluorophenyl)vinylidene)heptan-1-ol (4.8b): ${ }^{1} \mathrm{H}$ NMR $\left(600 \mathrm{MHz}, \mathrm{CDCl}_{3}\right): \delta$ 7.22-7.26 (m, 2H), 6.97-6.70 (m, 2H), 6.20 (quintet, $J=2.0 \mathrm{~Hz}, 1 \mathrm{H}$ ), $3.76(\mathrm{t}, J=6.0 \mathrm{~Hz}$, $2 \mathrm{H}), 2.31-3.37$ (m, 2H), 2.09-2.12 (m, 2H), $1.68(\mathrm{br} \mathrm{s}, 1 \mathrm{H}), 1.43-1.49(\mathrm{~m}, 2 \mathrm{H}), 1.34-1.40$ (m, 2H), $0.88(\mathrm{t}, J=7.5 \mathrm{~Hz}, 3 \mathrm{H}) .{ }^{13} \mathrm{C}$ NMR $\left(150 \mathrm{MHz}, \mathrm{CDCl}_{3}\right): \delta 201.7,162.6(\mathrm{~d}, J=$ $244.4 \mathrm{~Hz}), 131.3(\mathrm{~d}, J=3.3 \mathrm{~Hz}), 127.8(\mathrm{q}, J=8.4 \mathrm{~Hz}), 115.5,105.9,95.08(\mathrm{t}, J=8.5 \mathrm{~Hz})$, 60.9, 35.9, 32.7, 29.7, 22.4, 23.8. HRMS Calculated for $\left[\mathrm{C}_{15} \mathrm{H}_{19} \mathrm{FO}+\mathrm{Na}\right]+:$ 257.1312, Found: 257.1312. Enantiomeric excess was determined by HPLC with a Chiralcel AS-H column; $\lambda=254 \mathrm{~nm}$; eluent: Hexane/Isopropanol = 97/3; Flow rate: $0.5 \mathrm{~mL} / \mathrm{min} ; \mathrm{t}_{\mathrm{R}}=$ $15.5 \mathrm{~min}, \mathrm{t}_{\mathrm{R}}=21.1 \mathrm{~min} ; 90 \%$ ee. 


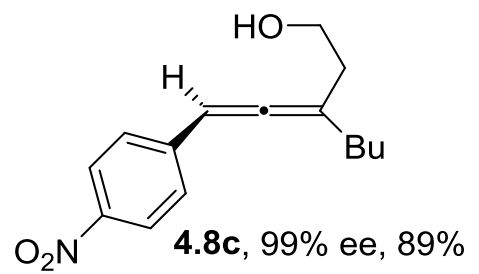

3-(2-(4-Nitrophenyl)vinylidene)heptan-1-ol (4.8c): ${ }^{1} \mathrm{H}$ NMR (600 $\left.\mathrm{MHz}, \mathrm{CDCl}_{3}\right)$ : $\delta$ 8.14-8.16 (m, 2H), 7.39-741 (m, 2H), 6.25 (quintet, $J=2.8 \mathrm{~Hz}, 1 \mathrm{H}), 3.79$ (t, $J=6.3 \mathrm{~Hz}$, 2H), 2.36-2.44 (m, 2H), 2.14-2.17 (m, 2H), 1.61 (br s, 1H), 1.43-1.53 (m, 2H), 1.34-1.40 $(\mathrm{m}, 2 \mathrm{H}), 0.89$ (t, $J=7.5 \mathrm{~Hz}, 3 \mathrm{H}) .{ }^{13} \mathrm{C} \mathrm{NMR}\left(150 \mathrm{MHz}, \mathrm{CDCl}_{3}\right): \delta 204.4,146.4,142.9$, 126.8, 124.1, 106.9, 94.9, 60.7, 35.7, 32.4, 29.6, 22.4, 13.8. Calculated for $\left[\mathrm{C}_{15} \mathrm{H}_{19} \mathrm{NO}_{3}+\mathrm{Na}\right]^{+}:$284.1257, Found: 284.1257. Enantiomeric excess was determined by HPLC with a Chiralcel AS-H column; $\lambda=254$ nm; eluent: Hexane/Isopropanol = 90/10; Flow rate: $1 \mathrm{~mL} / \mathrm{min} ; \mathrm{t}_{\mathrm{R}}=10.7 \mathrm{~min}, \mathrm{t}_{\mathrm{R}}=15.8 \mathrm{~min} ; 99 \%$ ee.

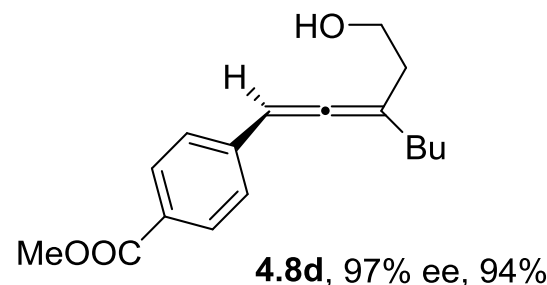

Methyl 4-(3-(2-hydroxyethyl)hepta-1,2-dienyl)benzoate (4.8d): ${ }^{1} \mathrm{H}$ NMR (600 MHz, $\left.\mathrm{CDCl}_{3}\right): \delta 7.95-7.96(\mathrm{~m}, 2 \mathrm{H}), 7.31-7.33(\mathrm{~m}, 2 \mathrm{H}), 6.22$ (quintet, $\left.J=3.0 \mathrm{~Hz}, 1 \mathrm{H}\right), 3.90(\mathrm{~s}$, $3 \mathrm{H}), 3.77(\mathrm{t}, J=6.3 \mathrm{~Hz}, 2 \mathrm{H}), 2.34-2.42(\mathrm{~m}, 2 \mathrm{H}), 2.11-2.15(\mathrm{~m}, 2 \mathrm{H}), 1.68$ (br s, 1H), 1.42$1.50(\mathrm{~m}, 2 \mathrm{H}), 1.34-1.39(\mathrm{~m}, 2 \mathrm{H}), 0.88(\mathrm{t}, J=7.5 \mathrm{~Hz}, 3 \mathrm{H}) .{ }^{13} \mathrm{C} \mathrm{NMR}\left(150 \mathrm{MHz}, \mathrm{CDCl}_{3}\right)$ : $\delta 203.3,166.9,140.5,129.9,128.2,126.2,106.2,95.5,60.8,51.9,35.7,32.5,29.7,22.4$, 13.9. Calculated for $\left[\mathrm{C}_{17} \mathrm{H}_{22} \mathrm{O}_{3}+\mathrm{Na}\right]^{+}: 297.1461$, Found: 297.1462. Enantiomeric excess was determined by HPLC with a Chiralcel AS-H column; $\lambda=254 \mathrm{~nm}$; eluent: Hexane/Isopropanol = 96/4; Flow rate: $1 \mathrm{~mL} / \mathrm{min} ; \mathrm{t}_{\mathrm{R}}=16.3 \mathrm{~min}, \mathrm{t}_{\mathrm{R}}=18.2 \mathrm{~min} ; 97 \%$ ee .

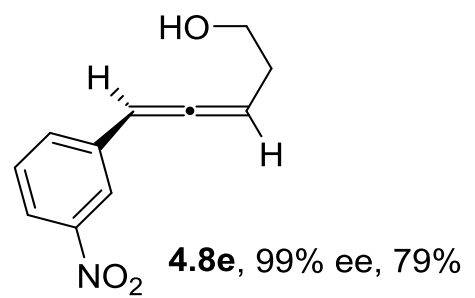


5-(3-Nitrophenyl)penta-3,4-dien-1-ol (4.8e): ${ }^{1} \mathrm{H} \mathrm{NMR}\left(600 \mathrm{MHz}, \mathrm{CDCl}_{3}\right): \delta$ 8.12-8.13 (m, 1H), 8.02 (dd, $J=7.8 \mathrm{~Hz}, 1.8 \mathrm{~Hz}, 1 \mathrm{H}), 7.58$ (d, $J=7.8 \mathrm{~Hz}, 1 \mathrm{H}), 7.43-7.46(\mathrm{~m}, 1 \mathrm{H})$, 6.23 (quintet, $J=3.0 \mathrm{~Hz}, 1 \mathrm{H}), 5.71(\mathrm{q}, J=6.6 \mathrm{~Hz}, 1 \mathrm{H}), 3.80(\mathrm{t}, J=6.0 \mathrm{~Hz}, 2 \mathrm{H}), 2.42-$ $2.45(\mathrm{~m}, 2 \mathrm{H}) .{ }^{13} \mathrm{C} \mathrm{NMR}\left(150 \mathrm{MHz}, \mathrm{CDCl}_{3}\right): \delta 206.5,136.9,132.4,129.4,121.6,121.3$, 93.7, 92.9, 61.8, 31.8. Calculated for $\left[\mathrm{C}_{11} \mathrm{H}_{11} \mathrm{NO}_{3}+\mathrm{Na}\right]^{+}$: 228.0631, Found: 228.0628 . Enantiomeric excess was determined by HPLC with a Chiralcel OD-H column; $\lambda=254$ $\mathrm{nm}$; eluent: Hexane/Isopropanol $=95 / 5$; Flow rate: $1.0 \mathrm{~mL} / \mathrm{min} ; \mathrm{t}_{\mathrm{R}}=14.4 \mathrm{~min}, \mathrm{t}_{\mathrm{R}}=17.5$ min; $99 \%$ ee.

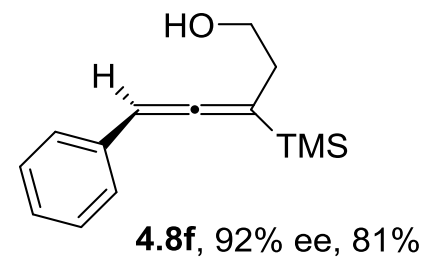

3-(Trimethylsilyl)-5-phenylpenta-3,4-dien-1-ol (4.8f): ${ }^{1} \mathrm{H}$ NMR $\left(600 \mathrm{MHz}, \mathrm{CDCl}_{3}\right)$ : $\delta$ 7.26-7.30 (m, 2H), 7.21-7.23 (m, 2H), 7.13-7.16 ( m, 1H), $5.95(\mathrm{t}, J=3.3 \mathrm{~Hz}, 1 \mathrm{H}), 3.80(\mathrm{t}$, $J=6.3 \mathrm{~Hz}, 2 \mathrm{H}), 2.33-2.43(\mathrm{~m}, 2 \mathrm{H}), 1.60$ (brs, 1H), $0.16(\mathrm{~s}, 9 \mathrm{H}) .{ }^{13} \mathrm{C} \mathrm{NMR}(150 \mathrm{MHz}$, $\left.\mathrm{CDCl}_{3}\right): \delta 204.9,135.4,128.7,126.1,125.8,98.1,90.3,62.2,32.5,-1.5$. Calculated for $\left[\mathrm{C}_{14} \mathrm{H}_{20} \mathrm{OSi}+\mathrm{Na}\right]^{+}:$255.1176, Found: 255.1175 . Enantiomeric excess was determined by HPLC with a Chiralcel OD-H column; $\lambda=254 \mathrm{~nm}$; eluent: Hexane/Isopropanol = 95/5; Flow rate: $0.8 \mathrm{~mL} / \mathrm{min} ; \mathrm{t}_{\mathrm{R}}=7.5 \mathrm{~min}, \mathrm{t}_{\mathrm{R}}=13.4 \mathrm{~min} ; 92 \%$ ee.

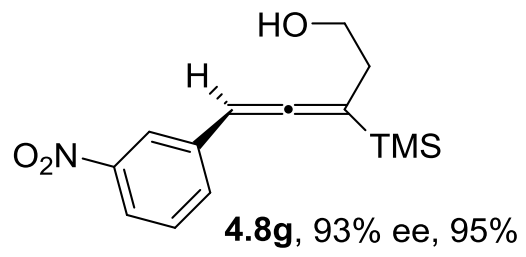

3-(Trimethylsilyl)-(2-(3-Nitrophenyl)vinylidene)pentan-1-ol (4.8g): ${ }^{1} \mathrm{H}$ NMR (600 $\left.\mathrm{MHz}, \mathrm{CDCl}_{3}\right): \delta 8.11-8.12(\mathrm{~m}, 1 \mathrm{H}), 8.00-8.02(\mathrm{~m}, 1 \mathrm{H}), 7.57-7.59(\mathrm{~m}, 1 \mathrm{H}), 7.44(\mathrm{t}, J=7.8$ $\mathrm{Hz}, 1 \mathrm{H}), 6.24$ (quintet, $J=2.9 \mathrm{~Hz}, 1 \mathrm{H}), 3.79$ (t, $J=6.3 \mathrm{~Hz}, 2 \mathrm{H}), 2.35-2.45(\mathrm{~m}, 2 \mathrm{H}), 2.12-$ 2.19 (m, 2H), 1.66 (brs, 1H), 1.44-1.59 (m, 2H), 1.34-1.43 (m, 2H), $0.20(\mathrm{~s}, 9 \mathrm{H}) .{ }^{13} \mathrm{C}$ NMR (150 MHz, $\left.\mathrm{CDCl}_{3}\right): \delta 203.1,148.7,137.8,132.1,129.4,121.3,121.0,107.1,94.5$, 60.7, 35.7. Calculated for $\left[\mathrm{C}_{11} \mathrm{H}_{19} \mathrm{NO}_{3}+\mathrm{Na}\right]^{+}$: 284.1257, Found: 284.1257. Enantiomeric 
excess was determined by HPLC with a Chiralcel AS-H column; $\lambda=254 \mathrm{~nm}$; eluent: Hexane/Isopropanol = 95/5; Flow rate: $1.0 \mathrm{~mL} / \mathrm{min} ; \mathrm{t}_{\mathrm{R}}=13.4 \mathrm{~min}, \mathrm{t}_{\mathrm{R}}=25.0 \mathrm{~min} ; 95 \%$ ee .

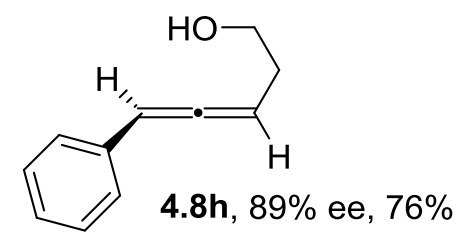

5-Phenylpenta-3,4-dien-1-ol (4.8h): (Known compound, see: Sherry, B. D.; Toste, F. D. J. Am. Chem. Soc. 2004, 126, 15978-15979). ${ }^{1} \mathrm{H}$ NMR (600 MHz, $\left.\mathrm{CDCl}_{3}\right): \delta$ 7.28-7.30 (m, 4H), 7.18-7.21 (m, 1H), 6.19 (quintet, $J=3.0 \mathrm{~Hz}, 1 \mathrm{H}), 5.61$ (q, $J=6.6 \mathrm{~Hz}, 1 \mathrm{H}), 3.79$ (t, $J=6.3 \mathrm{~Hz}, 2 \mathrm{H}), 2.38-2.42$ (m, $2 \mathrm{H}), 1.50$ (brs, $1 \mathrm{H}) .{ }^{13} \mathrm{C} \mathrm{NMR}\left(150 \mathrm{MHz}, \mathrm{CDCl}_{3}\right): \delta$ 205.7, 134.4, 128.7, 126.9, 126.7, 95.2, 91.5, 61.9, 32.1. Enantiomeric excess was determined by HPLC with a Chiralcel OD-H column; $\lambda=254 \mathrm{~nm}$; eluent: Hexane/Isopropanol = 97/3; Flow rate: $0.5 \mathrm{~mL} / \mathrm{min} ; \mathrm{t}_{\mathrm{R}}=28.6 \mathrm{~min}, \mathrm{t}_{\mathrm{R}}=32.4 \mathrm{~min} ; 90 \%$ ee .

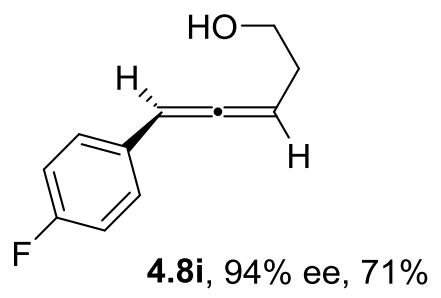

5-(4-Fluorophenyl)penta-3,4-dien-1-ol (4.8i): ${ }^{1} \mathrm{H}$ NMR (600 MHz, $\left.\mathrm{CDCl}_{3}\right): \delta$ 7.23-7.26 (m, 2H), 6.97-7.00 (m, 2H), 6.15 (quintet, $J=3.2 \mathrm{~Hz}, 1 \mathrm{H}), 5.61$ (q, $J=6.8 \mathrm{~Hz}, 1 \mathrm{H}), 3.77$ (t, $J=6.3 \mathrm{~Hz}, 2 \mathrm{H}), 2.37-2.41(\mathrm{~m}, 2 \mathrm{H}), 1.68$ (brs, $1 \mathrm{H}) .{ }^{13} \mathrm{C} \mathrm{NMR}\left(150 \mathrm{MHz}, \mathrm{CDCl}_{3}\right): \delta$ 205.5, $161.1(\mathrm{~d}, J=244.2 \mathrm{~Hz}), 130.4(\mathrm{~d}, J=2.7 \mathrm{~Hz}), 128.0(\mathrm{~d}, J=7.7 \mathrm{~Hz}), 115.5(\mathrm{~d}, J=$ $21.3 \mathrm{~Hz}), 94.1,91.7,61.9$, 32.0. Calculated for $\left[\mathrm{C}_{11} \mathrm{H}_{11} \mathrm{FO}+\mathrm{Na}\right]^{+}:$201.0686, Found: 201.0687. Enantiomeric excess was determined by HPLC with a Chiralcel OD-H column; $\lambda=254 \mathrm{~nm}$; eluent: Hexane/Isopropanol $=98 / 2$; Flow rate: $0.6 \mathrm{~mL} / \mathrm{min} ; \mathrm{t}_{\mathrm{R}}=24.3 \mathrm{~min}, \mathrm{t}_{\mathrm{R}}$ $=26.6 \mathrm{~min} ; 94 \%$ ee .

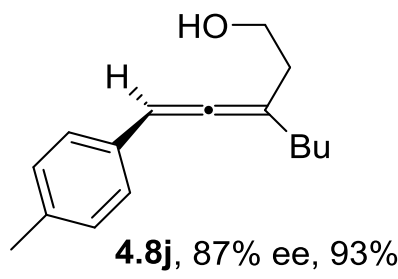


3-(2-p-Tolylvinylidene)heptan-1-ol (4.8j): ${ }^{1} \mathrm{H}$ NMR $\left(600 \mathrm{MHz}, \mathrm{CDCl}_{3}\right): \delta$ 7.16-7.18 (m, 2H), 7.10-7.13 (m, 2H), 6.17 (quintet, $J=3.2 \mathrm{~Hz}, 1 \mathrm{H}), 3.76$ (t, $J=6.0 \mathrm{~Hz}, 2 \mathrm{H}), 2.29-2.39$ (m, 2H), 2.33 (s, 3H), 2.08-2.12 (m, 2H), 1.65 (br s, 1H), 1.42-1.51 (m, 2H), 1.32-1.39 (m, 2H), $0.88(\mathrm{t}, J=7.2 \mathrm{~Hz}, 3 \mathrm{H}) .{ }^{13} \mathrm{C} \mathrm{NMR}\left(150 \mathrm{MHz}, \mathrm{CDCl}_{3}\right): \delta 201.4,136.5,132.3,129.4$, 126.3, 105.6, 95.9, 60.9, 35.9, 32.8, 29.7, 22.4, 21.1, 13.9. Calculated for $\left[\mathrm{C}_{16} \mathrm{H}_{22} \mathrm{O}+\mathrm{Na}\right]^{+}$: 253.1563, Found: 253.1559. Enantiomeric excess was determined by HPLC with a Chiralcel OD-H column; $\lambda=254 \mathrm{~nm}$; eluent: Hexane/Isopropanol =97/3; Flow rate: 0.5 $\mathrm{mL} / \mathrm{min} ; \mathrm{t}_{\mathrm{R}}=14.8 \mathrm{~min}, \mathrm{t}_{\mathrm{R}}=17.3 \mathrm{~min} ; 87 \%$ ee.

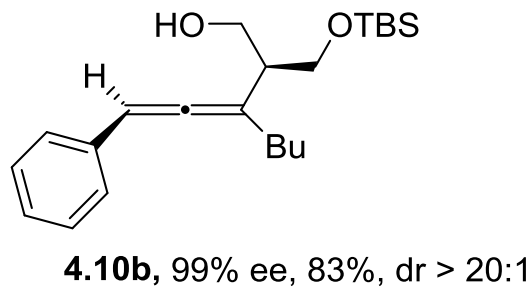

2-((t-Butyl)dimethylsilane-oxy-methyl)-3-(2-phenylvinylidene)heptan-1-ol $\quad$ (4.10b):

(Ref. see: Sherry, B. D.; Toste, F. D. J. Am. Chem. Soc. 2004, 126, 15978-15979). ${ }^{1}$ H NMR $\left(600 \mathrm{MHz}, \mathrm{CDCl}_{3}\right): \delta$ 7.54-7.55 (m, 1H), 7.24-7.39 ( m, 3H), 7.16-7.19 (m, 1H), $6.19(\mathrm{q}, J=2.8 \mathrm{~Hz}, 1 \mathrm{H}), 3.90(\mathrm{dd}, J=9.6 \mathrm{~Hz}, 4.2 \mathrm{~Hz}, 1 \mathrm{H}), 3.71-3.83$ (m, 2H), 2.68 (br s, $1 \mathrm{H}), 2.41-2.45(\mathrm{~m}, 1 \mathrm{H}), 2.28(\mathrm{dt}, J=8.1 \mathrm{~Hz}, 1.8 \mathrm{~Hz}, 1 \mathrm{H}), 2.08-2.17$ (m, 2H), 1.32-1.55 $(\mathrm{m}, 4 \mathrm{H}), 0.89(\mathrm{~s}, 9 \mathrm{H}), 0.88(\mathrm{t}, J=7.8 \mathrm{~Hz}, 3 \mathrm{H}), 0.06(\mathrm{~s}, 3 \mathrm{H}), 0.05(\mathrm{~s}, 3 \mathrm{H}) .{ }^{13} \mathrm{C} \mathrm{NMR}(150$ $\left.\mathrm{MHz}, \mathrm{CDCl}_{3}\right): \delta 202.1,135.2,128.5,126.7,126.4,106.6,97.0,66.0,65.4,46.8,32.2$, 30.7, 29.8, 25.8, 18.5, 18.2, 13.9. Calculated for $\left[\mathrm{C}_{22} \mathrm{H}_{36} \mathrm{O}_{2} \mathrm{Si}+\mathrm{Na}\right]^{+}:$383.2377, Found: 383.2377. Enantiomeric excess was determined by HPLC with a Chiralcel OD-H column; $\lambda=254 \mathrm{~nm}$; eluent: Hexane/Isopropanol $=98 / 2$; Flow rate: $1.0 \mathrm{~mL} / \mathrm{min} ; \mathrm{t}_{\mathrm{R}}=4.8 \mathrm{~min}, \mathrm{t}_{\mathrm{R}}$ $=5.6 \mathrm{~min} ; 99 \%$ ee . 


\section{Appendix 3: ${ }^{1} \mathrm{H}$ NMR, ${ }^{13} \mathrm{C}$ NMR, HPLC Spectra and Crystal Structure}

\section{A3.1: ORTEP Drawing of Crystal Structure of 2.5ba}

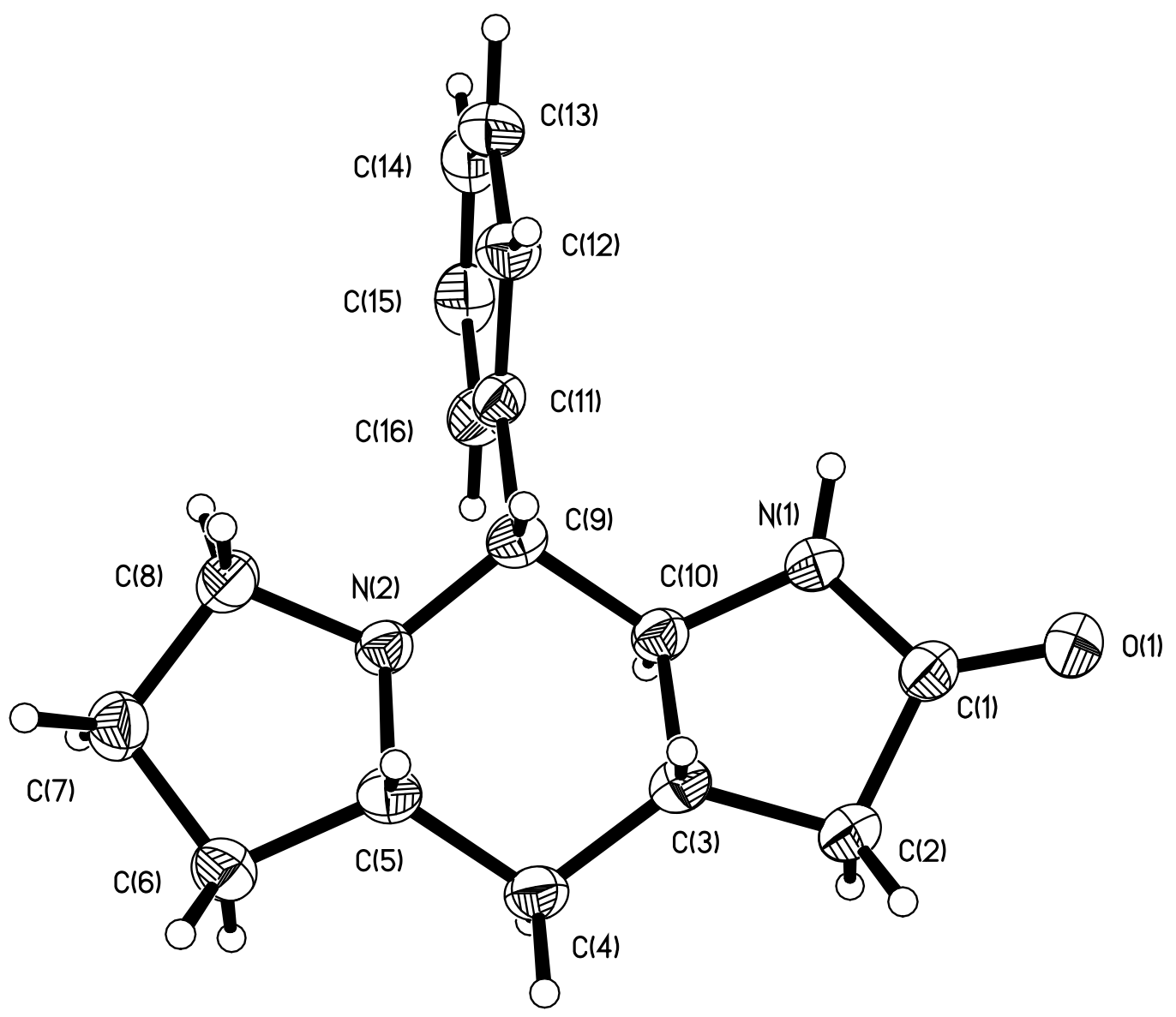

Figure A1: Perspective view of the molecular structure of $\mathrm{C}_{16} \mathrm{H}_{20} \mathrm{~N}_{2} \mathrm{O}$ with the atom labeling scheme. The thermal ellipsoids are scaled to enclose $30 \%$ probability. CCDC number: 904686 


\section{A3.2: NMR Spectra of New Compounds}

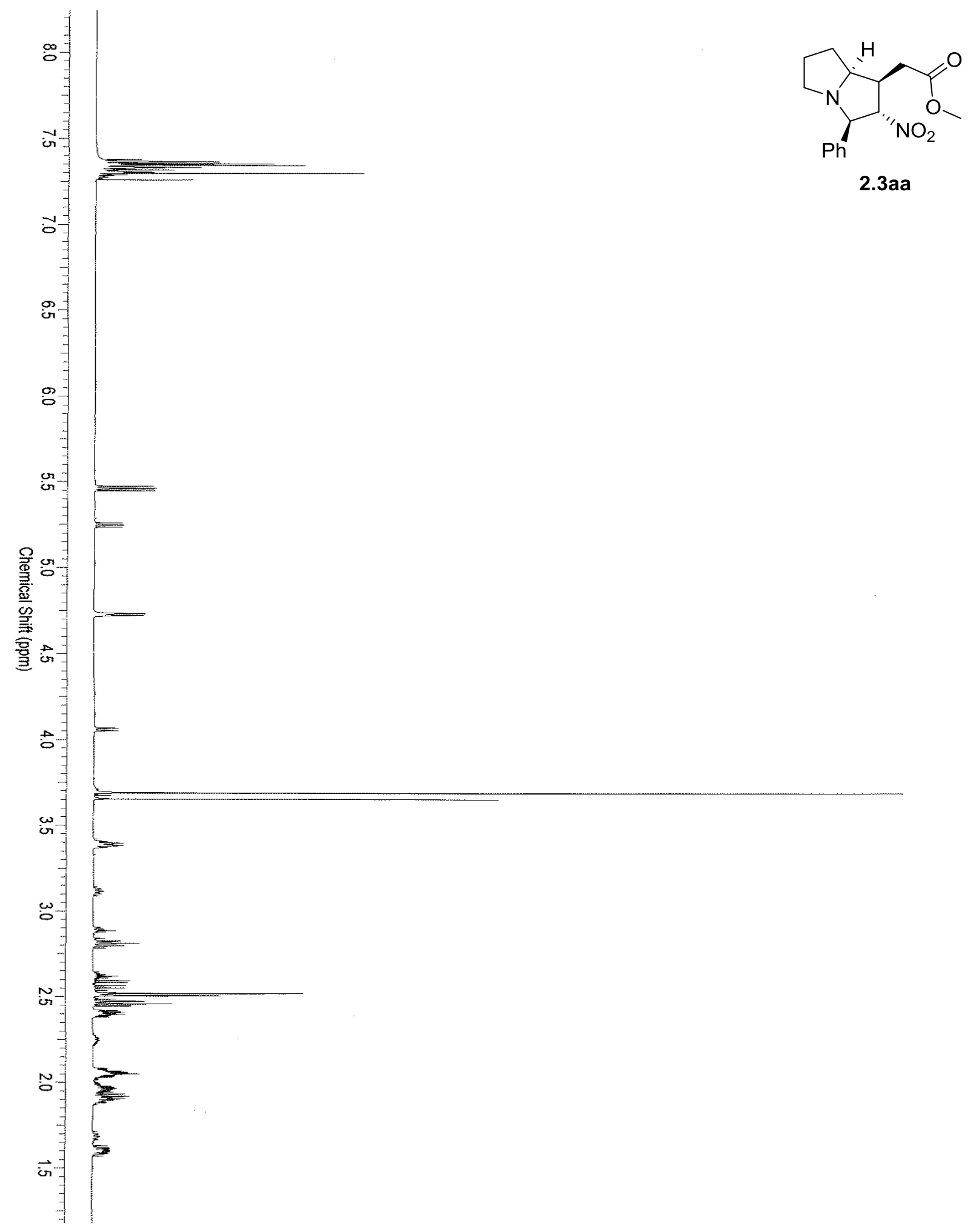




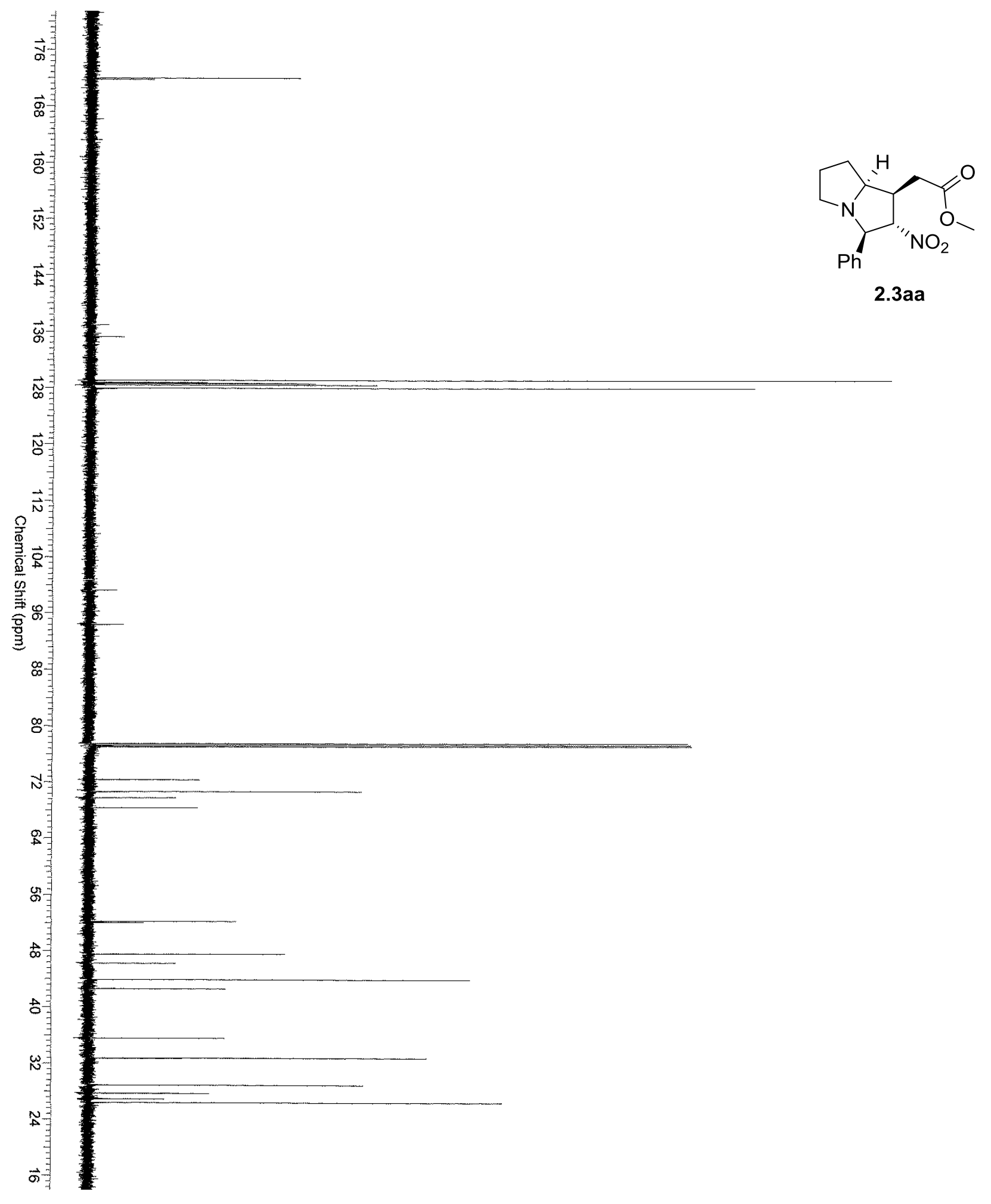




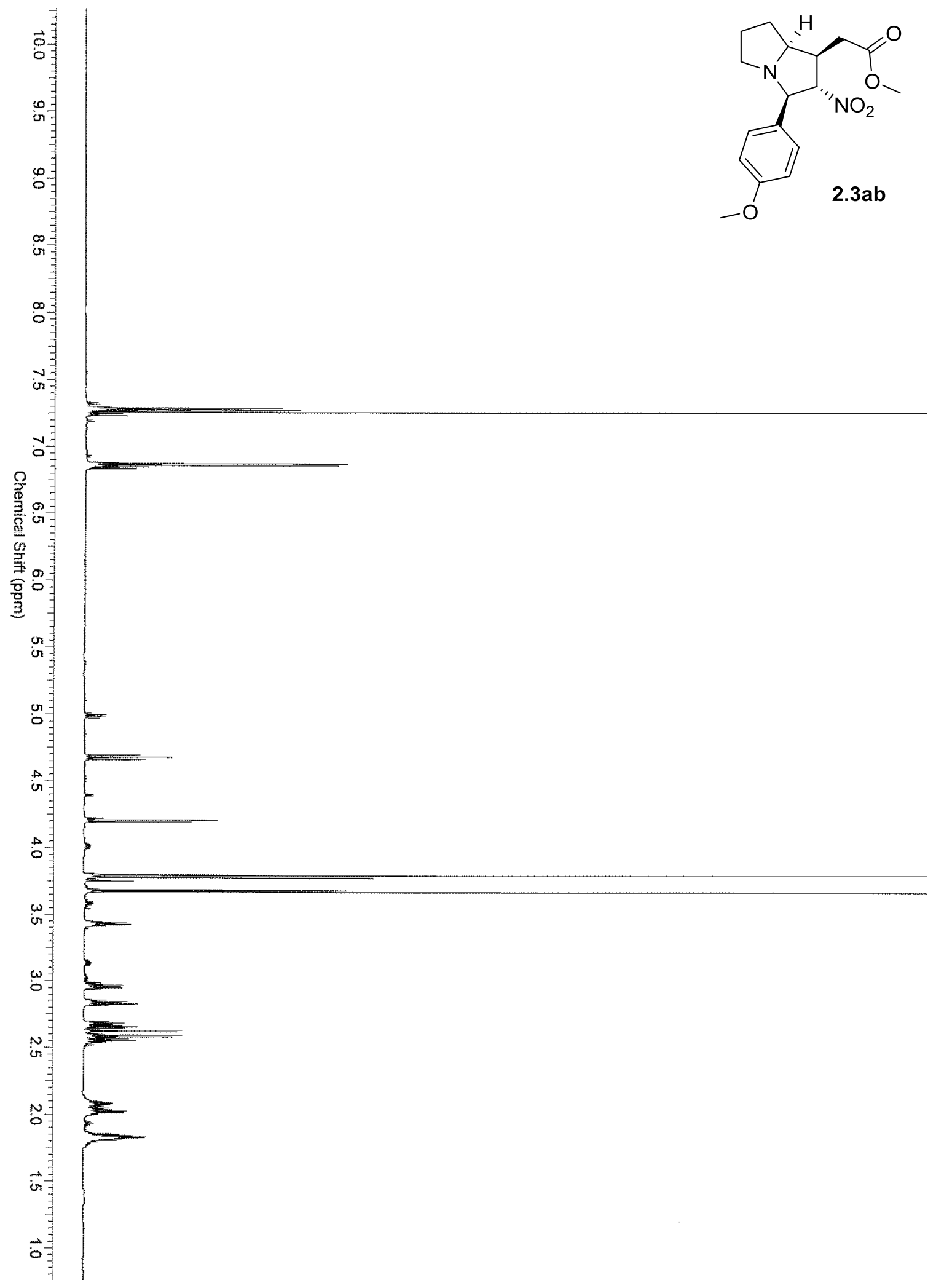




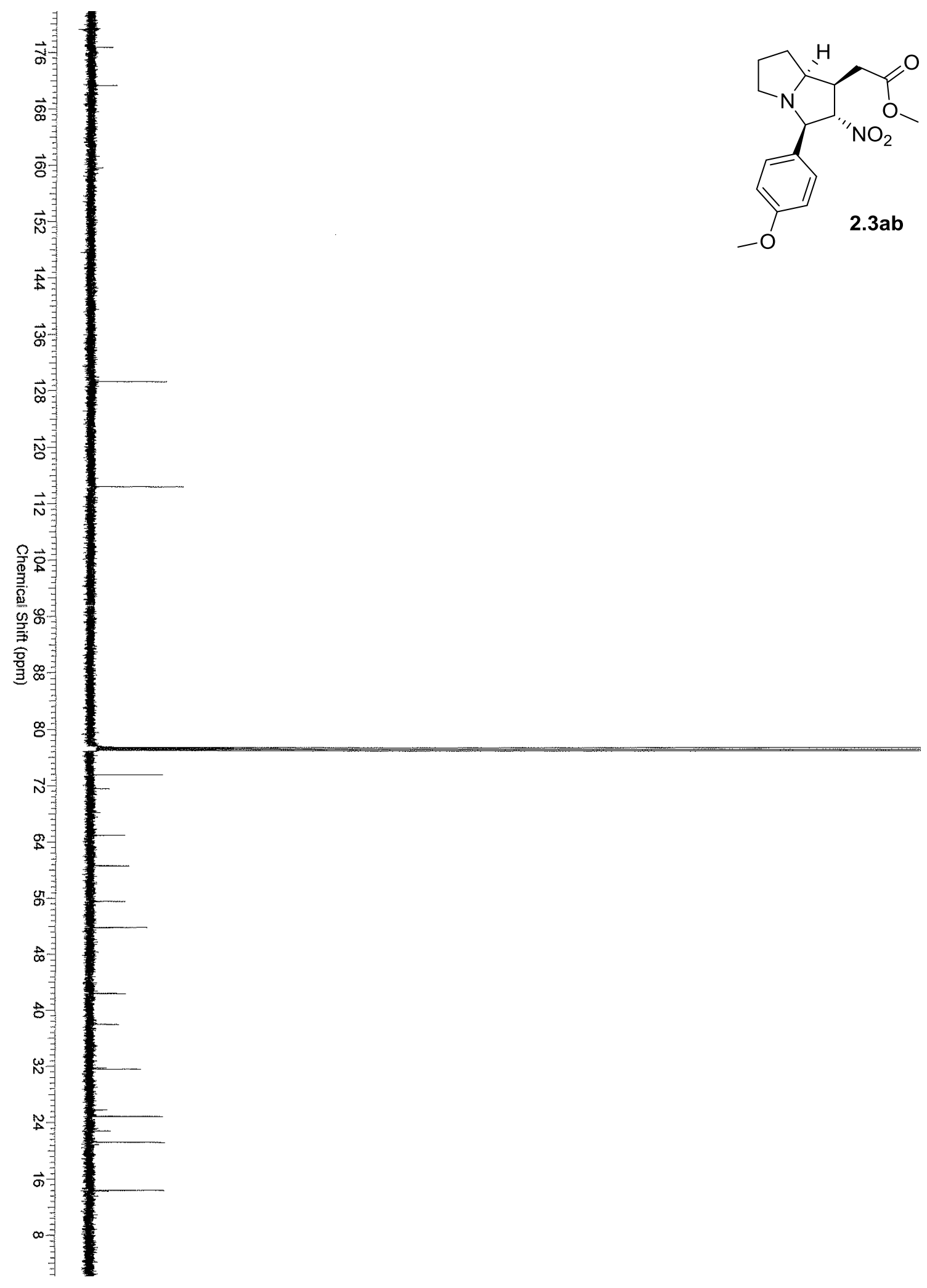




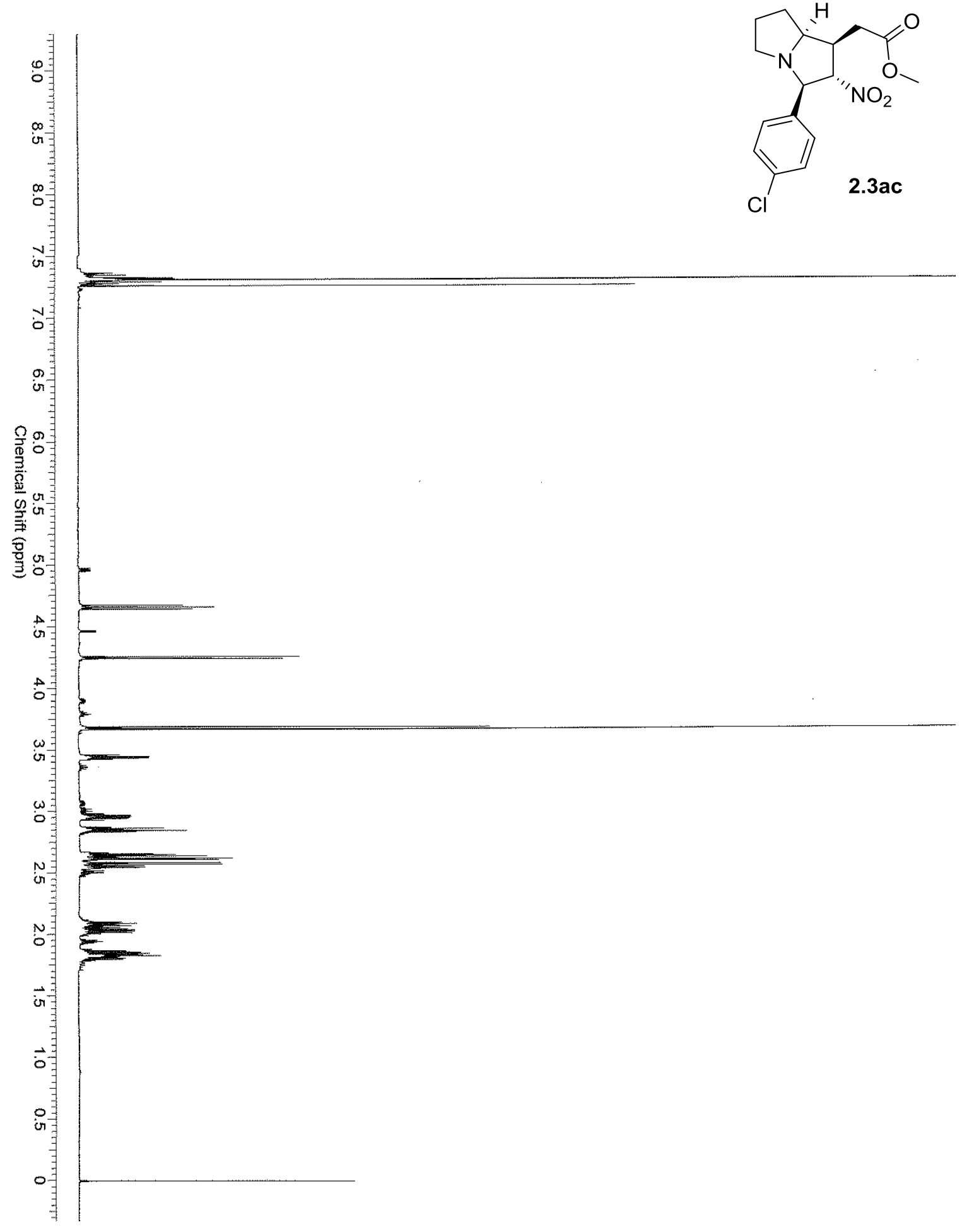




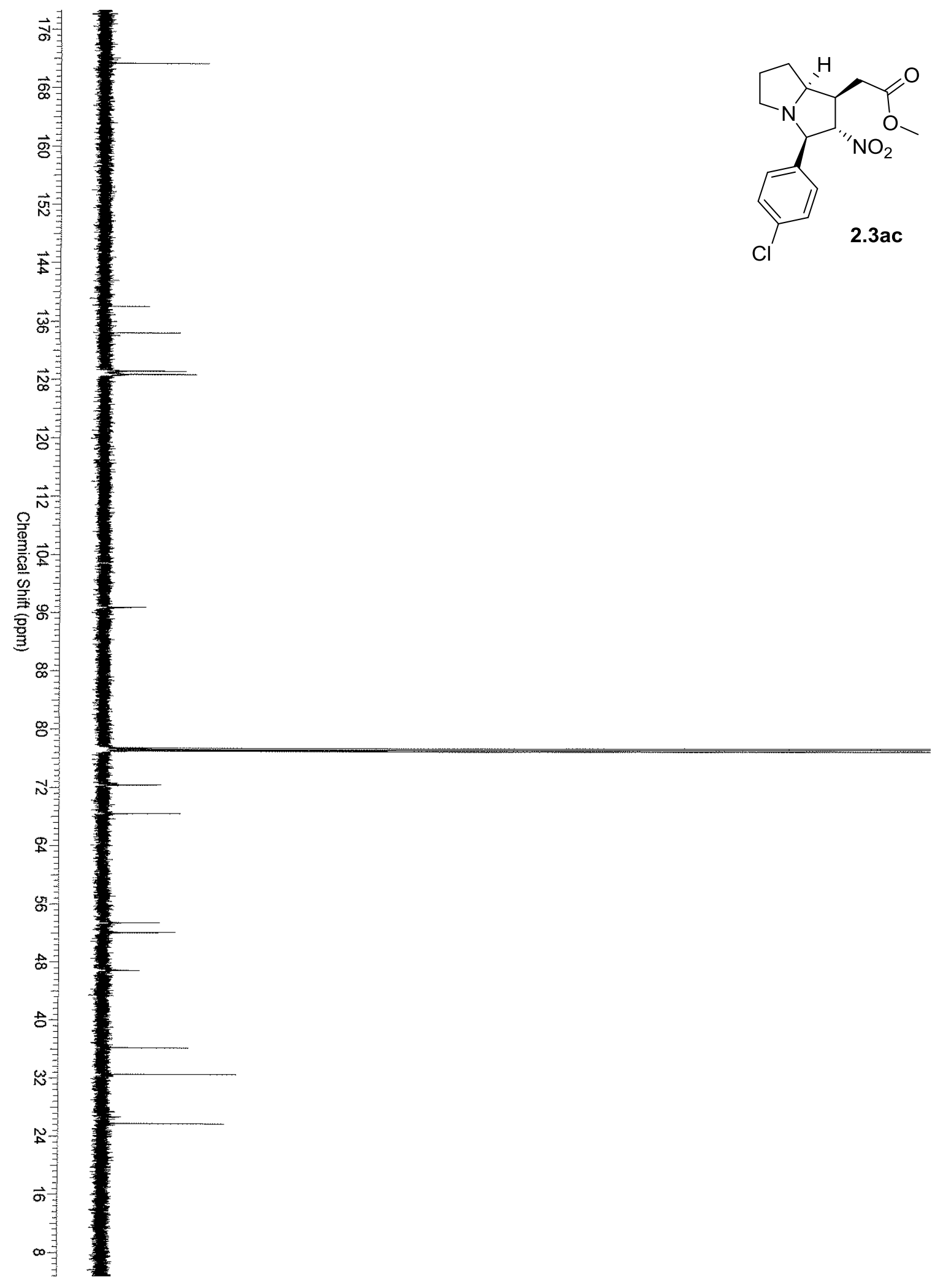




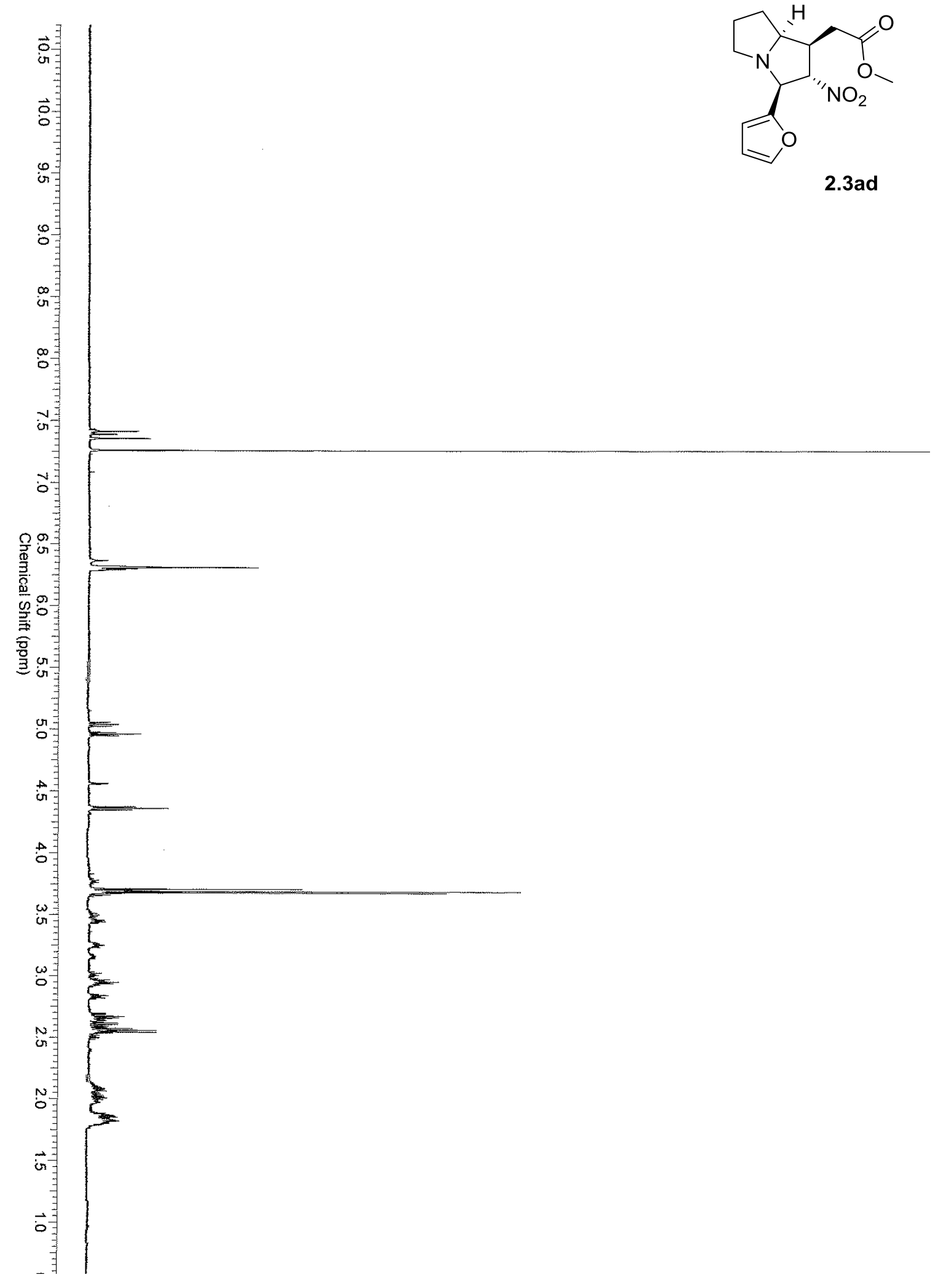




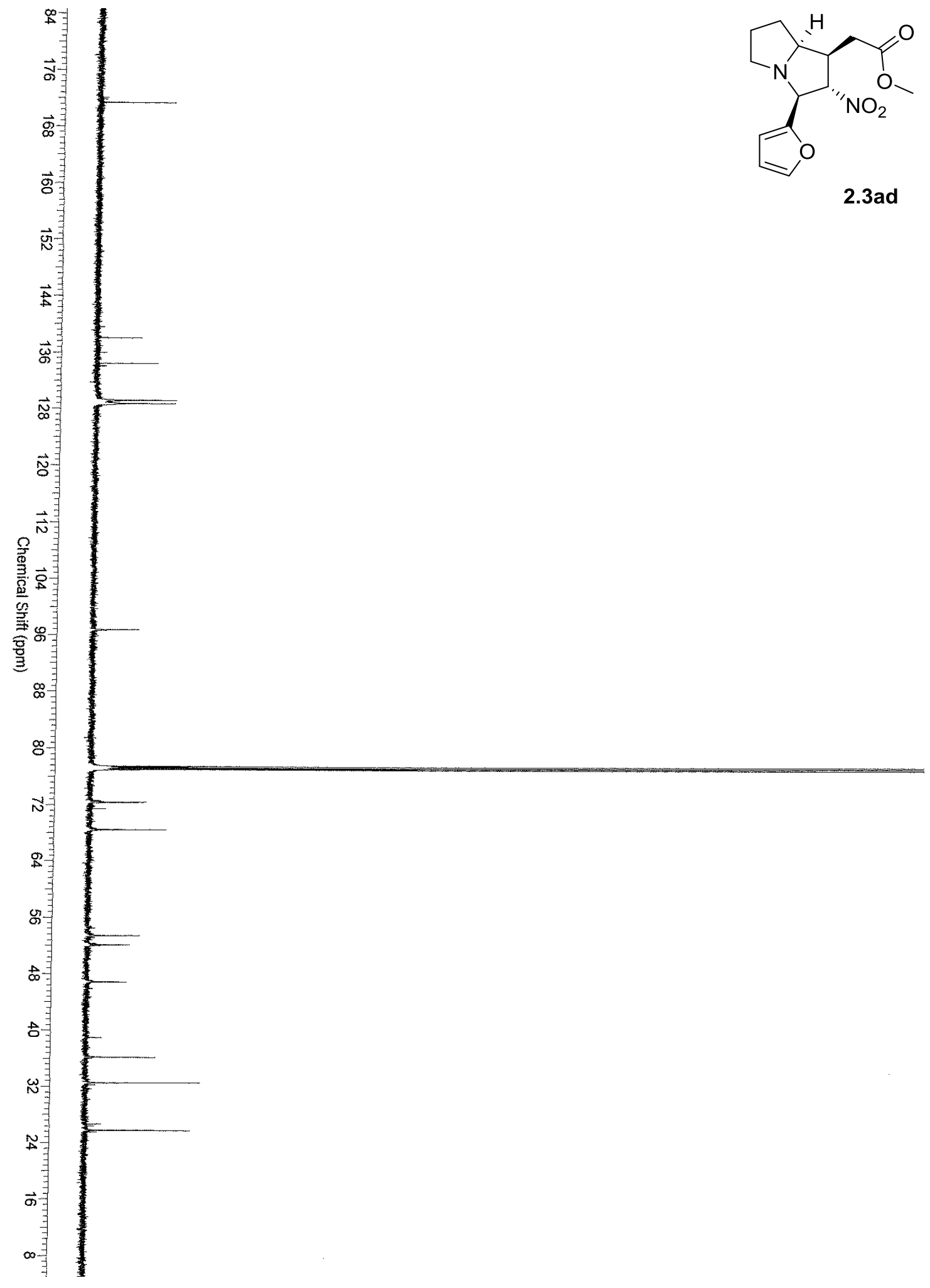




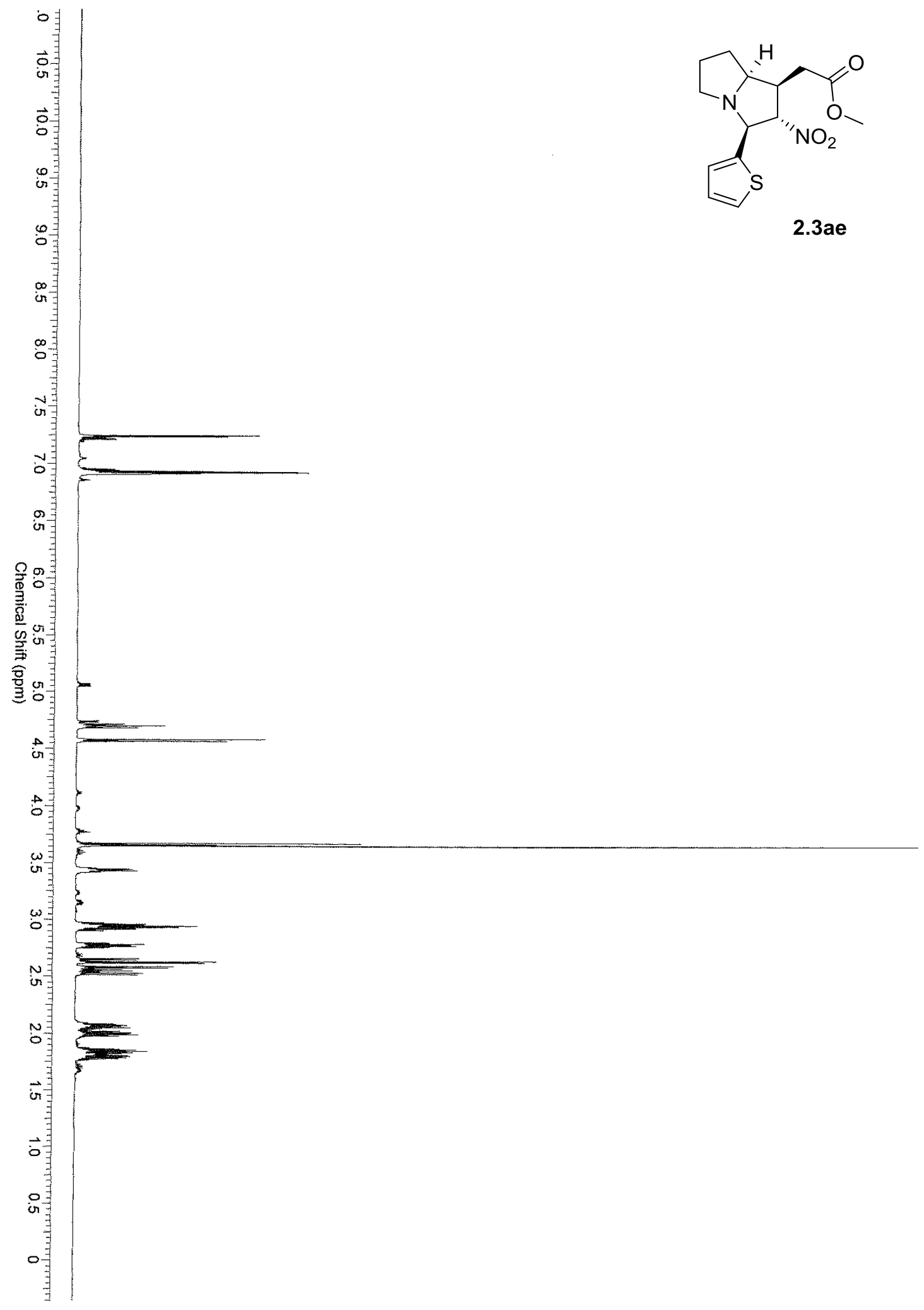




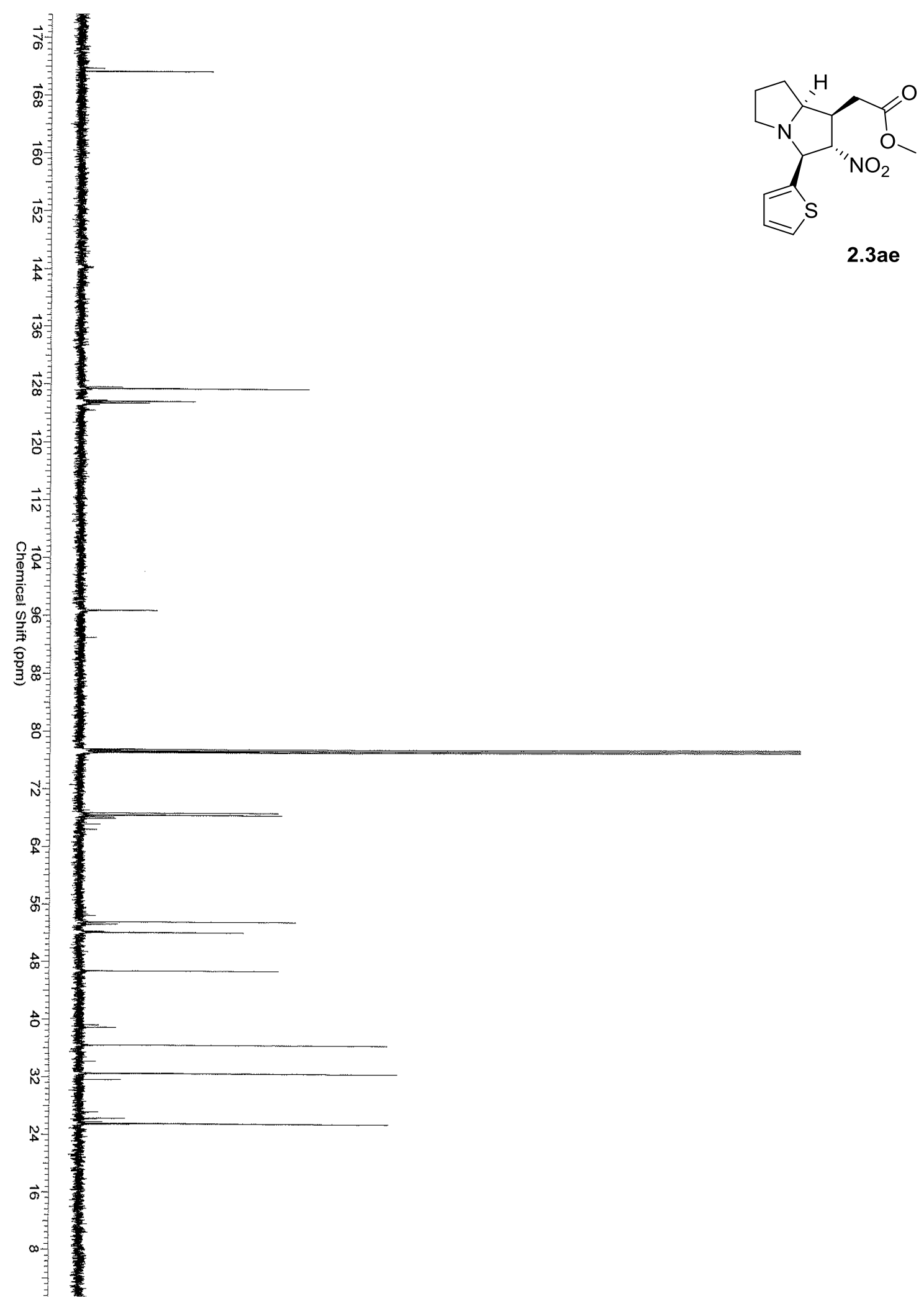




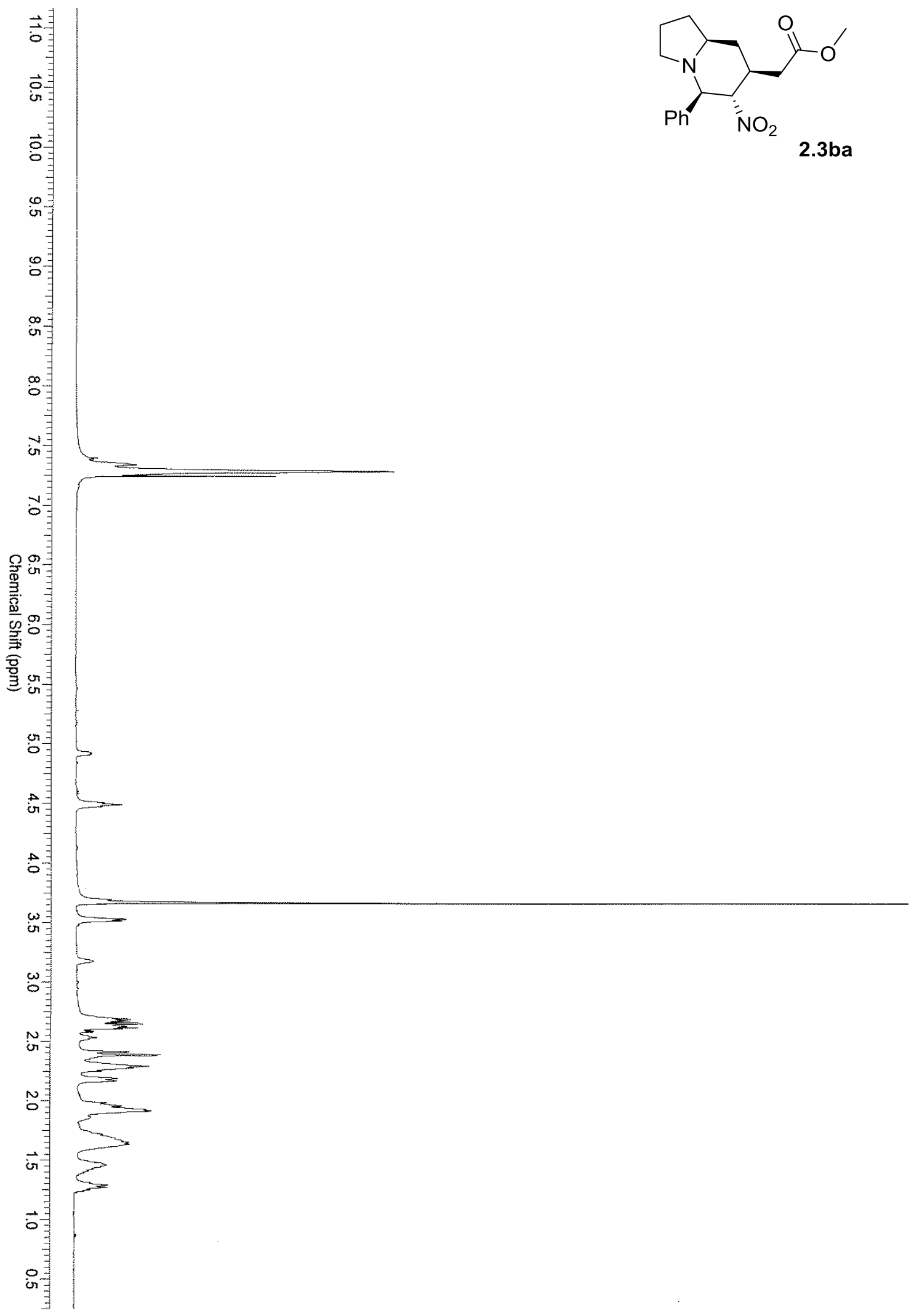




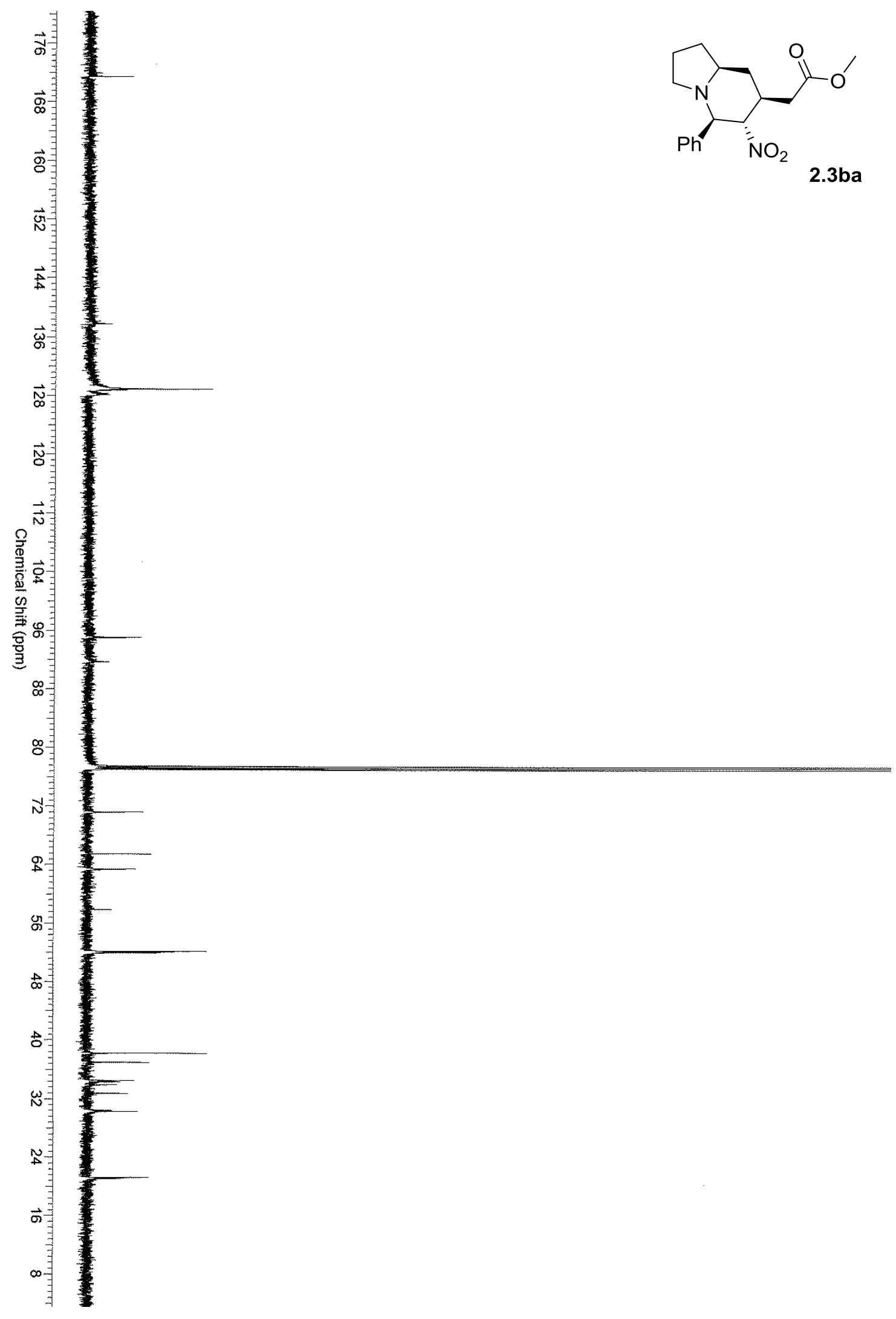




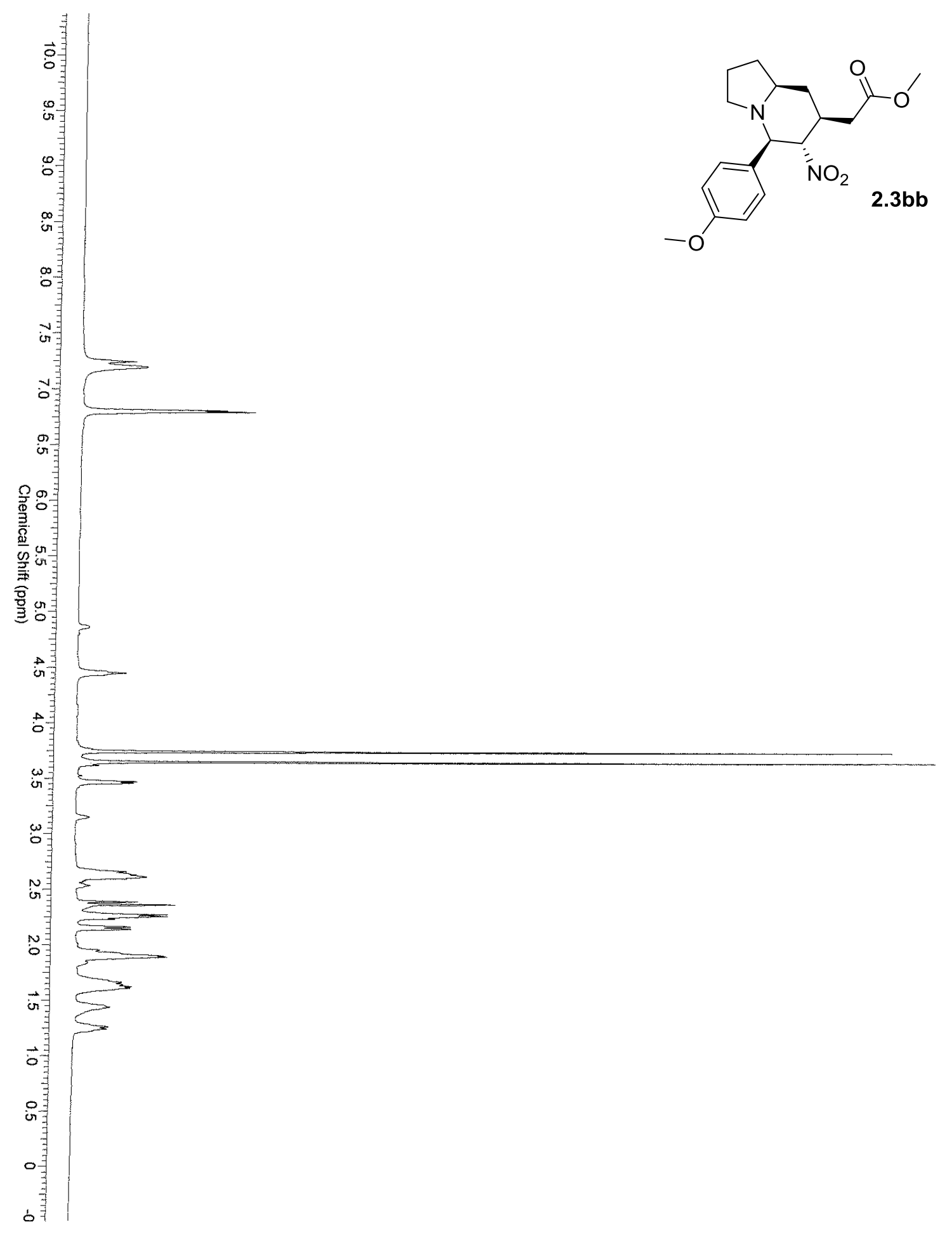




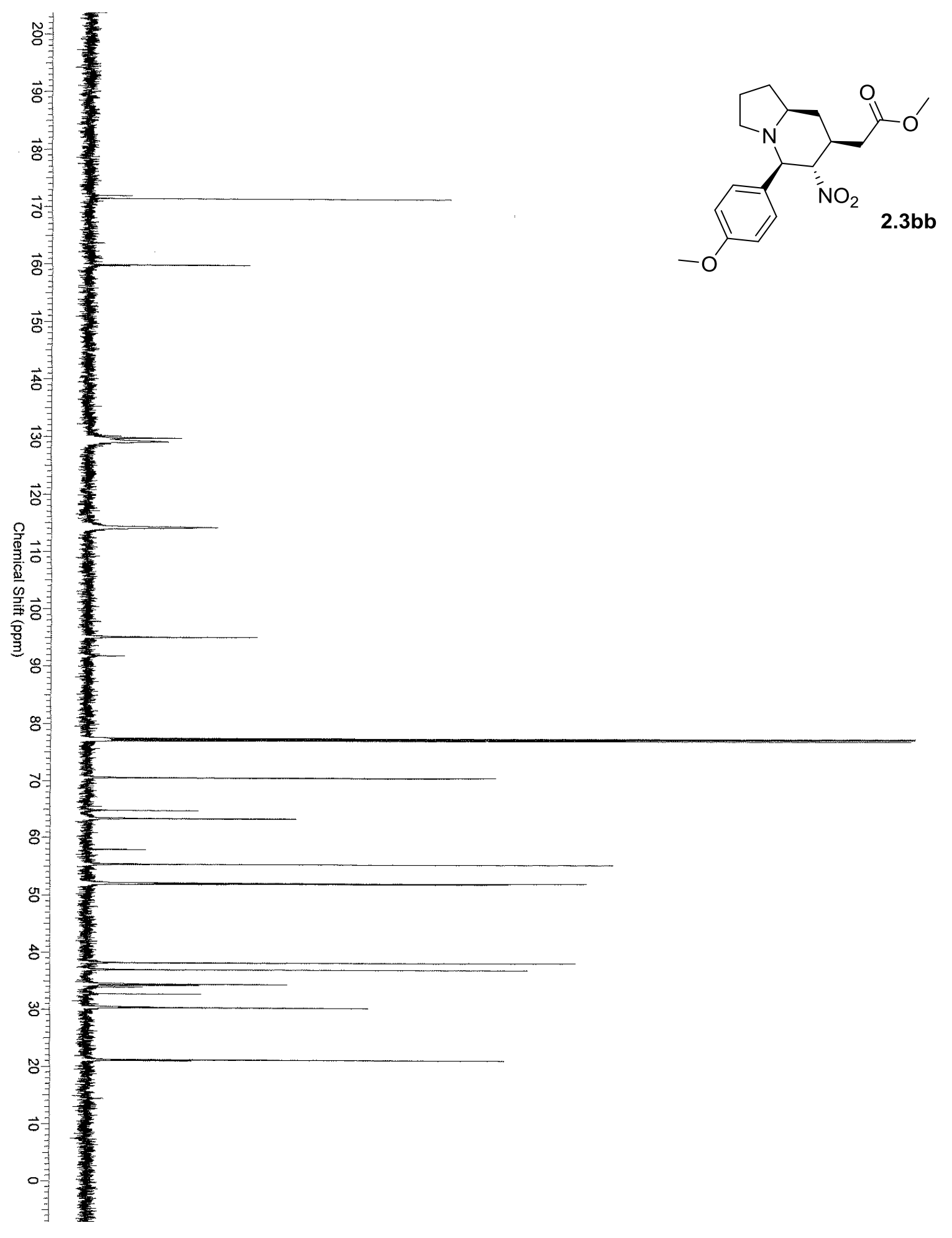




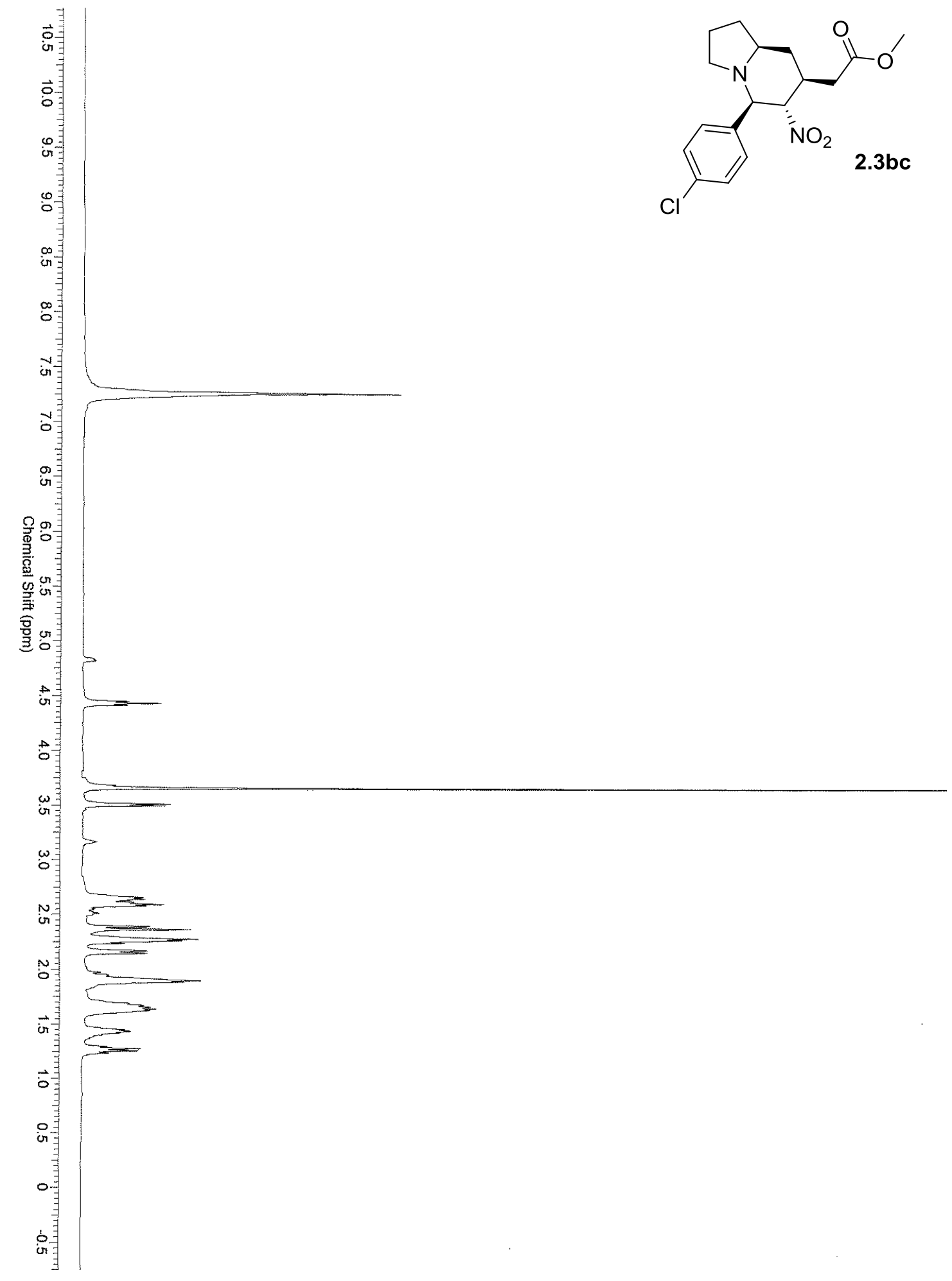




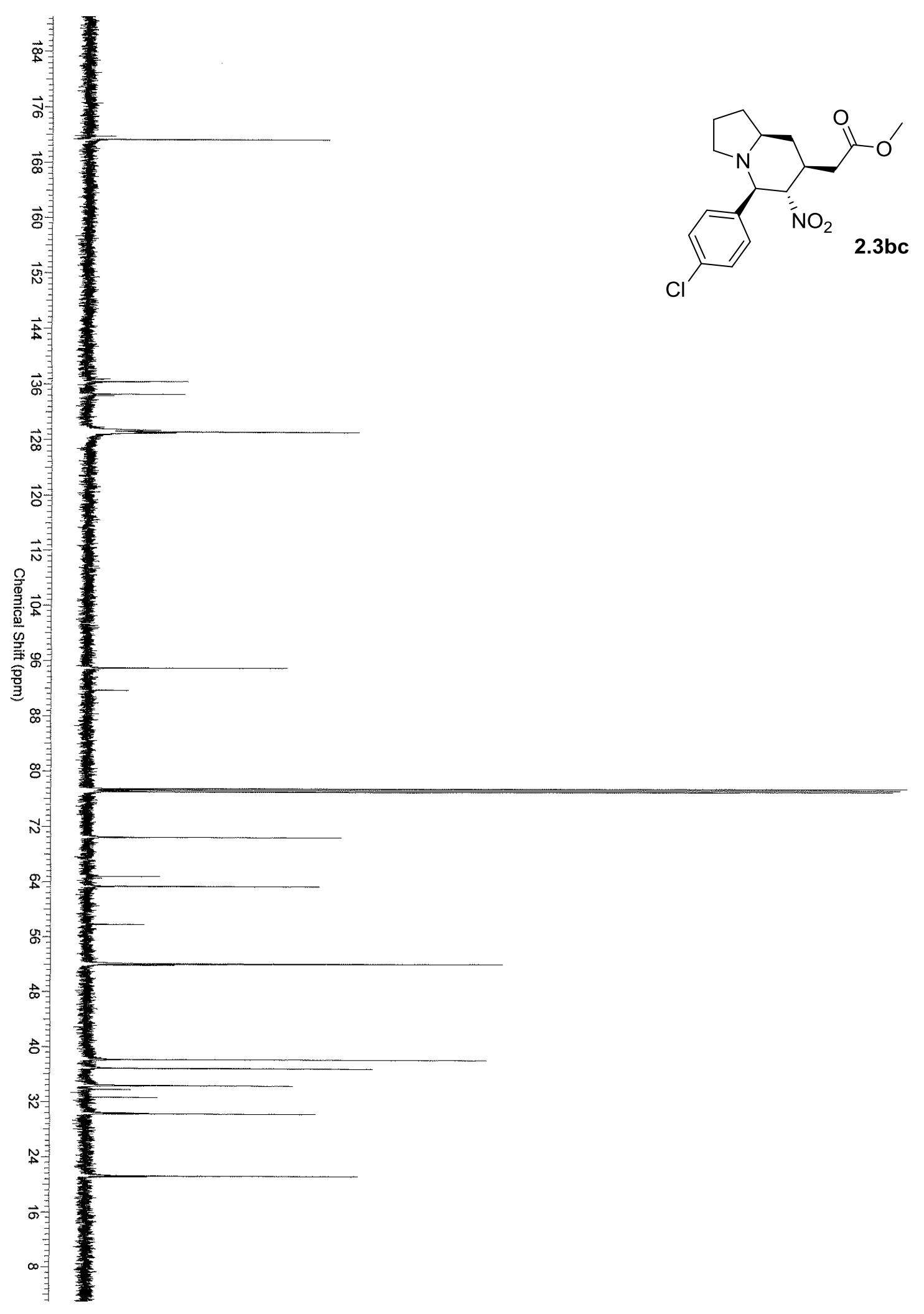




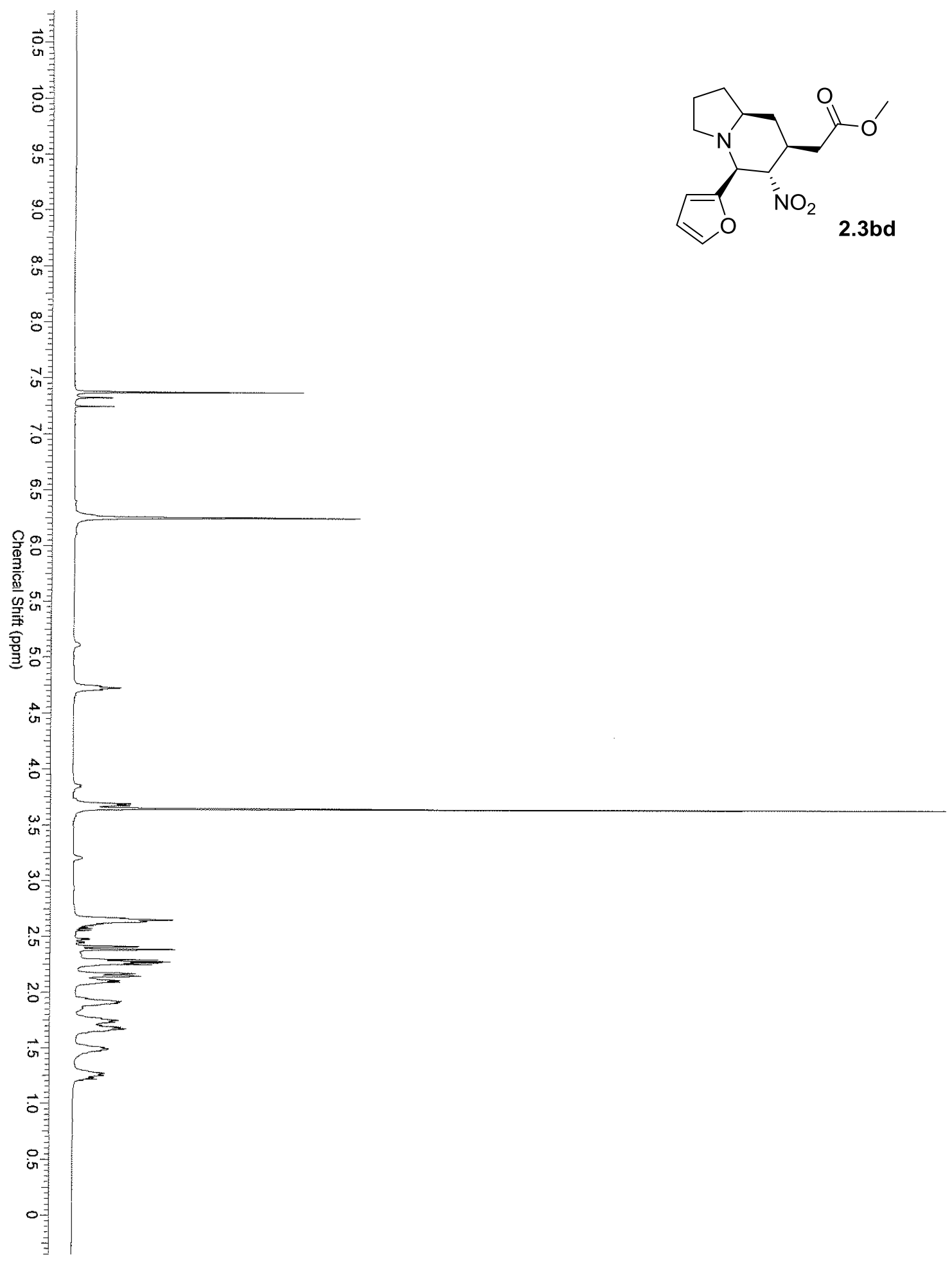




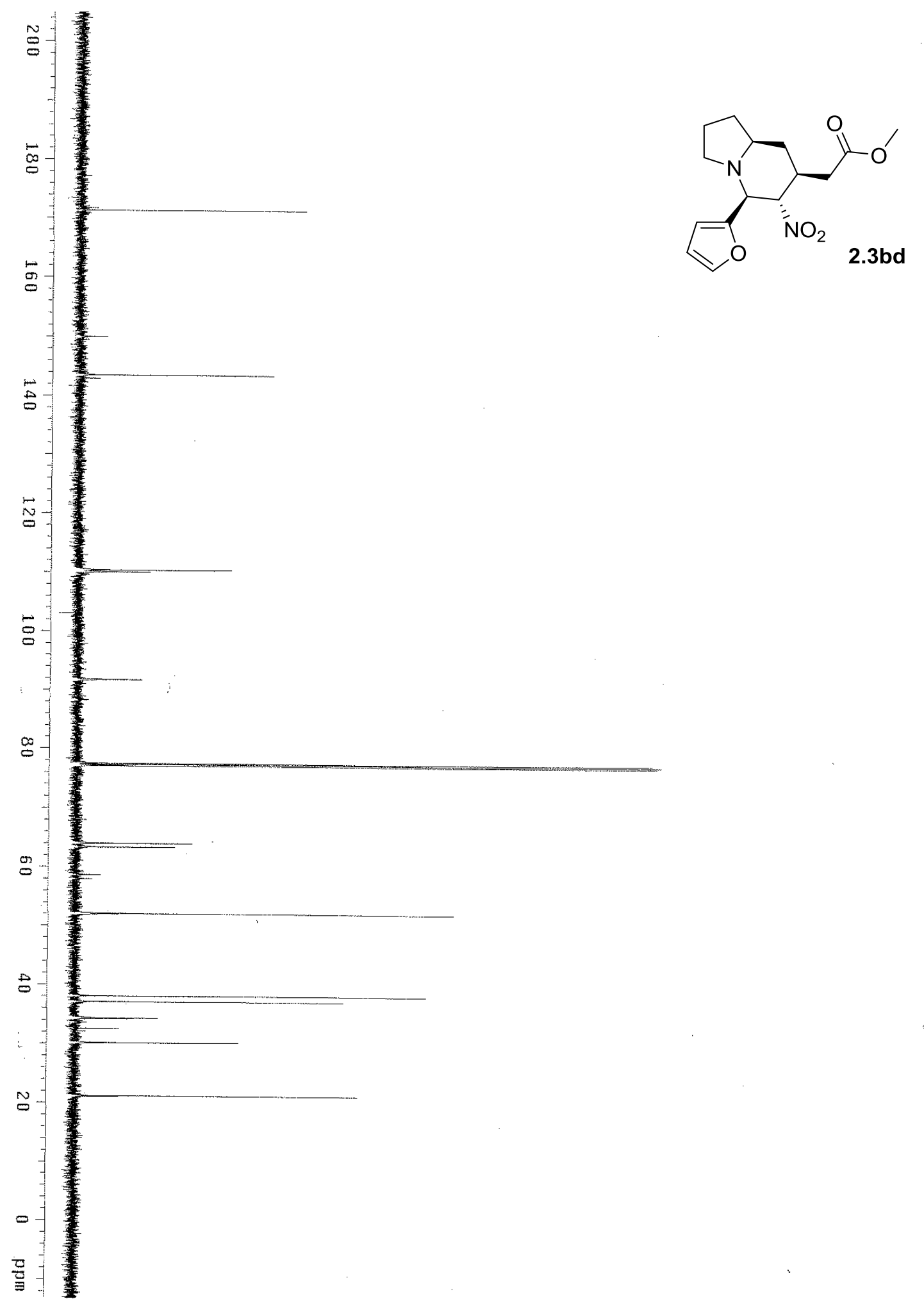




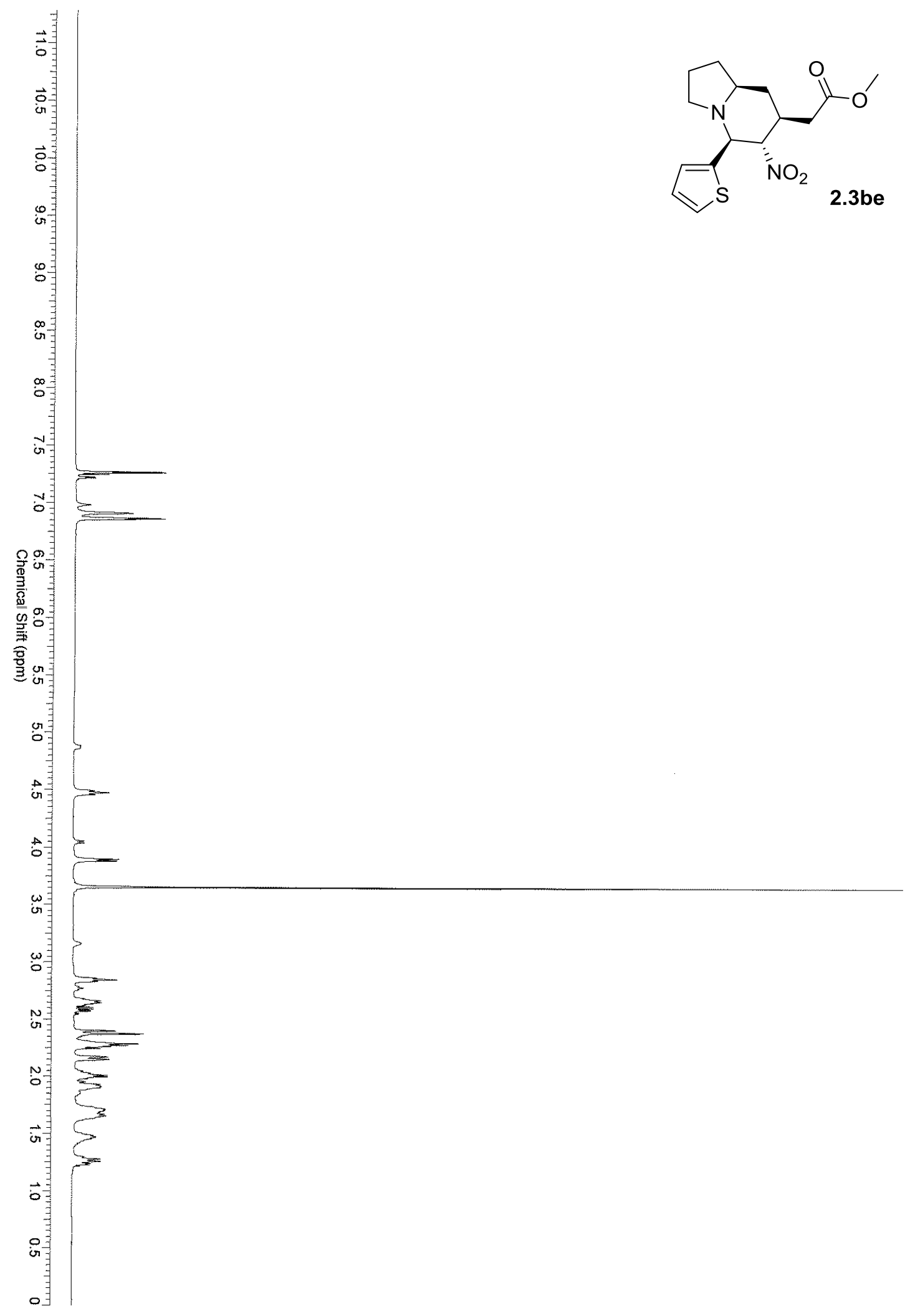




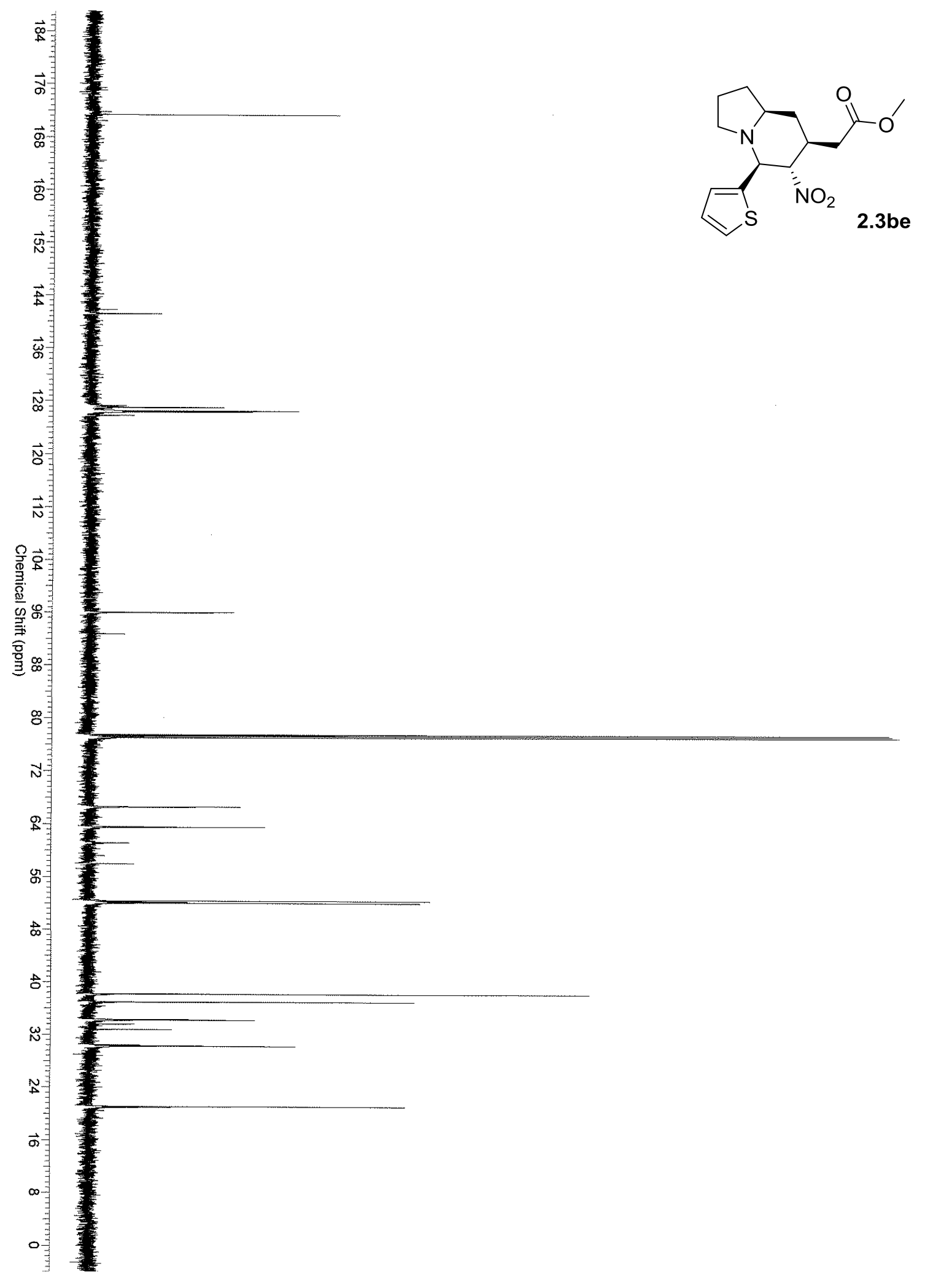




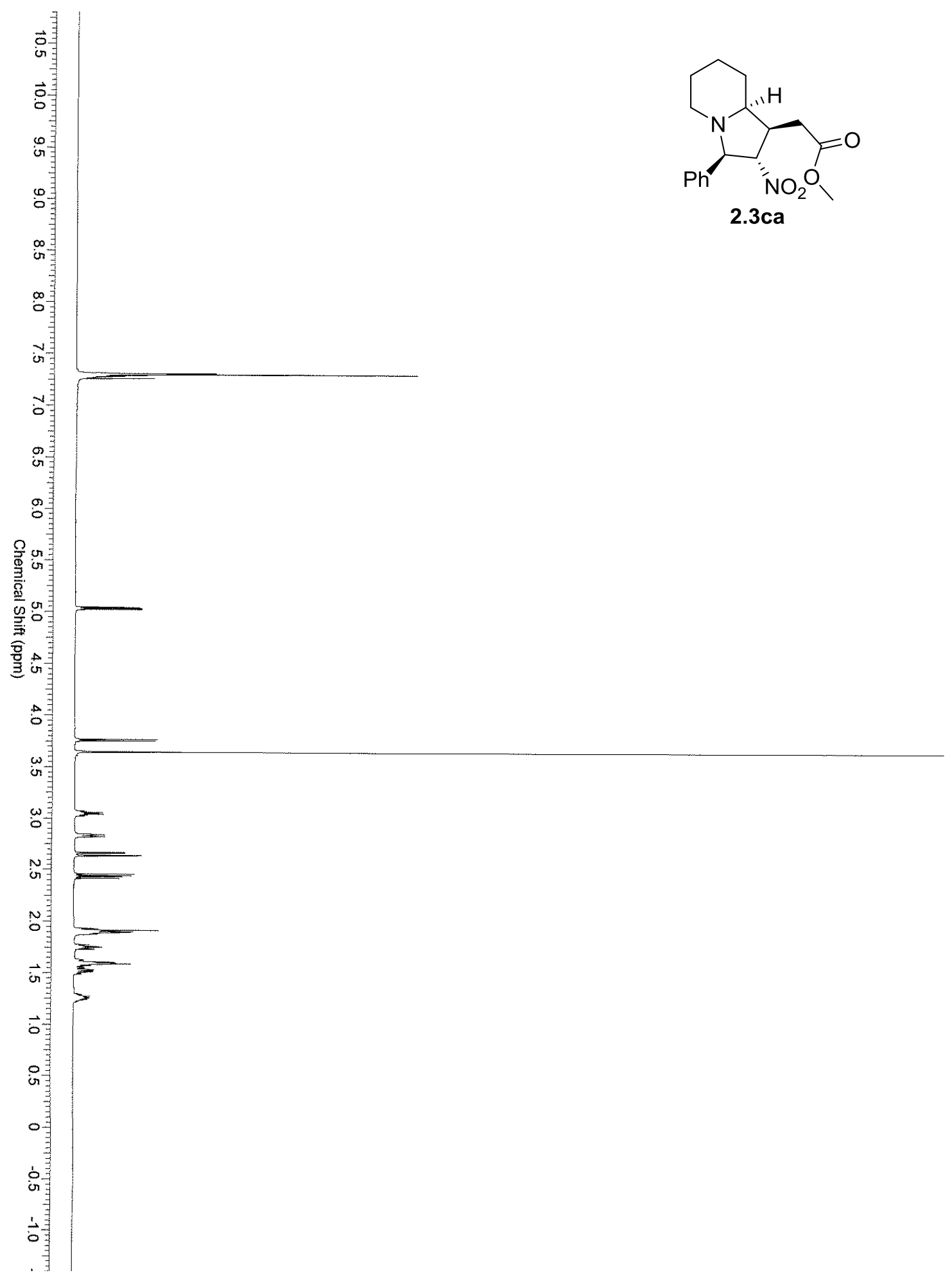




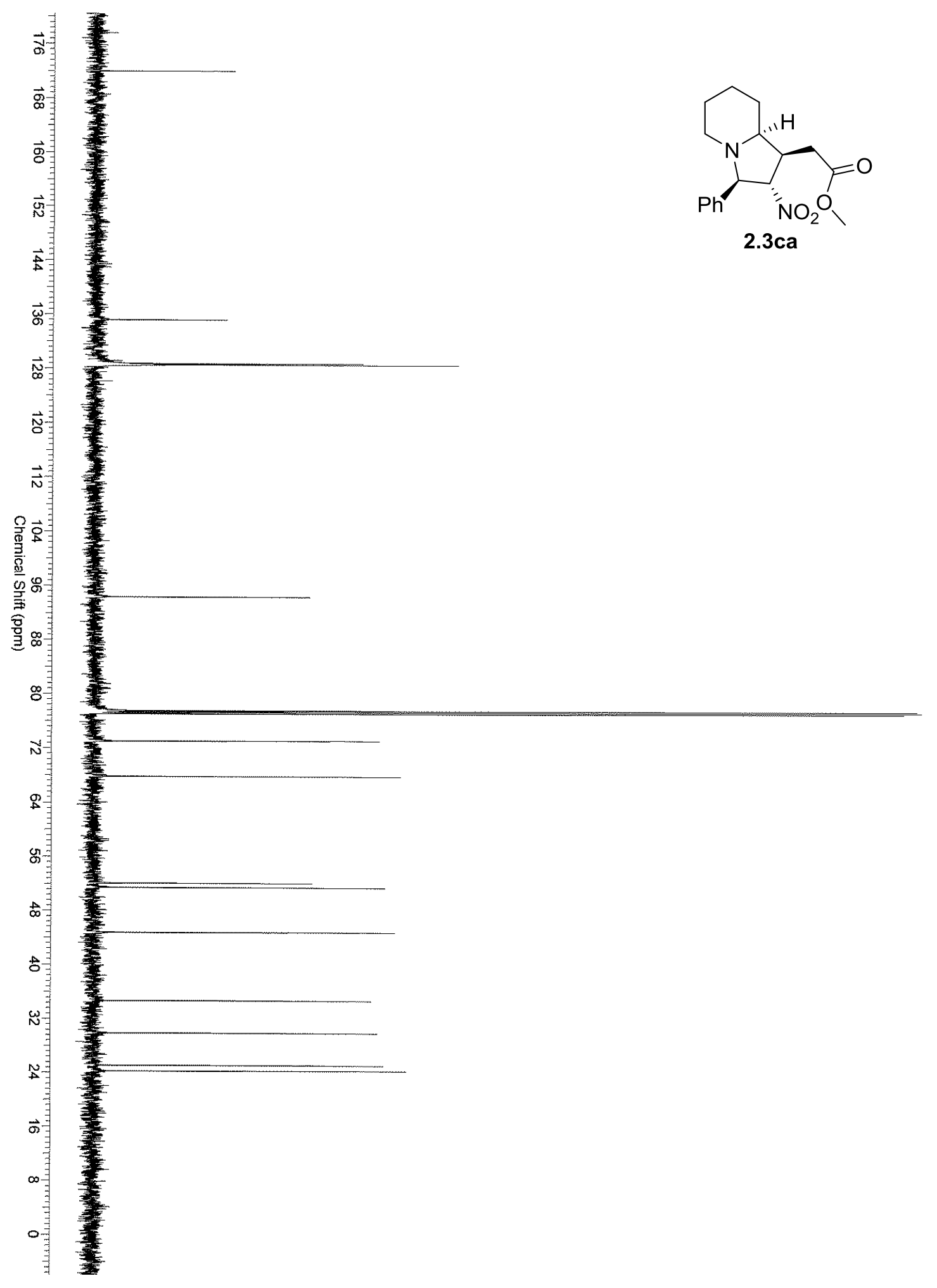




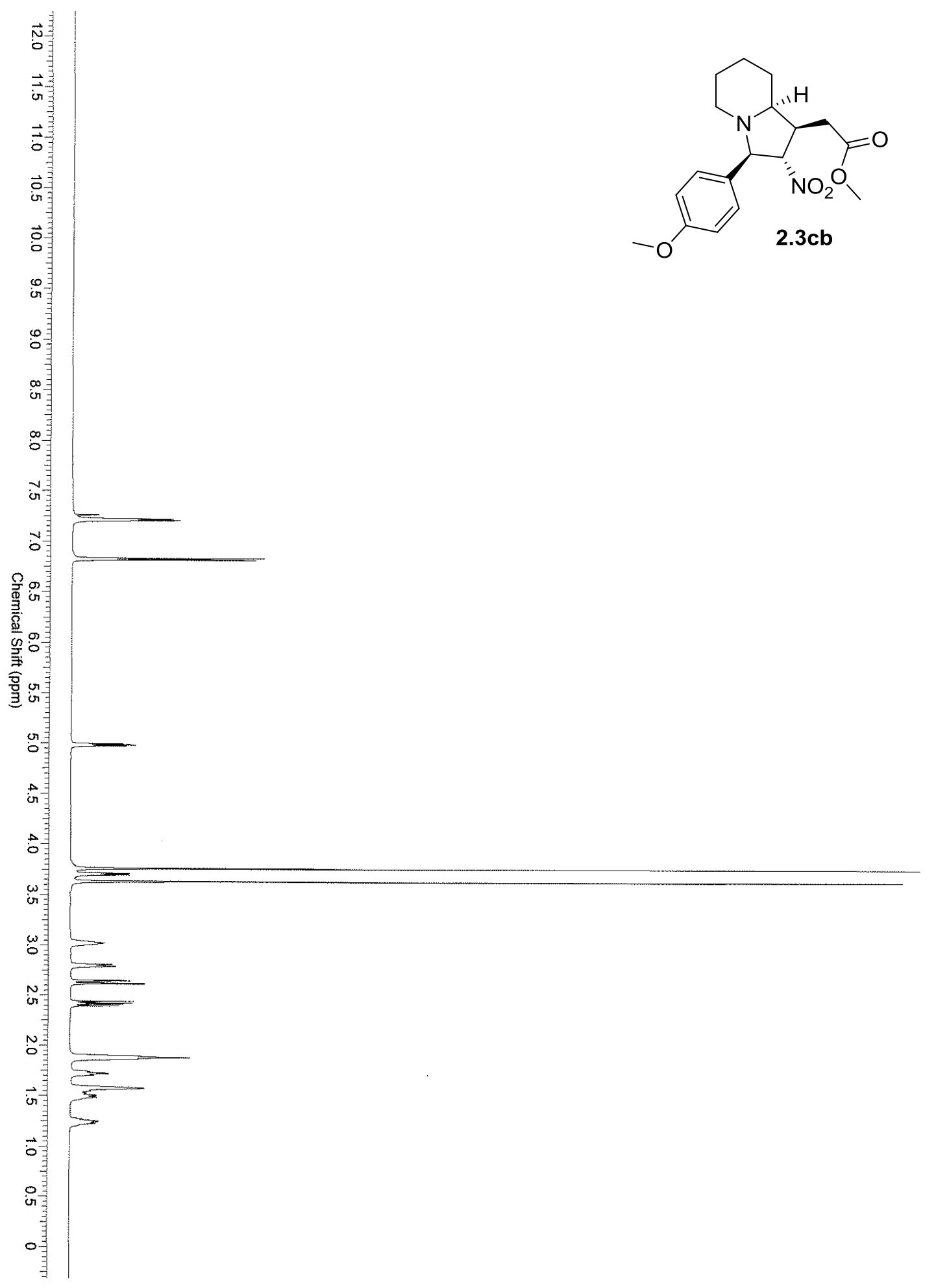




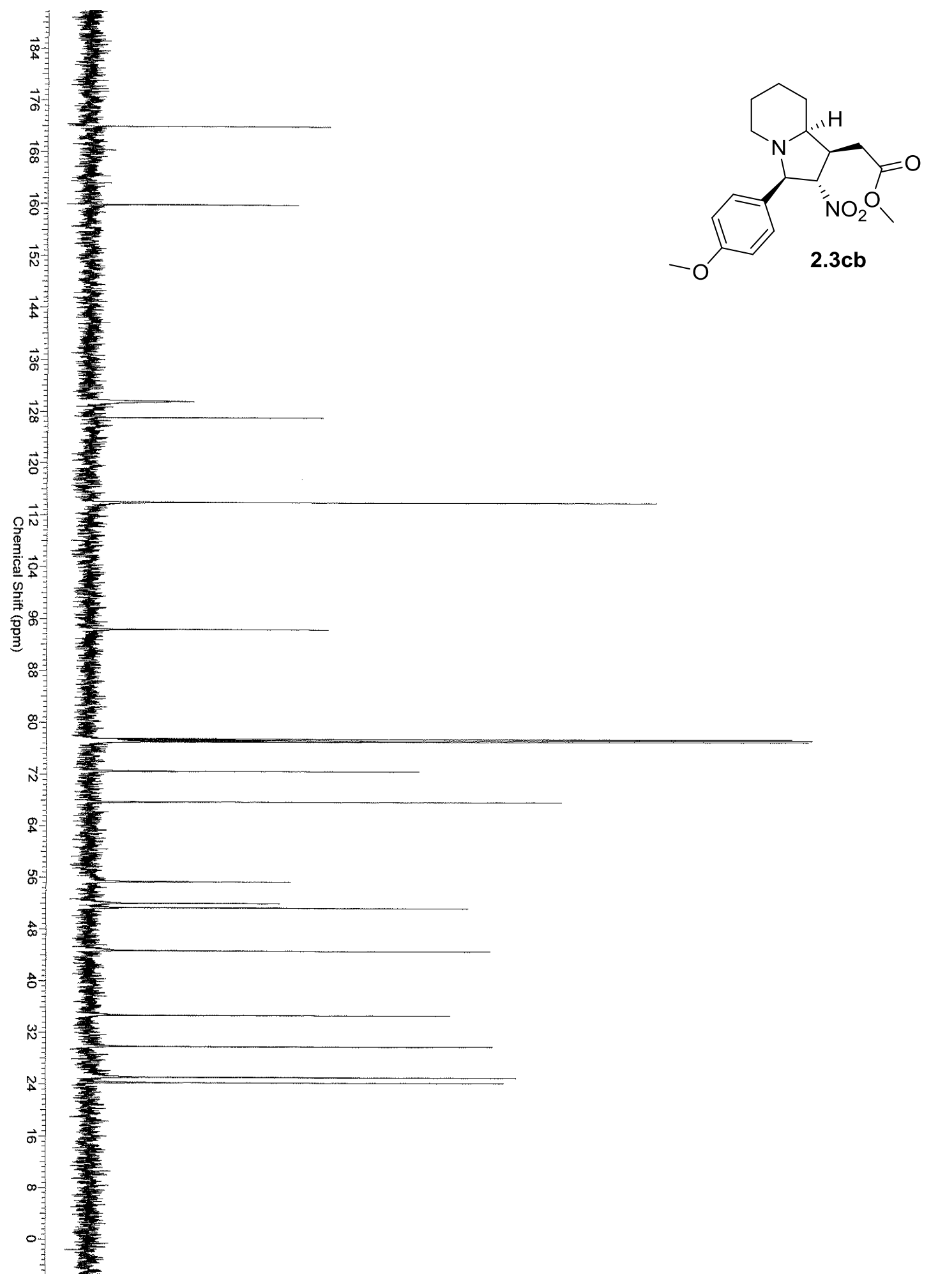




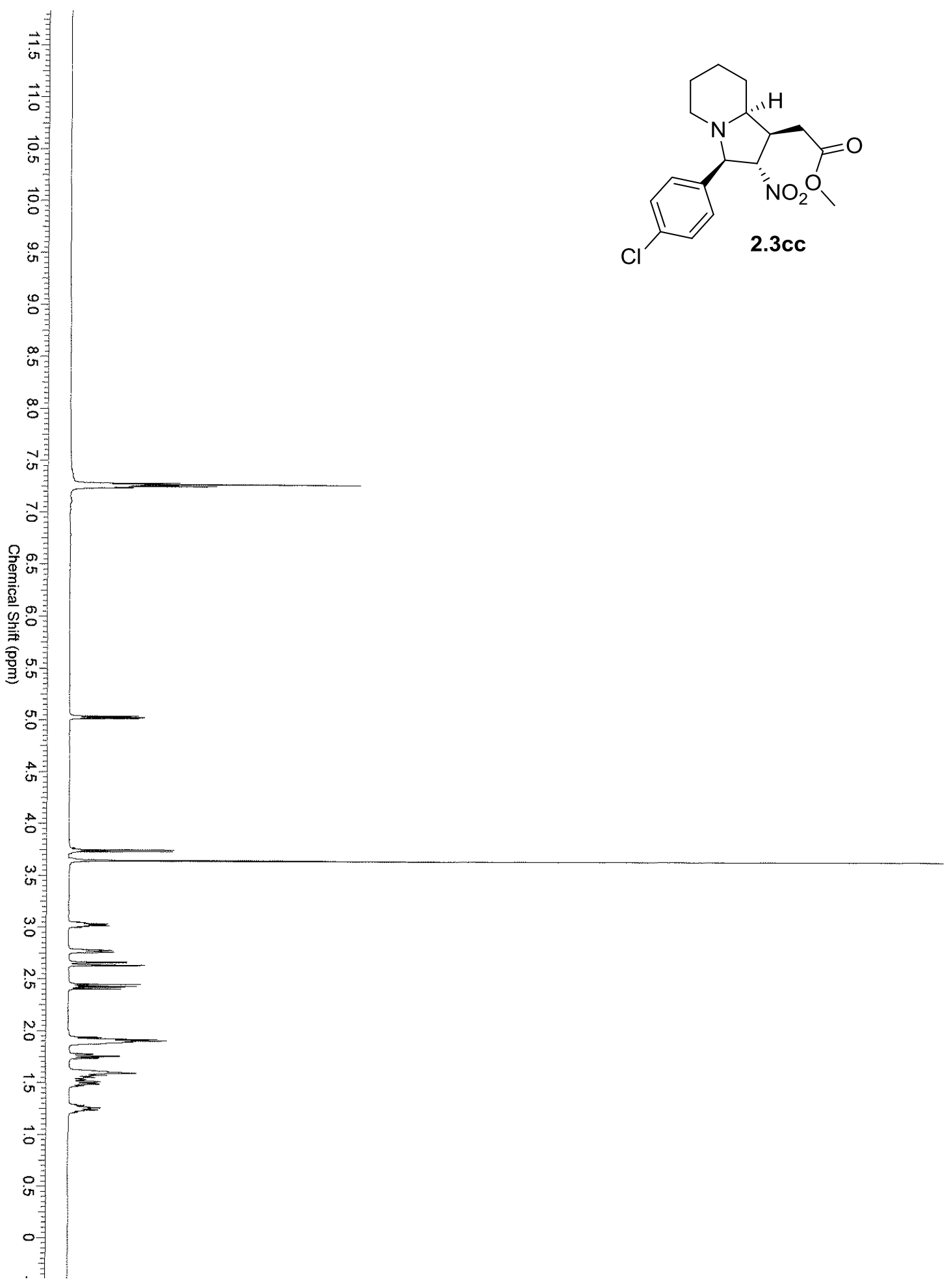




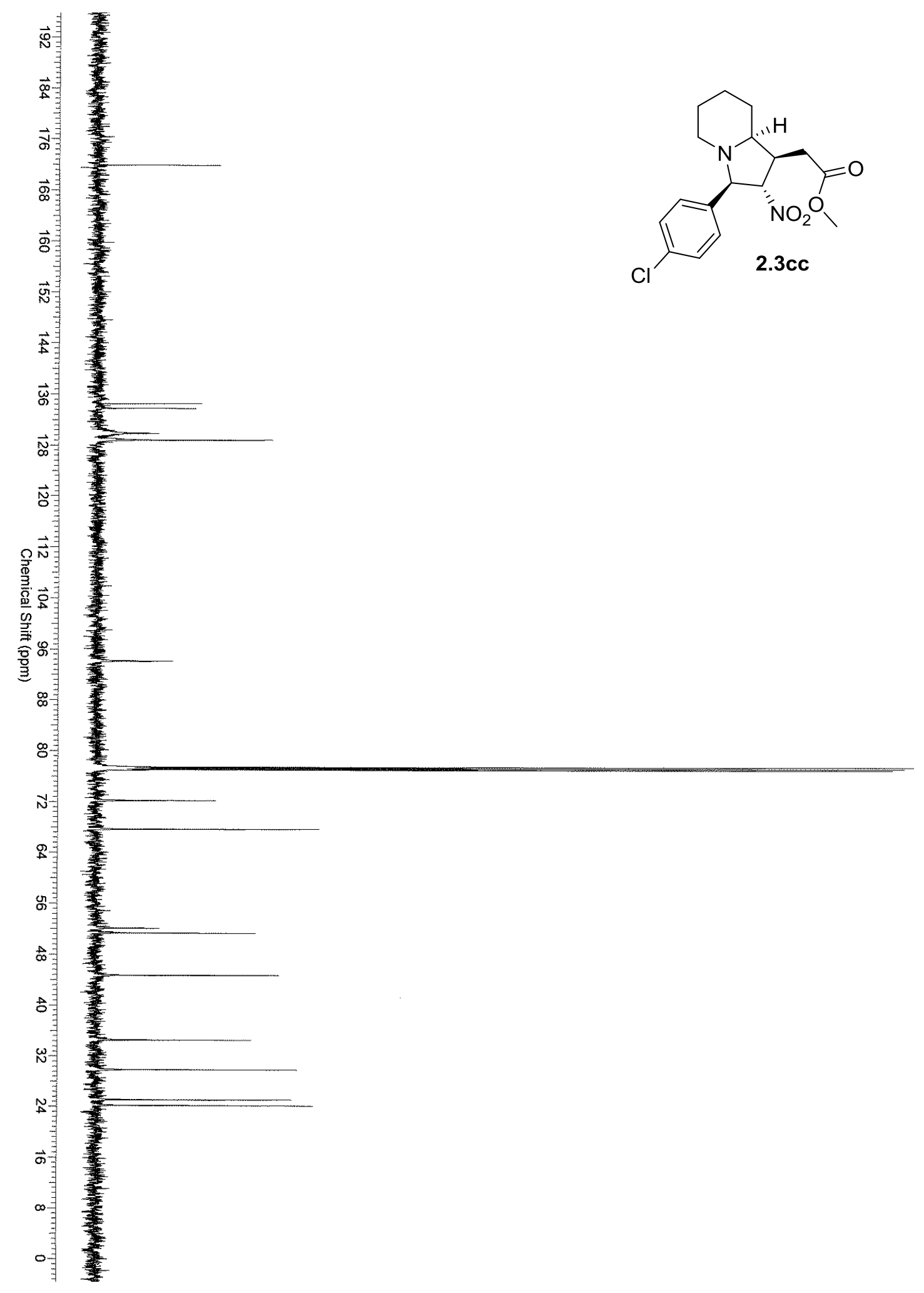




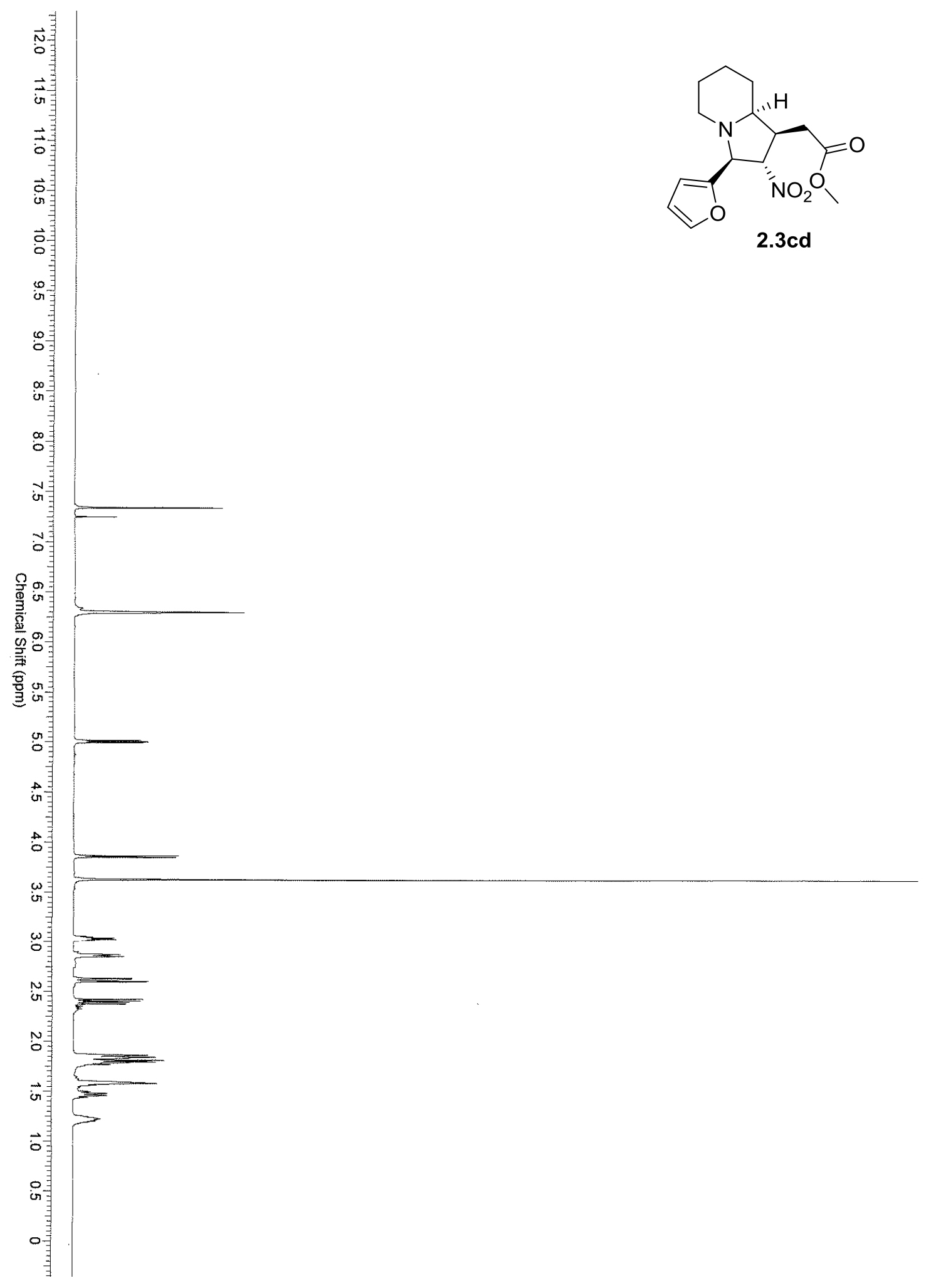




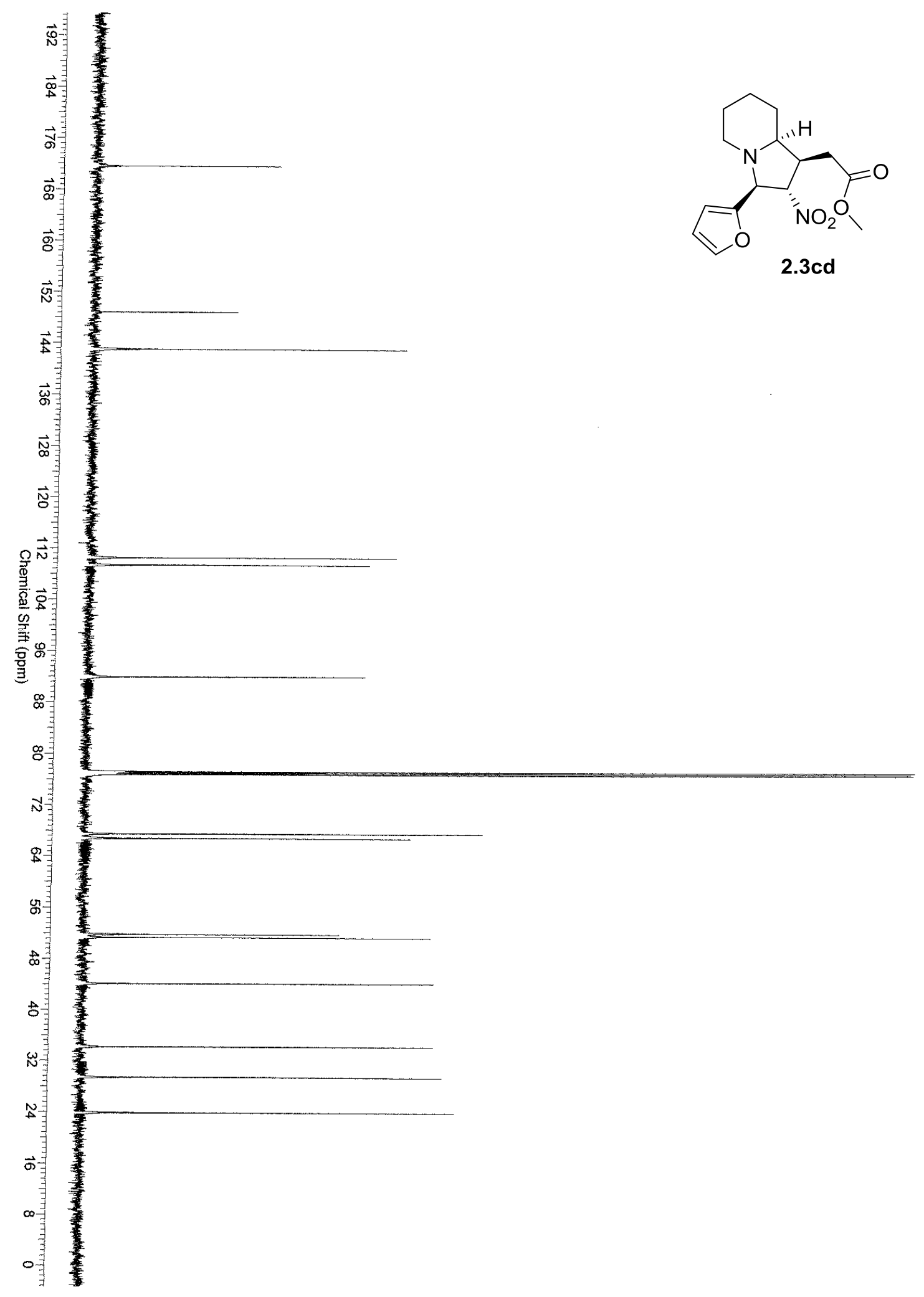




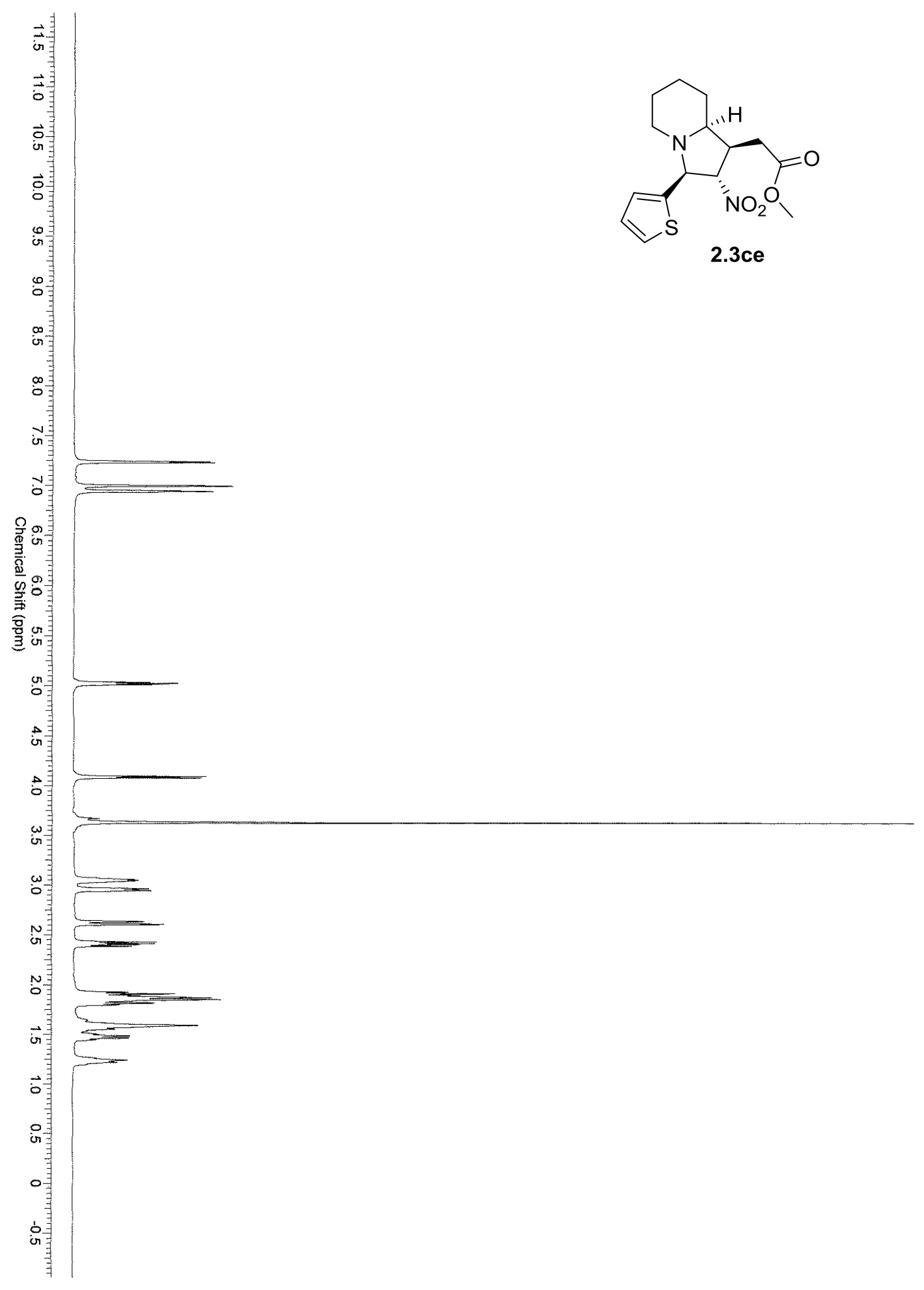




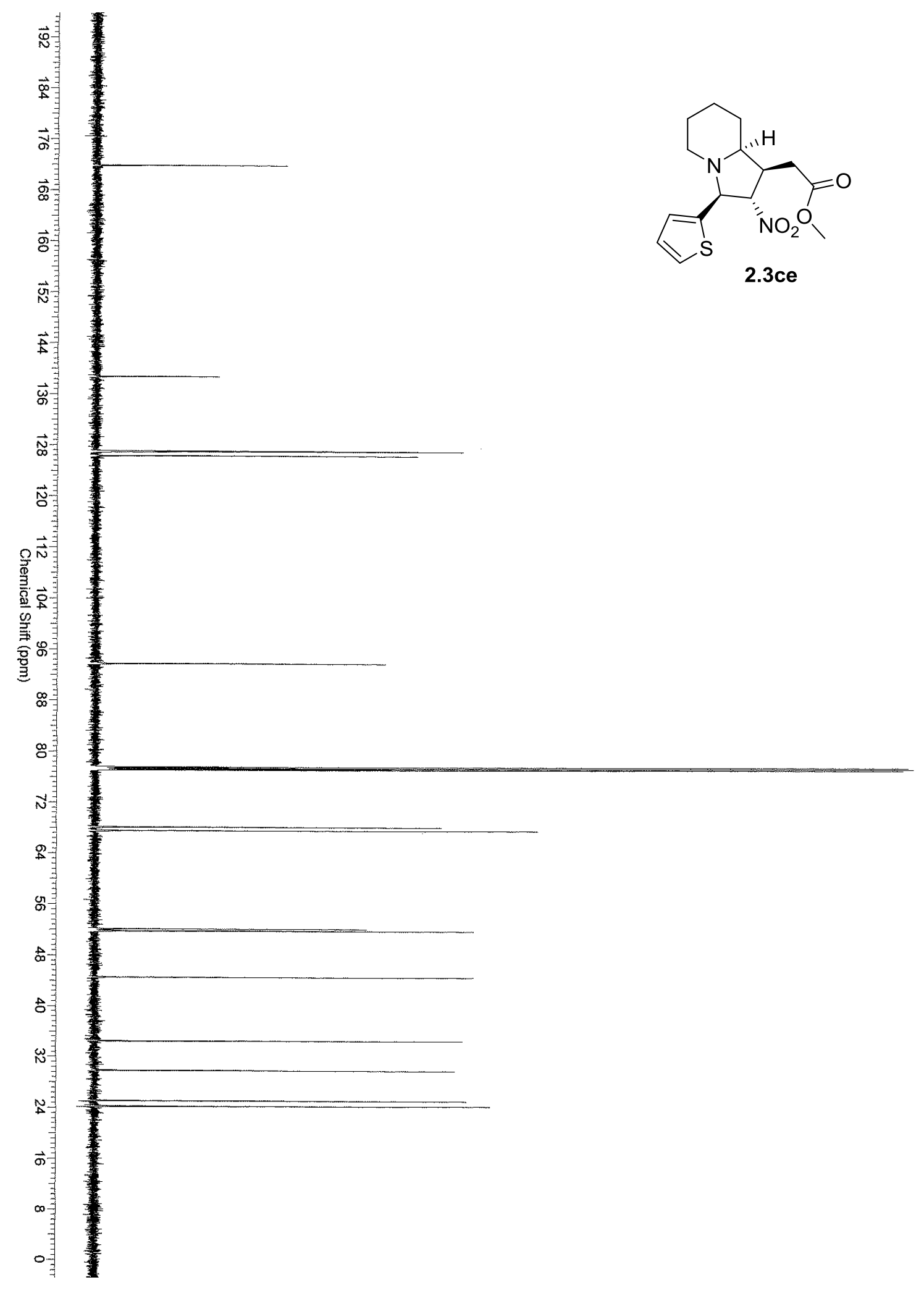




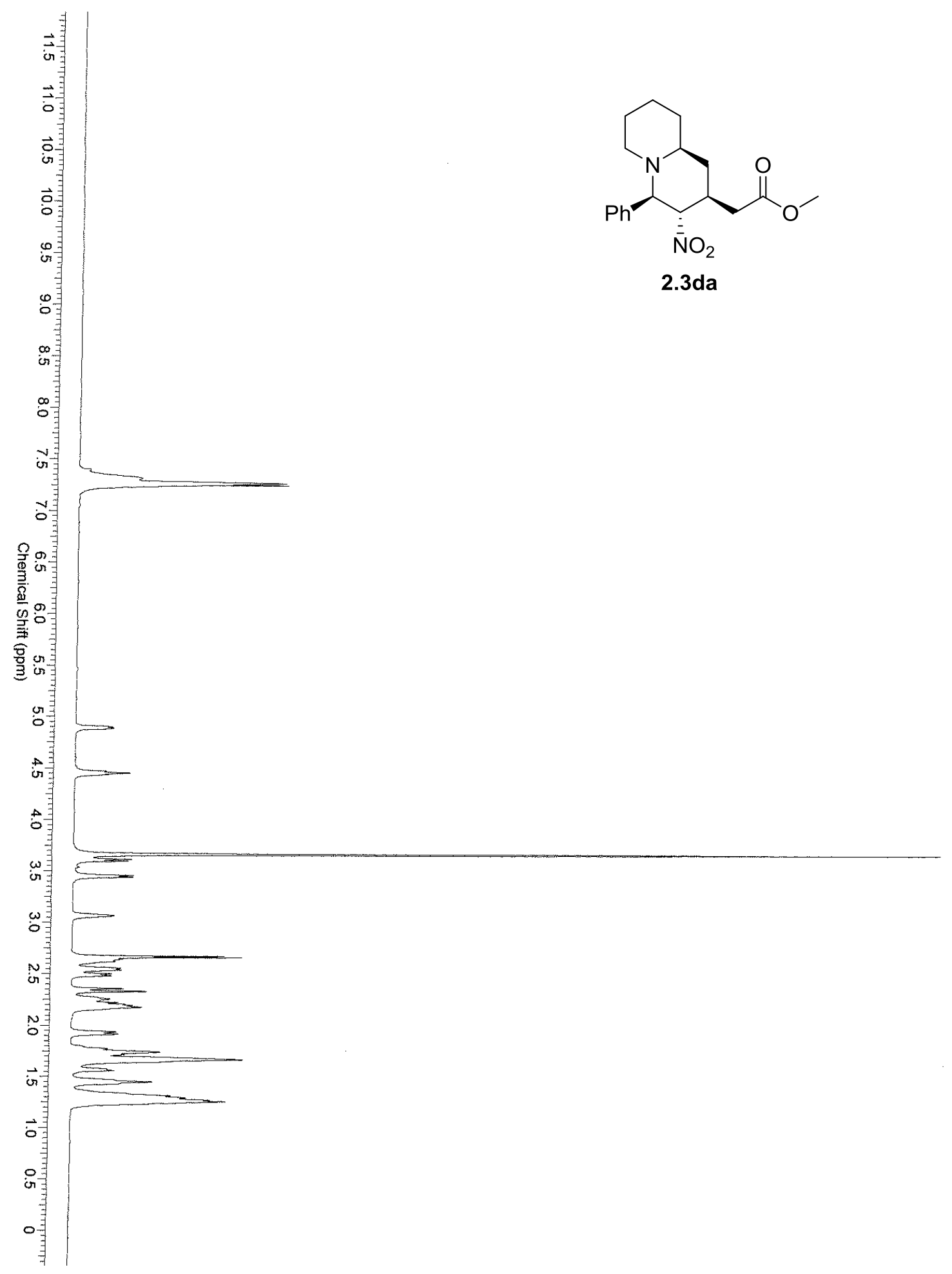




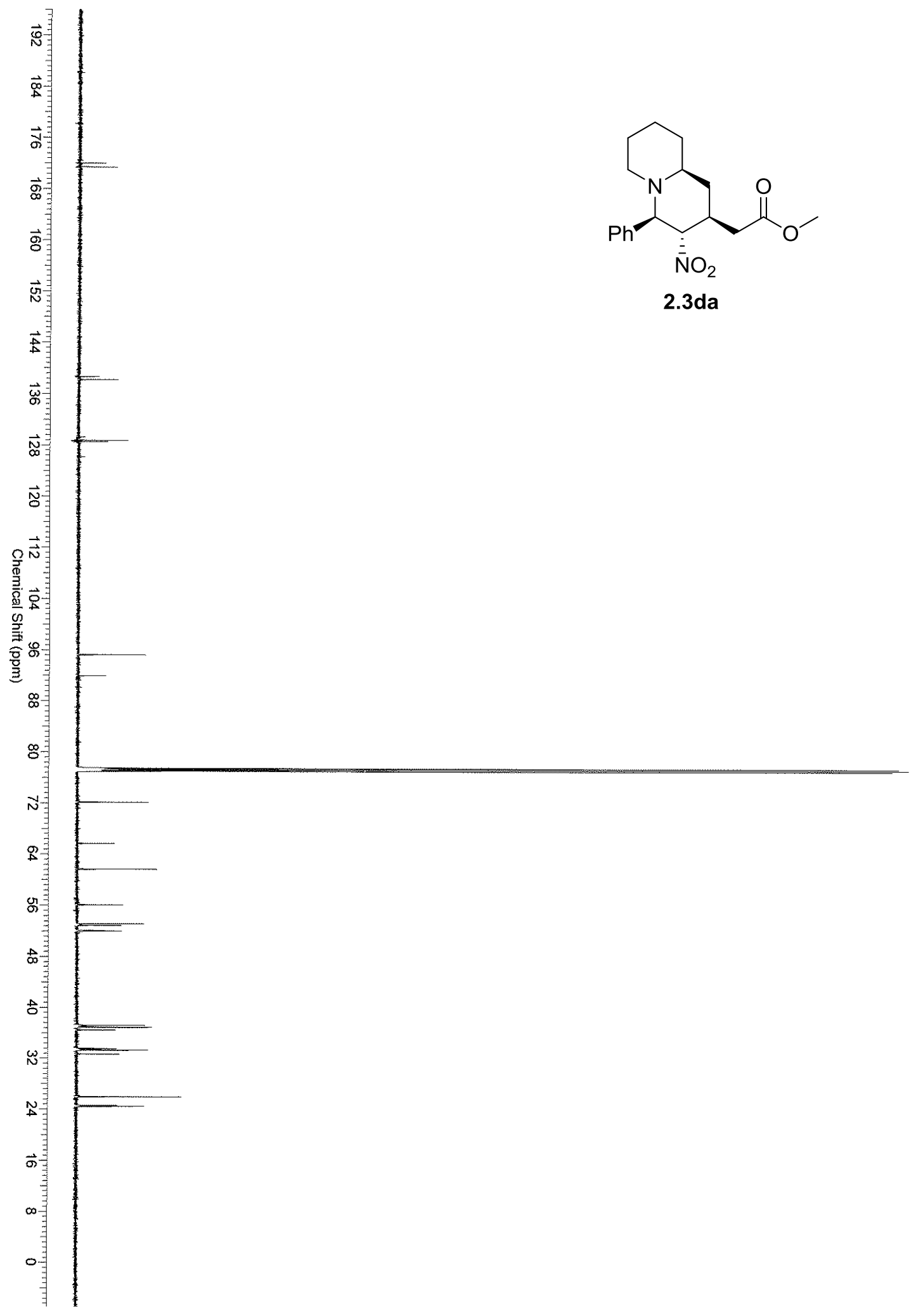




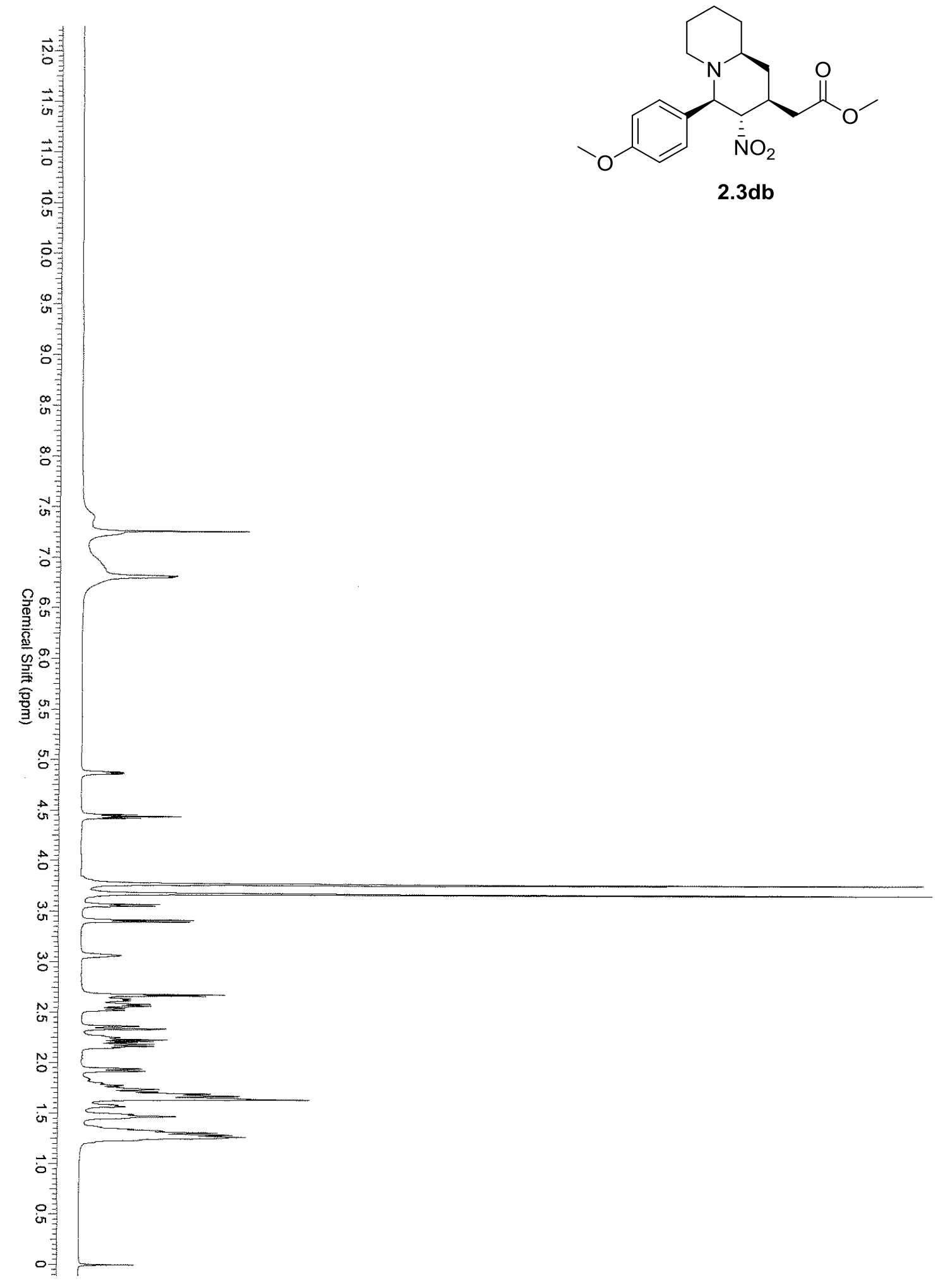




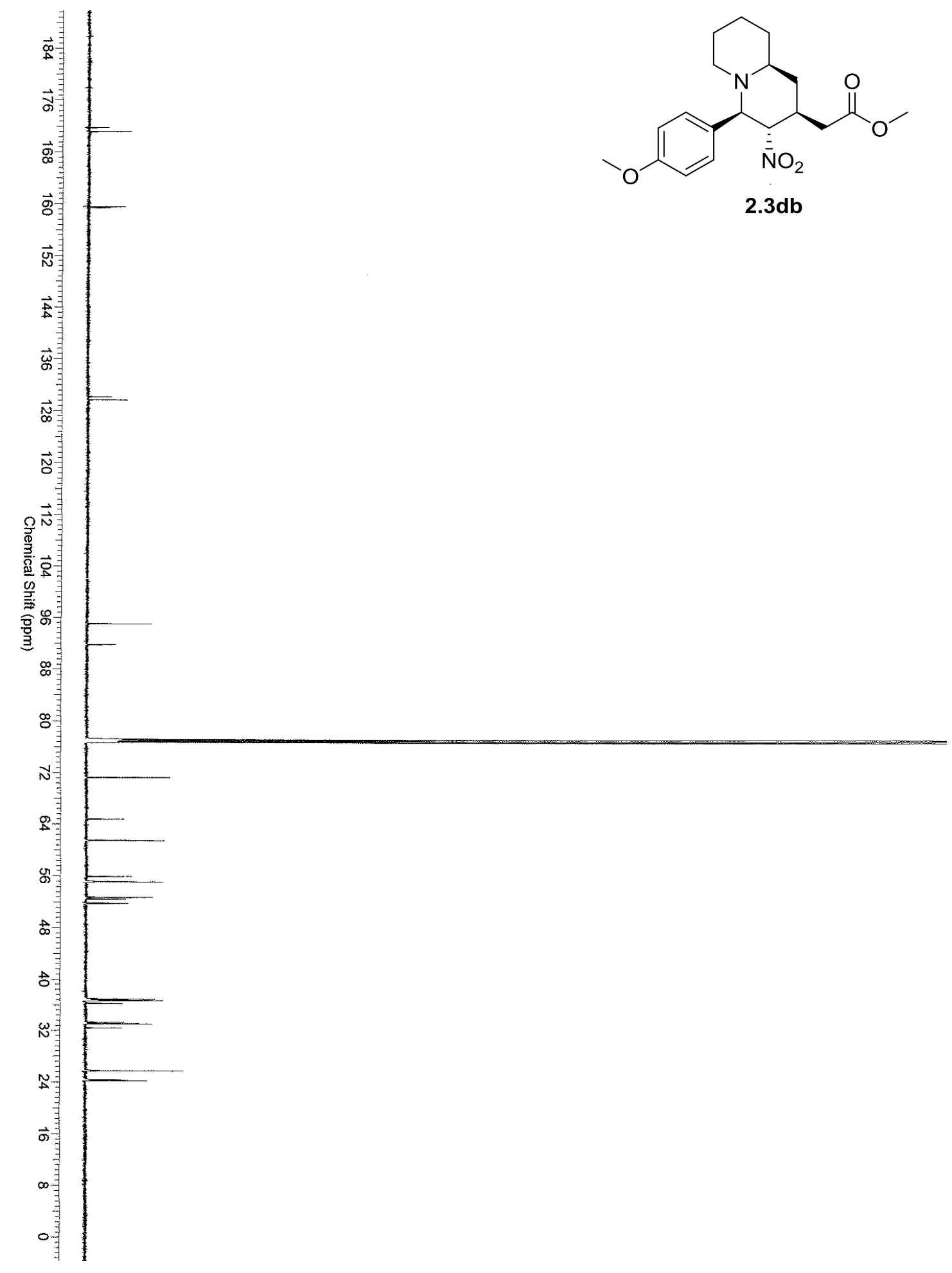




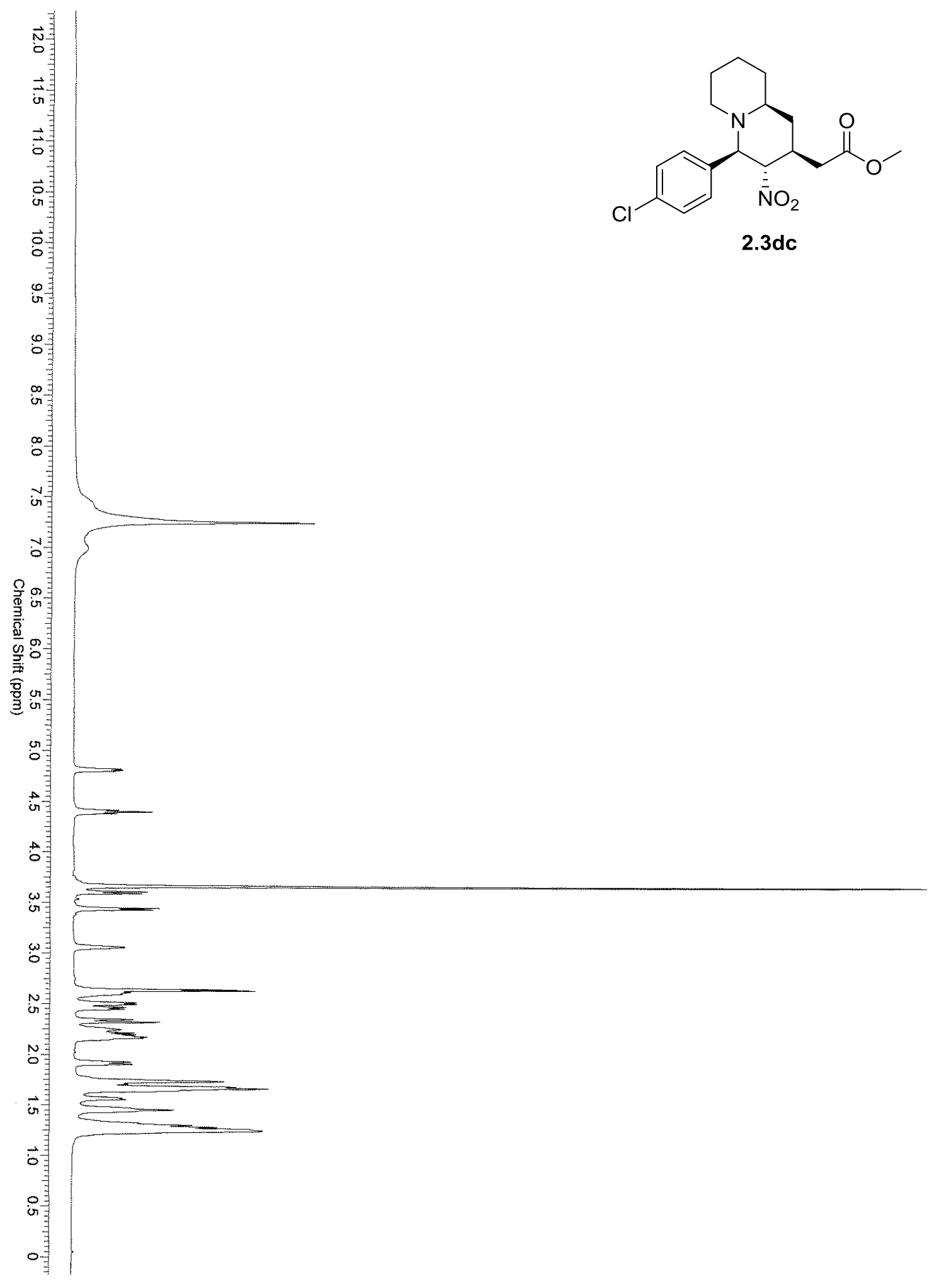




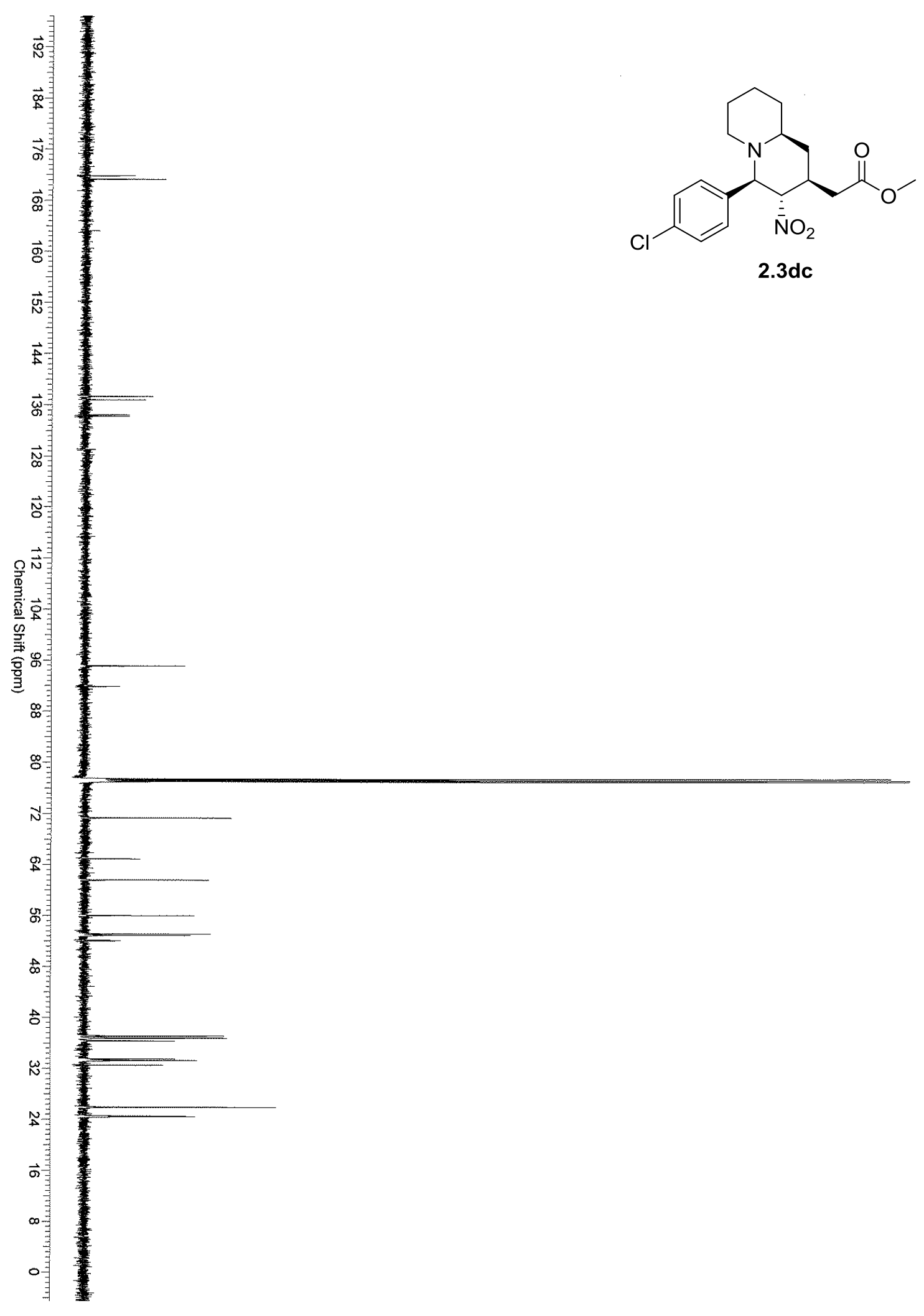




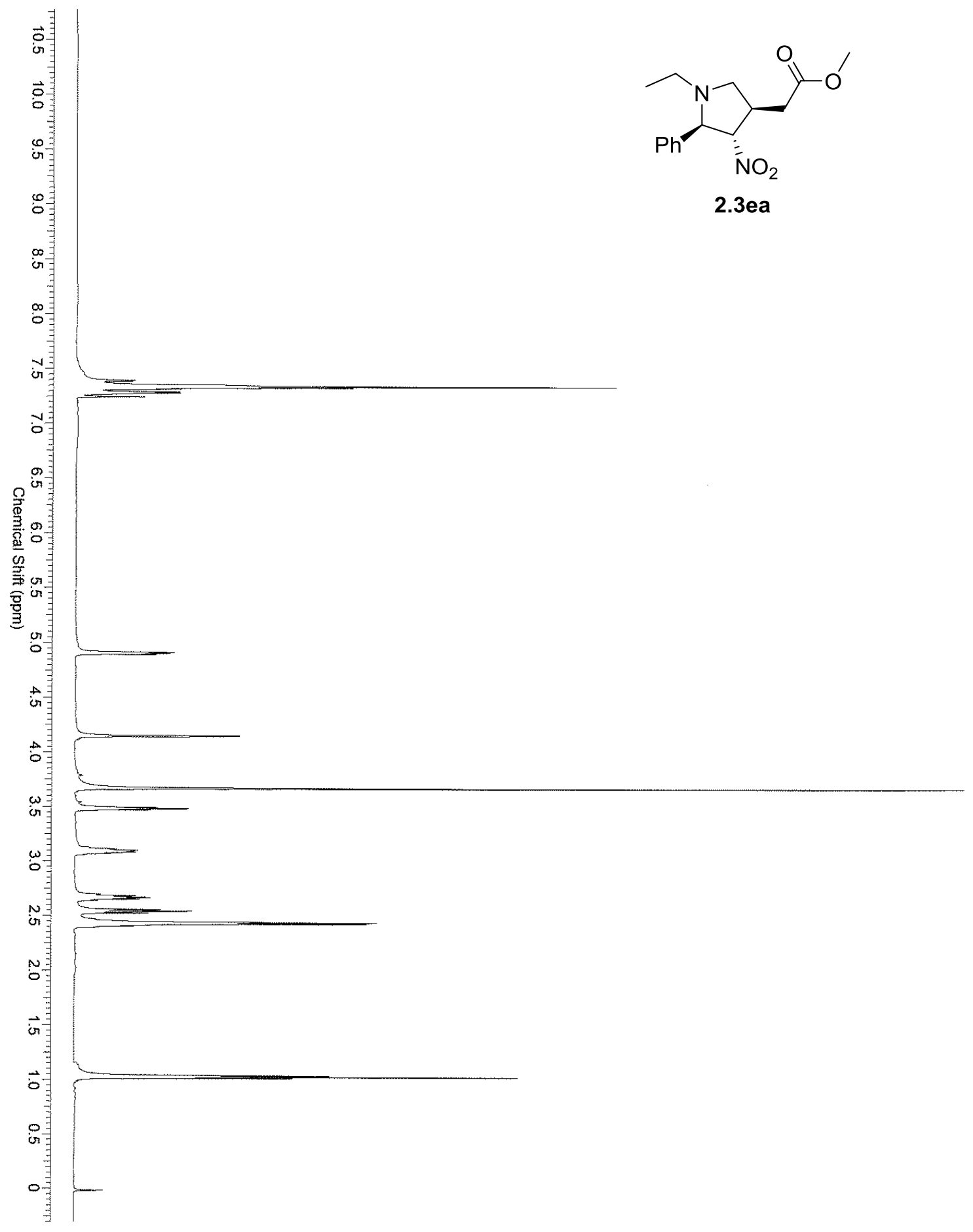




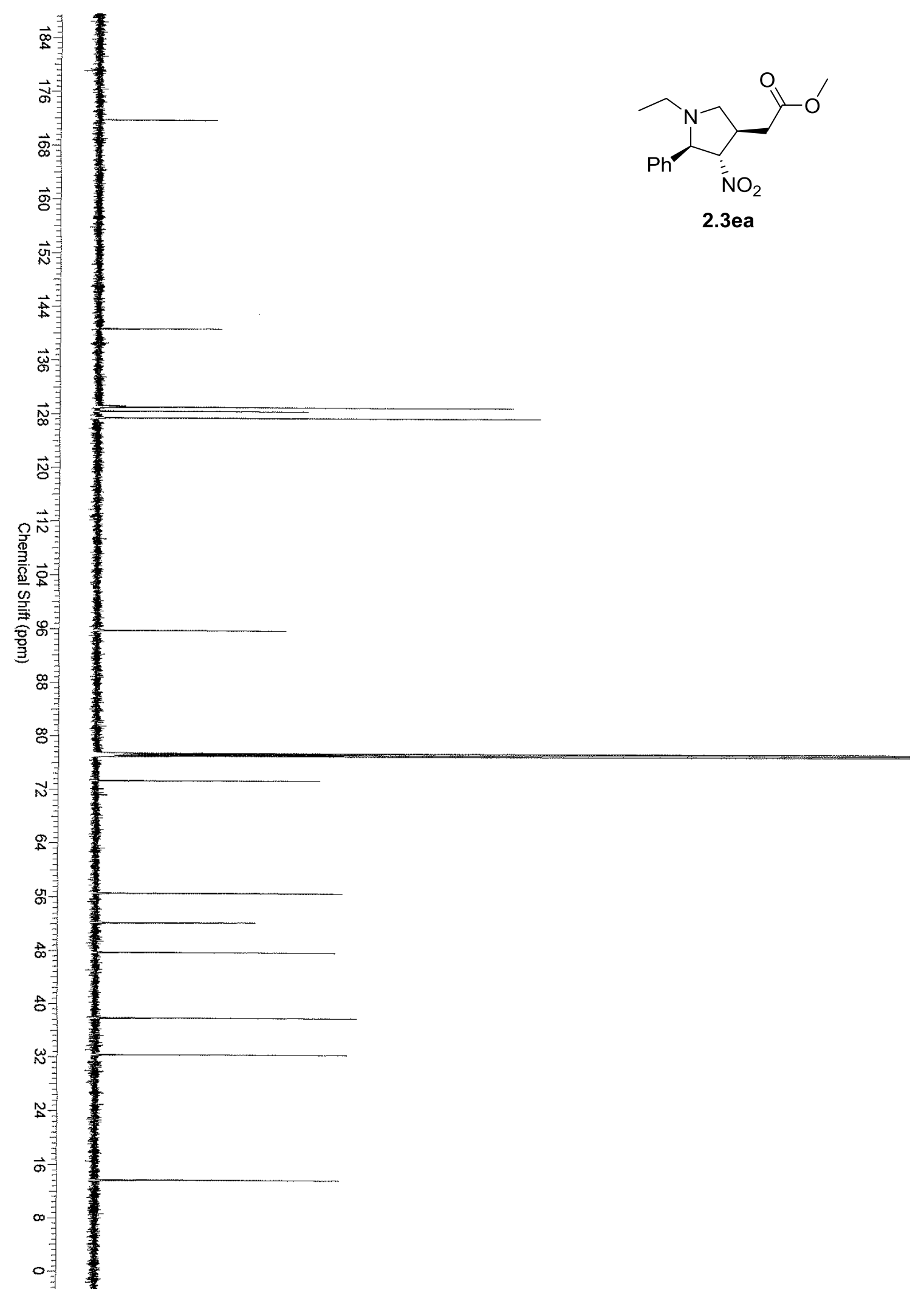




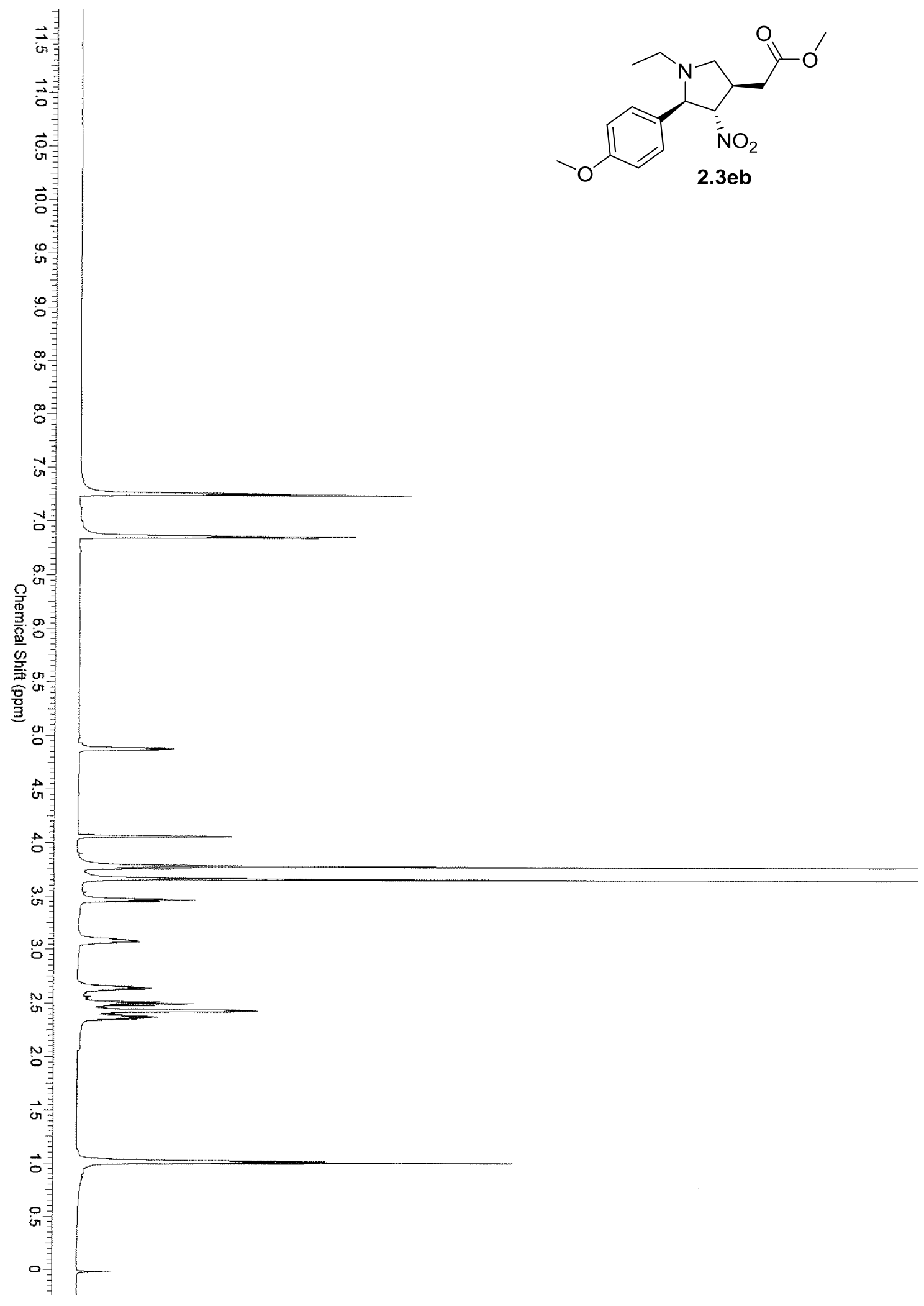




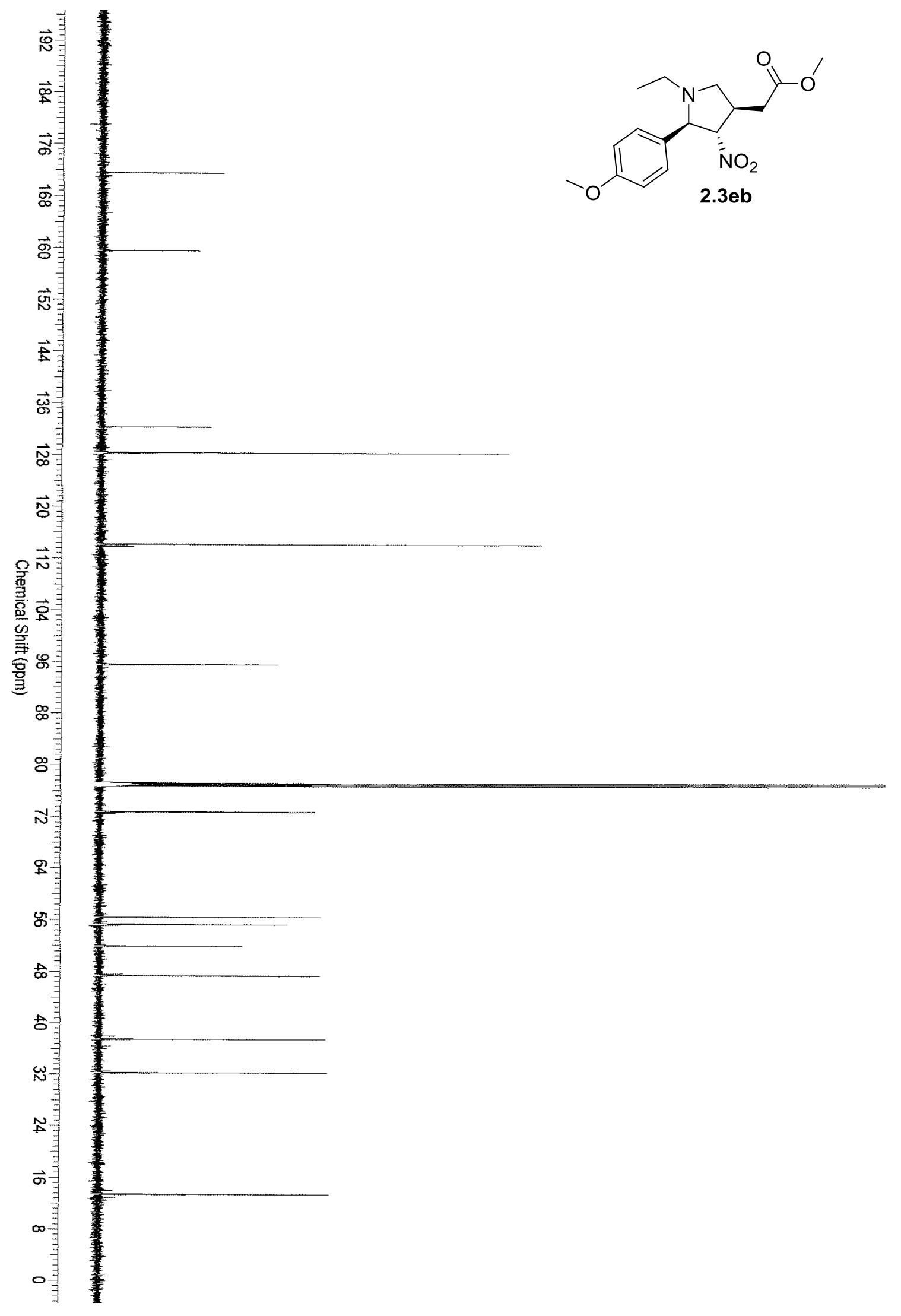




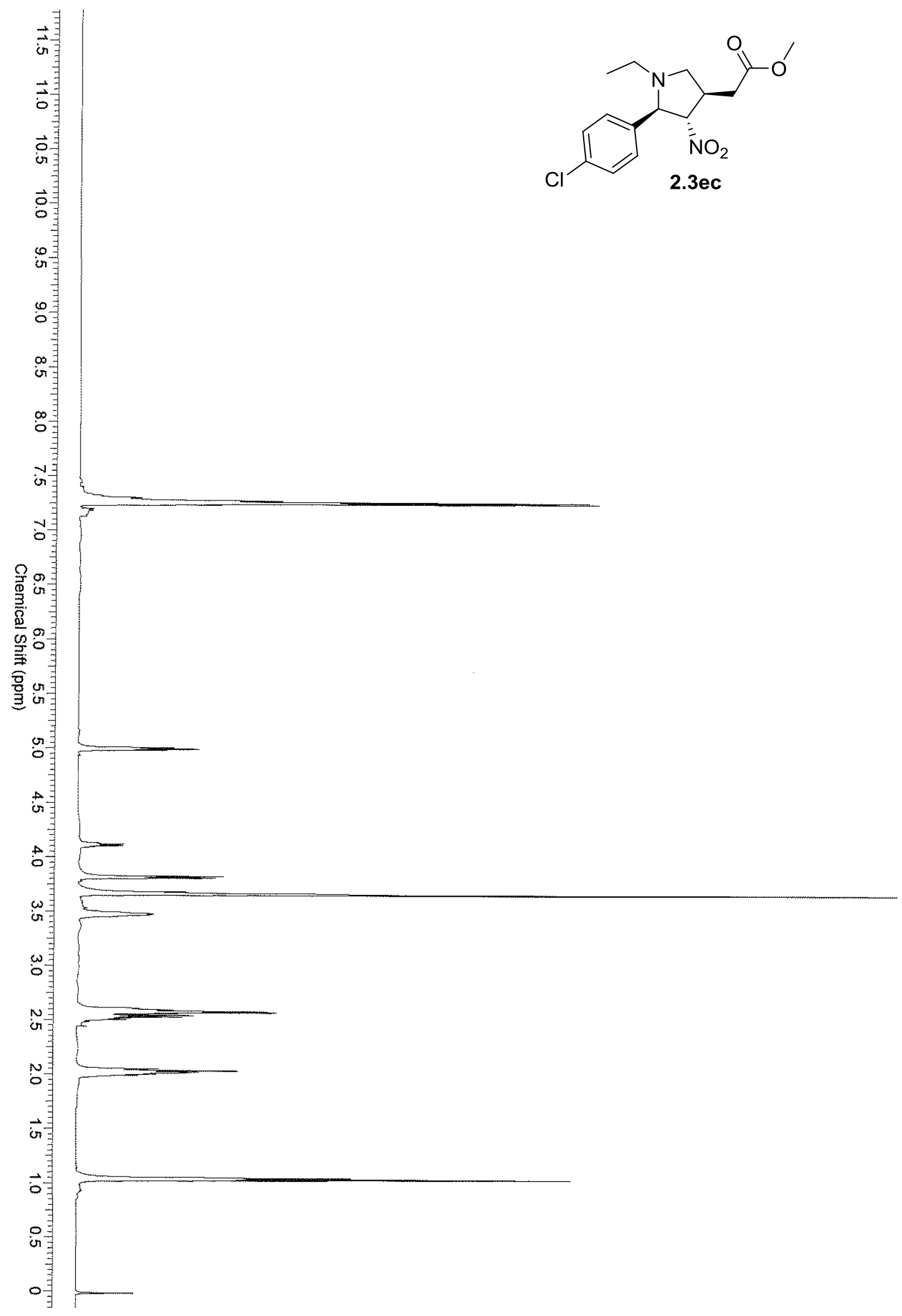




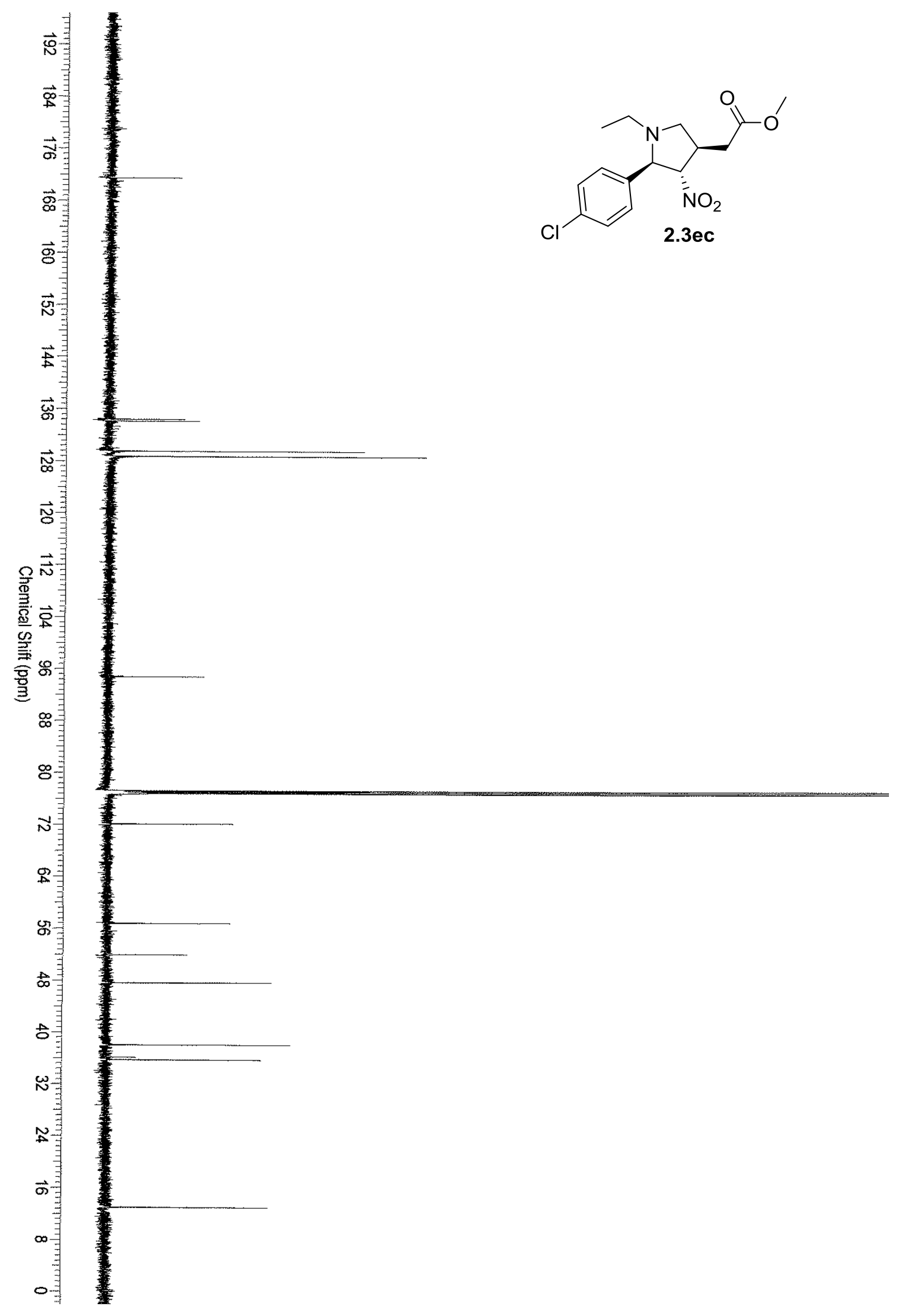




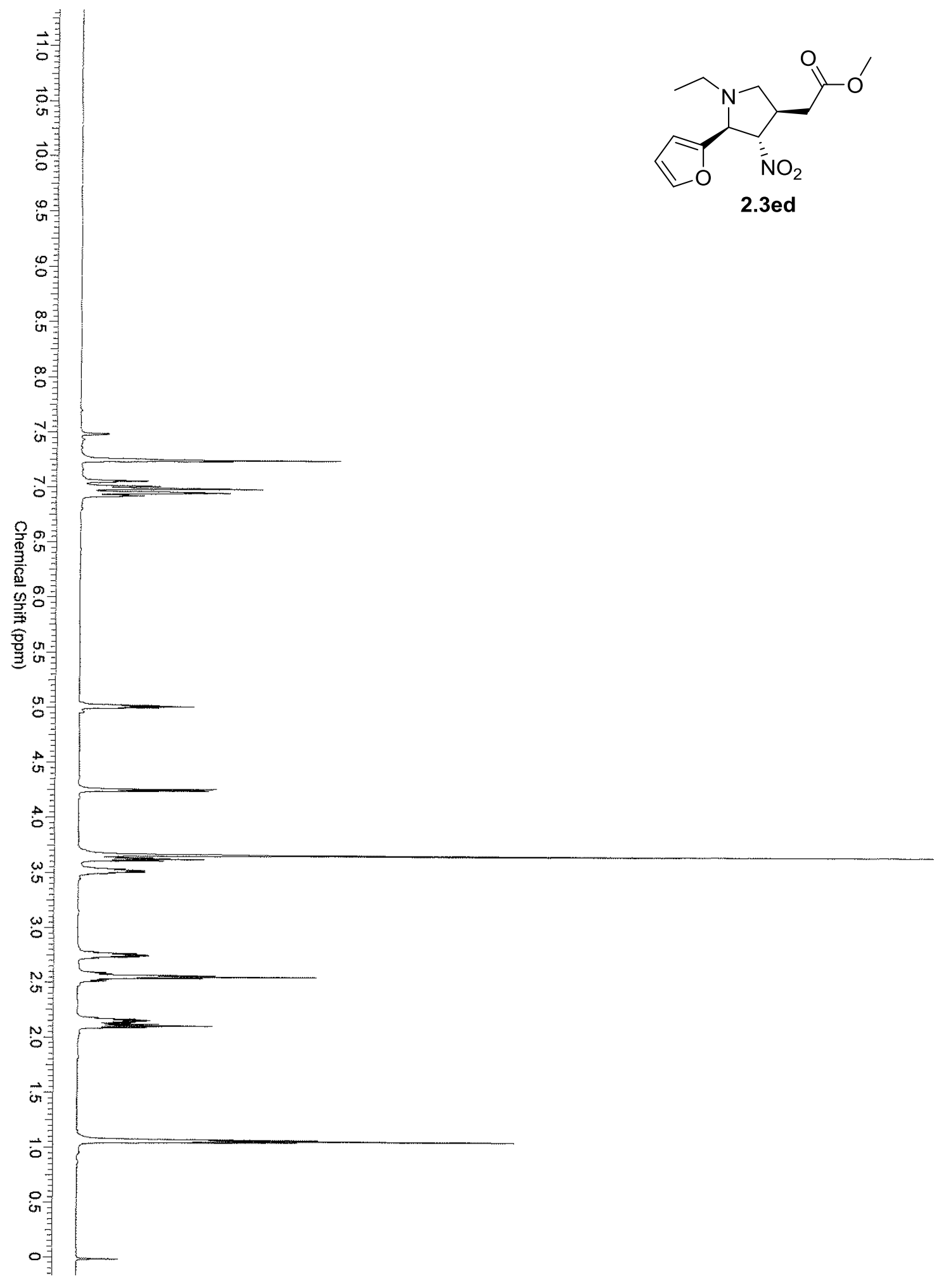




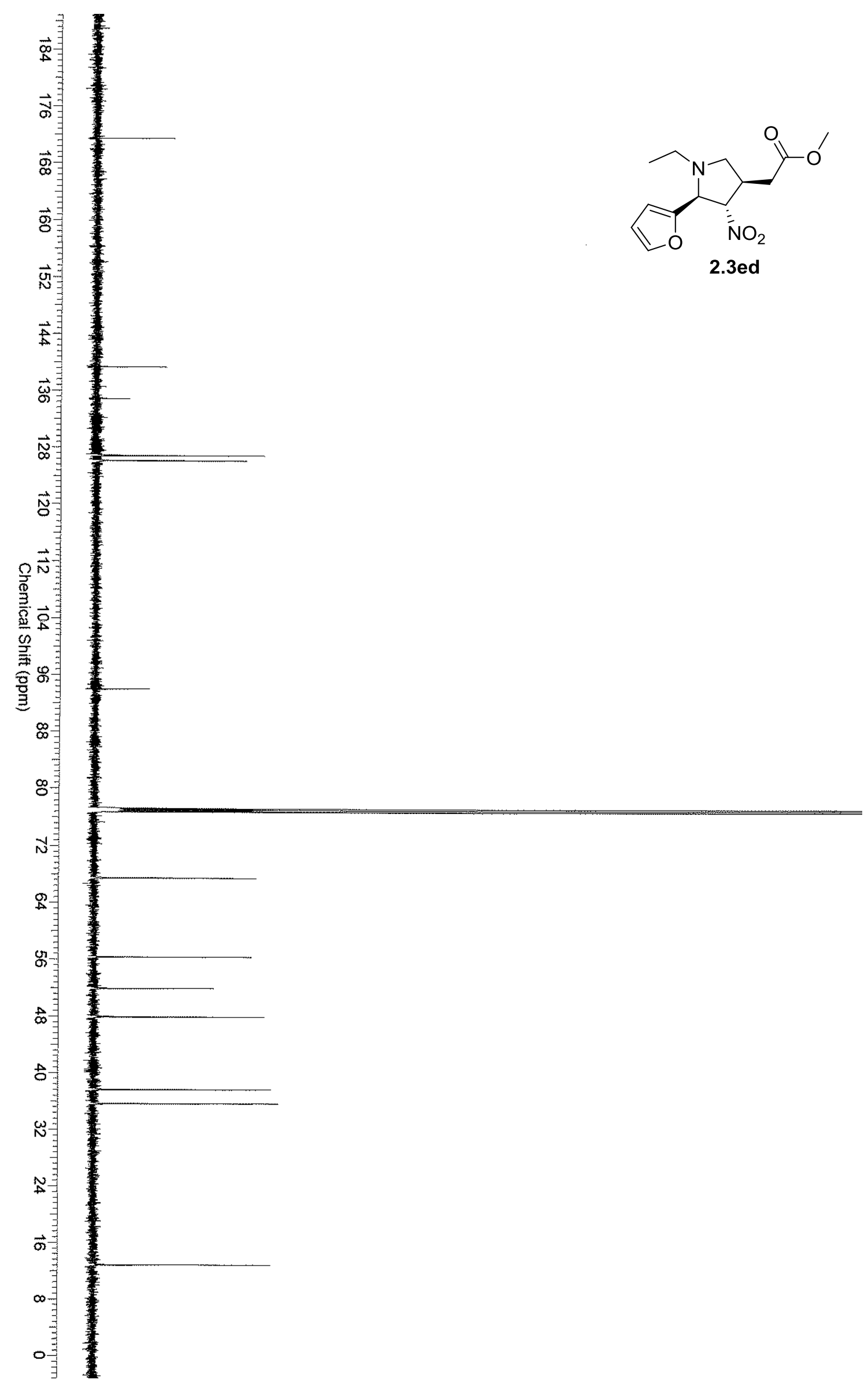




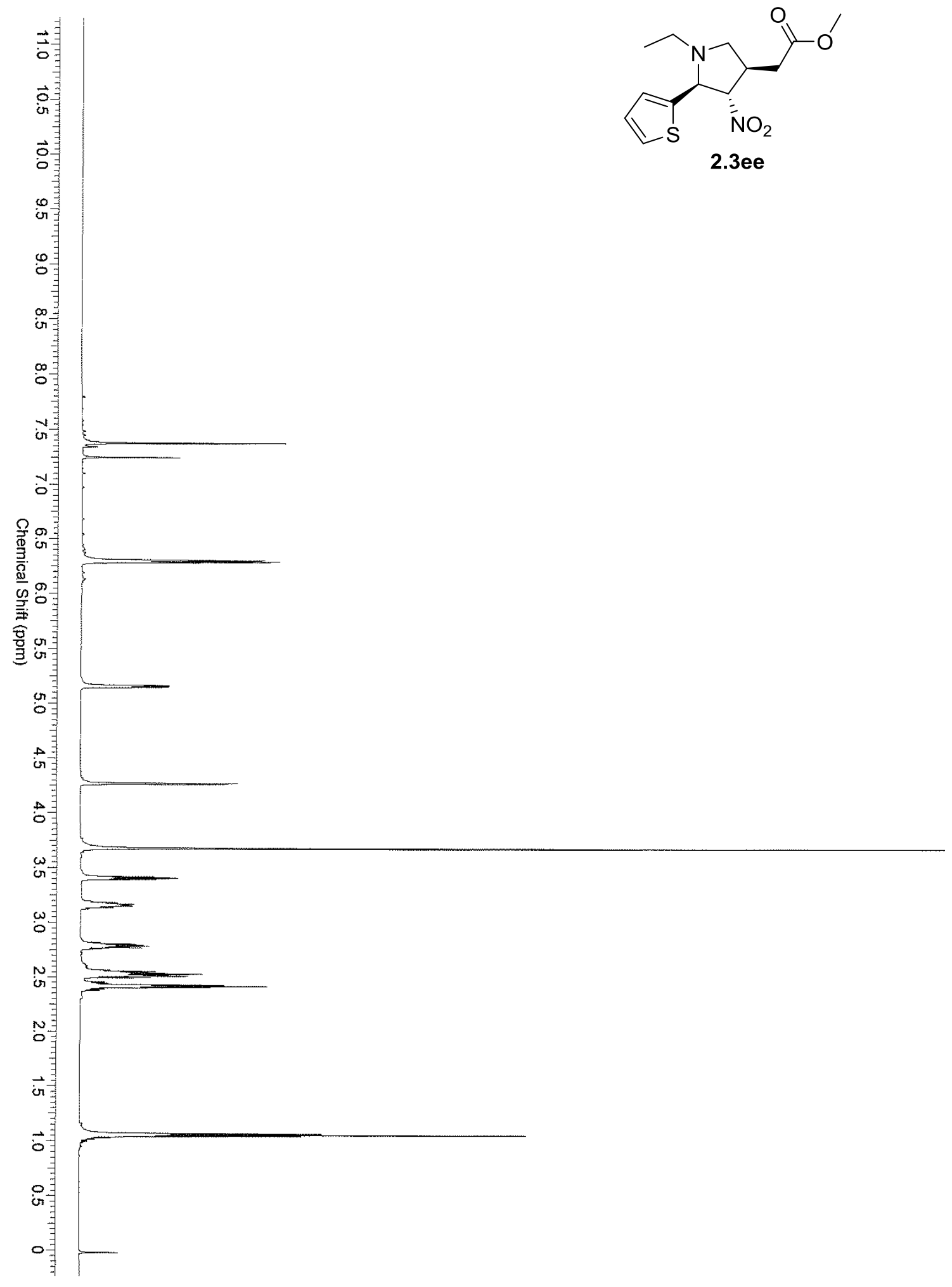




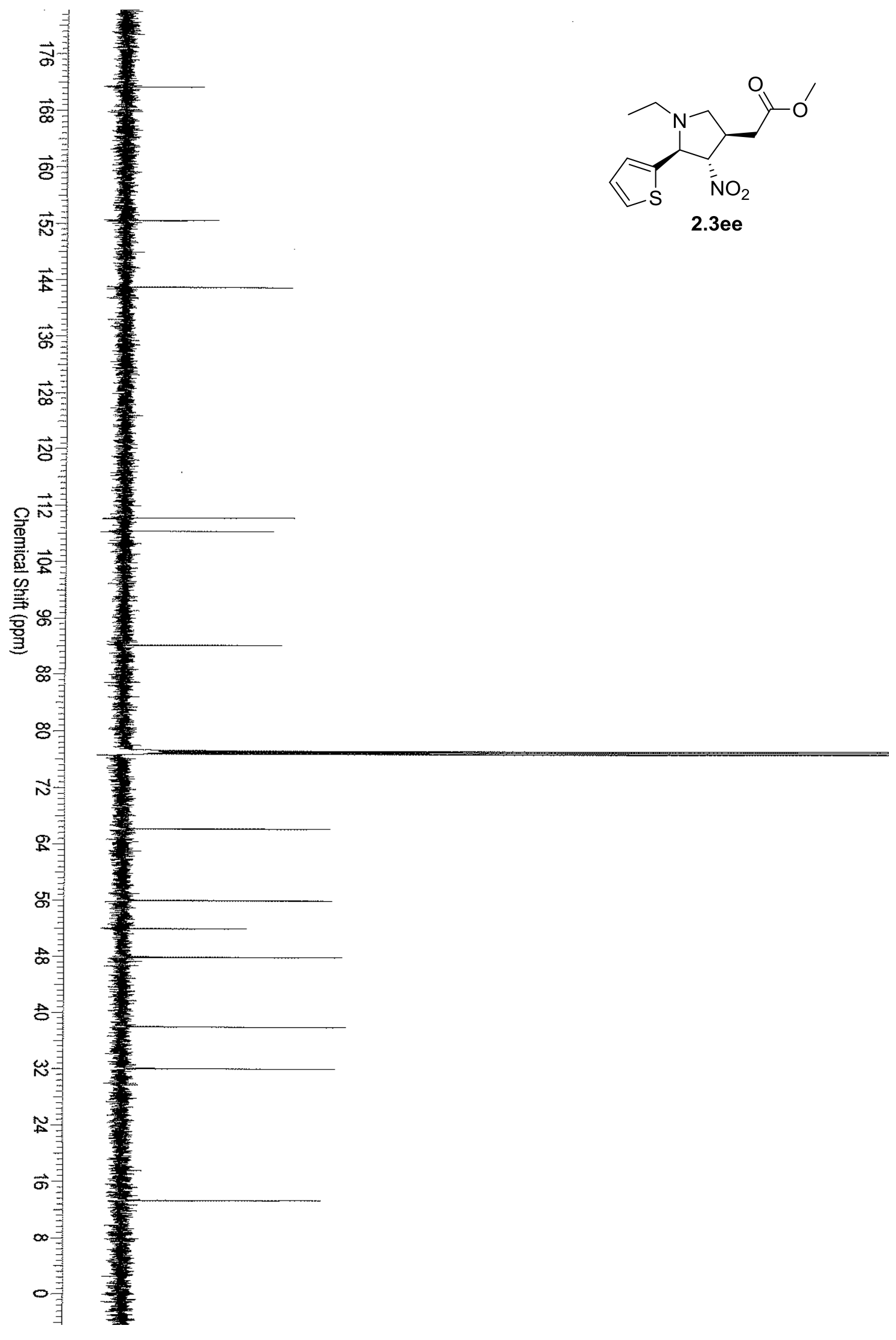




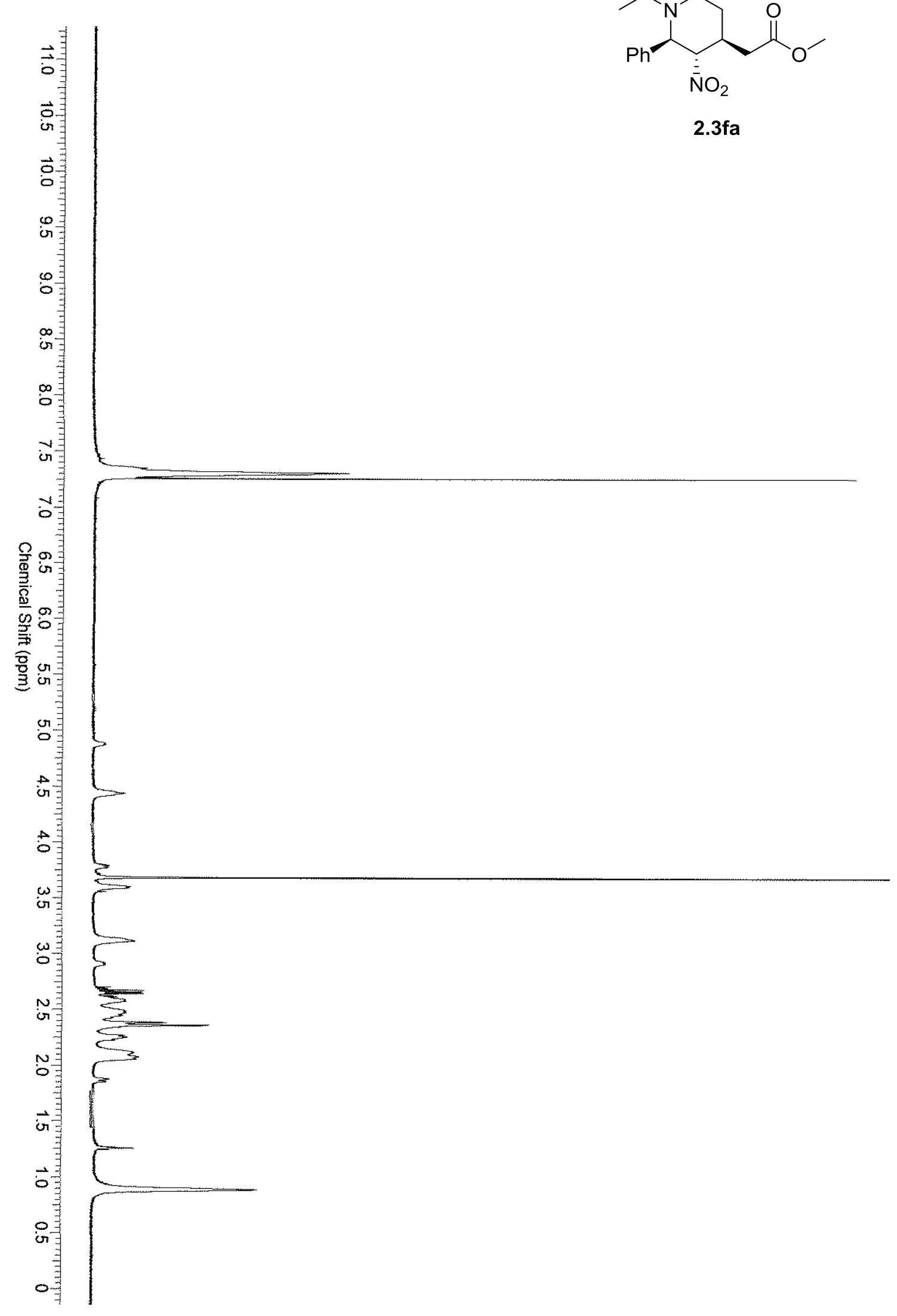




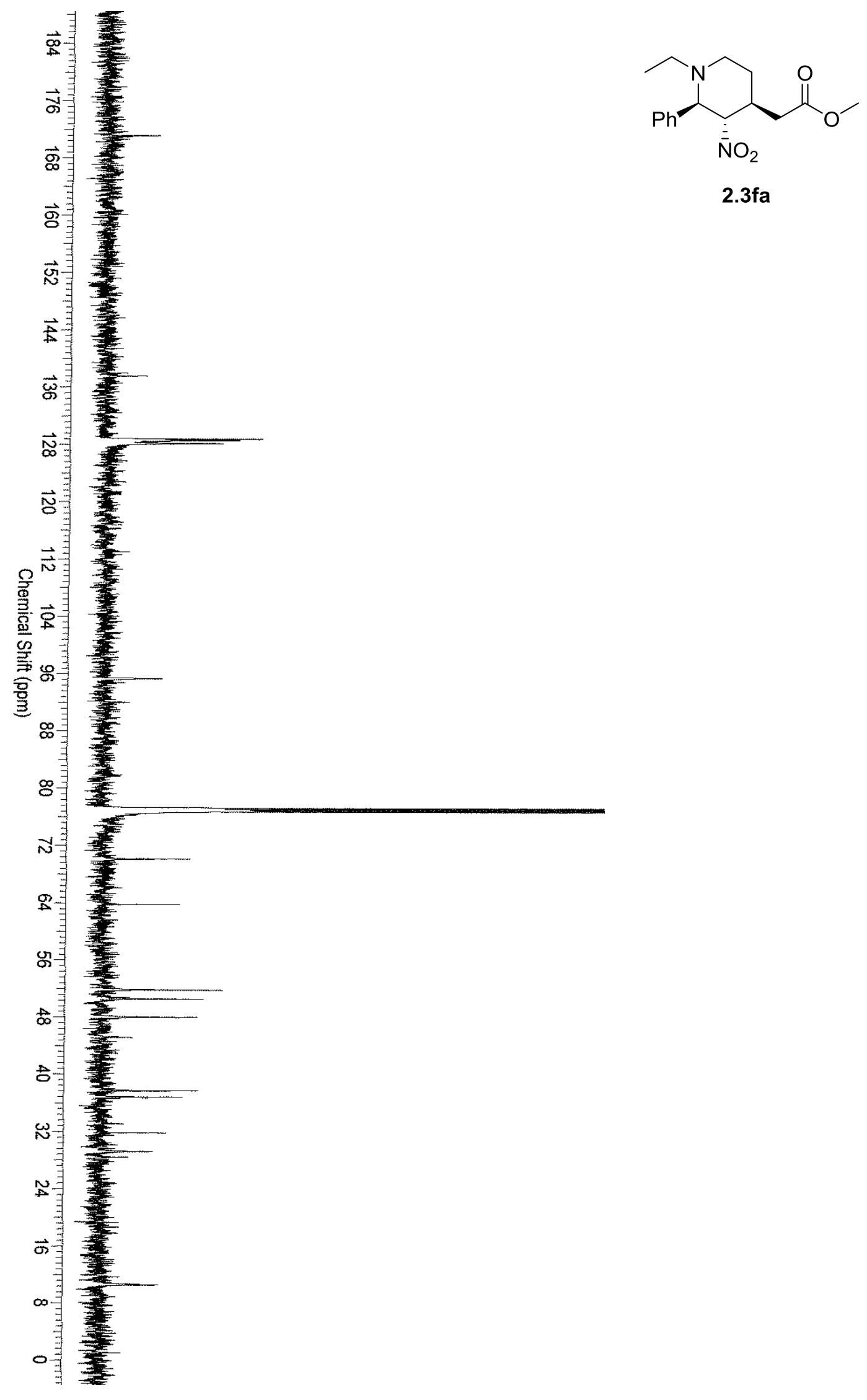




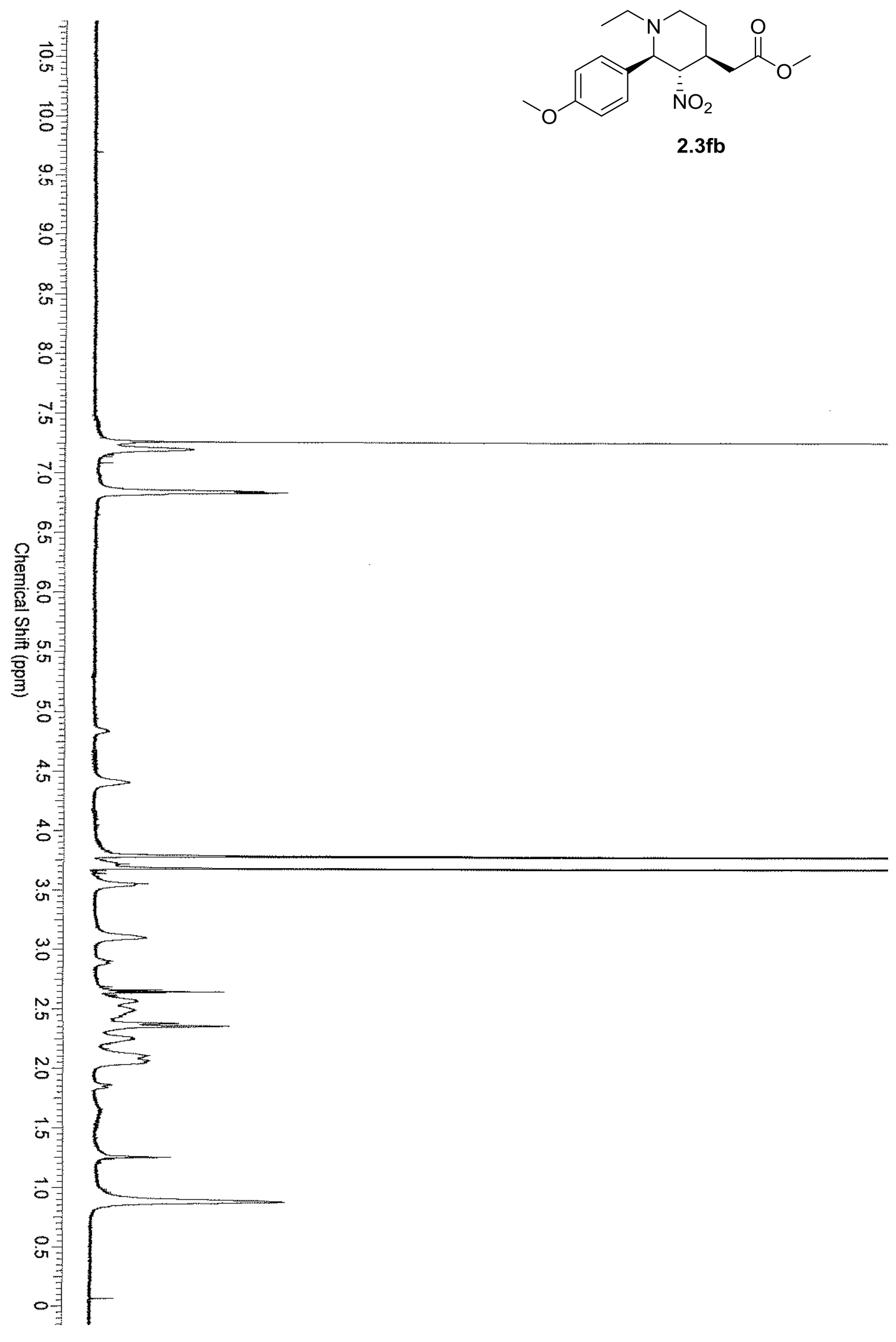




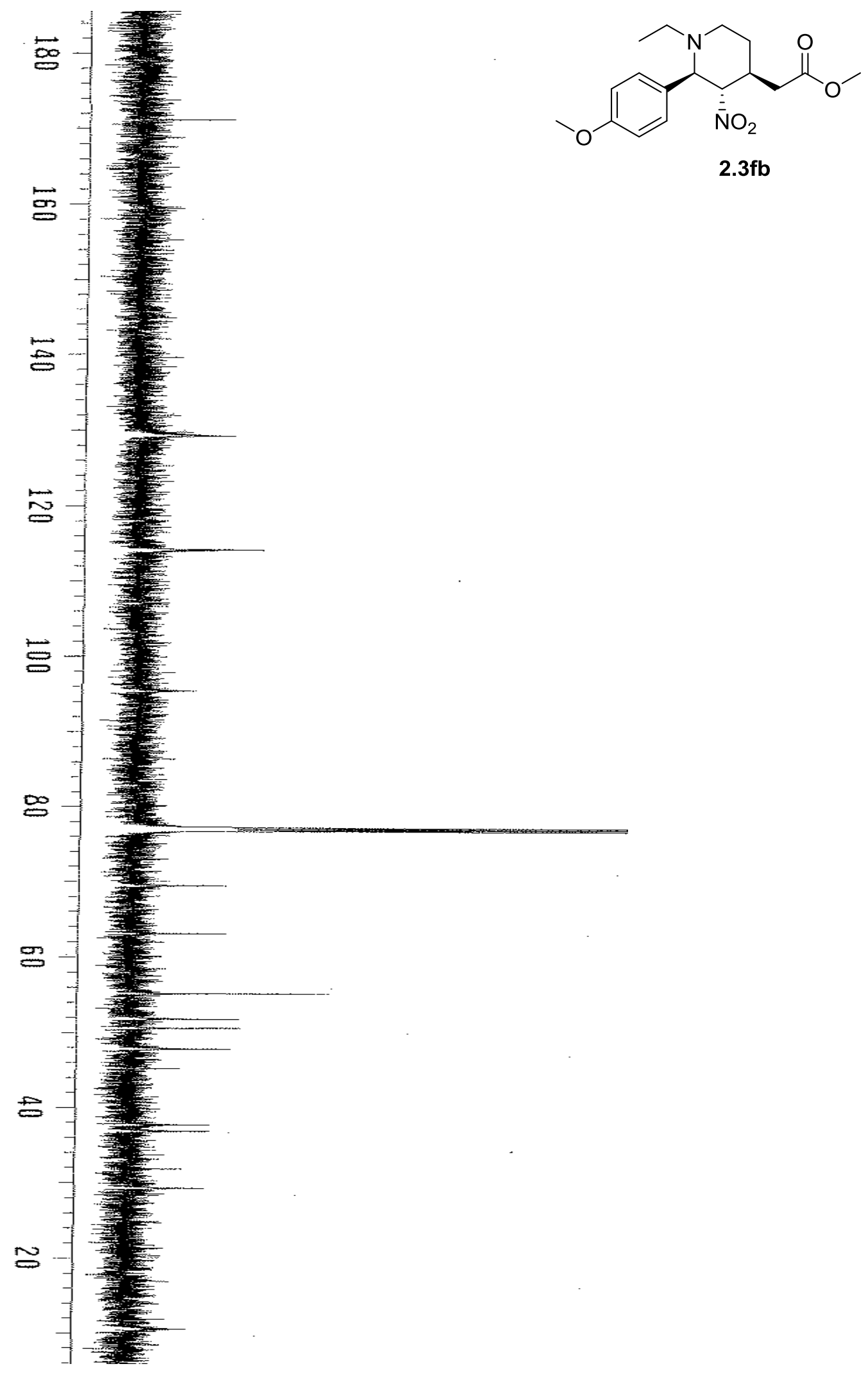




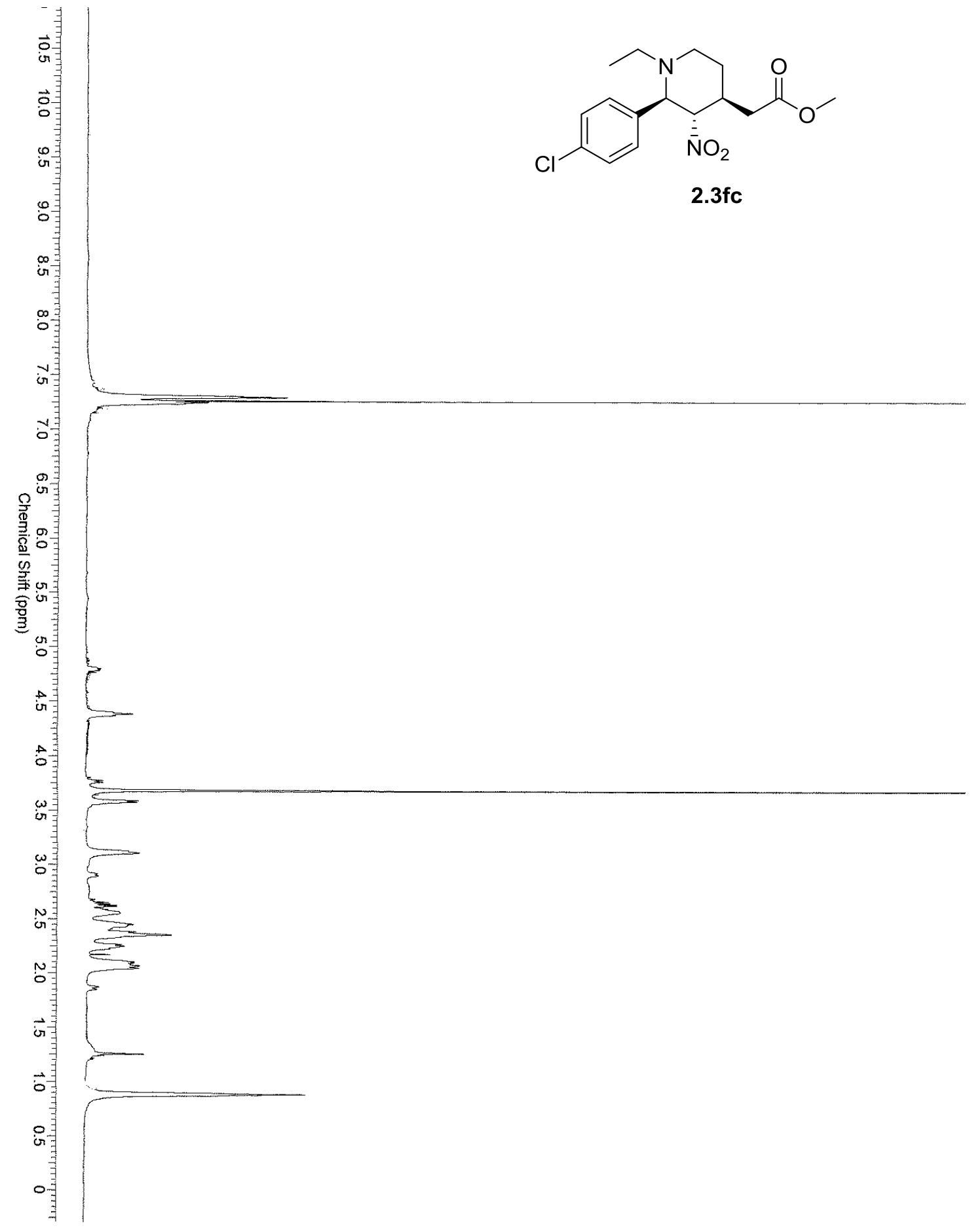




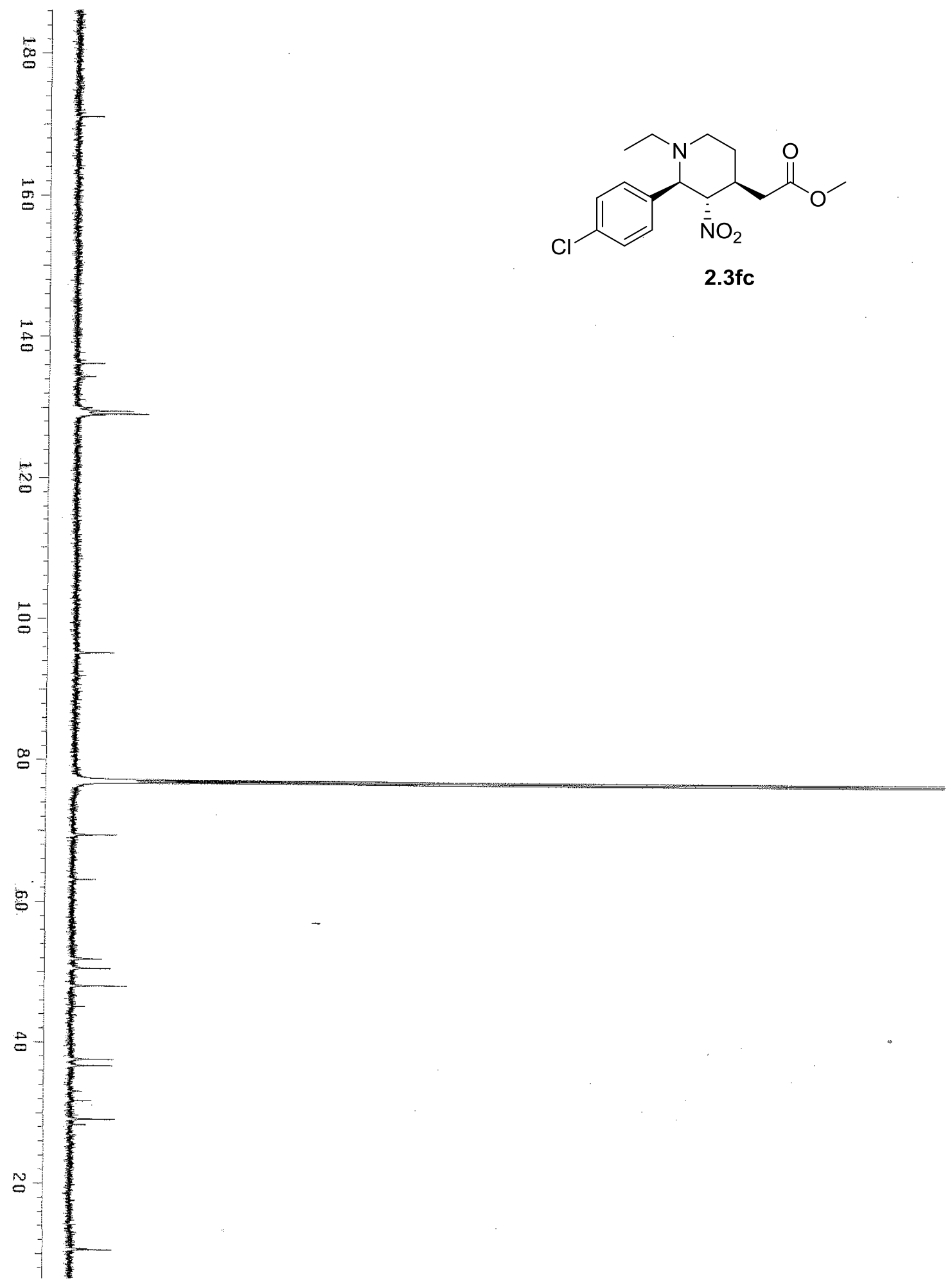




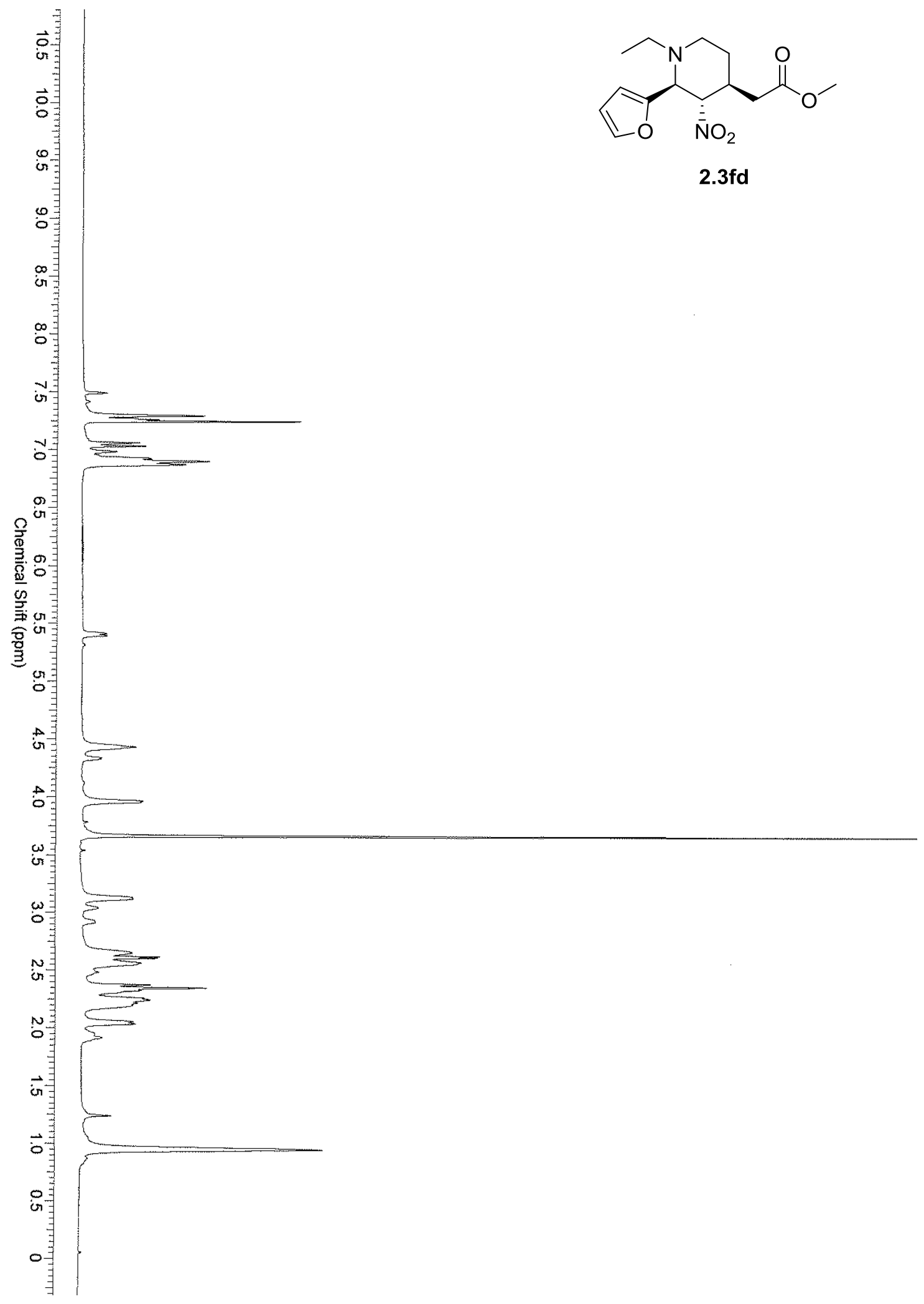




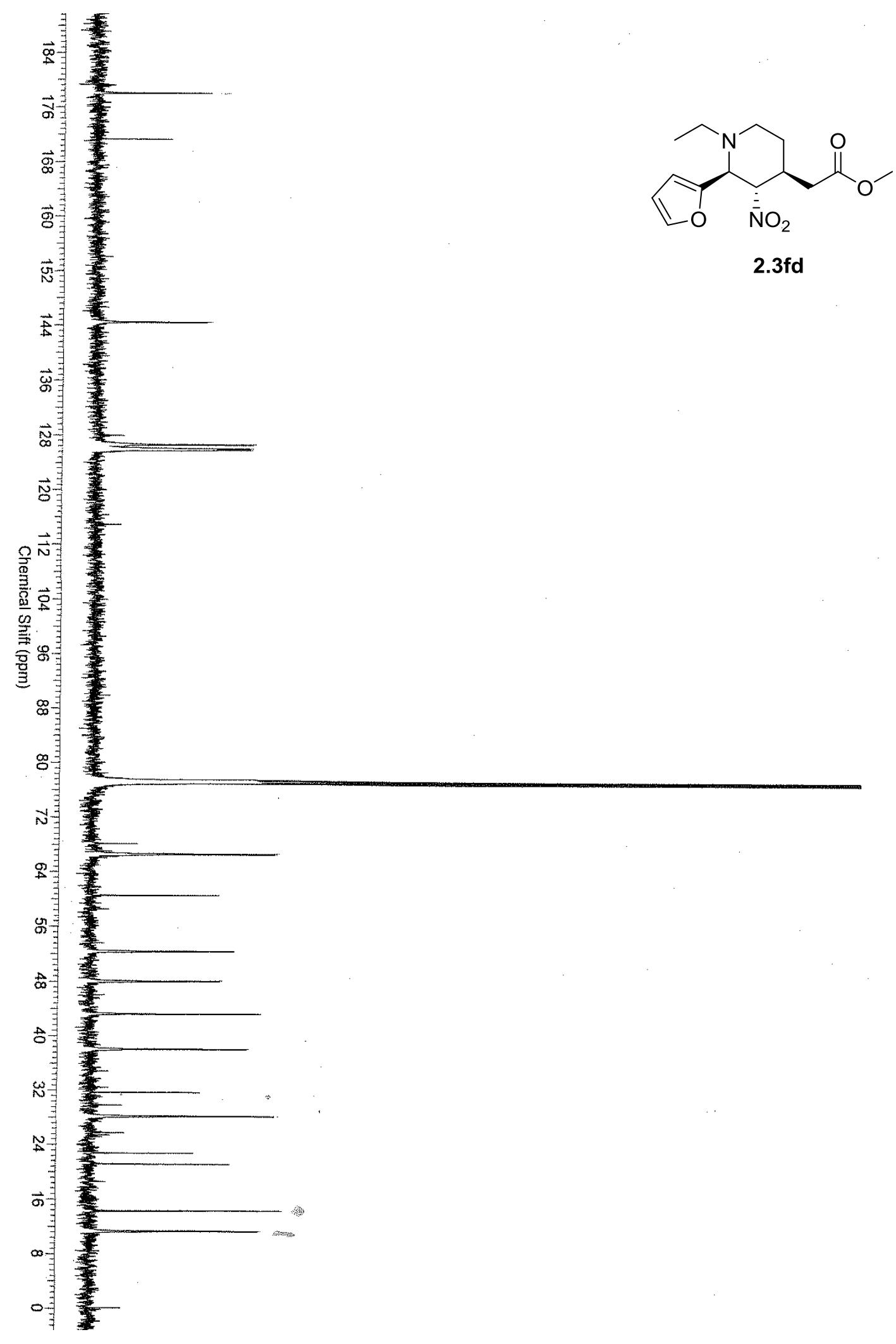




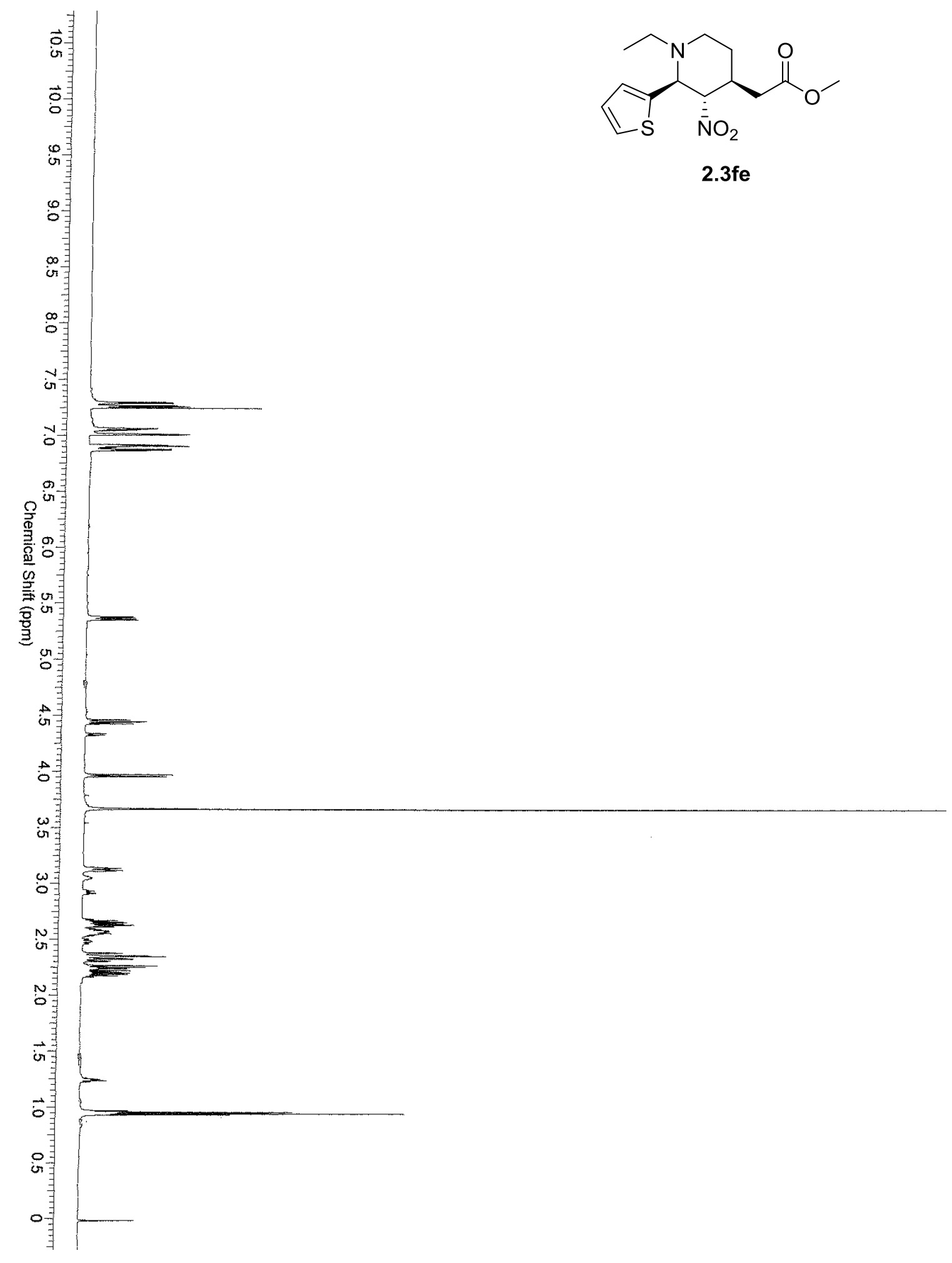




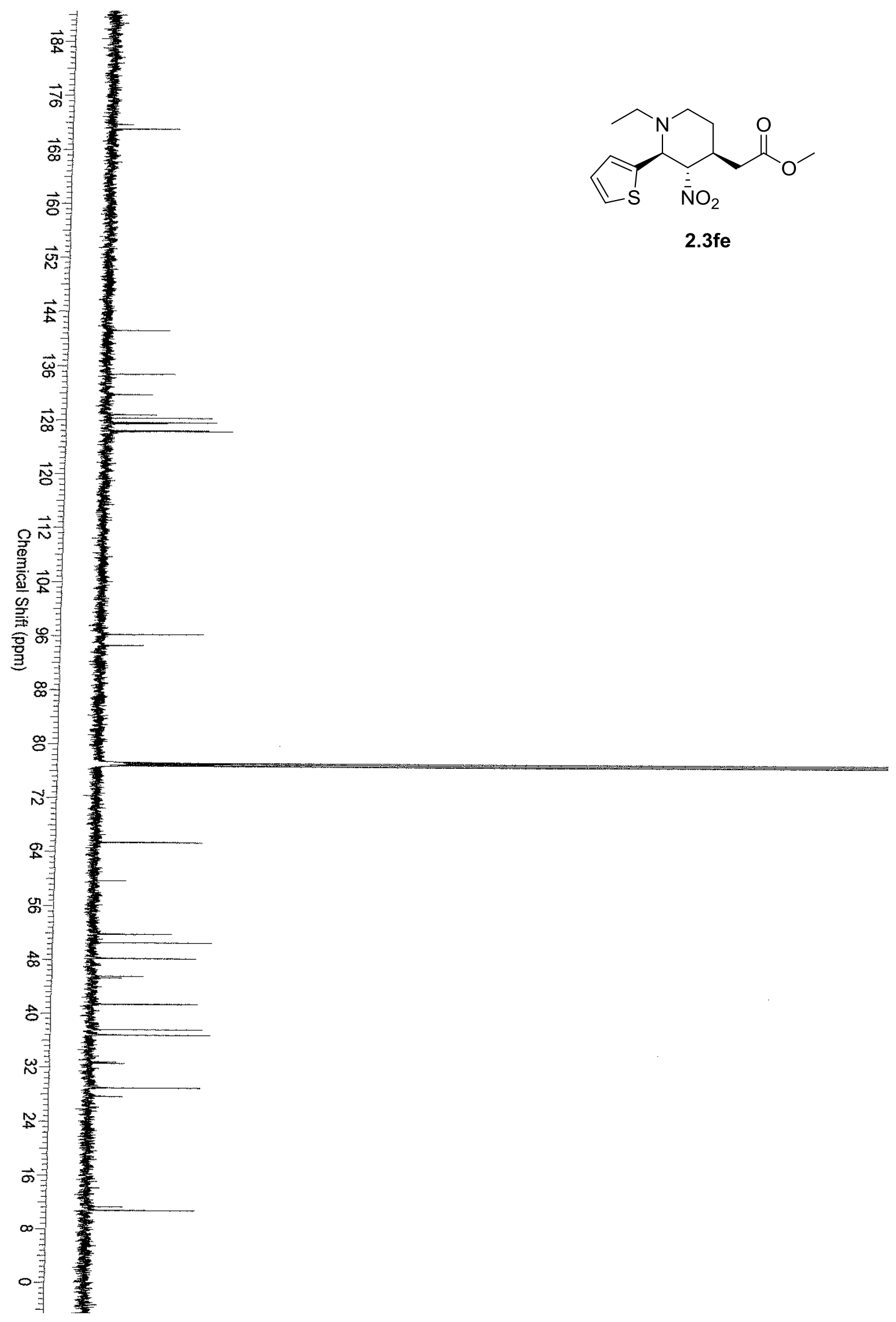




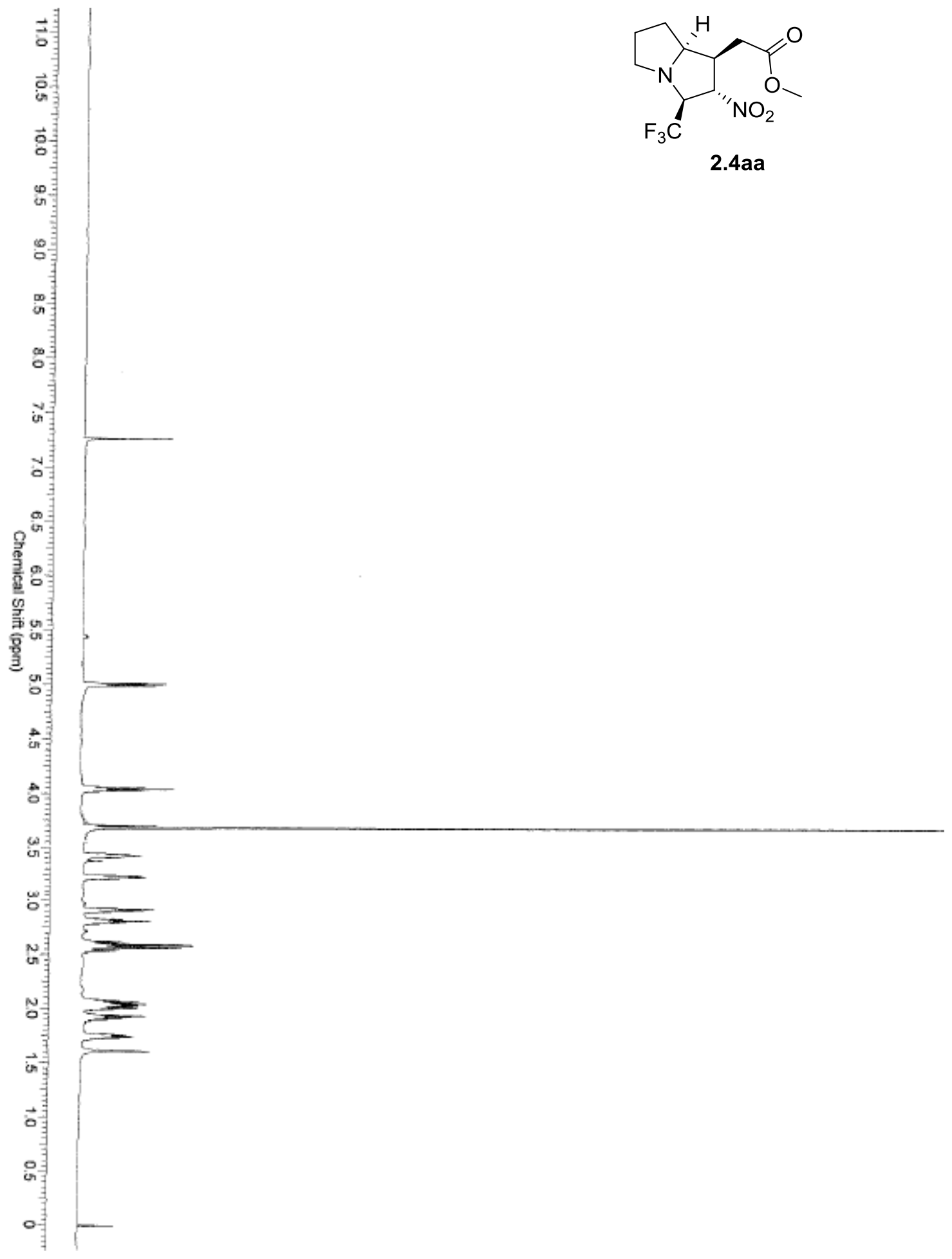




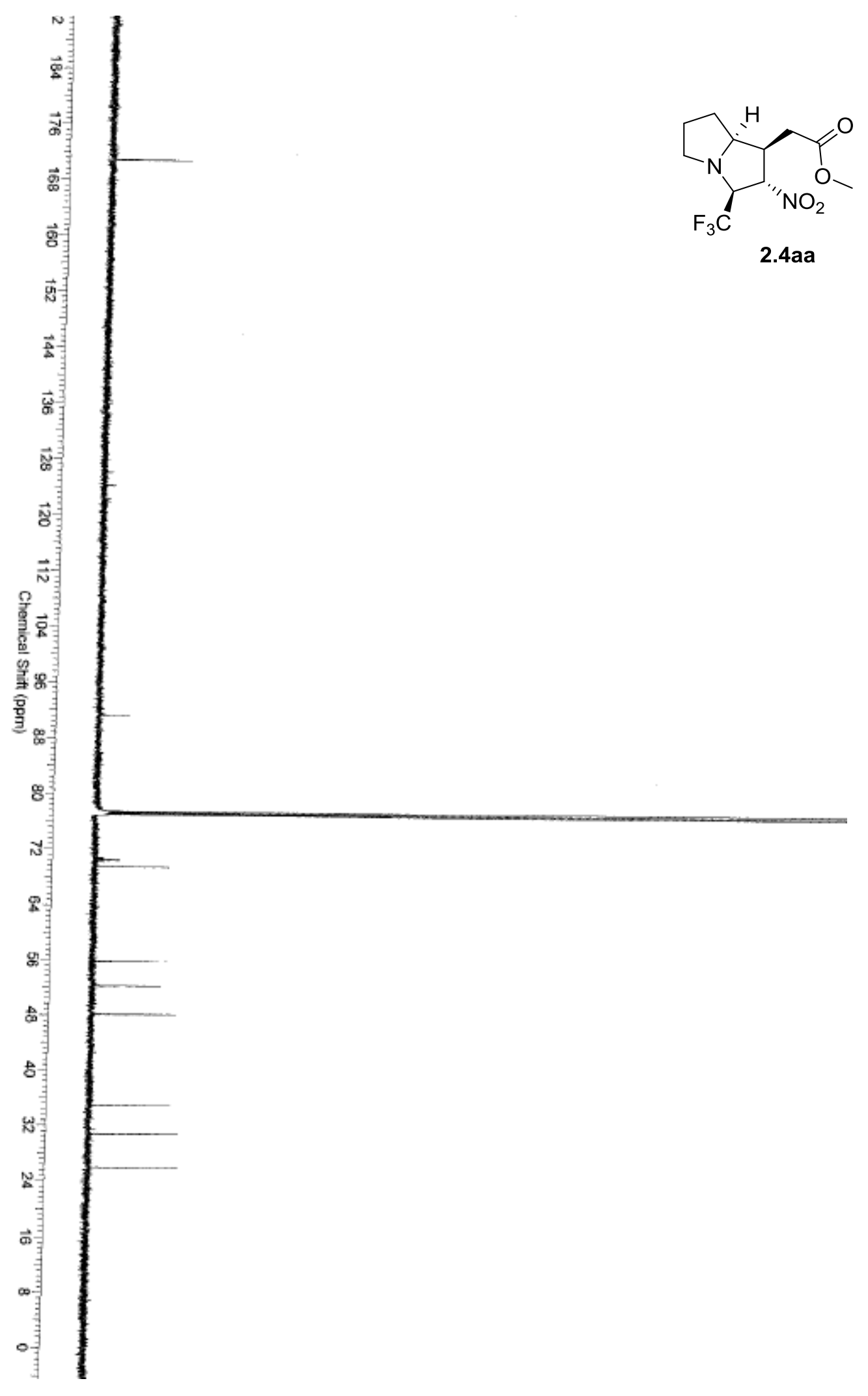




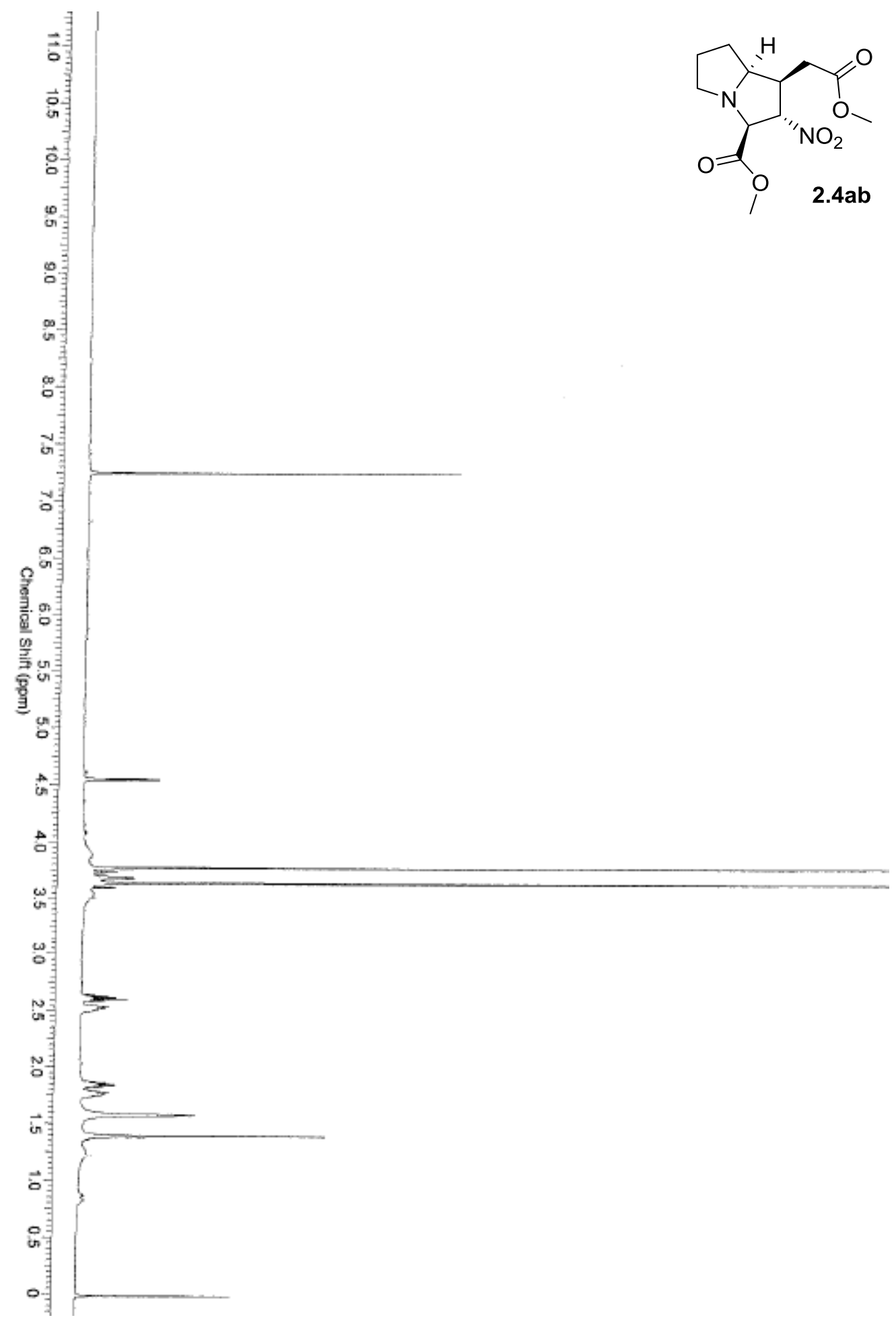




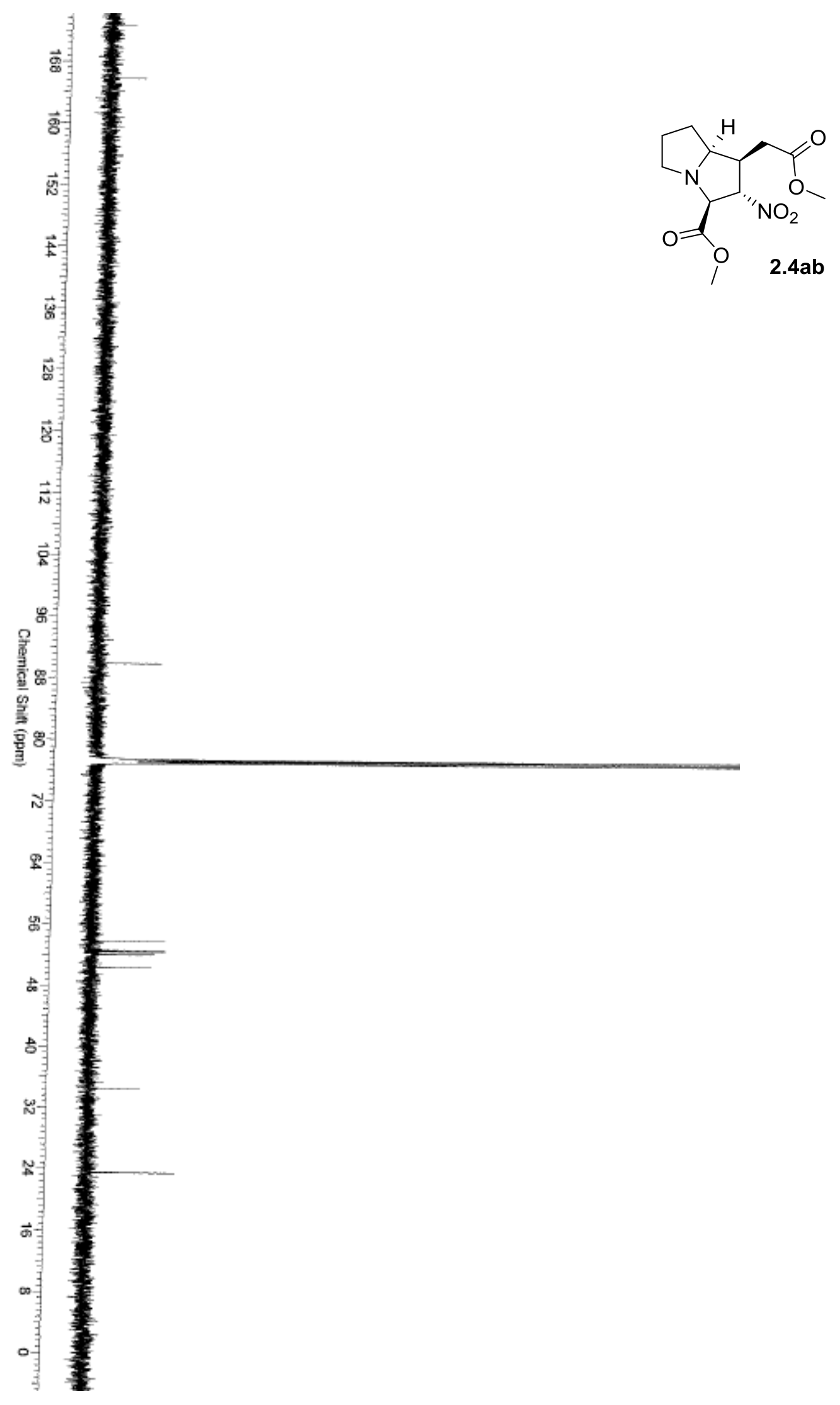




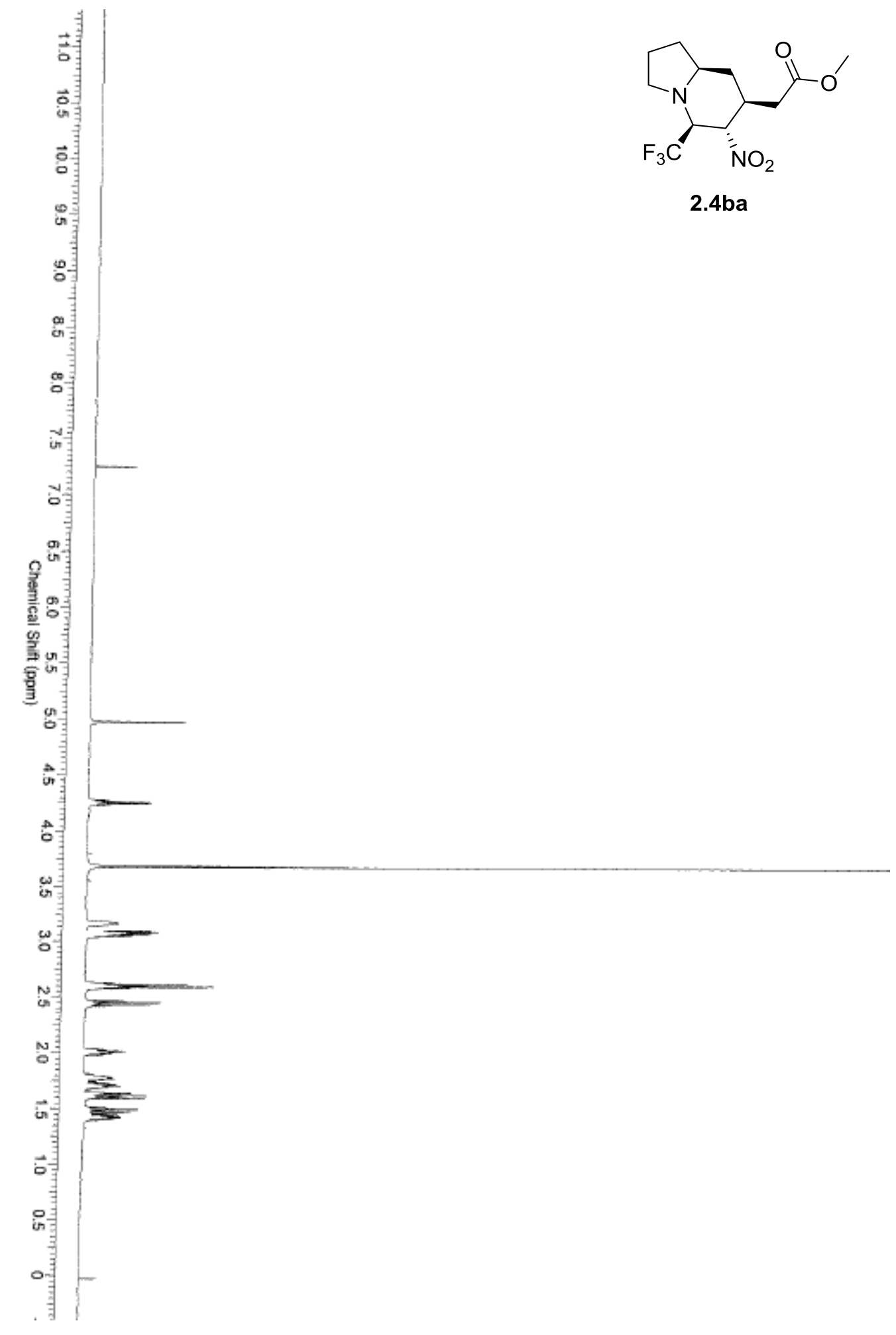




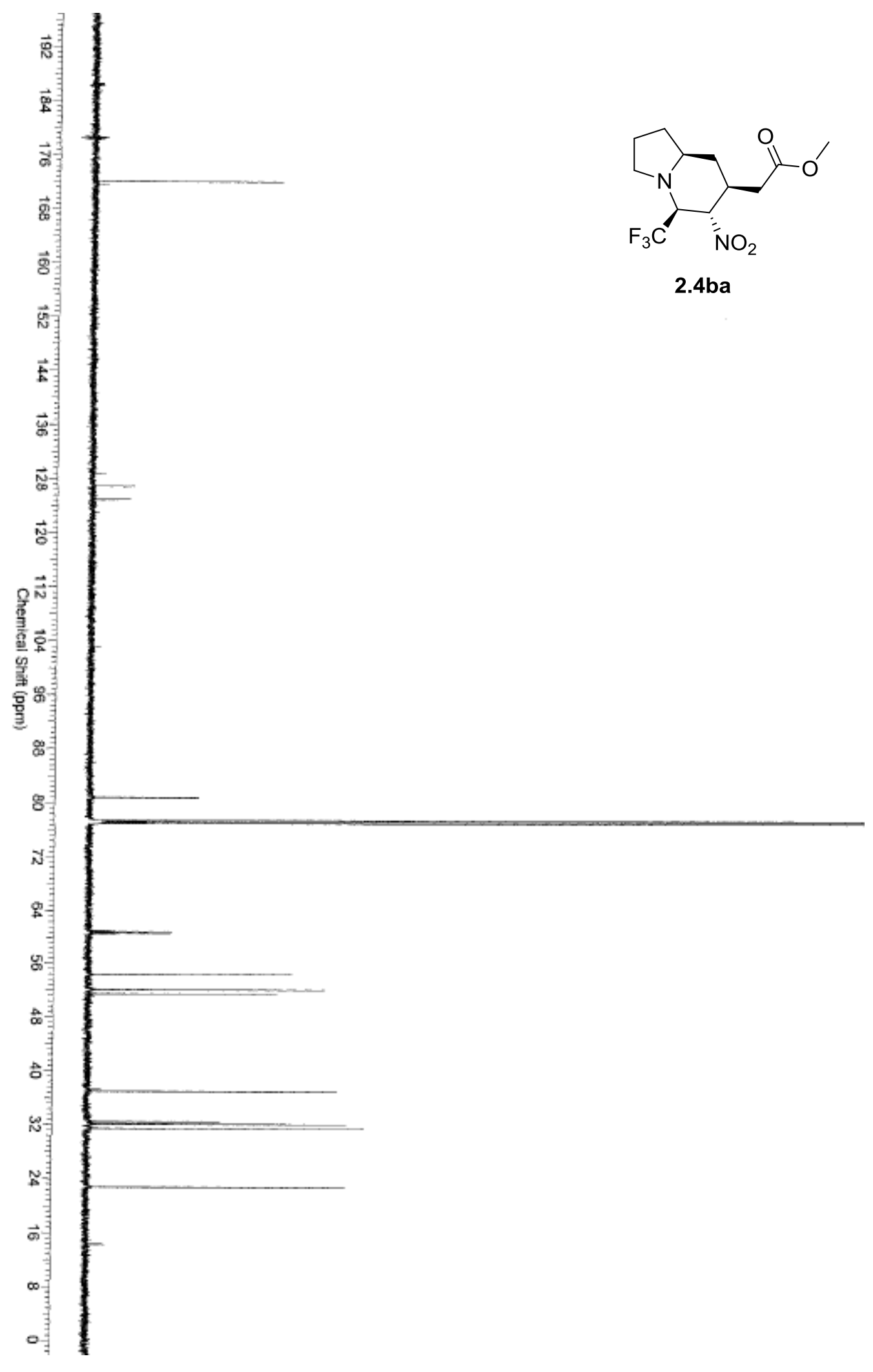




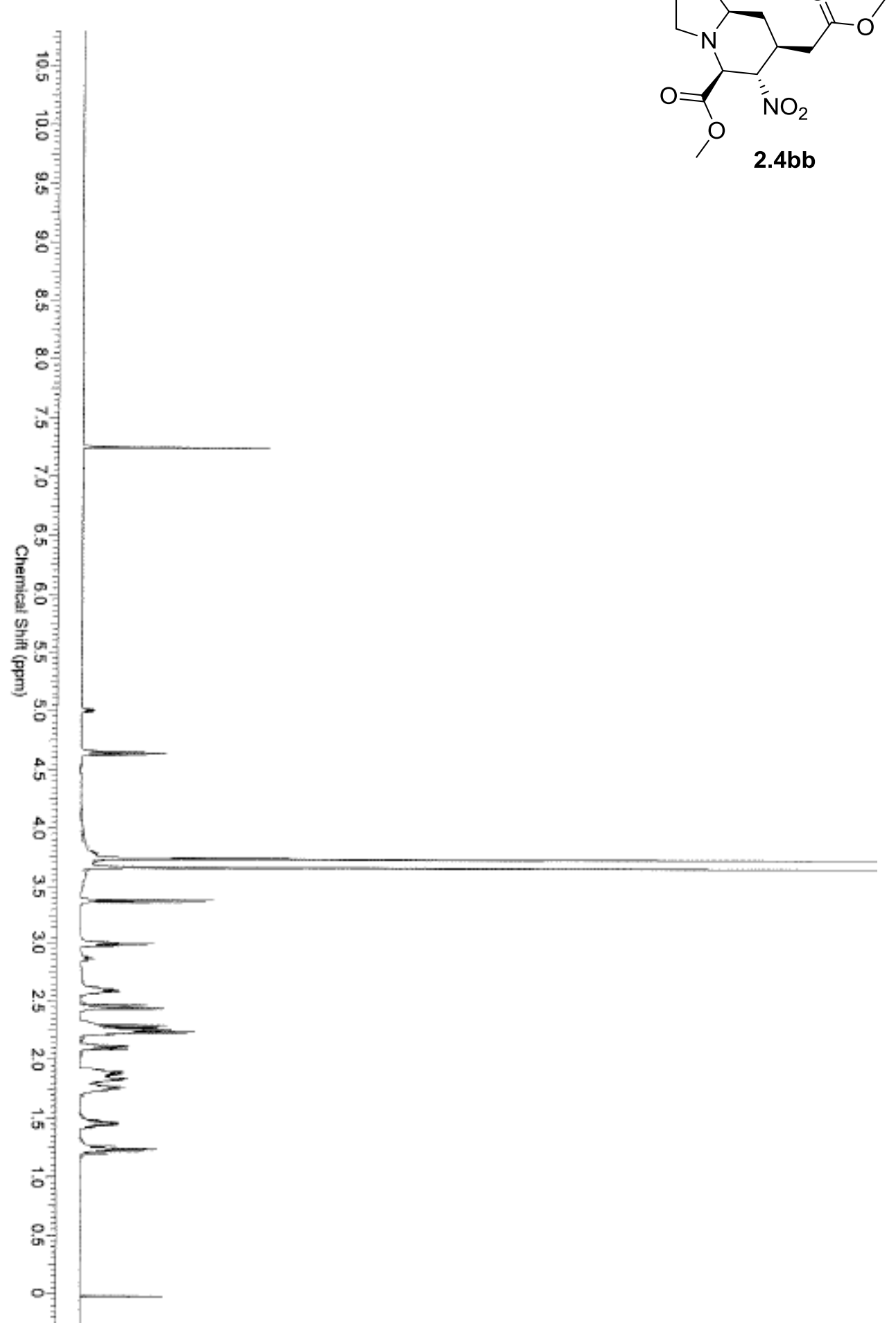




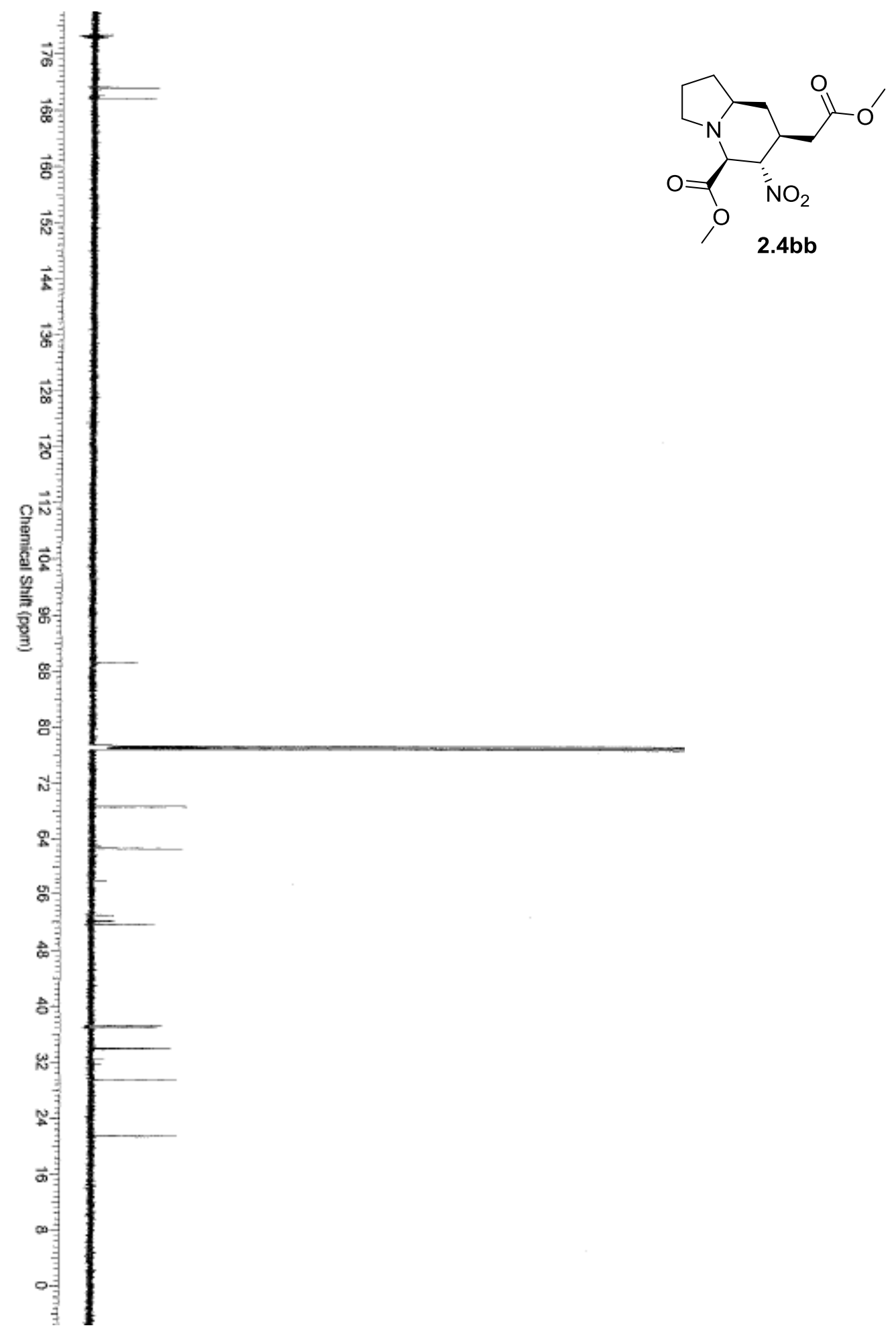




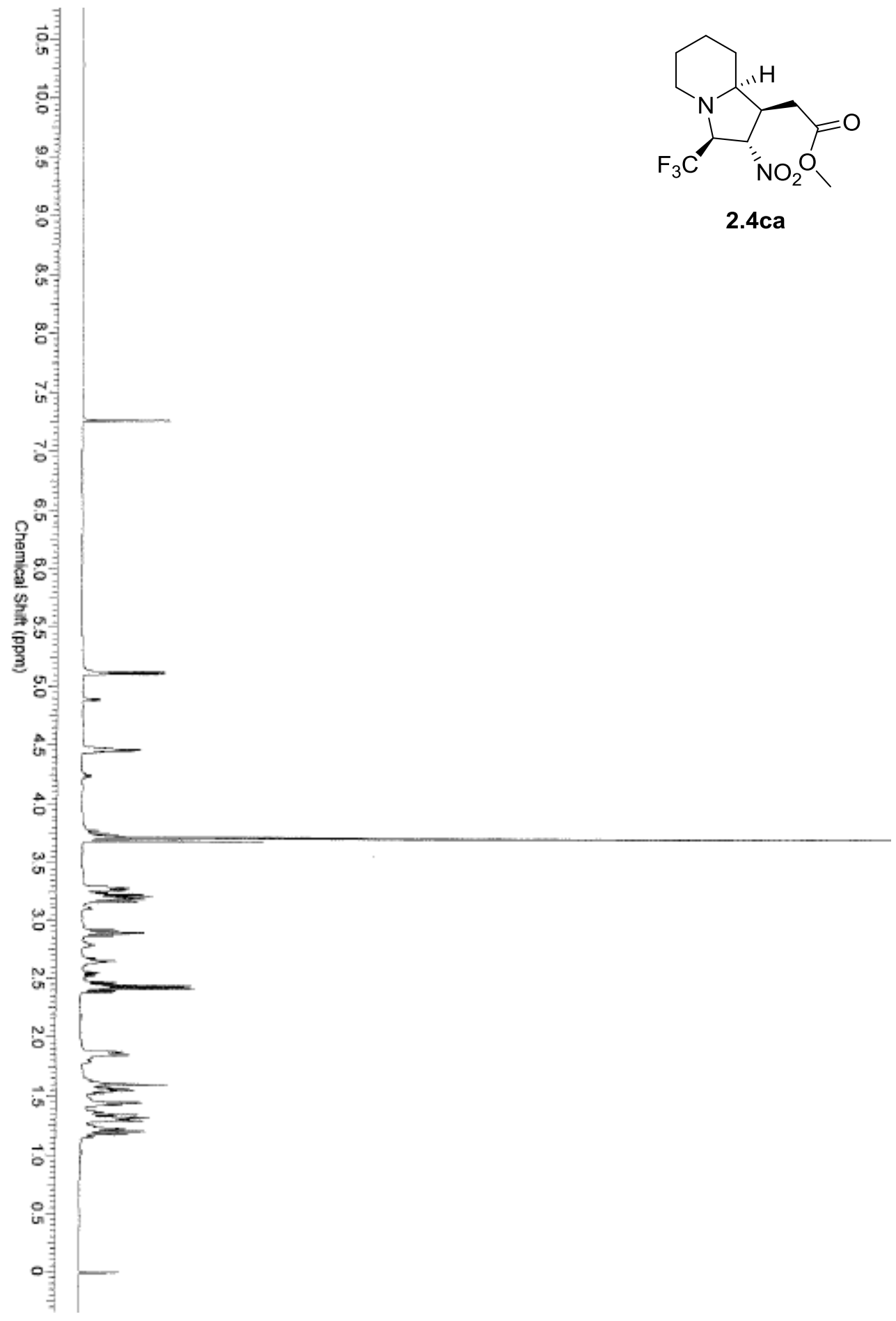




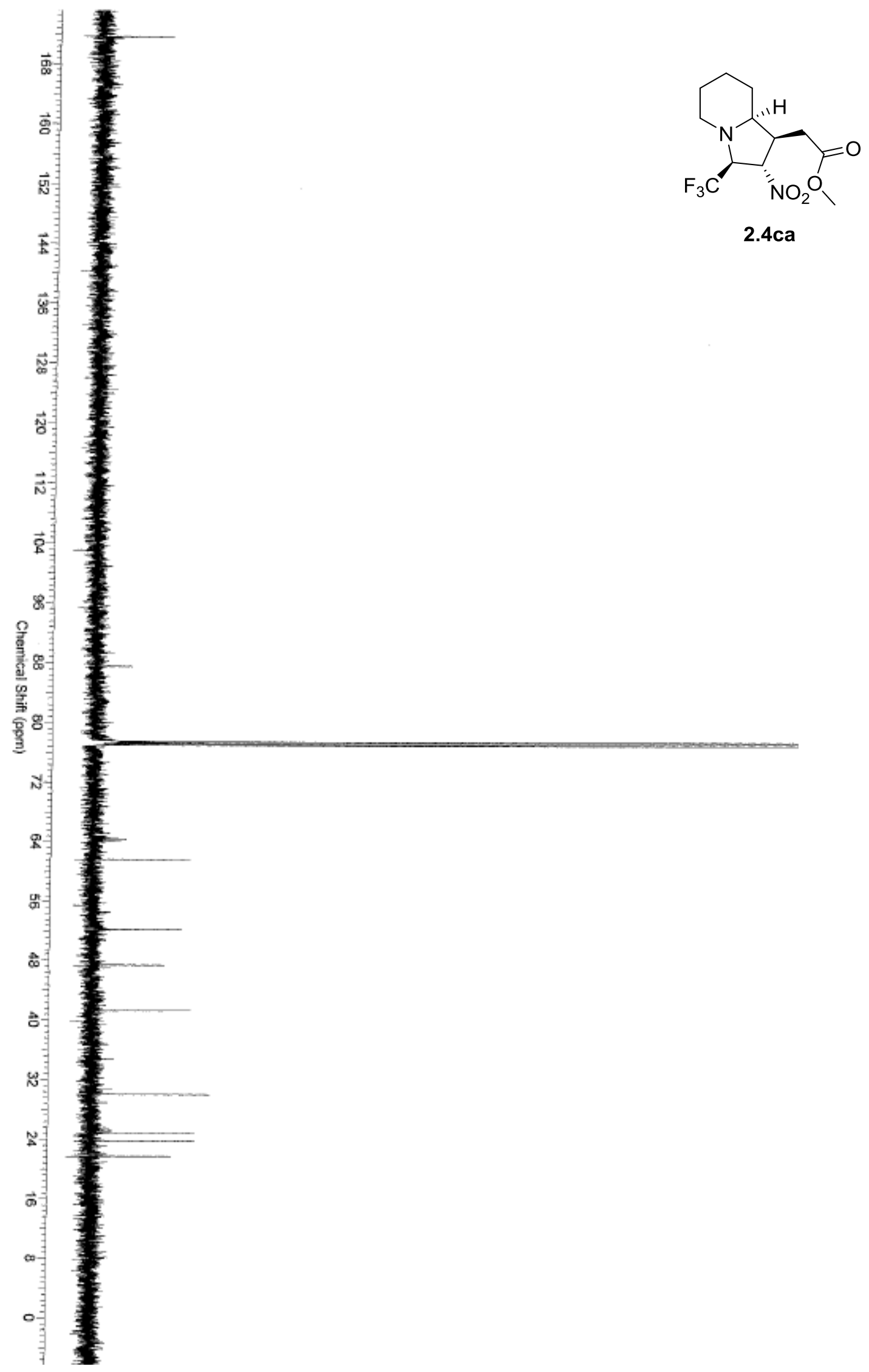




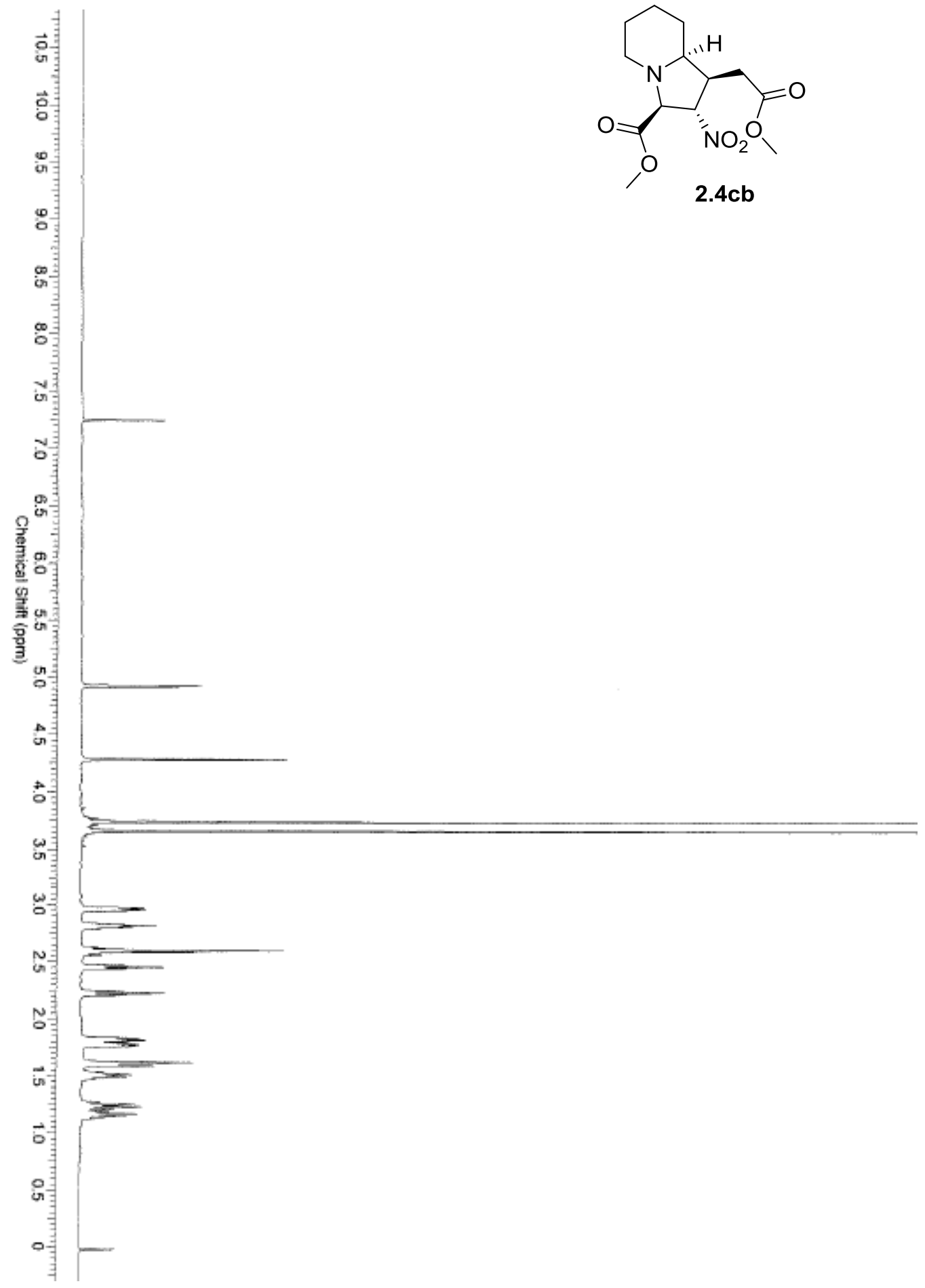




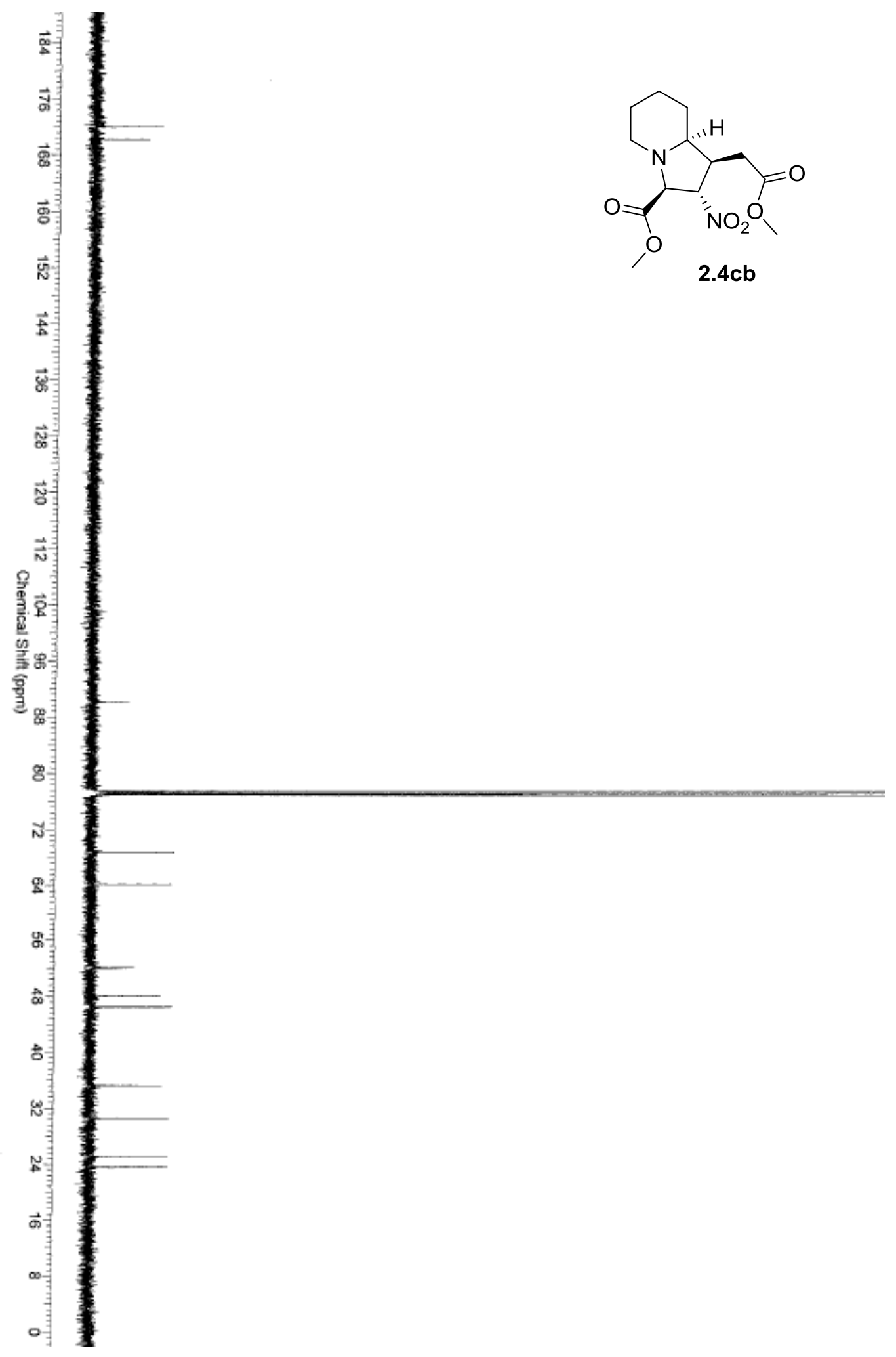




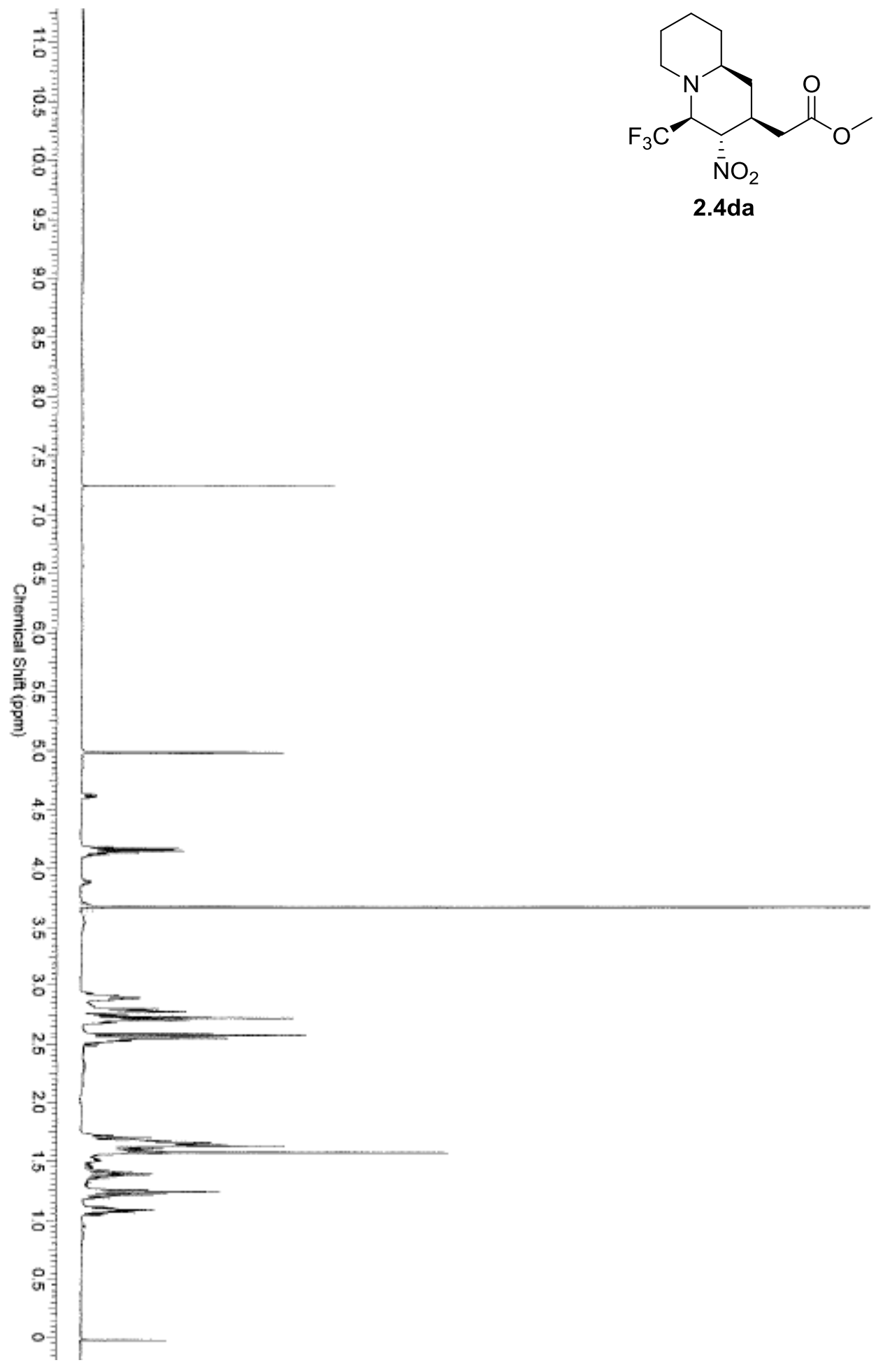




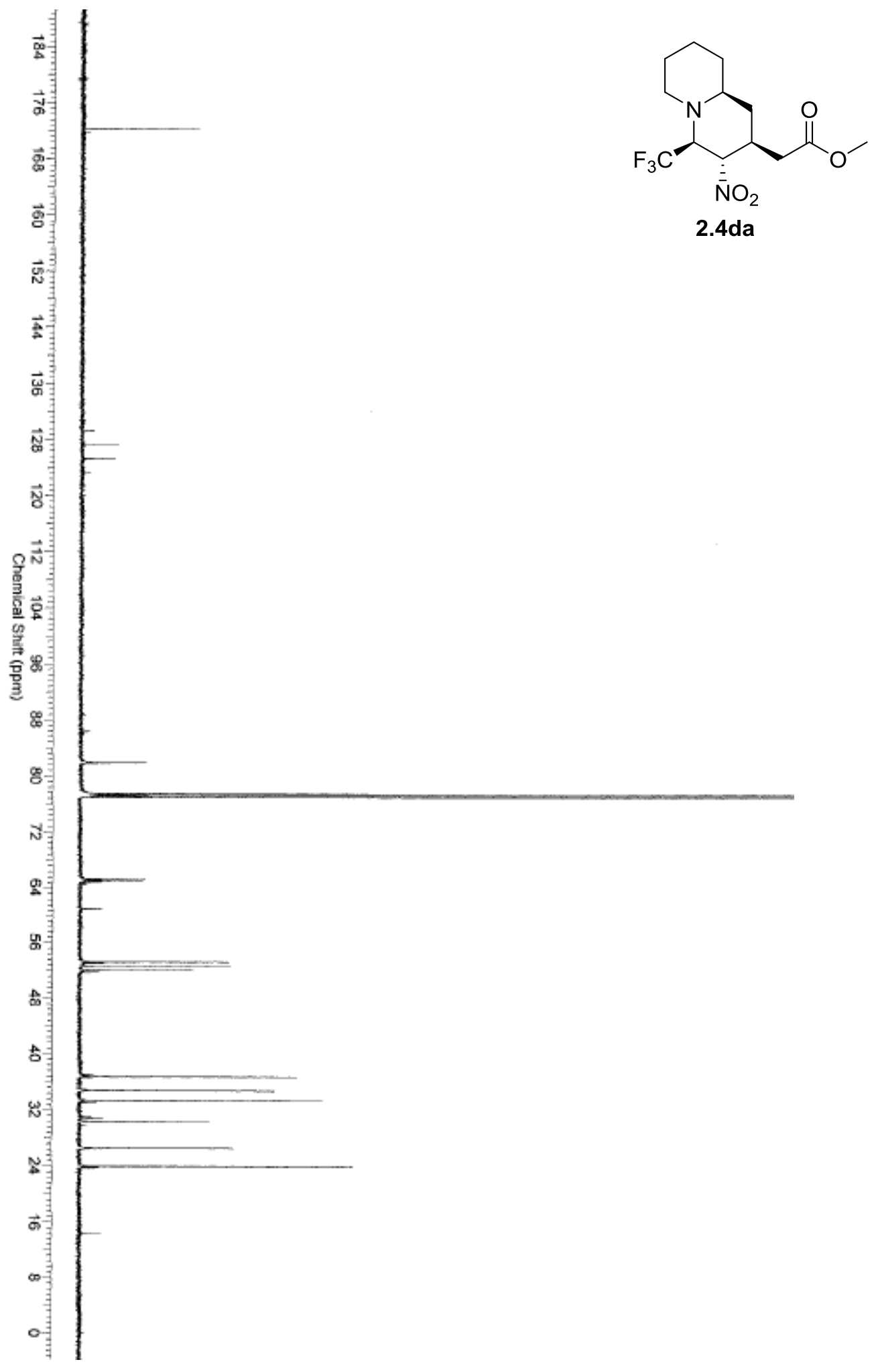




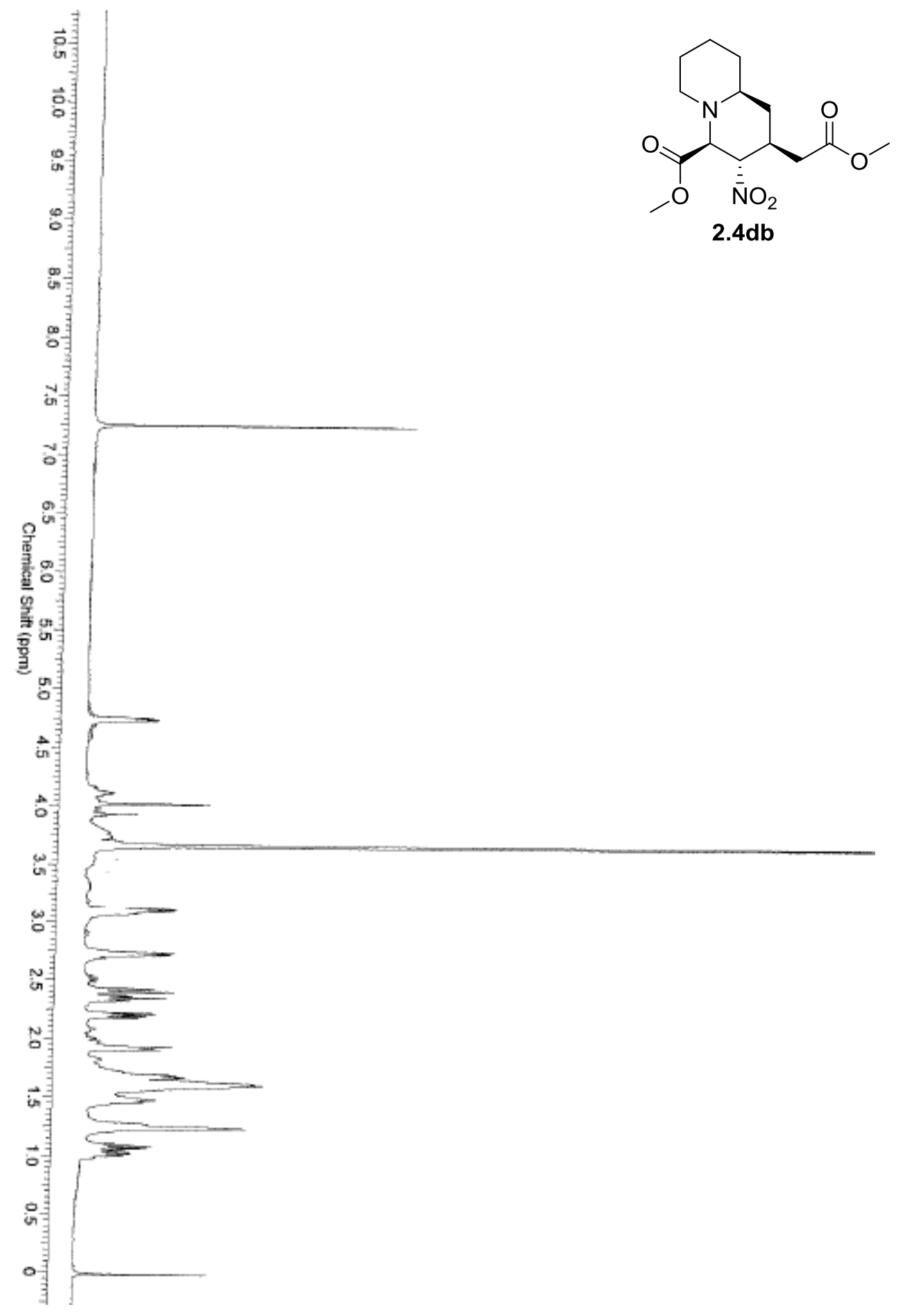




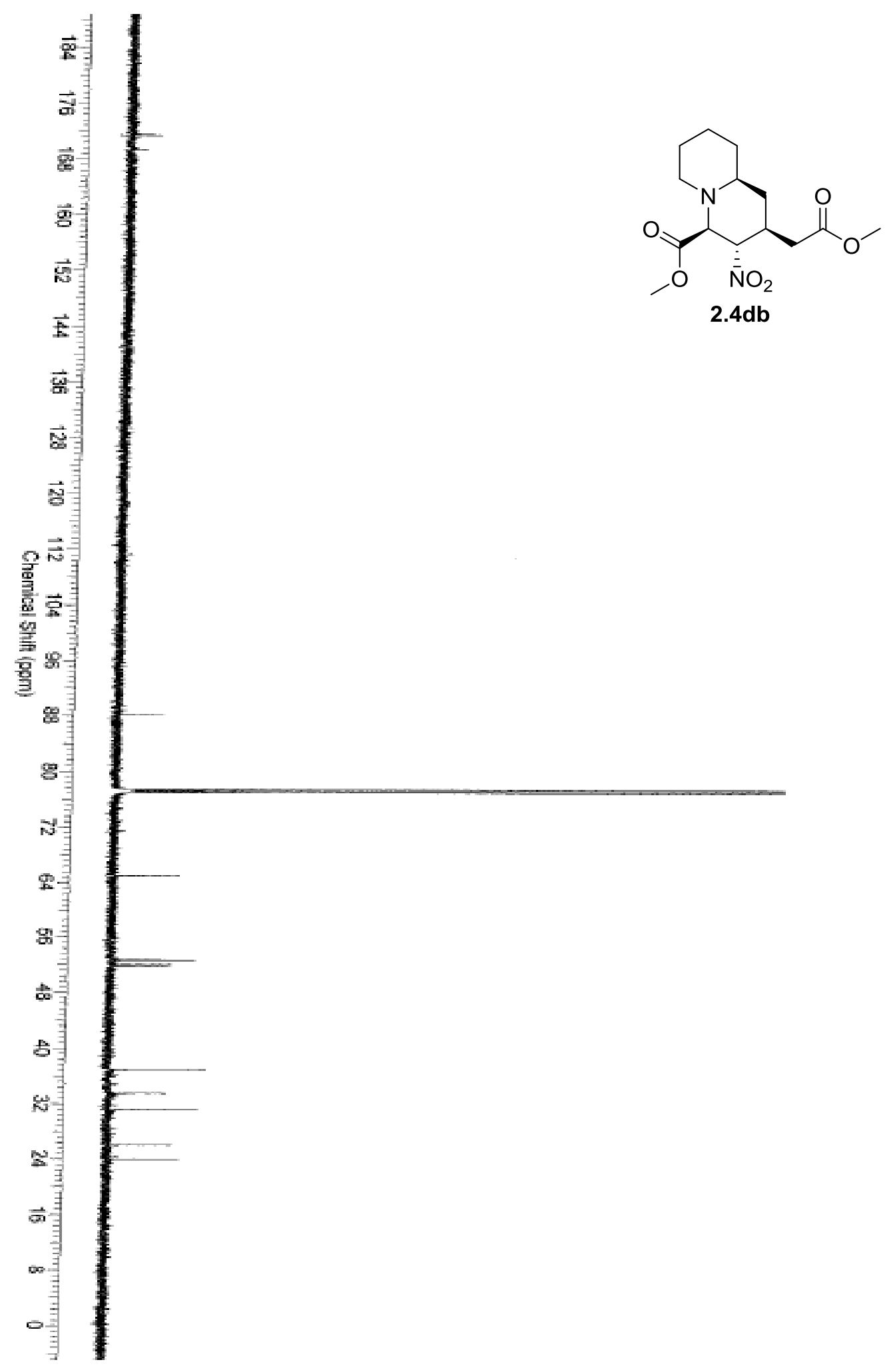




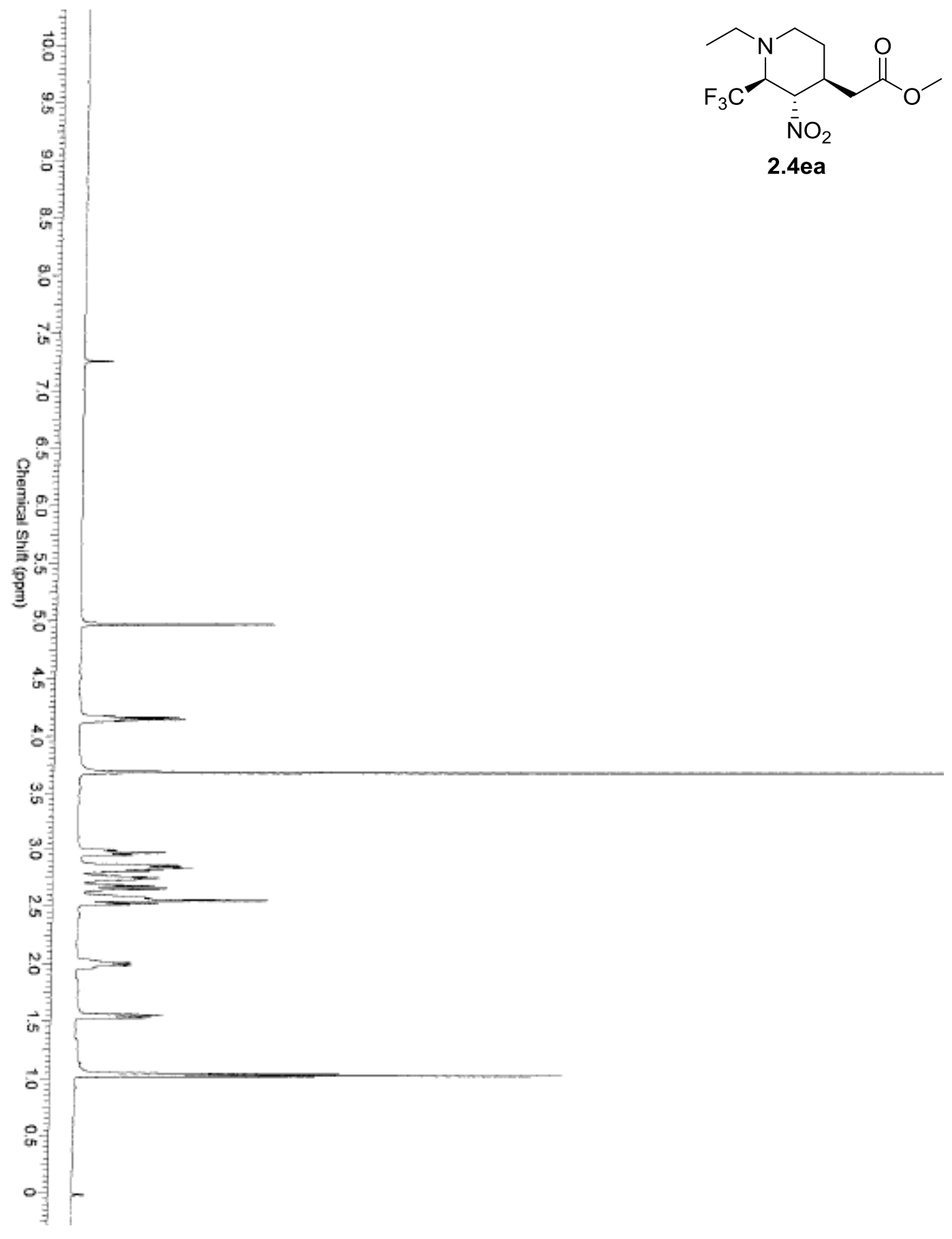




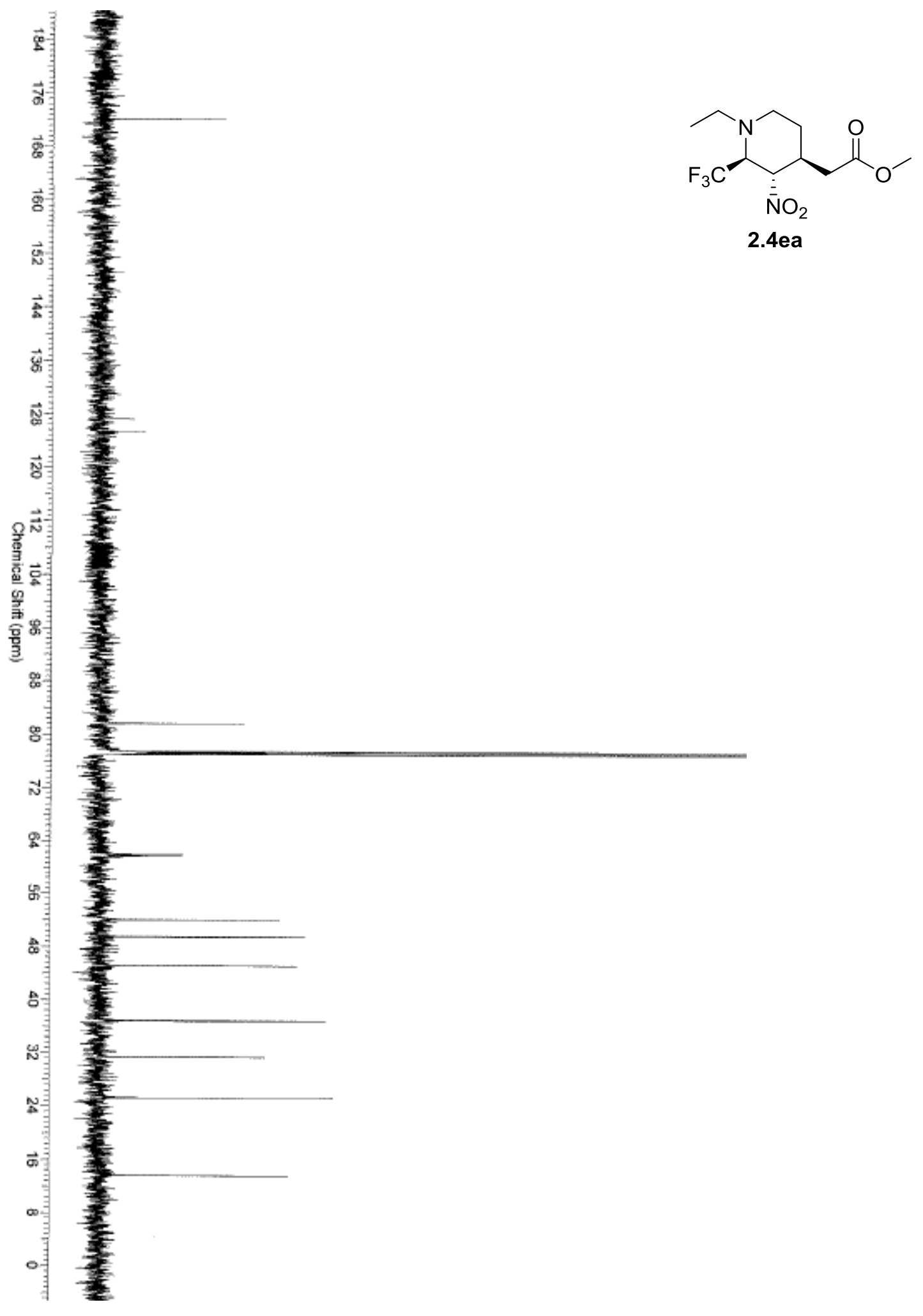




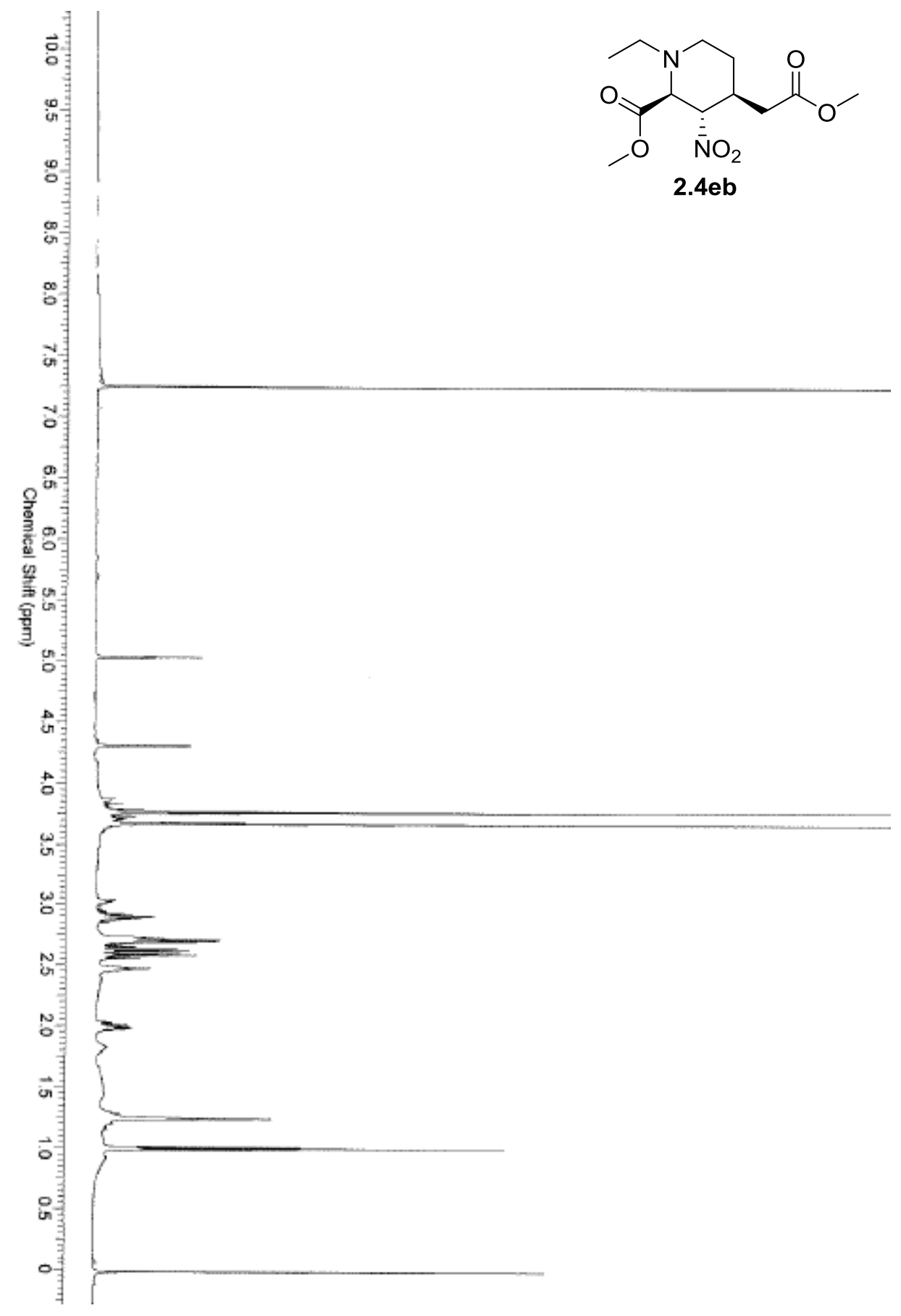




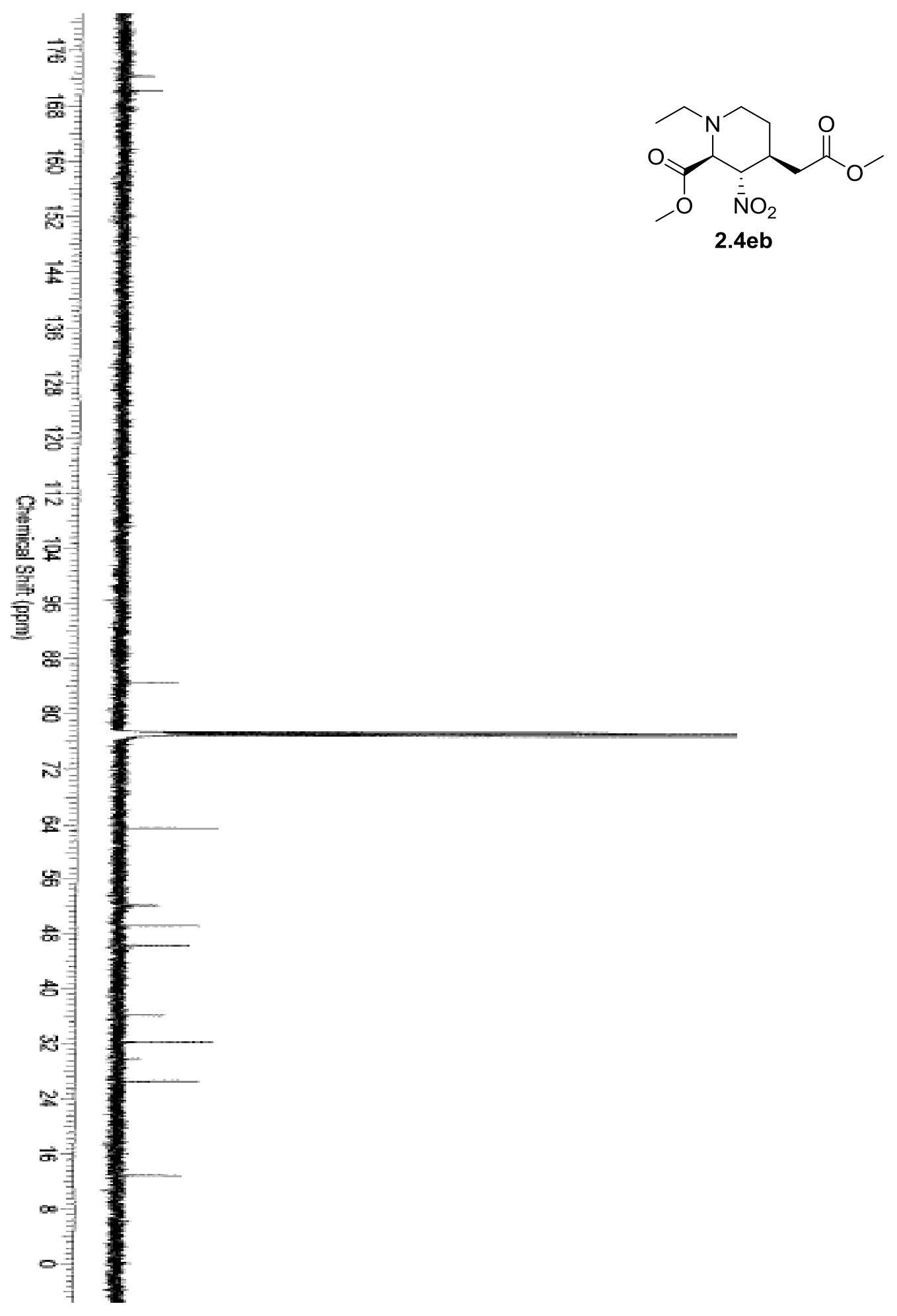




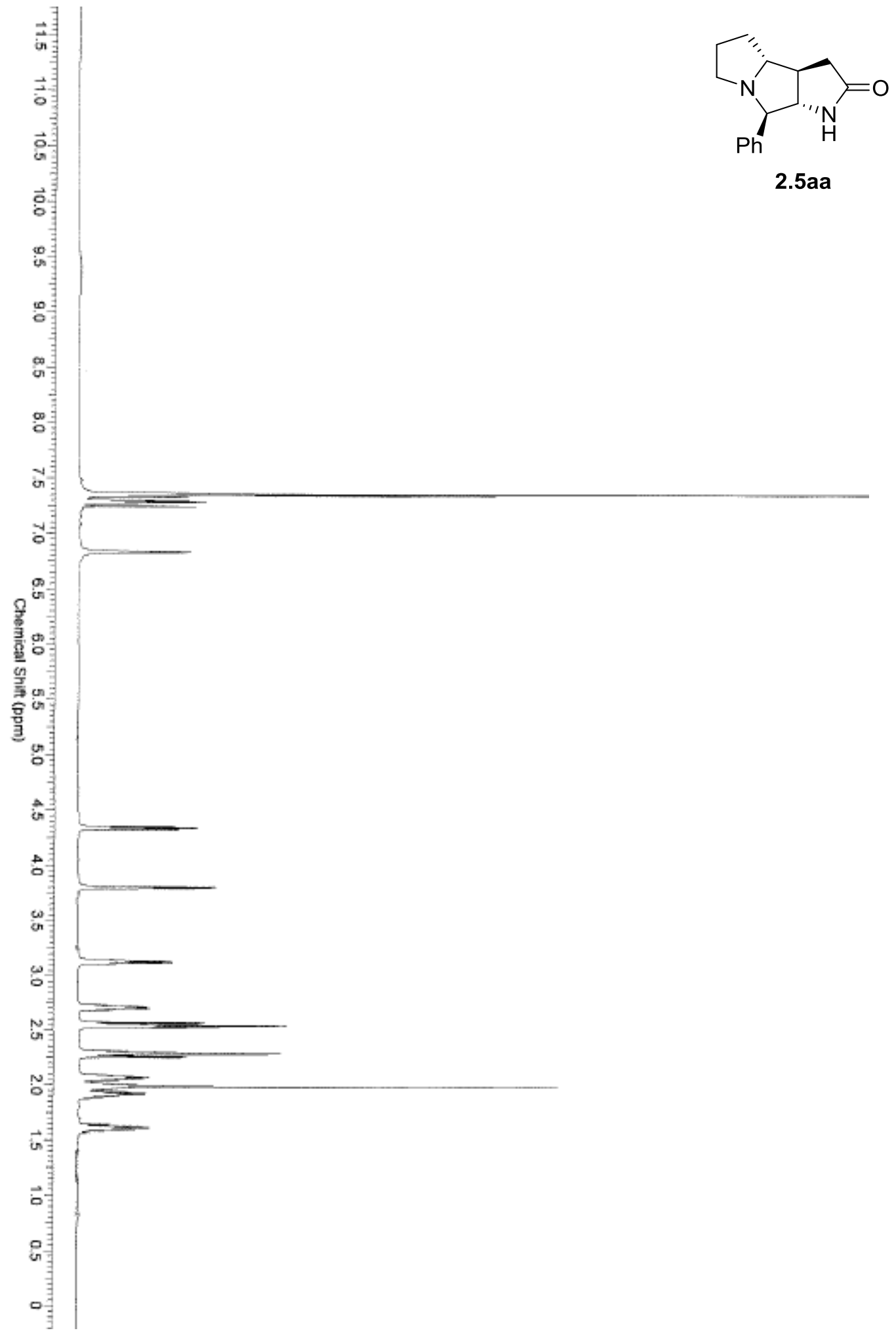




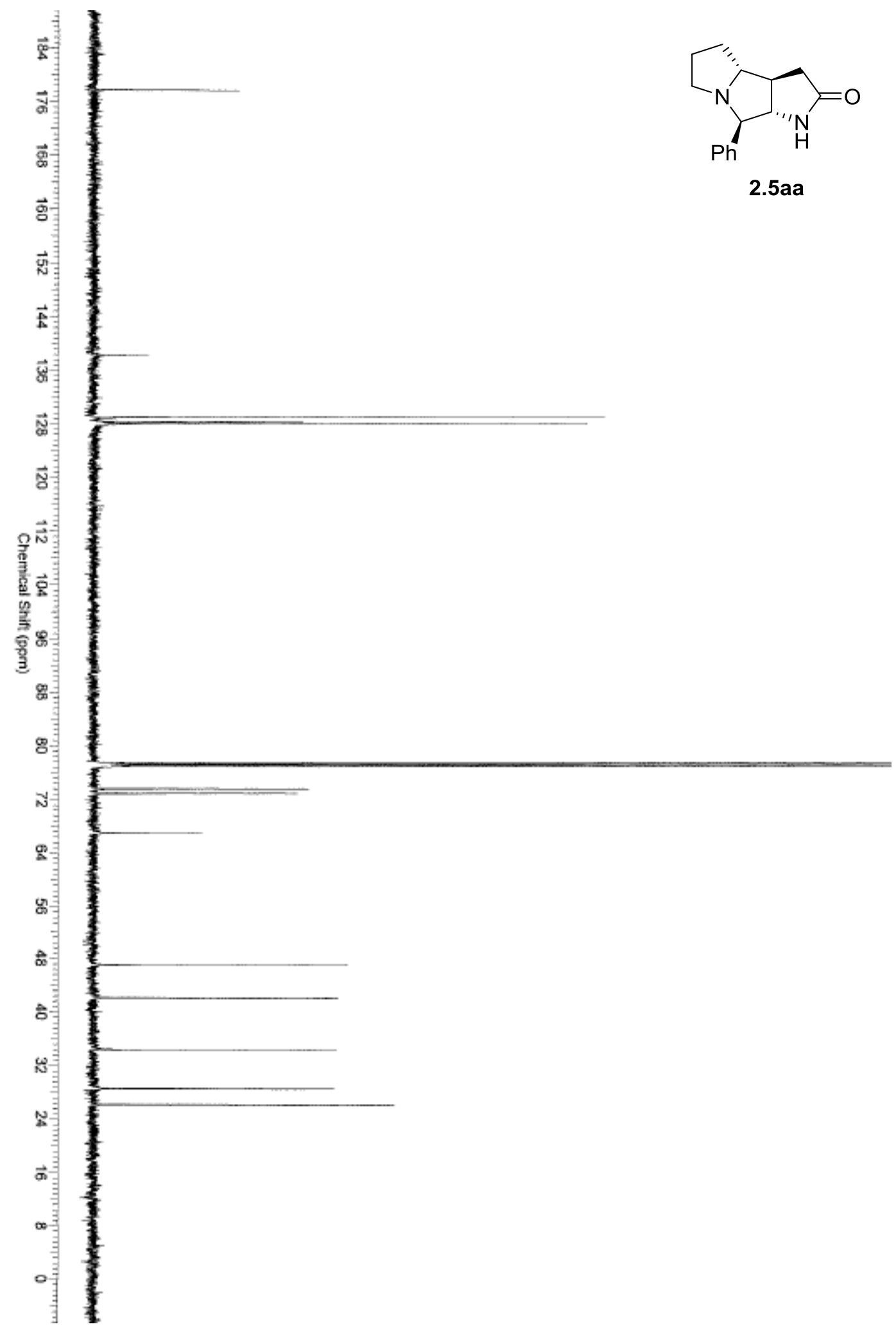




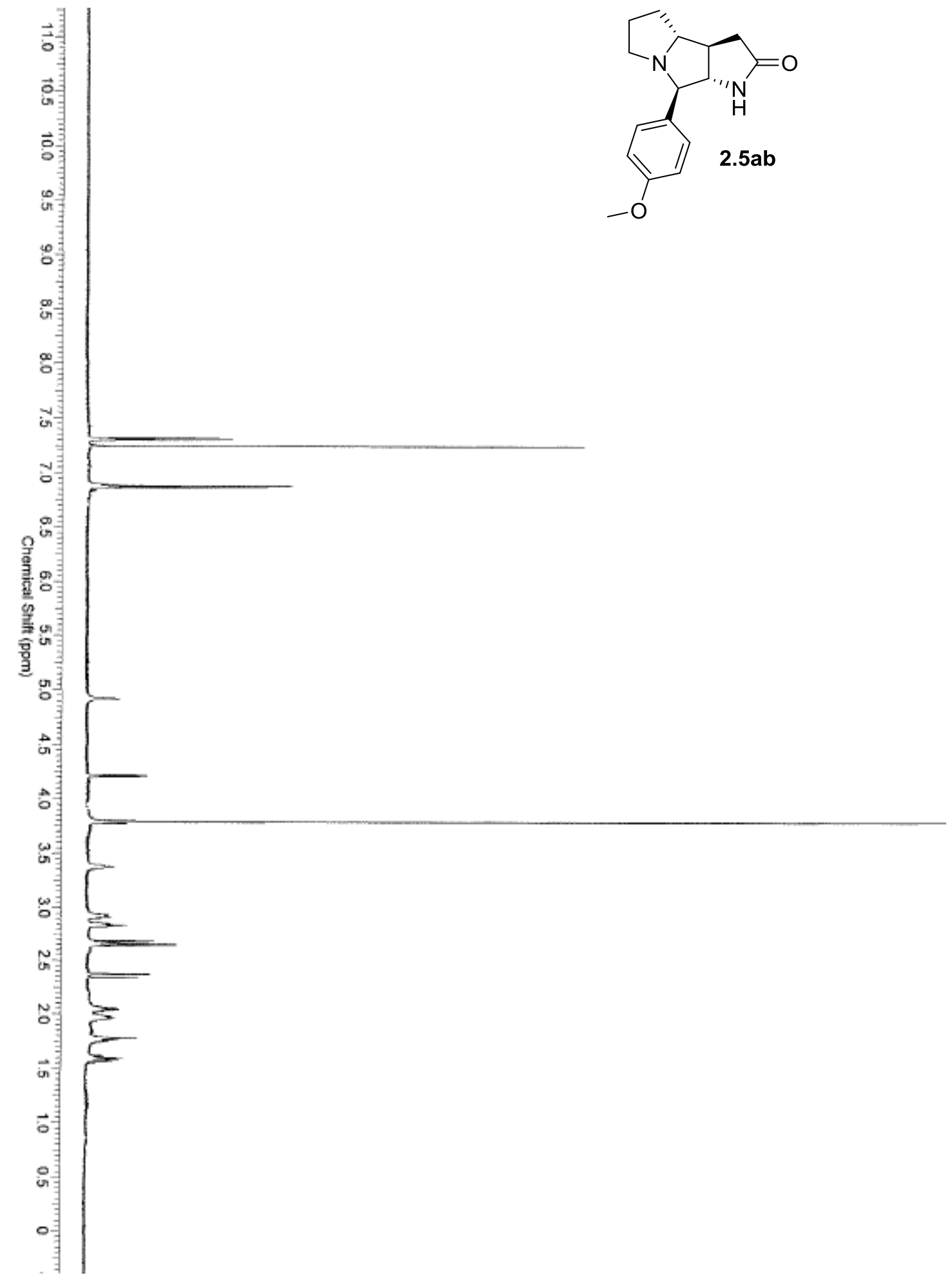




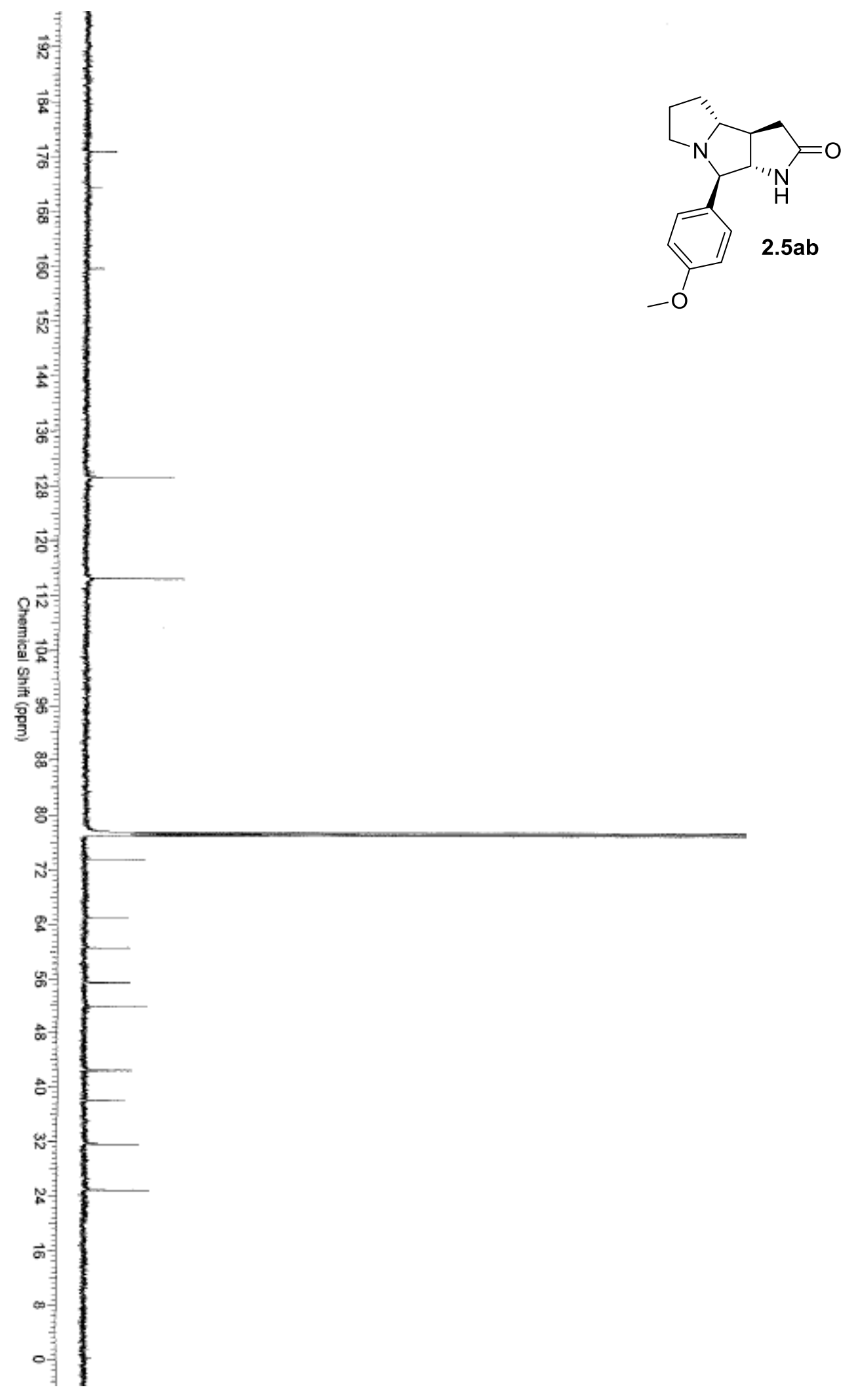




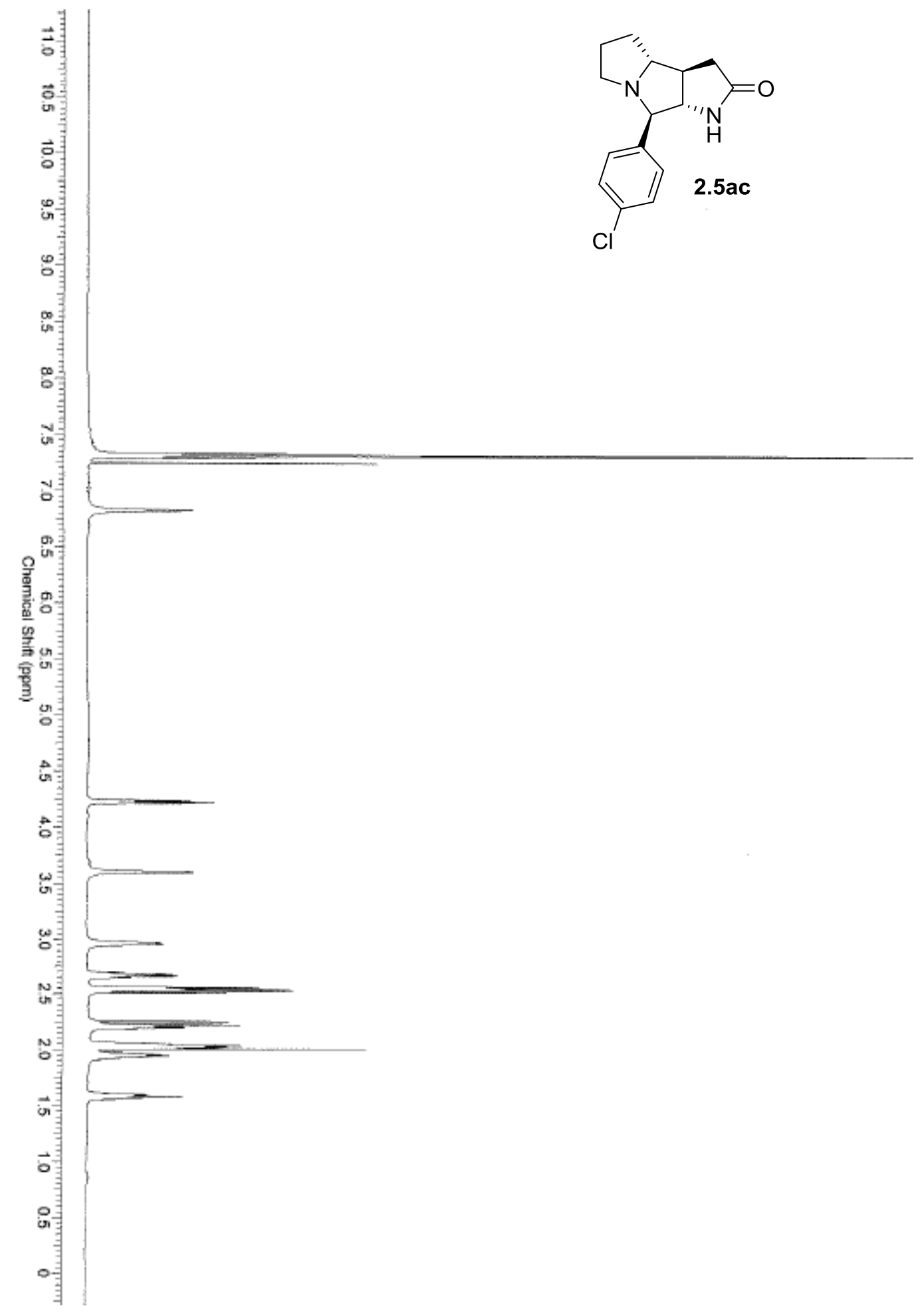




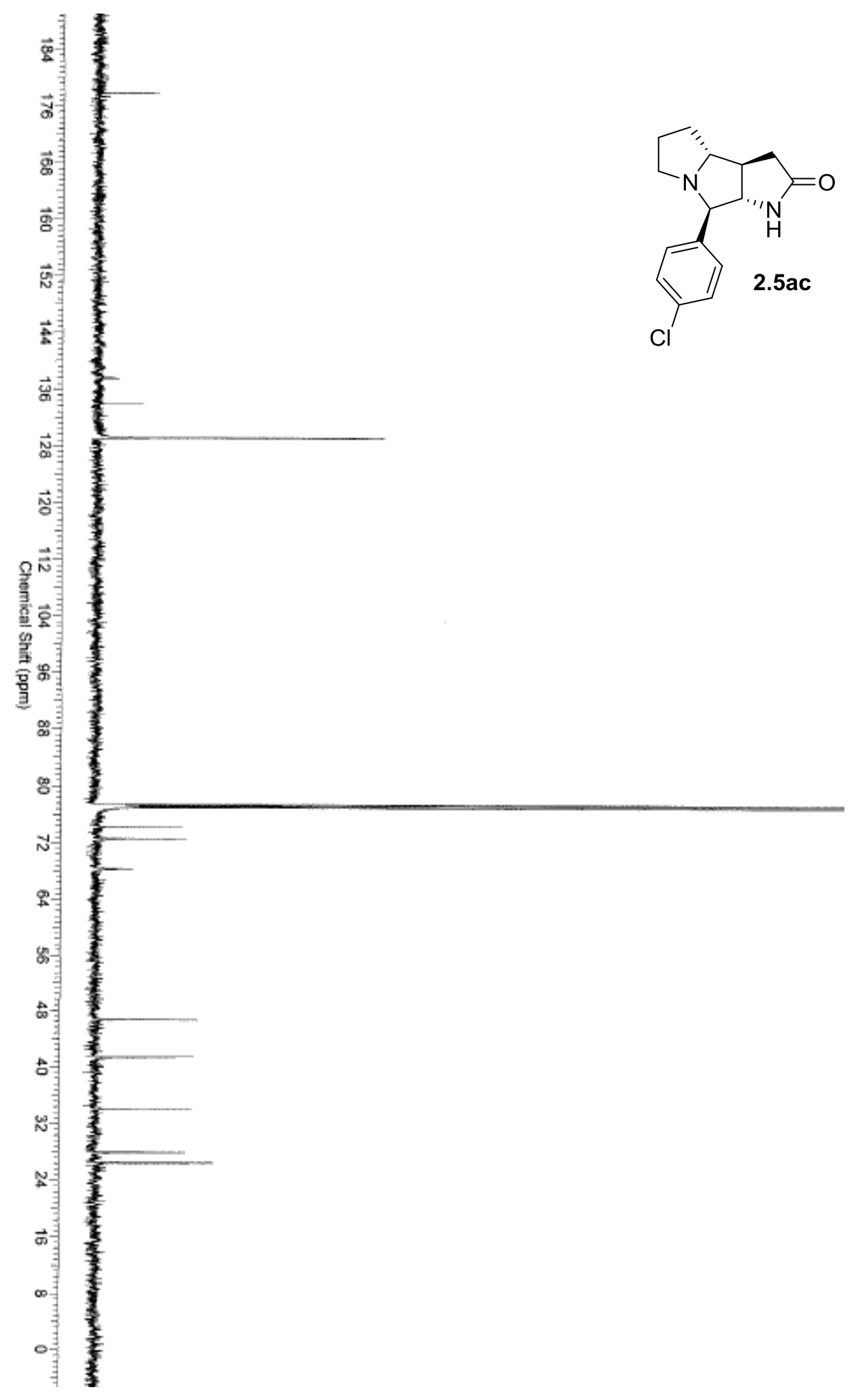




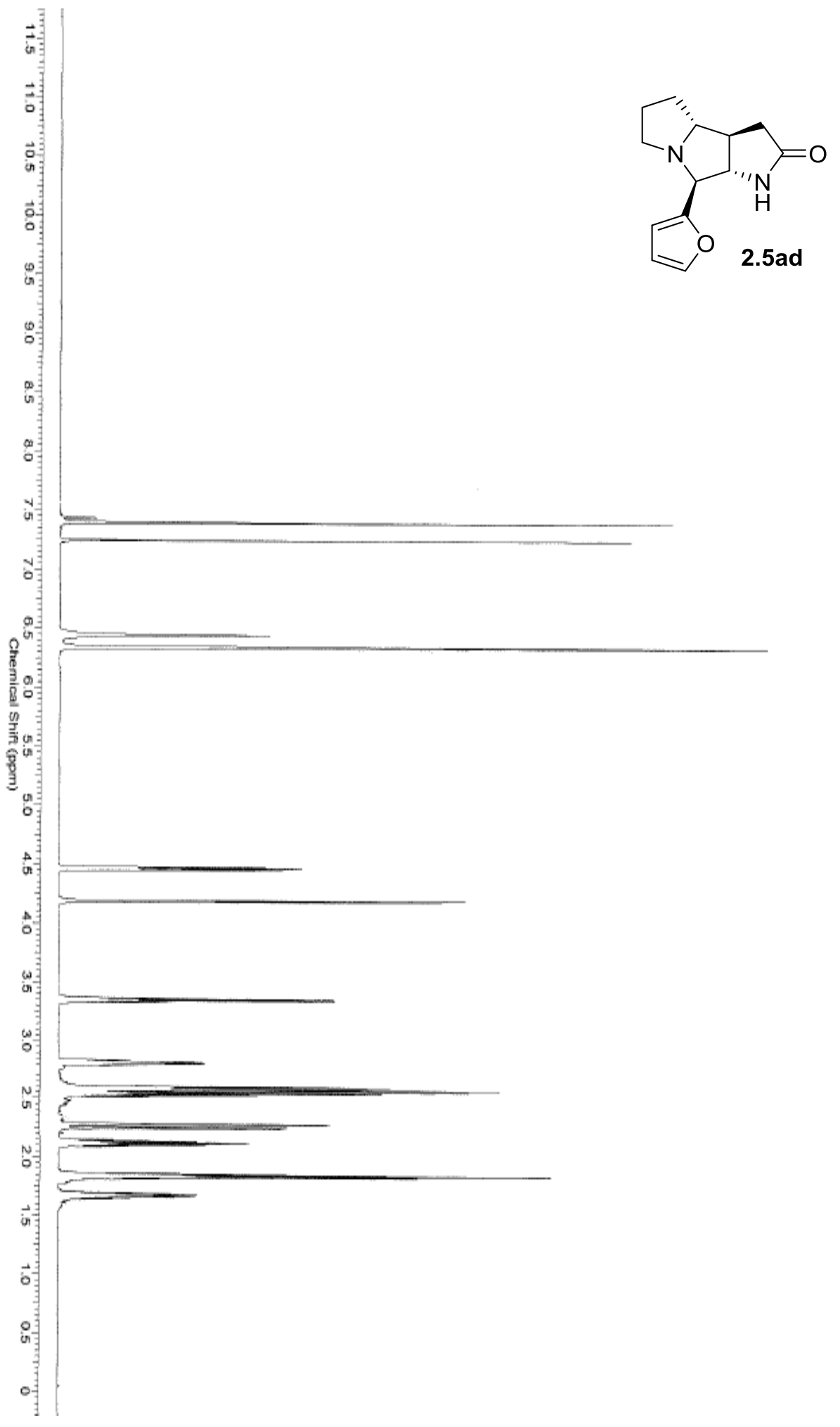




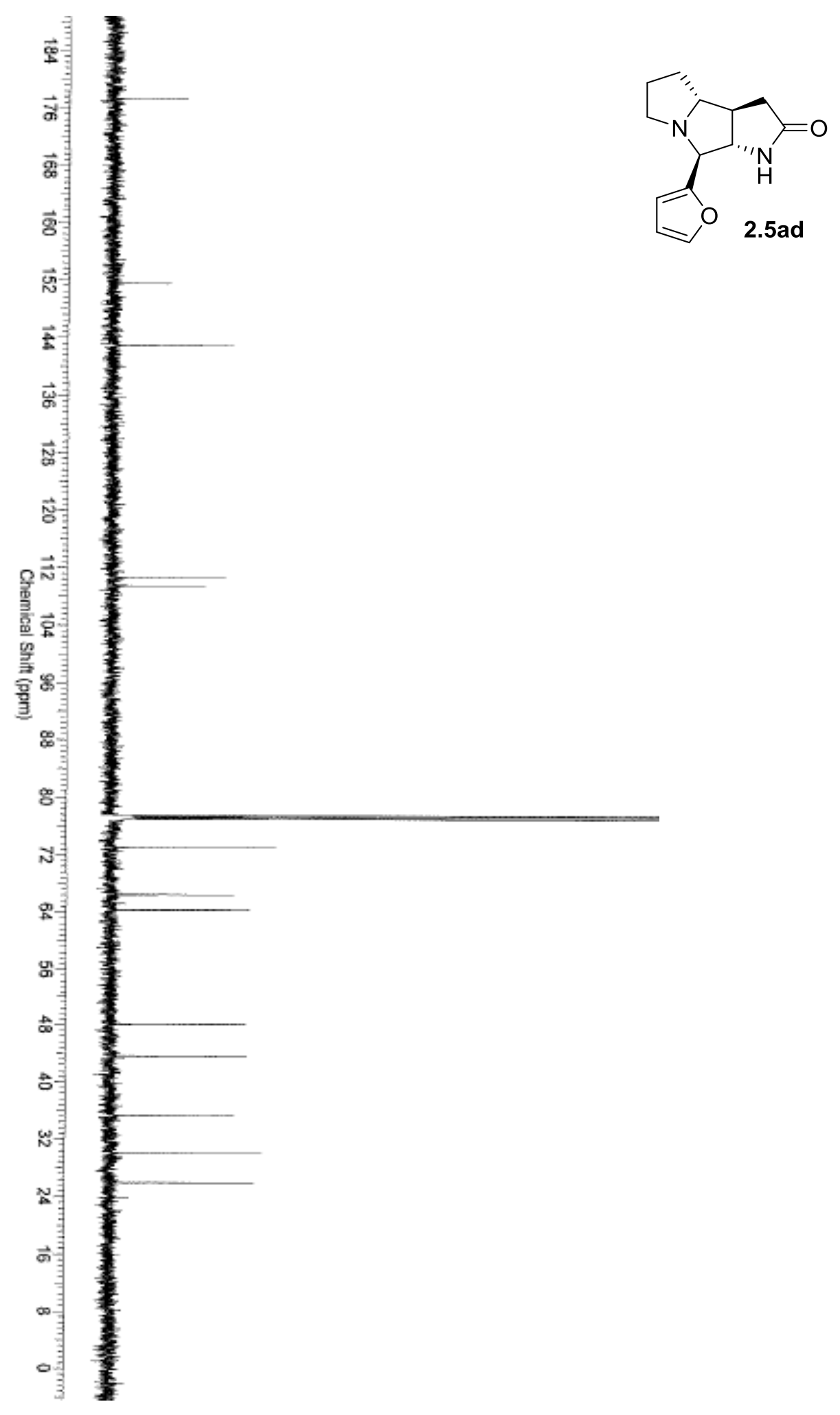




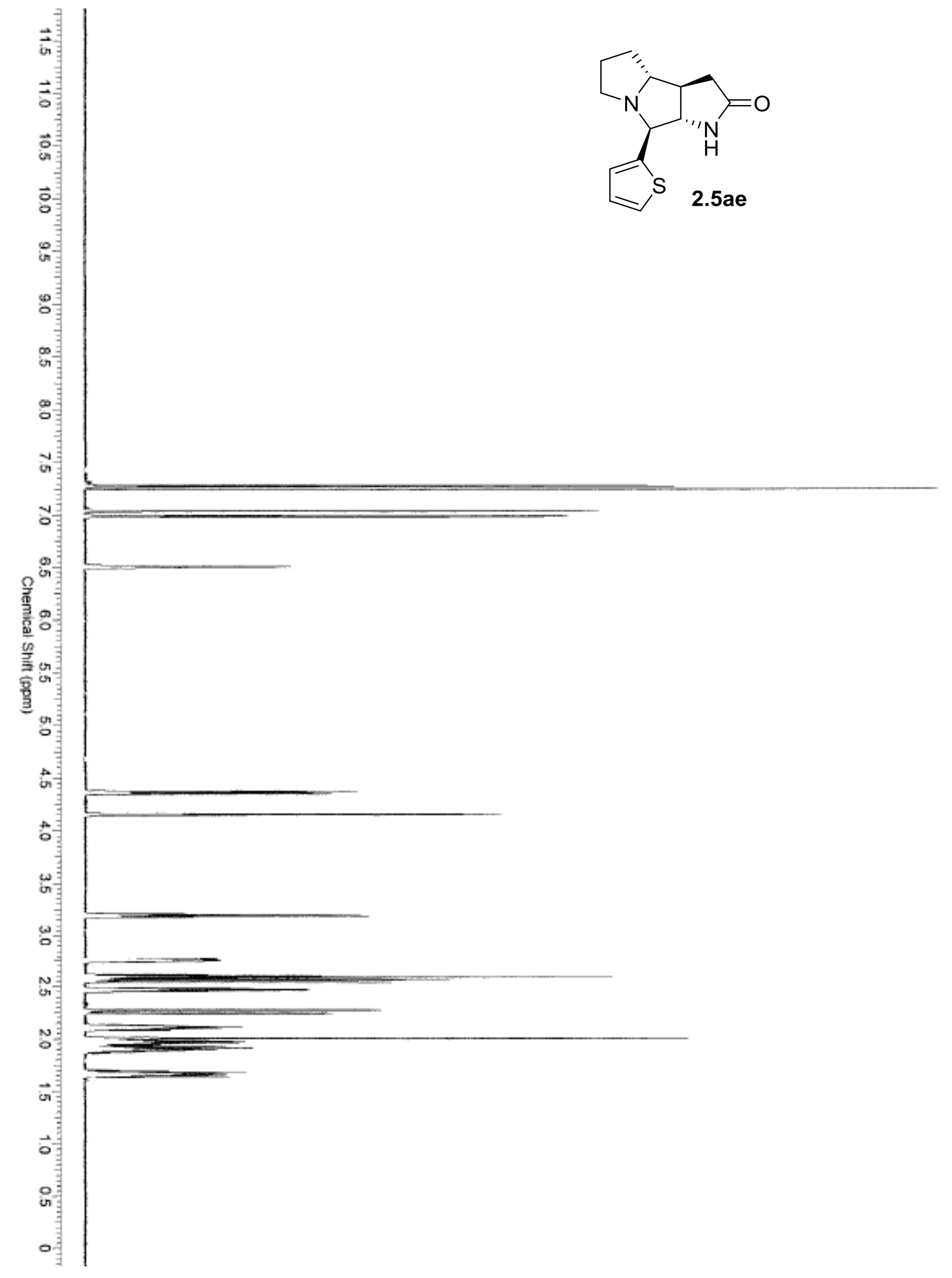




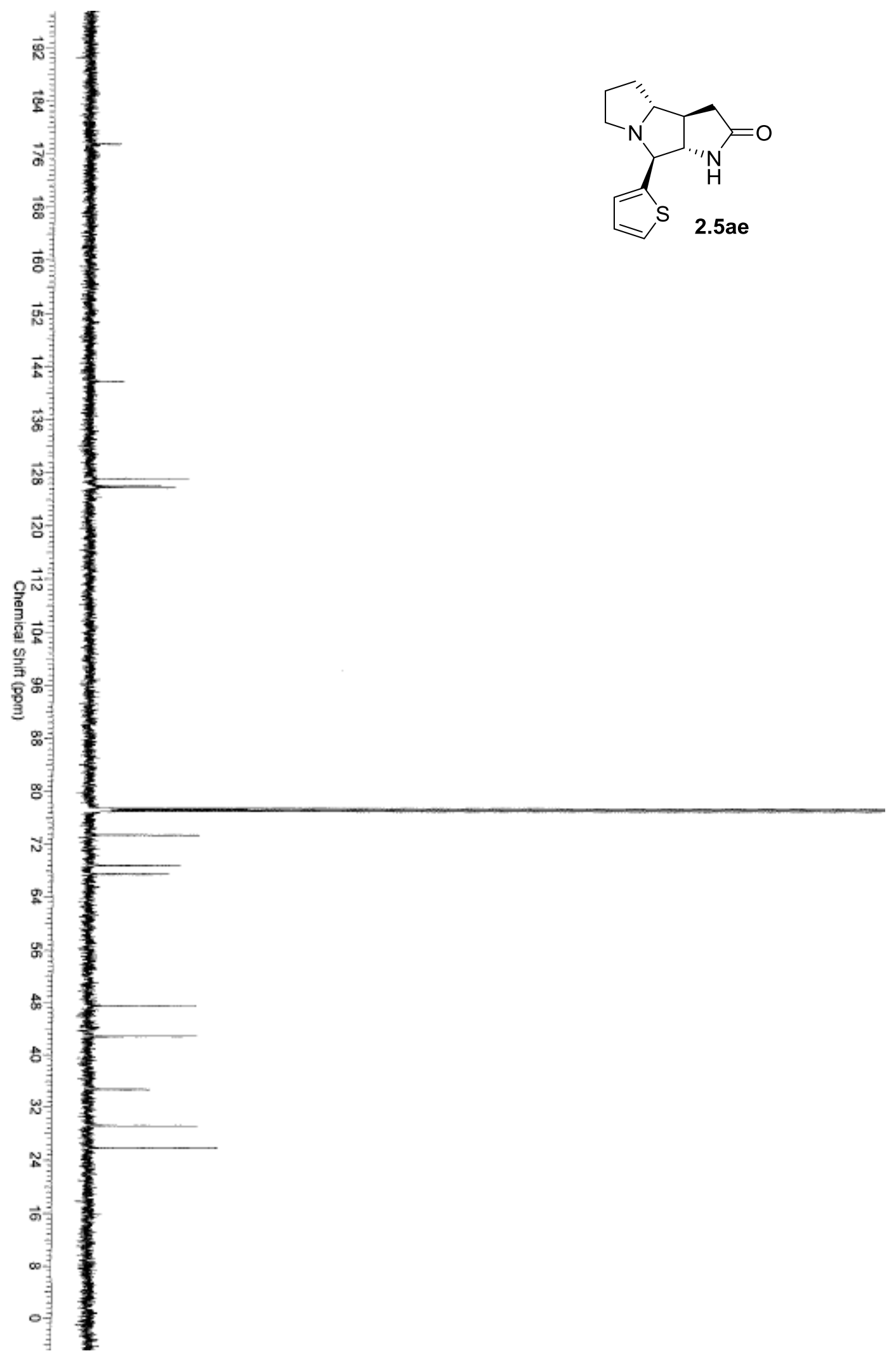




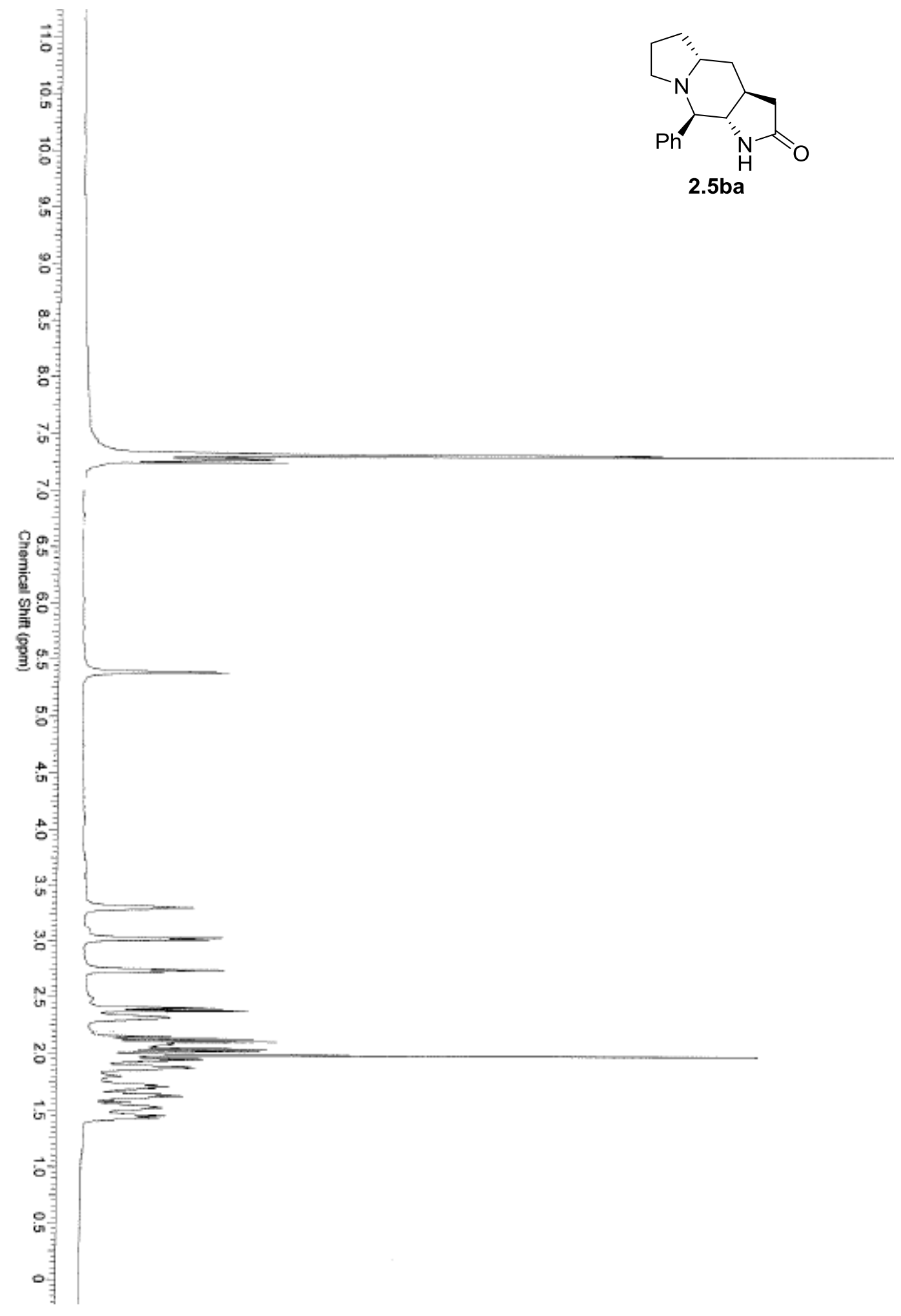




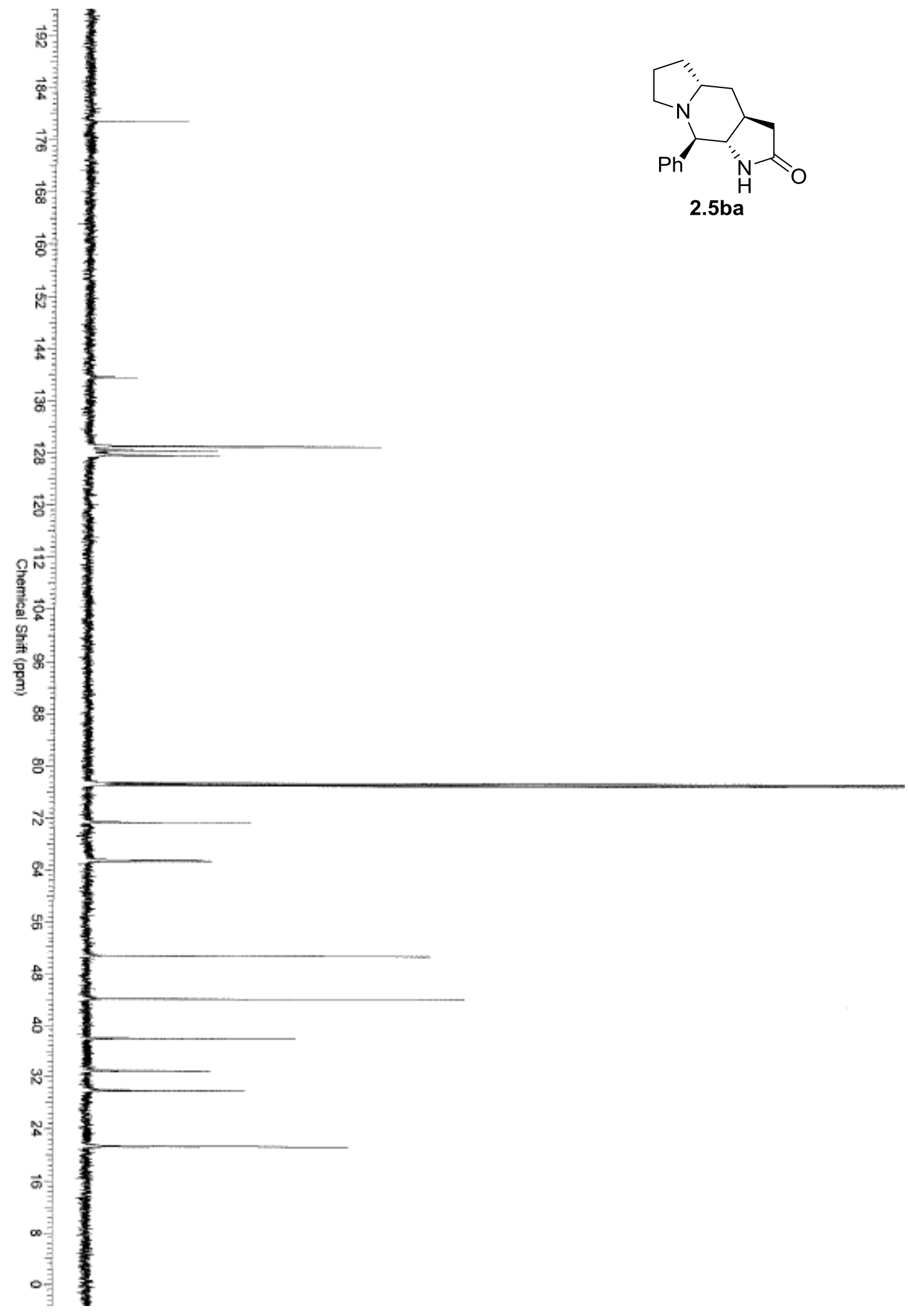




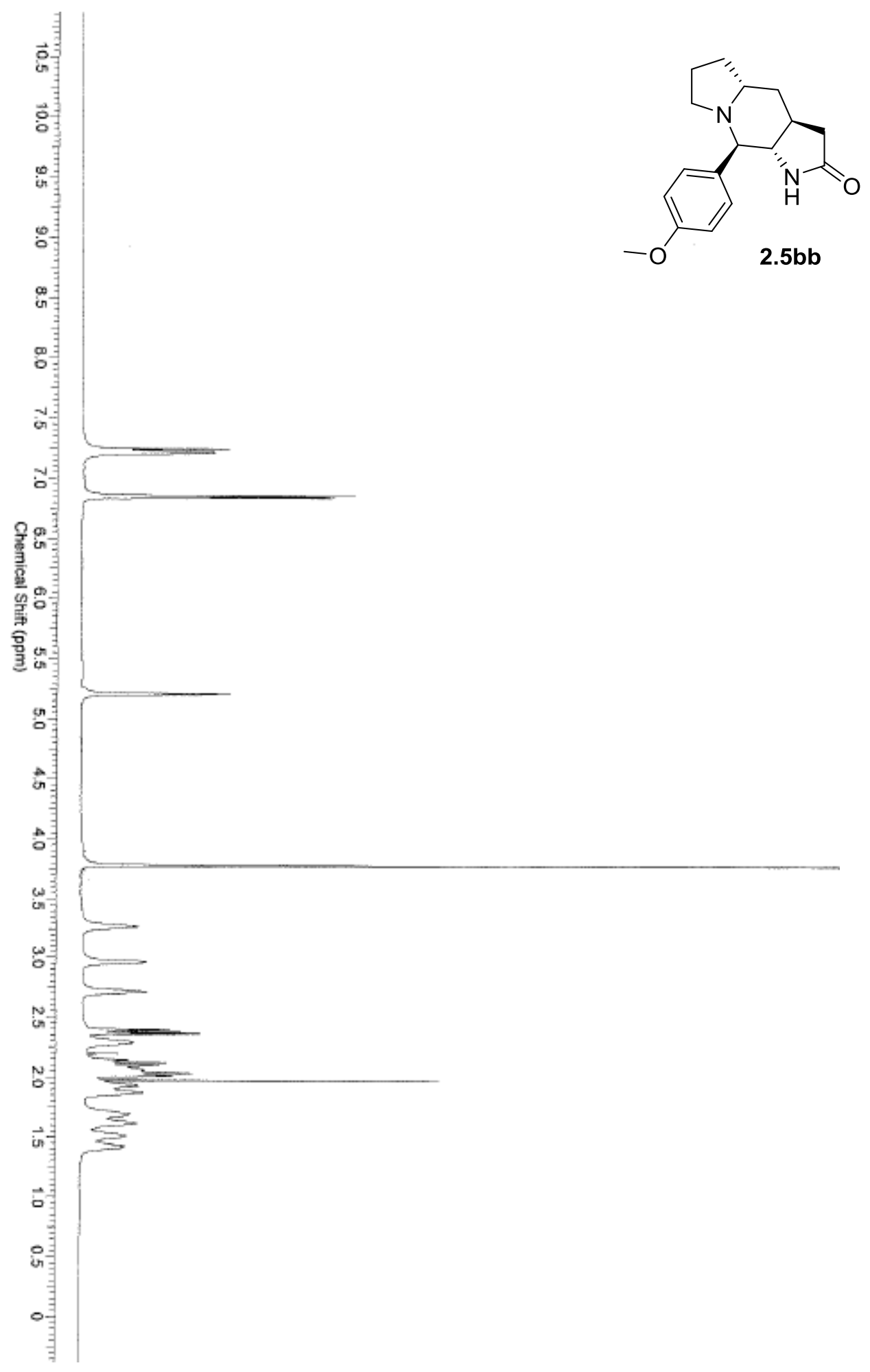




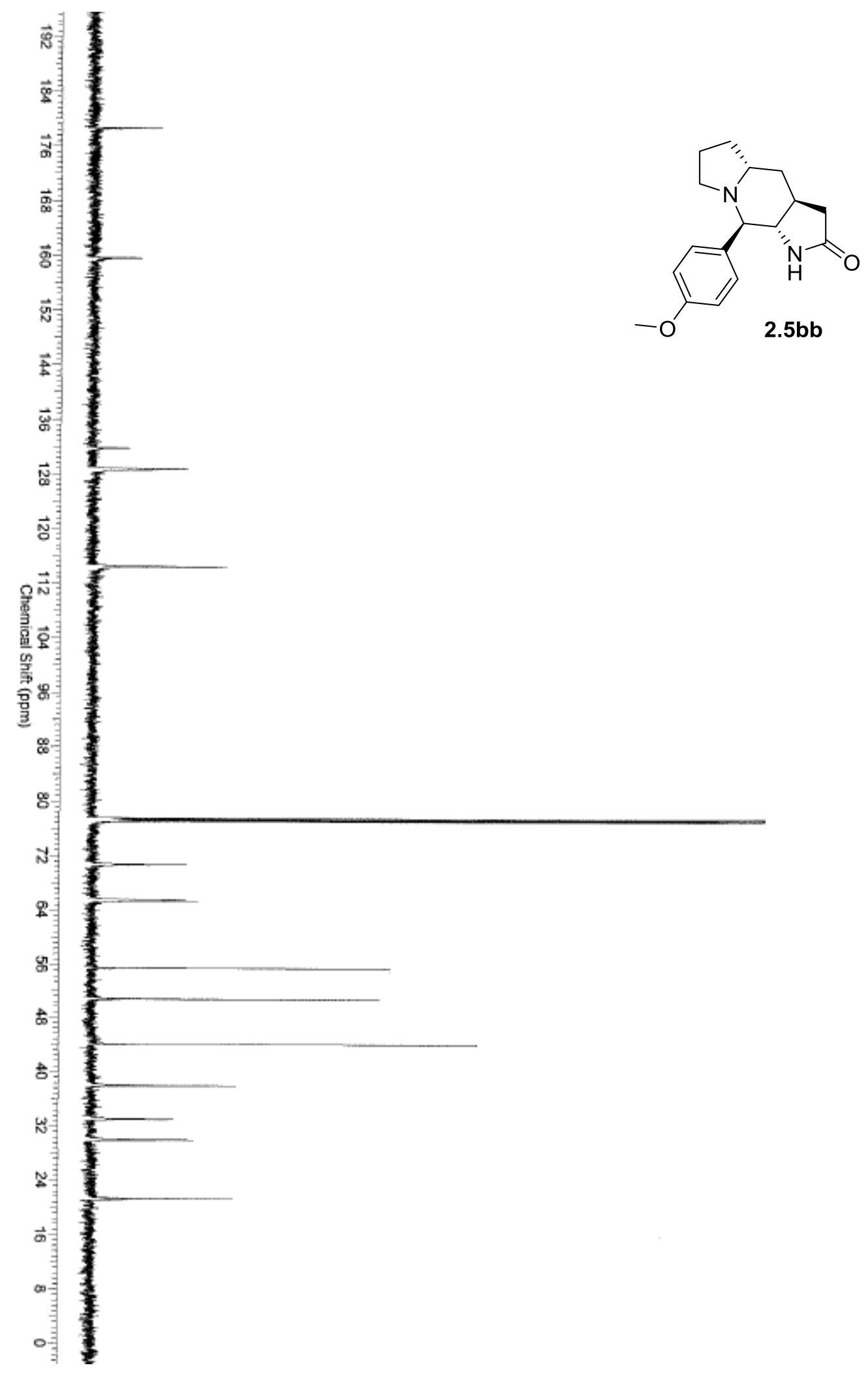




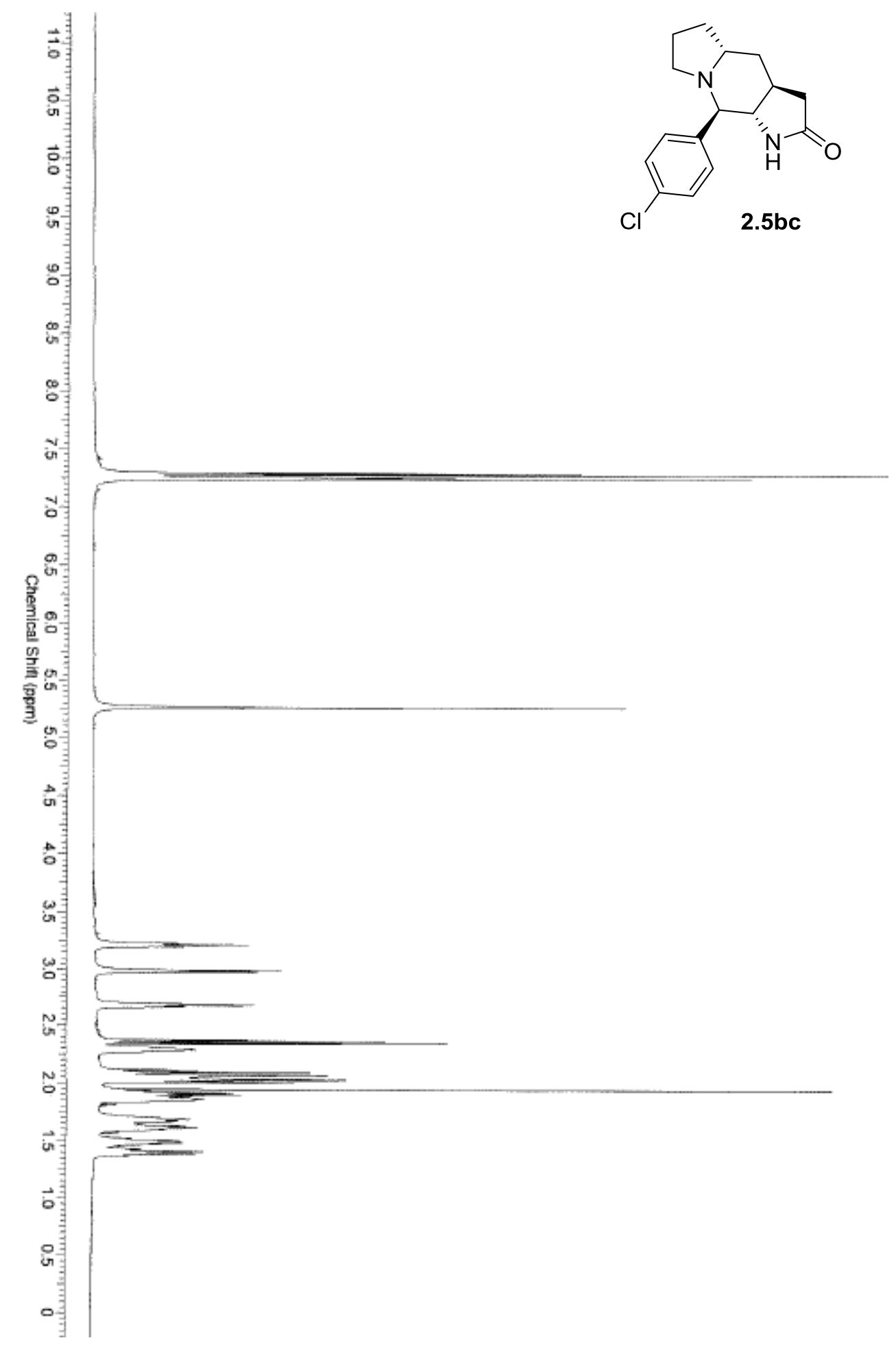




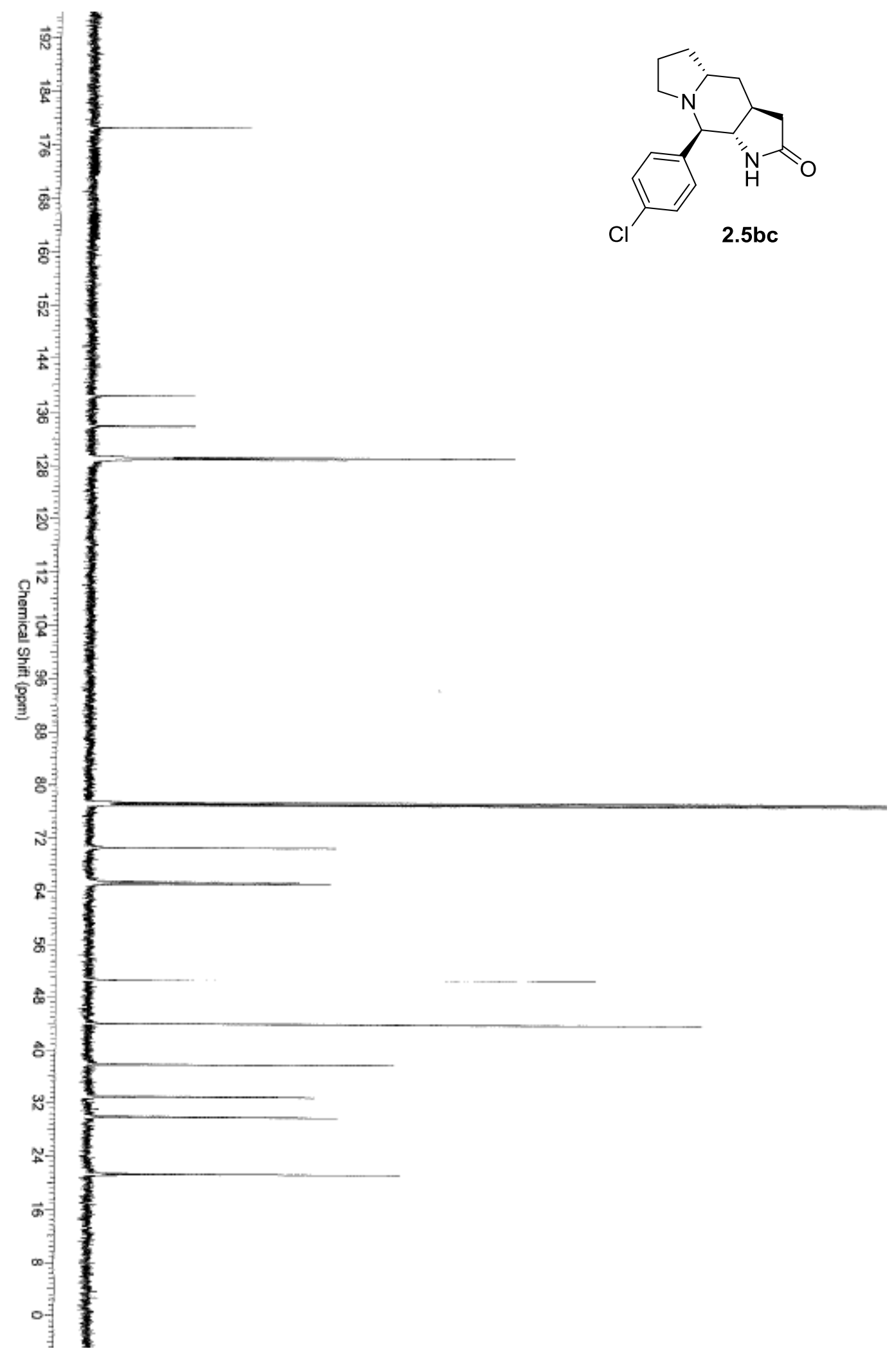




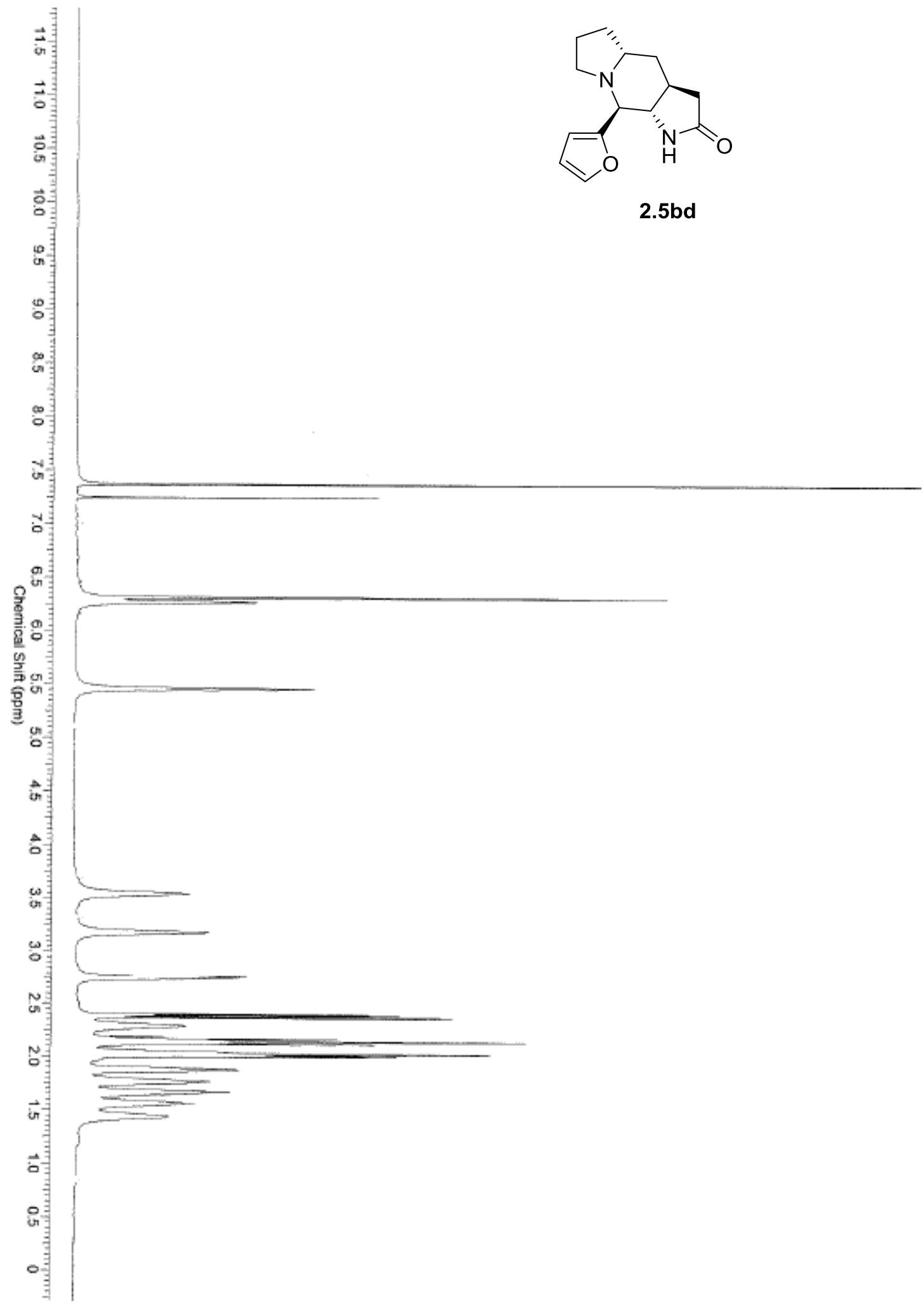




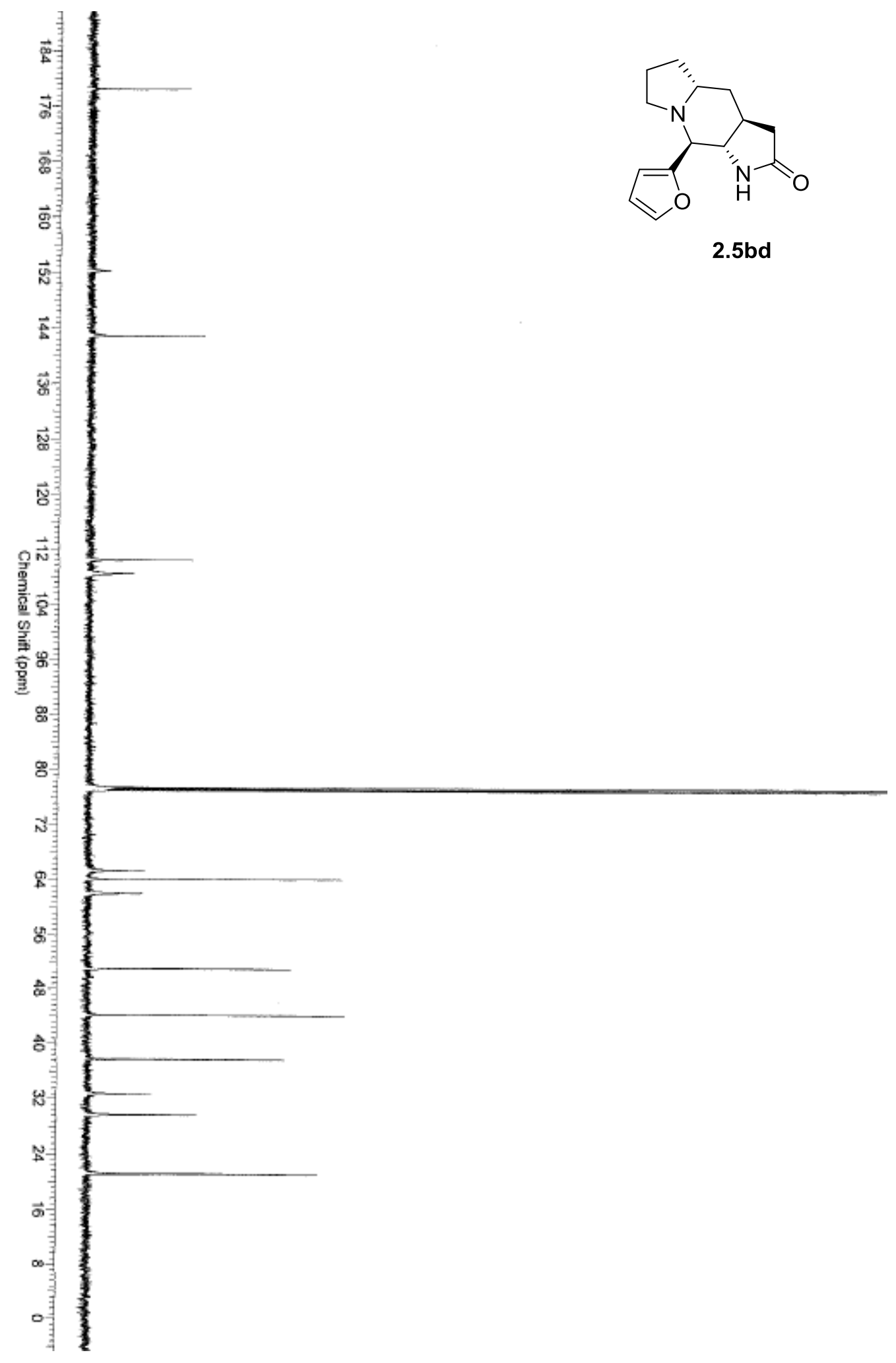




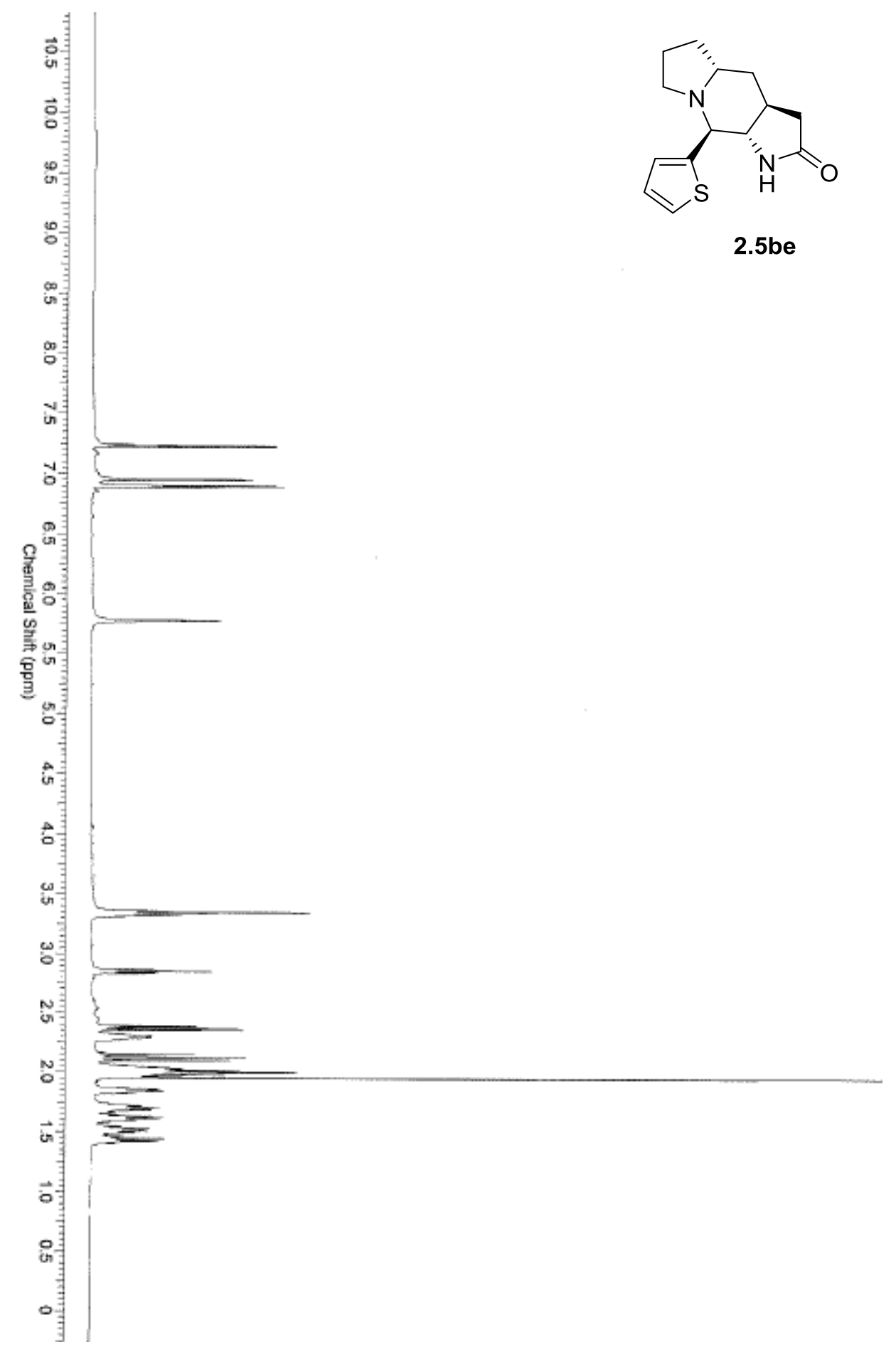




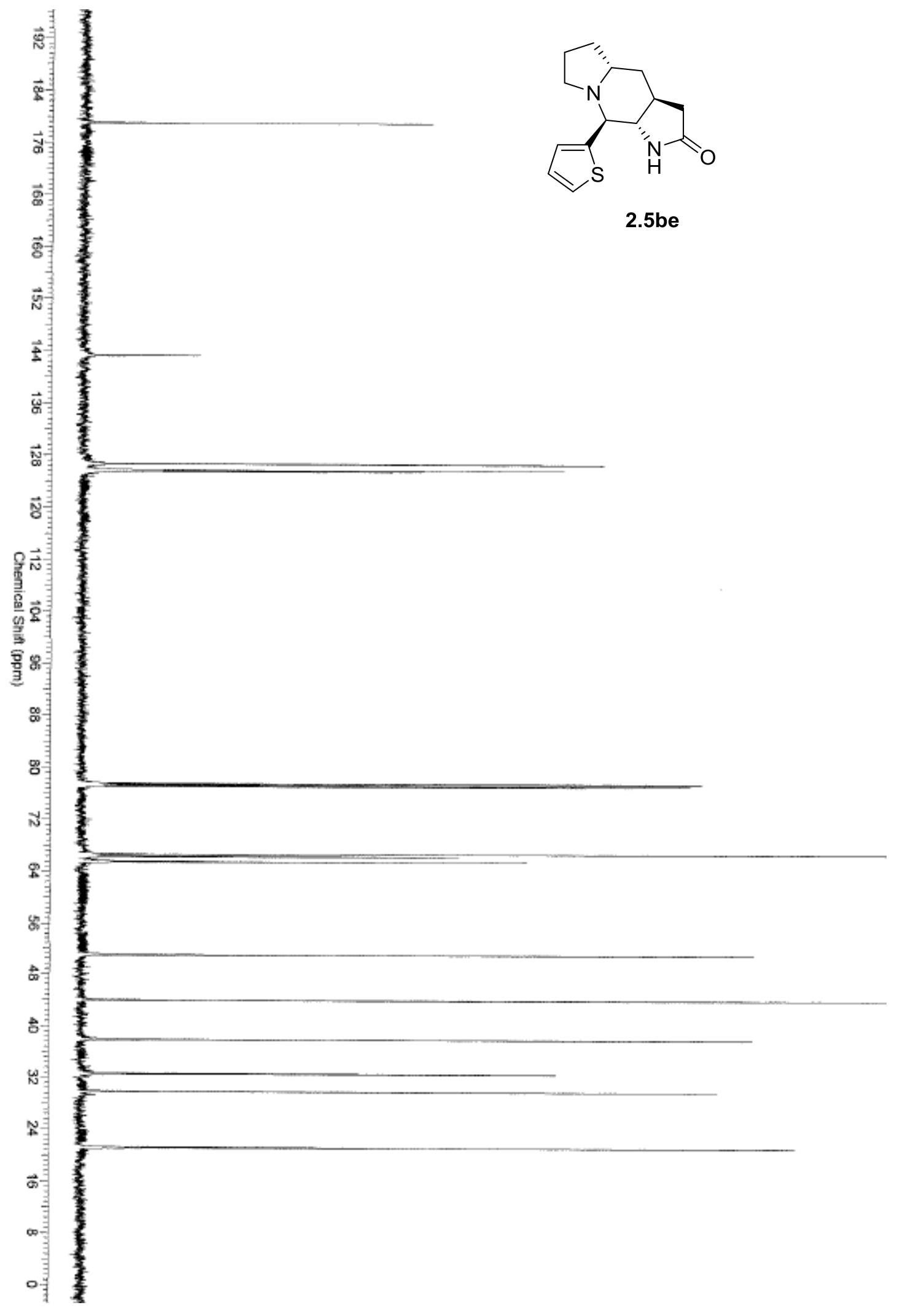




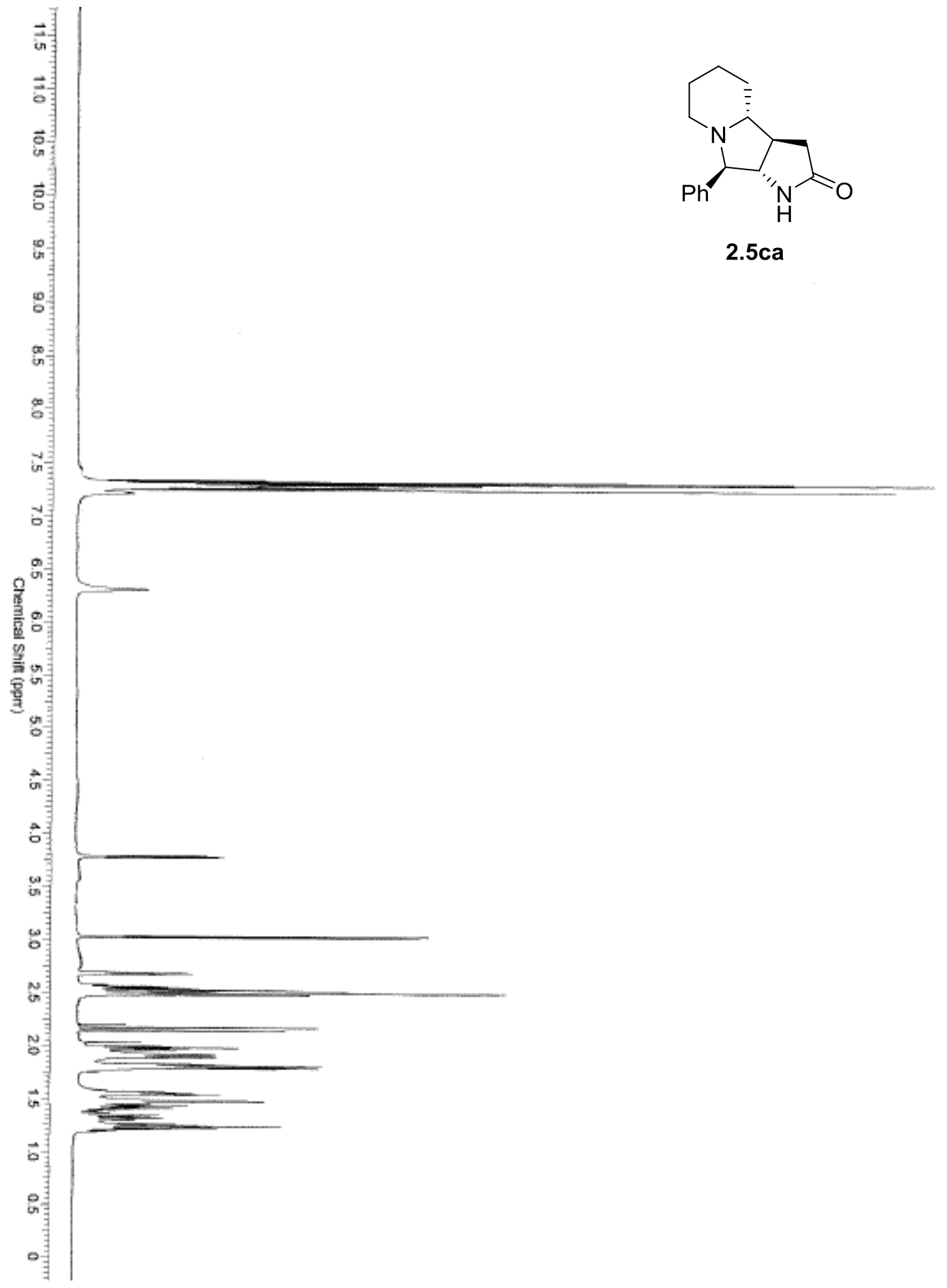




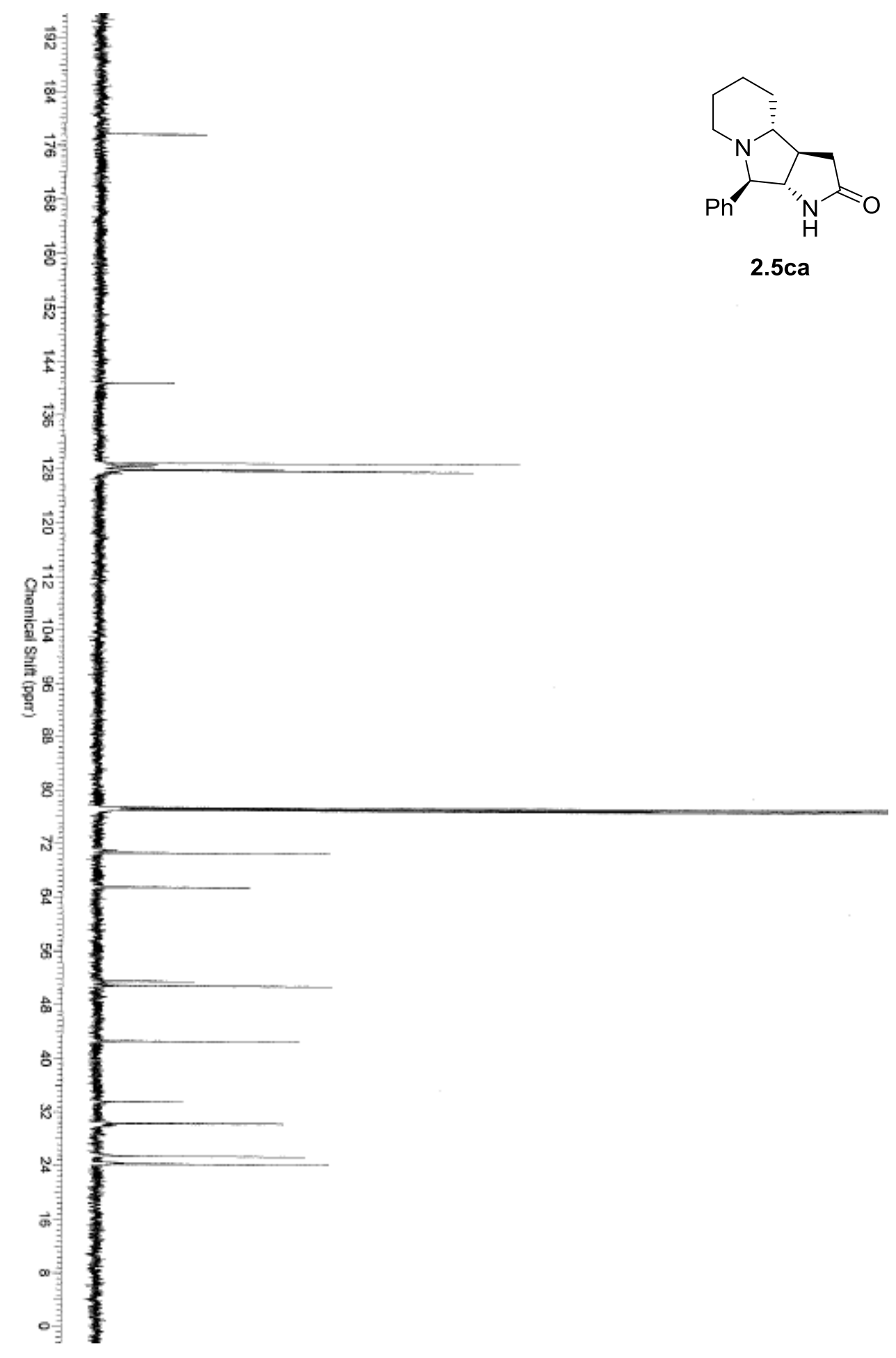




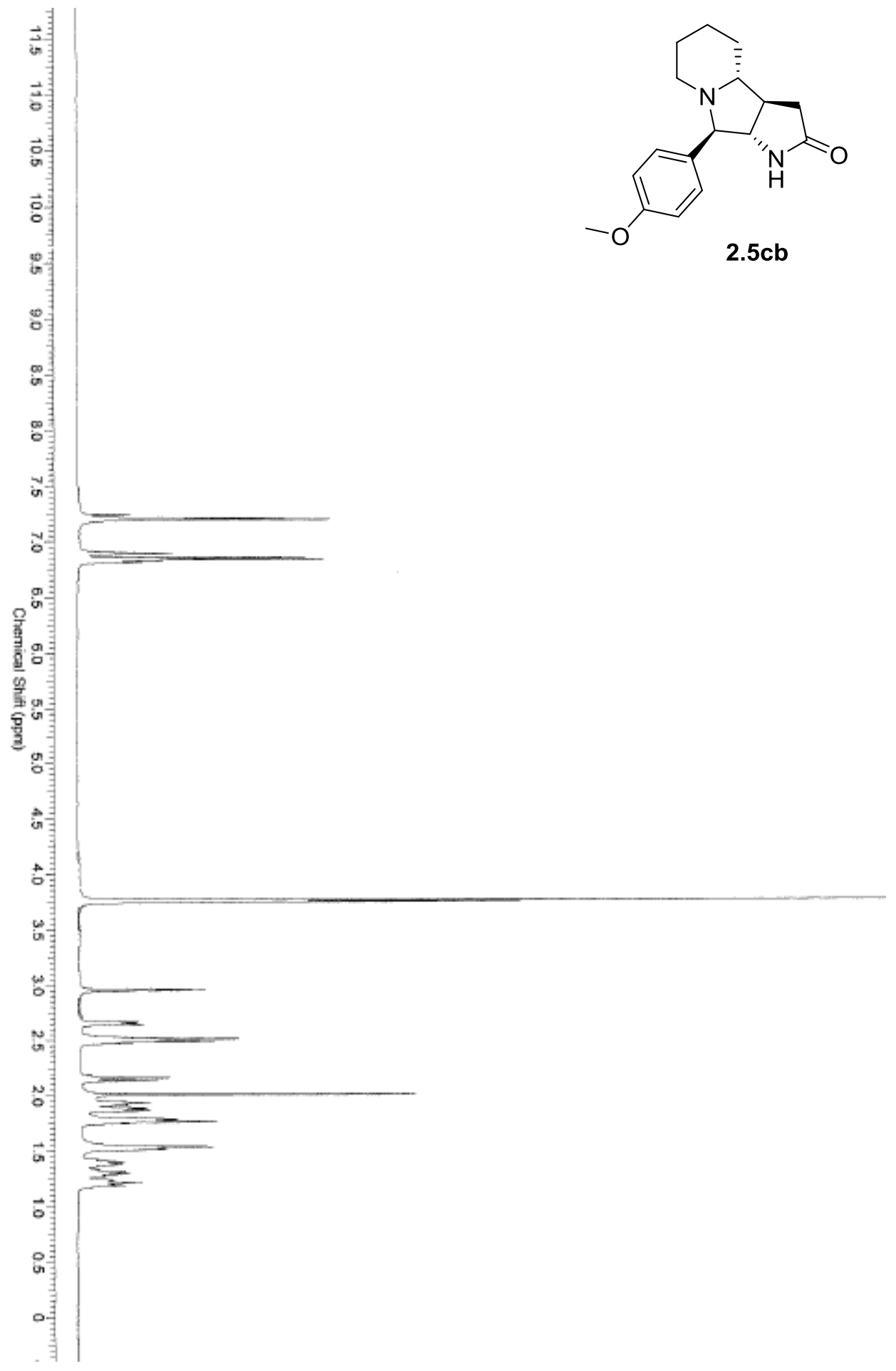




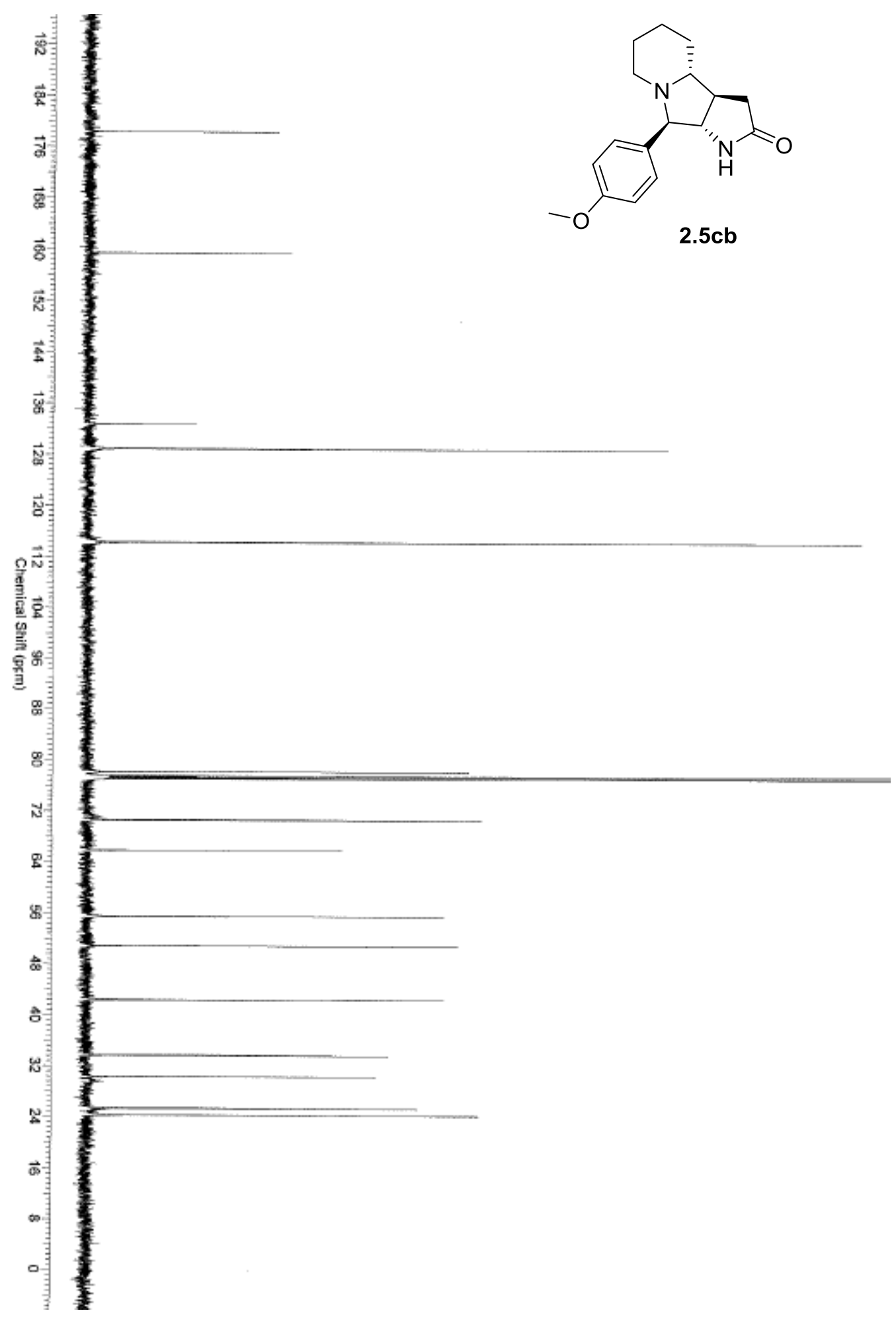




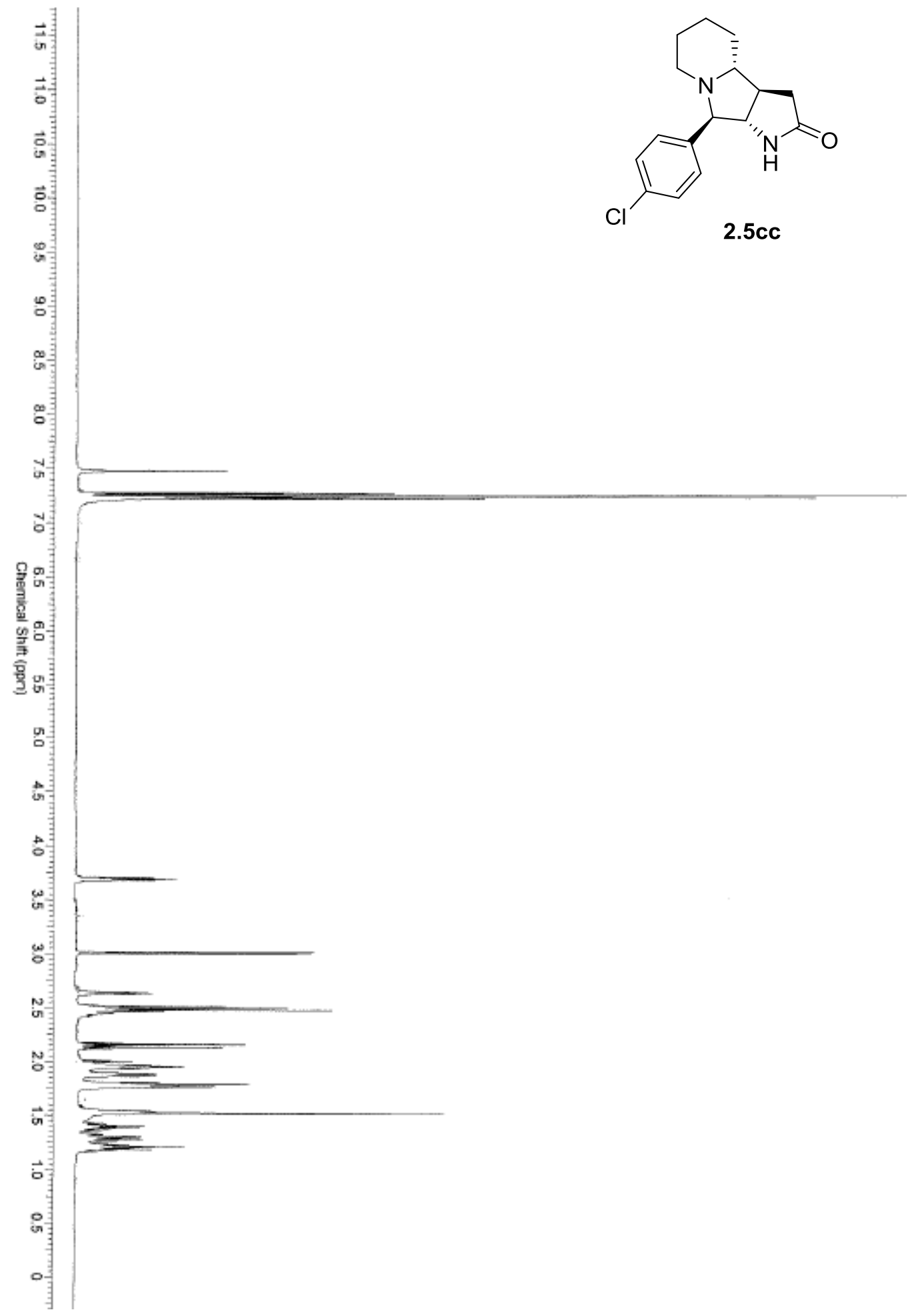




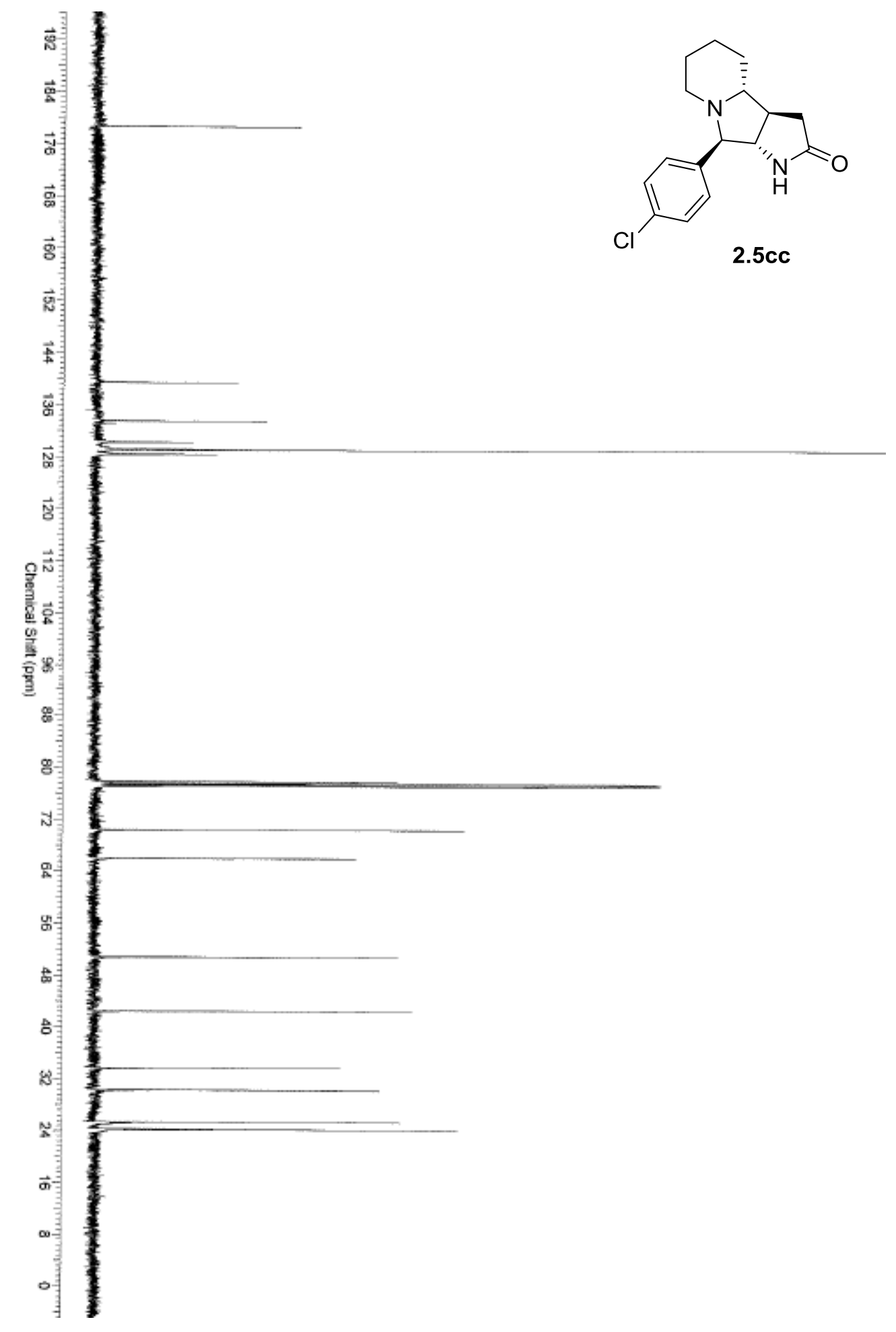




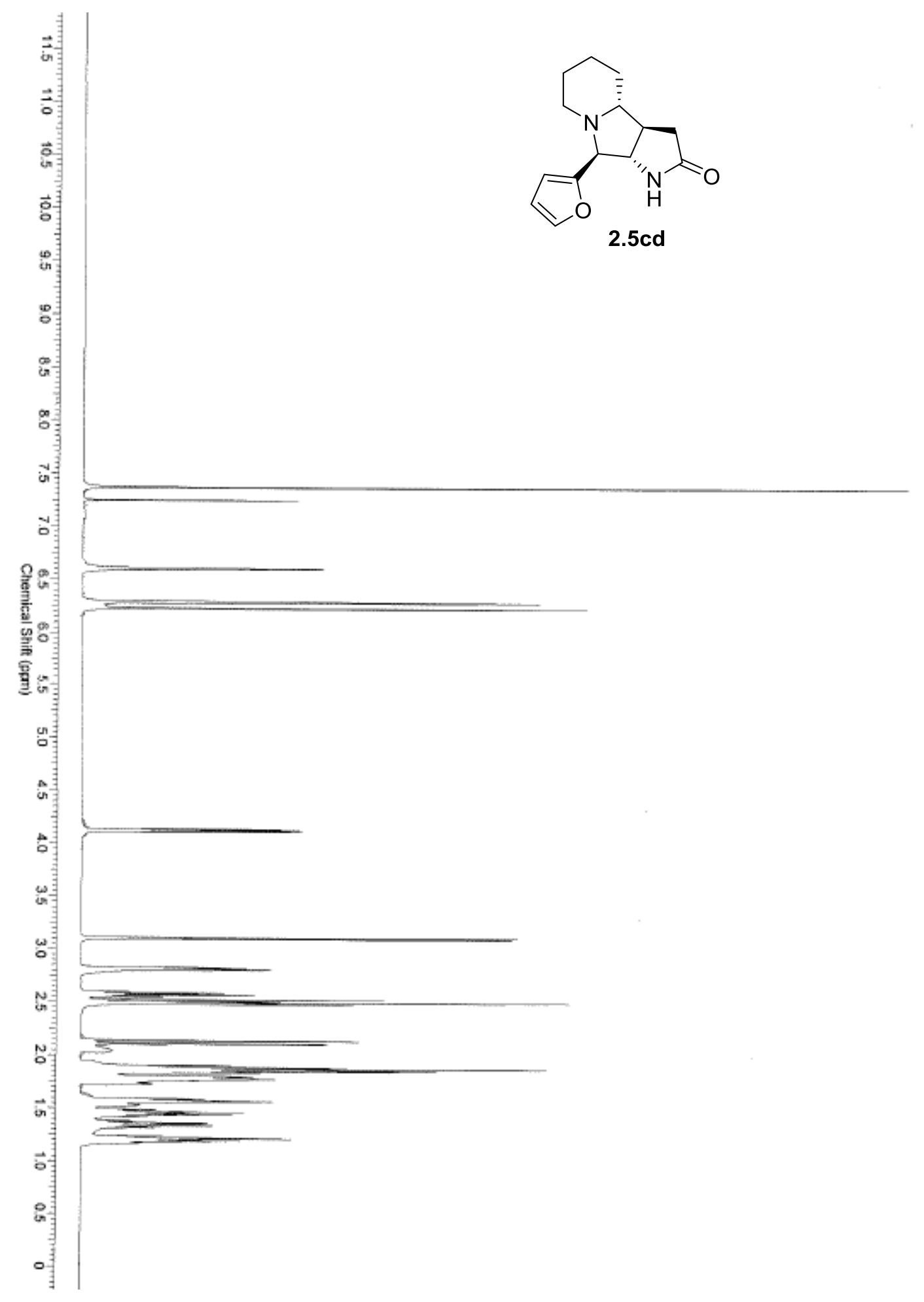




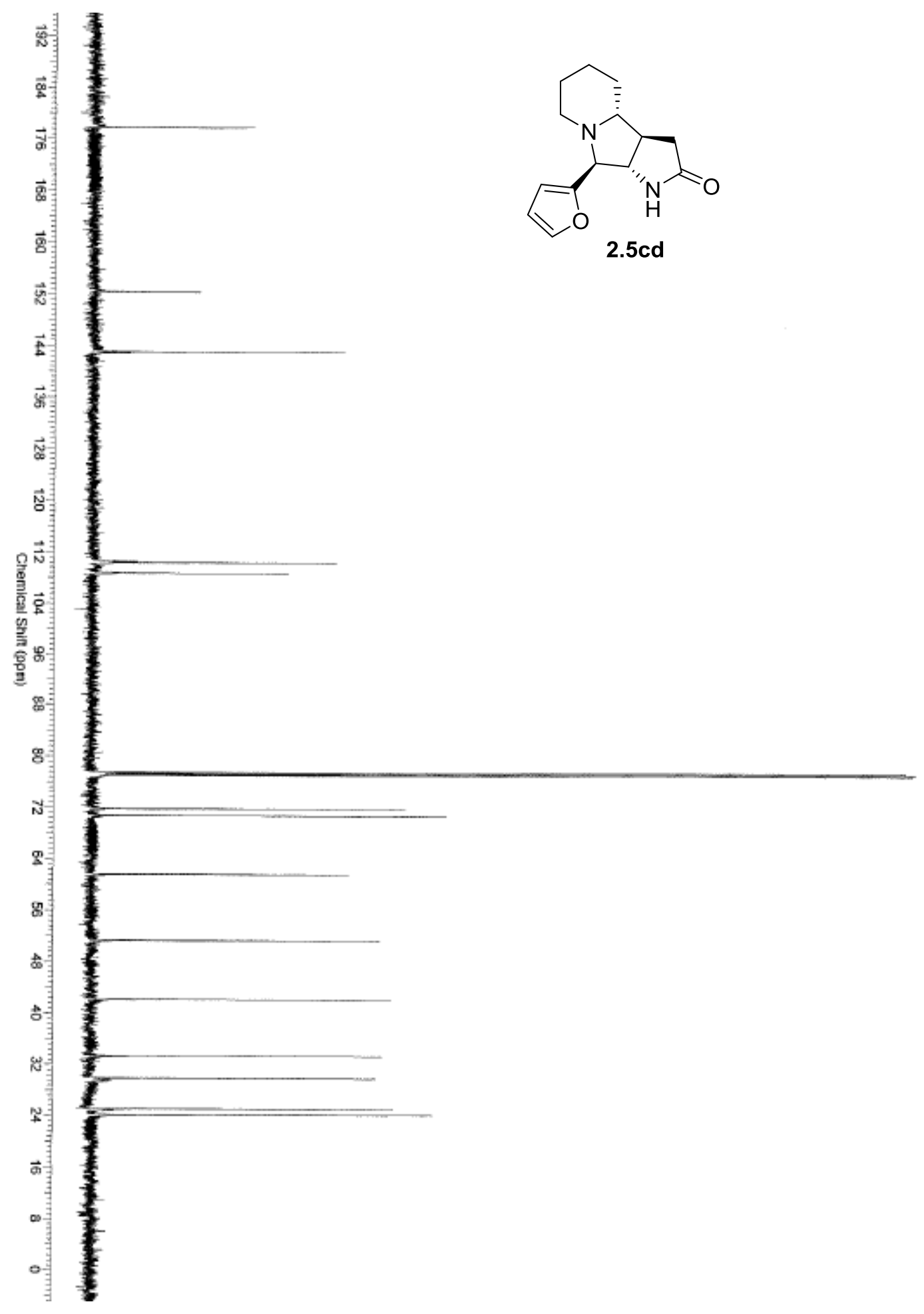




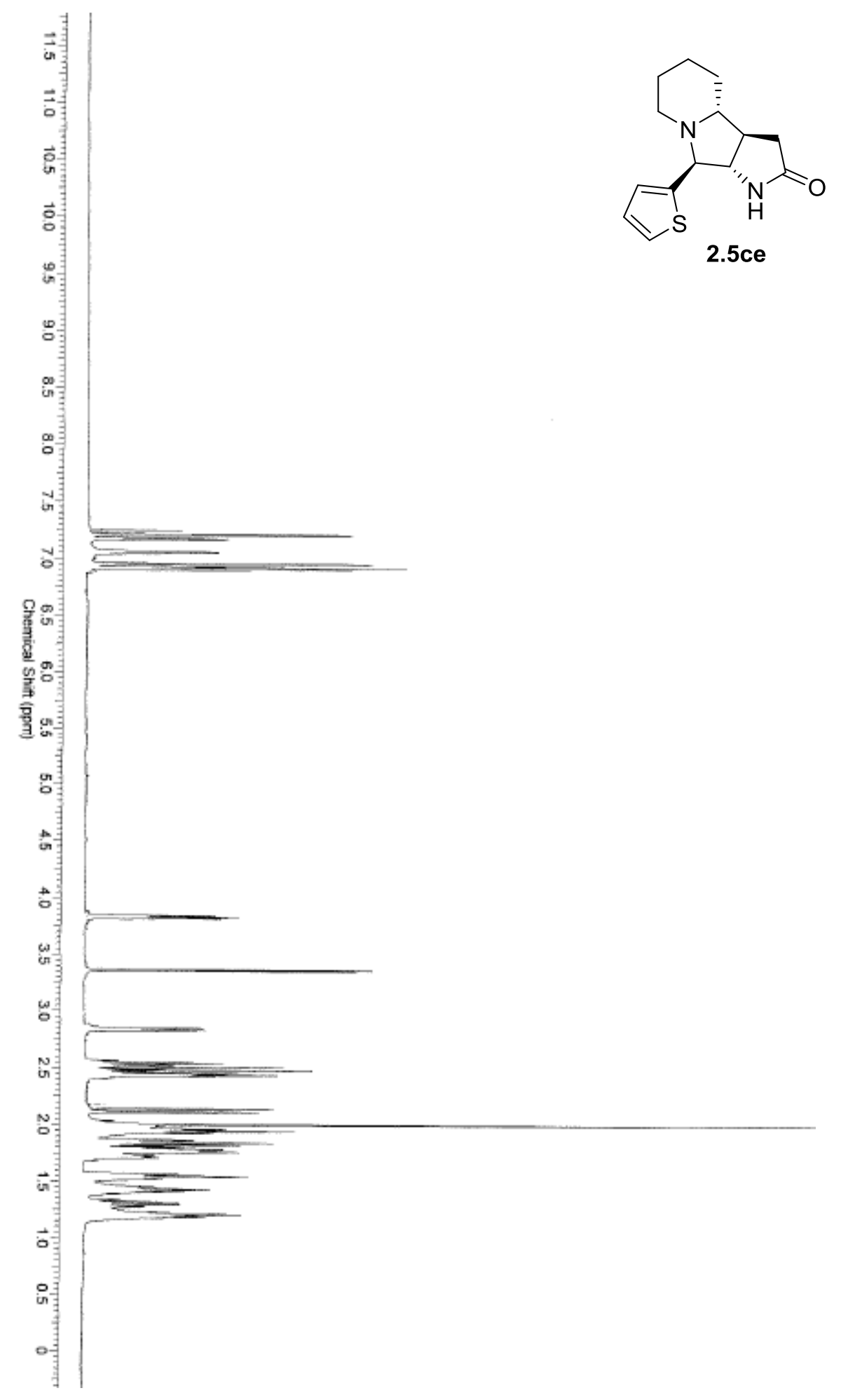




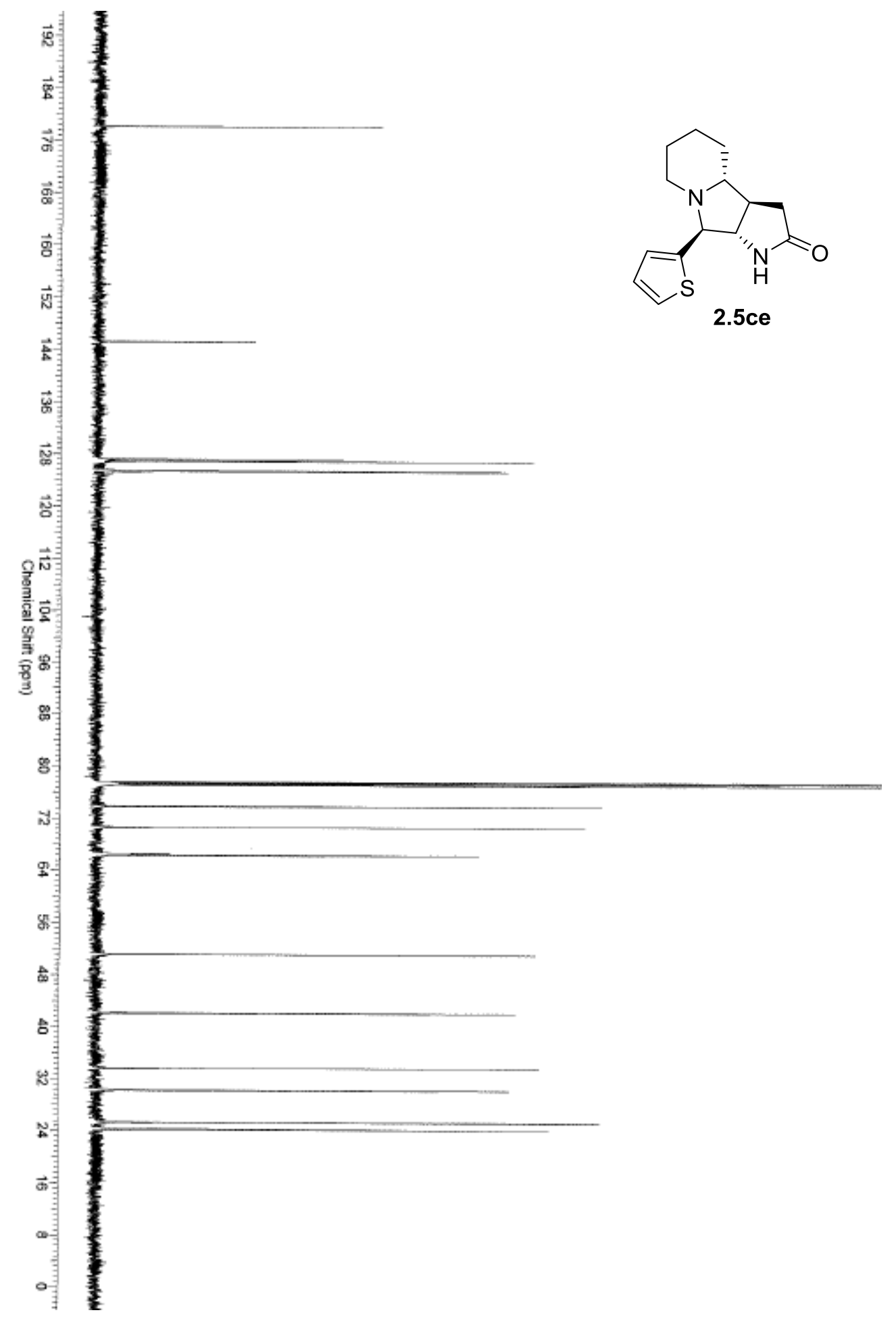




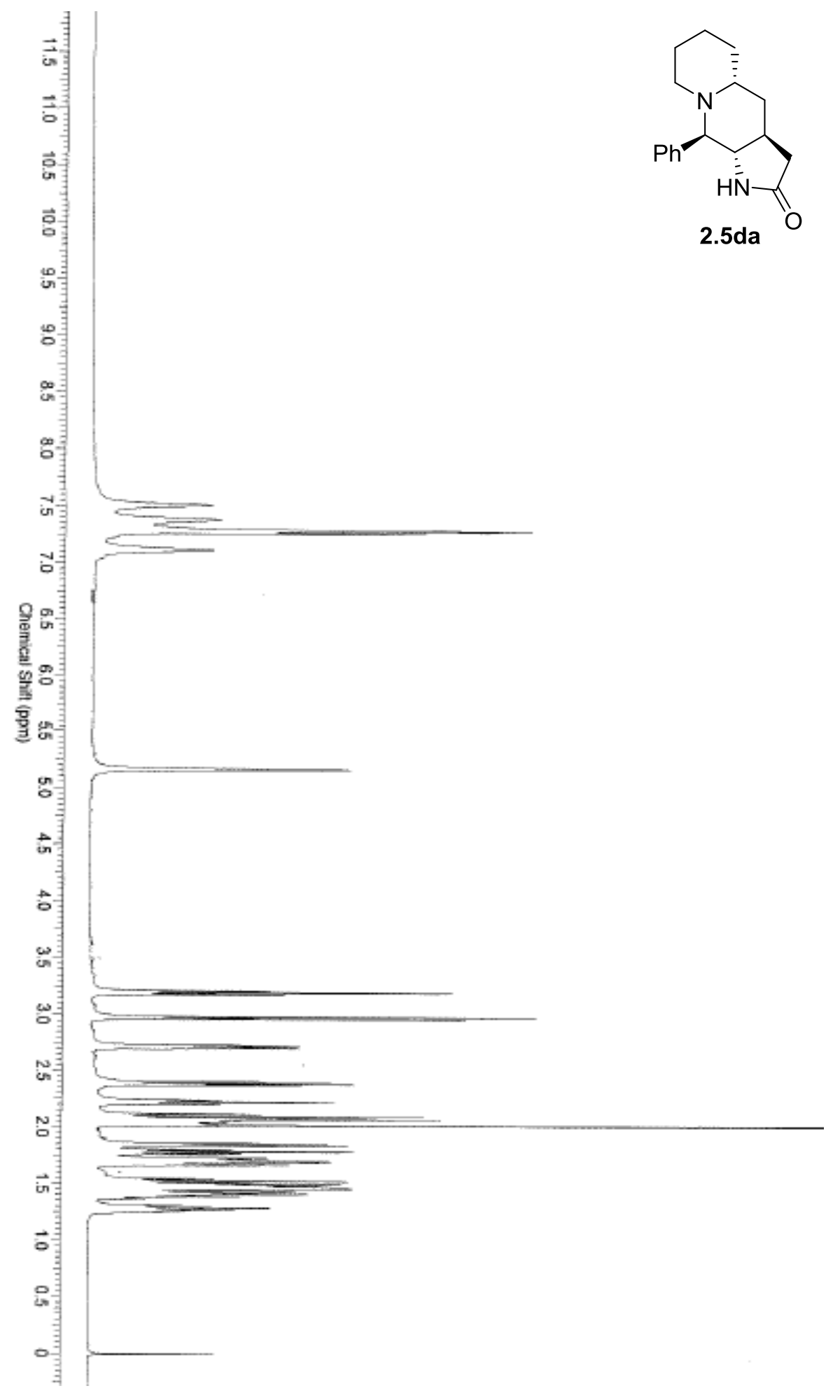



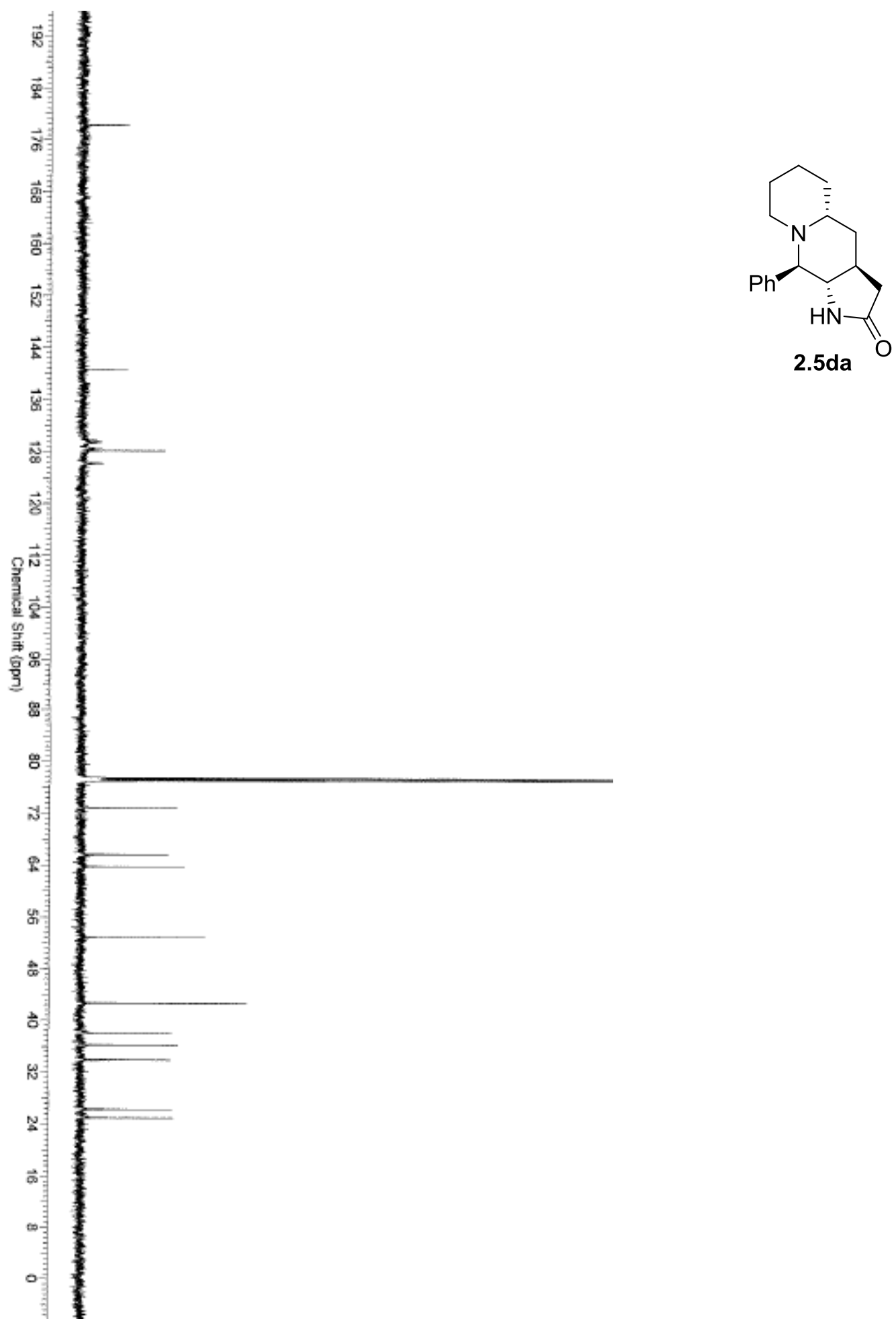


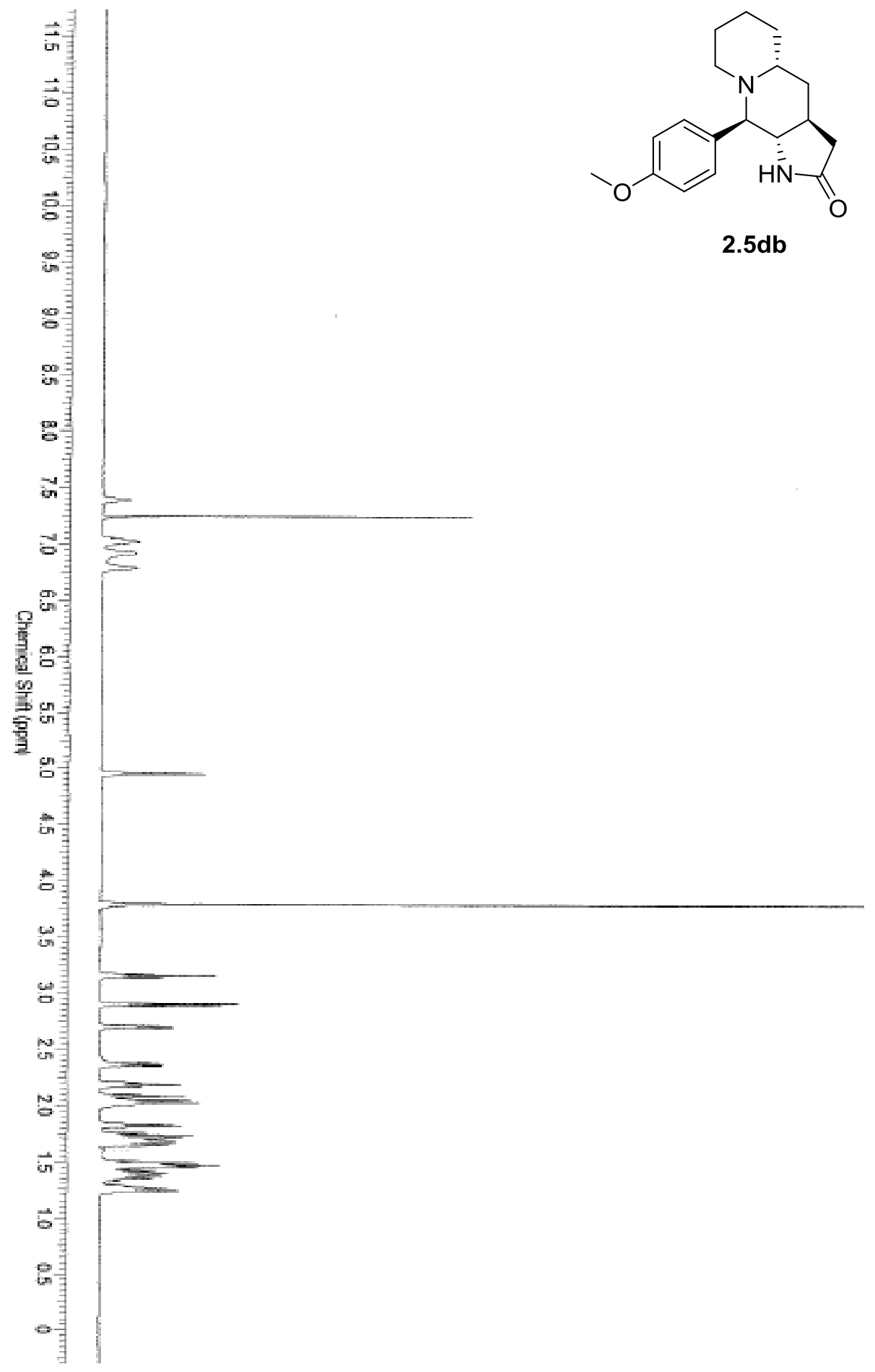




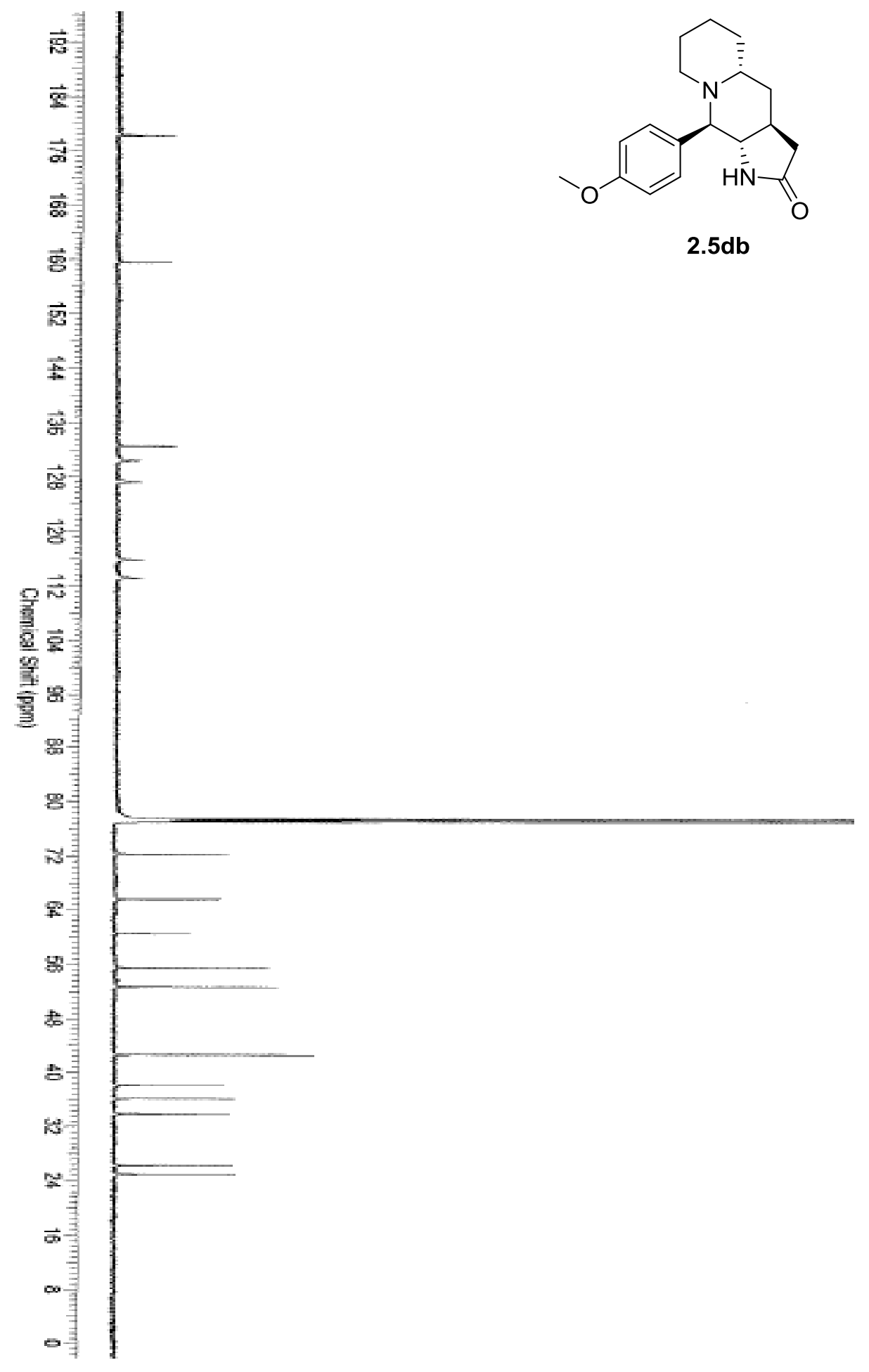




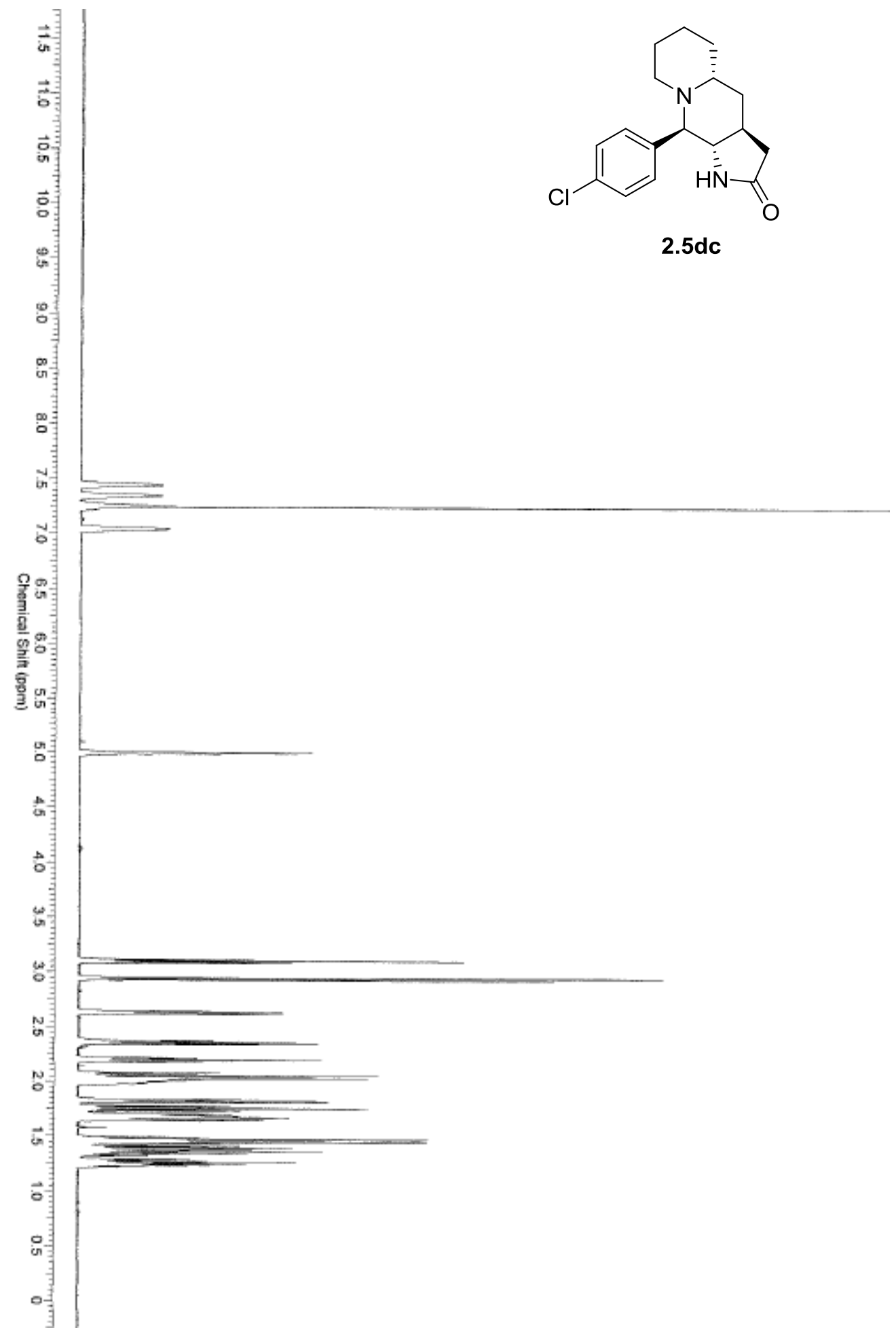




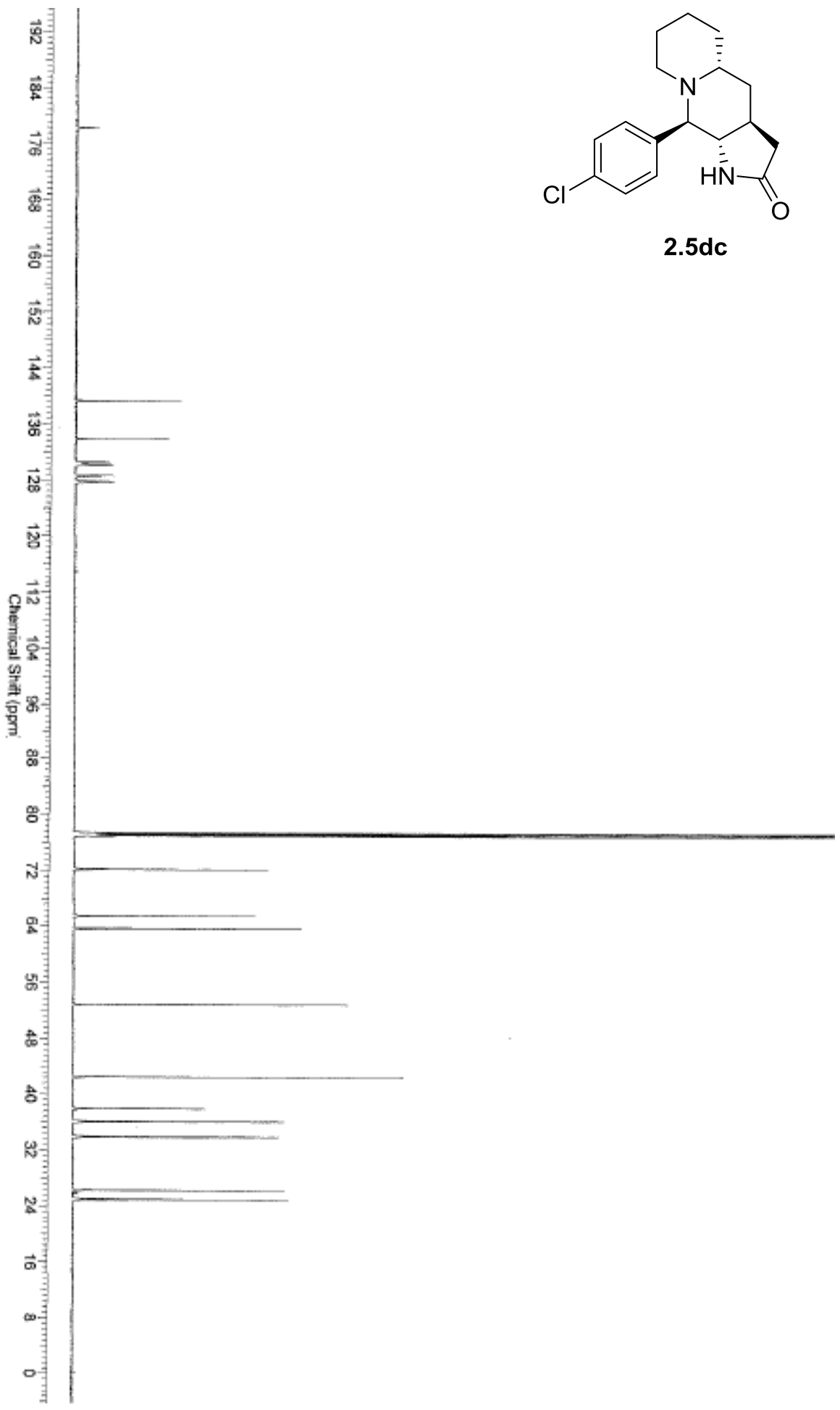




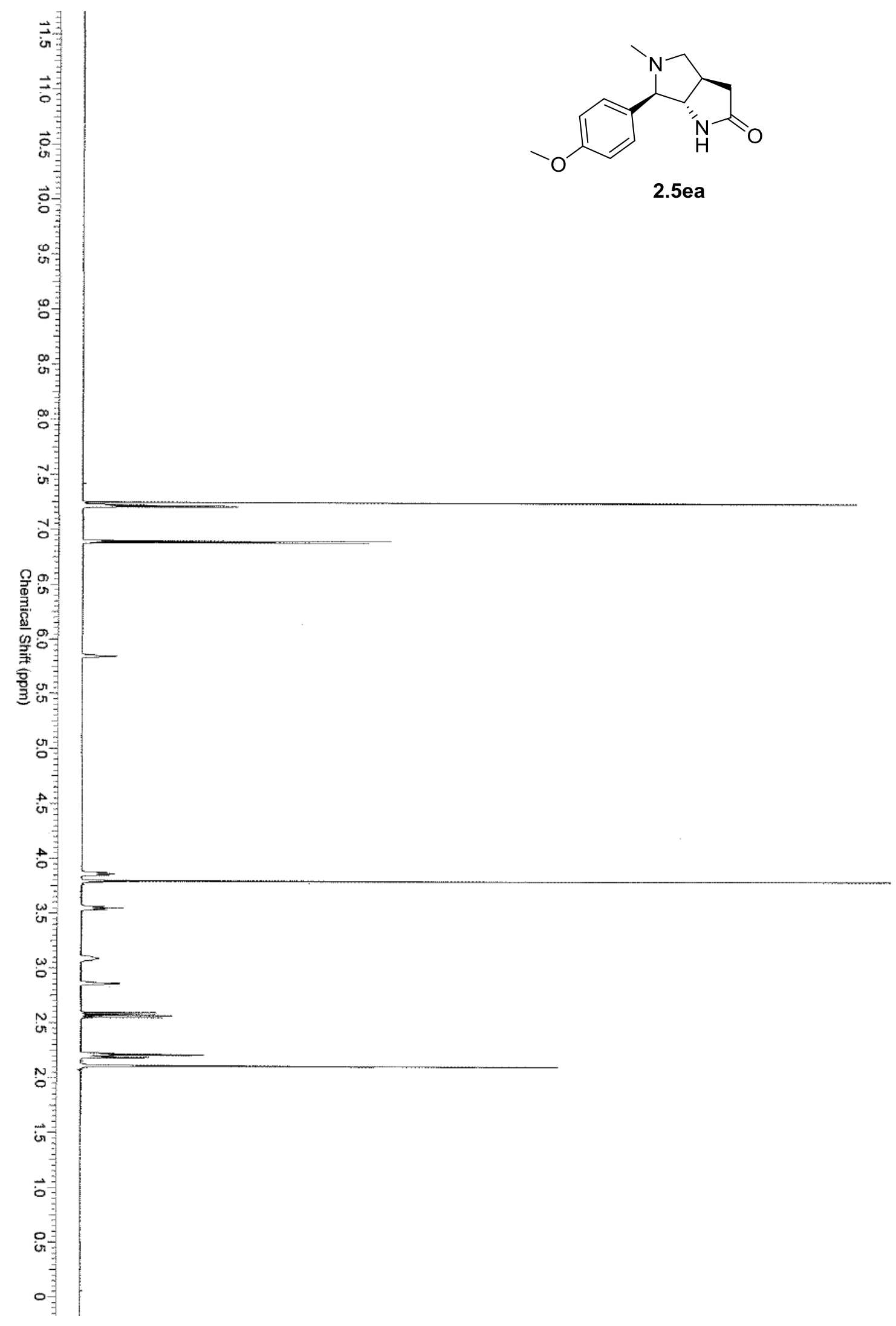




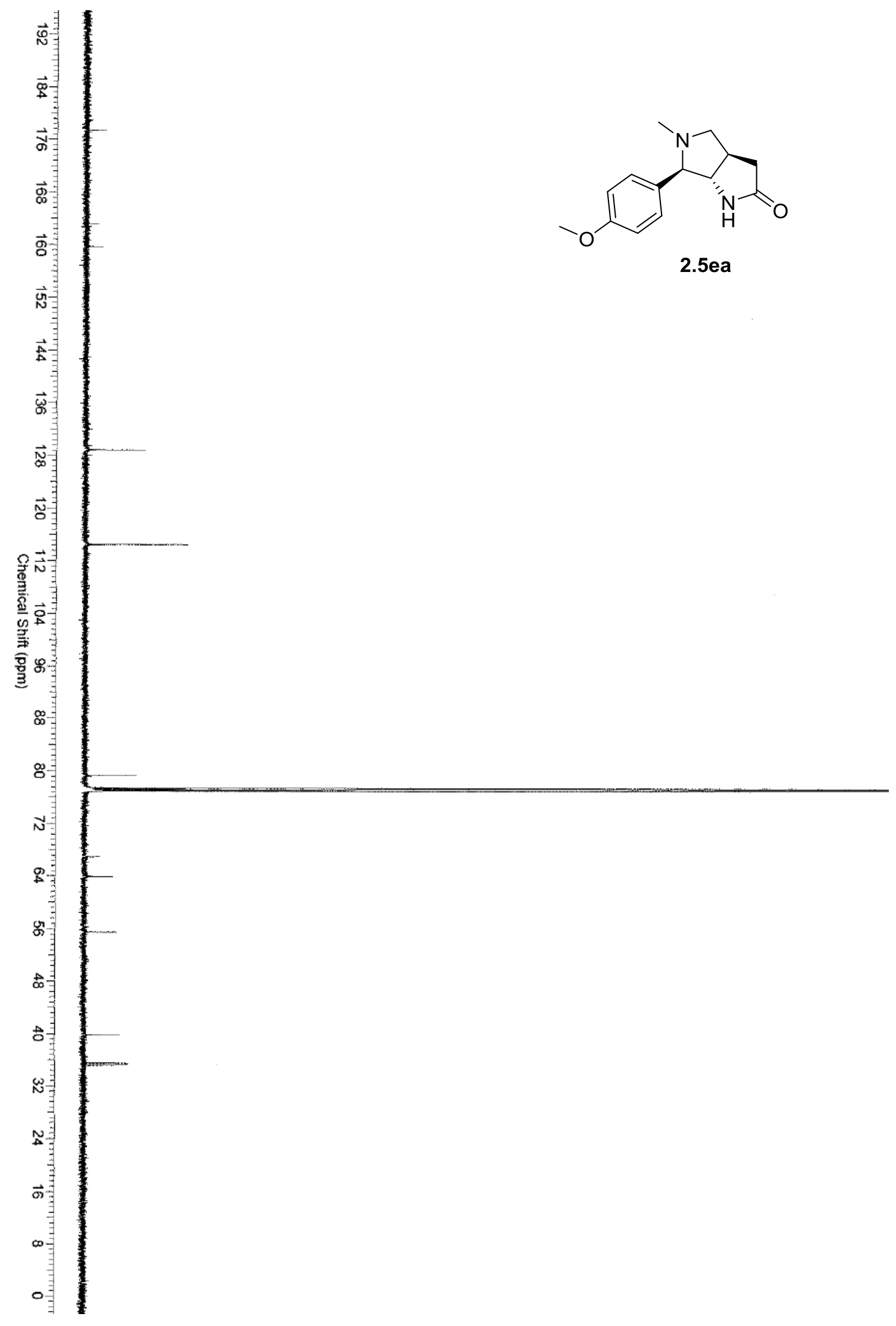




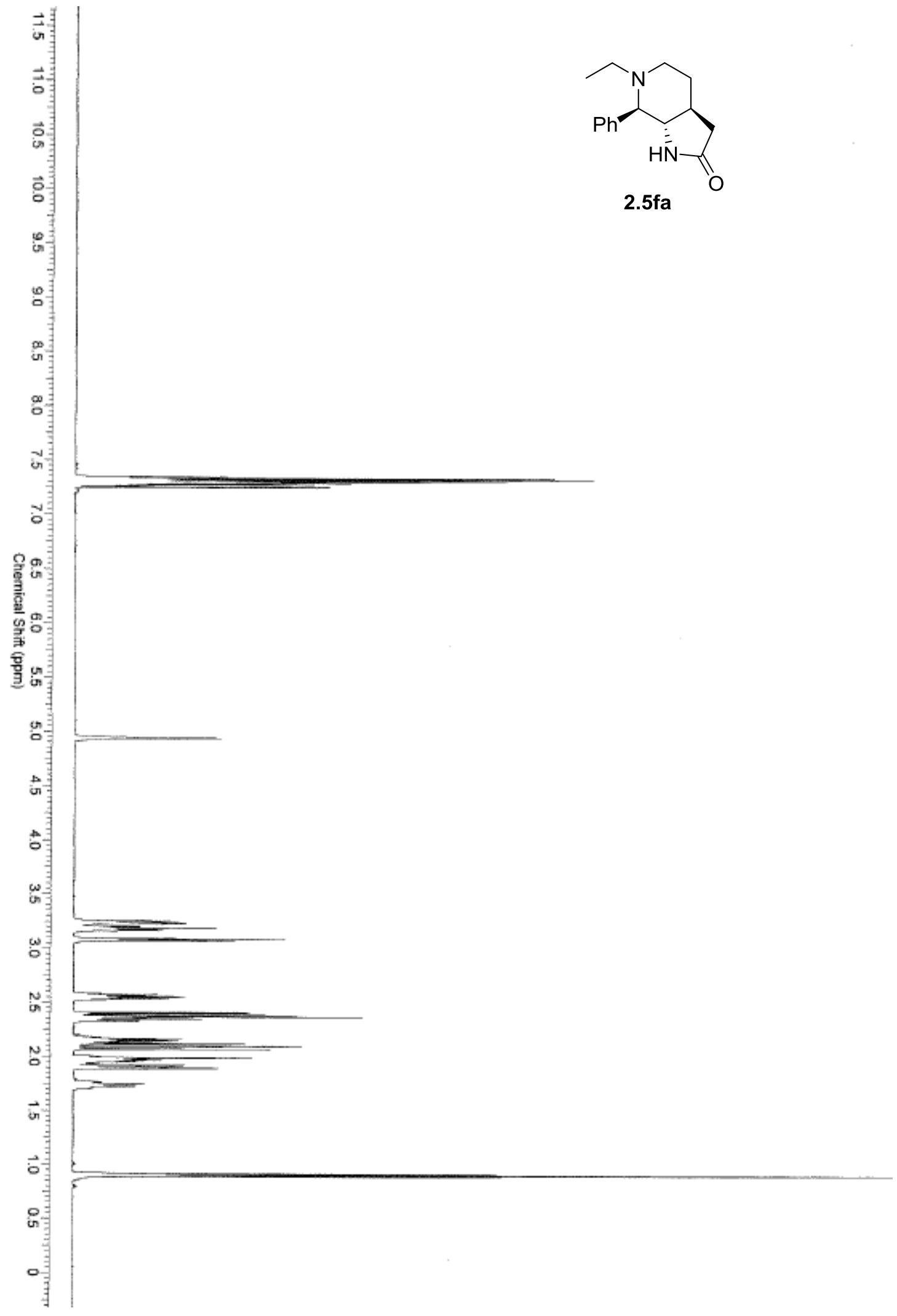




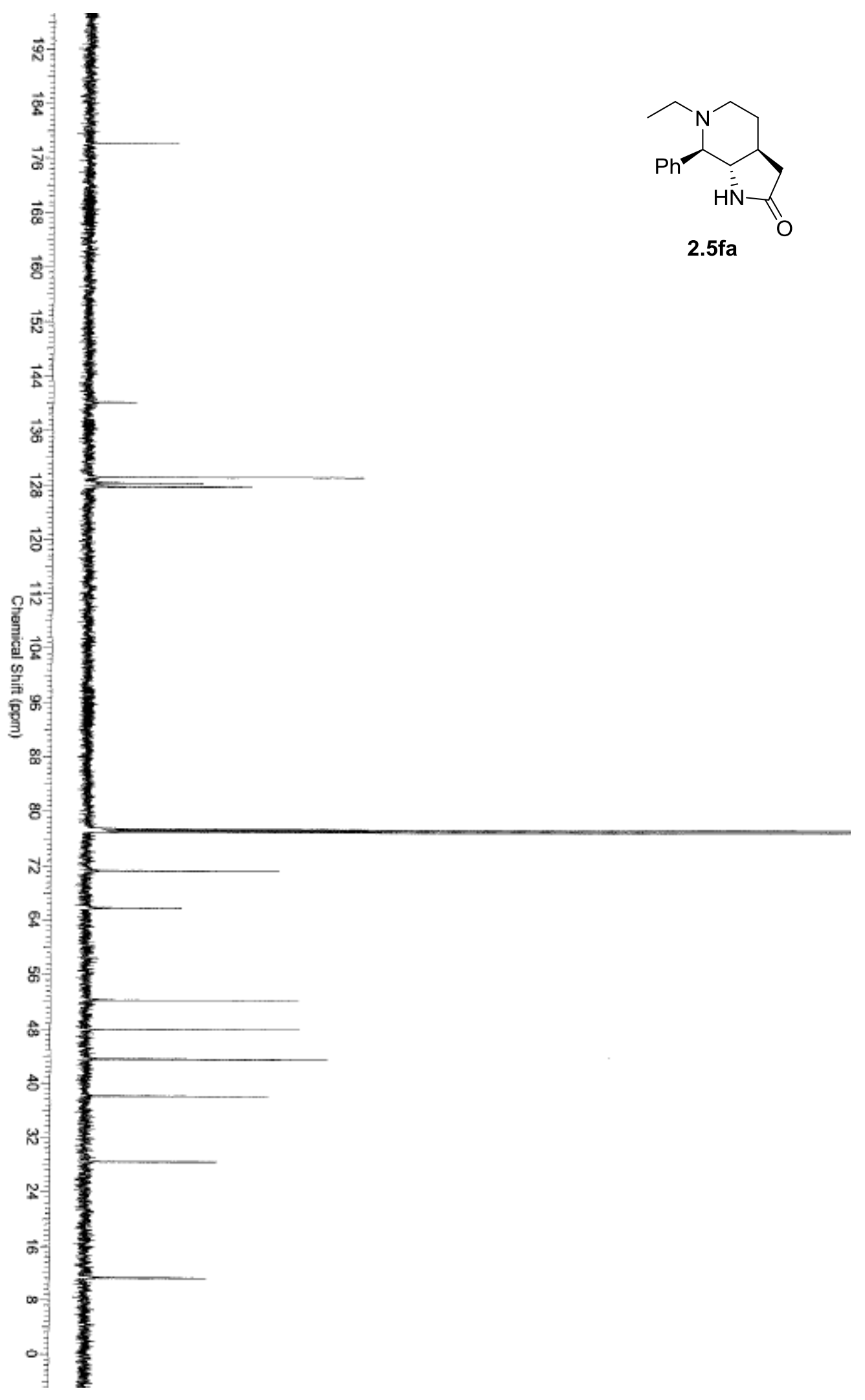




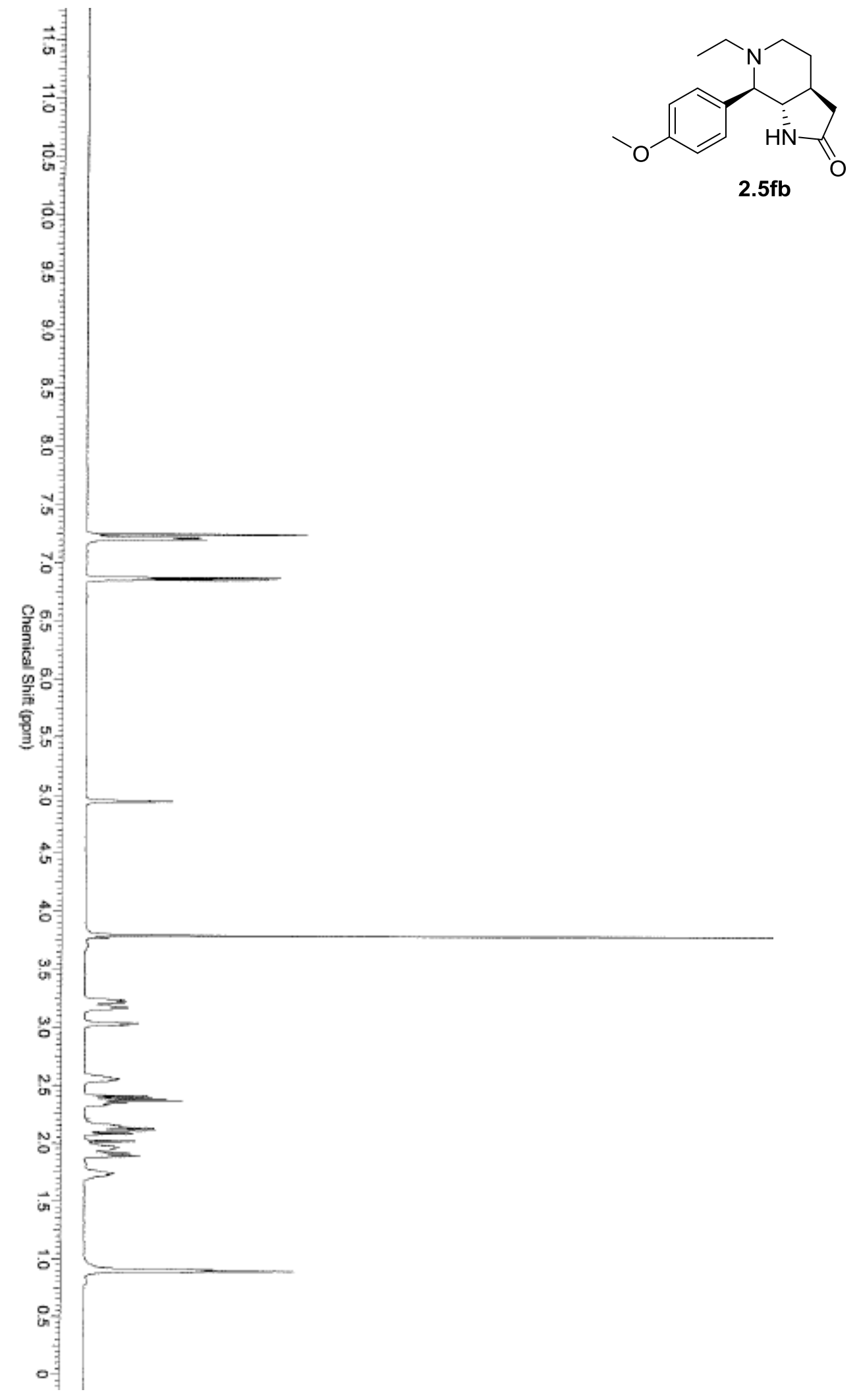




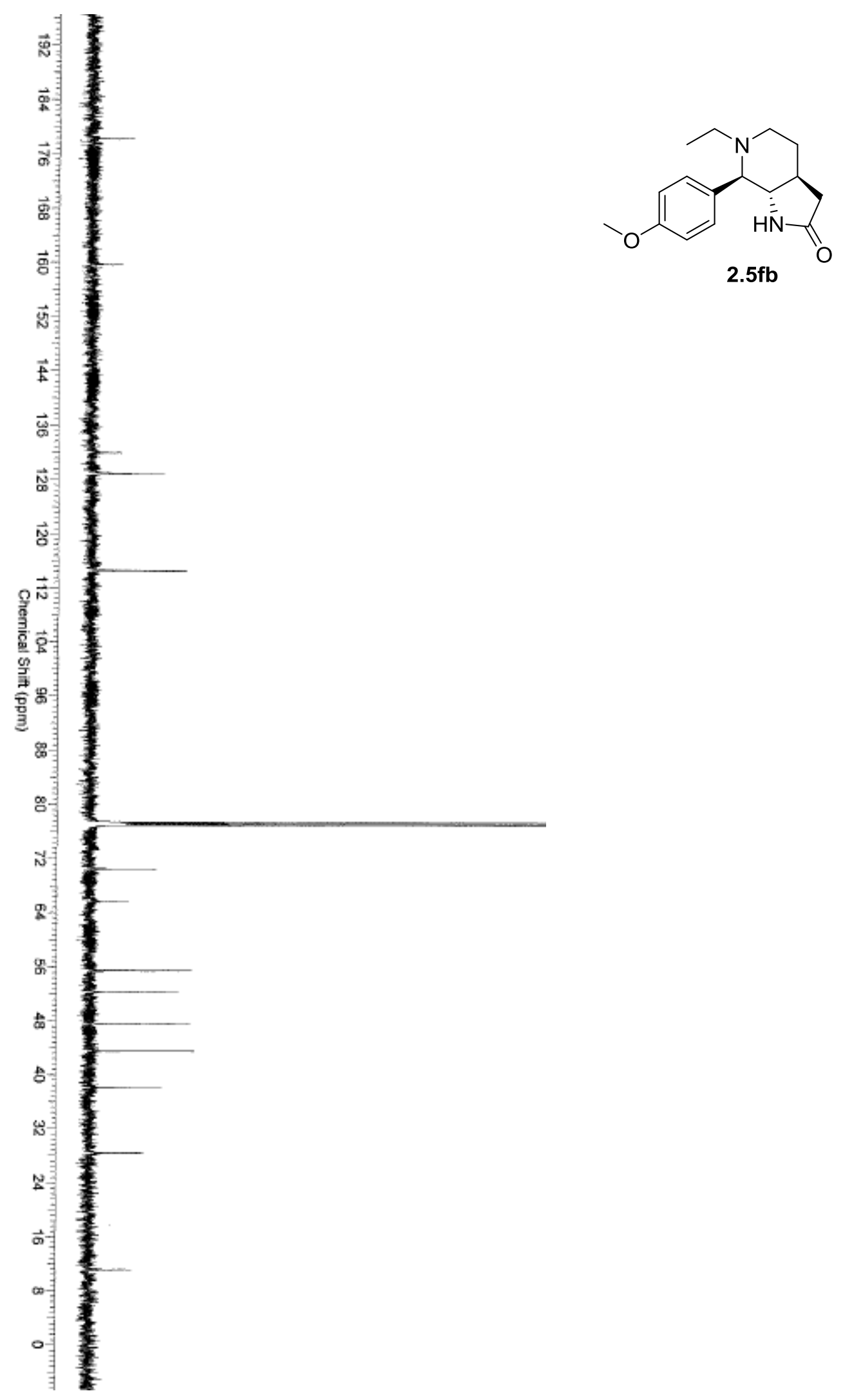




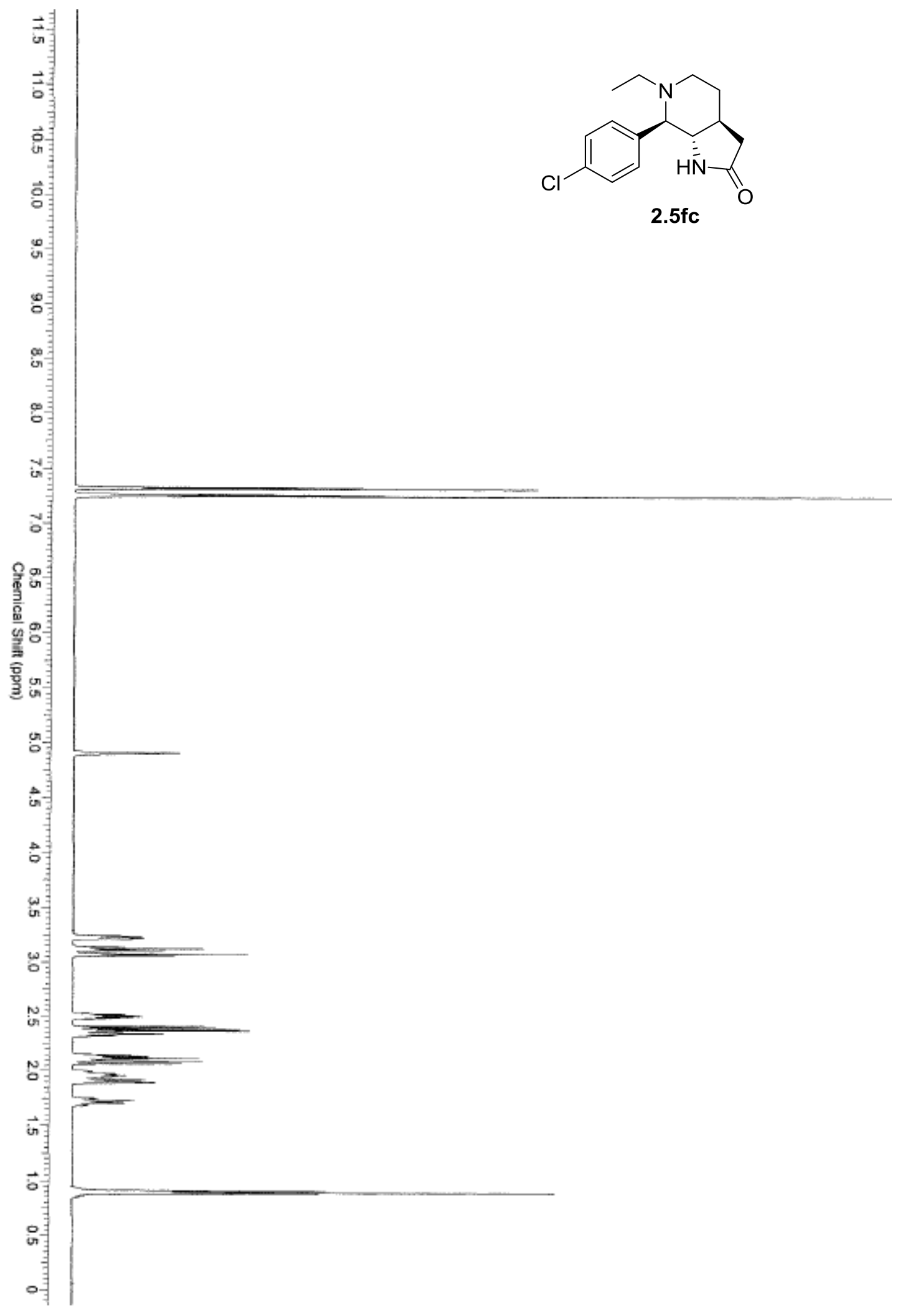




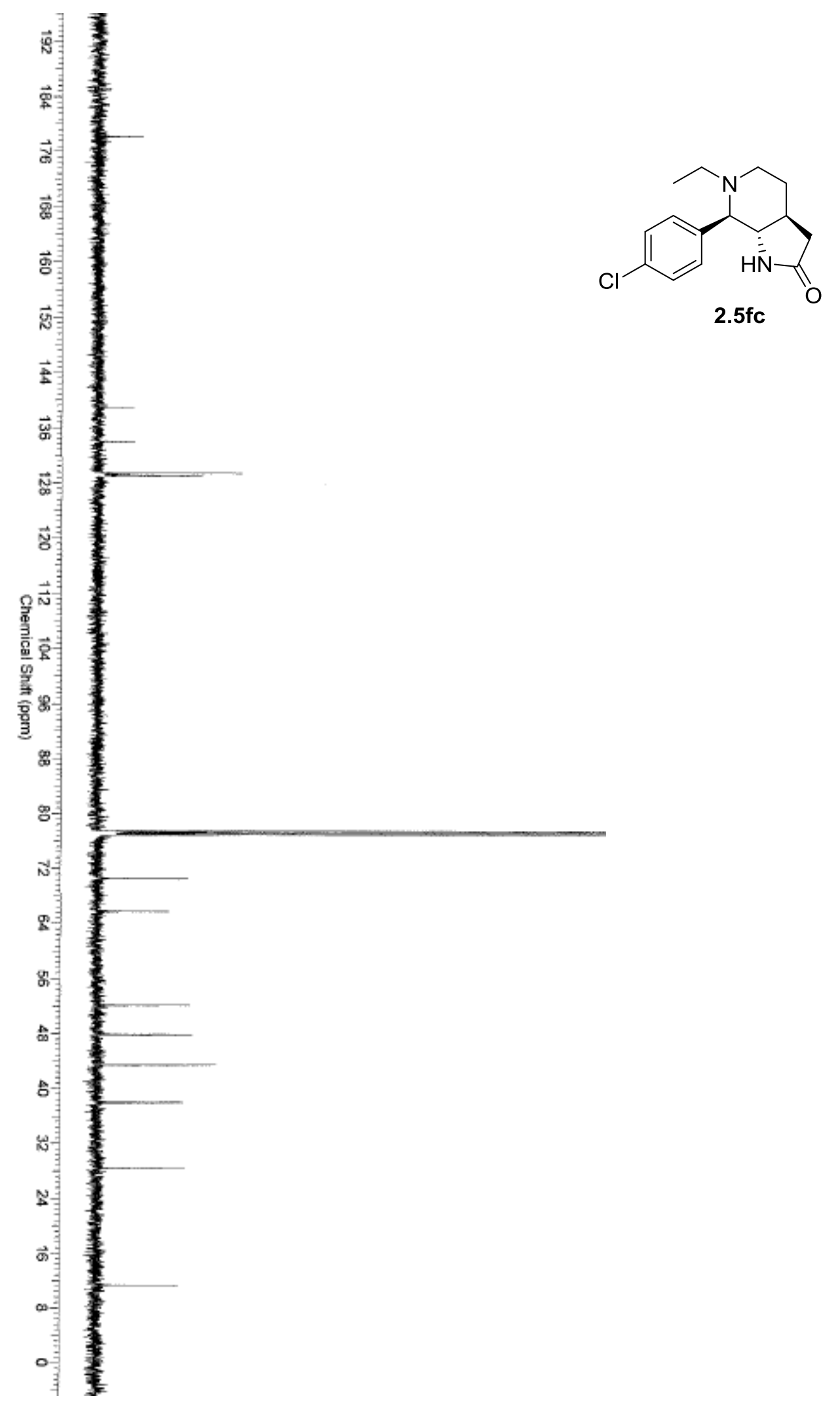




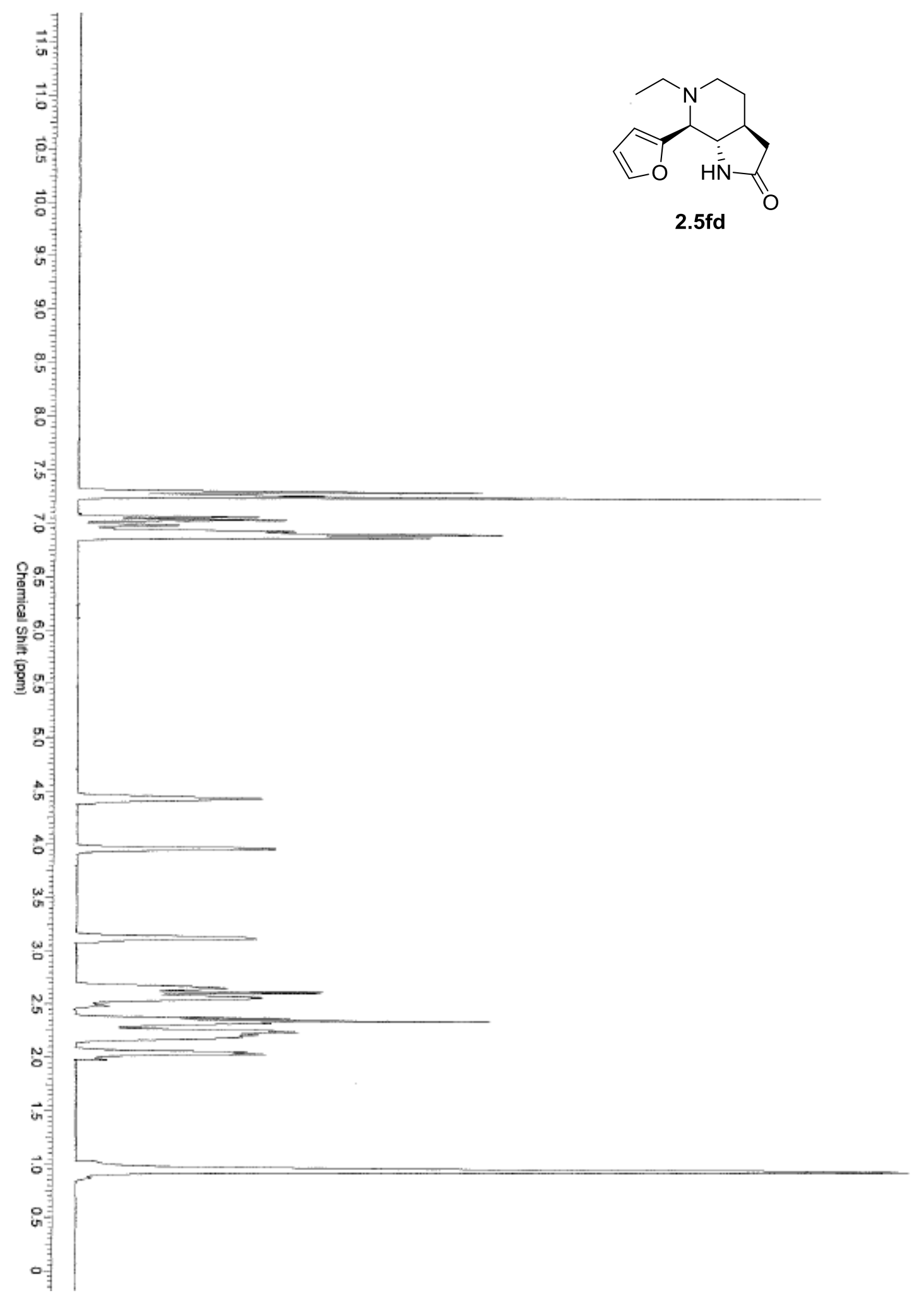




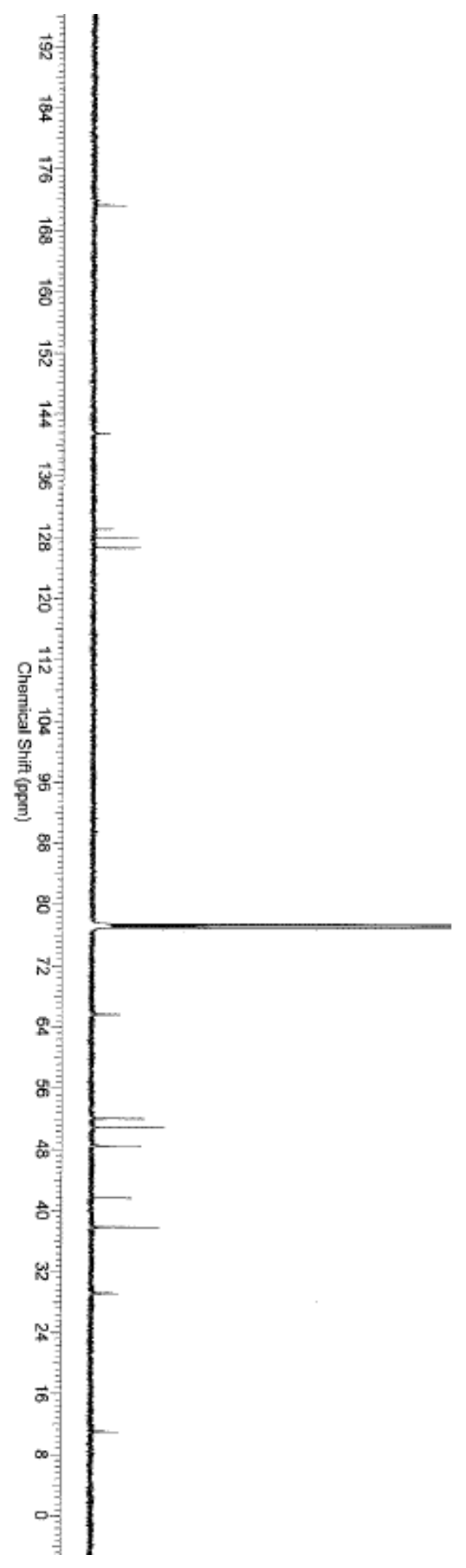




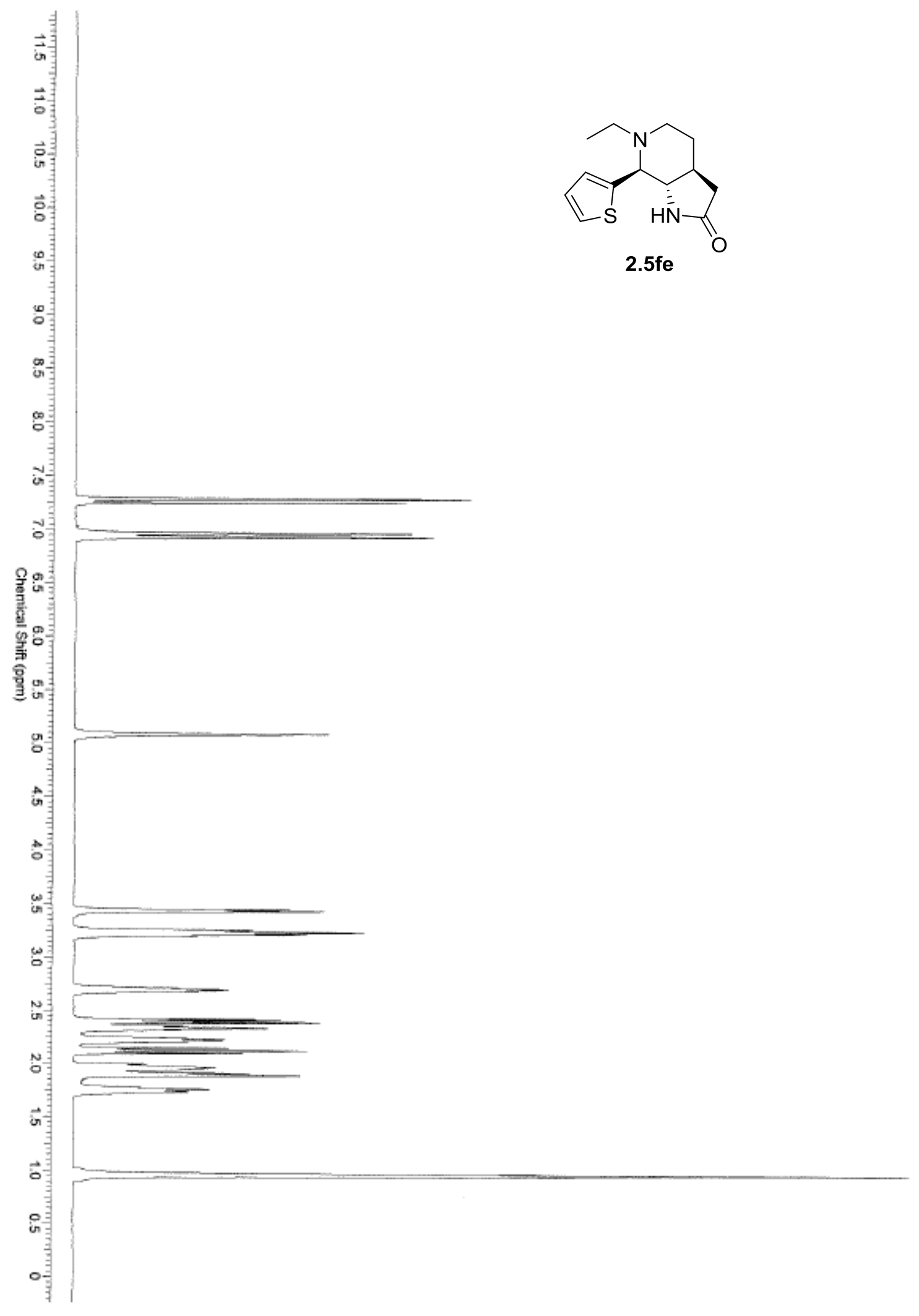




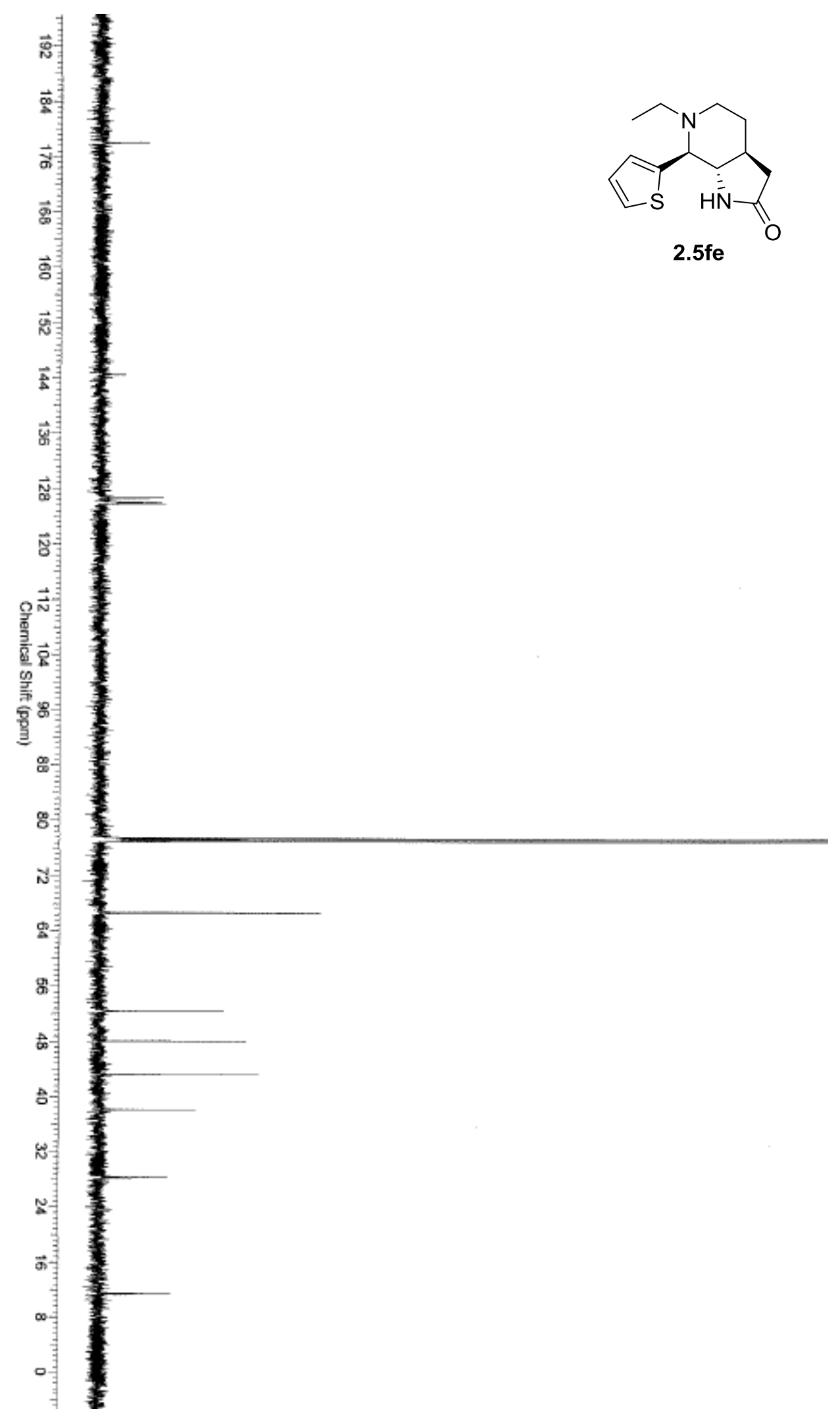




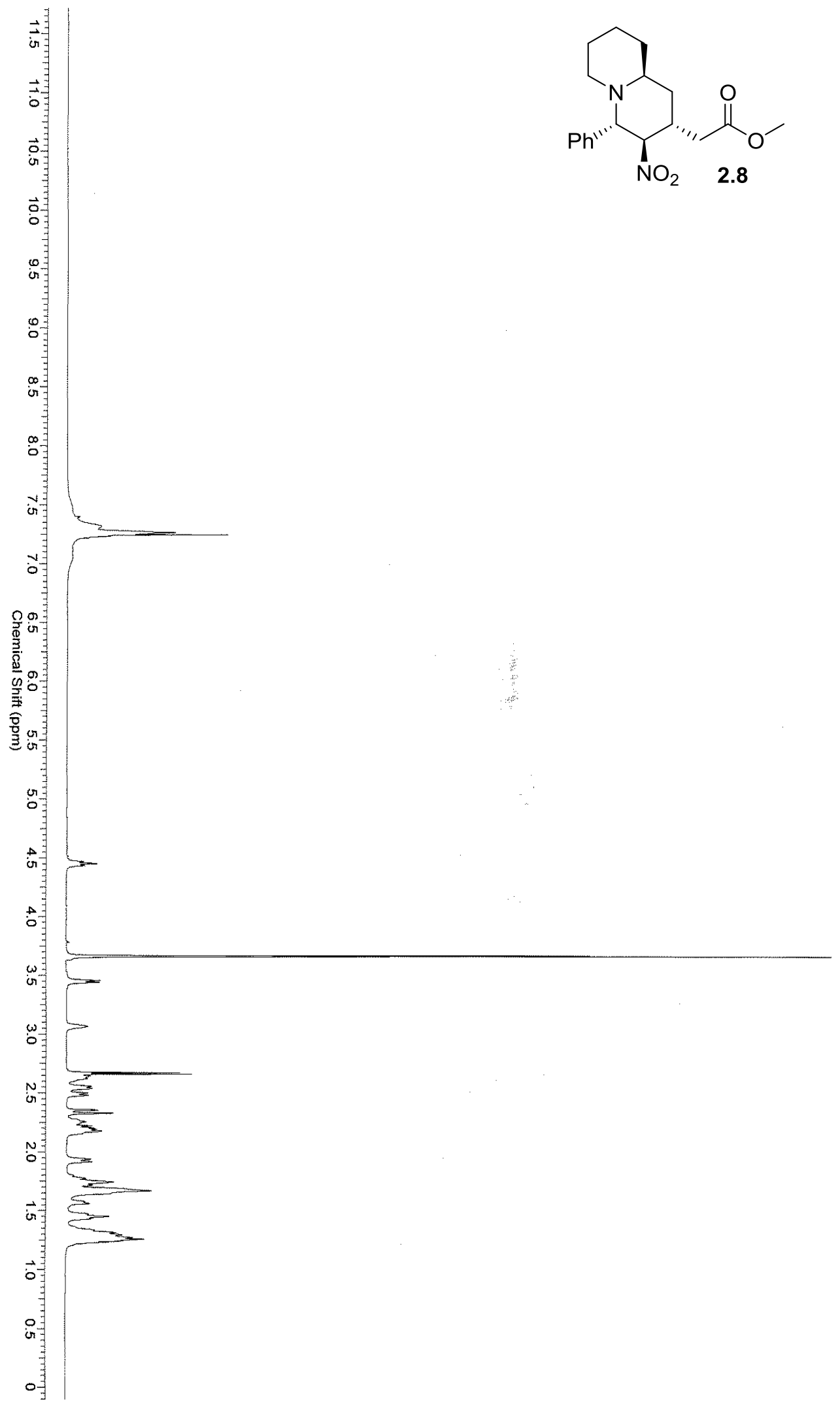




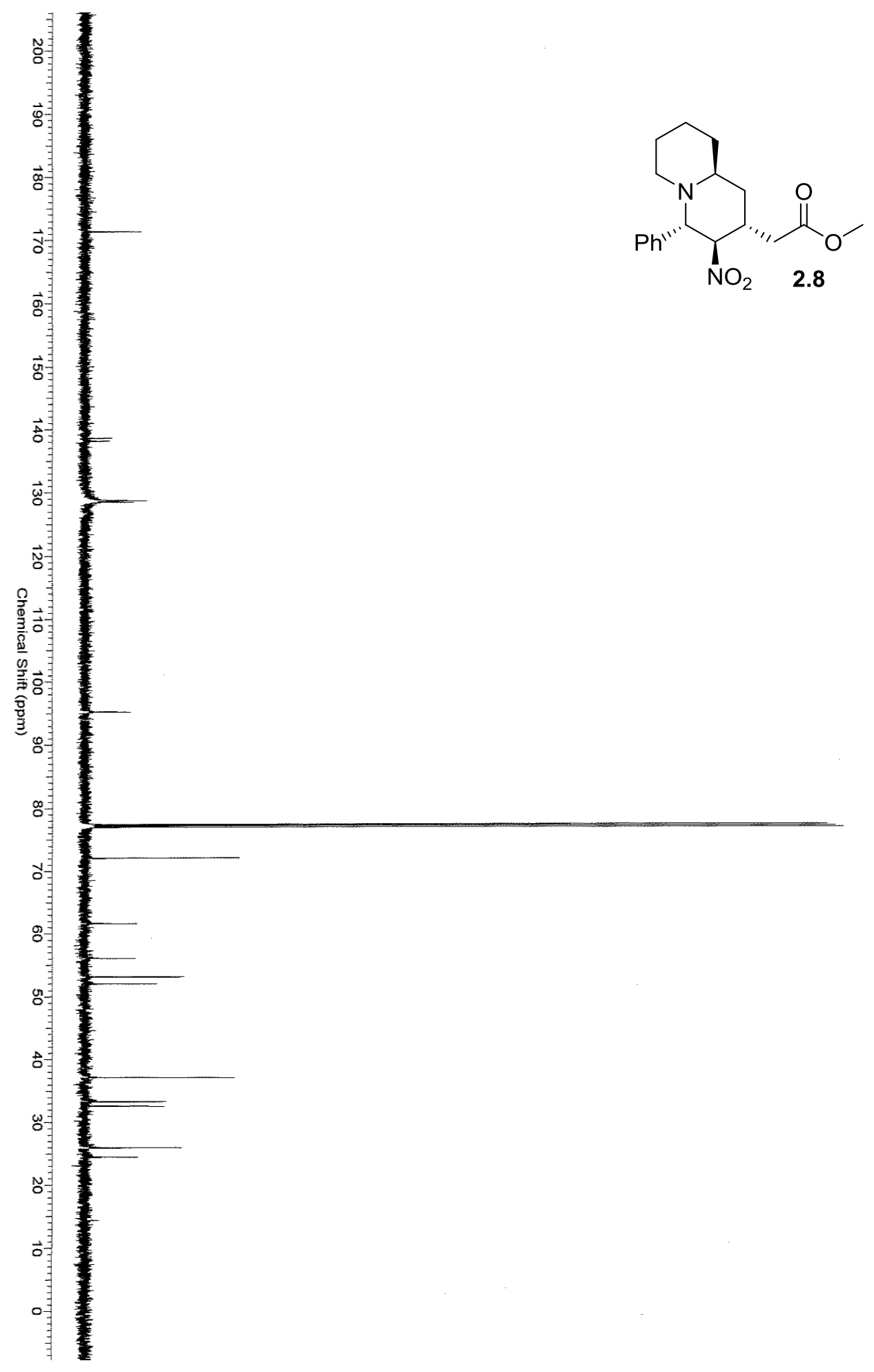




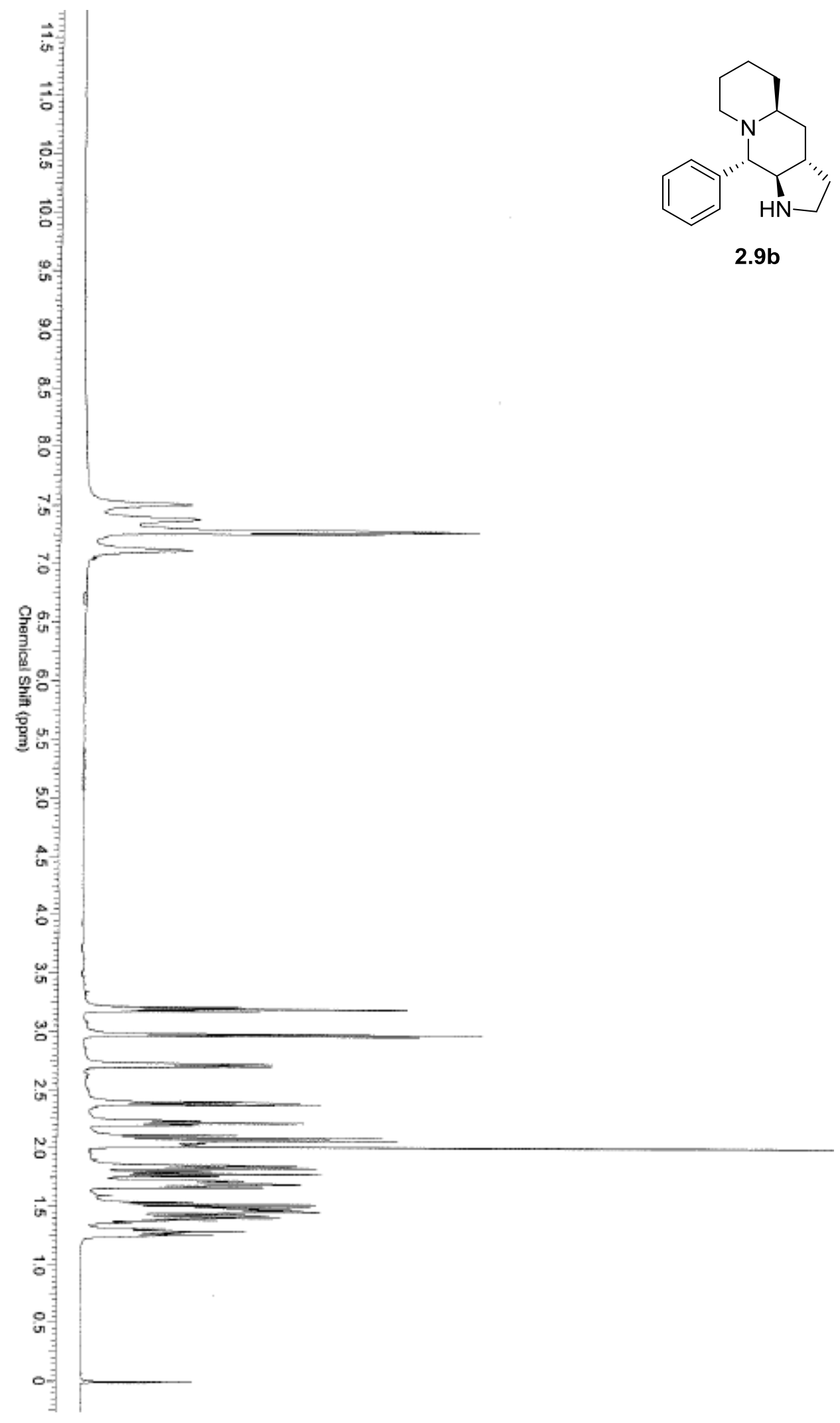




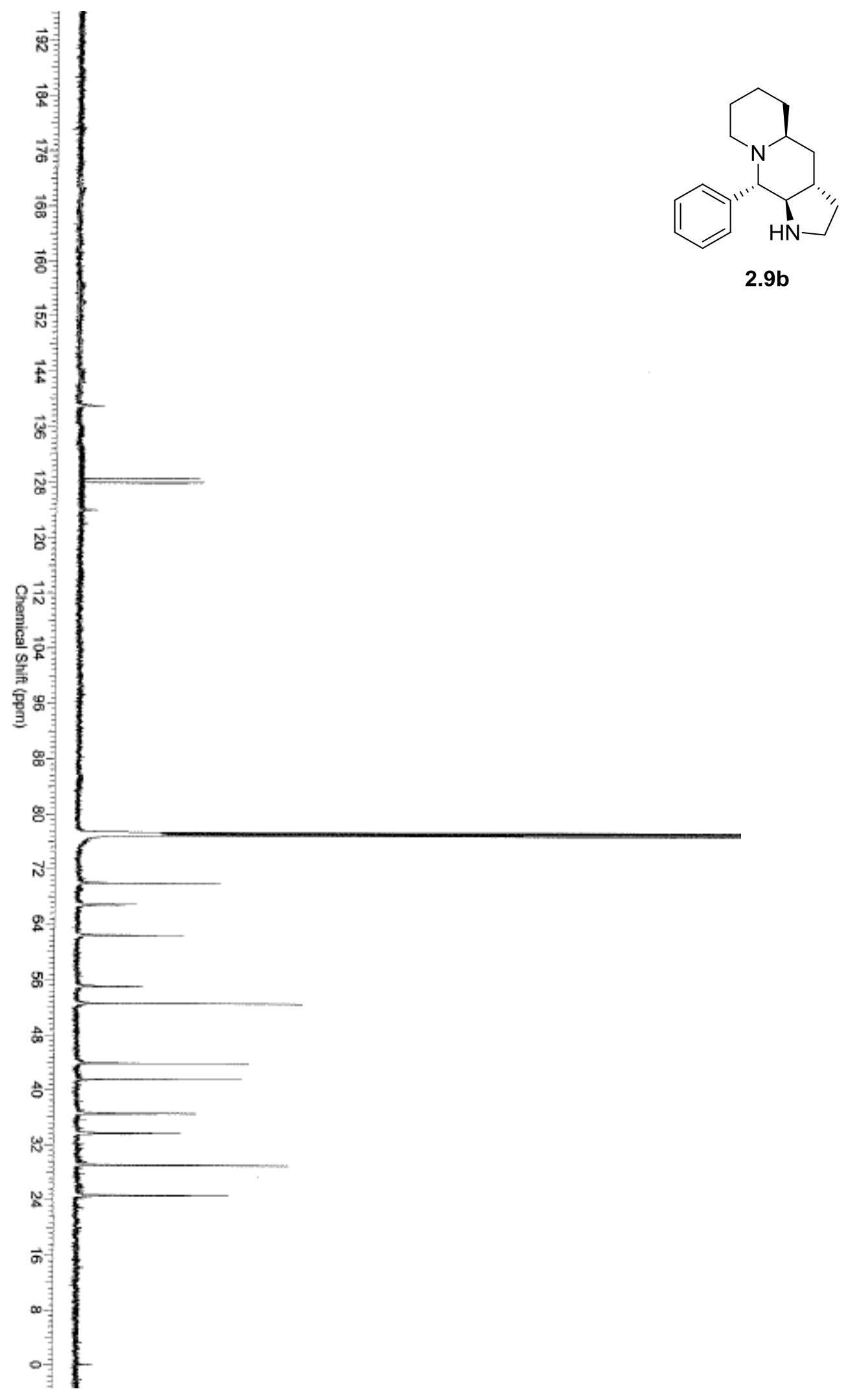




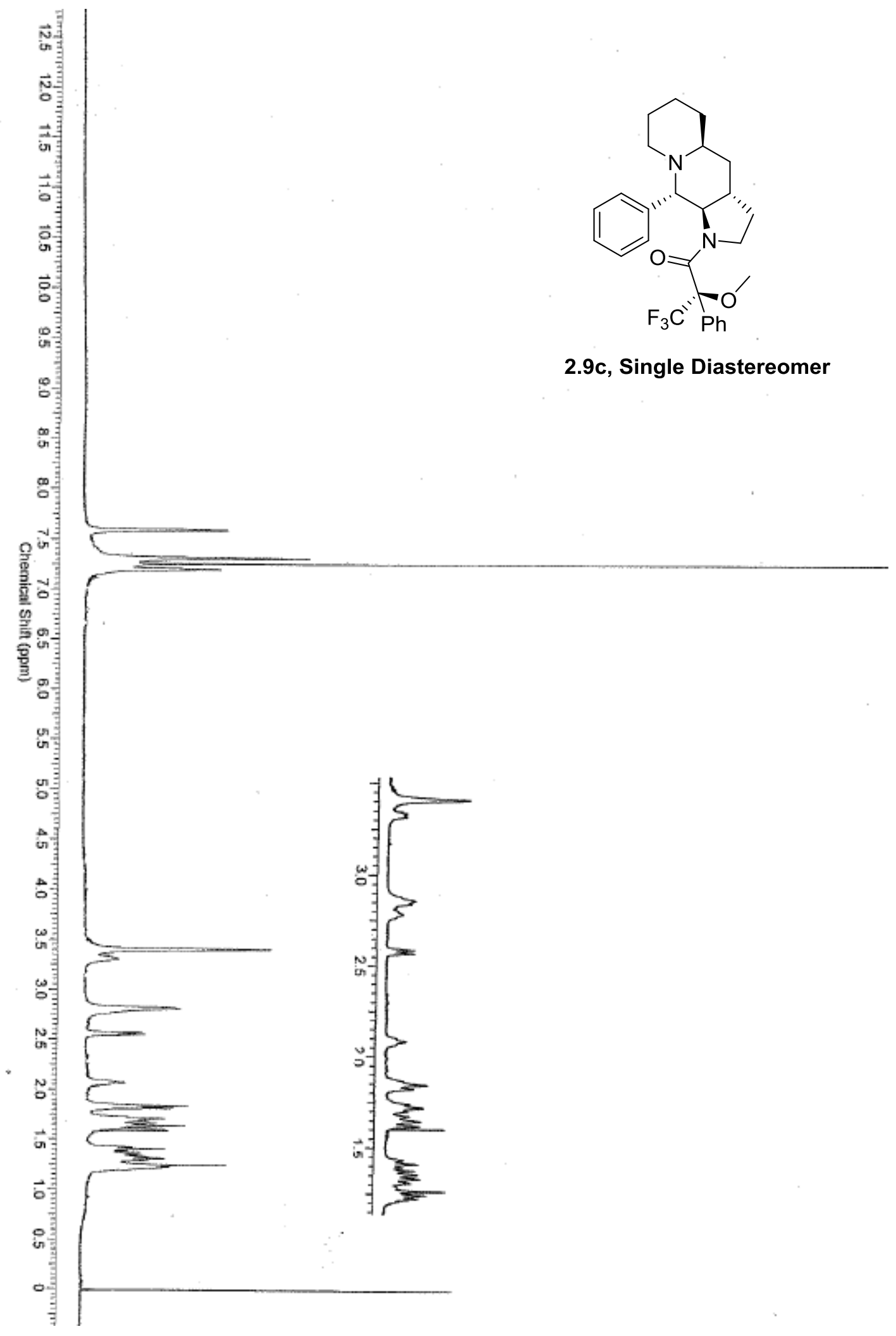




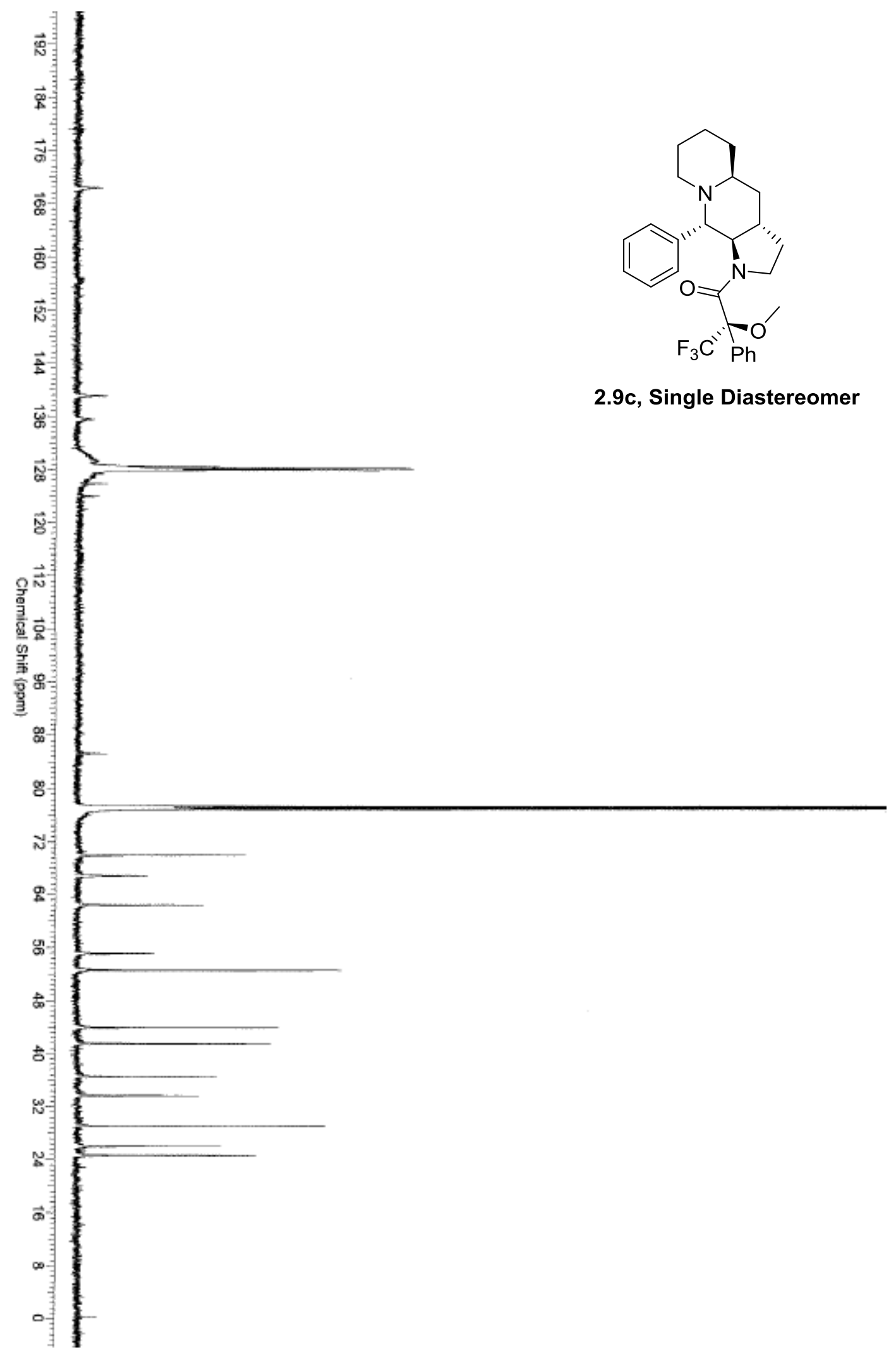




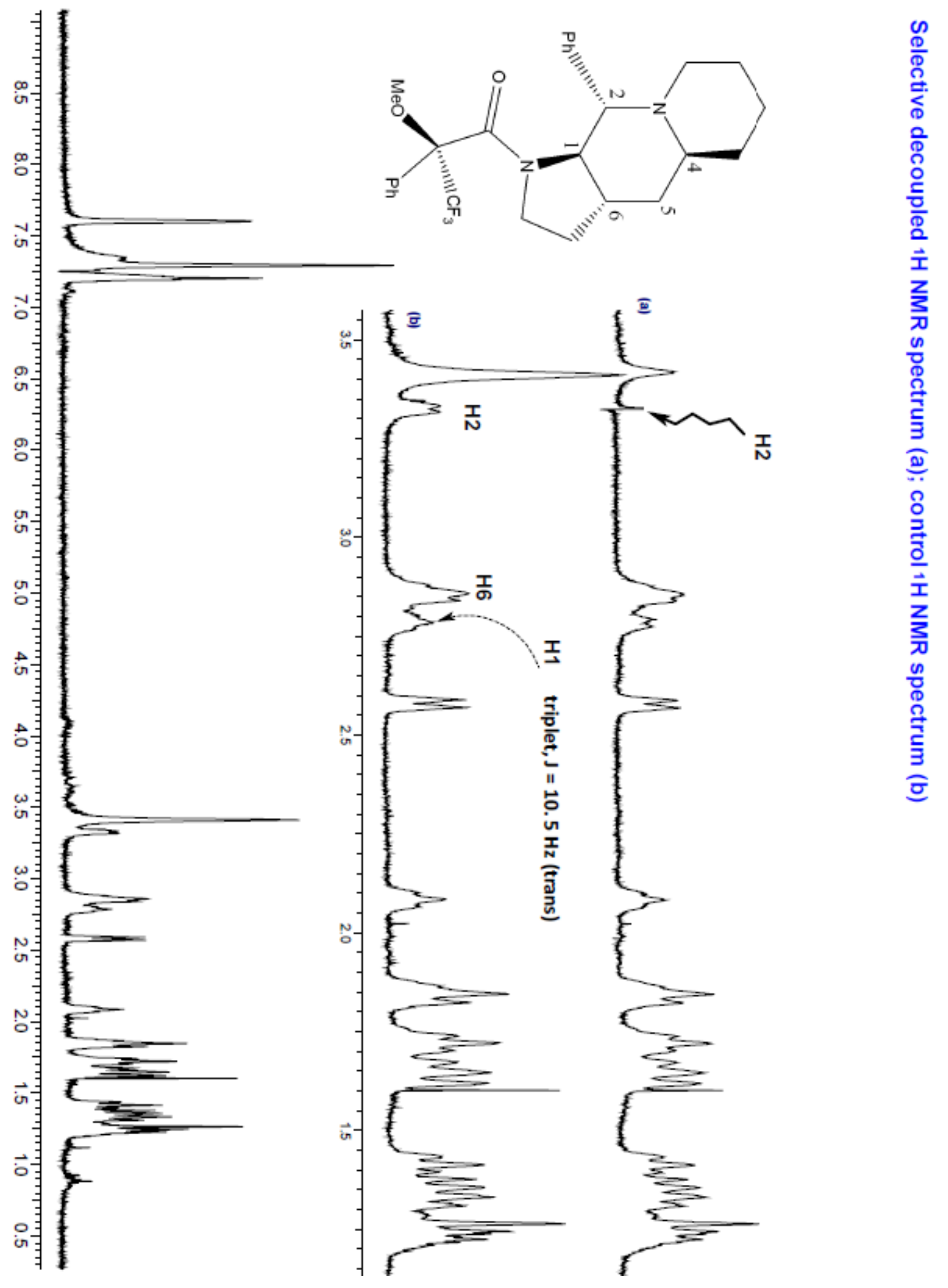




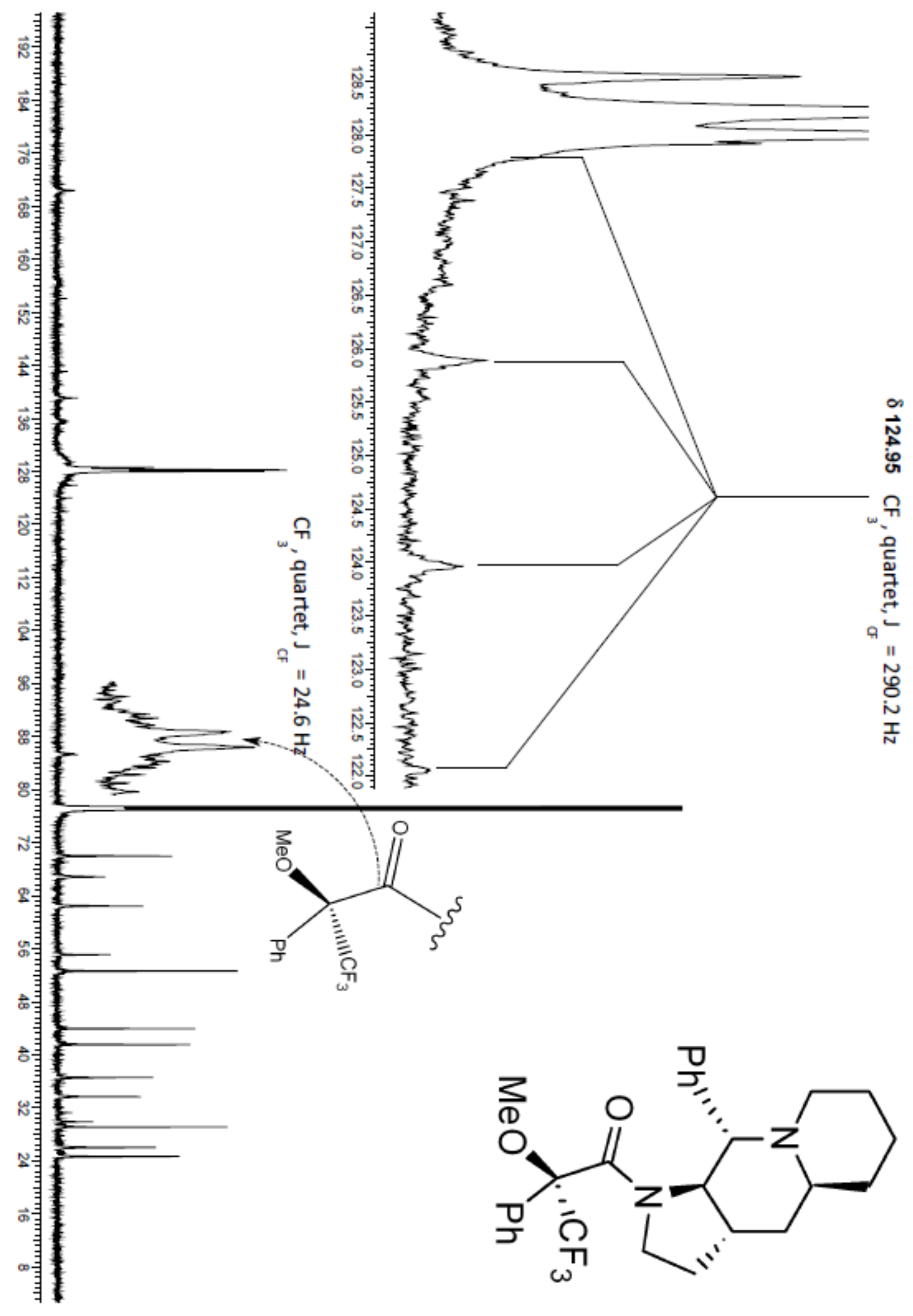


Detail $1 \mathrm{D}$ and $2 \mathrm{D}$ Analysis of 2.3aa and 2.5ba

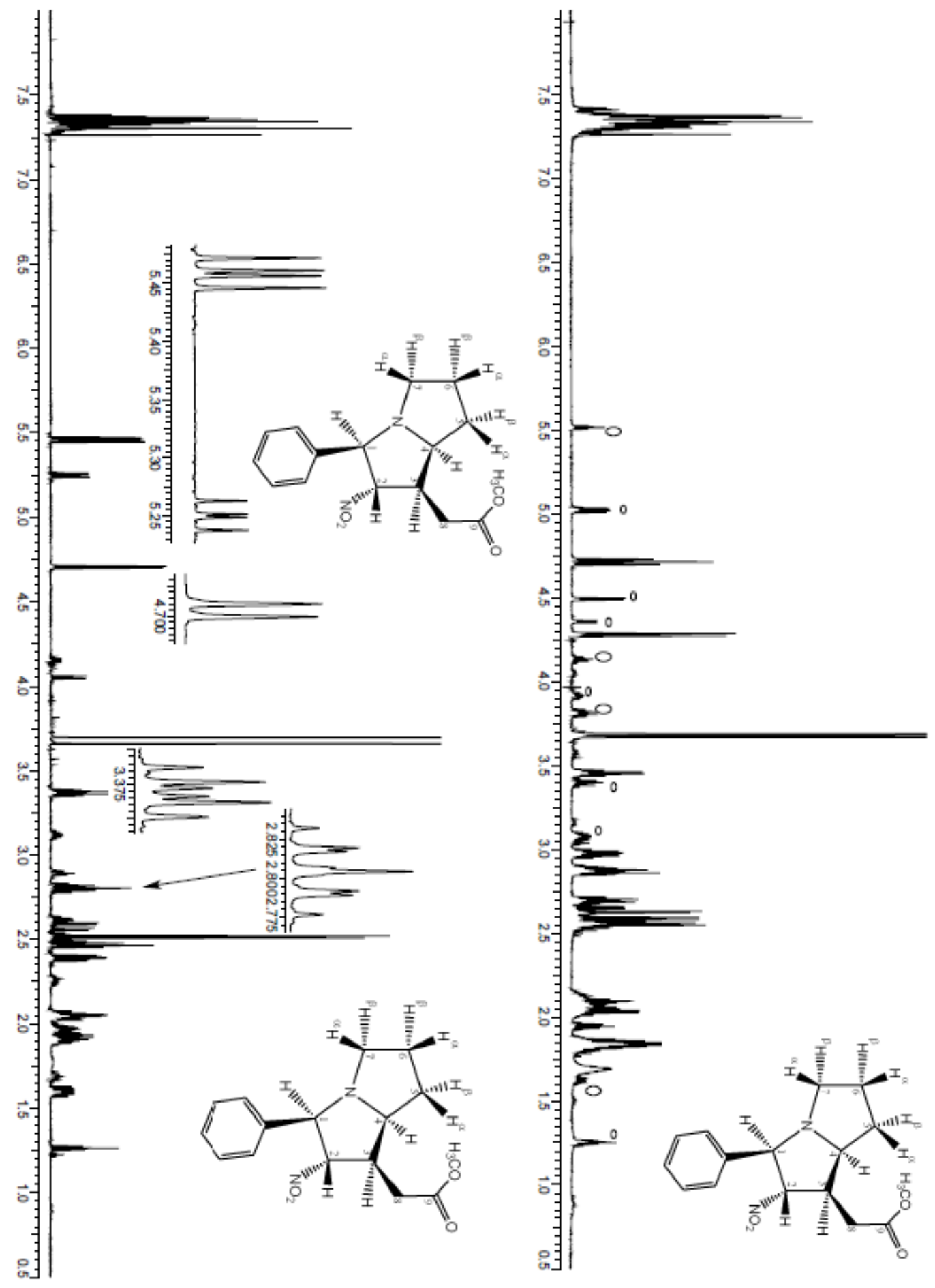




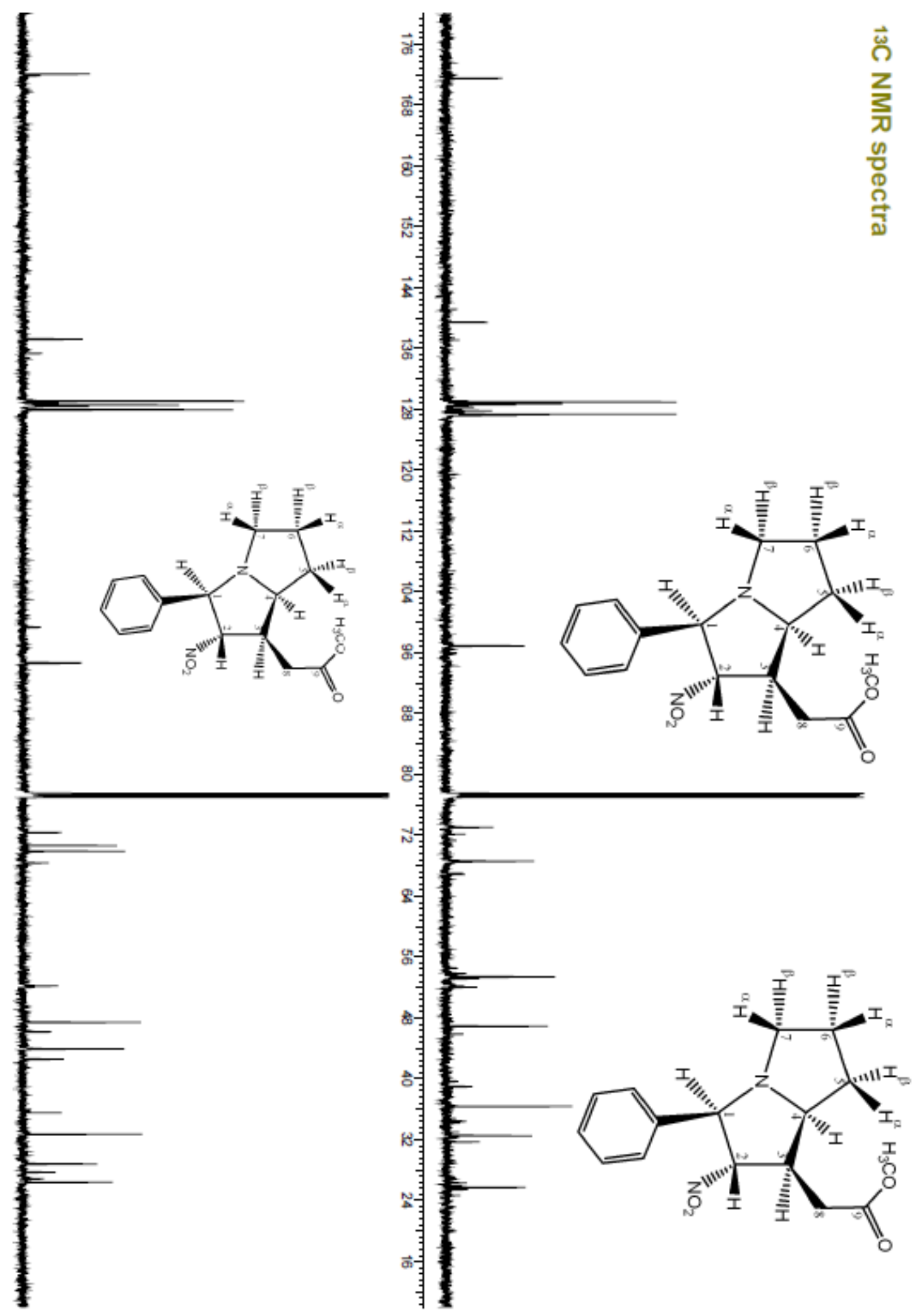




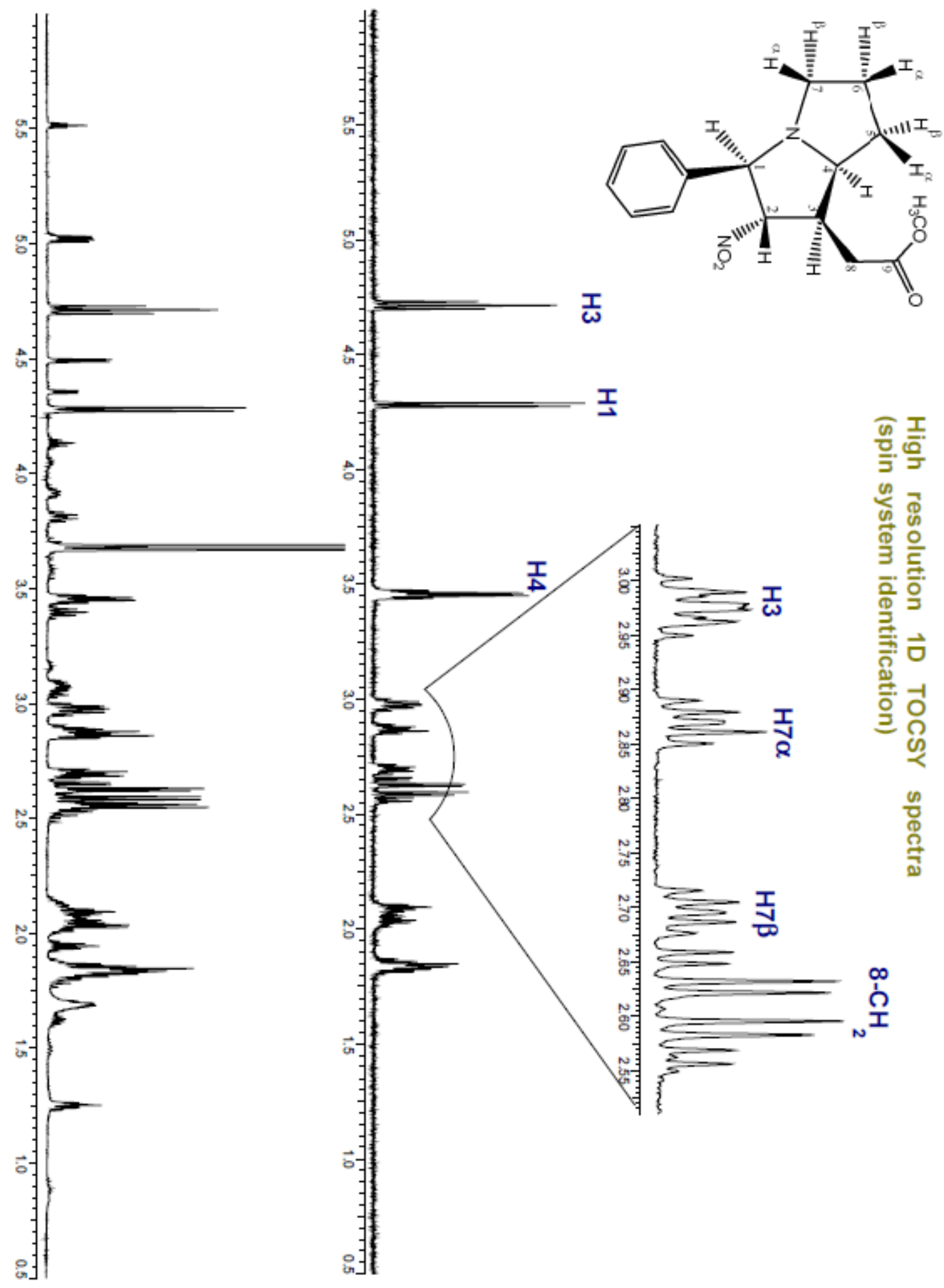



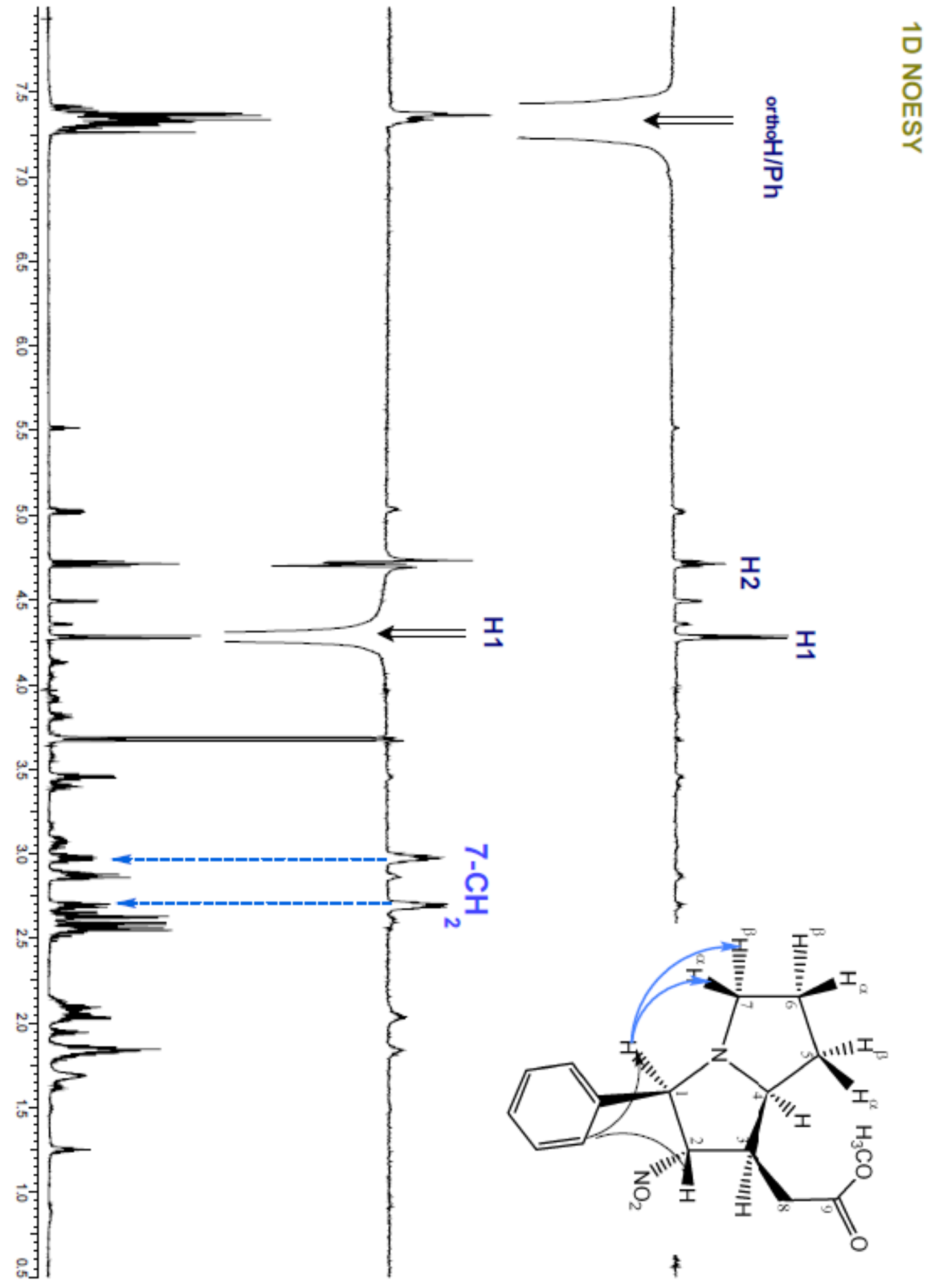


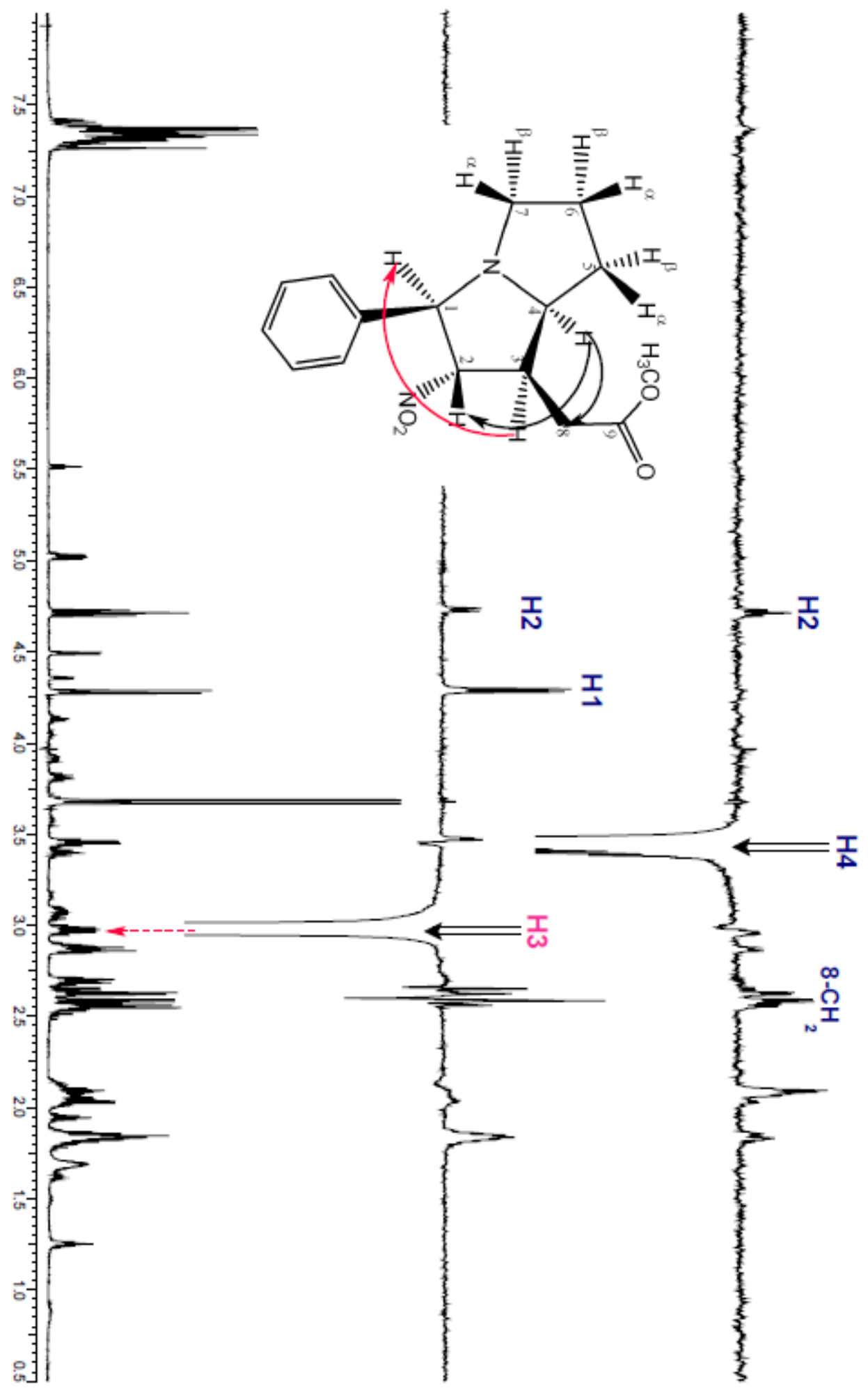

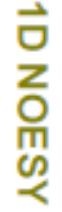




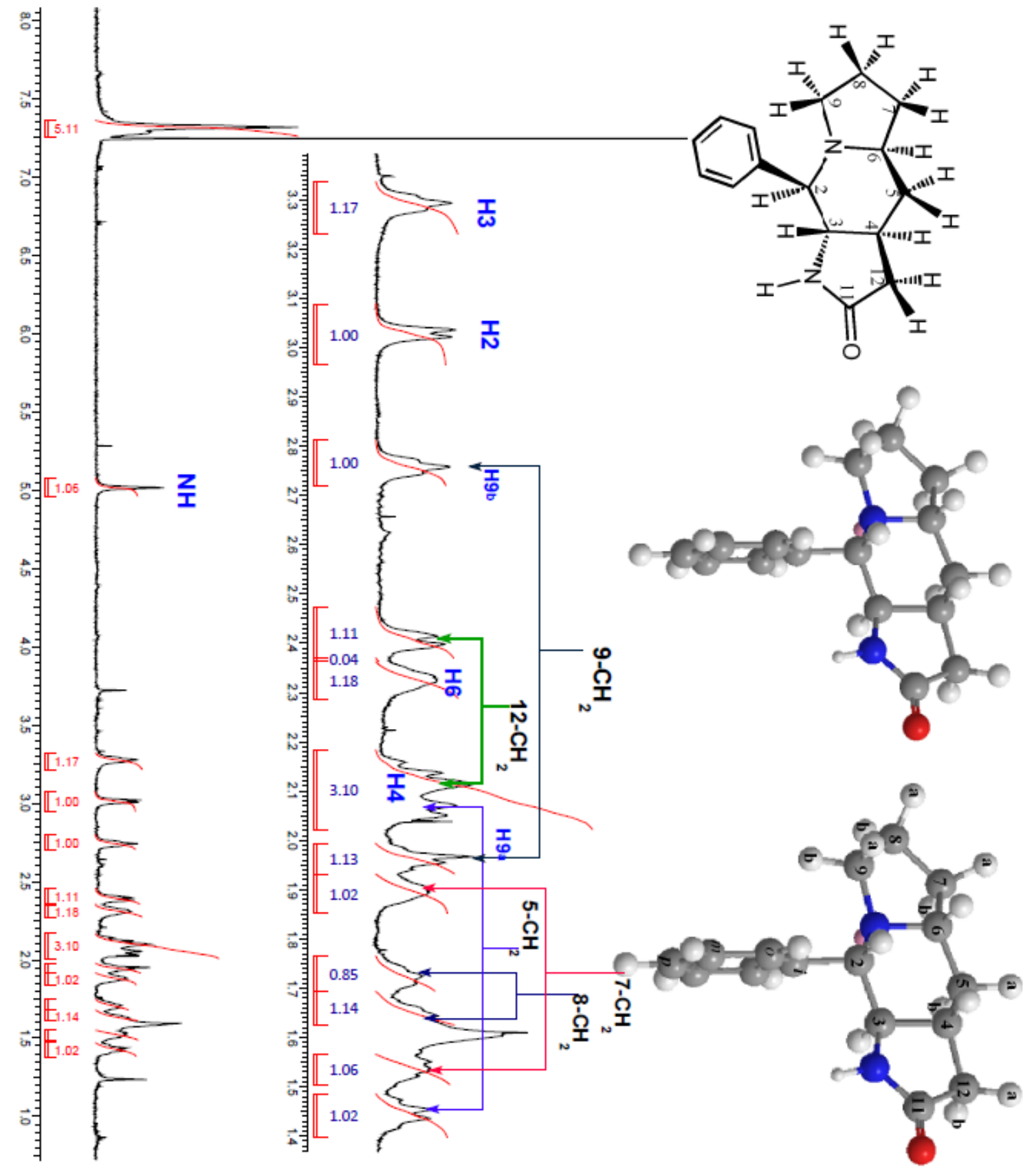




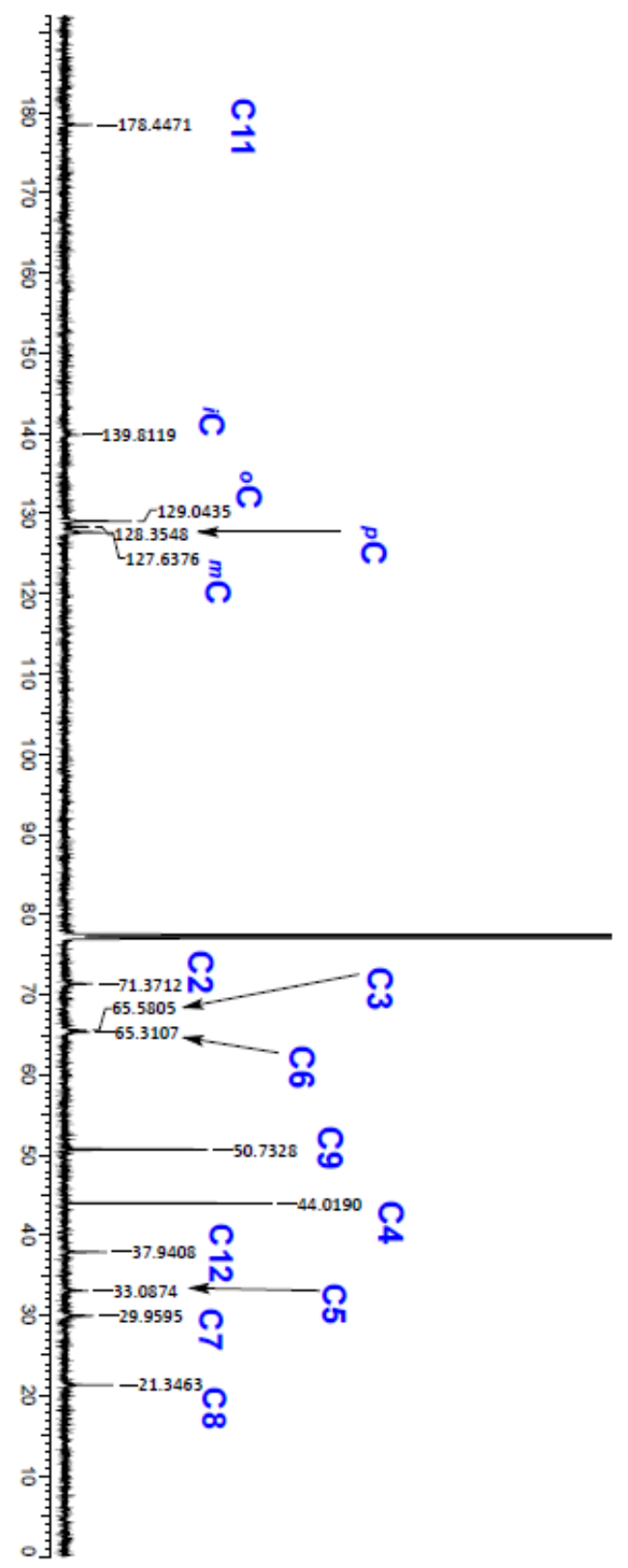

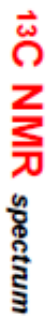

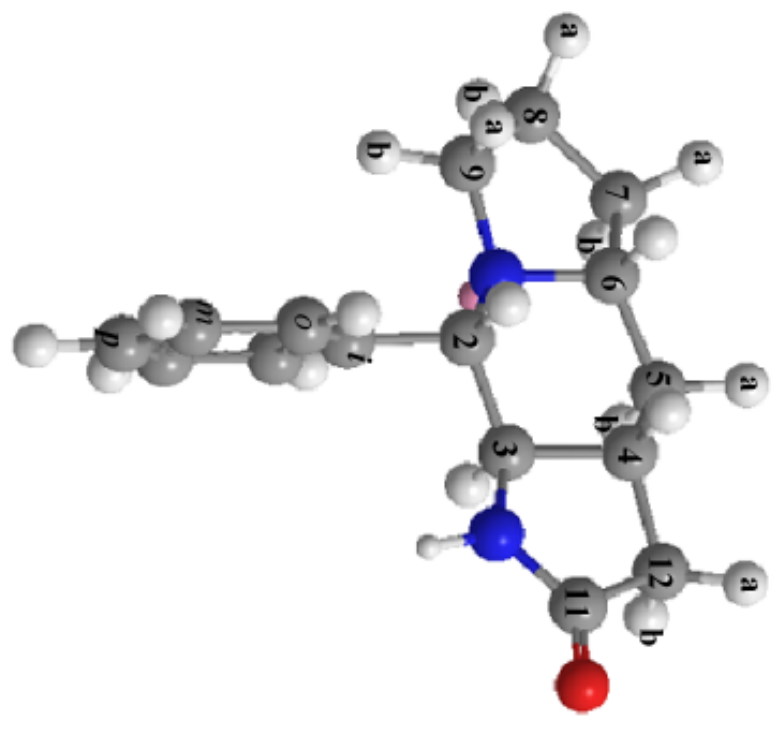




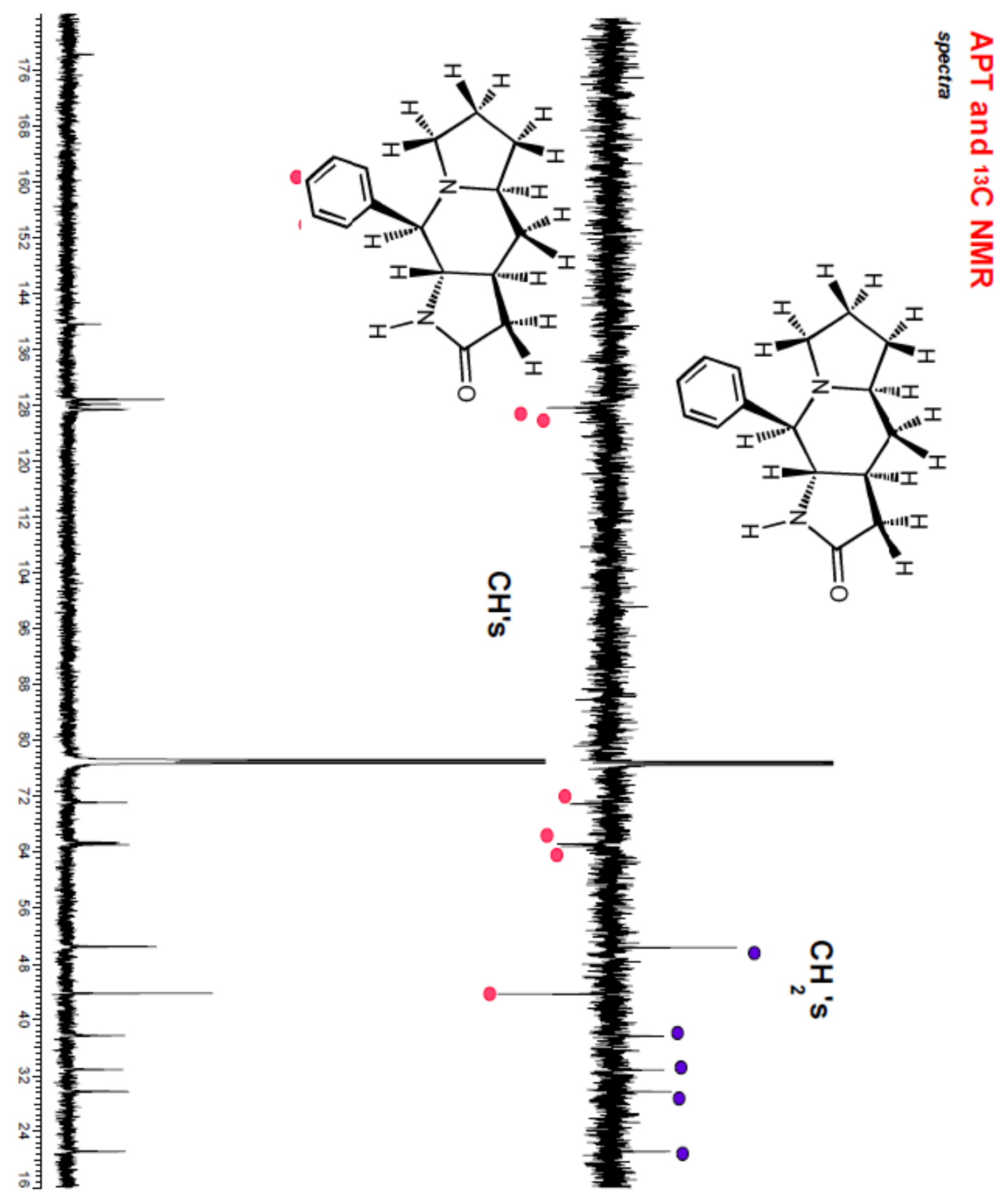


gCOSY

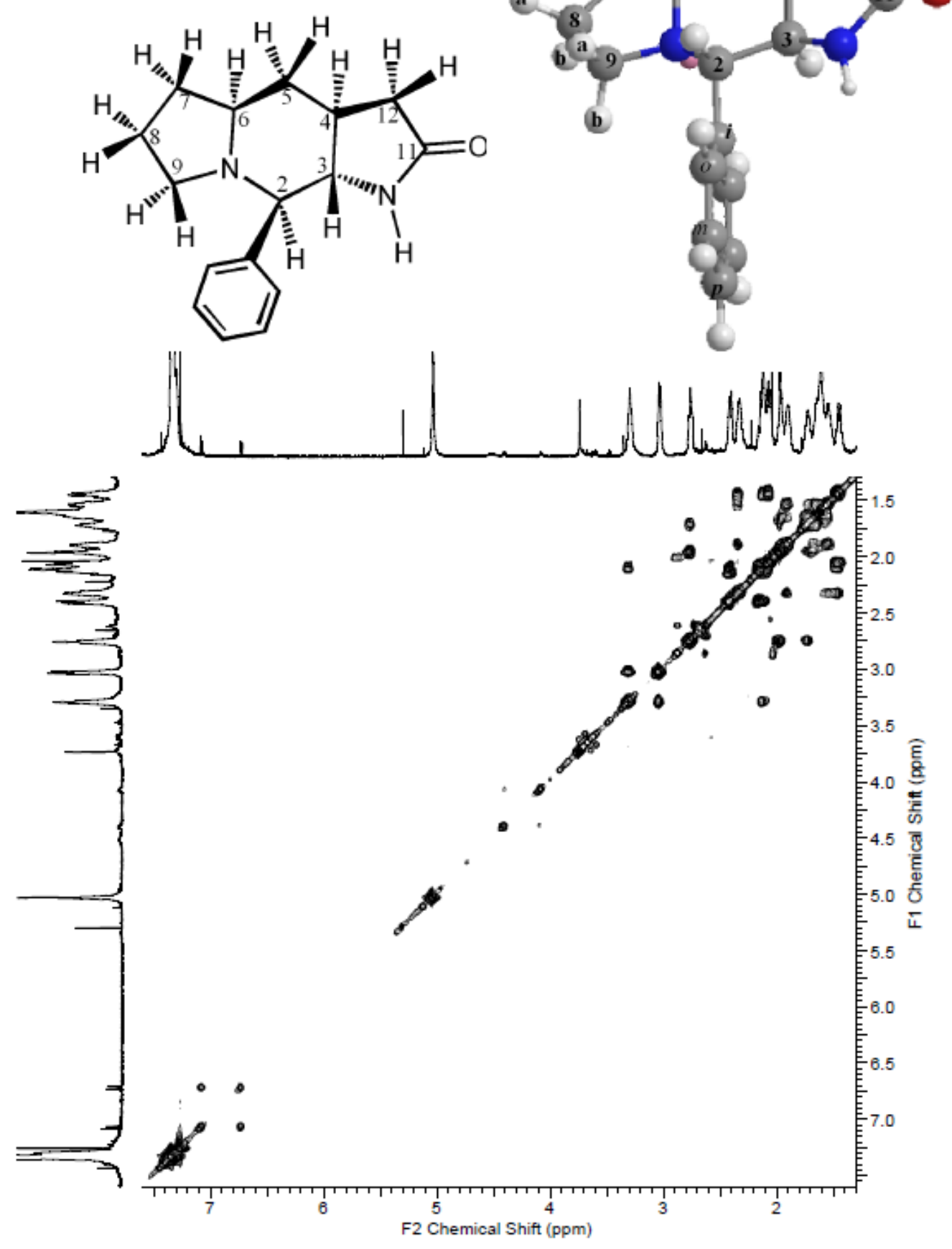


gCOSY

aliphatic region
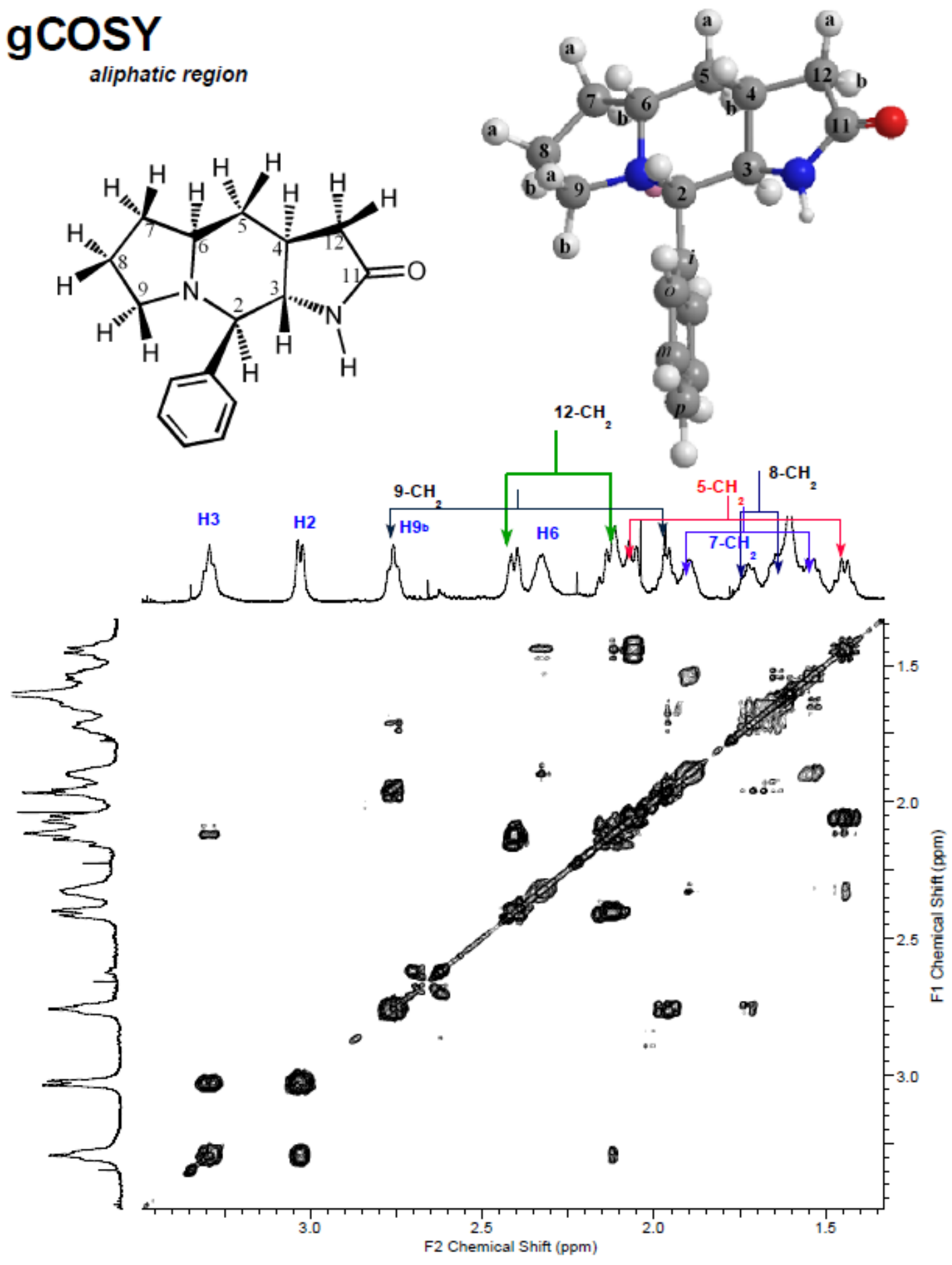


\section{D TOCSY}

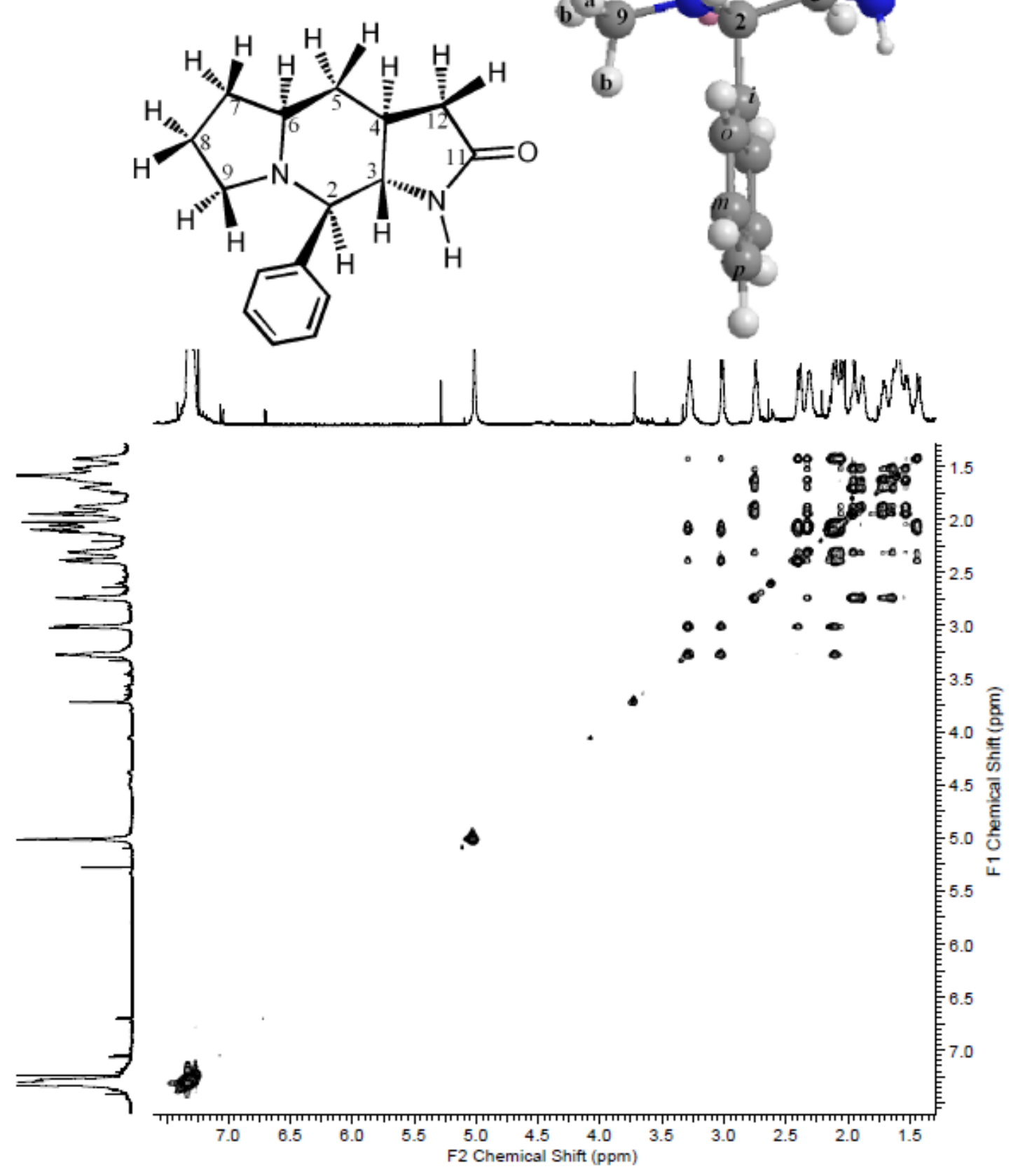




\section{D TOCSY \\ aliphatic region}

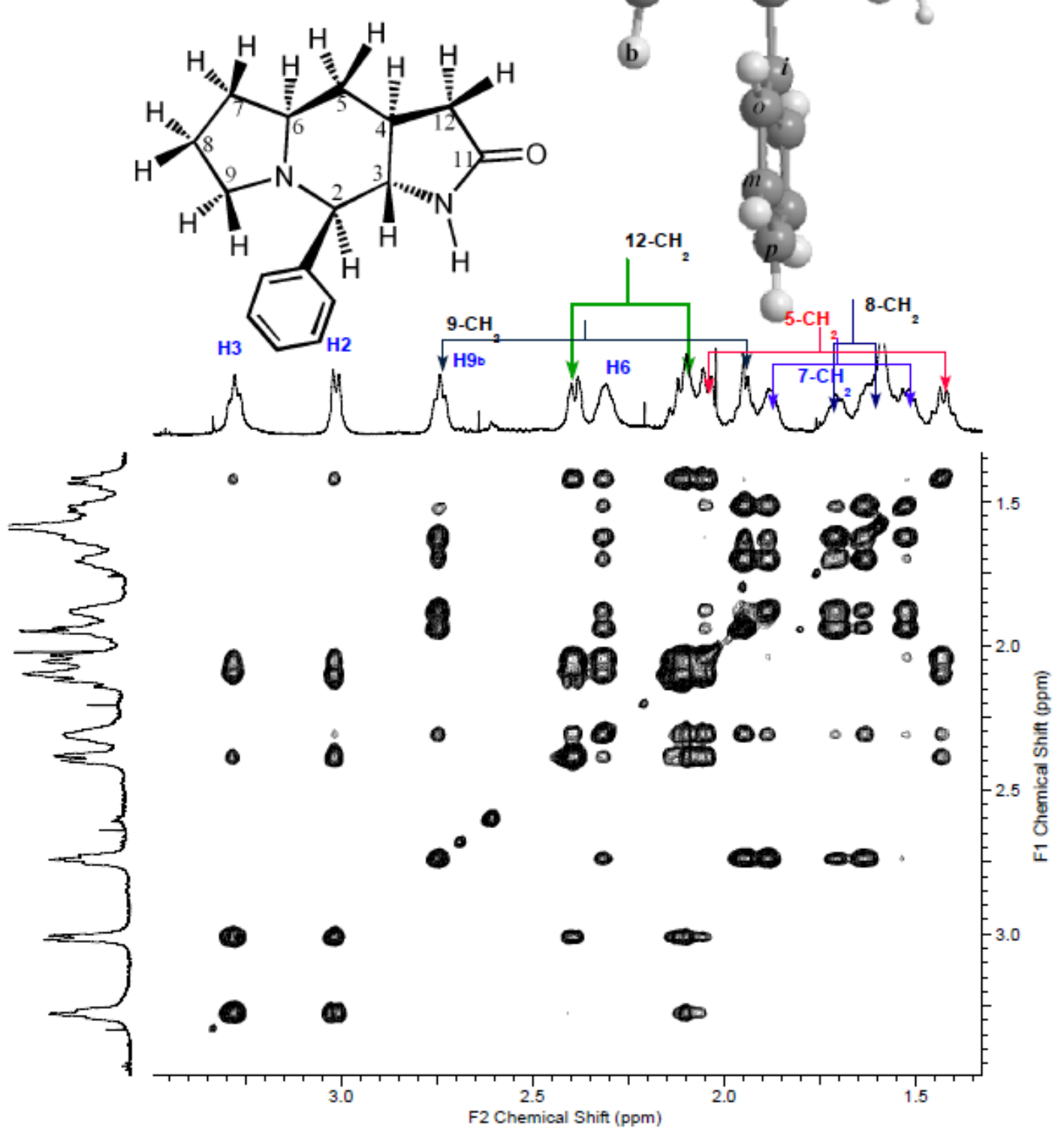


2D NOESY

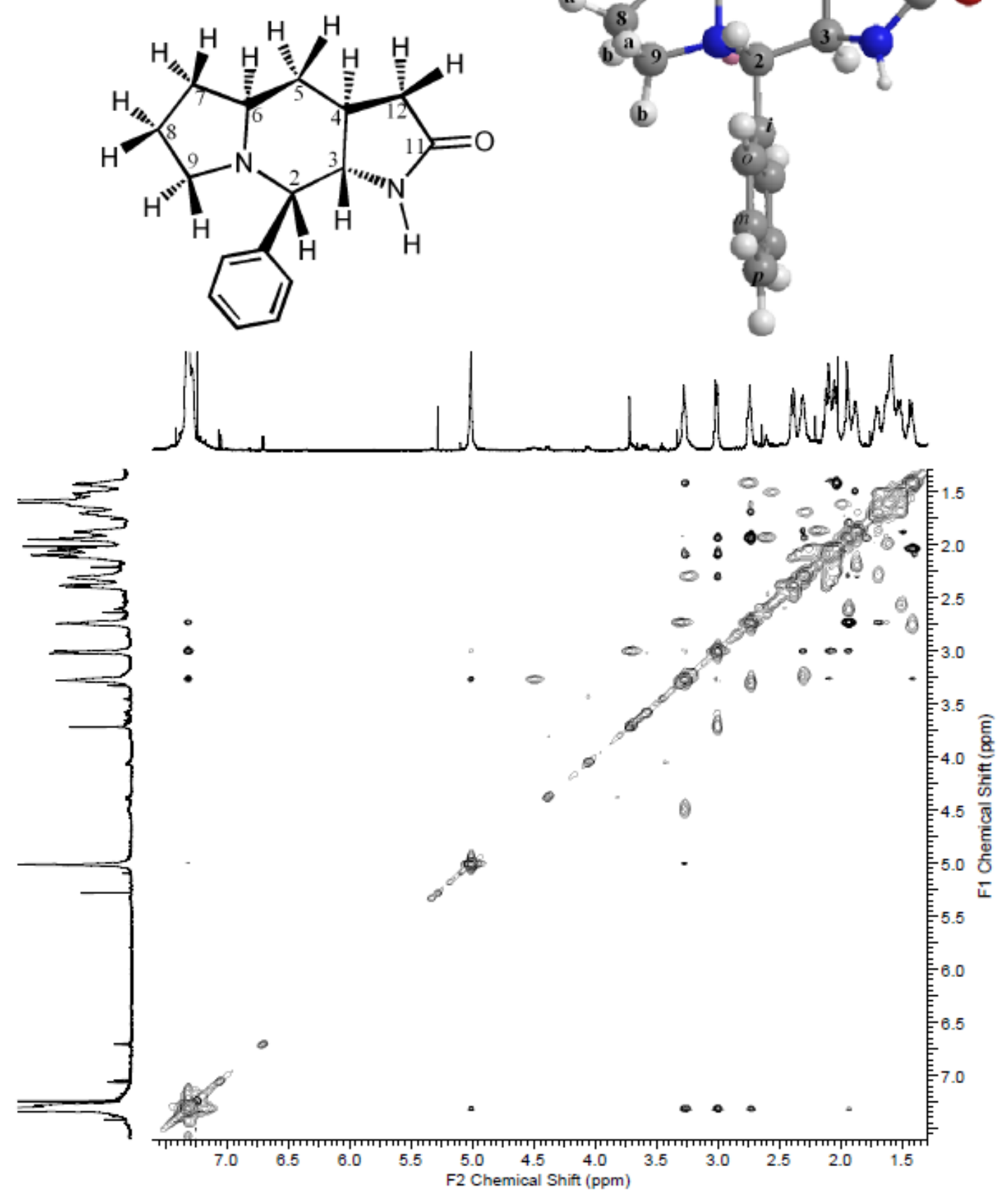




\section{D NOESY}

aliphatic region

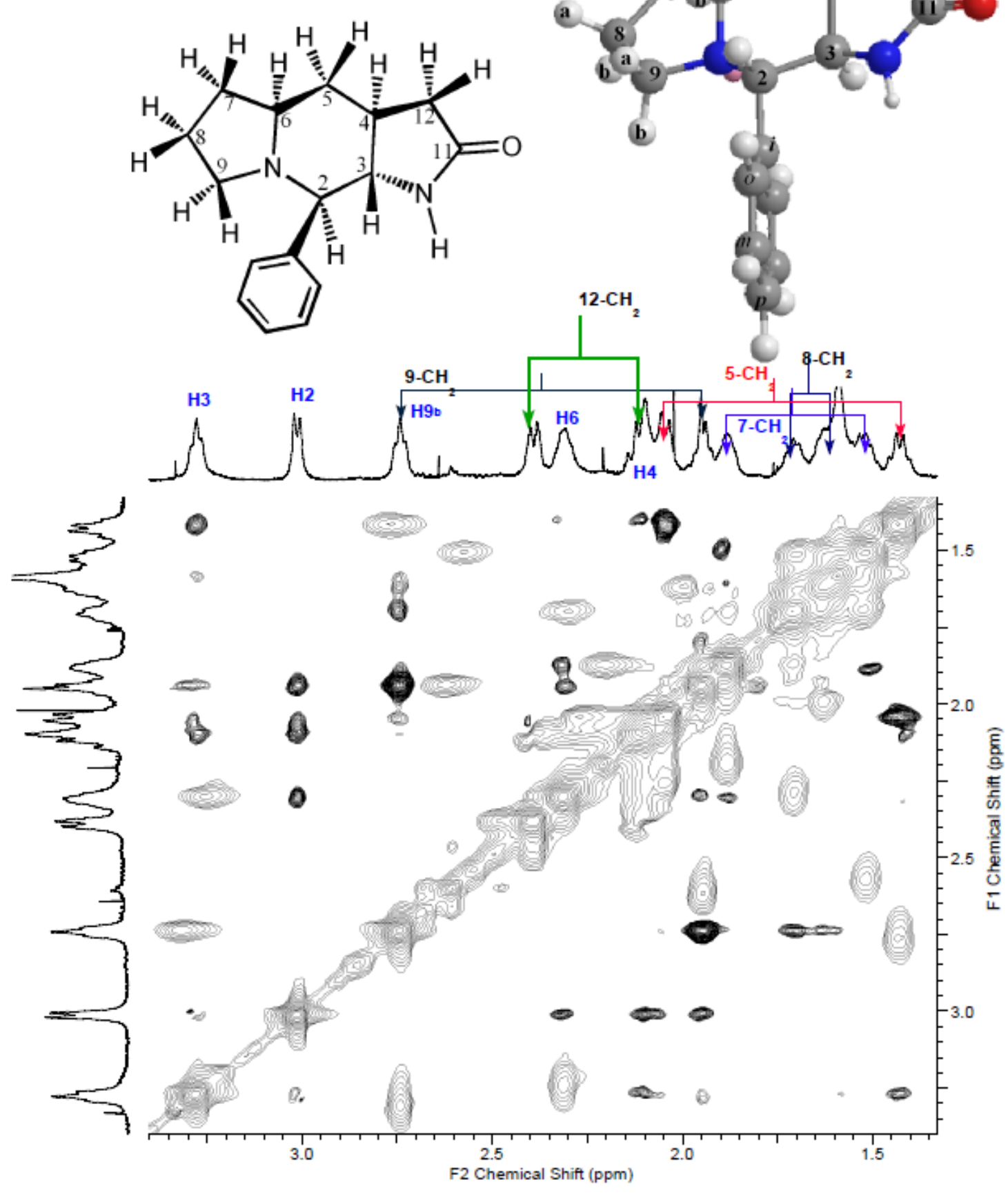


NOESY correlations between $\mathrm{H} 3$ and $\mathrm{H} 5 \mathrm{~b} / \mathrm{H} 12 \mathrm{~b}$

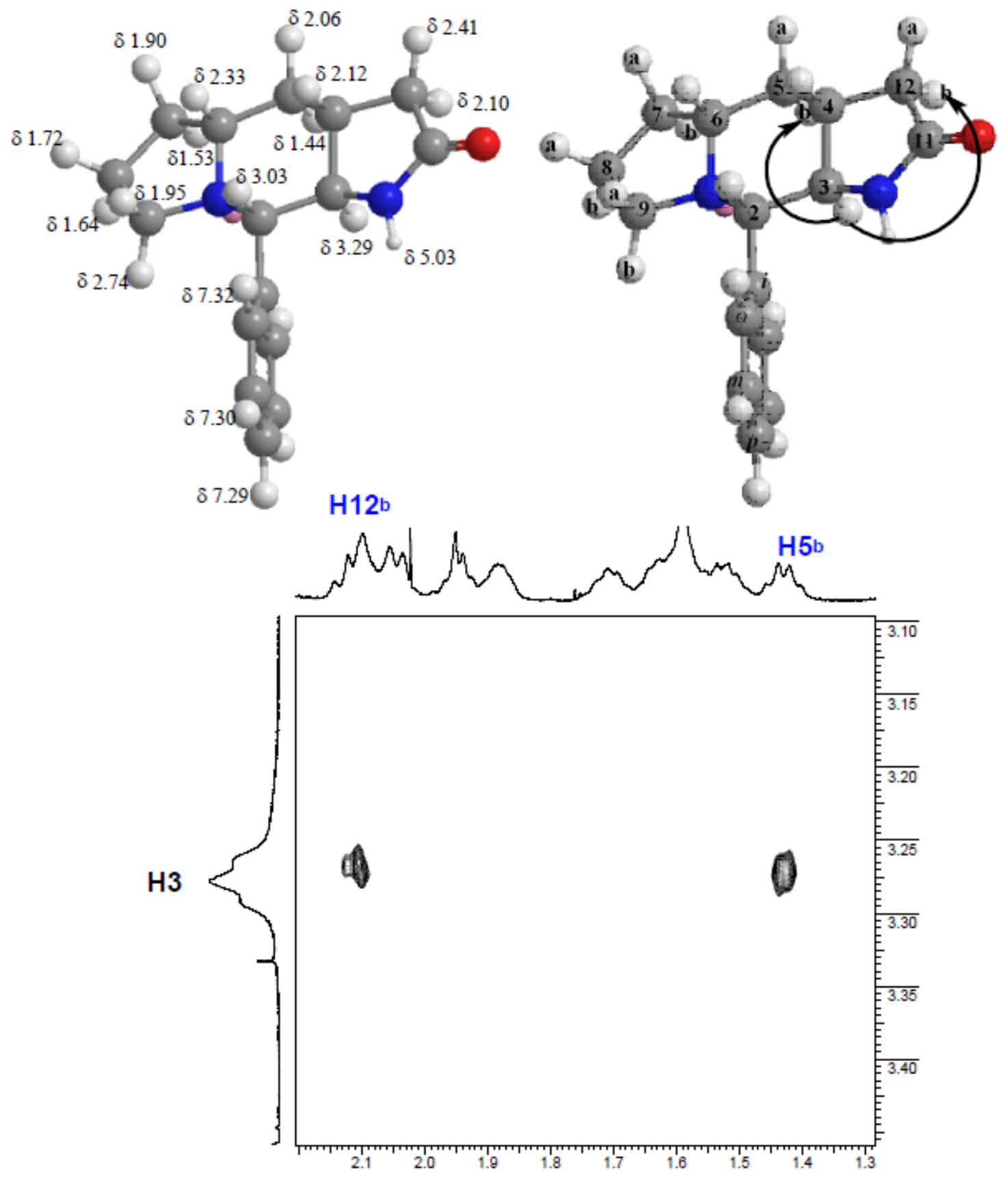


NOESY correlations between $\mathrm{H} 2$ and $\mathrm{H} 4 / \mathrm{H} 6 / \mathrm{H} 9 \mathrm{a}$
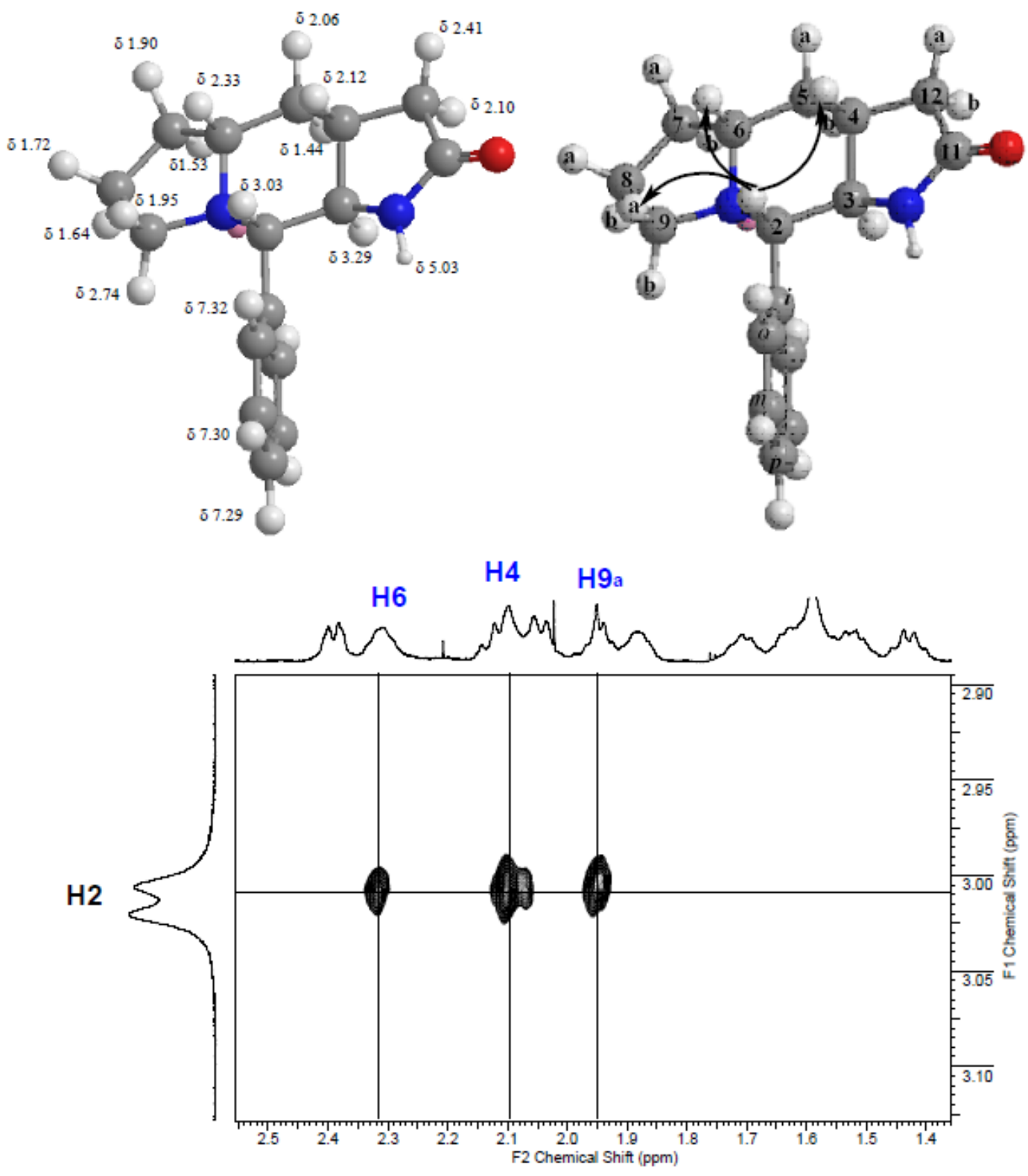


\section{NOESY correlations between orthoH/Ph and $\mathrm{H} 2 / \mathrm{H} 3 / 9-\mathrm{CH}_{2}$}
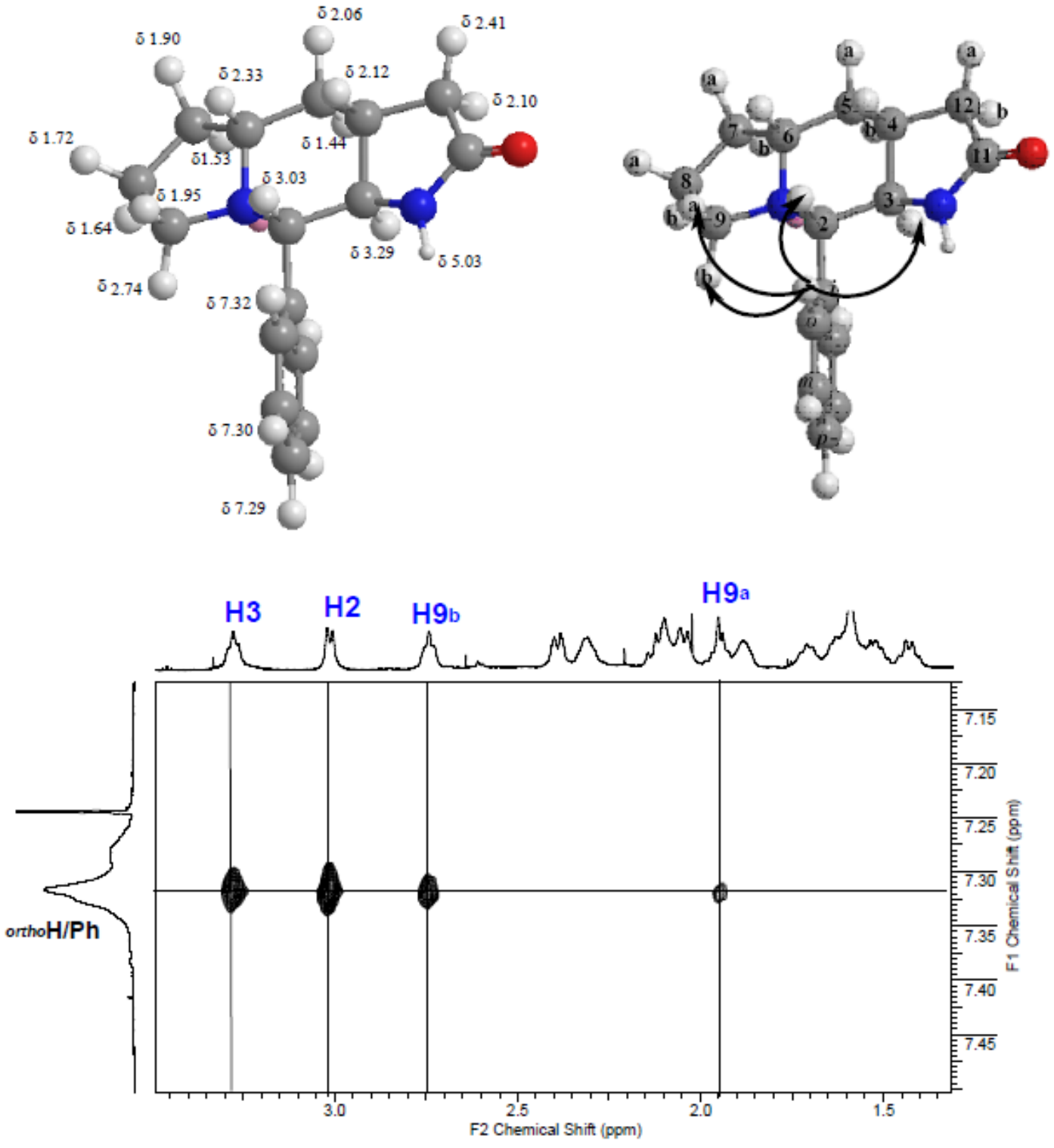


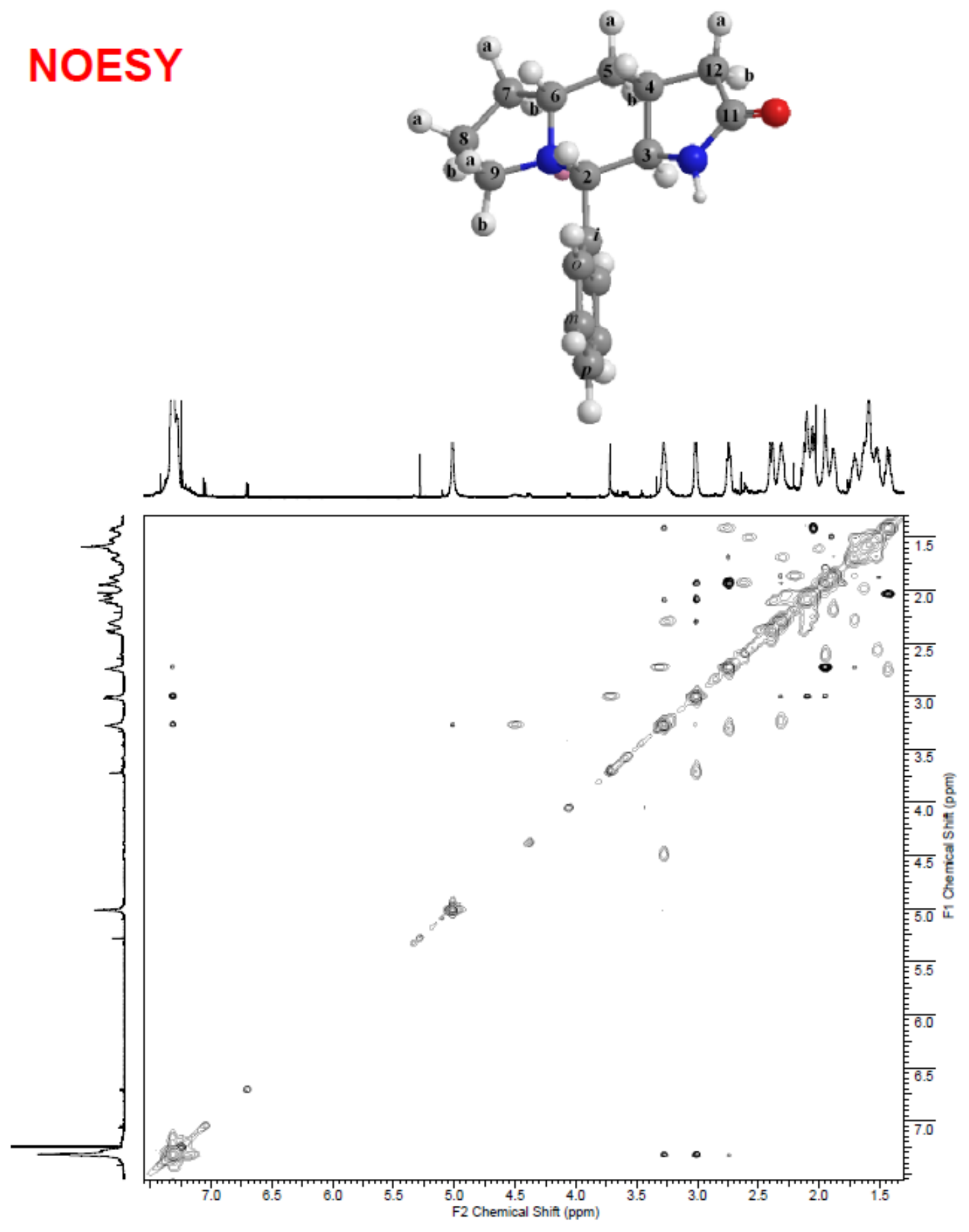


NOESY

aliphatic region
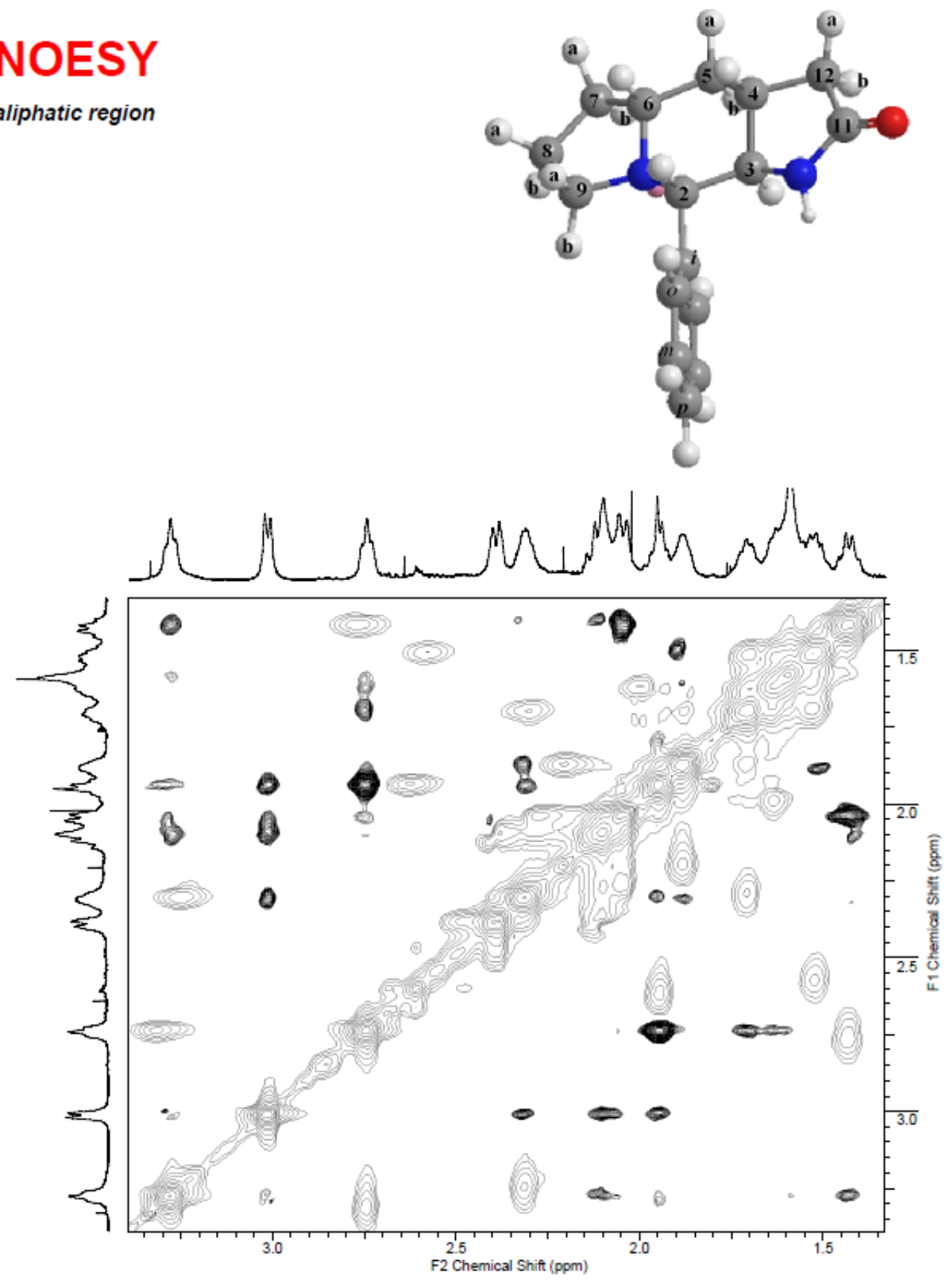


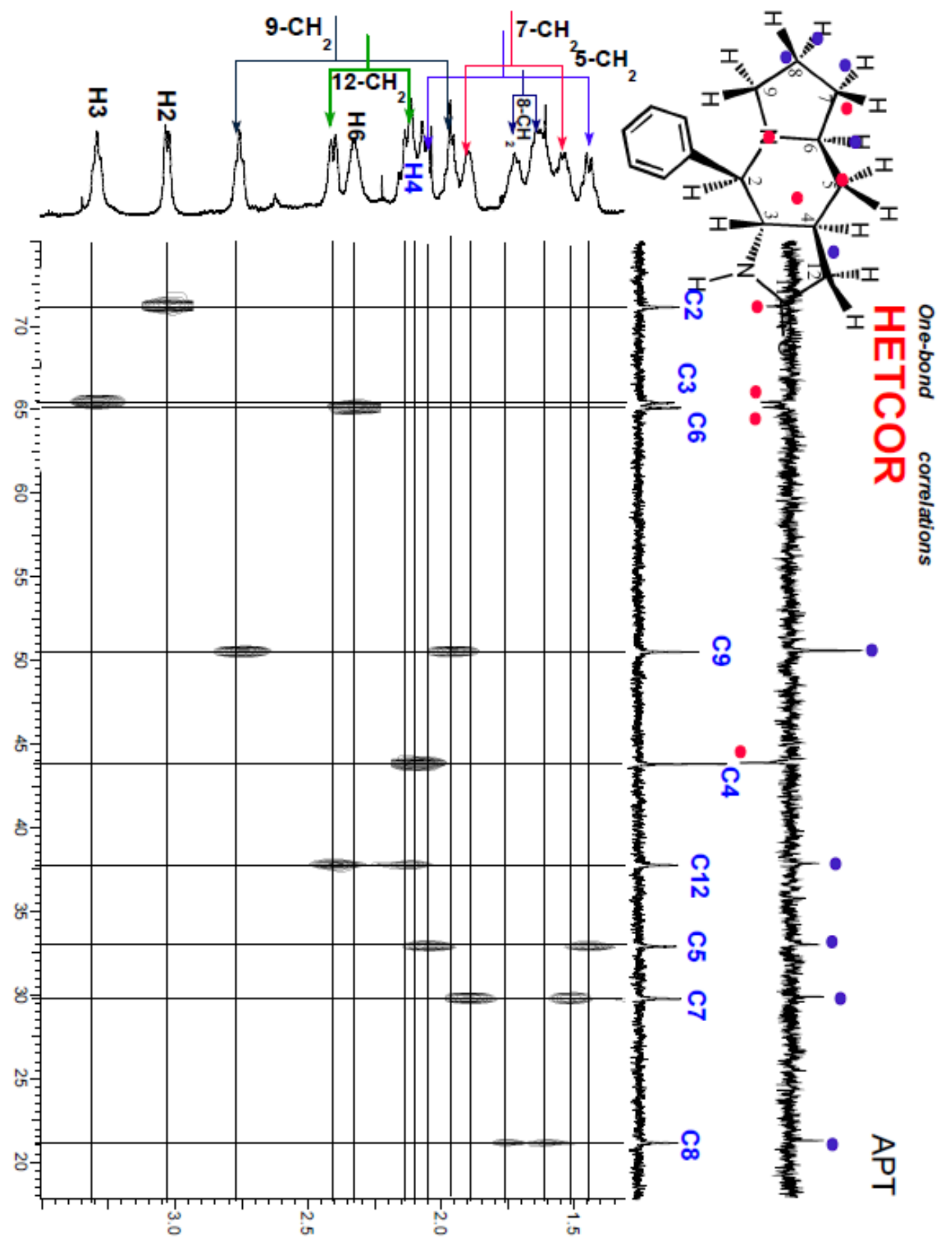



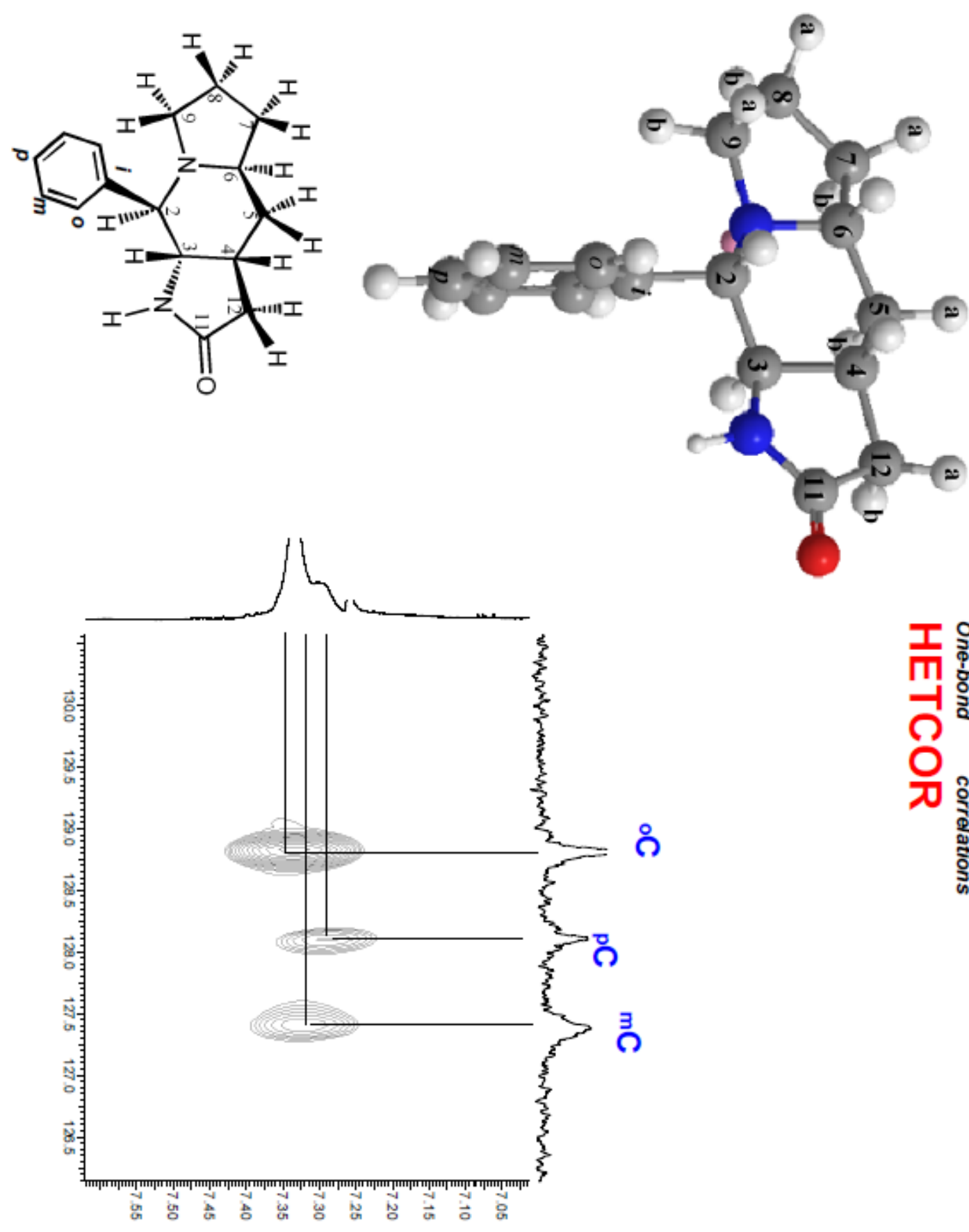

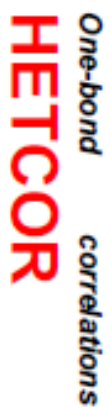



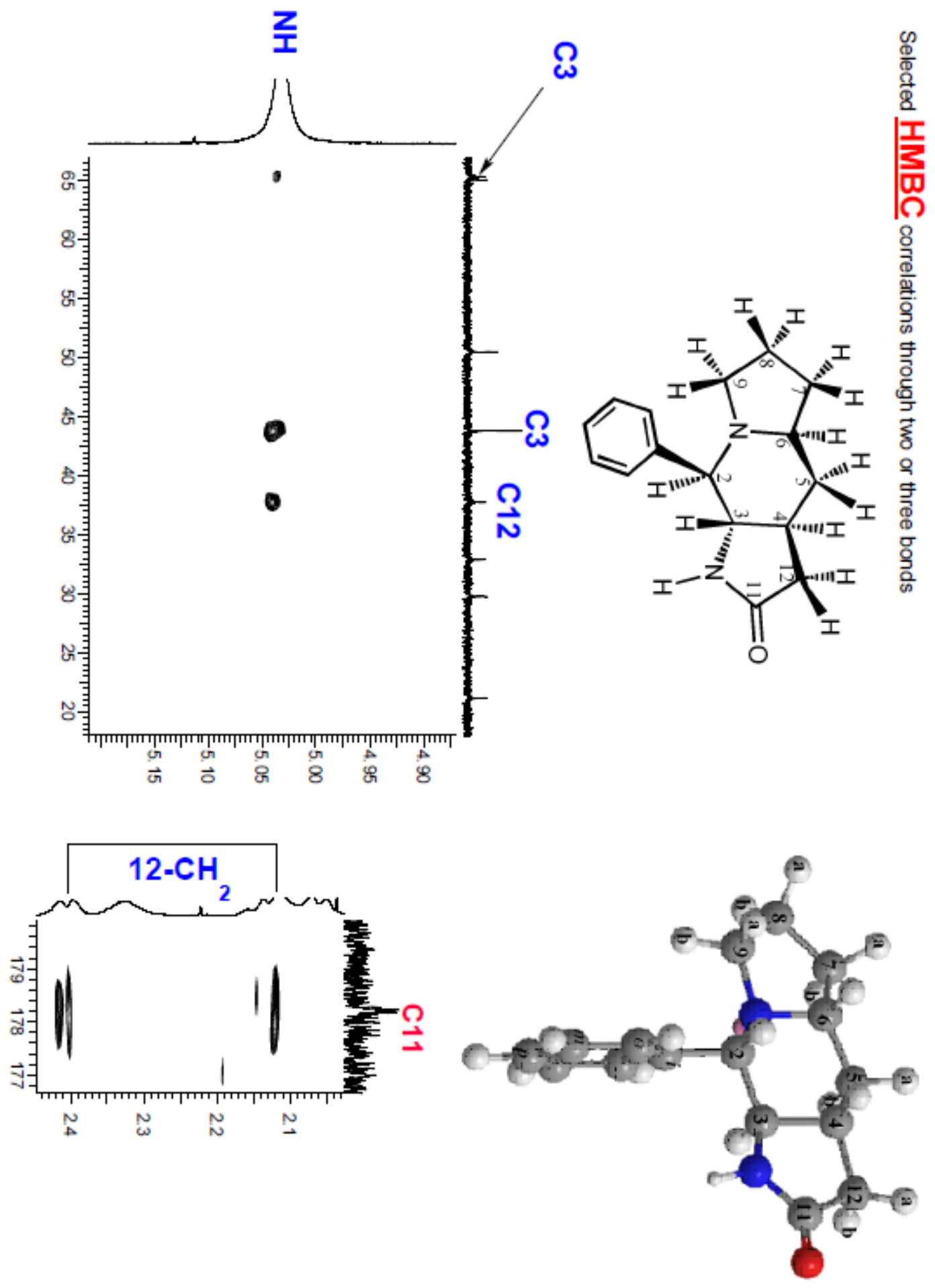

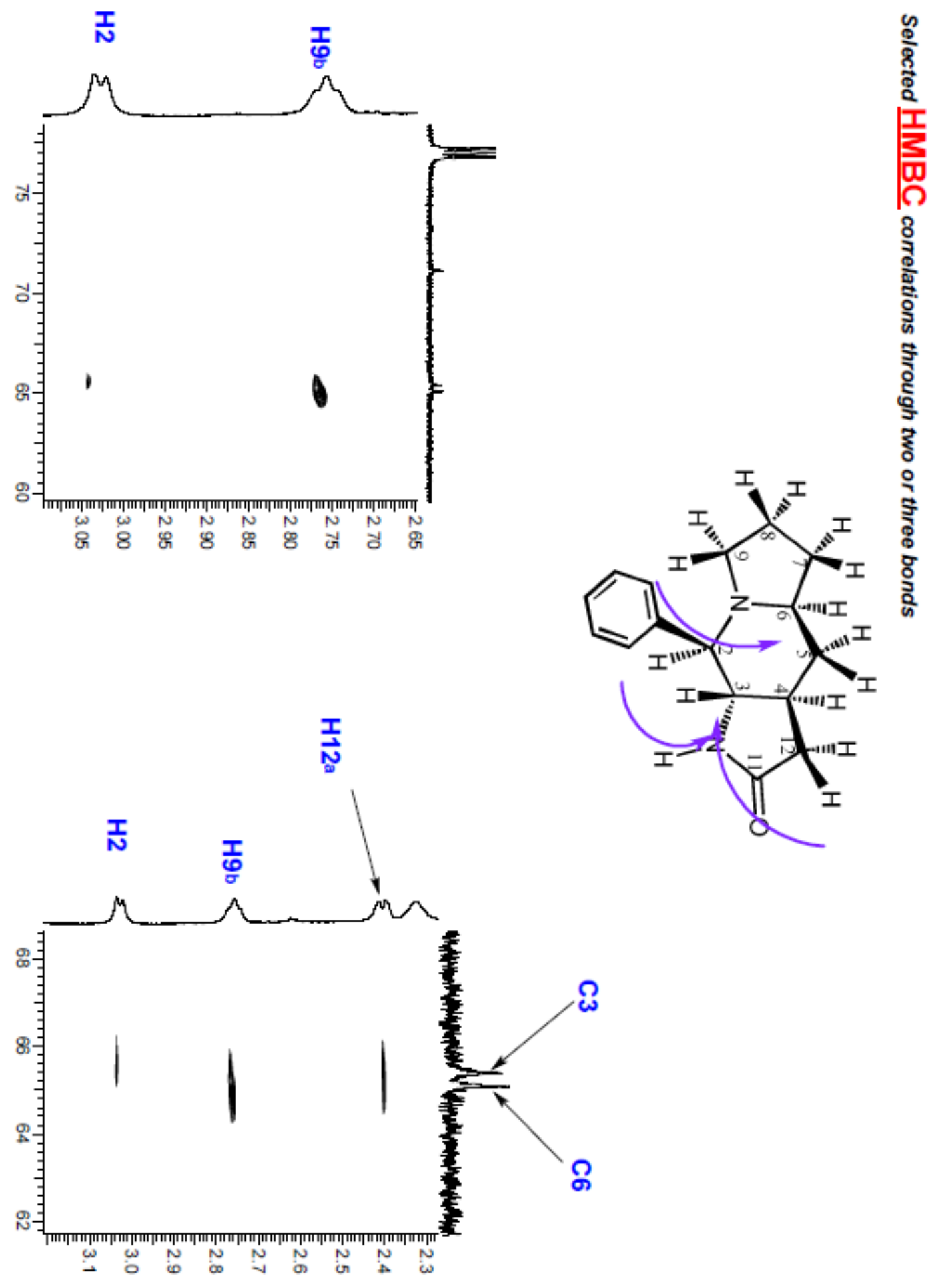
Series of selective decoupled 1H NMR spectra

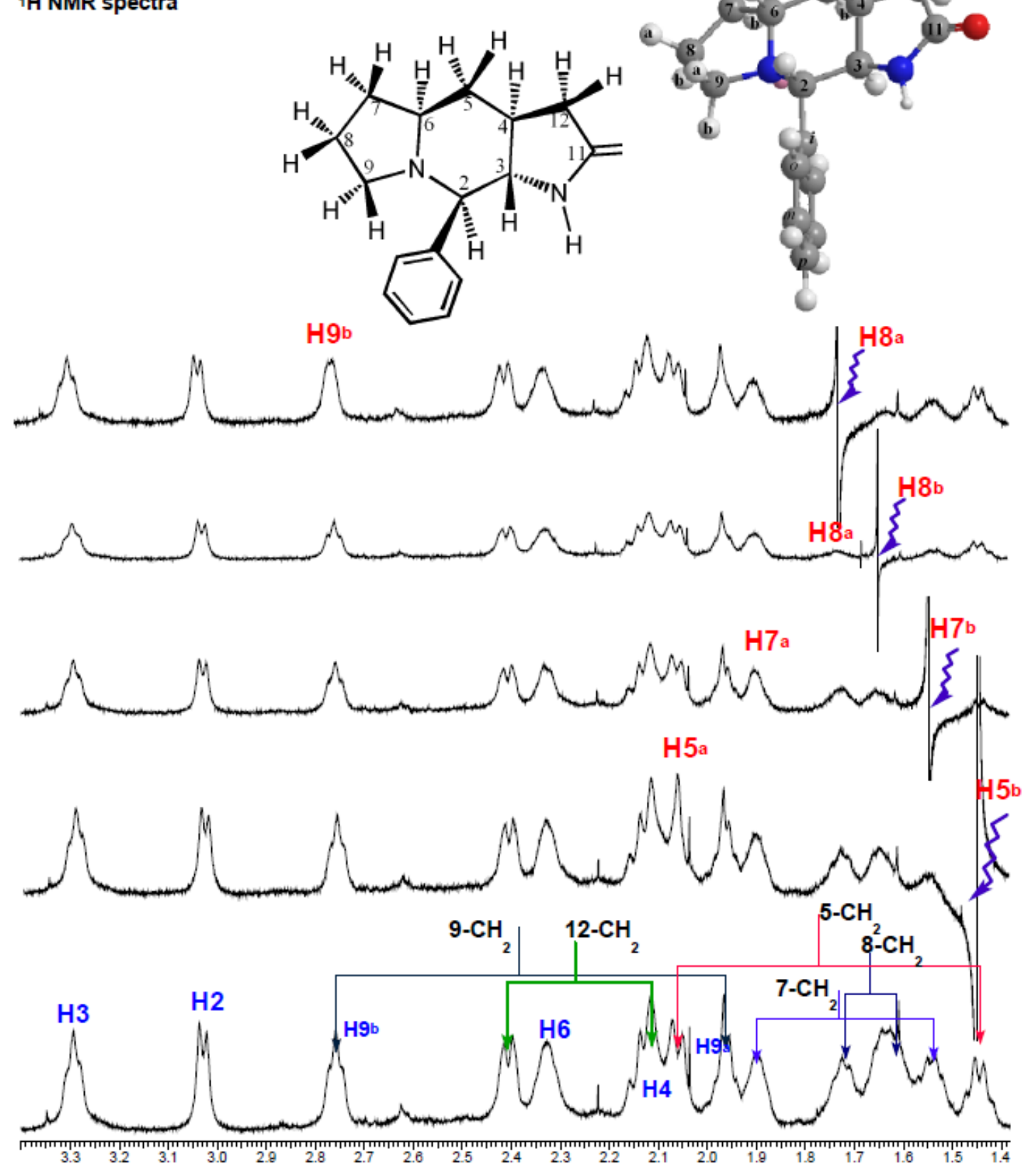


Series of selective decoupled 1H NMR spectra
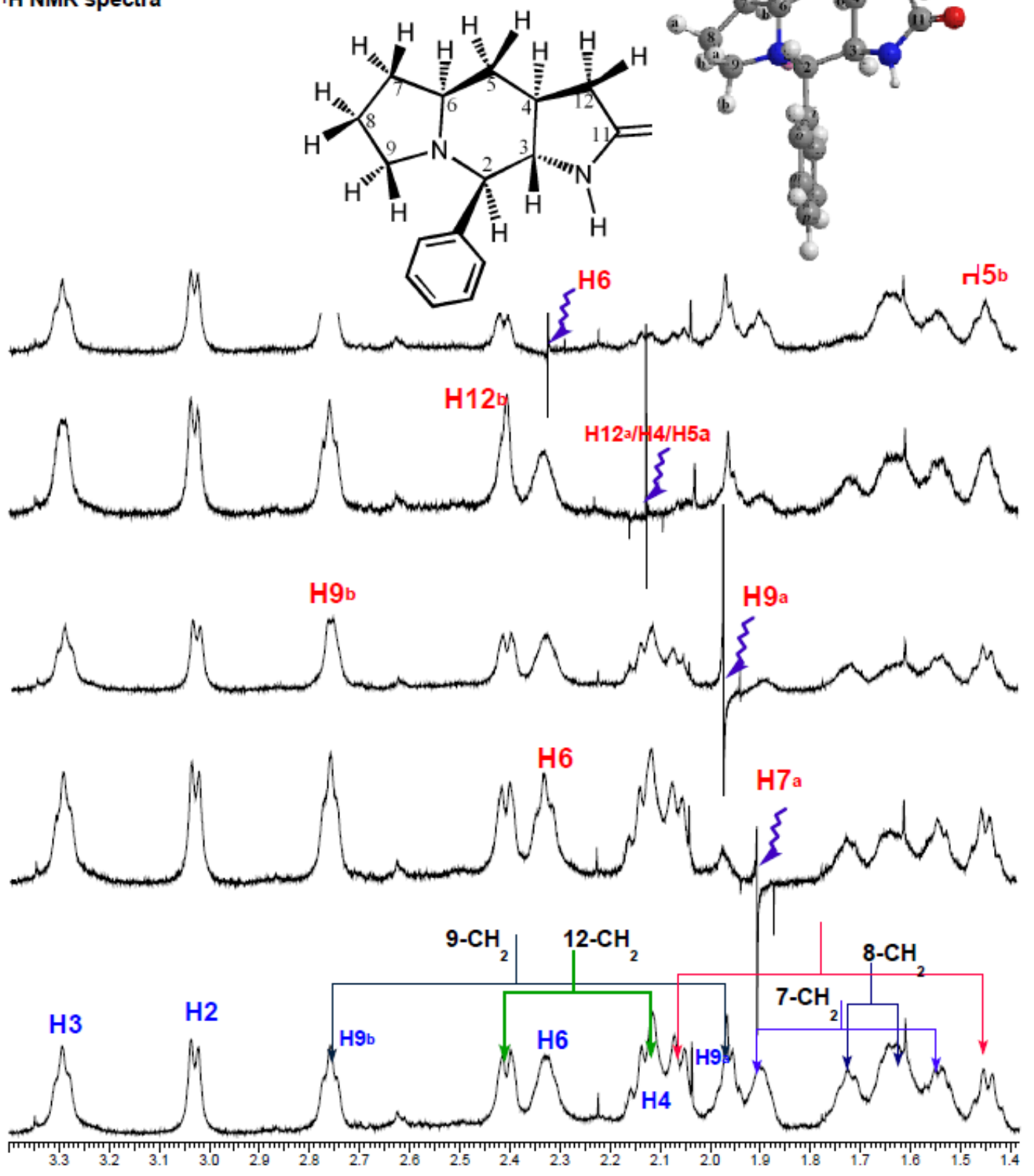
Series of selective decoupled iH NMR spectra

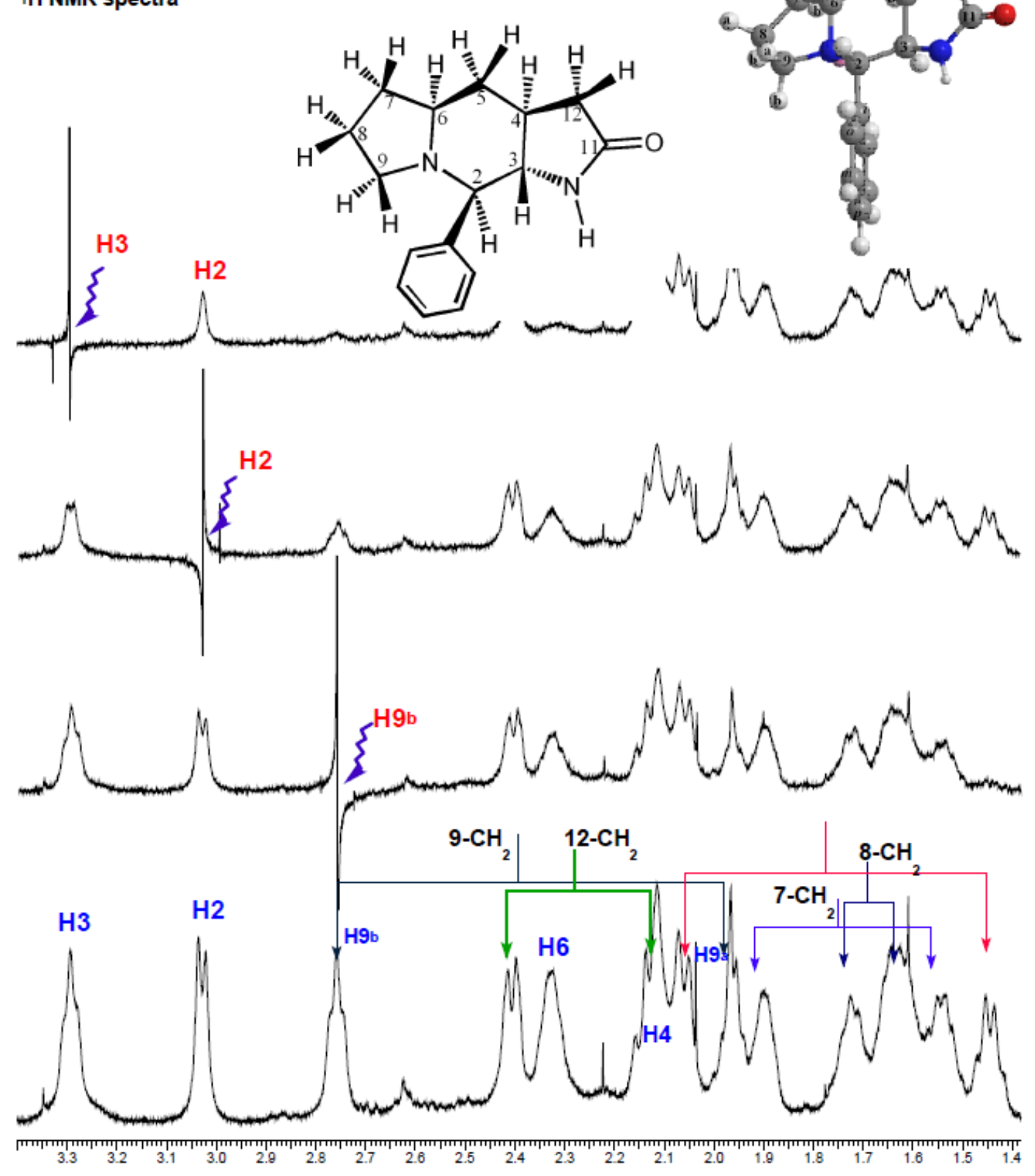




\section{Series of 1D TOCSY spectra: Spin system identification}

\section{Selective excitation of $\mathrm{H} 9 \mathrm{~b}$}

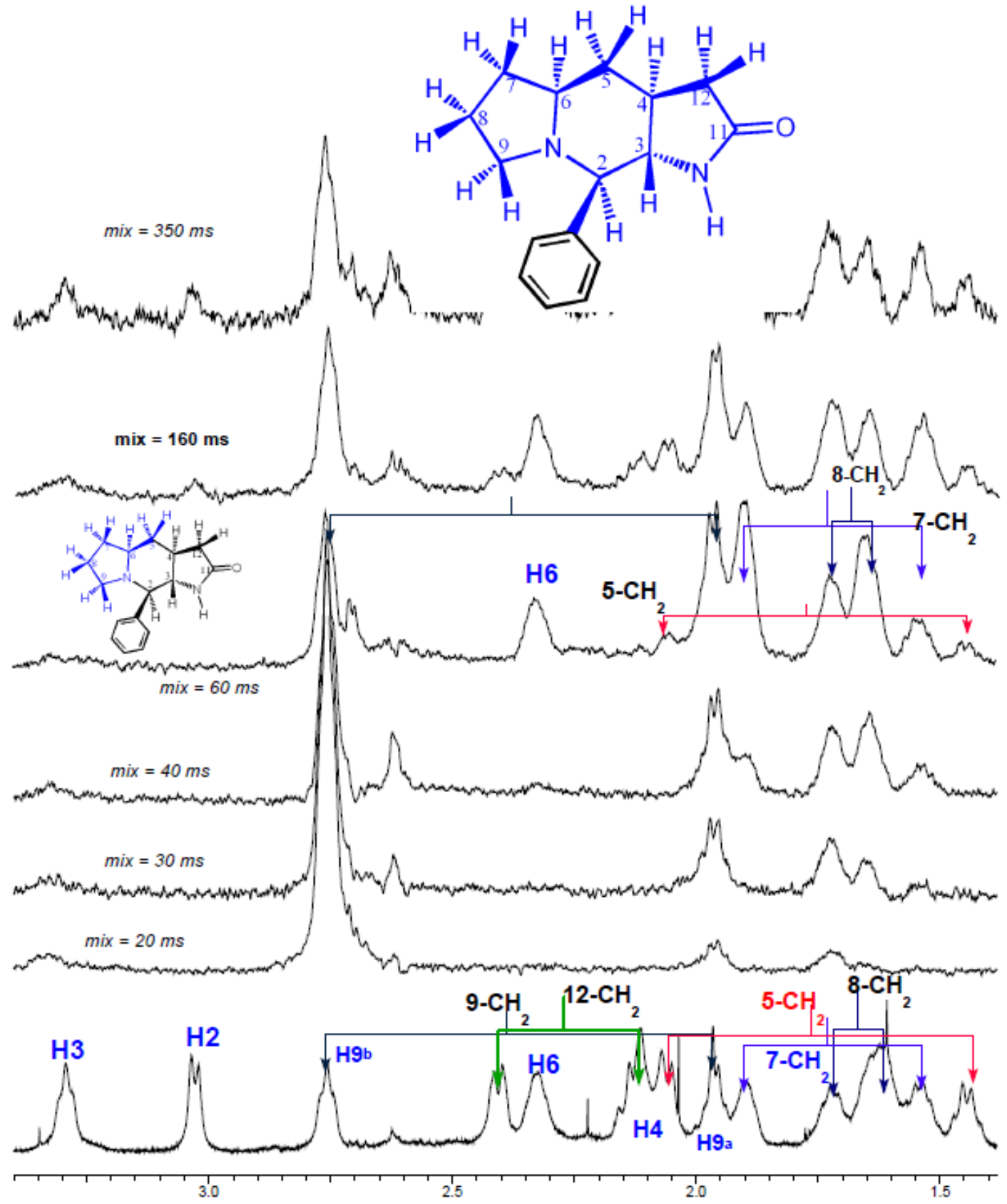


Series of 1D TOCSY spectra:

Selective excitation of $\mathrm{H} 3$

1

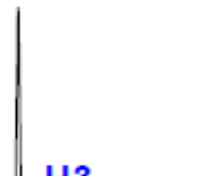

$\mathrm{H} 2$

mix $=80 \mathrm{~ms}$

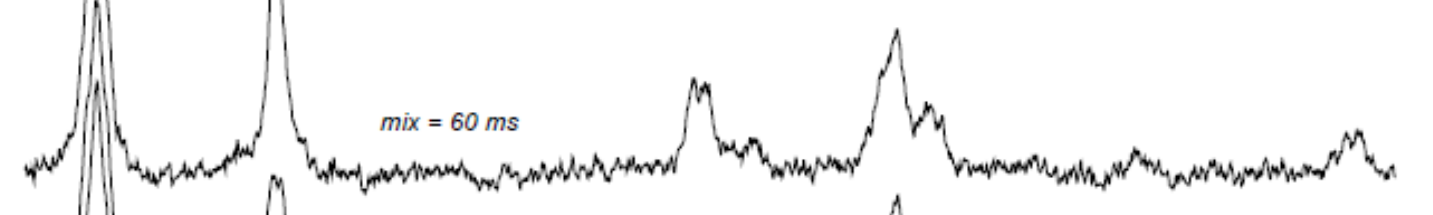
.

mix $=40 \mathrm{~ms}$
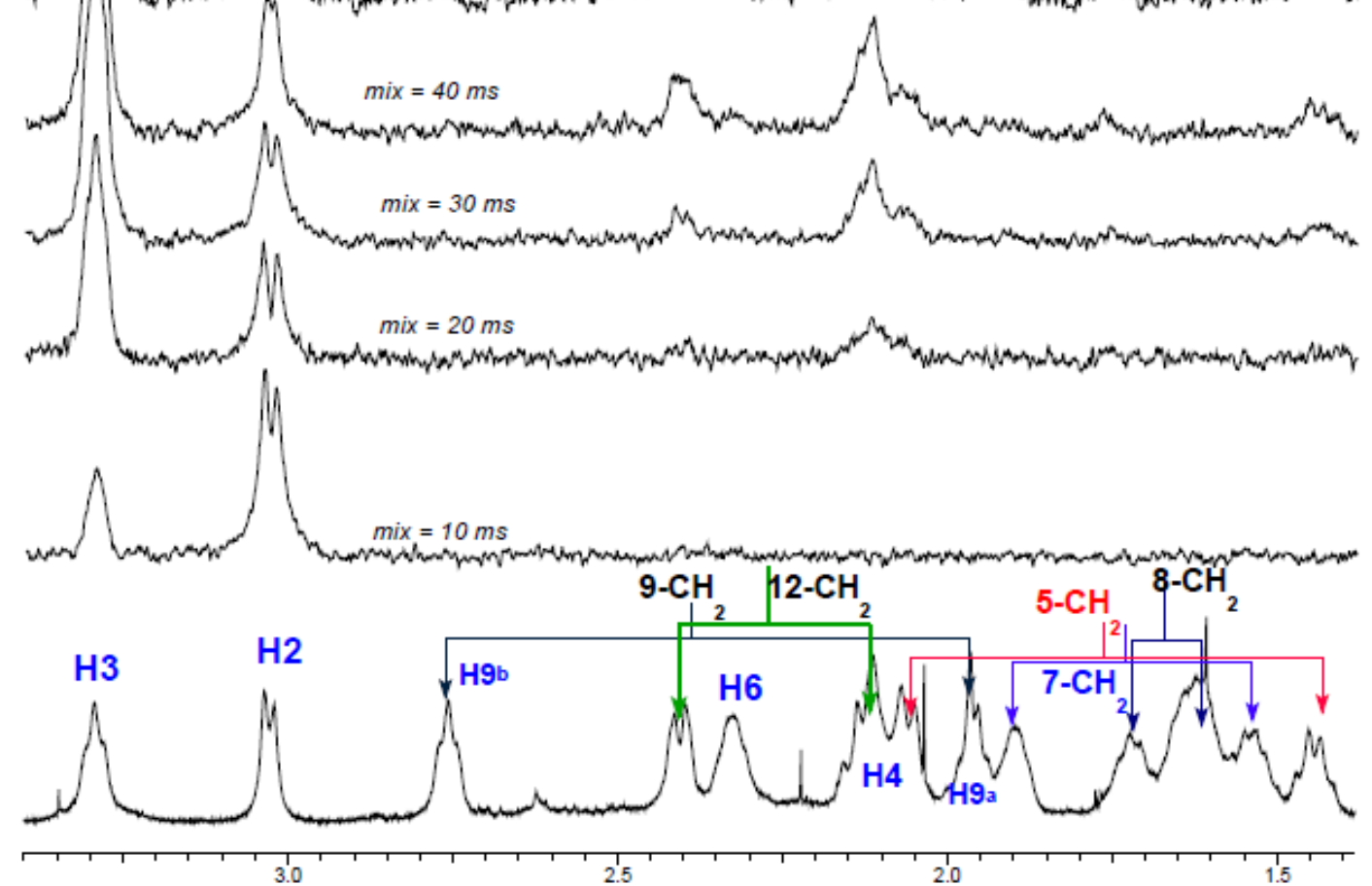


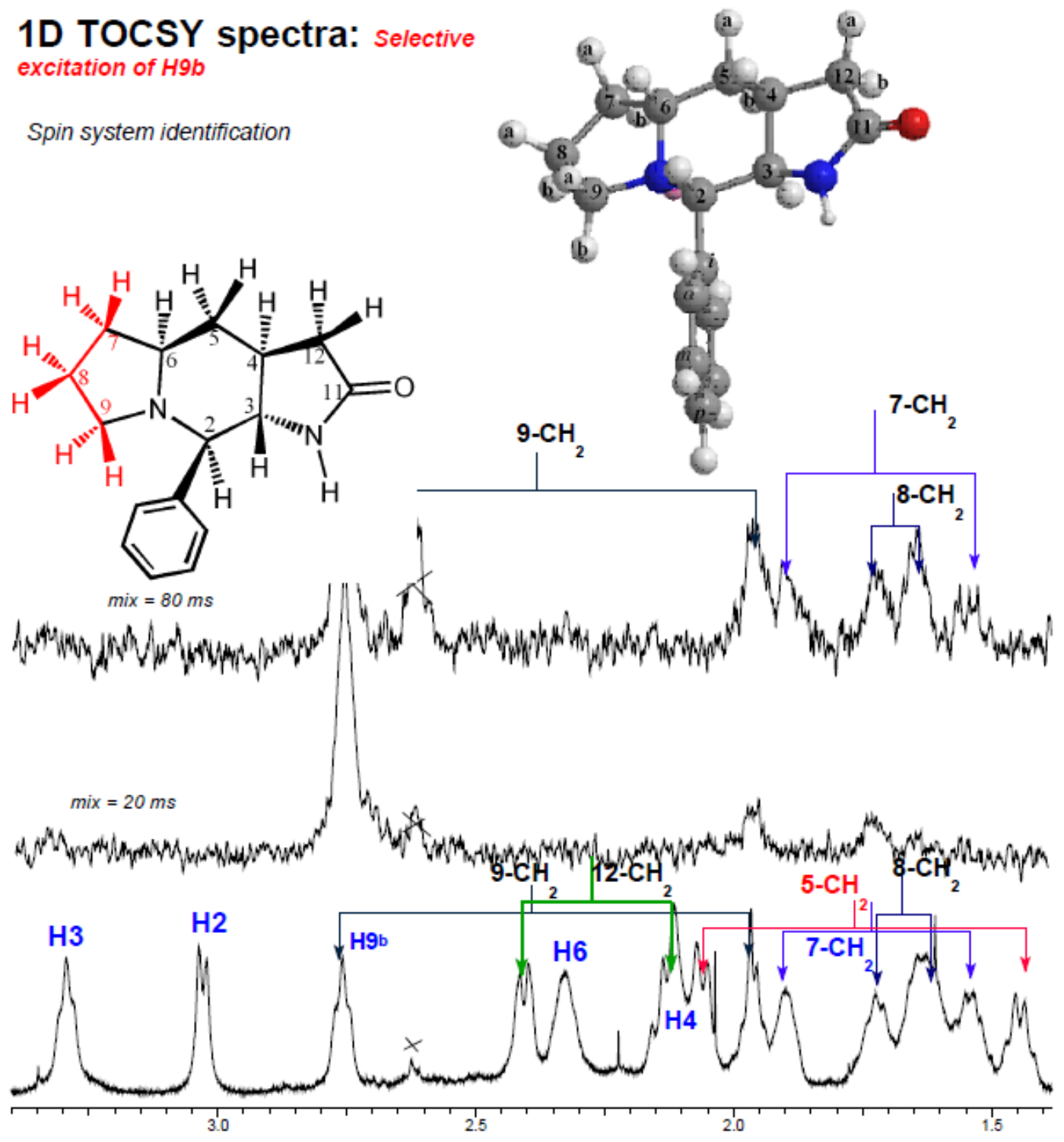




\section{D TOCSY spectrum: selective

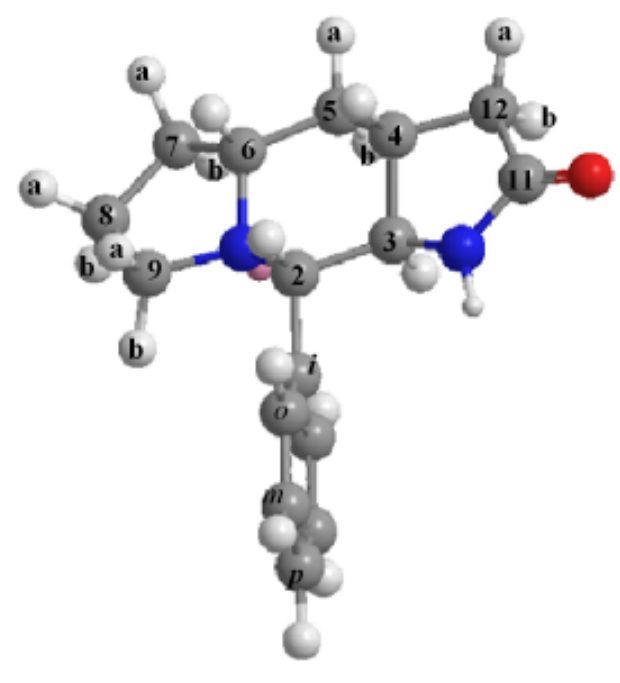

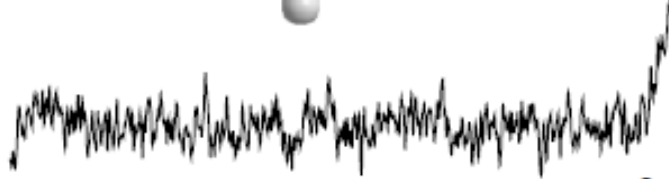

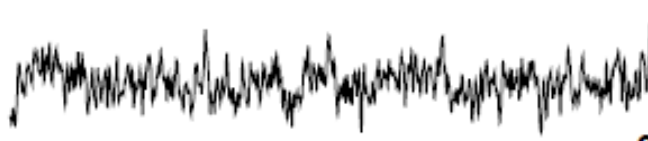

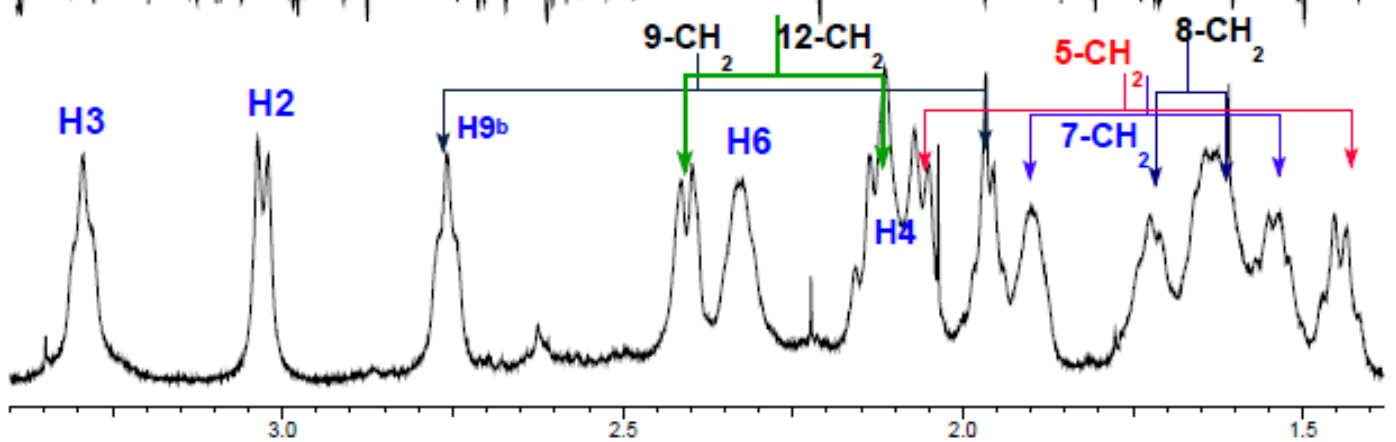

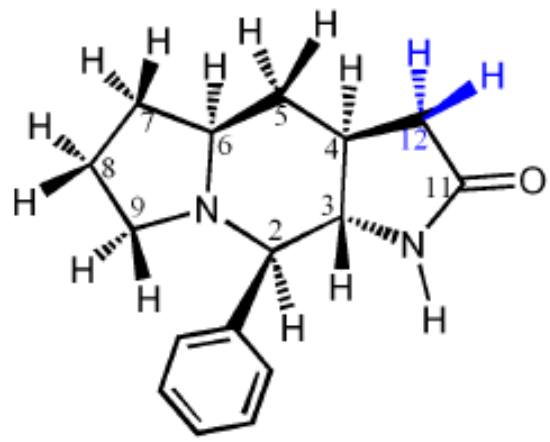




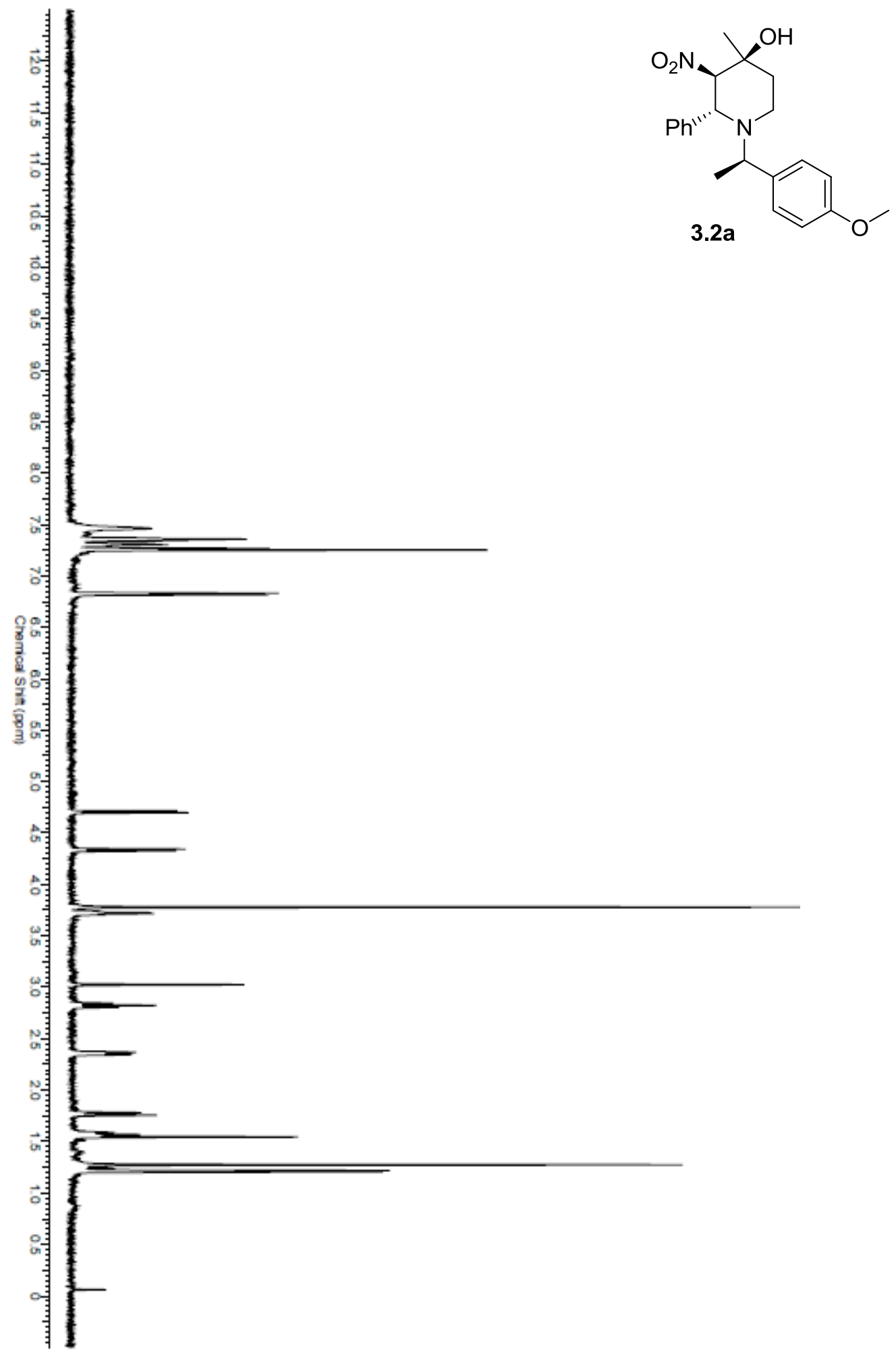




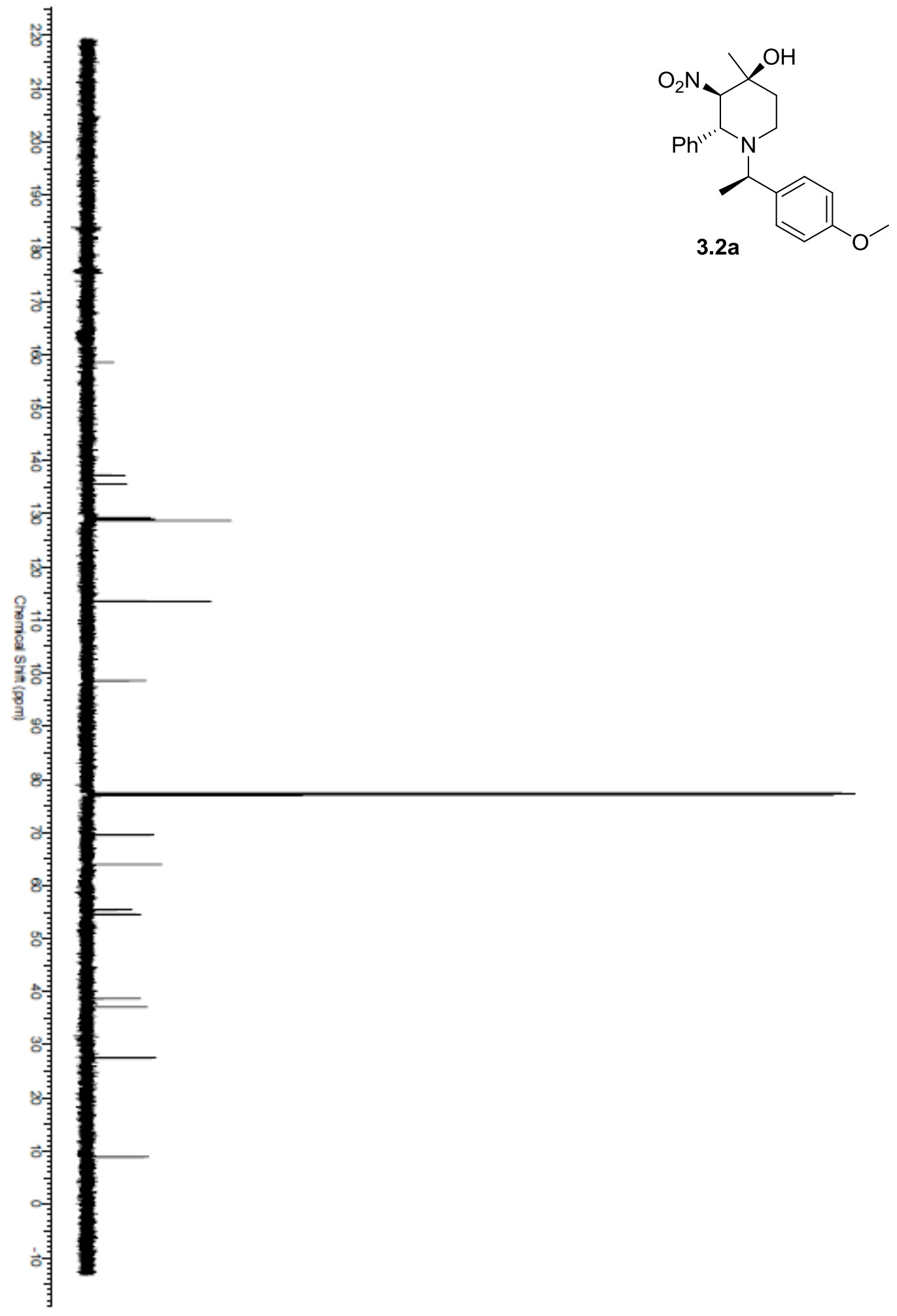




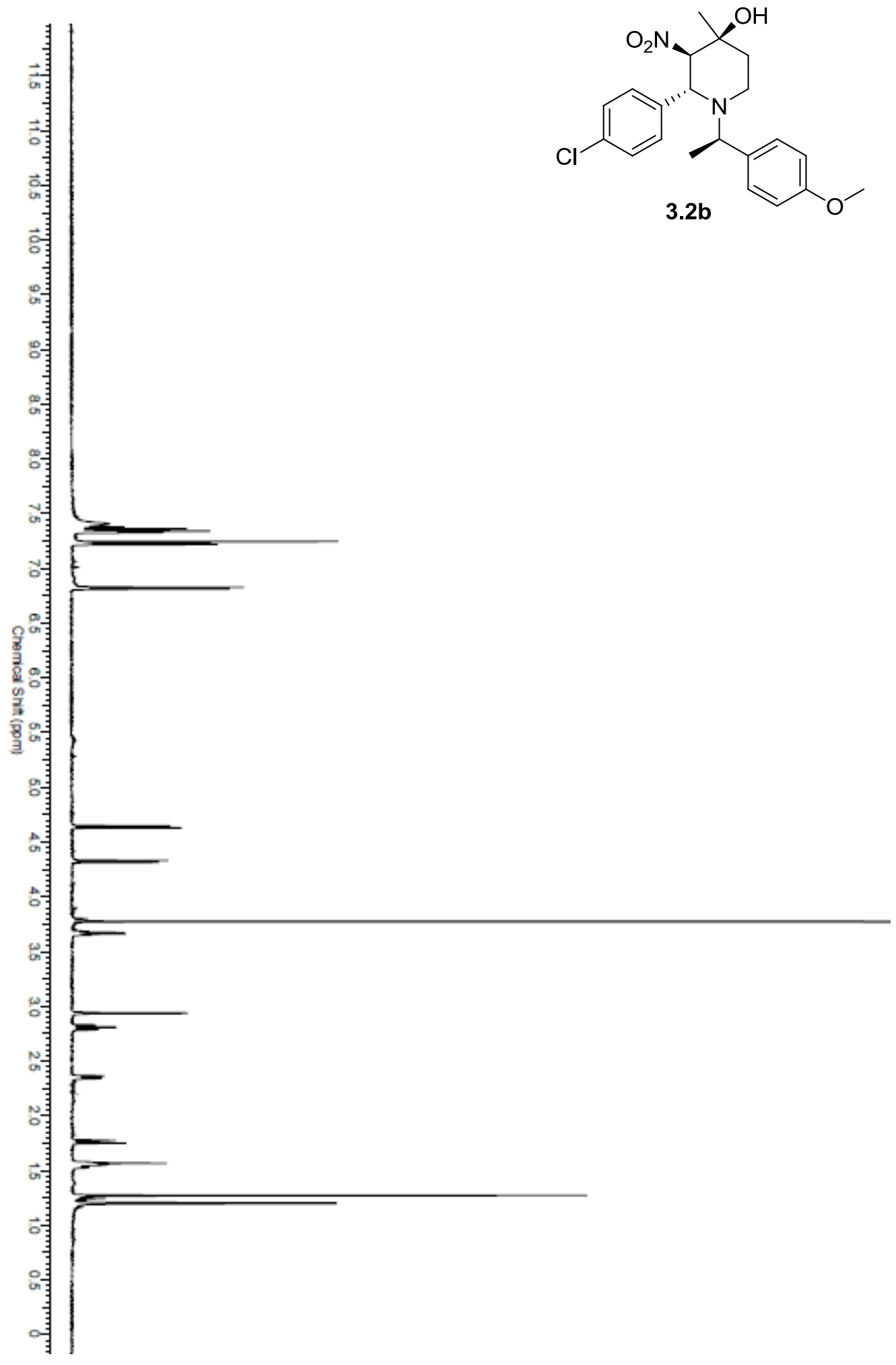




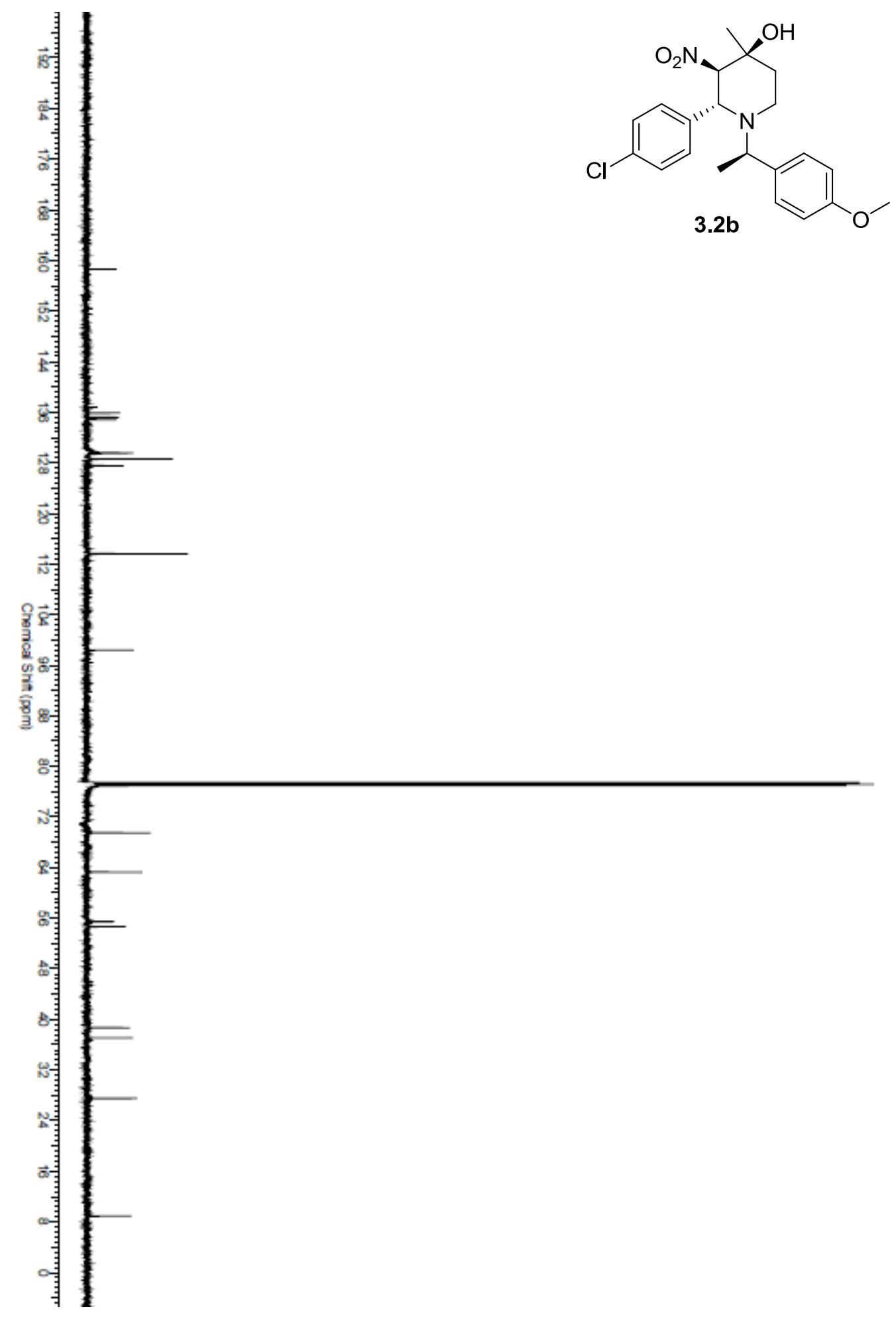




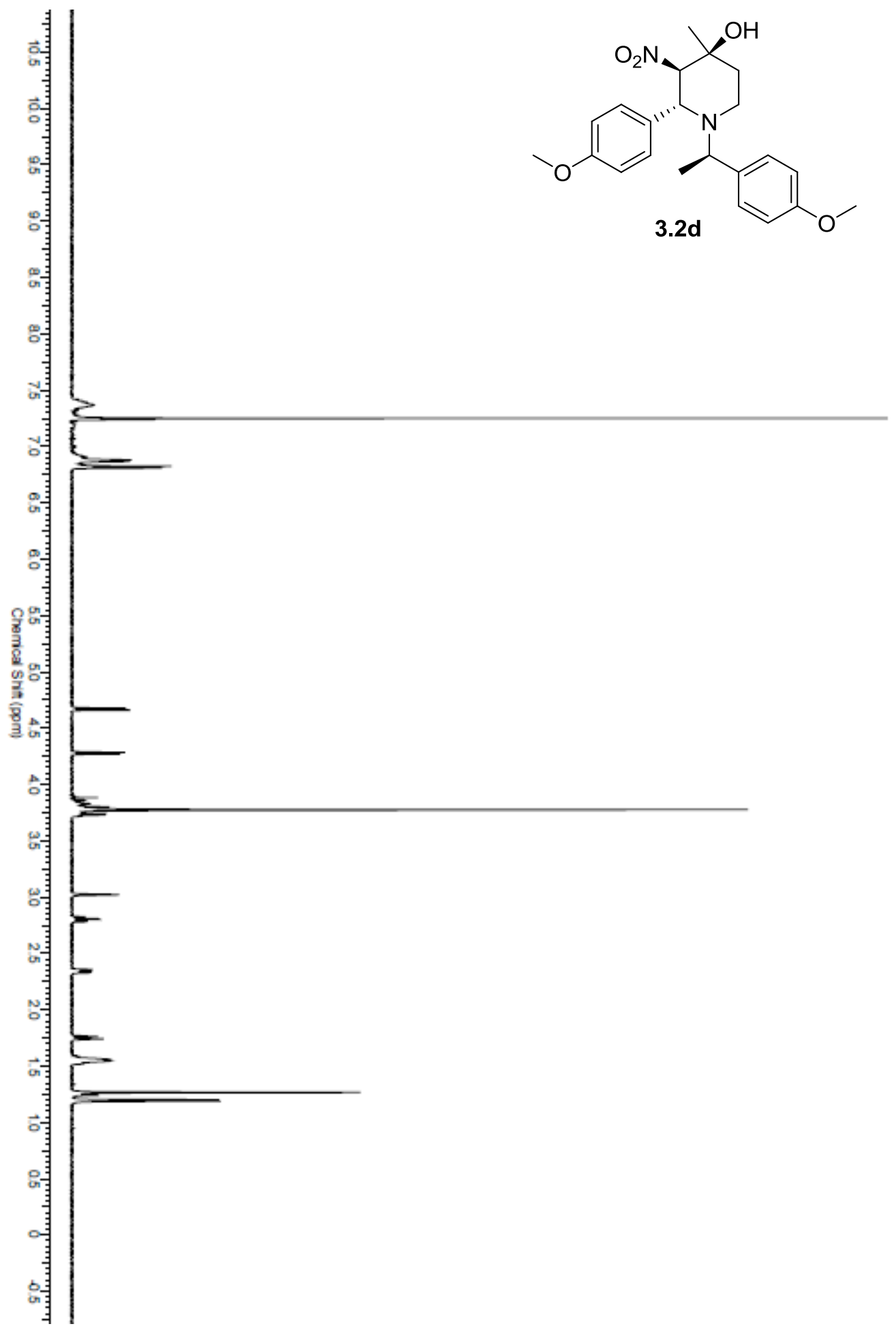




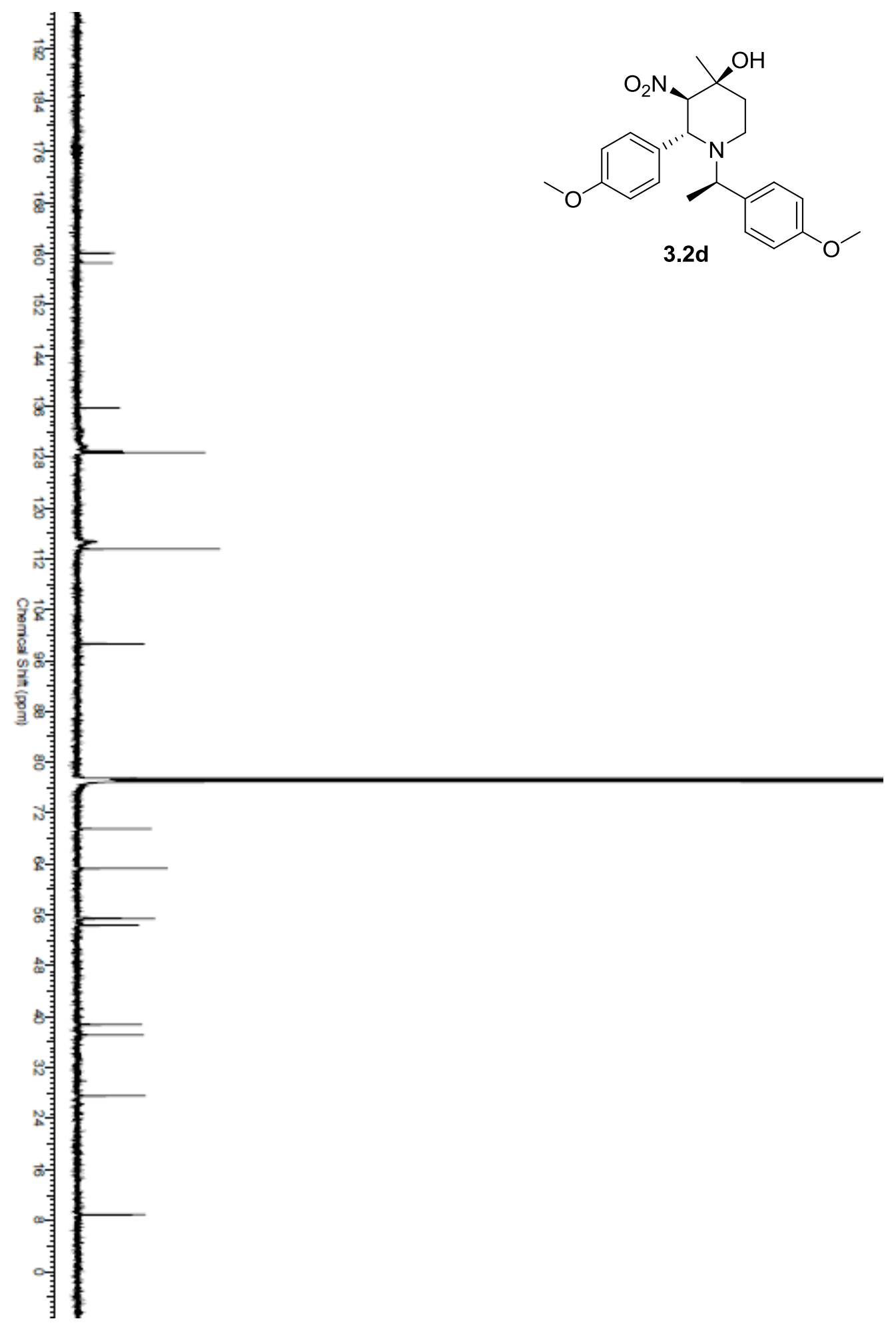




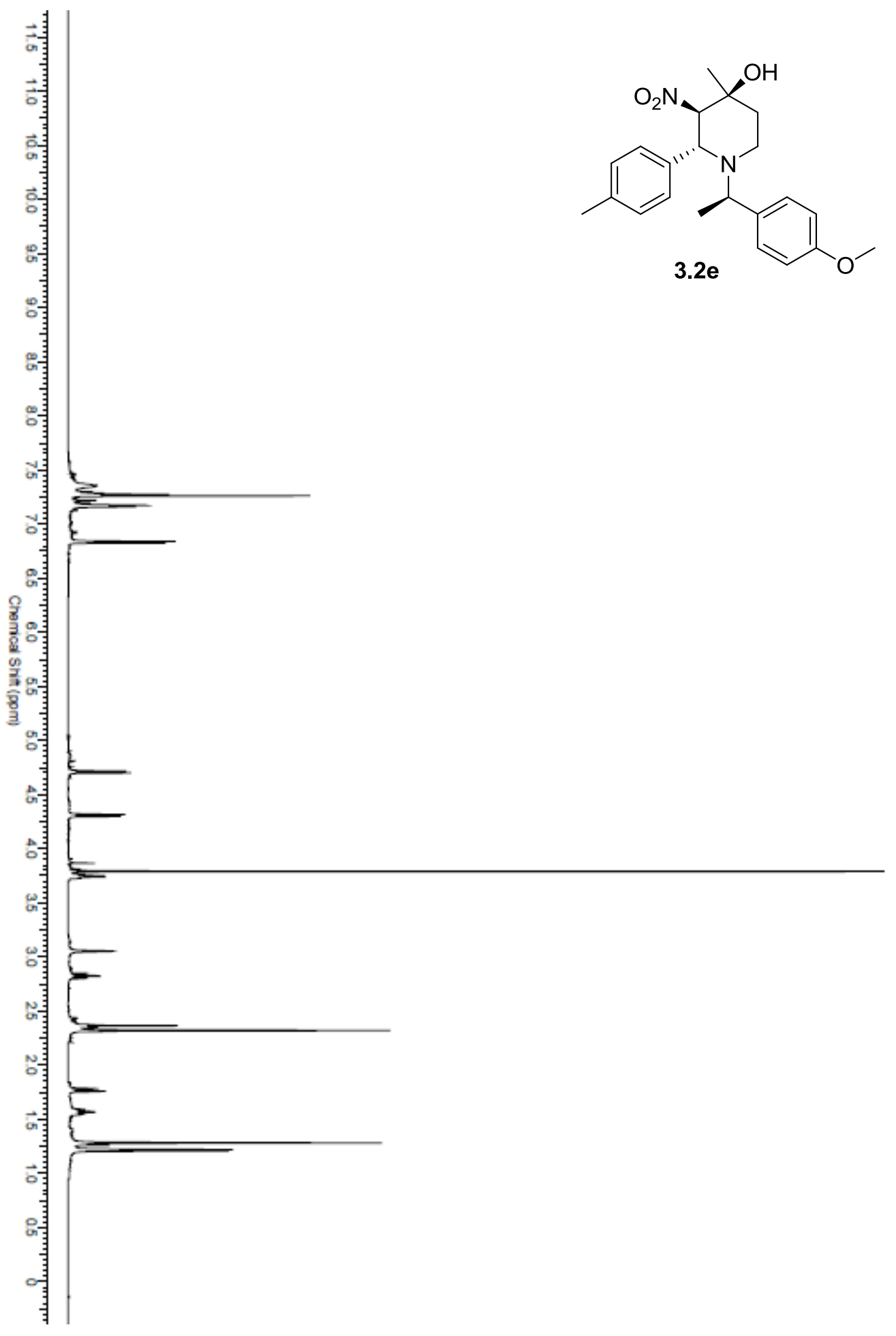




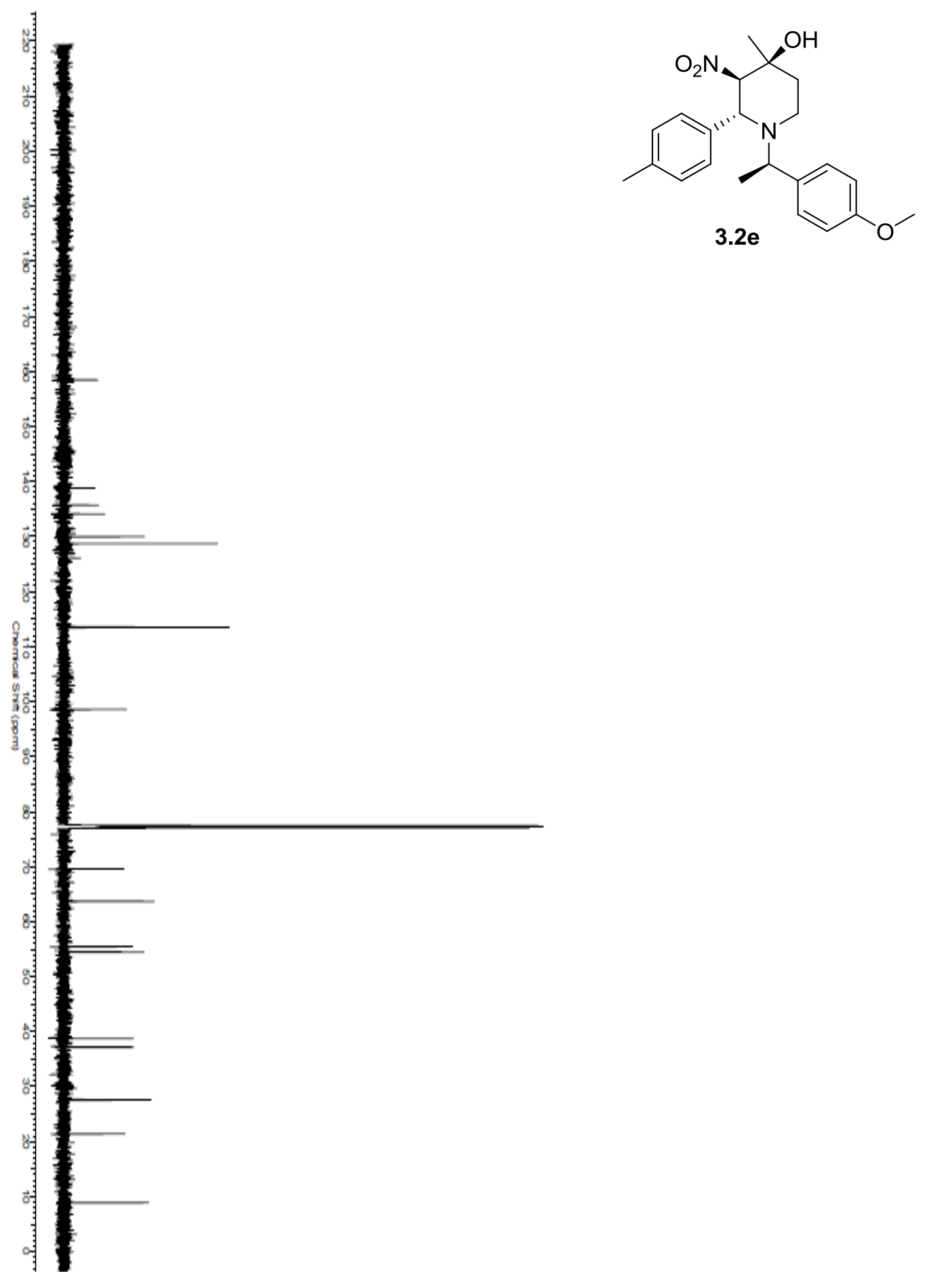




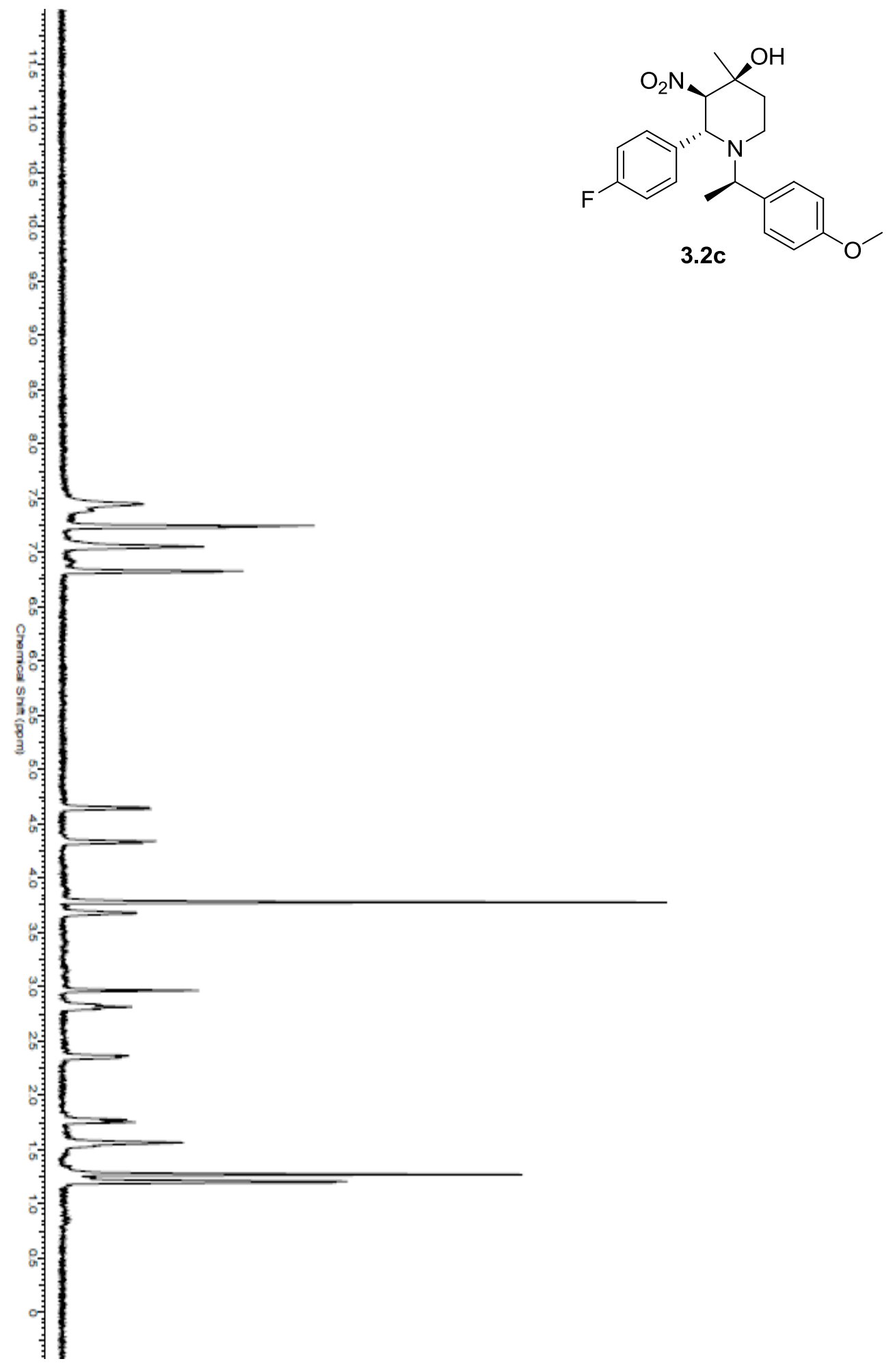




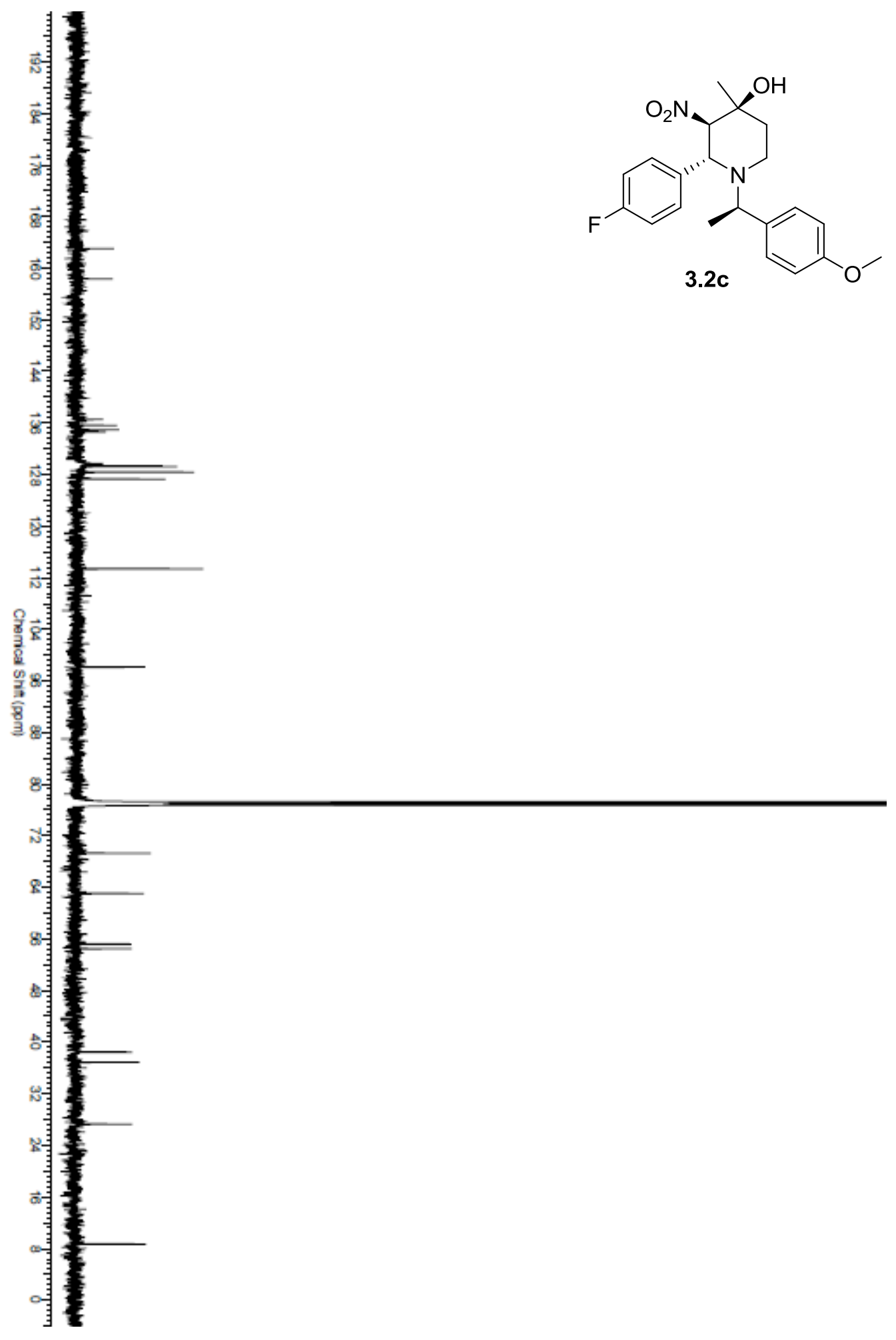



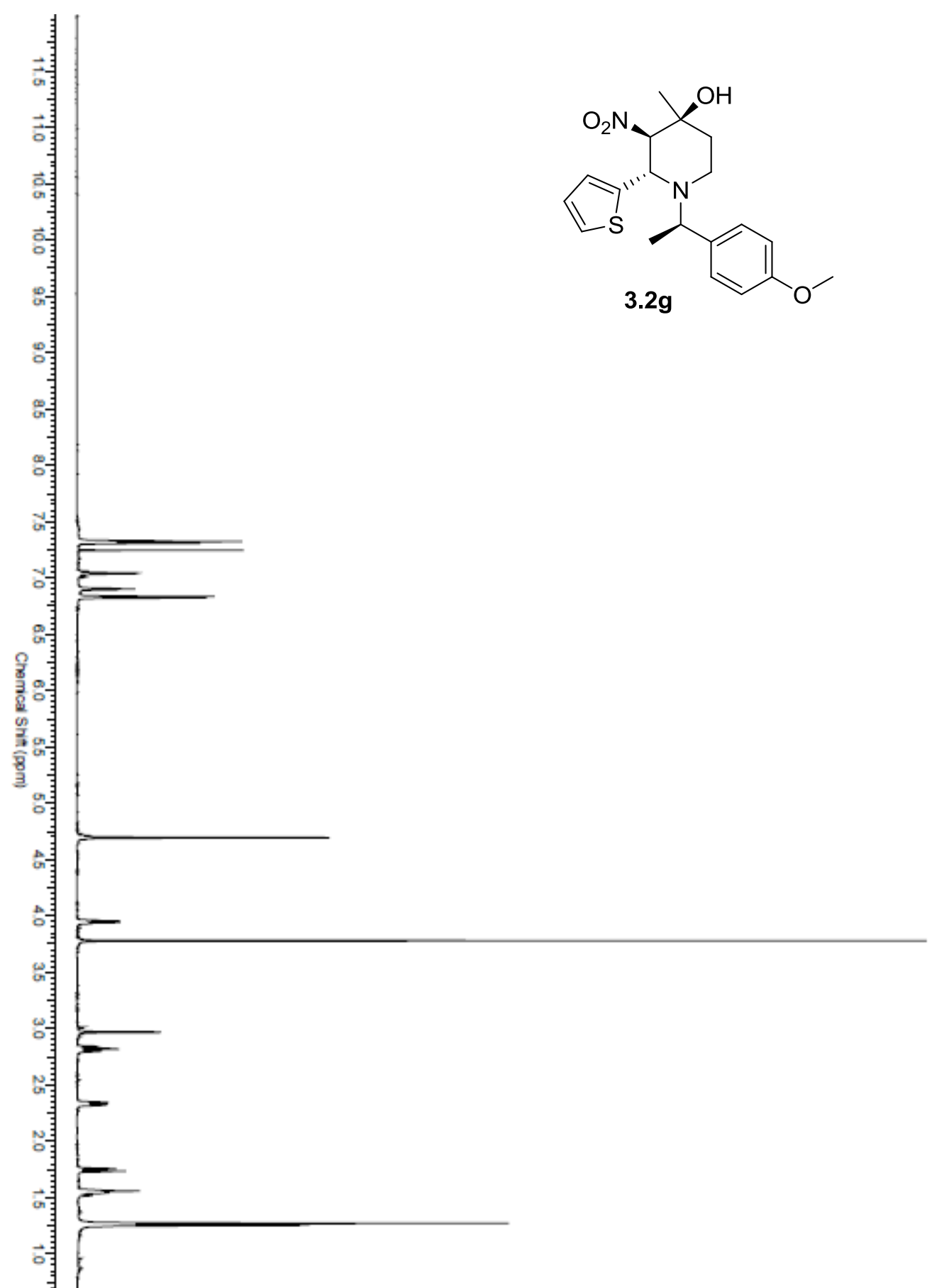

316 


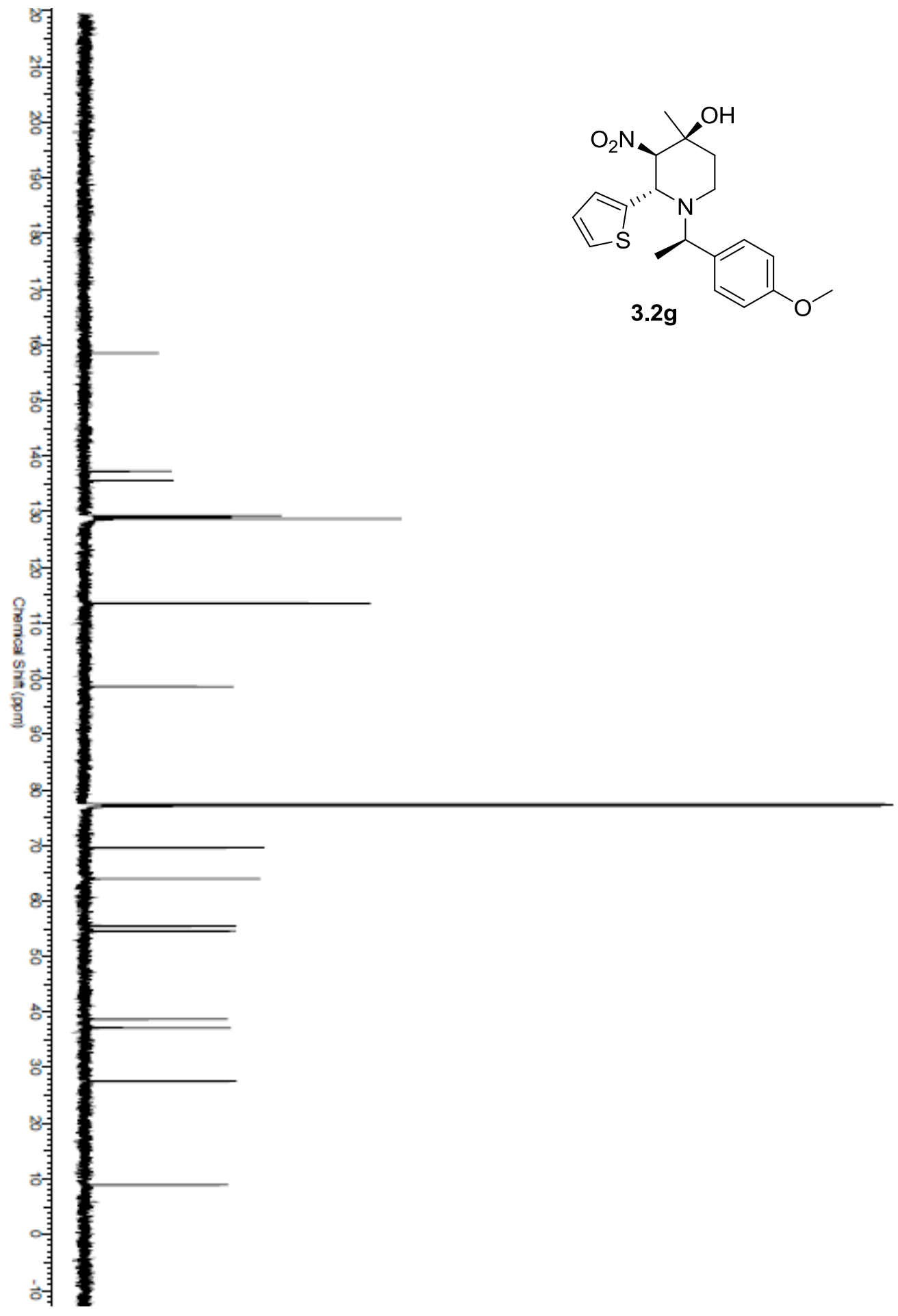




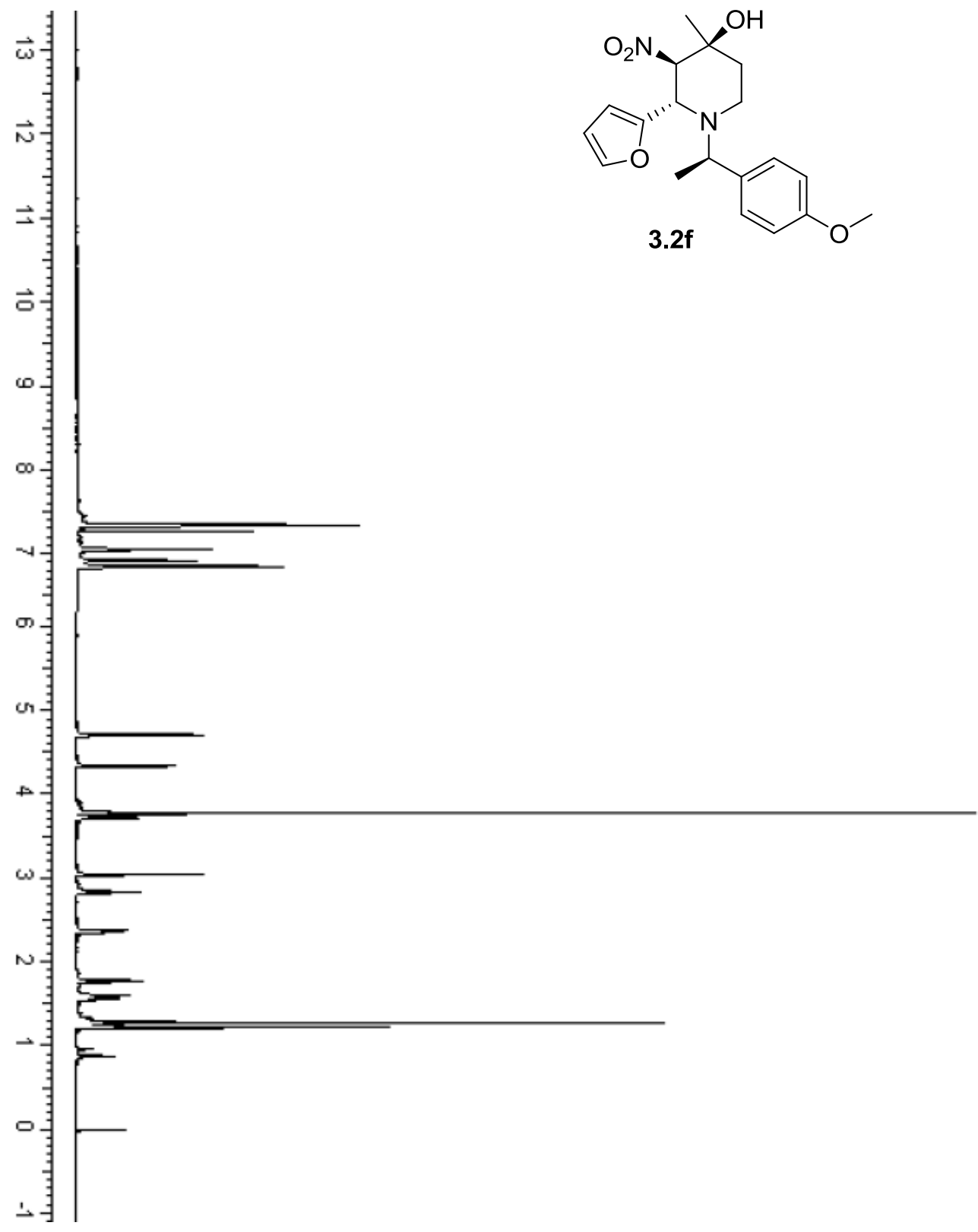




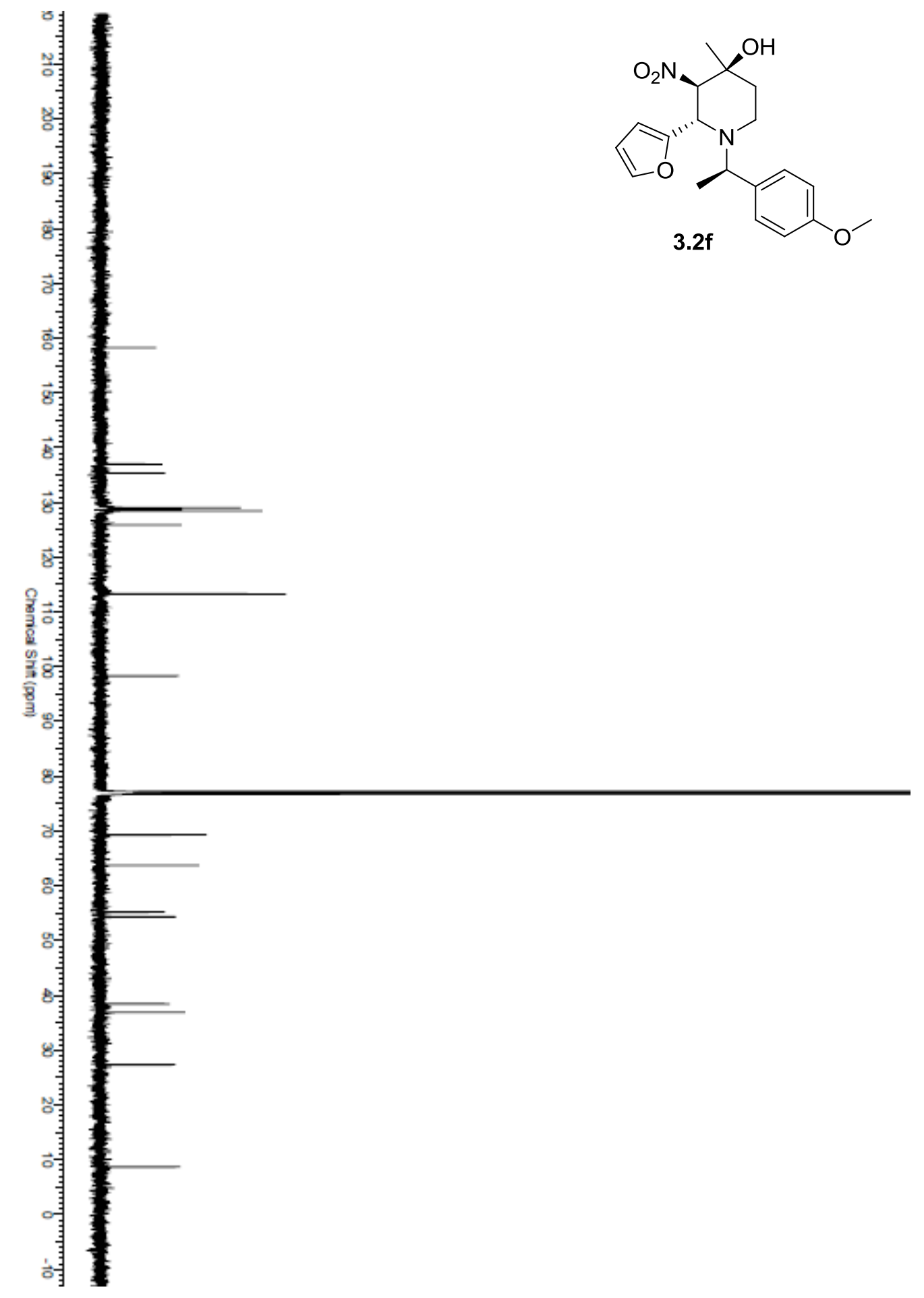




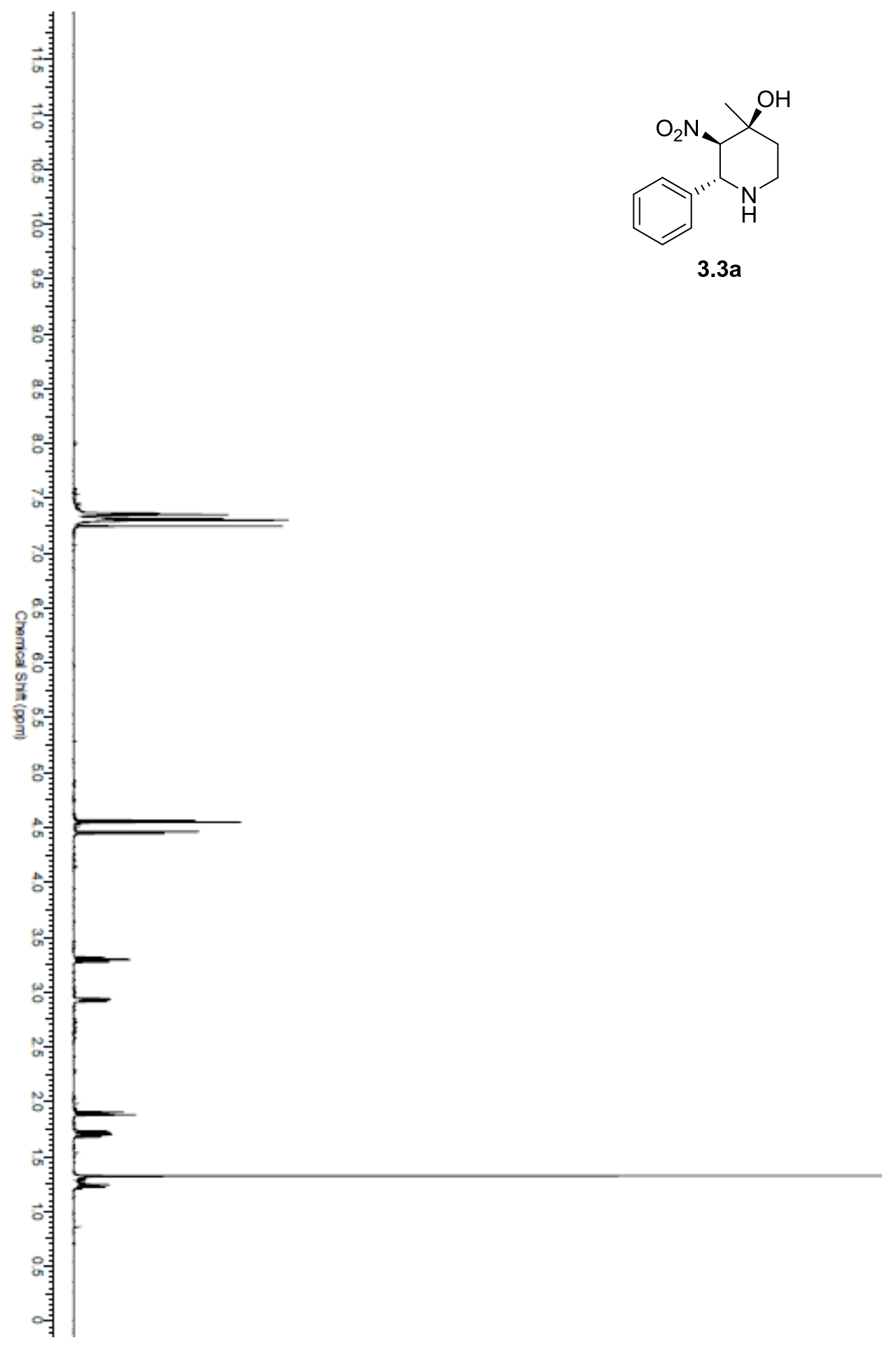




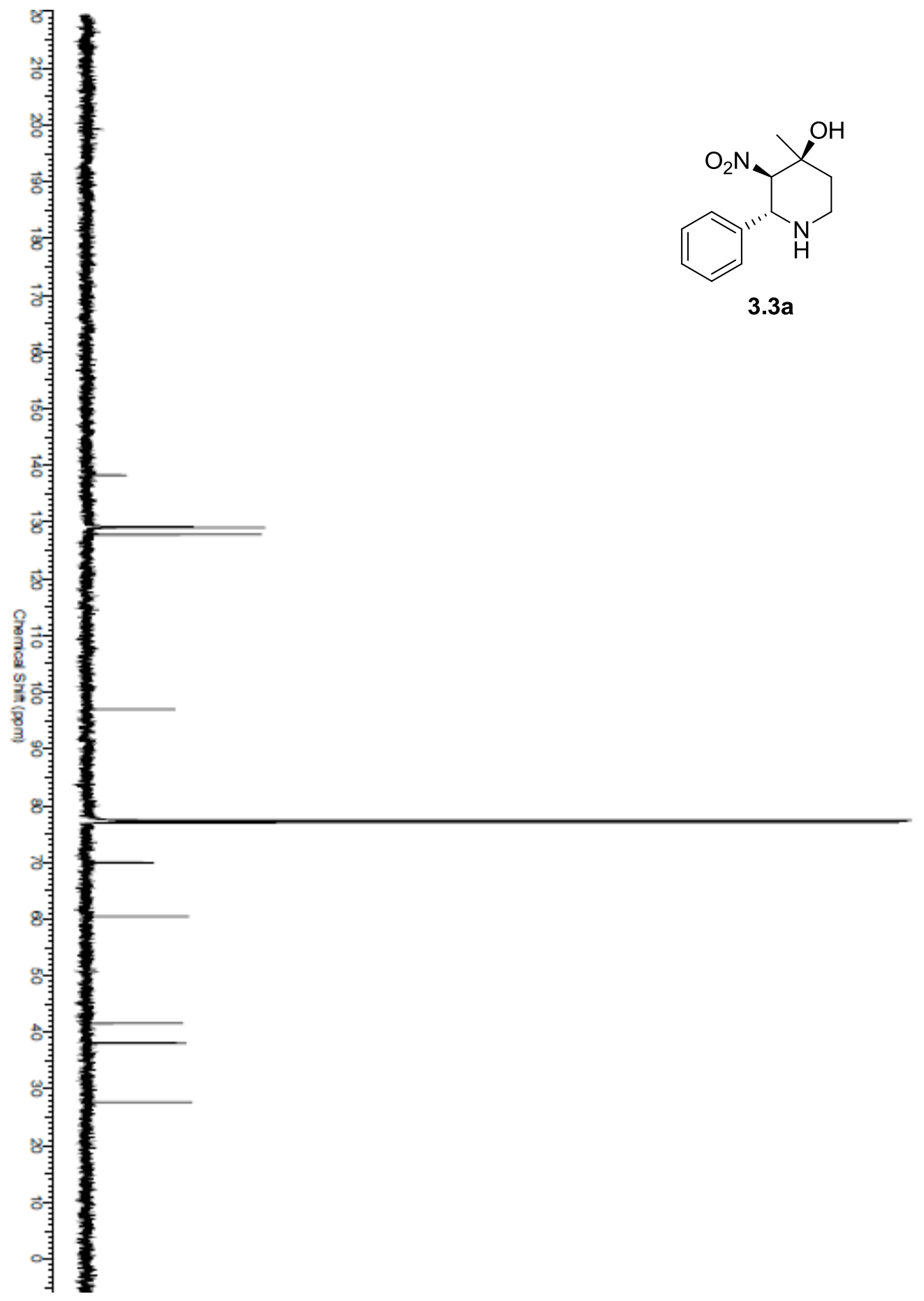




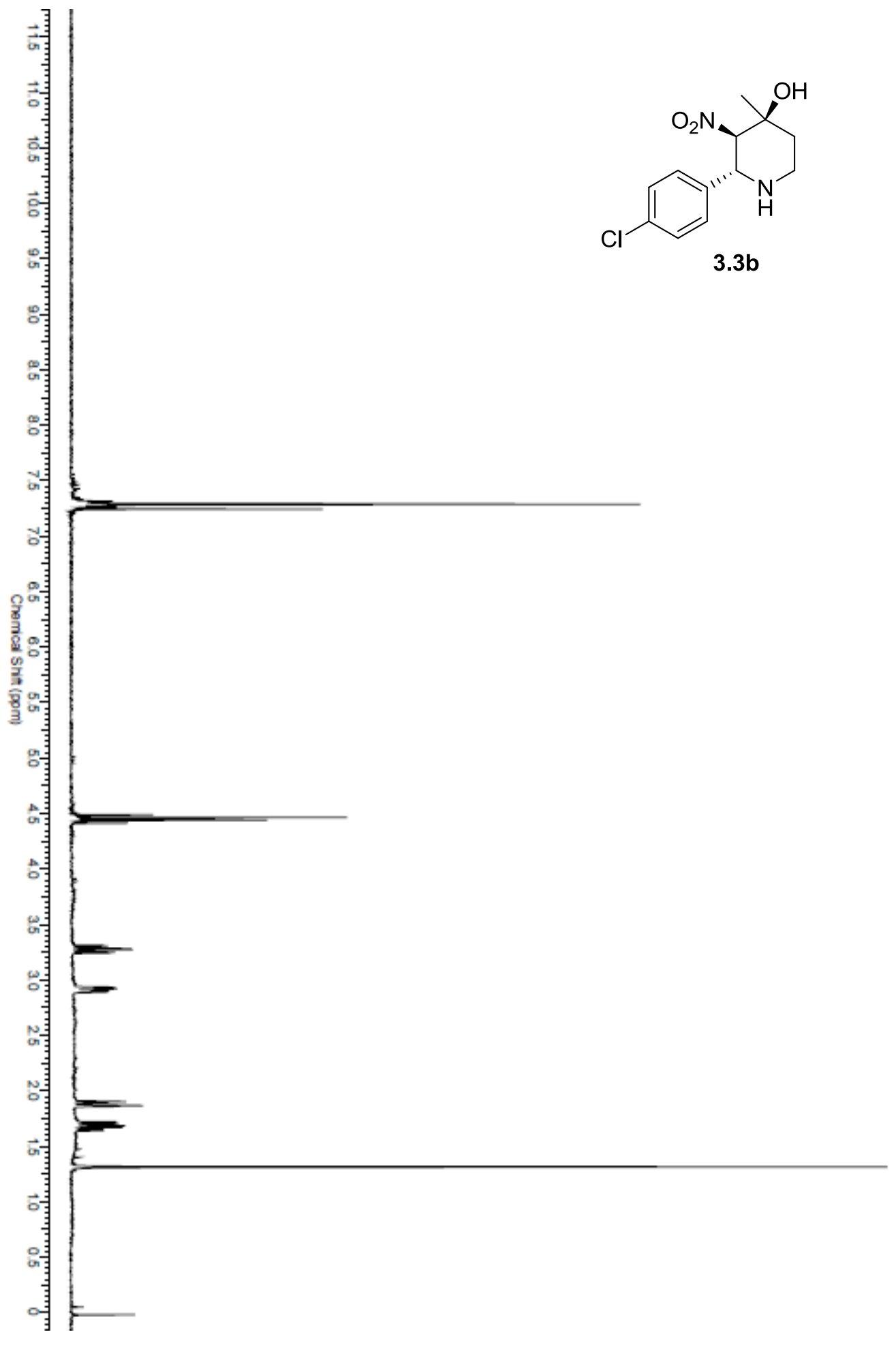




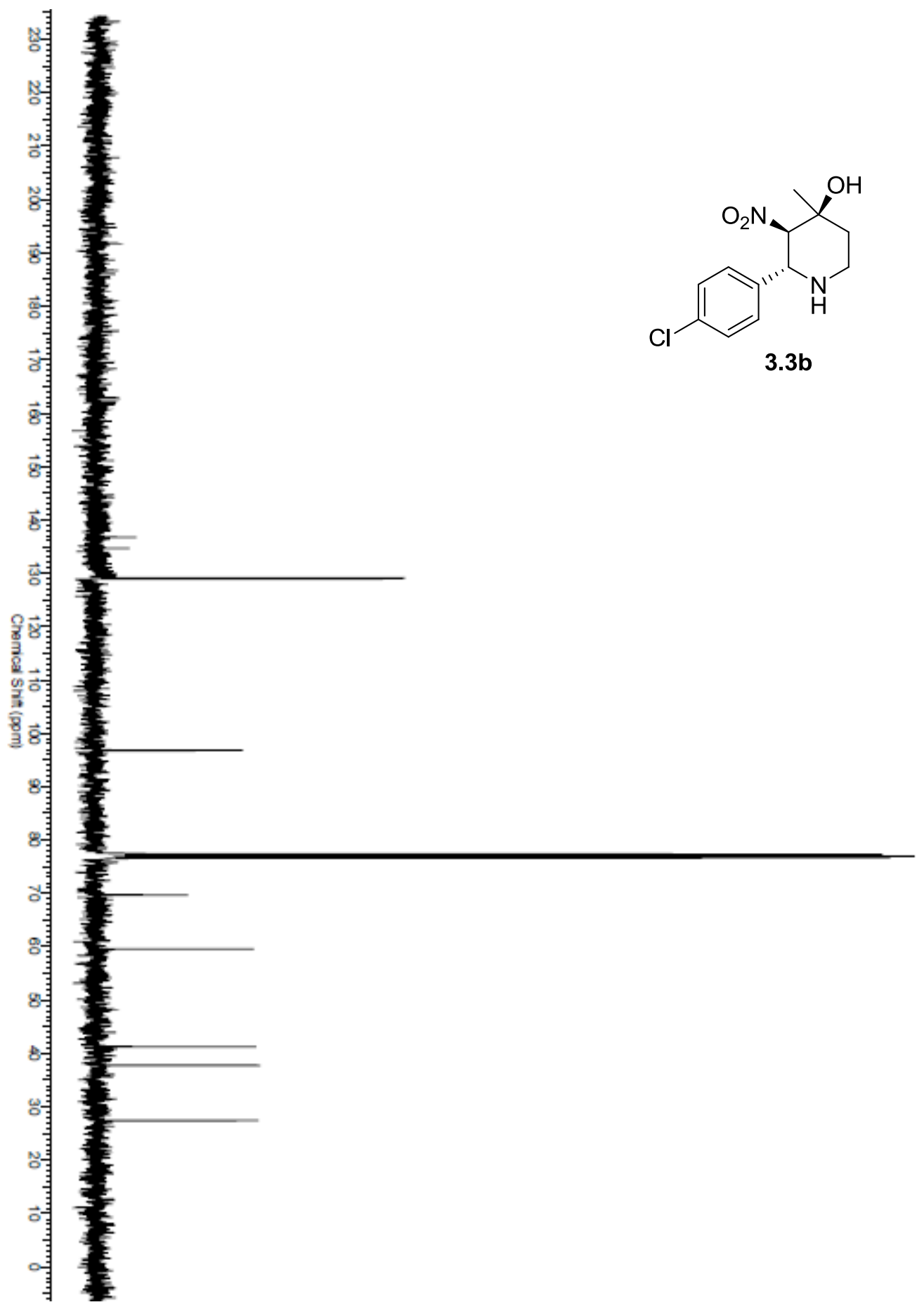




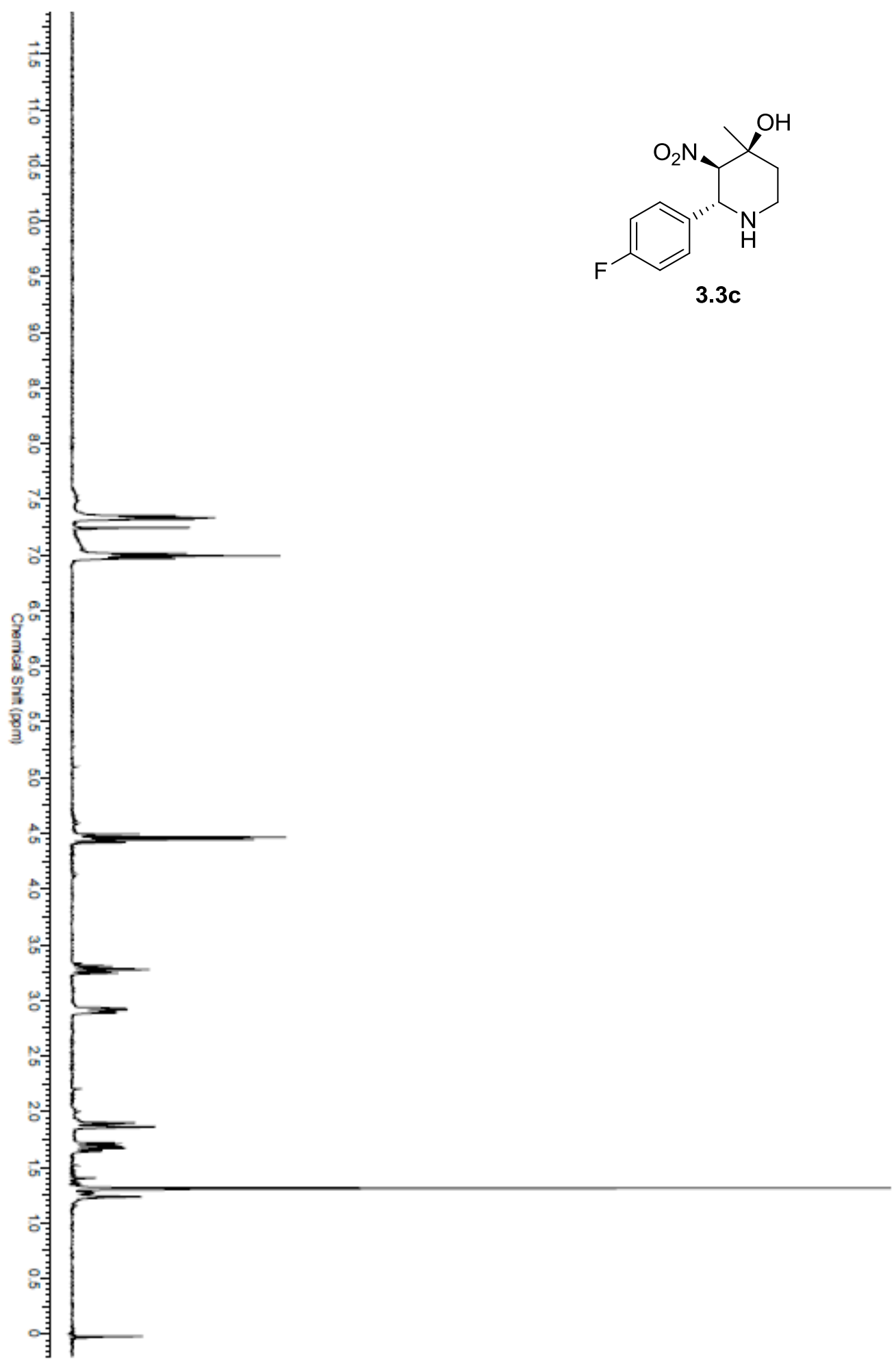




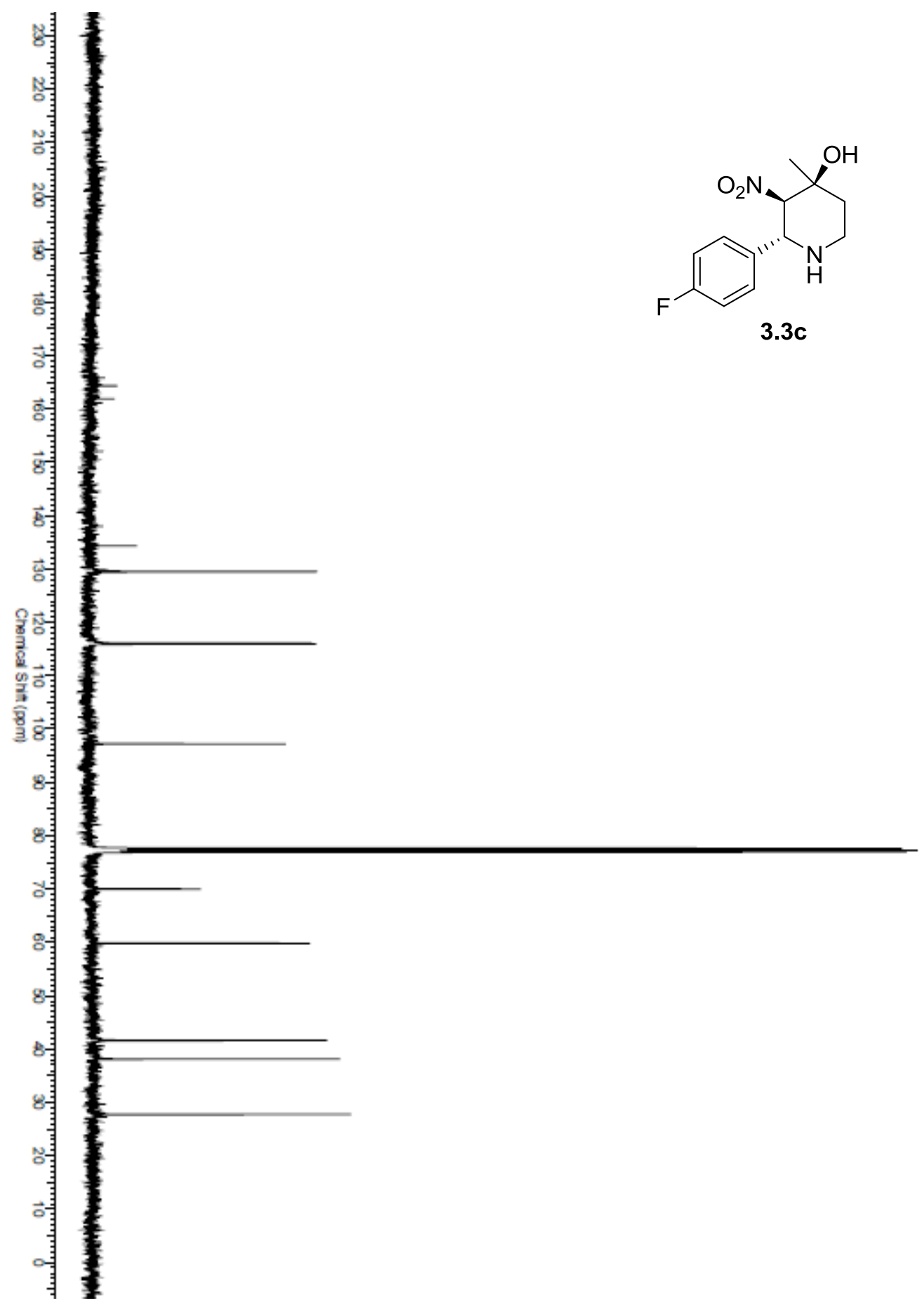




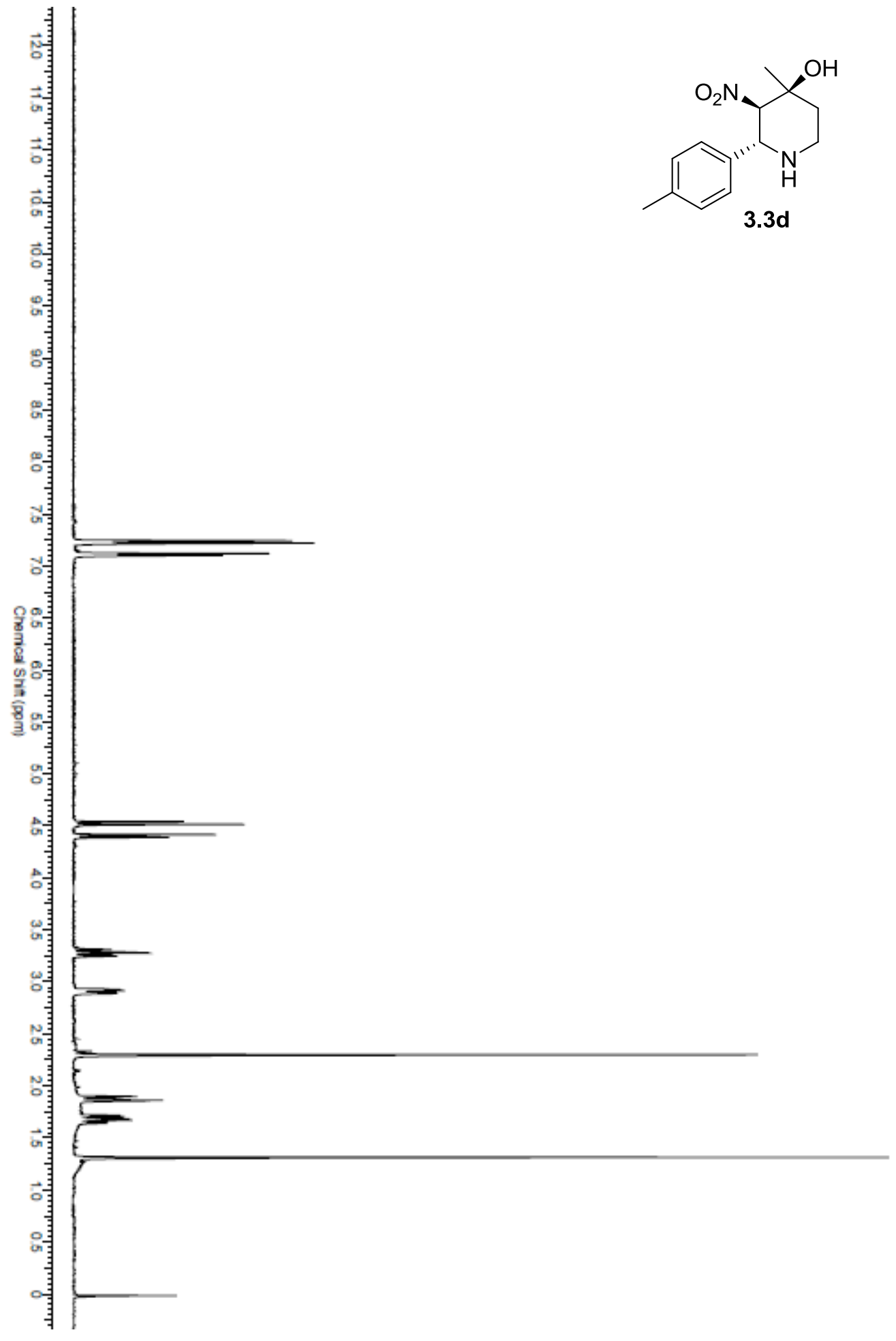




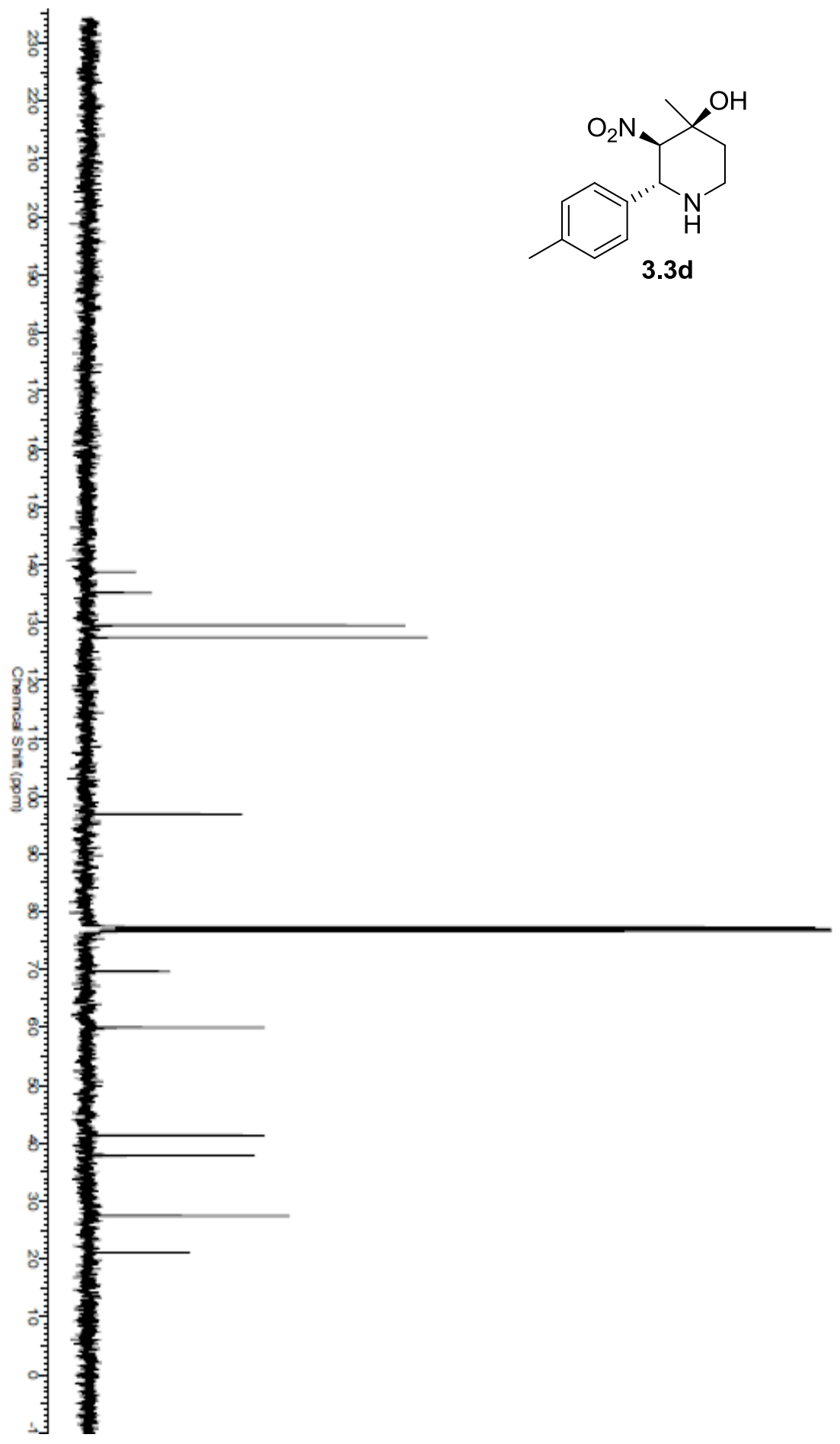




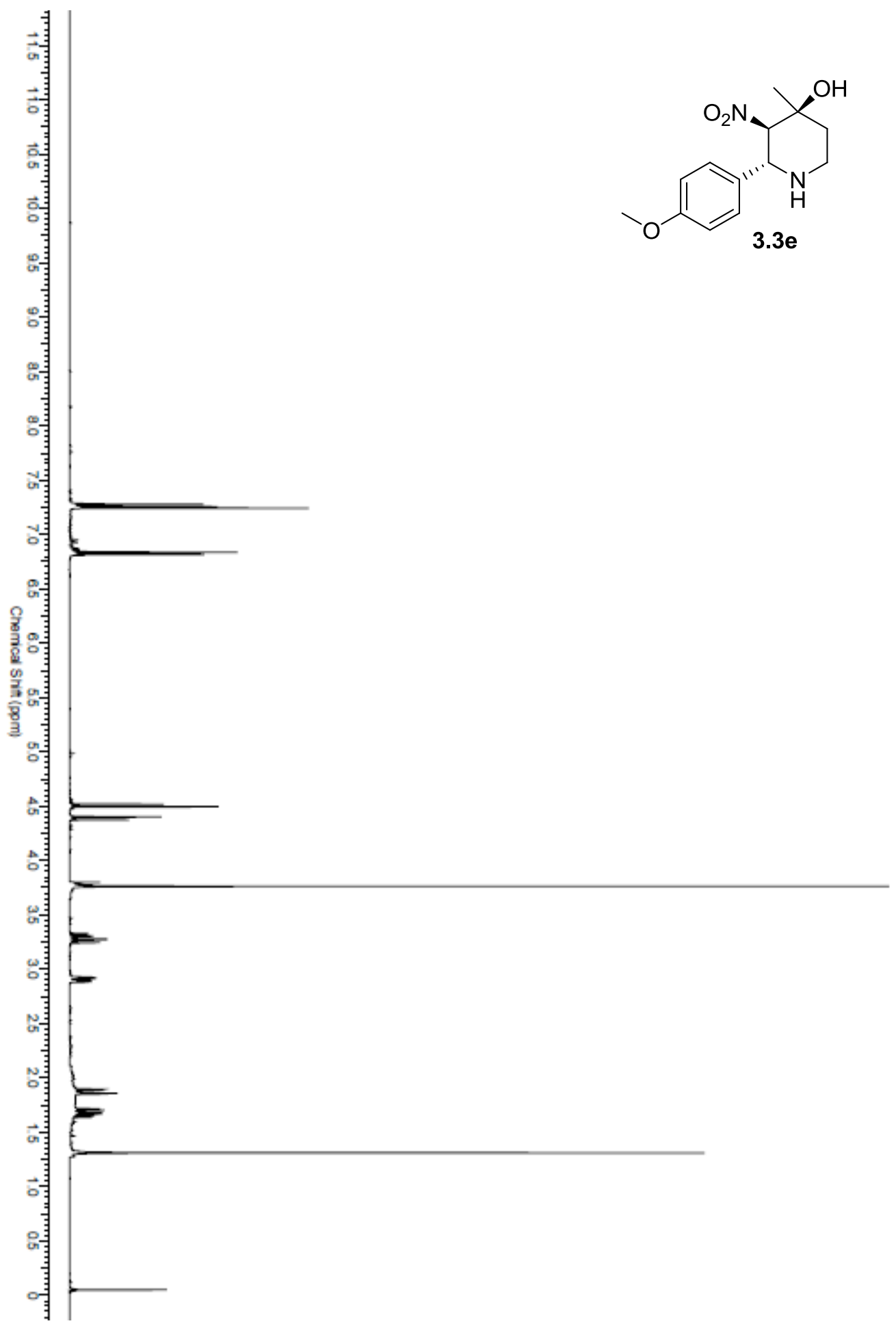




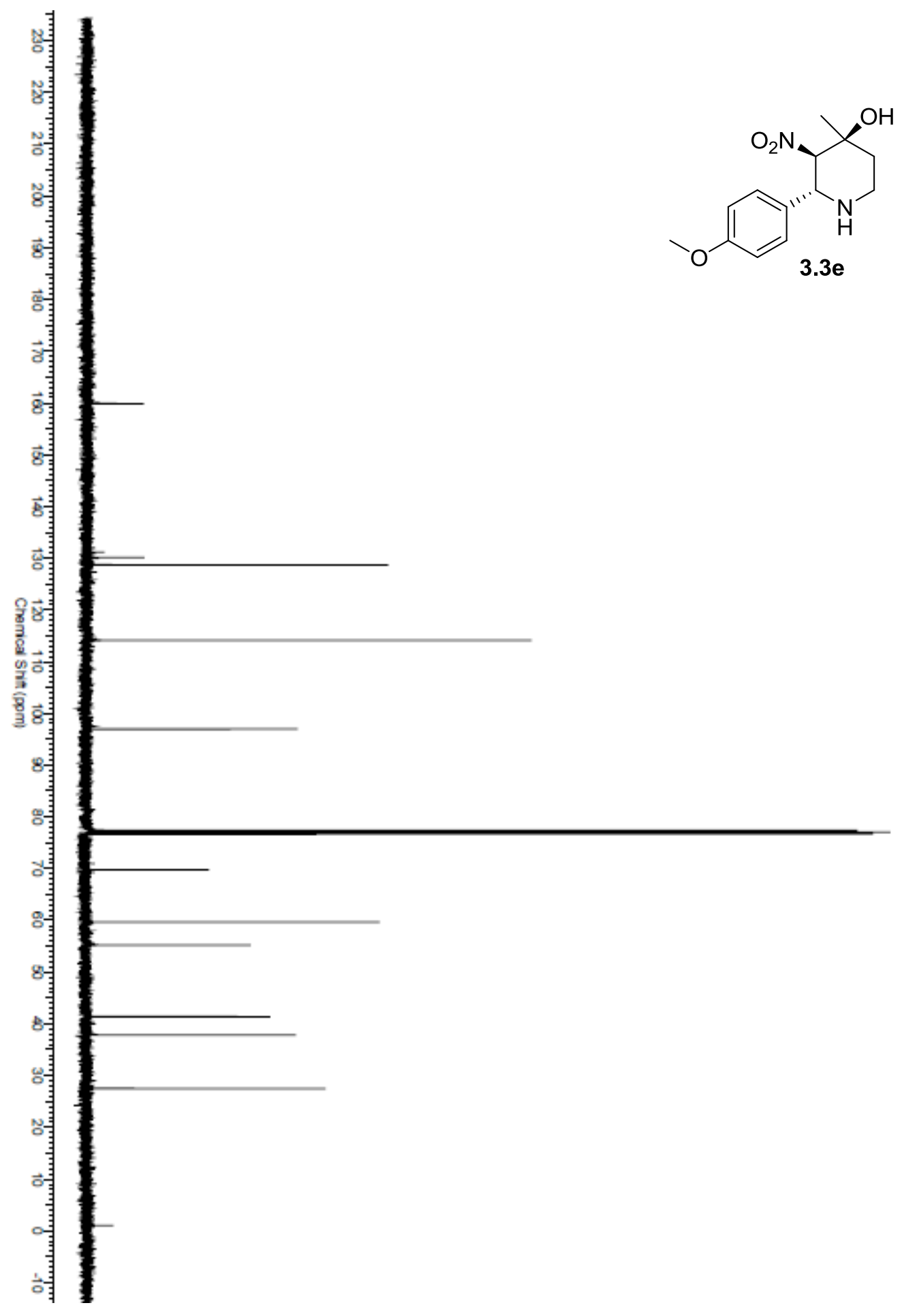




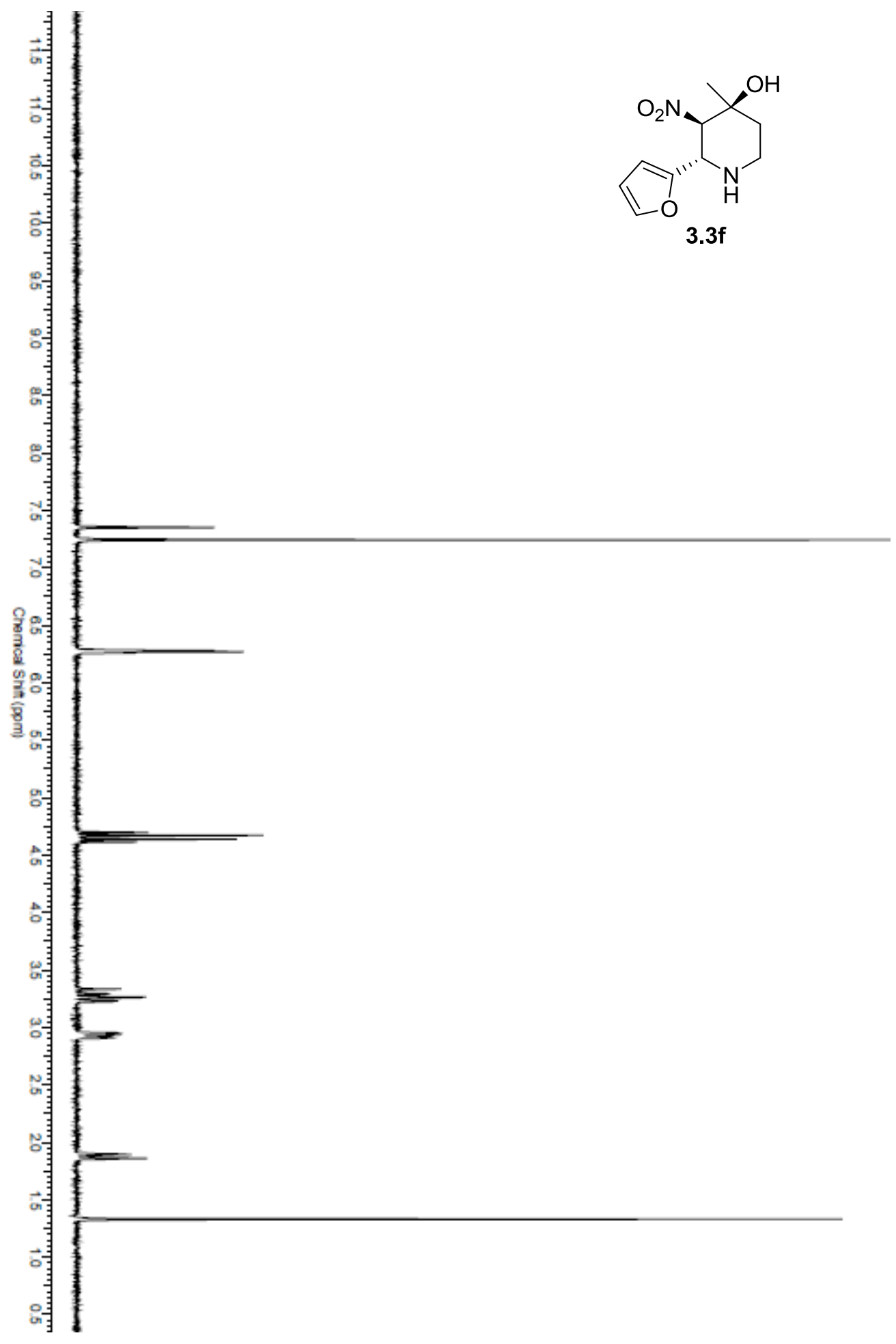




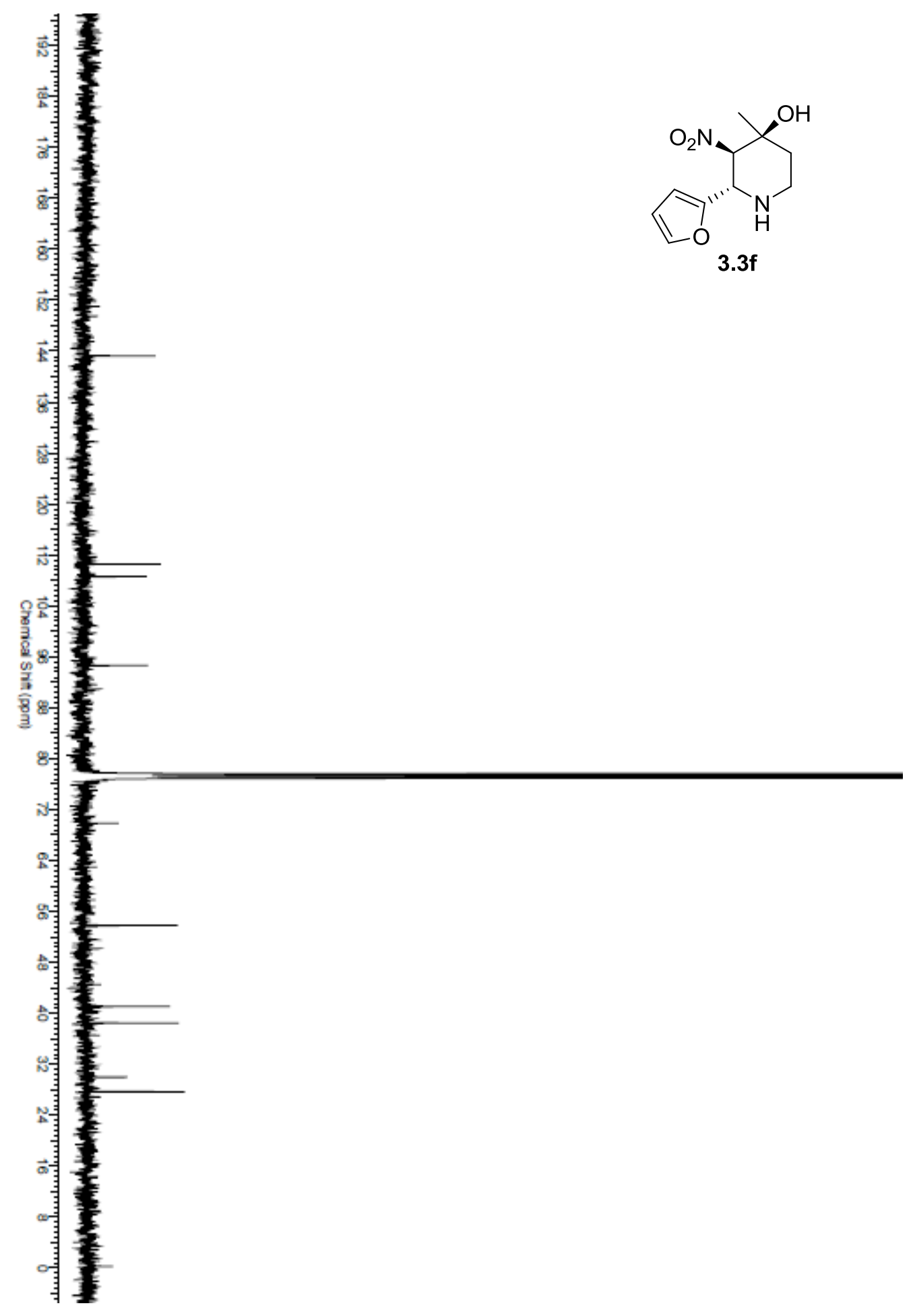




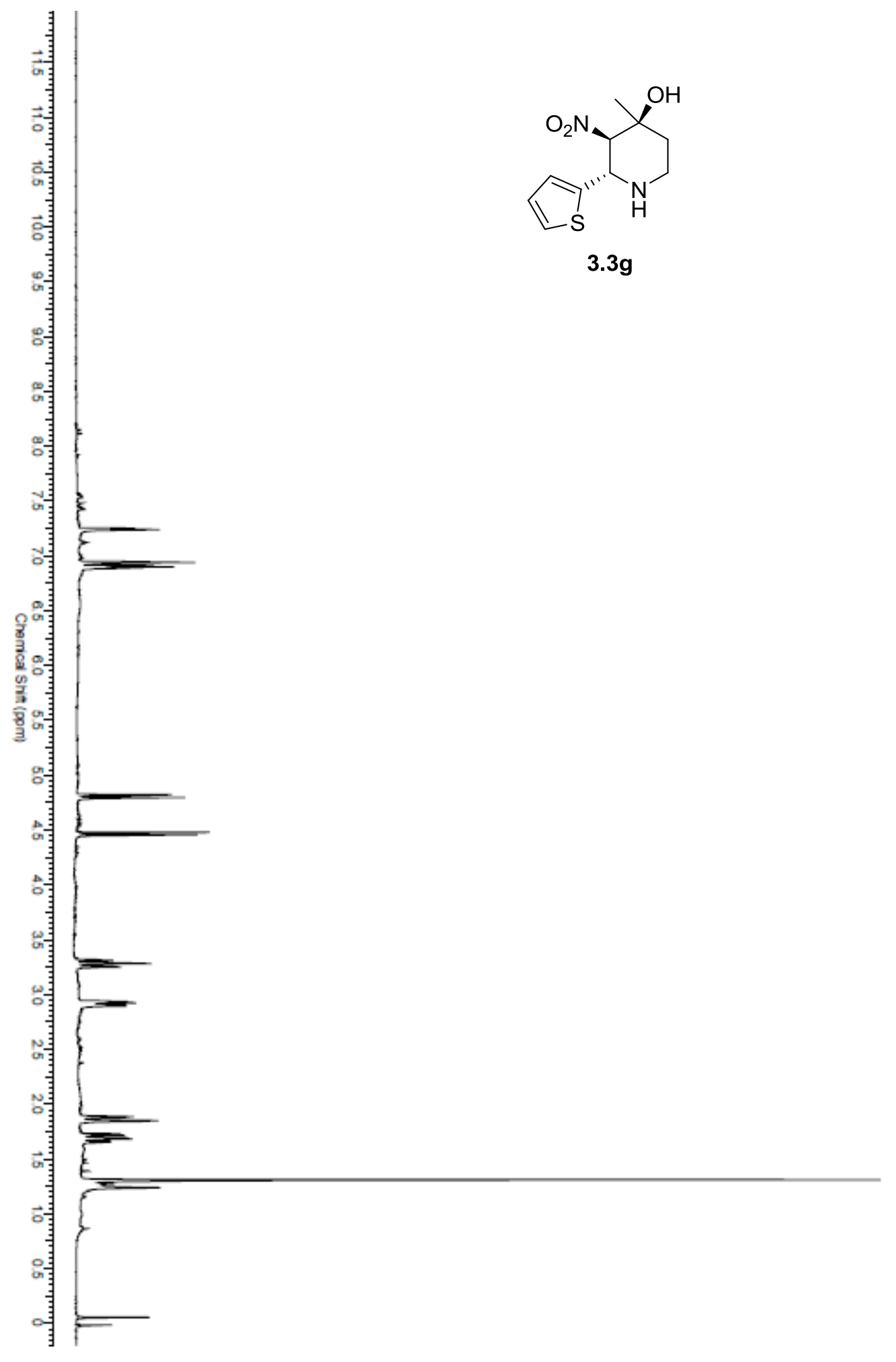




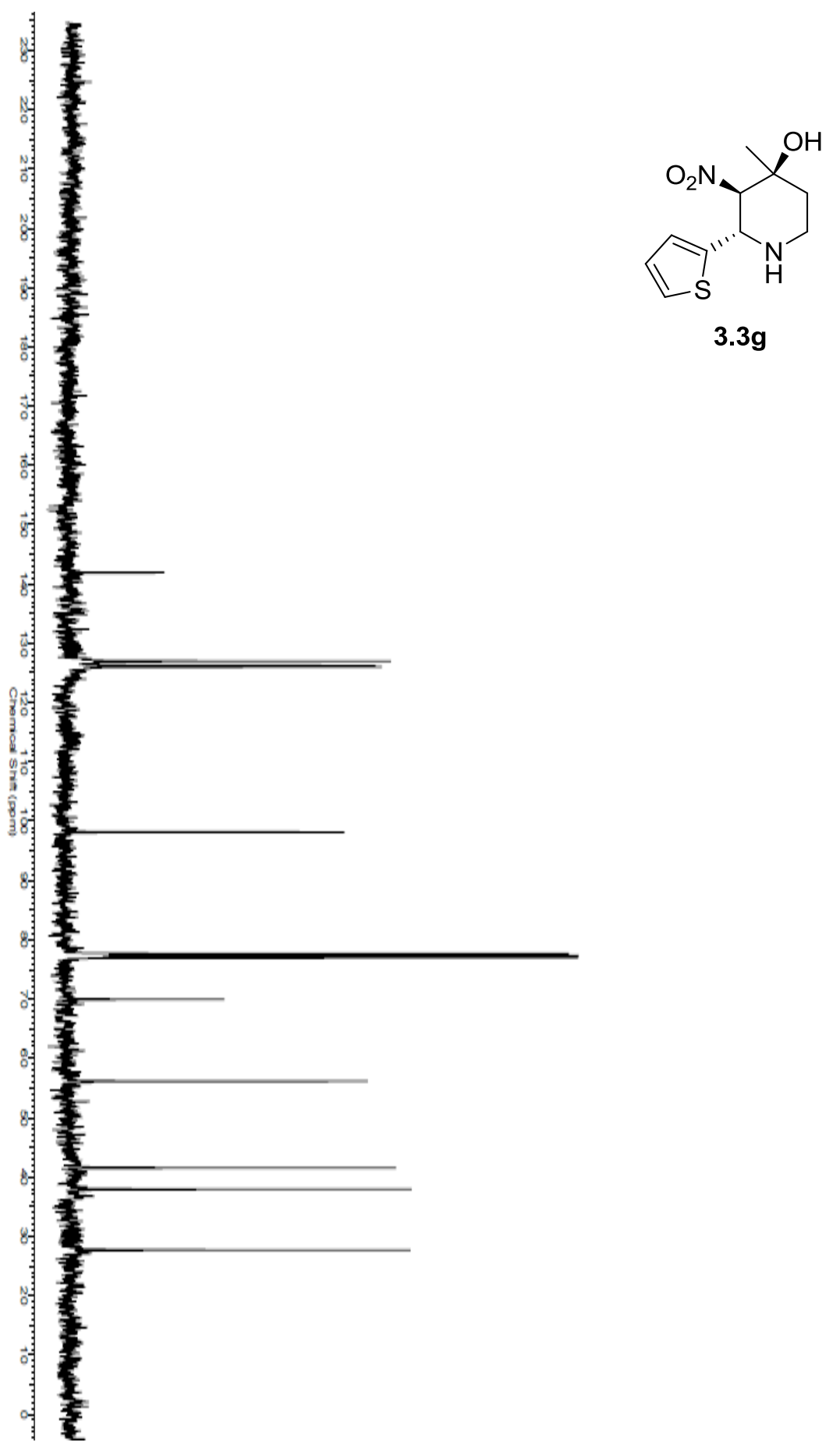




\section{A3.3: HPLC Profiles: Racemates and Enantiopure products}
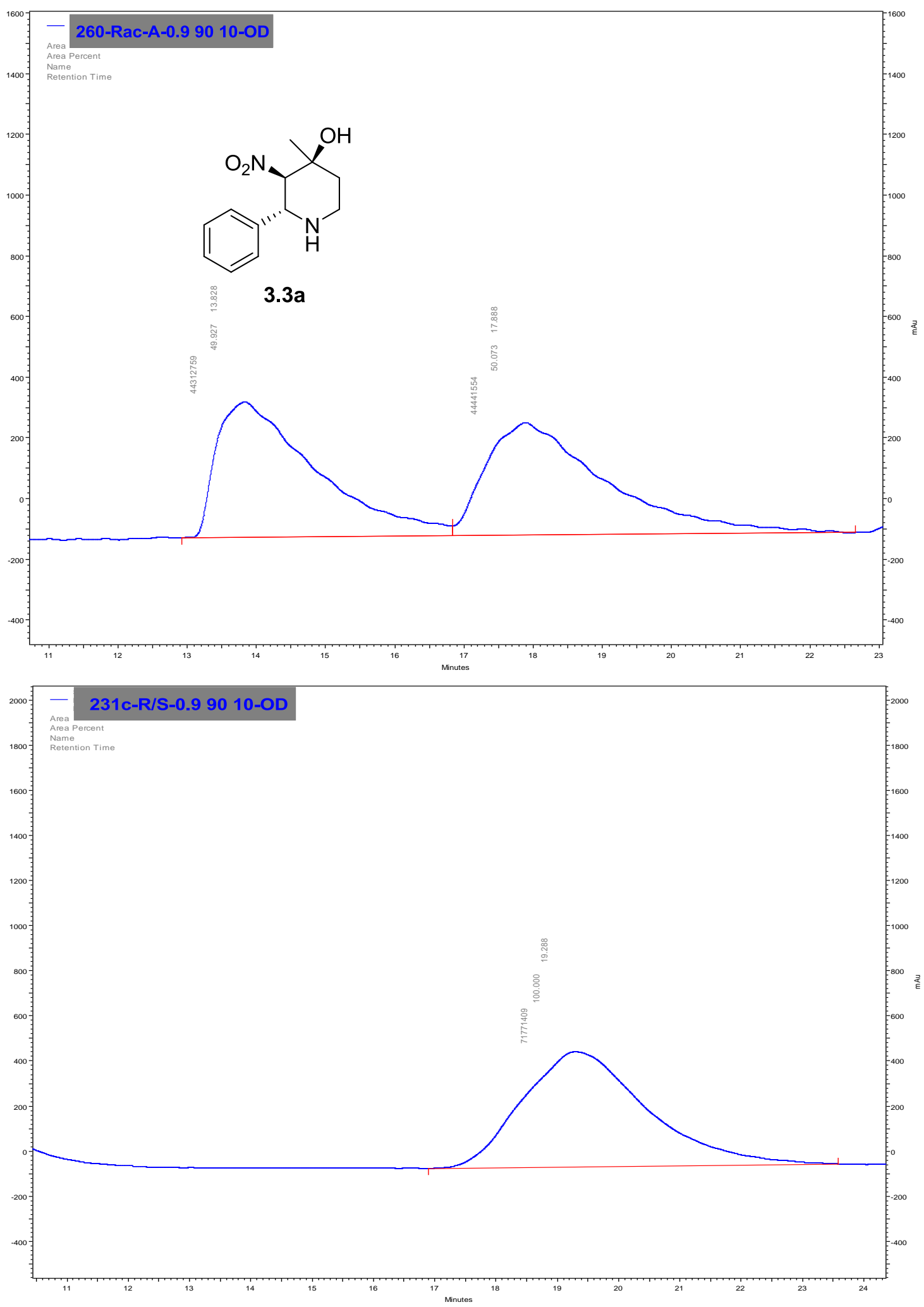

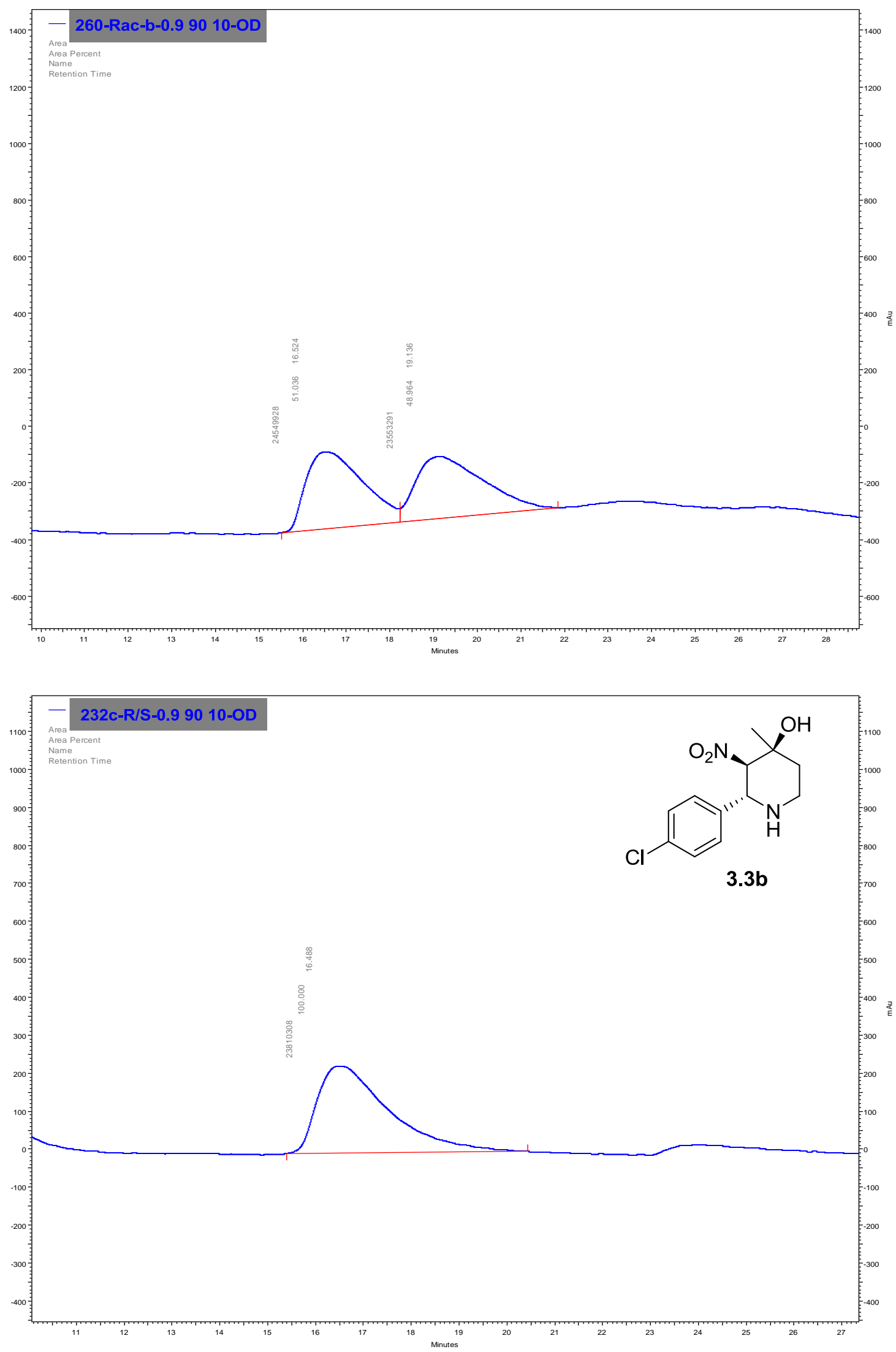

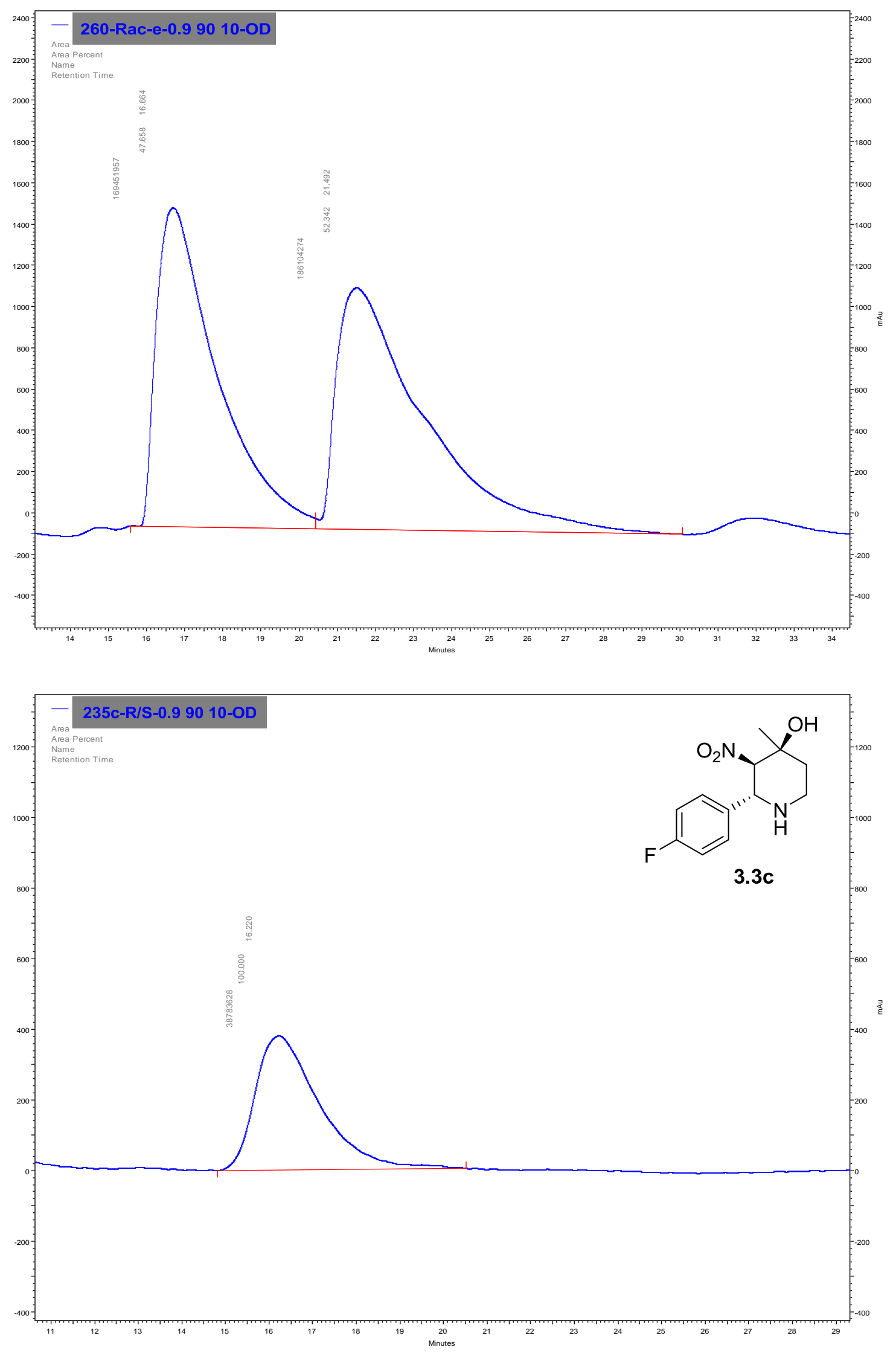

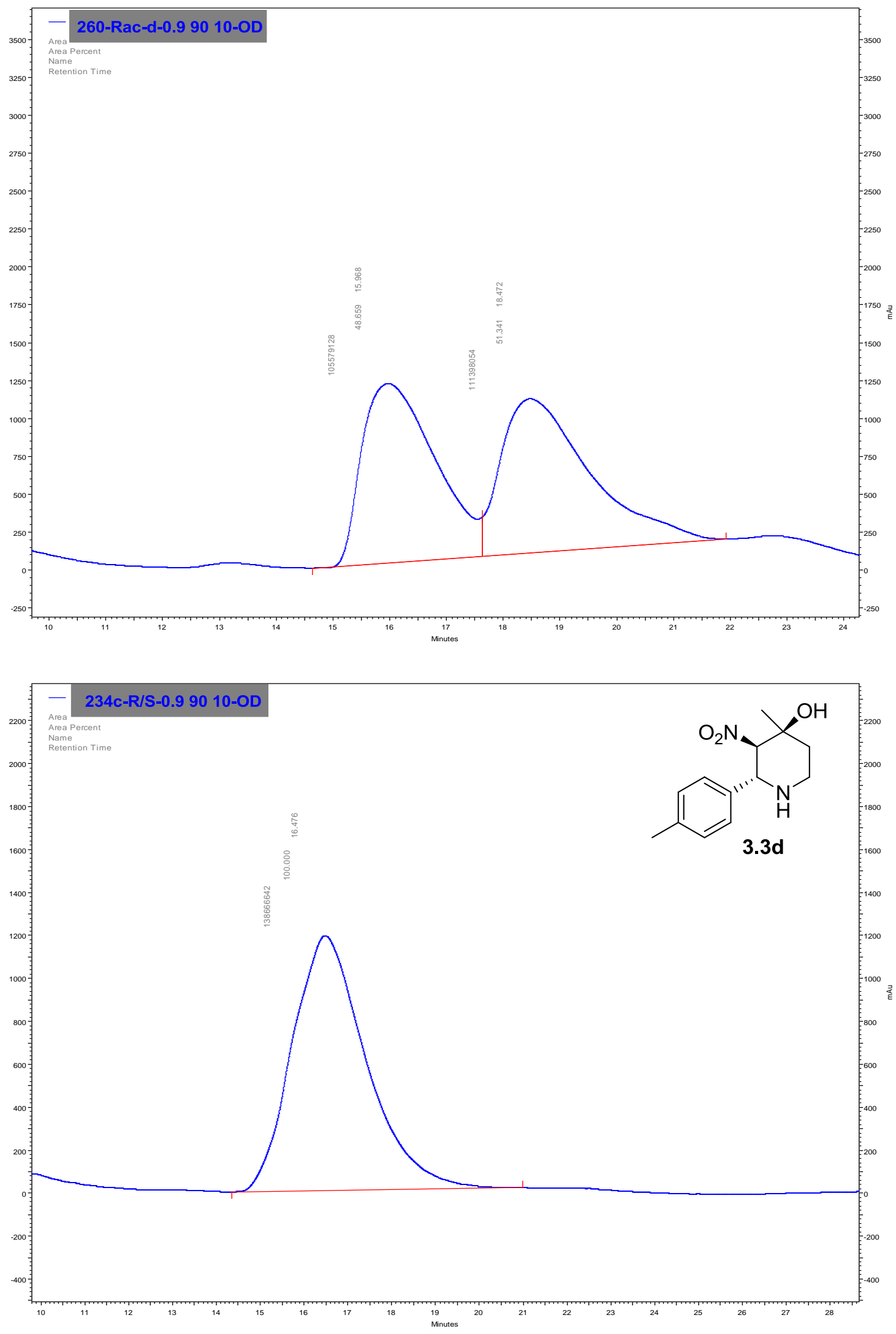

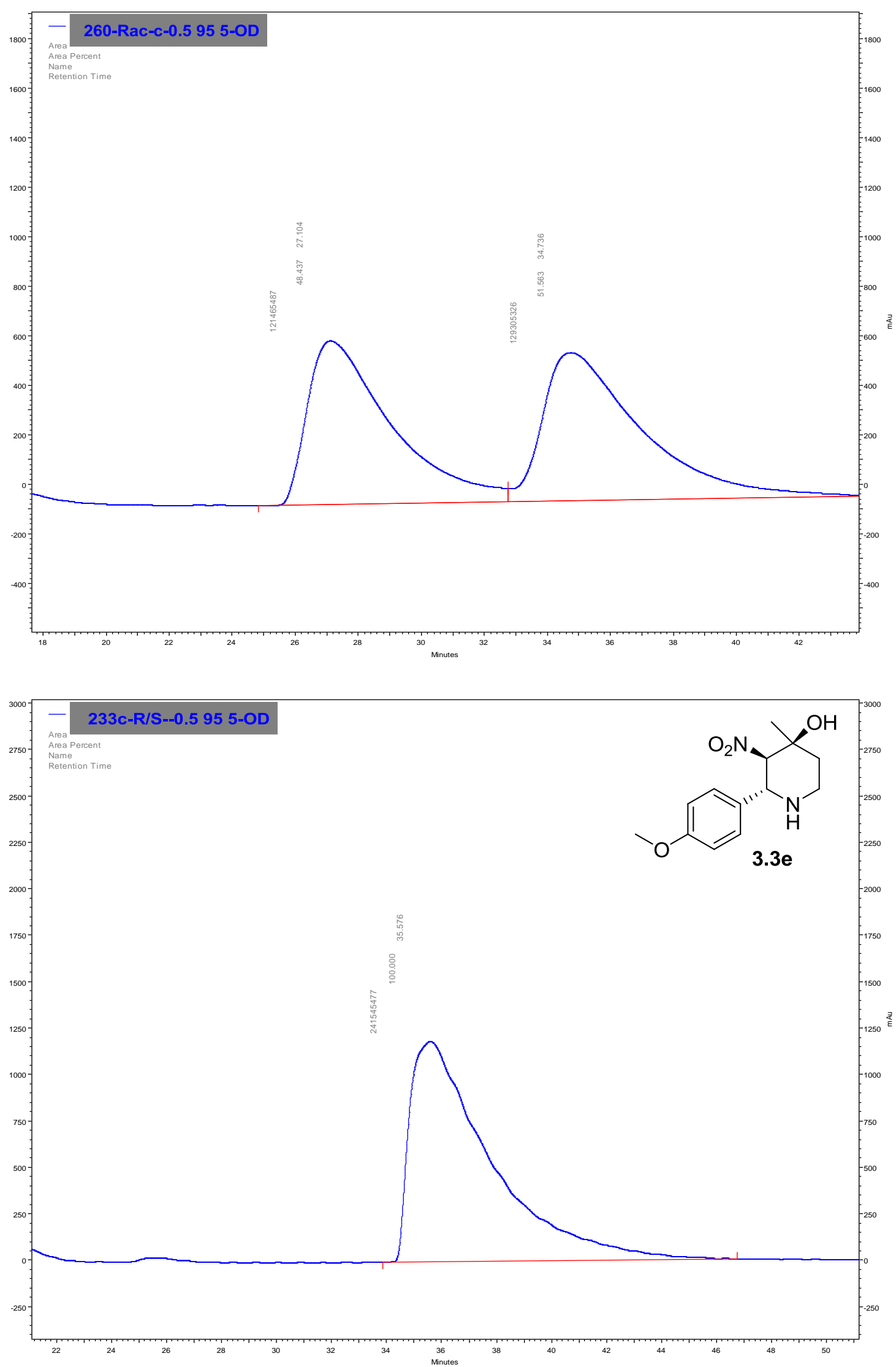

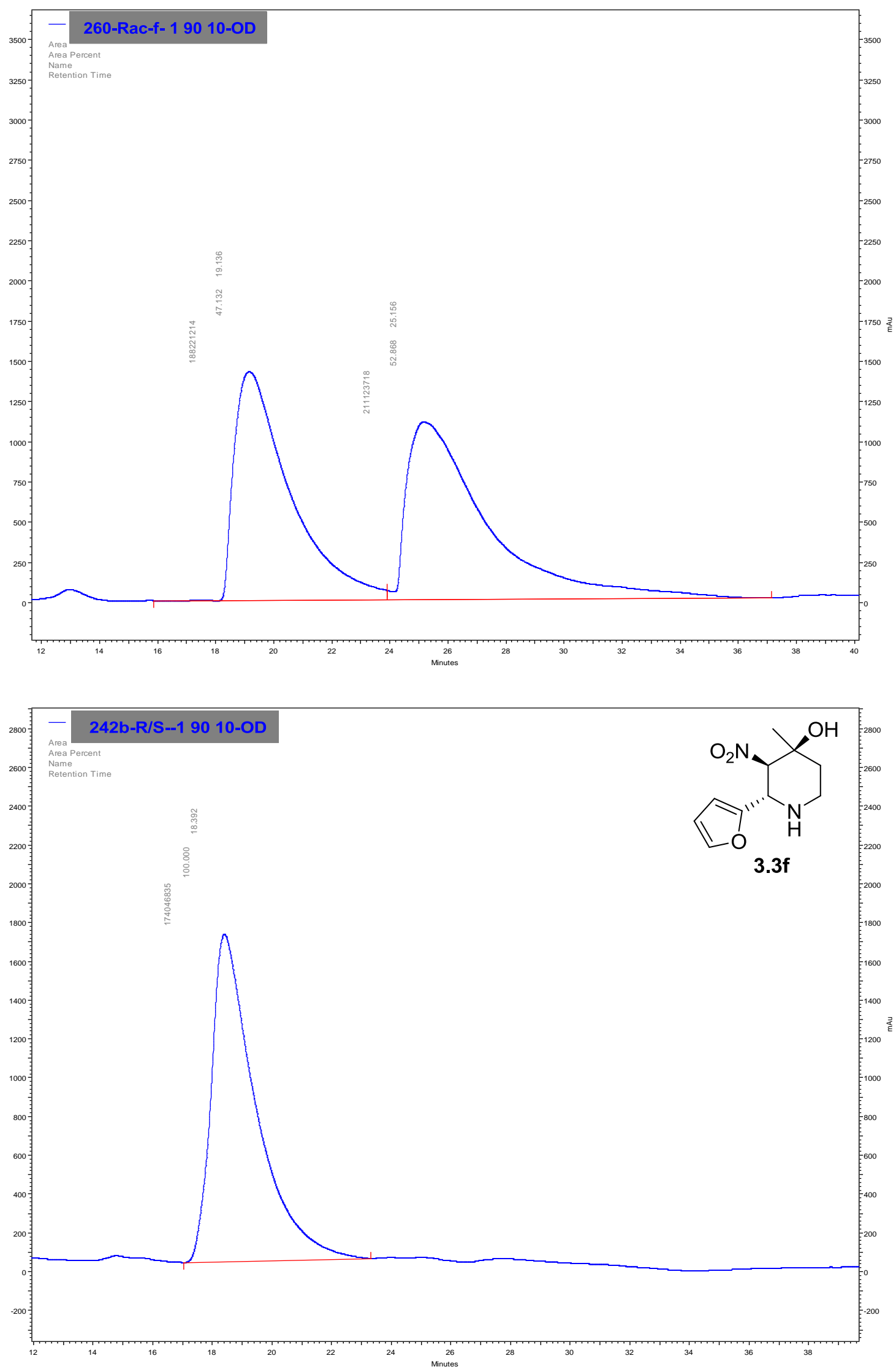

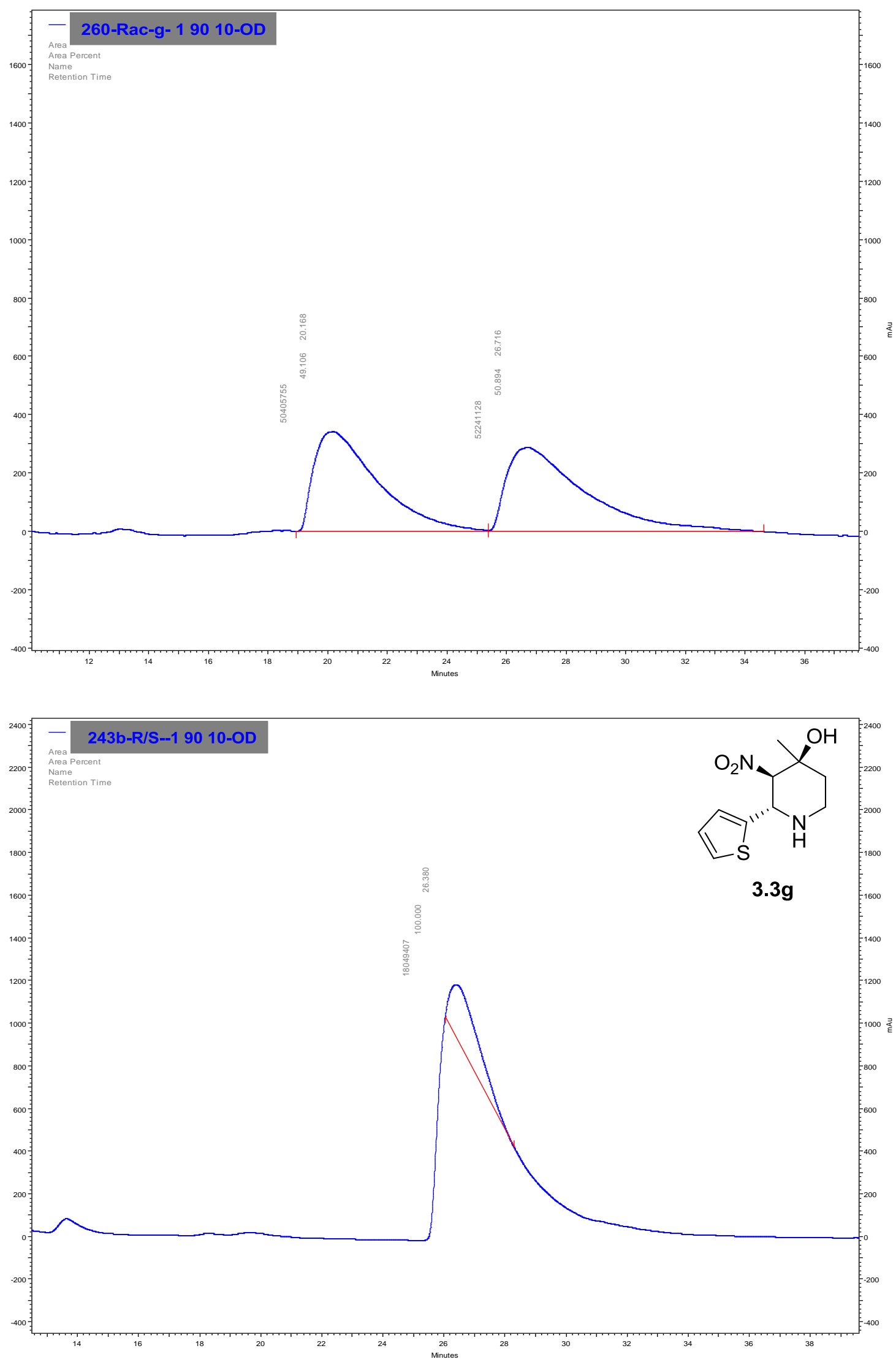


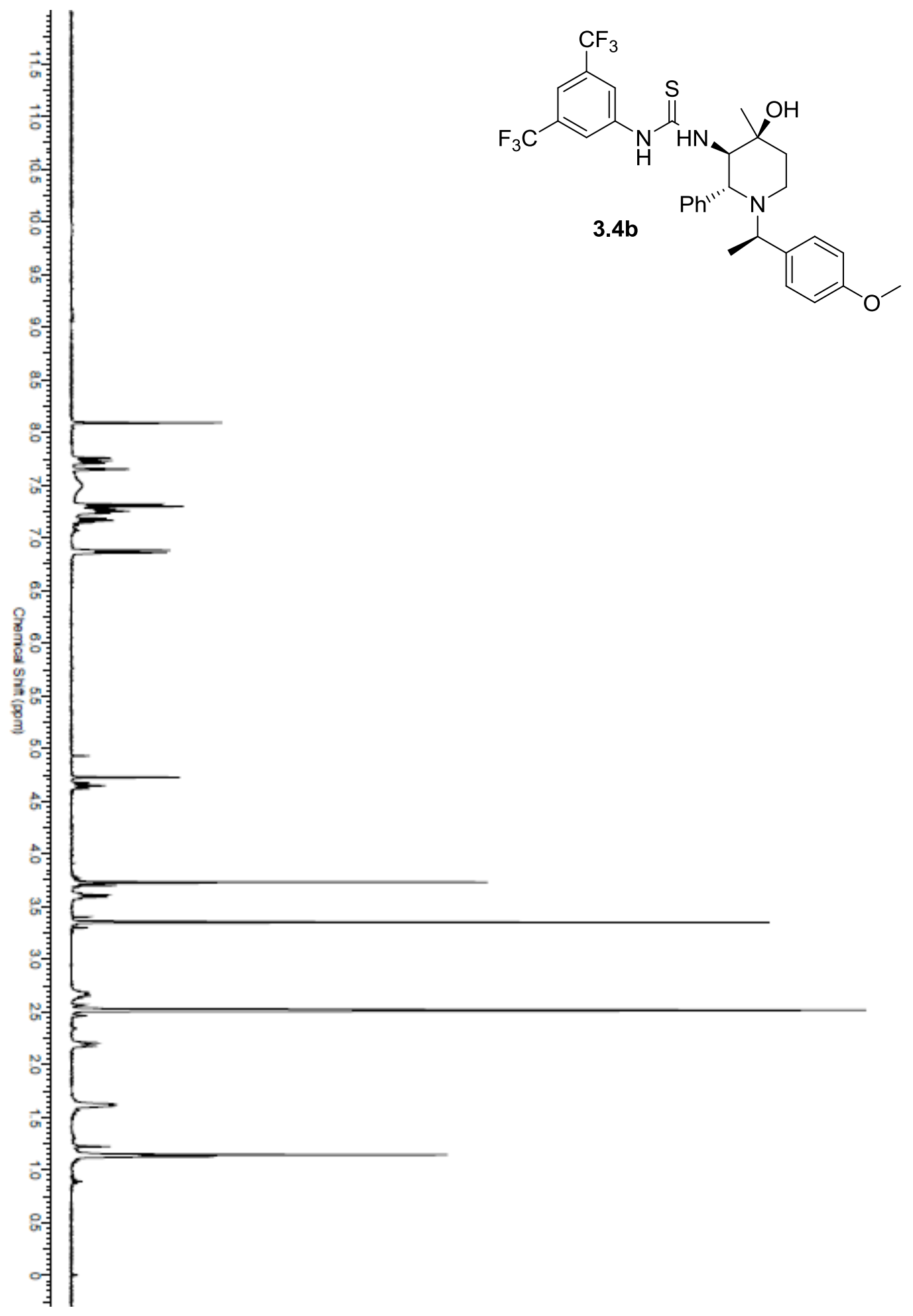




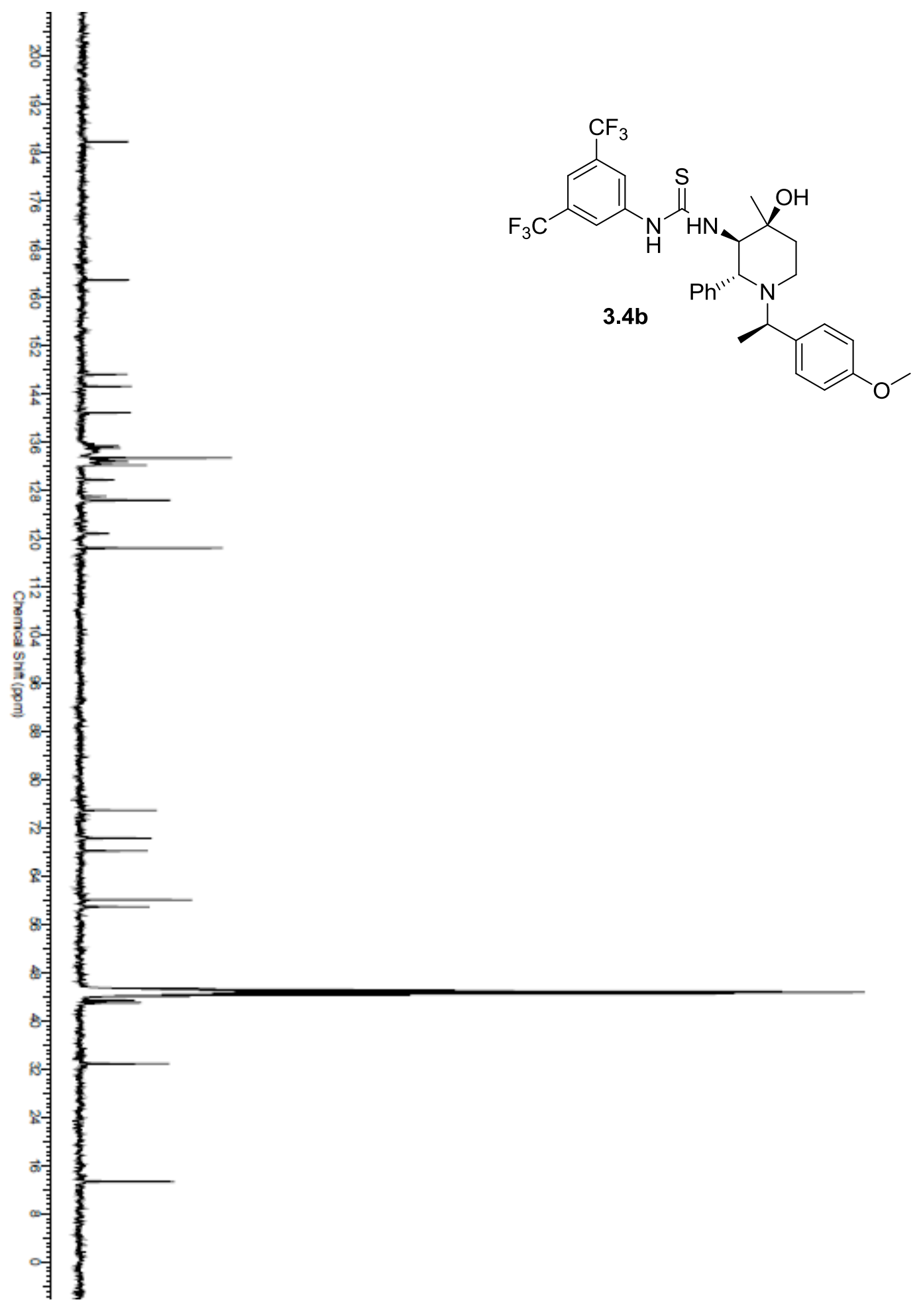




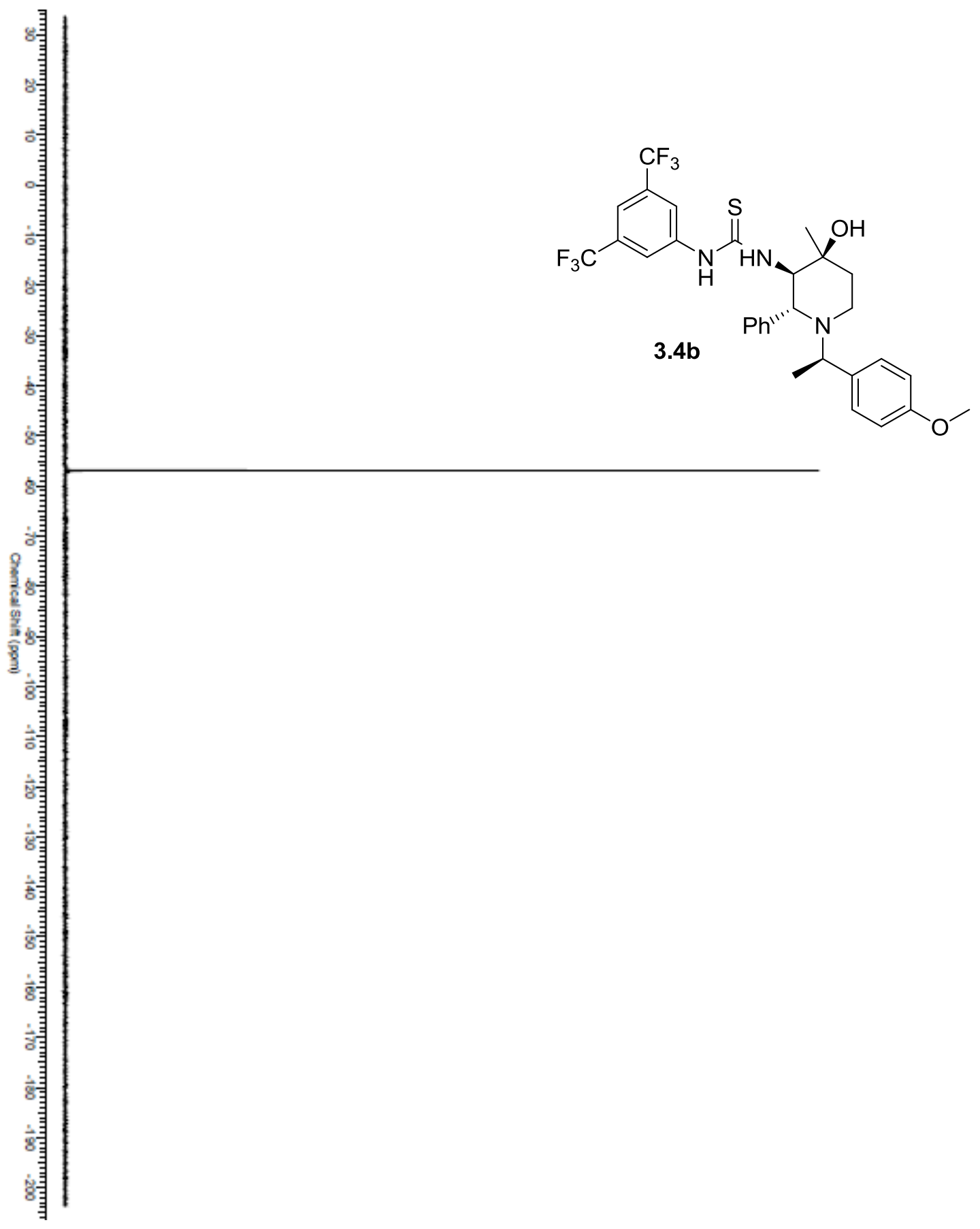



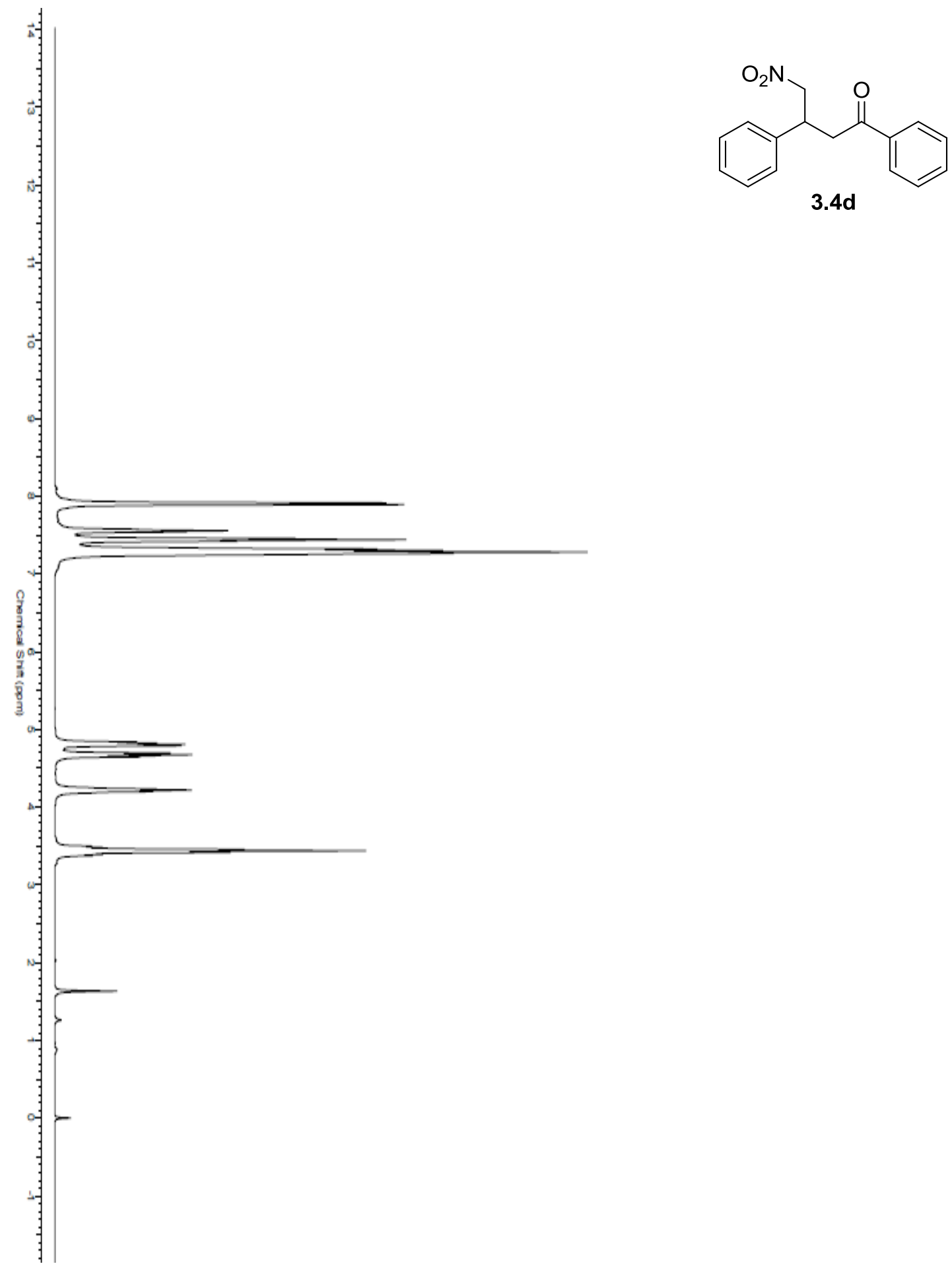


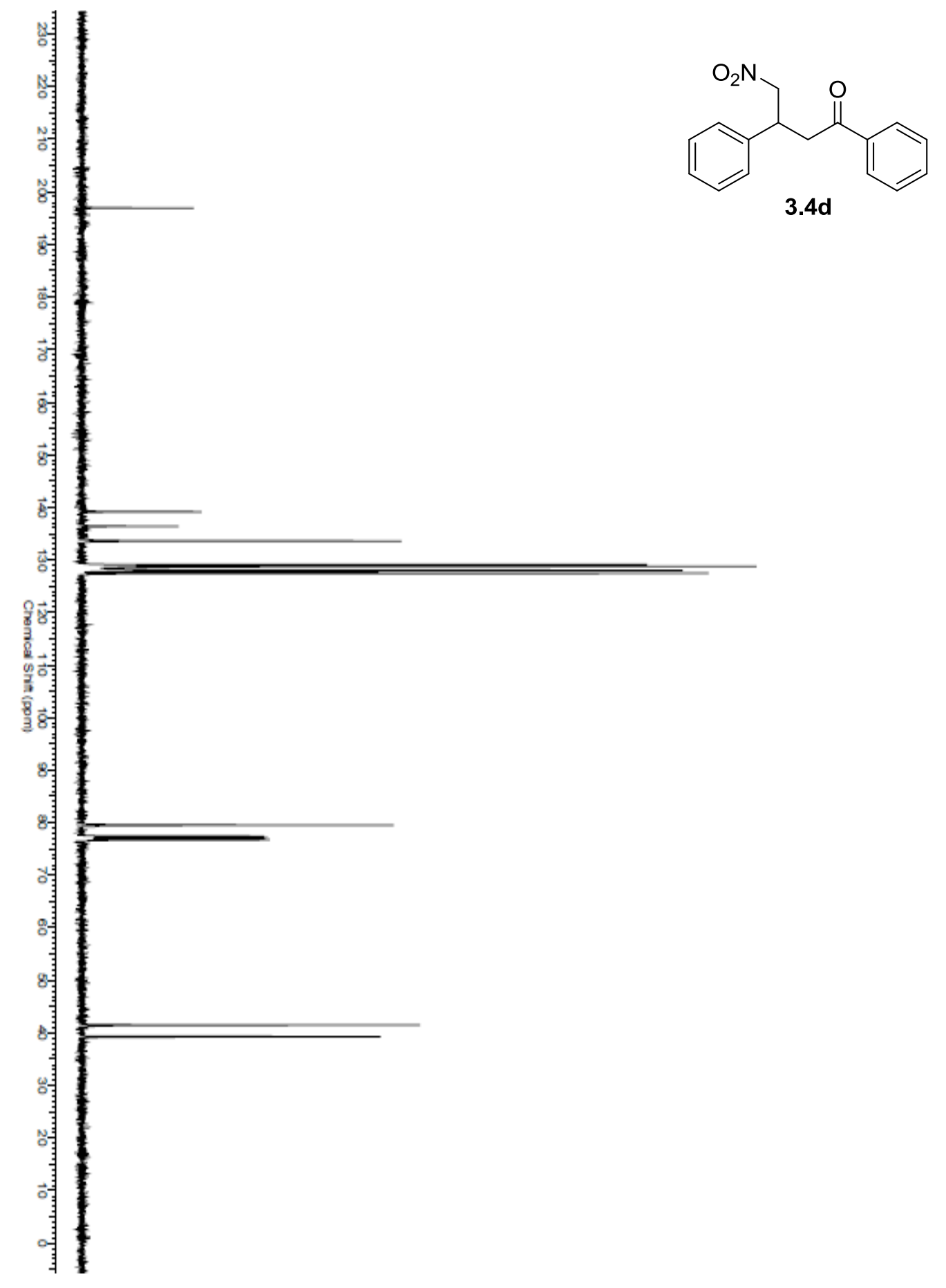




\section{HPLC of 3.4d}
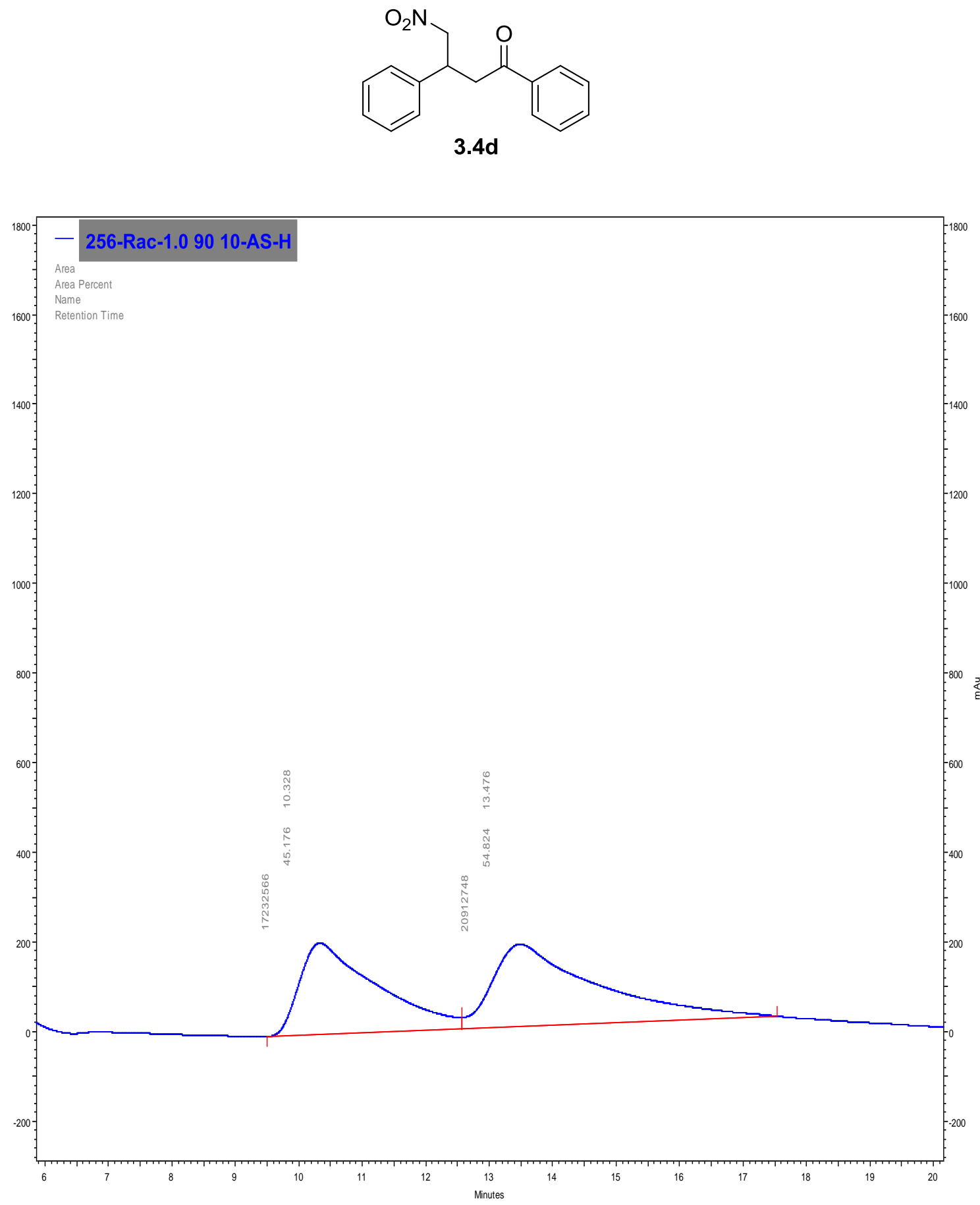

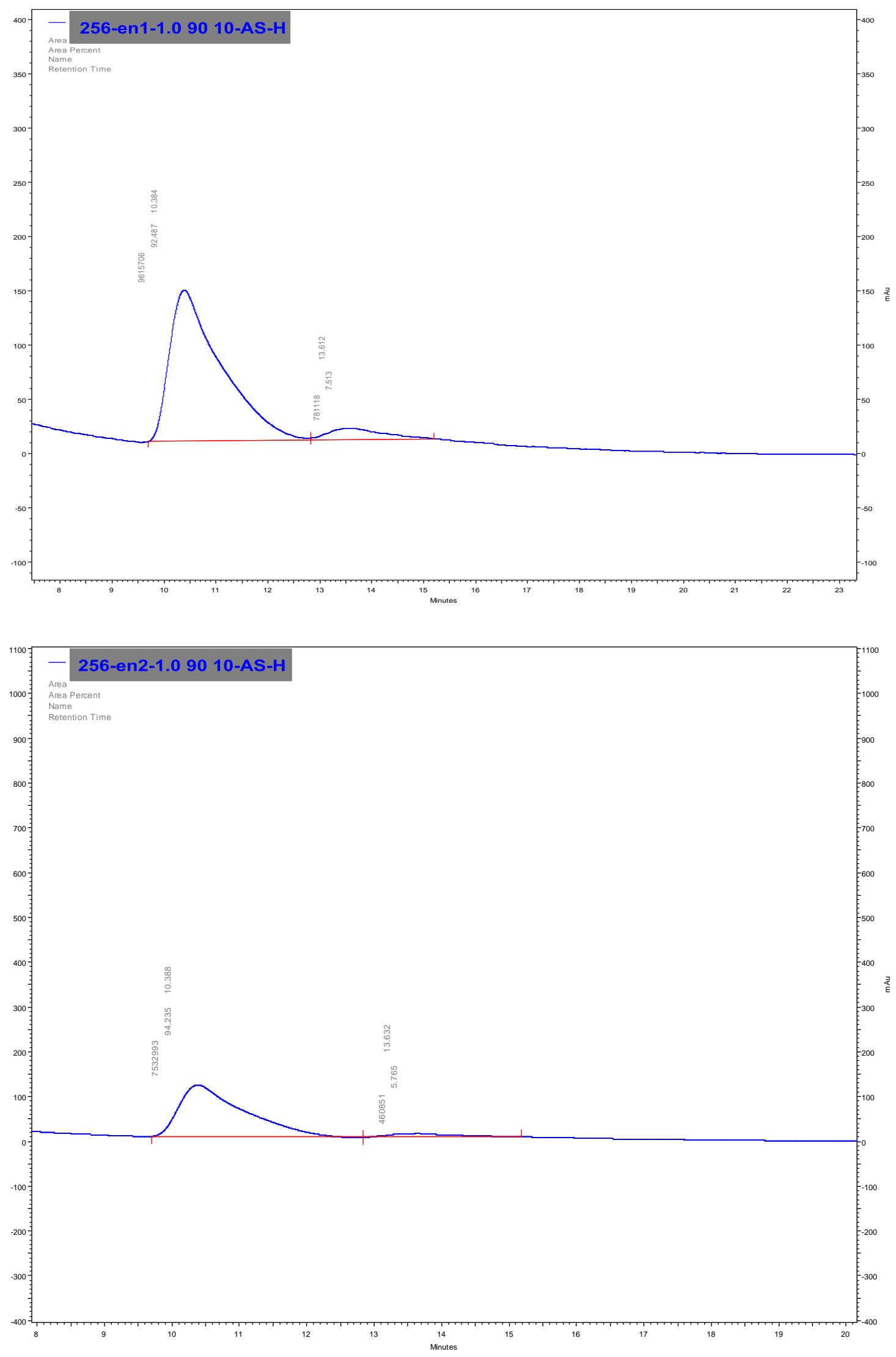